HIGHER

EDUCATION

AND

INNOVATION

Design of an Innovative Teaching 


\section{HIGHER EDUCATION AND INNOVATION}

Design of an Innovative Teaching Module for an Intensive Programme on Aeolian Architecture

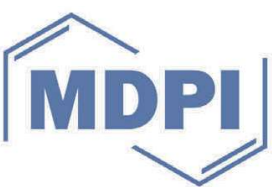




\section{Erasmus+}

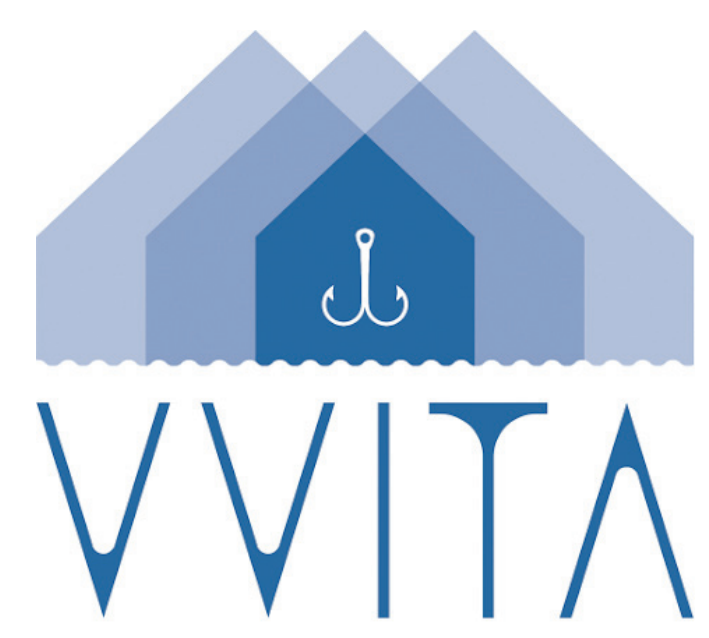

\section{ACKNOWLEDGEMENTS}

The authors acknowledge the research framework and financial support provided by the European Community, that has financed the project "Modernizing Learning and Teaching for Architecture through Smart and Long-lasting Partnerships leading to sustainable and inclusive development strategies to Vitalize heritage Villages through Innovative Technologies" - VVITA, under the programme ERASMUS+; key action KA2 - Cooperation for Innovation and the Exchange of Good Practices; action KA203 - Strategic Partnerships for higher education. The European Commission's support for the production of this publication does not constitute an endorsement of the contents, which reflect the views only of the authors, and the Commission cannot be held responsible for any use which may be made of the information contained therein.

All images belong to the authors, except if differently specifieds in the caption.

Layout by Sebastiano Greco 


\section{HIGHER EDUCATION AND INNOVATION}

Design of an Innovative Teaching Module for an Intensive Programme on Aeolian Architecture

Editors: Vincenzo Sapienza, Luca Finocchiaro, Marius Voica

Authors: Alessandra Bonazza, Simona Calvagna, Rosa Caponetto, Luca Finocchiaro, Antonio Gagliano, Mihaela Hărmănescu, Elena Cristina Mândrescu, Michele Mangiameli, Giuseppe Mussumeci, Gianluca Rodonò, Vincenzo Sapienza, Alessandro Sardella, Markus Schwai, Marius Voica

VVITA Participants: Chiara Bertolin, Ivo Caliò, Simona Calvagna, Luca Finocchiaro, Antonio Gagliano, Marina Mihăilă, Mihaela Hărmănescu, Elena Cristina Mândrescu, Giuseppe Margani, Adrian Moleavin, Gianluca Rodonò, Vincenzo Sapienza, Markus Schwai, Marius Voica

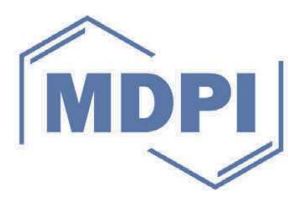





\section{EDITORIAL OFFICE}

MDPI

St. Alban-Anlage 66

4052 Basel, Switzerland

ISBN 978-3-03943-712-2 (Hbk)

ISBN 978-3-03943-711-5 (PDF)

doi.org/10.3390/books978-3-03943-711-5

(C) 2021 by the authors. Chapters in this volume are Open Access and distributed under the Creative Commons Attribution (CC BY 4.0) license, which allows users to download, copy and build upon published articles, as long as the author and publisher are properly credited, which ensures maximum dissemination and a wider impact of our publications. 


\section{CONTENTS}

\section{INTRODUCTION}

Vincenzo Sapienza, Luca Finocchiaro, Marius Voica

11 PART I - INTENSIVE PROGRAMME DESIGN

Didactic module

Gianluca Rodonò, Simona Calvagna

Rural built heritage in marginal areas Simona Calvagna, Gianluca Rodonò

VVITA project

Luca Finocchiaro, Mihaela Hărmănescu, Elena Cristina Mândrescu, Marius Voica

Intensive programme in VVITA project

Vincenzo Sapienza

Swot analysis and innovation

Vincenzo Sapienza, Markus Schwai

42 REFERENCES

45 PART II - AEOLIAN TEACHING MODULE DESIGN

Location

Vincenzo Sapienza

Aeolian intensive period

Simona Calvagna

\section{REFERENCES}

79 PART III - AEOLIAN TEACHING MODULE CONTRIBUTIONS

81 STAFF CONTRIBUTIONS

Constructive characteristics of typical aeolian architecture and methods for evaluation of sustainability

Rosa Caponetto

Assessment of energy performance of a typical aeolian building in the framework of the italian energy certification procedure

Antonio Gagliano 
GIS technology using free and open source software Michele Mangiameli, Giuseppe Mussumeci

The heritage of hand-built terraces in the Aeolian Islands: sharing best practice for resilience improvement and cultural heritage preservation in a changing environment

Alessandro Sardella, Alessandra Bonazza

\section{STUDENT CONTRIBUTIONS}

The "controlled transformation" of vernacular architecture

Gianluca Rodonò

Introduction to the archipelago

Angelo Monteleone

Filicudi open space

Sebastiano Greco, loana-Mihaela lordache, Maria Iuca, Alexandra Ivănescu, Stefanie Katharina Stanke

\section{Traditional atmosphere}

Diana Bădicu, Andrei-Mihai Bosnyak, Adina Popa, Agata Lipari Galvagno, Anna Scandura, Filipova-Jeni Nankova

\section{Canale nord shading}

loana Capotă, Iulia Panait, Ivan Attardo, Noemi D'Amico, Alla Aniskova, Ilya Pugachenko

\section{Keep the tradition}

Diana Neagu, Corina Șerban, Antonio Artino, Sharon Gibilras, Jingjing Zhou

Nature in architecture

Alexandru-Marian Mărginean, Ana Maria Petrescu, Giulia Fiore, Jessica Caruso,

Irhana Šehović, Marija Katrina Dambe

\section{Rural wellness}

Oana-Maria Anghel, Theodora Bratu, Diana-Nicole Serban, Claudio Torre, Florian Betat

\section{CONCLUSIONS}

Vincenzo Sapienza, Luca Finocchiaro, Marius Voica

\section{ACRONYMS}

\section{BIOGRAPHIES}





\section{INTRODUCTION}

The present book shows the first results of the project $V$ VITA.

VVITA is the acronym of "Modernizing Learning and Teaching for Architecture through Smart and Long-lasting Partnerships leading to sustainable and inclusive development strategies to Vitalize heritage Villages through Innovative Technologies". It is inserted in the Erasmus+ program, measure K2 Strategic Partnership for Higher Education. It involves professors and students of the Ion Mincu University of Architecture and Urbanism of Bucharest (UAUIM), which is the leader, the University of Catania (UNICT), and the Norwegian University of Science and Technology of Trondheim (NTNU).

The core of the project consists of three Intensive Periods (IP), each of them hosted in one of the country partners of the project. $I P$ is a tool adopted in the Erasmus+ Program to encourage transnational teaching and learning of special subjects, through short courses in which involved are students and professors of universities of foreign countries, grouped in a Strategic Partnership.

The IPS of VVITA are addressed to develop innovative methodologies in the teaching of refurbishing and revitalizing local, vernacular architecture. Such courses are called Innovative Teaching Modules (ITM). For Norway, an ITM was in last June 2018 and it was located in Lofoten, an archipelago off the Scandinavian Atlantic coast, 70 - N. For Italy, an ITM was in last September 2018 and it was in the Aeolian Islands, 32 miles off the Sicilian northern coast. An ITM in Romania was programmed for May 2019 , in the Danube Delta, off the coast of the Black Sea. These places are very interesting; their peculiarity is the strong relation between architecture and coastal landscape. Unfortunately, they show wide marginal areas that are unexploited. Therefore, the project is addressed to the revitalization process of them, through architecture. The ITM is composed by different modes: lectures, practice, and workshop. Each mode is connected with the others to form a system. In order to achieve this synergy, it is very important to have a careful design of the teaching module. In the contemporary view of this subject, binomial teaching-learning is considered indivisible, as well as the partnership between teachers and learners. The learning outcomes are strictly related to this relation, which is also the target of the teaching design.

The design of an ITM is the target of VVITA that is assigned to UNICT. In particular, this book deals with the generic design of an ITM and its contextualization in the module of the Aeolian Islands, called the Aeolian Teaching Module (ATM).

This book is composed of three parts.

The first one begins with a theoretical introduction on the didactic design, addressed to show how it is possible to strength the partnership between teachers and learners. After, it describes the characteristics of the VVITA project, the generic ITM, and a SWOT analysis of the ITM design. 
Part II contains the design of the ATM; it speaks about the features of the location and describes the activities carried out there. Part III is divided in two sub-parts. The first one consists of the contributions of the staff involved in the ATM. In particular, it is formed by a corpus of propaedeutic lectures (on the particularity of the place, on the calculation of the comfort conditions, on the evaluation of the local building, and on the use of the GIS technology). The second half is formed by the final reports of the student groups, a contribution from each one of them. After a GIS analysis of the assigned area, they show the revitalization of the building chosen as the case study. 
PART I
INTENSIVE PROGRAMME DESIGN

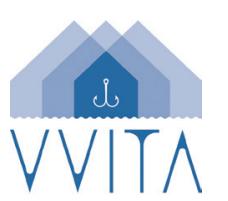




\section{DIDACTIC MODULE}

\section{ABOUT THE UNIVERSITY'S DIDACTIC DESIGN}

With regard to the pedagogic field, since the Bologna Process, learner-centered methodology (active-learning) has spread and developed [1,2]. This methodology is based on the planning of learning outcomes; it has been adopted in the policy of the State Members of the EU and finally, in practice. Thanks to this, a new approach on teaching design has been broadly shared; it refers to constructivist theories (Piaget, Vygotskyl and contemplates strategies, methodologies, and actions addressed to the creation of profitable occasions of learning, rather than a mere transmission of contents.

Learning is the result of a succession of assimilation activities, with the related "adjustment" of learners that actively "build" their learning; therefore, it is no longer possible to think about learning as an independent action, related only to the ability of teachers to explain subjects. Thus, binomial teaching-learning is considered indivisible, as well as the partnership between teachers and learners.

The student is the protagonist of his learning and he is guided by the professor mediator in a process that leads him to the planned outcomes. Didactic design is aimed at defining the environment in which he progresses, thanks to the teacher's guidance and his active participation. The design defines the rules of the relationship between learners and teachers in order to have a prepositive dialogue, based on the learners' perceptions of the task assigned to them; it defines also teaching methods and evaluation modality, in order to compare effective learning outcomes with the planned ones.

This kind of approach, affirmed some decades ago in the international scenario, has been encouraged by the cultural debate in the European Community on the theme of higher education. Following this approach, the present university learning programs are addressed to define the outputs of the educational processes and the skills related to them.

In this context, the EU focuses on two strategies.

The first one is the intergovernmental agreement known as the Bologna Process [3]; it began in 1999 and has been signed by most of the representatives of the governments of the Old Continent, at different moments. Its aim is to give a response to the needs that emerged from the Agreement of Sorbonne (1998), to harmonize the European system of higher education, as a prereqvisite to enhance international mobility. This target has been obtained by defining two cycles of the degree course (Bachelor and Master), which are completed by the course of Philosophiae Doctor (PhD). In the successive meetings, and especially in the Bergen one (2005), a framework for the qualifications of higher education was defined [4]. Every country listed there has promised to arrange its higher education system according to this document.

Among the main outputs, there are the Dublin Descriptors [5] that define five skills 


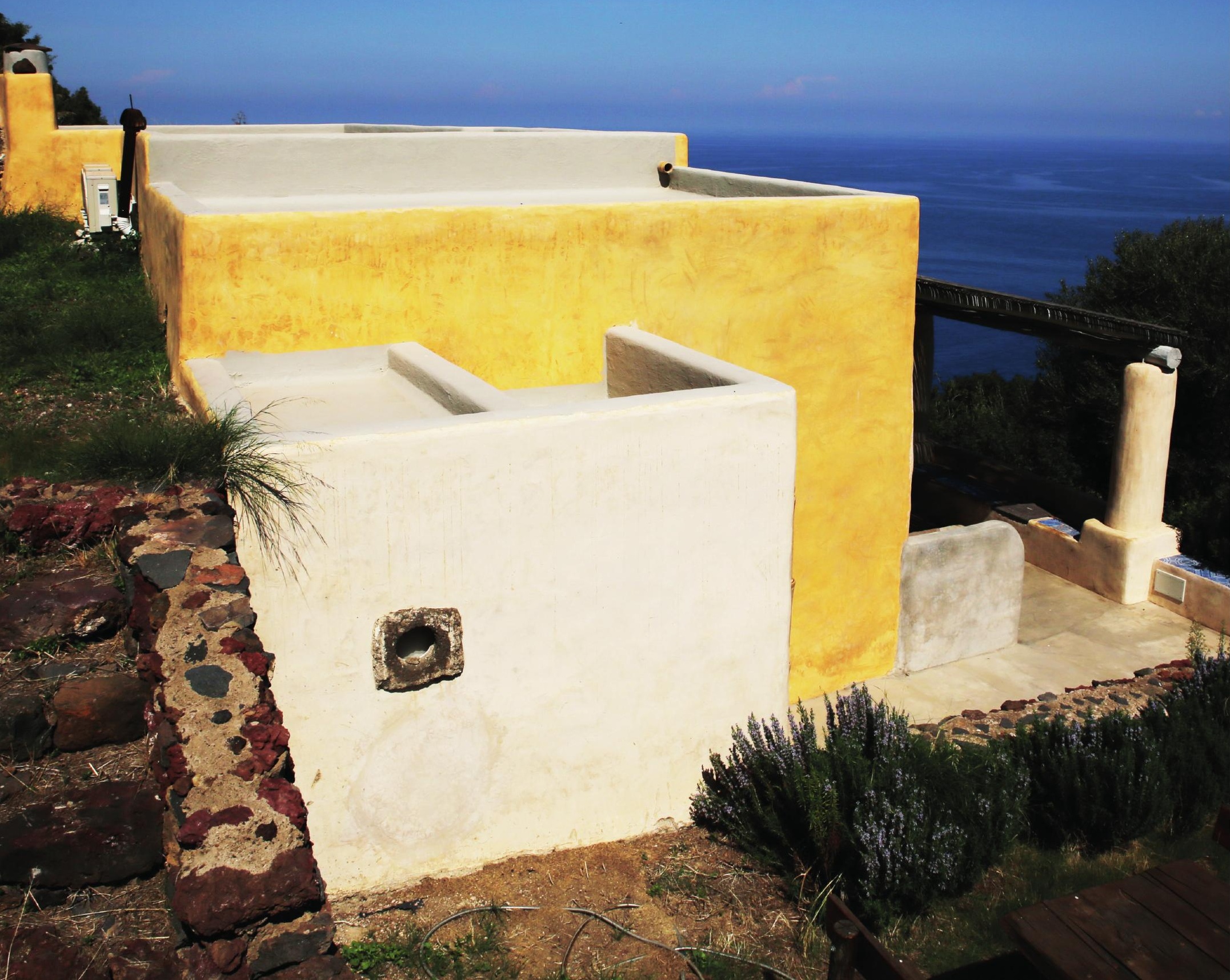


of learning to acquire to have the correspondent license in the attended course:

- knowledge and understanding:

- applying knowledge and understanding;

- making judgements;

- communication skills;

- learning skills.

Apart from the harmonization of the structure of the courses and apart from the definition of the learning typology, the process has the goal to define a quality standard for higher education processes. For this specific aim, in Bologna, they defined standards and guidelines to assure the quality level of the higher education field [6,7].

The second strategy of the European Community is out of the traditional educational system. It promotes an education strategy for the entire duration of life, which is called Lifelong Learning; it is both formal and informal. The document which promotes such strategy is the European Qualifications for lifelong learning (EQF) [8, 9], which provides indications on the qualification levels adopted as a guide for education systems. In this document described above, the qualification level depends on certified knowledge, competence, and skills.

Another project related to didactic design is Tuning [10], which has involved a number of European Universities under the financing of the European Commission. Its main output is a guide to program degree profiles, considering competence and learning outcomes [11]. It is possible to define the acquired skills as the ability of the learners to use knowledge and competence acquired in the attended course. The skills must be related to the learning outcomes. They are the result of the entire learning experience. The teaching staff can use them to verify if students have developed the competence related to the qualification level that the course aims at. 


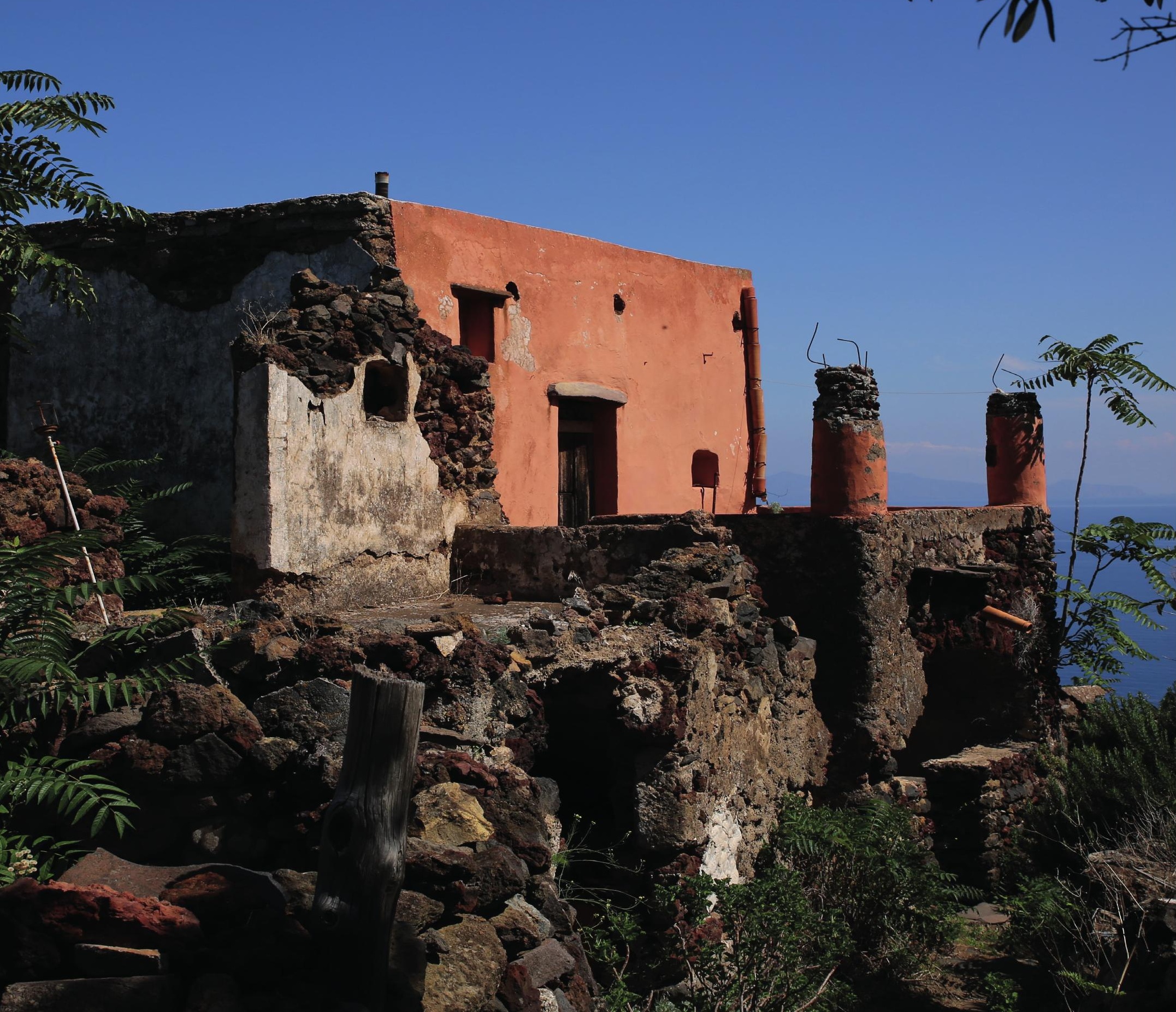




\section{INTENSIVE PROGRAMME IN ERASMUS+}

The idea of supporting the insurgency of a common European feeling through young mobility was born at the end of the sixties. Firstly, this idea was proposed by Sofia Corradi [12] (also known as "Mamma Erasmus"); she was a pedagogue and an advisor of the Italian Conference of the University Rectors (CRUI) that adopted and supported this proposal.

Thanks to this push, the European Community defined the first programme for young mobility in the field of education, training, youth, and sport. The program, which was triennial, was launched in 1987 and was called Erasmus [13]. This is the backronym of "EuRopean Community Action Scheme for the Mobility of University Students"; it refers to Desiderius Erasmus of Rotterdam (1466/69-1536), a Dutch philosopher and theologian who visited most of the countries in Europe, to understand costumes and cultures. For this reason, he became a model of European intellectual life during the Renaissance and he could be considered an icon of the European Union, still now.

After its birth, the mobility programme has continuously been renewed. Thanks to it, more than 3 million students have had the possibility of spending a semester in other countries (not necessary belonging to the EU).

An important tool introduced by Erasmus is the Intensive Programme (IP) of study. This kind of activity consists of a short course in which students and professors of universities of foreign countries are involved, grouped in a Strategic Partnership [14]. The goal is to encourage transnational teaching and learning of special subjects. The theme of the IP must be added to the ordinary curricular courses [15]. Before it begins, the university partners must declare the number of credits (CFU) the participants will get through their participation. This will be established according to the subject and the length of the IP, for specific degree courses. IPs are shorter than ordinary courses. They last from a minimum of ten days to six weeks.

An IP can be done once or it can be repeated for a limited number of years. It may not consist of research activities or conferences but should provide something new in terms of learning opportunities and skills.

The IPs were introduced with the Lifelong Learning Programme in 2007-2013 [16], which is the financial instrument available to the European Commission for its directly managed education and training policies, during the period covered by the European Union's current financial perspective. The Lifelong Learning Programme continued the main actions launched under previous programmes and has six sub-programmes [17]:

- Comenius:

- Erasmus programme;

- Leonardo da Vinci;

- Grundtvig;

- Transversal programme;

- Jean Monnet Programme.

Its objectives were first, to support the development of quality lifelong learning and 
thereafter, to help member states of the European Union to develop their own education and training systems.

The programme supported three types of actions: connections between countries, exchanges between individuals, and exchanges between institutions. The IP is a sub-action of the third action.

The Lifelong Learning Programme was substituted by the Erasmust programme in 2014-2020, which maintains the structure of the previous one; it improves the number of sub-programmes and maintains also the possibility of the use of IPS.

The number of IPs required and realized has been increasing over time. In the last year, the European Community financed almost two hundred IPs only for Italy [18]. This is the measure of the success of the introduction of this tool.
Architectural and engineering subjects fit very well with the IP, because they allow the students to have direct knowledge of the sites and buildings with which they can be involved. In this case, it could be strategic to accompany the initial lectures with practice and workshops. With the first ones, you can contextualize the concepts in the local landscape or tradition; with the second one, you can address the attention of the students to the design or redesign, which is the first target of this matter.

\begin{tabular}{|l|l|}
\hline \multicolumn{2}{|l|}{ European Union Programmes } \\
\hline $1986-1989$ & Erasmus \\
\hline $1994-1999$ & Socrates I \\
\hline $2000-2006$ & Socrates II \\
\hline $2007-2013$ & Lifelong Learning Programme \\
\hline $2014-2010$ & Erasmus+ \\
\hline
\end{tabular}

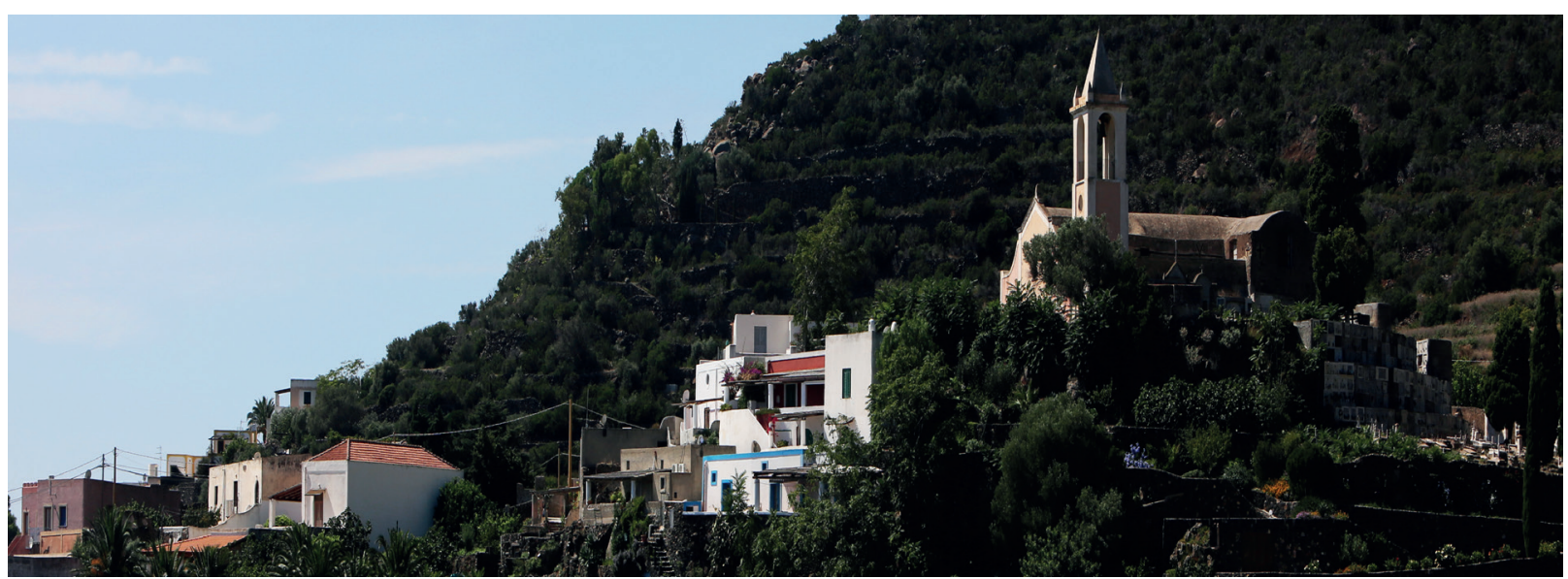




\section{RURAL BUILT HERITAGE IN MARGINAL AREAS}

\section{WHAT DOES IT MEAN, MARGINAL?}

If we accept the common definition of marginal as an element of secondary importance, not essential for the functioning of a system, we should think of marginal architectures as a low-quality space, without a precise role, a residual space in a state of partial abandonment, like a waste [19].

These connotations can be observed at the margins of urban settlements, close to cities, in those areas of transition between dense and widespread settlement that, in the best case, configure urban peripheries, and which degenerate into informal settlements such as slums and favelas. In this case, the margin is considered an urban and metropolitan phenomenon. The urban peripheries associate the physical condition of "margin" with respect to the dense city with a social marginality, determined by the proximity to non-lieux [20] or abandoned areas (industrial or infrastructural friches) and the absence of services and functional mix (dormitory districts). The degrading conditions of the suburbs are well known and have been a field of study and experimentation for several decades [21]. In Italy, the experience promoted by Renzo Piano, as part of his lifetime senator activity, is significant. At the end of 2013, he launched the G124 program, through which every year, a group of young architects, under his guidance, is recruited to experiment concretely his strategy of "mending the suburbs", aimed at increasing the quality of life of these places through micro-interventions with tangible results, framed in a long-term overview [22].

If we focus our attention not so much on the edge of urban conurbations, but on those areas whose marginality is determined by the condition of being outside the main centers of economic and cultural development (the cities), we are faced with the Ignored Realm recently defined by Rem Koolhaas as "Countryside"[23]. The impressive exhibition at the Guggenheim Museum in New York poses the provocative question: "Are we really heading to an absurd outcome where the vast majority of mankind lives in only 2 percent of the heart's "overpopulated" surface - and the remaining 98 percent would be inhabited by only one-fifth of humanity, staying there to service them?". The forecast of the UN report to which Koolhaas refers [24] seems to confirm the phenomenon of Total Urbanization that Henri Lefebvre prefigured as an inescapable world scenario [25]. By turning the spotlight on the enormous territory of the countryside, it highlights its complexity and asymmetric relations with urban settlements, in which all services are centralized and to which the countryside directs its production. In this sense, there is no real limit between city and countryside, but there is a hybridization between the two systems in favor of Total Urbanization - as observed by Lefebvre which has exploded the long-established sociospatial boundaries (city-countryside), creating a densely urbanized landscape whose contours are extremely difficult to theorize [26]. 
This perspective changes if the concepts of limit and threshold are reconsidered. If the countryside is a continuous system with respect to the city, is it possible to identify new margins with respect to these new ways of global urban settlement?

There are places from which it is possible to observe or inhabit the world in a different way. Marginal areas are outside the dominant economic, financial, cultural, and mobility flows, so one can see in them the permanence of characteristics related to the past. These are often places that are difficult to access or with unfavorable living conditions; remote places, where urbanization processes have had difficulty in arriving due to geographical, political, or social causes, or isolated places that dot the urbanized countryside, the last strongholds of stories linked to the land and people who have resisted the processes of homologation of industrialized society. Therefore, marginal architectures should be considered as an expression of geographical and geomorphological hostile conditions that characterize part of the Earth; on the other hand, they can be understood as an expression of the authentic bond between man and places. Marginal architectures are less interested in contemporary standardization processes, with a more authentic link with their landscape. In marginal areas landscapes, it is possible to perceive this harmonic union, without the anthropic dimension being predominantly overwhelming on the natural one, erasing the signs of the place [27].

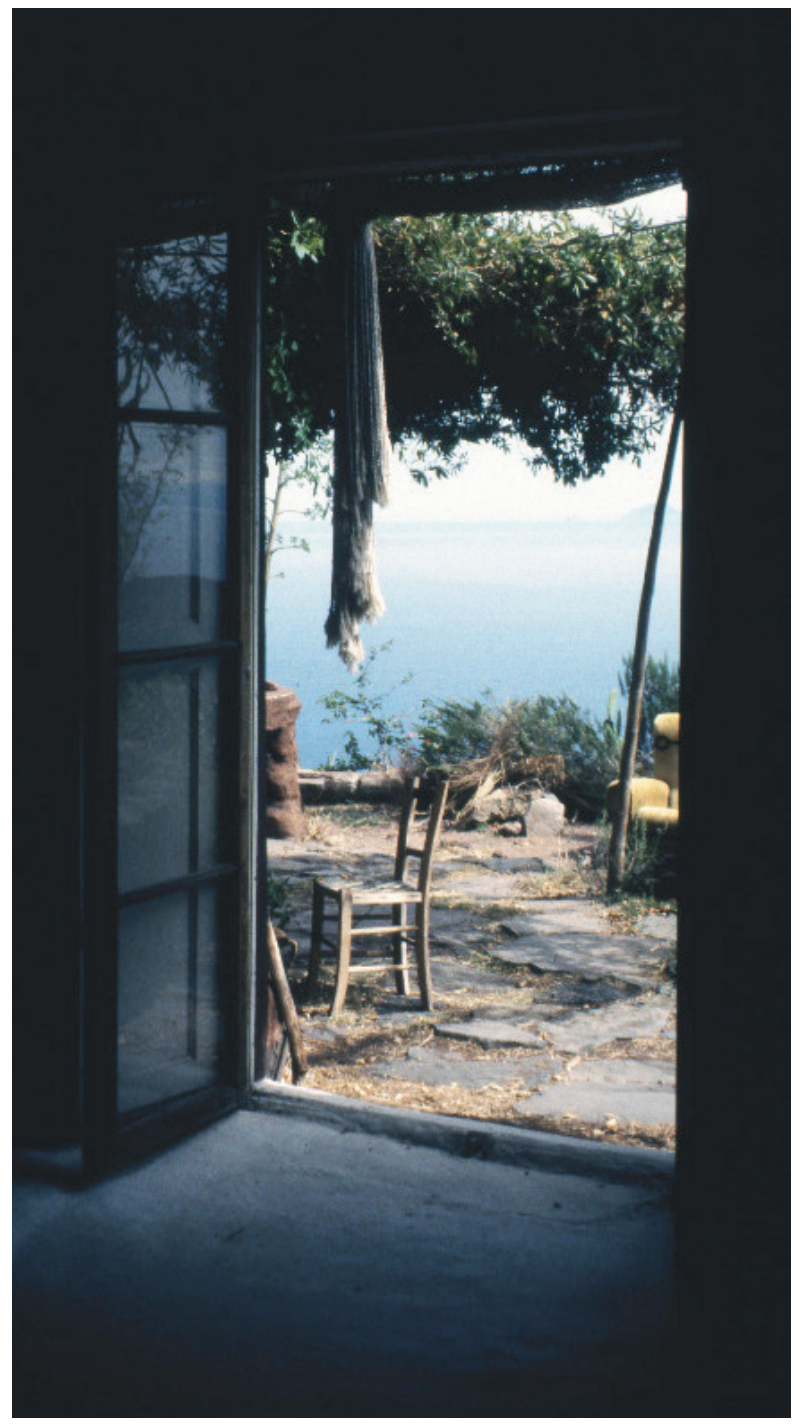




\section{WHY STUDY MARGINAL}

Marginal architecture constitutes a line of research in the debate on contemporary architectural design. What Carlo Aymerich [28] points out about the dichotomy of positions in which architectural culture recognizes and divides itself is relevant in this context. The first position is identifiable in the "bigness" of which Koolhaas speaks [29], in the paradigm of the large dimension, which concentrates its attention in cities and large metropolises. The proposed models are characterized by an overwhelming, shining visibility, with sensual geometries and iridescent shapes and colors. For these realizations, tools, techniques, and materials currently available allow for the experimentation of constructive innovations until recently unimaginable, while often involving high investments.

Diametrically opposed is a methodological approach that has a deep distrust in development models based on linear and quantitative growth and that translates into a philosophy that shifts the attention from the city to the territory, to the rural landscape and small towns with their traditional and pre-modern construction.

In the latter theoretical frame of reference is the interest in marginal architecture expressed by this work.

The didactical experimentation which is illustrated in this book is led within the framework of the study of rural built heritage in marginal areas as a resource for the architectural design.

The study of rural marginal contexts is not only aimed at their preservation, requalification, and recovery through updating interventions, but is considered a source of inspiration to identify new paths to achieve a new quality of the built environment. Through a decisive innovation in the context of interventions on existing heritage based on traditional approaches, this study relaunches the role of the building sector as a driving force to promote inclusive and sustainable development, towards a partnership of technical scientific skills. It is precisely to follow the logic of a development that is as sustainable and inclusive as possible; today the basic architecture of rural areas deserves new attention. We can define this kind of architecture as "vernacular" because of its indissoluble link to the societies that produce it and to the environment in which it is located [30].

The principles guiding this architecture can help to overcome the limits within which the architecture of globalization and industrialization is increasingly imprisoning human habitats, tending towards standardization and consumption of environmental and energy resources. On the one hand, there is a link to the physical dimension of living, which is expressed through constructive sincerity, anchorage to places, and more generally, with a sort of hybridization between architecture, nature, and construction [31]. On the other hand, vernacular architecture in marginal rural areas is strongly linked to the place and respectful of nature's rhythms. Even though rural set- 
tlements do not necessarily have the comforts of contemporary living and do not guarantee inclusion and fairness of access to infrastructure and social services; they favor the rediscovery of authentic contact with the natural dimension of living and with human measures.

The presence of cultural heritage and typical productions could often represent a valid starting point for the launch of a development program, with the aim of both increasing the residents' well-being level and resolving any environmental criticalities [27, 32].

The study of these forms of settlement prior to industrial urbanization - and today's alternatives to it - is even more interesting following the spread of the COVID pandemic of our times, which has shown how the system of continuous and immoderate growth is not compatible with the essential right to health of the human population [33].
Starting from these considerations, the didactic experimentation carried out within the VVITA project, illustrated in the following pages, wants to sensitize the new generations of designers to the lesson given by the minor architectures present in marginal rural areas, considered as built heritage. The latter is not only considered a value to be protected, but a tool for the requalification of degraded areas or for the revitalization of abandoned areas. The aim of the design simulations led into the workshop has been to transform the condition of marginality into opportunities for experimentation of alternative and innovative habitats. The challenge posed by a project centered on the principles of vernacular architecture is therefore to transform marginal places from derelict to privileged for the observation and practice of new lifestyles and ways of living. 


\section{VVITA PROJECT}

\section{VVITA PROJECT}

VVITA is the acronym of the project called "Modernizing Learning and Teaching for Architecture through Smart and Long-lasting Partnerships leading to sustainable and inclusive development strategies to Vitalize heritage Villages through Innovative Technologies" [34]. It is inserted in the Erasmust program, measure K2 Strategic Partnership for Higher Education. It involves professors and students of the Ion Mincu University of Architecture and Urbanism of Bucharest (UAUIM), a project leader, the University of Catania (UNICT), and the Norwegian University of Science and Technology (NTNU) of Trondheim.
The project proposes a transnational cooperation that raises the question of higher education in Europe and underlines the thematic approach of the complexity of current rural heritage conditions, actual chances and challenges where the traditional division of disciplines is outdated [35]. The overall goal of the project is to enhance the quality and the relevance of higher education in architecture on current approaches of revitalization of rural build heritage environments, rural landscape, and traditional construction systems by improving and diversifying the curricula in the university partners involved in VVITA project.

\begin{tabular}{|c|c|c|c|}
\hline \multicolumn{4}{|c|}{ VVITA project team [36] } \\
\hline UAUIM & UNICT & NTNU & Associated Partners \\
\hline \multicolumn{3}{|c|}{ Partner institution Project Manager } & $\begin{array}{l}\text { The Danube Delta National Institute for } \\
\text { Research and Development (DDNI) }\end{array}$ \\
\hline Marius Voica & Vincenzo Sapienza & Luca Finocchiaro & INCD URBAN-INCERC \\
\hline \multicolumn{3}{|c|}{ Project Management Team } & Association "Ivan Patzachin - Mila 23" \\
\hline Elena Cristina Mândrescu & Ivo Caliò & Chiara Bertolin & Association Save Danube and Delta \\
\hline Mihaela Hărmănescu & Antonio Gagliano & Markus Schwai & National Institute of Patrimony \\
\hline Andra Panait & Giuseppe Margani & & Technische Universität Wien \\
\hline \multirow[t]{2}{*}{ Marina Mihăilă } & Simona Calvagna & & $\begin{array}{l}\text { International Center for the Conservation } \\
\text { of Architectural Heritage }\end{array}$ \\
\hline & Gianluca Rodonò & & \\
\hline
\end{tabular}




\section{VVITA}

Rural Forward Platform
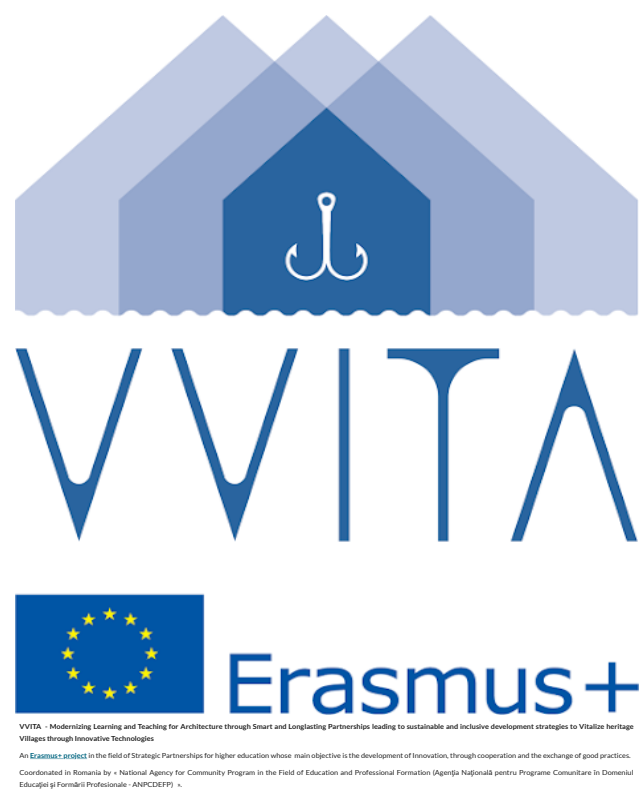

Start 001-11-2017.

$\begin{array}{llc}\text { Sfistofca } & \text { Filicudi } & \text { Lofoten } \\ \substack{\text { Danube Delta, } \\ \text { Romania }} & \begin{array}{c}\text { North Sicily, } \\ \text { Italy }\end{array} & \text { Northern } \\ \text { Norway }\end{array}$
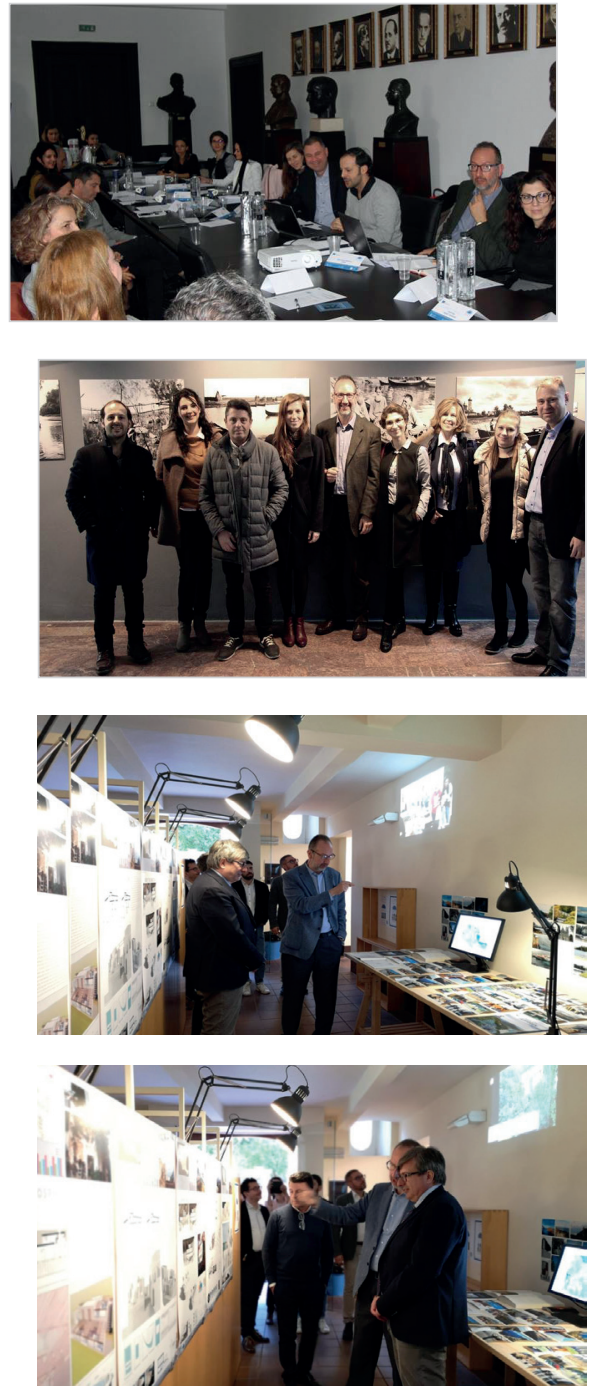
This international cooperation will take steps towards the establishment of intercultural changes and the enhancement of different learning processes and teaching modules in education tradition across cultures.

The project has a social inclusion approach in the selected local rural settlements with social, civic, interethnic, and intercultural dimensions, and disadvantaged and remote architectural heritages through the activity of the Intensive Programme (IP), hosted by each partner institution.

These IPS, which are the core of the $\mathrm{V} V I$ TA project, serve as local teaching laboratories where the proposed Innovative Teaching Module (ITM) is implemented and tested, as well as the developed methodological guideline, which will lead to a sustainable and inclusive development of strategies to vitalize the heritage of villages.

The VVITA project is directly addressed to participants of the partner higher education institutions: teachers and students, in the related disciplines of rural built heritage, but also to the associated partners and different stakeholders in academia and professions.

For Italy, the IP is hosted in the Aeolian Islands and it is called Aeolian Teaching Module (ATM); its official name is "Multicultural applied study on rural sustainable spontaneous heritages, approaching multi-inter-criteria analysis for risk evaluations of energy and mechanical performances".

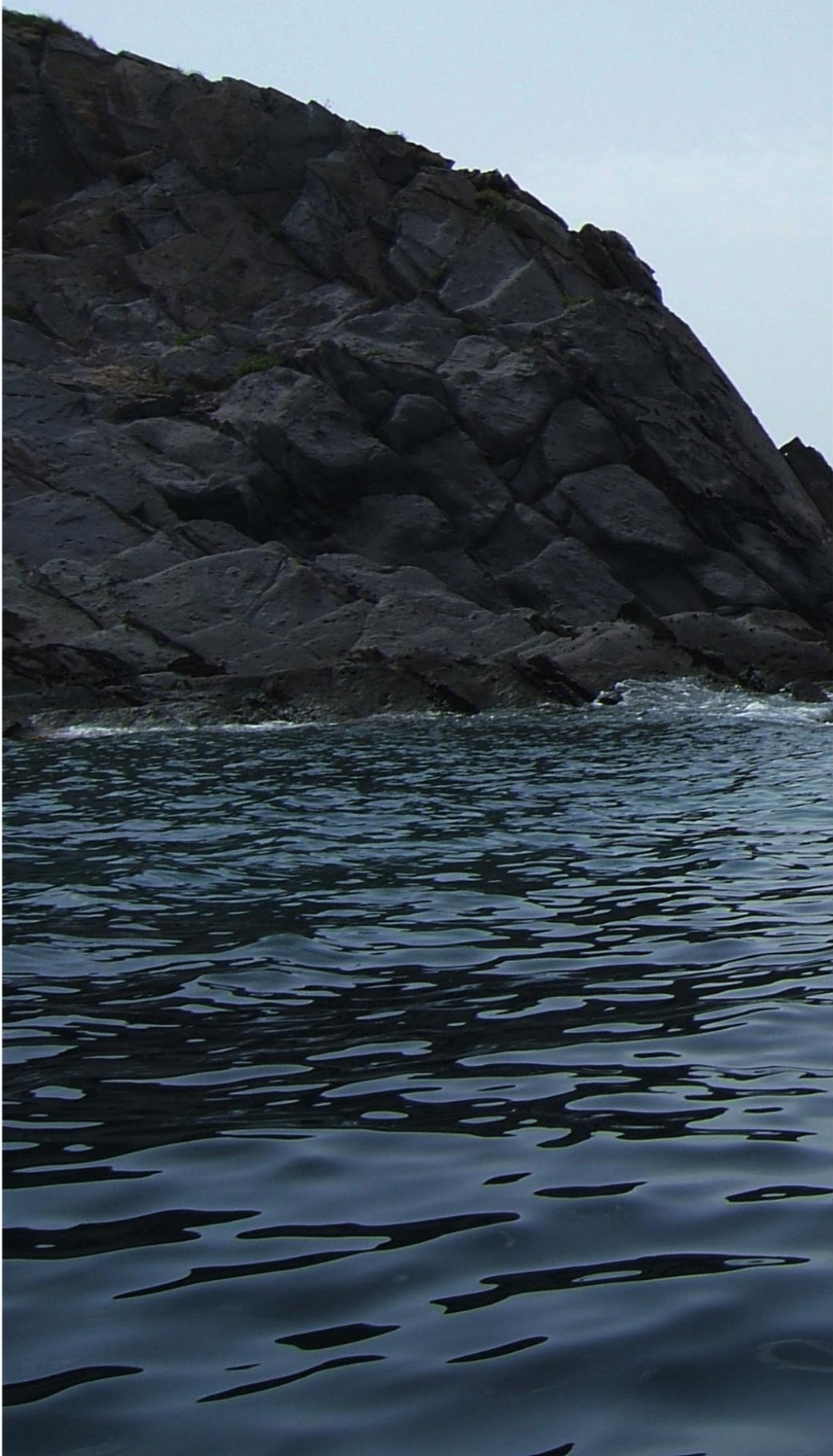




\section{COLLOCATION IN THE CURRICULUM STUDIORUM}

The ITMs of the VVITA project are addressed to students who come from the partner universities and from different degree courses. In particular, UAUIM consists of three faculties: Faculty of Architecture, Faculty of Urban Planning, and Faculty of Interior Architecture. Within its higher education expertise area, the university offers full-time degree programs that are conducted in English for the architecture fields of study and French for the urbanism field of study. All these three courses are suitable for the VVITA project.

UNICT was founded in 1434 and it is one of the oldest Italian universities. Among the most frequented degree courses, there is Engineering, which is divided in two main branches: Information and Communications Technology and Civil Engineering and Architecture. This second branch is carried out by the Department of Civil Engineering and Architecture (DICAR), with seven degree courses. Among them, a degree course in Architectural Engineering is listed. It has very high performance, because it has recognition by the European Community and also, it allows its graduates to write themselves both in the list of engineers and in the list of architects. It fits very well with the subject of VVITA.
The Faculty of Architecture at NTNU is internationally recognized for its tight connection between teaching and research activities. New knowledge is continuously developed with a critical and multidisciplinary approach in the areas of architecture, urban planning, design, and visual arts, with an emphasis on sustainability, health, aesthetics, ethics, technology, and innovative processes and learning methods. The Faculty hosts four degree courses. Among them, Architecture and Sustainable Architecture have the largest relationship with VVITA.

In theory, all students of these courses can apply to take part in the VVITA activities, but the didactic modules are specially addressed to the students of the last years of the courses. In fact, in these ones, most of the professionalizing subjects are located. The related knowledge gives to the participants the chance to take part in the work of the ITM with a proactive role and the ITM is also an opportunity to apply these ones. The ITMs are also open to PhD students, with theses related to the themes of $\mathrm{VVI}$ TA, as evaluation of risks, energy efficiency, ecological architecture, rural heritage, or a rural landscape study area. 


\section{INTENSIVE PROGRAMME IN THE VVITA PROJECT}

\section{DURATION}

According to the rules established by the EU for the IP [14], the duration of the ITM is established to be for ten days. This slot could appear short. Indeed, the shortness is not a limitation, because it makes this activity similar to professional work, in which very often the designer is pushed to get a design proposal in a short amount of time, by clients, financial deadlines, opportunities of the building companies, and so on. In a typical day of the ITM, there are eight hours of work, from nine a.m. to six p.m., with an hour for the lunch. On some occasions, some common extra activities are organized, after the daily work.

There are some exceptions to this standard organization. For instance, on the first day, the activities begin in the evening to facilitate the participation of people coming from abroad. Vice versa, on the last day, there is a free afternoon, to allow the opportunity to organize the return trip. The internal transfer, from the hosting university to the location of the workshop, takes half a day.

The total amount is seventy-two hours. Ten hours are reserved for meetings: two hours for the ice breaker meeting, three for the intermediate presentation, and five hours for the final presentation. The lectures occupy sixteen hours: usually, the first two days after the first one. Practice occupies eight hours, satisfied especially in the first half of the ITM. The workshop takes up the other part of the duration, about thirtysix hours.

It is important to compile a calendar of the activities and a timetable in advance, to allow the participants to plan their journey. As to the period of the year, it is not simple to choose the best solution, because there are some contrasting needs that are not easy to reconcile.

Firstly, it is better to choose good seasons, spring and summer, because during the workshop, it is necessary to have the possibility

\begin{tabular}{|c|c|c|c|c|}
\hline \multicolumn{5}{|c|}{ Duration of the Innovative Teaching Module of VVITA } \\
\hline \multirow{6}{*}{$\begin{array}{l}\underset{0}{0} \\
\frac{0}{x} \\
x\end{array}$} & Meetings & Ice breaker meeting & Day I & \multirow{3}{*}{$10 \mathrm{~h}$} \\
\hline & & Intermediate presentation & Day VI & \\
\hline & & Final presentation & Day $X$ & \\
\hline & Frontal lessons & $\begin{array}{l}3 \text { half days } \\
4 \text { hours for each }\end{array}$ & Day $\|$ - III & $16 \mathrm{~h}$ \\
\hline & Practices & 4 quarters of the day & Spread & $8 \mathrm{~h}$ \\
\hline & Workshop & $\begin{array}{c}4.5 \text { days } \\
8 \text { hours for each }\end{array}$ & Day $V-X$ & $36 \mathrm{~h}$ \\
\hline
\end{tabular}


of working in the open air, for surveys and direct observations. Furthermore, on the one hand, it is necessary to take into consideration that students dislike missing exams. Therefore, they prefer to have a stop during the didactic periods of their university and participate in the ITM, rather than to miss sessions of exams. This preference is not so strong in the summer exam session, because it continues for a long time. On the other hand, the final part of the courses is generally rich of the most important topics and it is not advisable to lose it. Finally, you have to take into consideration the possibility of accommodation in the location of the workshop. Therefore, it is also necessary to exclude the high touristic season, in order to have more possibilities and reduce the cost. Considering the different needs, May or September could be chosen. If you chose April, a partial overlap with the Easter Holiday may reduce the loss of university lessons. This last option could be disagreed with the professors, for the requests of their family.

It is also necessary to take into consideration the needs of the teaching staff, but generally, the timetable has the necessary flexibility to recover the lost teaching hours, while the other business of research and academy is spread uniformly.

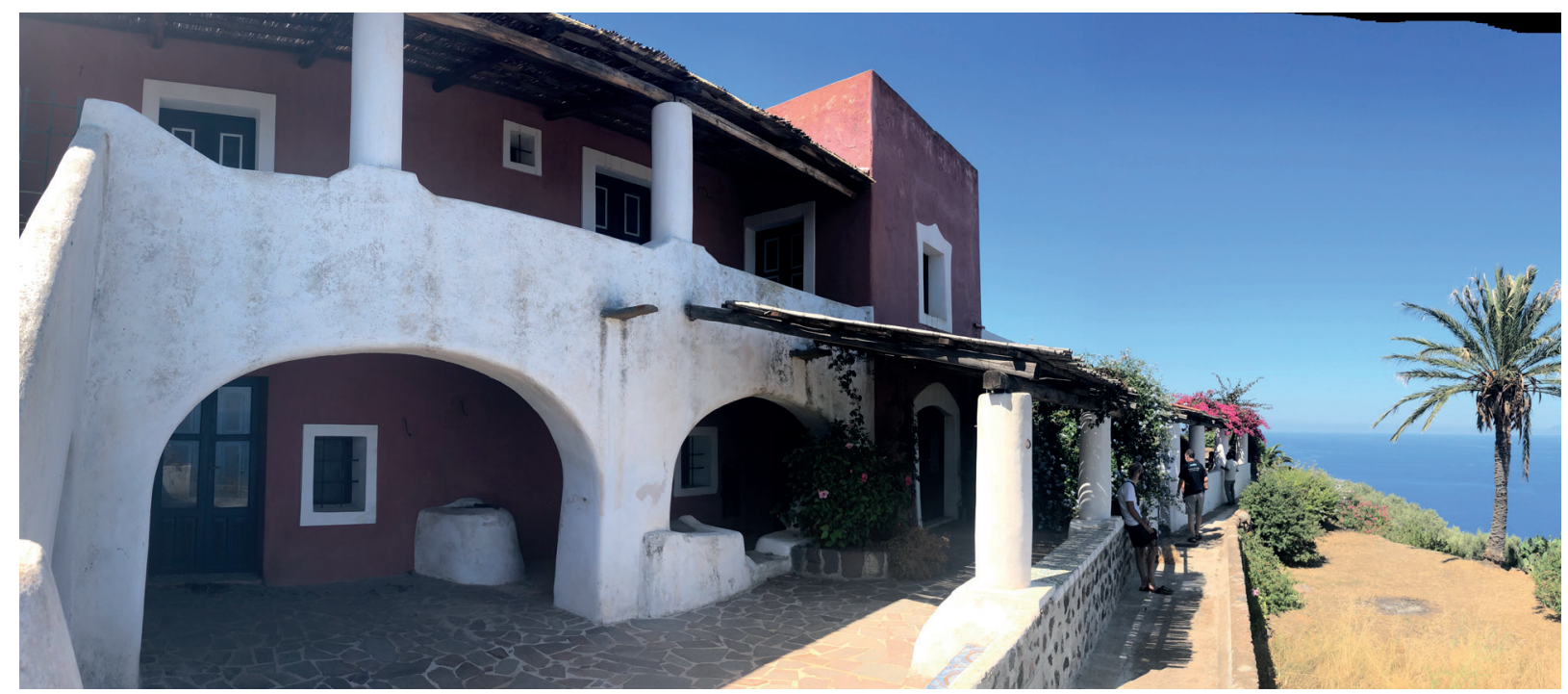




\section{PREREQUISITES}

The word "prerequisites" means the knowledge that students must have before starting the didactic activities. Their definition is a qualifying factor in the teaching design because, in case of lack thereof, the risk of inefficiency is very high. Without the need knowledge, in fact, it could be difficult to be efficient in the development of the works.

The prerequisites are not declared in the calls of the ITM because the participants must belong to the listed degree courses (and preferably, to the final years) or to PhD courses. Generally, these conditions are enough to have a conspicuous budget of knowledge in the field of architecture and engineering subjects.

In particular, ITM have two main activities: - the interpretation of the place:

- the realization of a revitalization design. In order to take part in the first activity, having good knowledge in the fields of History of Architecture, Representation Techniques, and Urbanism is required.

To take part in the second one, it is required to have a good knowledge in the fields of Architecture Design, Building Technology, Building Science, Building Physics, and Building Refurbishment and Restoration.

This list is generic; each ITM could require specific knowledge. The call of the project asks the candidates to show a list of acquired credits during their curriculum studiorum. During the selection phase, the commission of access has to check these documents because the nominations must take into consideration the knowledge already acquired by the candidates as well. At the end of the phase of selection, the commissions have to present a report to the staff, which could establish eventual adjustments of the didactic program, in order to take into consideration the level of knowledge.

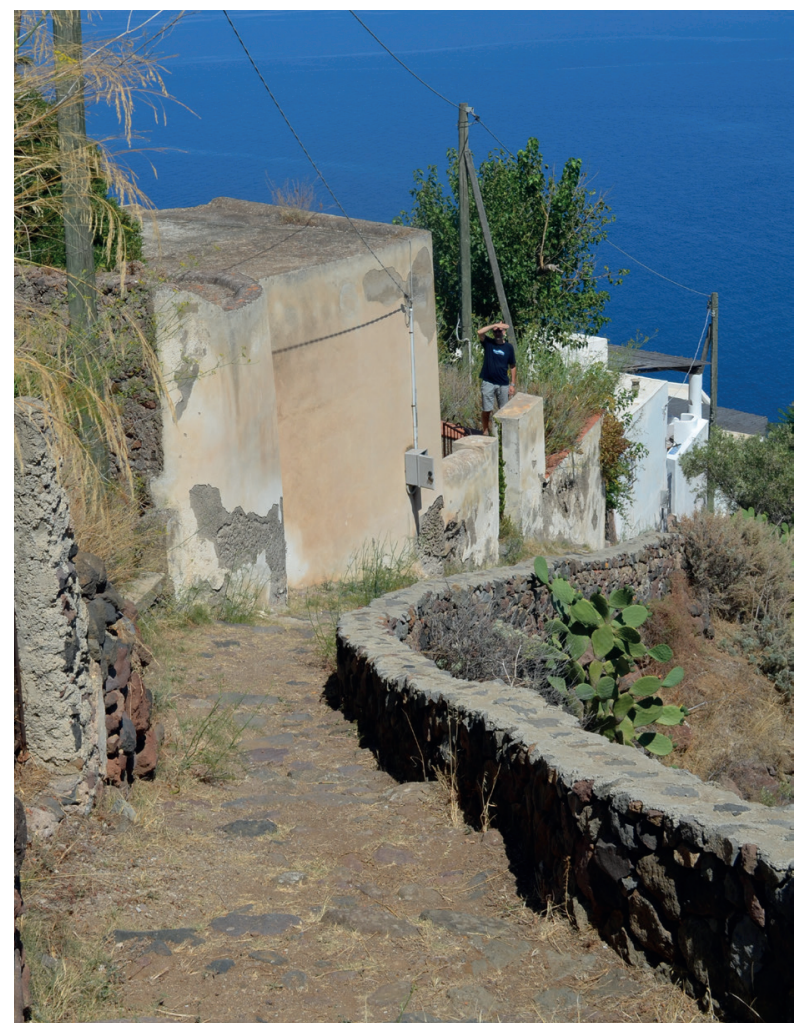




\section{STUDENTS' SELECTION}

Students are selected by following the procedure established in the project. In particular, the call of selection is published on the web site of the project and on the web sites of the partner universities. It is also advertised both in traditional and innovative ways. According to the first one, some posters are printed and located in the common parts of the buildings of the partner institutions. The call is also published through the social pages of each university department and is sent through some mailing lists, to follow an innovative way.

The call is opened at least three months before the ITM begins and it remains open for about three weeks.

As to the eligibility of the participants, students must belong to a degree course in Architecture, Urbanism/Landscape, Interior Design, Architectural Engineering, and Sustainable Architecture; it also allows in PhD students with a thesis on evaluation of Risks, Rural Heritage or Rural Landscape, and other similar themes.

Students who come from rural areas are preferred because they could take advantages from the contents of the project VVITA and increase the possibility of working in this field.

The Applicant Dossier must be composed of the following documents:

- Europass curriculum vitae: students have to specify the year of the course, passed exams with the evaluation, and the average of evaluations;
- Letter of intent (max 1 page), in which they have to show the reasons why they would like to take part in the project;

- Recommendation letter (not mandatory, max 1 page):

- Portfolio, underlying works of design, documentations, and past courses in the field of the project (built heritage, rural, sustainability in buildings, building techniques).

The list may consider other specific requests. For instance, the call may also request applicants to express a favorite field of work, in order to have a wide set of competences in the working group of the workshop.

Students have to apply by sending the form by email to the members of the project team, who are called to carry out the selection process. The process of selection is composed of two sessions: the first one is evaluation of the documents; the second one is an interview with each applicant this is not mandatory.

In the case of the number of applicants being lower than the number of positions, an extension of the deadline or a re-opening of the call are possible.

The students must be informed that they will receive a grant; the university may prefer to give a refund of the costs. In any case, it is not possible to exceed the unit costs determined by the European Commission, according to the Erasmust guideline and what the project VVITA establishes. 


\section{METHODOLOGY}

The ITM begins with the ice breaker meeting. It is addressed to stimulate the mutual knowledge of the members of staff. It may provide a tour of the city of the host university.

The teaching activity is composed of different parts, all connected among them, as to form a system. These parts are structured in the following way.

- LECTURES: The first phase of the ITM is dedicated to theory aimed at providing the knowledge necessary to carry out the workshop activities. These lessons are addressed both to cultural and technical issues; for the first subject, for instance, the historical evolution of the place, landscape features, and architectural characteristics may be focused on; for the second one, for instance, climate conditions, building characteristics, and technical software may be treated.

- PRACTICE: The lectures are accompanied by practice on the same subject. Thanks to this, the students have the possibility to contextualize knowledge, to apply skills, and to mature competences. Practice is mostly concentered in the first half of the module to intensify the relation with the linked lecture.

- WORKSHOP: Each partner of VVITA has chosen a place in which to have a design exercitation.
They are marginal and underexploited, even if they are located in touristic areas. They are also places in which there is a strong relation between architecture, landscape, and sea.

The workshop takes place in these chosen locations and consists of an immersive activity. Students are divided into heterogeneous work groups. A study area is assigned to each group, for the analysis.

The transfer journey to the location of the workshop takes place after the lectures and the related practice. It has some intermediate stops, in significant places. This way, the participants, have the possibility to approach gradually the landscape features and the cultural issues of the place.

On the first day of the workshop, it is good to organize a walk with all participants. It could also be an opportunity to visit all the buildings chosen as case studies. Before starting the workshop, it is important to explain the tasks. With a better knowledge of the place, the students could have a different perception of the work required. The attention must be addressed to the main elements of the place, i.e., relation between architecture and context, materials that are used in the construction process, water and waste systems, natural ventilation, daylighting, and so on.

The assignment of the case studies is realized thanks to a lottery, in order to give each group the same possibility. Working groups are formed so as to have represen- 


\begin{tabular}{|c|c|c|}
\hline & of the Innovative Teaching & VITA \\
\hline \multirow{2}{*}{ I day } & Arriving of the participants & \multirow{4}{*}{ Venue of the university } \\
\hline & Ice break meeting & \\
\hline Il day & \multirow{2}{*}{ Frontal lessons + practice } & \\
\hline III day & & \\
\hline \multirow{3}{*}{ IV day } & Internal transfer & \multirow{3}{*}{ Intermediate stop } \\
\hline & Approach to the location & \\
\hline & Practice & \\
\hline \multirow{2}{*}{$\vee$ day } & Acclimatization & \multirow{9}{*}{ Location of the workshop } \\
\hline & Workshop & \\
\hline \multirow{2}{*}{ VI day } & Workshop & \\
\hline & Intermediate presentation & \\
\hline \multirow{2}{*}{ VII day } & Workshop & \\
\hline & Practice & \\
\hline VIII day & Workshop & \\
\hline IX day & Workshop & \\
\hline \multirow{2}{*}{$x$ day } & Final presentation & \\
\hline & Going back of the participants & \\
\hline
\end{tabular}

tatives of all nationalities and of gender, in each of them.

The assigned tasks to students must be clear and proportioned to the real possibility to complete them. On the one hand, it is necessary to have a large range of requests, to meet the preferences and to improve the knowledge of the students. On the other hand, it is necessary to limit the requests, to improve the quality of the output. The tasks must approach different scales (districts and buildings), different subjects (architectures and technologies), and different results (knowledge of the place and revitalization designs).

The choice of the case studies is very important. It is possible to list the attributes that they must have. The case studies must 
represent the features of the place, but they must also have some peculiarities able to keep the attention of the students and to stimulate ideas for refurbishment design. Boundary and volume must be completely defined, but they can be ruined buildings or incomplete spaces. Finally, they must be easily accessible and easy to survey. Therefore, the staff have to choose the case studies with attention.

Along the ITM, two assessments are located, the final and the intermediate presentation of the students' work. In both of these, the working groups are called to show their work. In the first one, the teaching staff gives corrections and advice to each one. In the second one, they will highlight the strengths and weaknesses of the works.

It is good to prepare a booklet of the ITM.

This document has to show:

- synthesis of the didactic activities;

- description of the location;

- learning outputs;

- tasks for students;

- expected outcomes;

- working groups;

- links with other disciplines;

- calendar and timetable of all activities;

- practical and touristic information;

- suggestions for accommodations.

The booklet must provide also images of the locations, historical information, photos and descriptions of the case studies, maps of places, with the indication of meeting points and of transfers, and even blank pages, to use for notes. The booklet may be available online, or sent by email, to all participants. It is good to print a number of hard copies to deliver to the participants. By providing them with a badge, it is possible to help people to remember each other's names.

This could be informal (pins, bangles, or necklaces).

The didactic activities may be accompanied by collateral activities, that must have two goals:

- to increase the knowledge of the place;

- to increase the relationship among the participants.

These activities must be listed in the program because they could be relevant for someone, in relation to the assigned case studies or the specific task.

To obtain the first goal, these kinds of activities can be considered:

- Meetings, with someone who lives or works in the place, who can explain the strengths and weaknesses of the place, by telling of his experience;

- Seminaries, with experts of subjects related to the main interests of VVITA;

- Cineforum, with a film set in the spot;

- Visits to monuments, museums, belvederes, and so on.

For the second goal, these activities can be considered:

- Common lunches, dinners, or happy hours;

- Role-playing games;

- Sport activities (footing, trekking, hiking). 

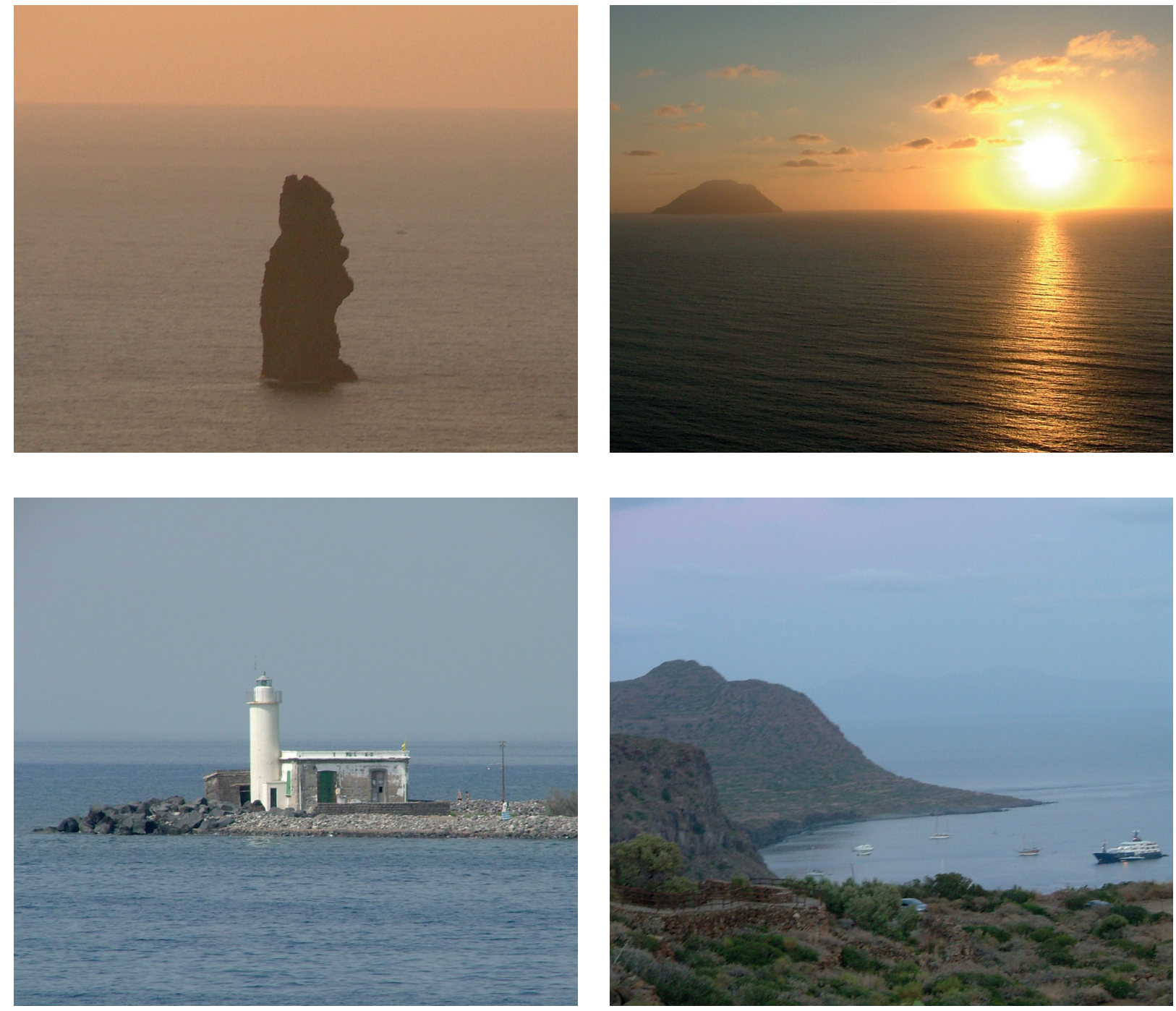


\section{ASSESSMENT CRITERIA AND METHODS}

The ITM learning process is based on the idea that design is the main educational tool in the architecture learning field. The student can experience his learning process through his insights and reasoning about his design proposal. The design proposal "mirrors the cognitive processes that take place in the mind of the student. Through the design proposal, the student situates himself in society and culture. The design proposal mediates teaching, and carries on the learning process" [36].

Therefore, the assessment of the learning outcomes is made through the evaluation of the coherence among the process, the visual representation of the design, and the previous analysis carried out in the field.

The management of the design process can be considered the main learning outcome of the ITM: through this process, students can

\begin{tabular}{|c|c|c|}
\hline \multicolumn{3}{|c|}{$\begin{array}{l}\text { Main learning outcomes of the Innovative } \\
\text { Teaching Module }\end{array}$} \\
\hline knowledge & skills & competences \\
\hline $\begin{array}{l}\text { principles and } \\
\text { strategies to } \\
\text { revitalize the local } \\
\text { built heritage }\end{array}$ & $\begin{array}{l}\text { use of specific } \\
\text { modelling } \\
\text { methods and } \\
\text { inter-disciplinary } \\
\text { design and } \\
\text { software }\end{array}$ & $\begin{array}{l}\text { application of } \\
\text { the acquired } \\
\text { knowledge } \\
\text { and skills on the } \\
\text { assigned site } \\
\text { environment }\end{array}$ \\
\hline
\end{tabular}

apply the acquired knowledge and skills on the assigned site. The assessment criteria related to the design process more specifically are:

- coherence between the conceptualization of the analysis carried out in the field and the design choices;

- depth and accuracy of the reading of the context information;

- ability in revitalizing the local built heritage through specific actions.

The evaluation of the outputs is realized by the staff during the workshop activities, with intermediate and final presentations of the work and public discussions and debates.

The students are also called to present a final report and a poster of their complete work, in order to show their learning experience. This request pushes them to have critical reflections on the work they have done. 


\section{POST-PROCESSING}

The final outputs of the ITM are refurbishment designs of local buildings or small areas, assigned as case studies. The word "design" must be taken in a wide meaning. In fact, the design could be composed of drawings and sketches but also by analysis, measures, thematic charts, and so on. In addition, the design could be addressed in various directions: from large scale, to detailed drawings; from numerical modelling, to aesthetical concept, and so on.

Each group of students must present its work at the end of the ITM. After, it has to compile a final report, within the deadline fixed by the teaching staff and according to a common layout. Both of these performances will be processed by the staff in order to evaluate the quality of the work and the achievement of the previewed outcomes to give to the participants the profit certificate.

The reports will be collected and published on the web site and in the final book of the project. The reports will be considered also in other dissemination activities, such as conferences.

The students may be called to produce further outputs, related to the collateral activities, as photos, videos, notes, or sketches. They will be used especially in the communication activities as exhibitions or competitions.

At the end of the ITM, the participants are also asked to compile a personal evaluation form. With it, they can highlight both the strengths and weaknesses of the module. The analysis of these data must be used in the design of other ITMs.

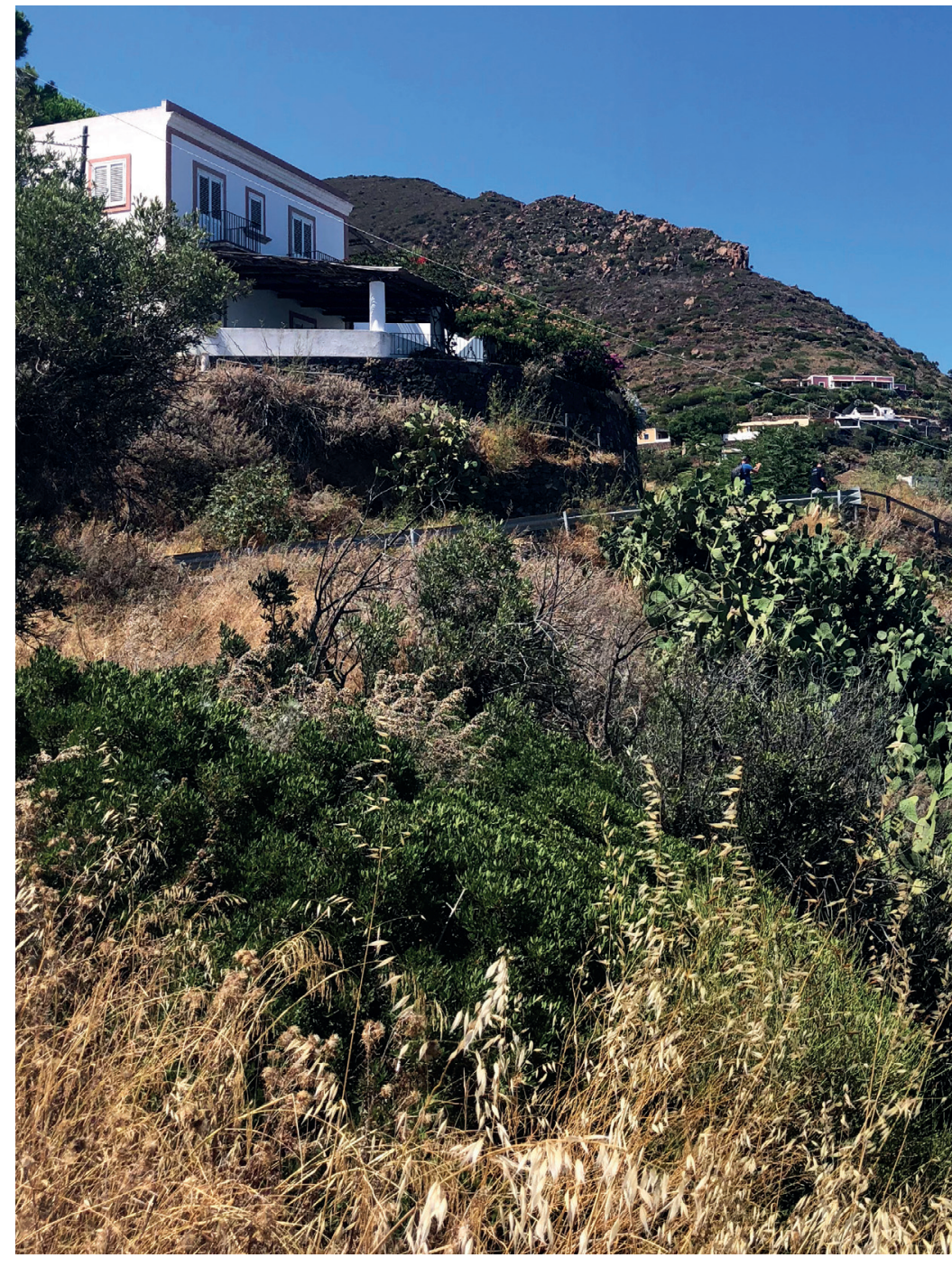




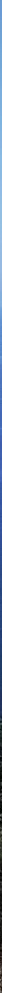




\section{SWOT ANALYSIS AND INNOVATION}

SWOT analysis [36] is a good tool to evaluate the main aspects of the ITM and to highlight the items that are important to control during its development.

- STRENGTHS: The main goal of the ITM is to design the revitalization of a particular place. For this reason, the possibility of living and working on this site is an important advantage to deepen the knowledge and interpretation of the site.

Knowledge of the location is already the first goal; in fact, thanks to the particularity of the chosen places, direct knowledge can improve the cultural background of the participants, both students and professors.

The nature of the ITM is multinational; this is an important richness because during meetings and practical works, it is possible to compare different opinions and points of view, which often arise from the participants' cultural background. These different views, opinions, and approaches create a big tank of possibilities.

The teaching staff of the ITM is varied; they have different ages, gender, and backgrounds. Each component brings interest into/inside the project. For this reason, goals and outputs have a multicultural nature. This is an important power point because gives the participants, especially the students, the ability to have a global approach to the subjects.

- OPPORTUNITIES: The VVITA project plans three ITMS, each one in a different partner country. Therefore, the participants have the opportunity to relate themselves with the other participants on different occasions, and in different places, with different building traditions. This means that not only are the local challenges of interest and will be dealt with, but also the particularity of each place's traditional way of doing things/of building things will be transferred knowledge.

The official language of the ITM is English. Generally, university students have a good level; nevertheless, the ITM is for them an opportunity to improve their knowledge of technical terms and idiomatic expressions.

- WEAKNESSES: The duration of the ITM must necessarily be short, to reduce the overlap with the regular university courses. For this reason, it is very important to control the development of the period and to respect the timetable.

Again, the short time makes the knowledge among the participants superficial. For this reason, the performance of the working groups may be not optimal.

Another point to take under control is the costs of the ITM, because the project has a maximum amount to refund to the participants. To avoid extra costs, it is very important to organize transfers, accommodation, and food, in advance.

Another challenge here is the language. Although, as described above, it is common to use English as a working language, the lack of enough words to describe situations, other than technical ones (which may 
be described with drawings), often leads to misunderstandings and thereafter to social inferences. This must be tackled because a side goal of the ITM is also to be a base for learning, to get to know other people, and friendships.

- THREATS: Since most of the activities during the ITM are outdoors and one particularity of the ITMs is its distant location, at difficult to reach points, the local climatic and weather conditions are a relevant fact. It is impossible to plan these, so it becomes an important part of planning alternative shuffling of activities.

Another local challenge is that most of the buildings are not inhabited and are therefore, often difficult to access. This is another theme to think about when planning. The shortness of the ITM could be a problem to balance the learning load. The period is full of activities llectures, practice, transfers, surveys, drawings, and so on) and so the risk of reducing the deepening of each activity and the quality of the outputs is very high.

The locations of the ITM are very interesting places, out of the common touristic tours. The participants could have the curiosity to discover these places and this could be a distraction from the production of the outputs.

It is very important to make the groups of students as homogeneous as possible, with the ice breaker meeting and with collateral activities, because it is important to contrast the trend of forming subgroups of students of the same nationality.

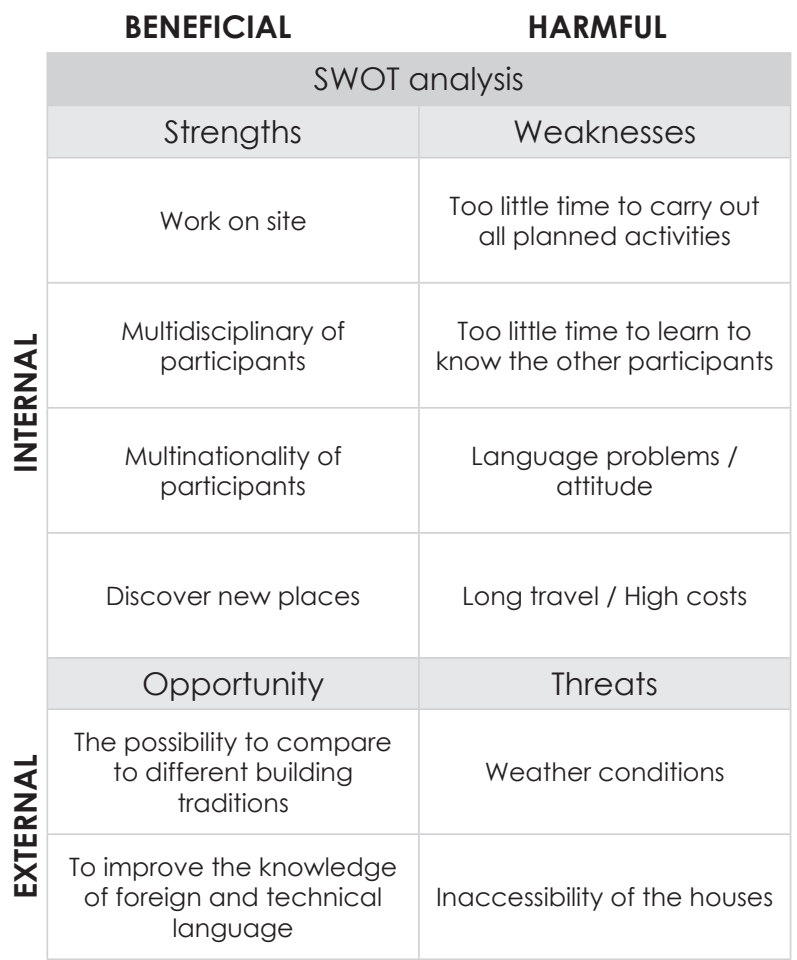




\section{REFERENCES}

[1] "European Higher Education Area" [Online]. Available: http://www.ehea.info/ (accessed on October, 2019).

[2] Luttazzo, G., La progettazione della didattica universitaria per risultati di apprendimento, in L. Galliani, C. Zaggia, A. Serbati (a cura di), Apprendere e valutare competenze all'università, Pensa Multimedia, Lecce 2001 (in Italian).

[3] "Consolidating the EHEA" [Online]. Availabe: http://www.processodibologna.it (in Italian), (accessed on October, 2019).

[4] Framework for the Qualifications of the European Higher Education Area. Ministry of Science, Technology and Innovation: Copenhagen, 2005.

[5] Joint Qualitative Initiative group, Shared "Dublin" descriptors for Short Cycle, First Cycle, Second Cycle and Third Cycle Awards, 2004.

[6] Standards and Guidelines for Quality Assurance in the European Higher Education Area, EURASHE; Brussels. 2015.

[7] "Standards and Guidelines for Quality Assurance in the European Higher Education Area" [Online]. Available: http://www.bdp.it/lucabas/lookmyweb/templates/up_files///Processo_Bologna/ENQA_report.pdf, (accessed on October, 2019).

[8] "European Commission" [Online] Available: https://ec.europa.eu/italy/ (in Italian), (accessed on October, 2019).

[9] European Parliament, Recommendation 2008/C 111/01/CE, Recommendation of the European Parliament and of the Council of 23 April 2008 on the establishment of the European Qualifications Framework for lifelong learning; Official Journal of the European Union, No. 51 in 5-6-2008; European Community: Bruxelles, 2008.

[10] "Tuning Educational Structures in Europe" [Online]. Available: http://www.unideusto.org/tuningeu/home.html (accessed on October, 2019).

[1 1] Lokhoff, J., Wegewijs, B., Durkin, K., Wagenaar, R., González, J., Katherine Isaacs A., Donà dale Rose, L., F., Gobbi, M.; A Tuning Guide to Formulating Degree Programme Profiles, Groningen and The Hague: Bilbao, 2010

[12] "Sofia Corradi - Mamma Erasmus" [Online]. Available: https://www.sofiacorradi.eu (accessed on October, 2019).

[13] "Erasmus Programme" [Online]. Available: c.europa.eu/programmes/erasmus-plus/about_en (accessed on October, 2019).

[14] "Welcome Europe" [Online]. Available: www.welcomeurope.com (accessed on October, 2019).

[15] Peritore C., Silvestri L.; Rapporto Annuale Erasmus a.a. 2012/2013, Indire: Rome, 2014, p. 29 (in Italian).

[16] Decision No.1720/2006/EC of the European Parliament and of the Council of 15 November 2006. 
[17] "Lifelong Learning Programme 2007-2013" [Online]. Available: https://en.wikipedia.org/wiki/Lifelong_ Learning_ Programme_2007\%E2\%80\%932013 (accessed on October, 2019).

[18] Pitoni I. (cured by); Rapporto annuale di monitoraggio Erasmus+ 2017, National Agency Erasmus+: Rome, 2019, p. 22 (in Italian).

[19] Marini S. Nuove Terre. Architetture e Paesaggi Dello Scarto. Macerata: Quodlibet; 2018 (in Italian).

[20] Augé M. Non luoghi. Introduzione a un'antropologia della surmodernità. Milano: Elèuthera; 2009 (in Italian).

[21] Nijman J, Wei YD, Urban inequalities in the 21st century economy, Applied Geography 117: 1-8, 2020.

[22] "Renzo Piano G124" [Online]. Available: https://www.renzopianog124.com (accessed on October, 2019).

[23] AMO, Koolhaas R. Countryside, A Report. Köln: Tachen; 2020.

[24] United Nations, Department of Economic and Social Affairs, Population Division, World Urbanization Prospects: The 2018 Revision, Methodology, Working Paper No. ESA/P/WP.252: New York, United Nations, 2018.

[25] Lefebvre H. The Urban Revolution. Minneapolis: University of Minnesota Press; 2003.

[26] Brenner N. Stato, spazio, urbanizzazione. Milano: Edizioni Angelo Guerini e Associati; 2016 (in Italian).

[27] Calvagna S., Gagliano A., Greco S., Rodonò G., Sapienza V.; Innovative Multidisciplinary Methodology for the Analysis of Traditional Marginal Architecture, Sustainability vol. 12 (4), 2020.

[28] Aymerich C, Dell'acqua AC, Fatta G, Pastore P, Tagliaventi G, Zordan L (a cura di). Architettura di base. Firenze: Alinea; 2007.

[29] Koolhaas R, Mastrigli G. (a cura di), De Pieri F. (trad. it. di), Junkspace. For a radical rethinking of the urban space, Macerata: Quodlibet; 2006.

[30] Noble A G. Traditional Buildings: A Global Survey of Structural Forms and Cultural Functions. London and New York: I.B. Tauris \& Co. Ltd; 2007.

[31] Calvagna S, Finocchiaro L, Sapienza V, Rodonò G. Ripensare vernacolare: per un'architettura tra paesaggio e tettonica. In: Conte A, Guida A, (a cura di) Patrimonio in divenire. Conoscere valorizzare abitare. Reuso Matera 2019. VII Convegno internazionale sulla documentazione, conservazione e recupero del patrimonio architettonico e sulla tutela paesaggistica. Roma: Gangemi Editore; p. 2327-2340, 2019 (in Italian).

[32] Ciaschi, A.; De Iulio, R. Aree Marginali e Modelli Geografici di Sviluppo. Teorie e Esperienze a Confronto; Sette Città: Viterbo, Italy, 2014 (in Italian). 
[33] Acuto M, COVID-19: Lessons for an Urban(izing) World, One Earth 2: 317-319, 2020.

[34] "VVITA - Rural Forward Platform" [Online]. Available: https://sites.google.com/view/vvita/home, (accessed on October, 2019).

[35] Sapienza V., Bertolin C., Caliò I., Finocchiaro L., Gagliano A., Hărmănescu M., Mândrescu E. C., Margani G., Mihăilă M., Panit A., Roronò G., Voica M.; VVITA project - sustainable and inclusive development of strategies to vitalize villages through innovative architecture technologies. In: 4th Biennial of Architectural and Urban Restoration (BRAU4), CICOP ITALIA: Florence, 2018.

[36] Pauwels, S., De Walsche, J., Declerck, L.; Architectural education and quality assurance in the European Higher Education Area: Design Research as a Plea for Academic Freedom. Open House International, 40(2), 63-73, 2015.

[37] Comino, E., Ferretti, V.; Regional energy planning through SWOT analysis and strategic planning tools.: Impact on renewables development, Renewable and Sustainable Energy Reviews, No. 11-6, pp. 1275-1287, 2007.

\section{Vincenzo Sapienzo}

Department of Civil Engineering and Architecture, University of Catania, Italy Mail: vincenzo.sapienza@unict.it

\section{Marius Voica}

Department of Architecture, Ion Mincu University of Architecture and Urbanism, Romania. Mail: mvoika@yahoo.com

\section{Luca Finocchiaro}

Department of Architecture and Technology, Norwegian University of Science and Technology, Norway.

Mail: luca.finocchiaro@ntnu.no

\section{Simona Calvagna}

Department of Civil Engineering and Architecture, University of Catania, Italy.

Mail: simona.calvagna@unict.i†

\section{Gianluca Rodonò}

Department of Civil Engineering and Architecture, University of Catania, Italy. Mail: gianluca.rodono@unict.it

\section{Markus Schwai}

Department of Architecture and Planning, Norwegian University of Science and Technology, Norway. Mail: markus.schwai@ntnu.no

\section{Mihaela Hărmănescu}

Urban Plannig Faculty, Ion Mincu University of Architecture and Urbanism, Romania.

Mail: mihaela.harmanescu@gmail.com

\section{Elena Cristina Mândrescu}

Department of Architecture, Ion Mincu University of Architecture and Urbanism, Romania.

Mail: cristinamandrescu@yahoo.com 
AEOLIAN TEACHING MODULE DESIGN

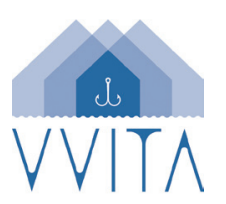




\section{LOCATION}

\section{AEOLIAN CONTEXT}

As the location for the Italian ITM of the VVITA project, the Aeolian Islands have been chosen; they are situated off the northern coast of sicily, less than 12 nautical miles from the Cape of Milazzo.

As it is known, the name refers to Aeolus, the Greek god of the winds, to highlight this characteristic. Ulysses, the Homeric hero, stopped here during his long voyage, and received a goatskin by the god, as a present. In it, there were collected all the winds to not disturb his sail back to Ithaca. The companions of Ulysses, jealous and ignorant, opened it to inspect, rousing a storm that shipwrecked themselves.

There are seven large inhabited islands and numerous rocky outcrops. The largest of the "Seven Sisters" (as the locals call them) is Lipari; it has assumed, since times gone by, the role of capital of the islands, even though Salina island has a larger economic presence. Their history is documented since the ancient times. Along the different ages, they had very prosperous periods, such as the free kingdom of the Eolinidi people during the VI century B.C. or the colonization of Lord Ruggero D'Altavilla The Normand; and depressed periods, for example the surrender to the Roman fleet of the Consul Aurelio Cotta during the Punic Wars (252 B.C.) or the sack of the Saracen pirate Ariadeno, called Barbarossa, in 1544 [1]. Recently, the Aeolian Islands have been rediscovered by the general public thanks to 'Stromboli', a famous Roberto Rossellini movie, played by Ingrid Bergman in 1949. It told a strong and tragic love story, in reference to a similar visual landscape.

Filicudi is located in the Western arm formed by the islands; it is one of the most isolated, with the nearer one, Alicudi. Although Stromboli is further off the Sicilian coast, Filicudi and Alicudi are more isolated by the fact that they are a considerable detour from the Milazzo-Lipari-Naples route, the most frequented by the merchant ships (in the past) and by the touristic ones (today). Nevertheless, Filicudi boasts the longest history: a prosperous community, that traded obsidian, lived in the little hill of Cape of Graziano, from the Neolithic to the Bronze Age. The relation between the inhabitants and the Natural Environment has created a tremendous landscape that is the result of an industrious work of the land. It is also recognized by UNESCO, which put the Aeolian Islands in its World Heritage List in 2000 [2]. Thanks to the isolation that has already been highlighted, Filicudi Island has preserved its landscape in a more efficient way.

In particular, it is characterized by two factors: the geomorphology of the soil and climate conditions. The first of them has an influence on human infrastructures, the second one on the architectural elements. During the past centuries, the local people have created an elaborate terracing system, with lava stone walls in Cyclopean Opus, to be able to cultivate their hilly estates. Nowadays, they are not in pristine condition, owing to the lack of maintenance, because the number of locals has 

reduced and the cultivable areas, with less accessibility, have been abandoned.

The climatic conditions of the island are those typical of Mediterranean countries (mild weather during the winter and hot dry summers), but here, these climatic conditions are extreme. The summer temperatures are up to $40^{\circ} \mathrm{C}$ for several days, and precipita- tion is limited to $30 \mathrm{~mm}$ for the entire summer (5\% of the total). Moreover, they are buffeted by strong Westerly winds (6-17 knots) [3]. To defend themselves from these adverse conditions, especially during the summer, the Filicudian builders set up a perfect machine à habiter, a comfortable, friendly place with quasi zero energy consumption.

\begin{tabular}{|c|c|c|c|c|c|}
\hline \multicolumn{6}{|c|}{ Climatic conditions [4] } \\
\hline & SPRING & SUMMER & AUTUMN & WINTER & YEAR \\
\hline \multicolumn{6}{|c|}{ TEMPERATURE $\left({ }^{\circ} \mathrm{C}\right)$} \\
\hline average maximum & 22 & 30 & 24 & 15 & 22.8 \\
\hline average minimum & 15 & 22 & 17 & 11 & 16.2 \\
\hline average daily range & 7 & 8 & 7 & 4 & \\
\hline \multicolumn{6}{|c|}{ RELATIVE HUMIDITY (in \%) } \\
\hline average on $7 \mathrm{~h}$ & 74 & 70 & 76 & 78 & $74-75$ \\
\hline average on $13 \mathrm{~h}$ & 60 & 55 & 64 & 70 & 62 \\
\hline \multicolumn{6}{|c|}{ CLOUD COVER DAYS } \\
\hline Clear or almost (0-1/8) & 20 & 45 & 24 & 13 & gg. 102 \\
\hline Cloudy (2-3/8) & 28 & 26 & 24 & 22 & gg. 100 \\
\hline cloudy-variable (4-6) & 25 & 15 & 25 & 28 & 99.93 \\
\hline overcast (7-8/8) & 19 & 6 & 18 & 27 & gg. 70 \\
\hline \multicolumn{6}{|c|}{ RAINFALL } \\
\hline precipitation & mm. 130 & 30 & 210 & 230 & $\mathrm{~mm} .600$ \\
\hline No. rainy days & 16 & 6 & 18 & 22 & tot. 62 \\
\hline \multicolumn{6}{|c|}{ PREVALENT WINDS } \\
\hline & \multicolumn{5}{|c|}{ northwesterly (Maestrale); westerly (Ponente); southeasterly (Scirocco) } \\
\hline
\end{tabular}



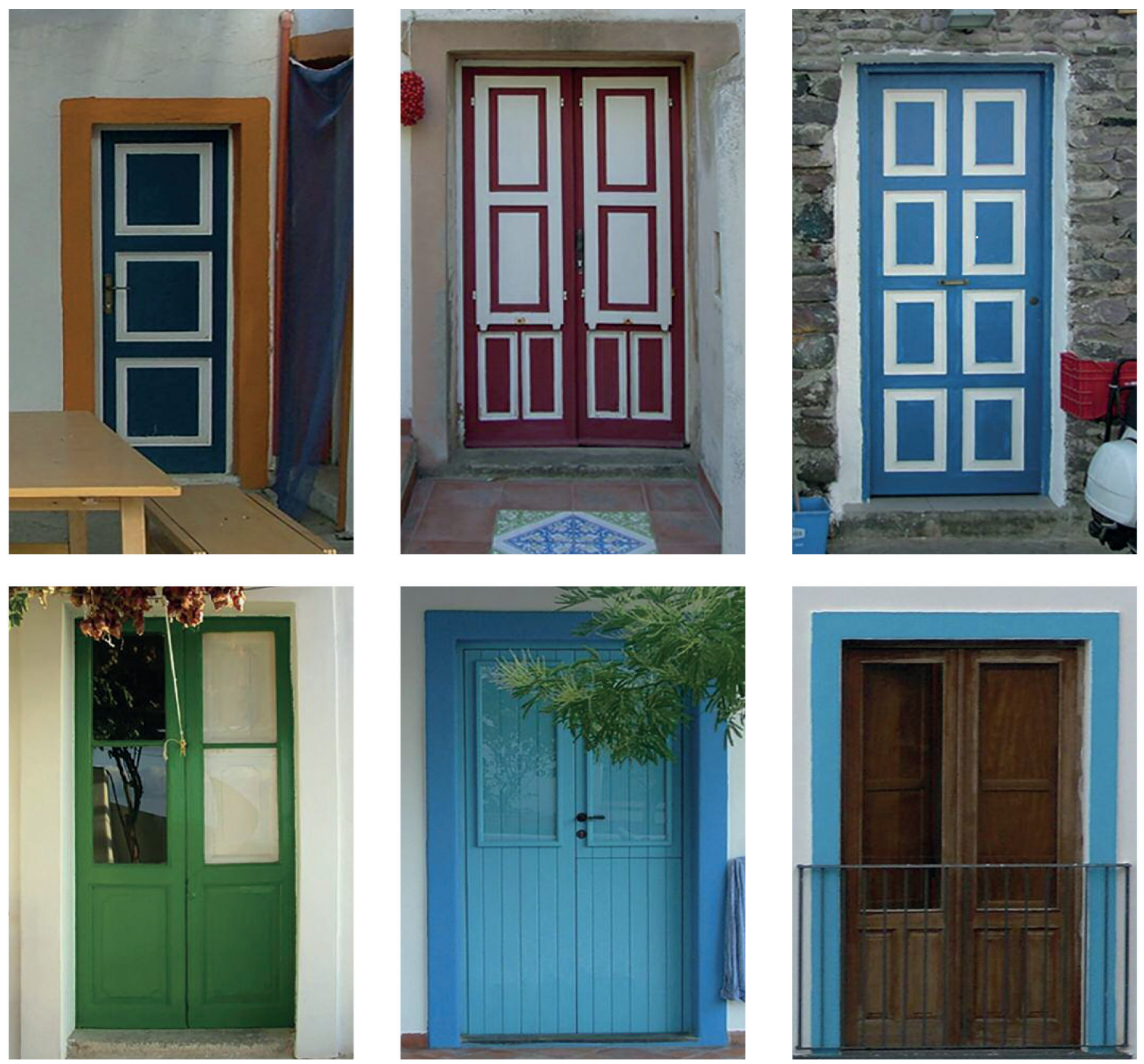


\section{CHARACTERISTICS OF AEOLIAN HOUSES}

As has already been said, on the isle of $\mathrm{Fi}$ licudi, the characteristics of the Aeolian houses have preserved their original shape, according to its isolation.

The Filicudian houses are organized on two levels, in general on two independent ones; the staircase is outdoors. The rooms are very large, squared, and directly interconnected, without a corridor; they are situated along two parallel lines, so the building has a quite regular volume, with two fronts: generally, one to the south and another one to the north.

A large terrace (called in local dialect bagghiu [4], from the Arabic word bahah for court) is set up in the front of the house, while at the back, there is a little yard. In the past, the front terrace was also used to work the rural products, it ends with a masonry seat (the bisolu [4]); its back is the parapet of the terrace. Sometimes, especially for the two-level houses, the bagghio is covered by a portico; its roof forms the terrace of the upper level.

The volcanic nature of the Aeolian Islands makes them particularly exposed to earthquakes and strongly influences the masonry type. In response to this circumstance, local builders have set up a really efficient construction system: with vertical elements that are firm and strong and horizontal elements that are light and flexible.

The masonry is composed of rough, basaltic stones. The edges of the building are built with squared stones, bigger and denser, to have a firmer construction. The walls are 60

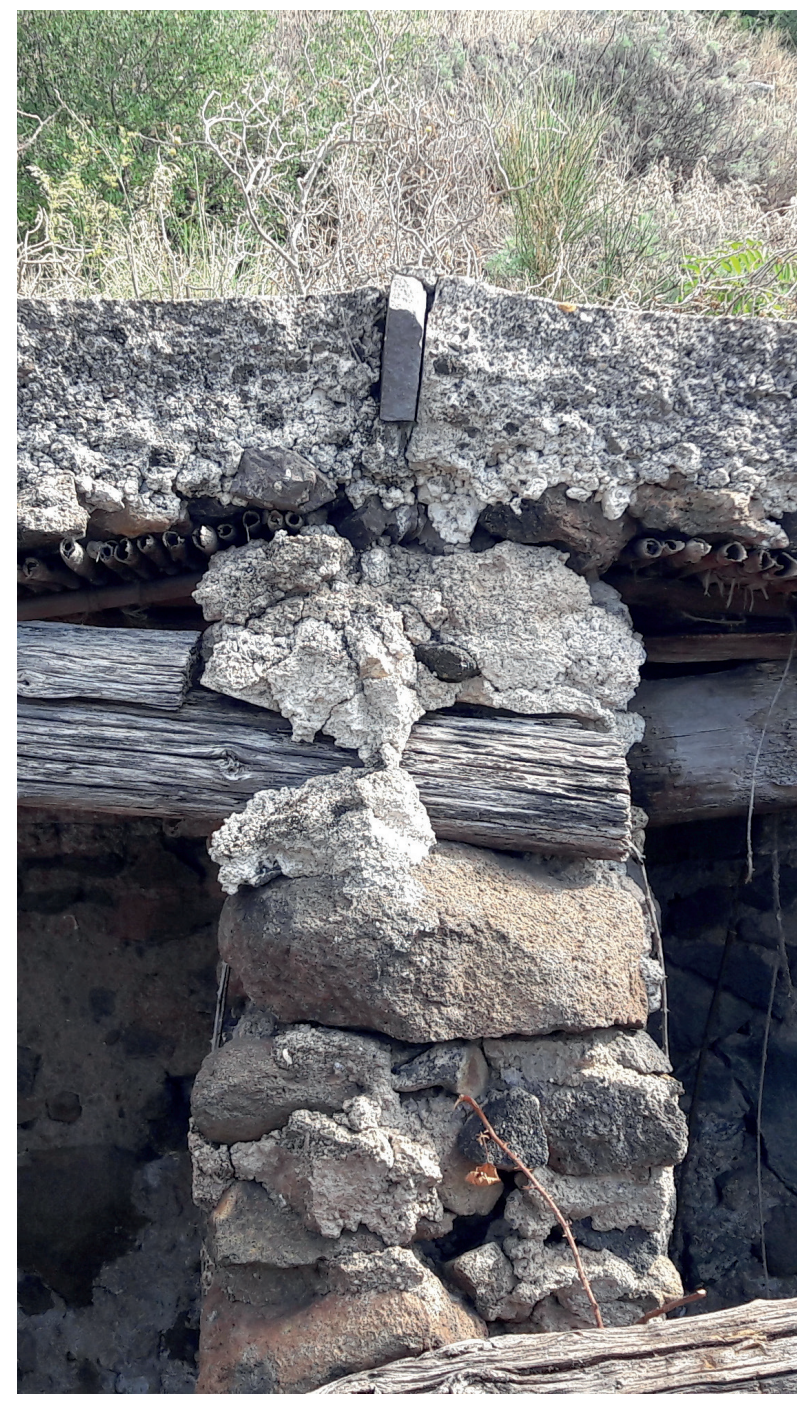


$\mathrm{cm}$ thick, on the ground floor, and $50 \mathrm{~cm}$ on the upper one [5].

The roofs are framed with a series of wooden beams, with a diameter of $15 \mathrm{~cm}$ and spaced by $50 \mathrm{~cm}$, that are inserted in the wall for two-thirds of its thickness, after pitching their ends to be waterproofed. A stronger beam (diameter $25 \mathrm{~cm}$ ) is set up orthogonally to them, as a cross-piece. The beams are walnut tree trunks, roughly decorticated, so their section is considerable tapered [6]. Cane roofing is set up on the upper side, framed on the wooden beams. The extrados is formed by a casting of lime putty and volcanic pumice, $15 \mathrm{~cm}$ thick; during the process of making it, the mixture was beaten in order to water-proof it [7]. Frequently, ground floor rooms are covered by a masonry vault, built with lava stones and lime. For this type of construction, they chose conical-shaped stones to arrange with the narrower lower part to contrast each one, on the surface of a continuous wooden cast. The finishing of the wall is a plaster of lime and volcanic sand, painted with lime milk, so the prevalent color is white. The only different notes are the windows and their lintels, shaped with the plaster and painted with a vivid tone (the predominant colors are blue, cyan-sea, red-clay, and green).

Due to exorbitant transportation costs, they used local building materials. The only imported ones were the lime, from Naples, and the wood and canes, from Calabria.

You can find the described building, with little variation, on the other island too. They formed a built landscape largely different from one that you can find in other parts of Sicily; the reason for this discrepancy is that a large part of the people who colonized the islands in the past centuries, to increase the local population, came from Campania and they brought with them the architectonical and building solutions of their region [8].

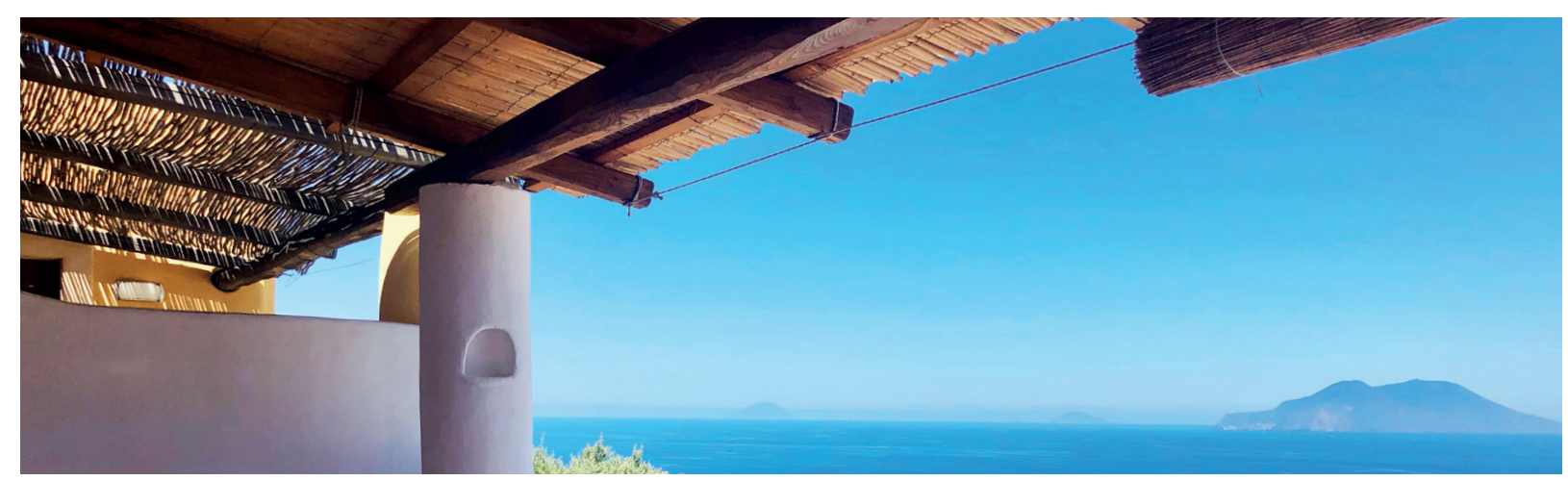




\section{SEISMIC RESISTANCE}

The Aeolian Islands are located in a high seismic area, according to their volcanic nature $[9,10]$; the Italian technical regulation classifies this area as level two [11]. This means that, in the past, strong earthquakes have been verified there and other events, with the same intensity, are expected there. By focusing on Filicudi, it is not possible to establish the exact effects of the earthquakes that occurred there in the past, because of the lack of documentation about them. On the isle, there are a large number of damaged buildings, but it is sure that most of the damages come from abandonment and from the absence of maintenance. In any case, most of the Filicudian buildings show a very good level of conservation, from the static point of view (plumb line, absence of cracks, preservation of secondary elements, etc.); all this shows is that the ancient Aeolian builders reached a very high capacity of construction.

This expertise was based on three key points: vertical elements that are firm and strong; horizontal elements that are light and flexible; and the global regularity of the building [6].

It is possible to analyze the main features of these three points.

- VERTICAL LOAD BEARING STRUCTURE: The Aeolian Islands are formed, almost exclusively, by lava stone; therefore, the houses are founded directly on bedrock, through an enlargement of the transversal section of the walls.
Lava stone is also the base material of the masonry, which is realized in roughly shaped blocks, linked with mortar. Thanks to the shortness of the interstoreys, the ratio between the height and transversal thickness is low; therefore, the walls can be considered not slender.

Another contribution to the strength of the vertical structure is due to the reciprocal connection between the convergent masonry walls in each corner.

This conformation, which is often found in the Southern part of Italy [7, 12], can assure high performance, from a mechanical point of view, as shown in the literature [49]. The shape and mutual connection of the blocks form the most important protection during earthquake stress [6, 13].

- HORIZONTAL STRUCTURES: There are two types of horizontal structure, which are masonry vaults and wooden floors. The first ones are used exclusively in basements. Vaults are recurrent to cover rooms with one or more rock walls because they are more suitable to absorb the horizontal thrust.

This is a recurrent situation because a large part of the island is hilly and so numerous buildings are partially excavated inside the rock.

The upper floors are built with wood. The wooden beams, which support the floors, link the opposite walls. Thanks to their tensile strength, they are able to distribute the stress among the vertical masonries more efficiently [13]. 
- GLOBAL CONFORMATION: Filicudian houses are formed by basic, regular geometric, small sized cells added one to each one. Windows and doors have limited dimensions and are central in the walls (this means away from the corners). This design approach meets the needs of mutual collaboration among the structural elements and assures wide distribution of stress [14].

Most of the lots of fields of Filicudi are along the hillside so it is very common to have constructions in the proximity of slopes; this condition increases the risk level. Another risk for the buildings could come from the substitution of the wooden roofs with reinforced concrete slabs because they have higher weight and lower ductility. In order to strengthen the buildings, it is necessary to solve these criticisms. The shear strength of the masonry walls could be improved by using polymer nets [15].

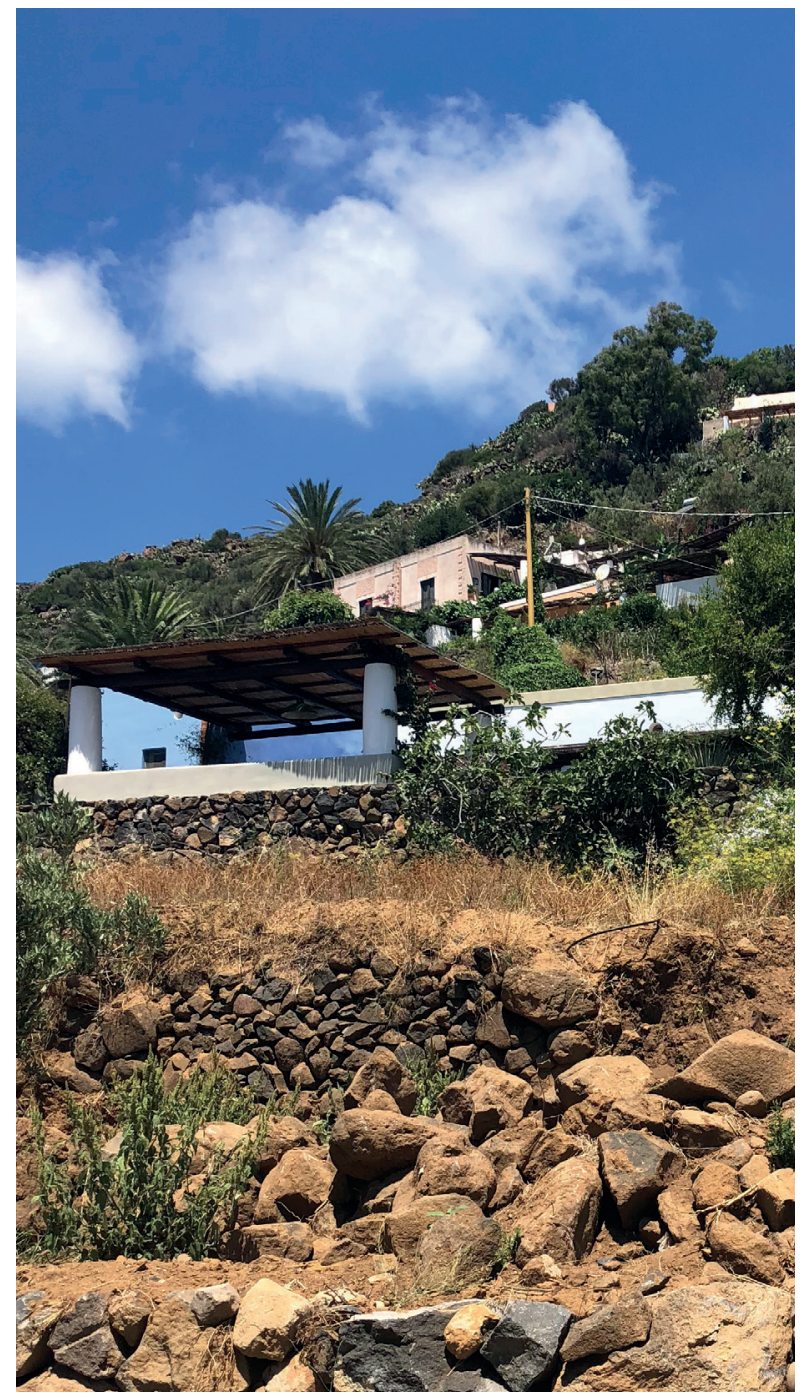




\section{BUILDING SUSTAINABILITY}

Every building element of spontaneous architecture has a justification in its function. Its aesthetic value and its influence on the architectonical image of the building are always secondary. According to this principle, you have the Filicudian houses. Here, the main goal was to obtain good protection from the harsh climate conditions, with the lowest cost.

Without the help of mathematic models or experimental results, builders of the past were able to determine the essential aim on which to focus their attention: the correct orientation and defence from daytime warming and shading; and now, these are the aims of sustainable design $[6,16]$.

- ORIENTATION: In the preindustrial age, when the Filicudian houses were born, the Sun's energy was precious, because it was the most important warming source. However, in Mediterranean regions, architecture is thought to defend its inhabitants from the excessive summer heat, first of all with a correct orientation.

This principle is strictly adhered to and it is one of the characteristics that formed the local landscape; in fact, it has conditioned the choice of the island's area where they have developed the residential agglomerations. Thus, the houses are set up along the hill slopes with better exposure, and they are approximately oriented along the same front line, at different altitudes.

Therefore, heliothermic control is more prevalent than the other factors that usually de- termine the orientation of the windows: the relation with the public space or with the other buildings and the panoramic view. However, that circumstance is facilitated by the local situation. In fact, you have to consider that in Filicudi, the idea of public space is sui generis because it is formed by an intricate network of mule tracks; they are so well integrated with the relative pertinent lots and homes that often you cannot separate limits and reciprocal boundaries. Regarding the buildings' access to panoramic views, this is not a problem; in fact the hills slope toward the sea and so the main front of the house is orientated towards it.

- BUILDING ENVELOPE: The defense from daytime warming depends on the massive nature of the building envelope. In the Filicudian houses, it is formed by walls and roofs that have an average weight and are relatively high. The solar radiation accumulates there during the morning and it is released slowly during the day so the peak of indoor temperatures is shifted in time. In particular, it is during the evening, when the temperature begins to cool. Thus, a percentage of the heat is dissipated outdoors, so the indoor temperature peak may be lower. You can quantify this propriety determining the offset temperature and the attenuation of the elements of the building envelope $[16,17]$.

As you know, the main role of the building envelope is to assure safety, from the static point of view. Therefore, good indoor environmental conditions act as an unforeseen 
feature which adds value to the building. However, there is a shrewdness directly addressed to this aspect: the white color of the façades. In fact, the local materials, the volcanic sands, are dark in color. To have a light dye, they had to import the milk-lime from another region, as was mentioned earlier.

- SHADING SYSTEM: You should consider the use of shade as a really important component in Mediterranean buildings. No one enjoys staying in an open square, during a hot, sunny day, without a good reason; they would look for a tree to protect themselves. Therefore, you should plan adequate shading elements for the buildings.

In the Filicudian houses, shade is obtained in a really elegant way: cane roofing, along the south façade. It is supported by strong wooden beams, which in turn are supported at either end from steel wall hooks on one side and big masonry pillars on the other. This last element is embodied in the parapet of the terrace and is called pulera $[4,6]$.

The cane roofing is kept in place by two purlins, one lower and one upper, attached to the wooden beams. Normally, the roof is laid in June and removed in September; in this way, it does not reduce the daylight flow during the winter season.

In addition, the houses have a secondary shading element; in fact, for each window, you have a cassina [4], which is a local version of the Venetian blind-rolling and with fixed blades.
- VENTILATION: A double opening system assures natural ventilation in the Filicudian houses. In fact, in addition to the ordinary windows, normally set up in the façade, with usual shapes and dimensions that bring light and air, they have some openings exclusively assigned for the ventilation of the rooms [6]. They have rather smaller dimensions and are squared, if they are situated over the regular windows (as a fanlight) or circular, when they are located alongside the window. In the internal wall, you have a draught opening, generally half-moon shaped.

- RAINWATER COLLECTION: Rainwater is a precious resource in Filicudi, because springs or courses of water are non-existent, including on other Aeolian Islands. Therefore, you must collect and preserve it in an underground cistern. Usually, it is under the terrace and its roof is part of the pavement and the parapet access-point is embodied in the boundary wall.

The drainpipes are made by stacking conically clay units, which are called catusi [41]. Often, they are substituted with a copper pipe in the refurbishment works, because it is longer lasting.

On the foot of the pipe, there is a flap which can be lowered (called in Italian travasatore), which is useful for discarding the first water of the raining season. In this way, you can wash the roof and the terrace from the dust accumulated during the dry season and preserve the cistern from the dirt. 


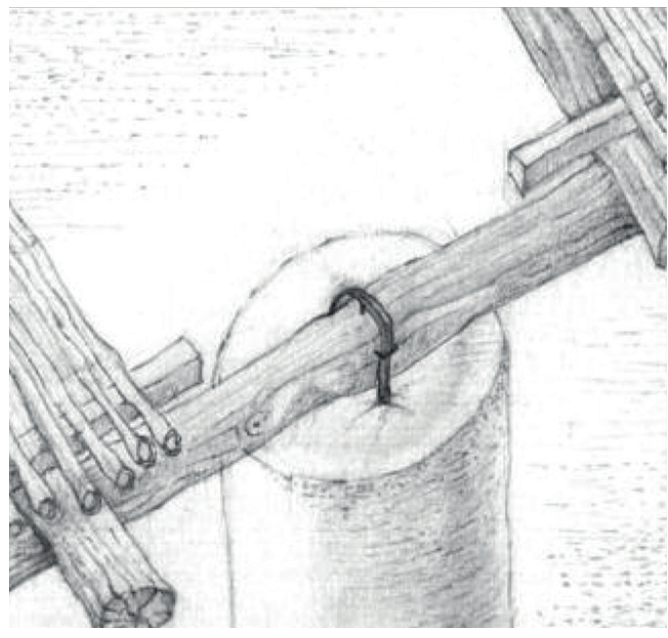

Detail of the cane roofing

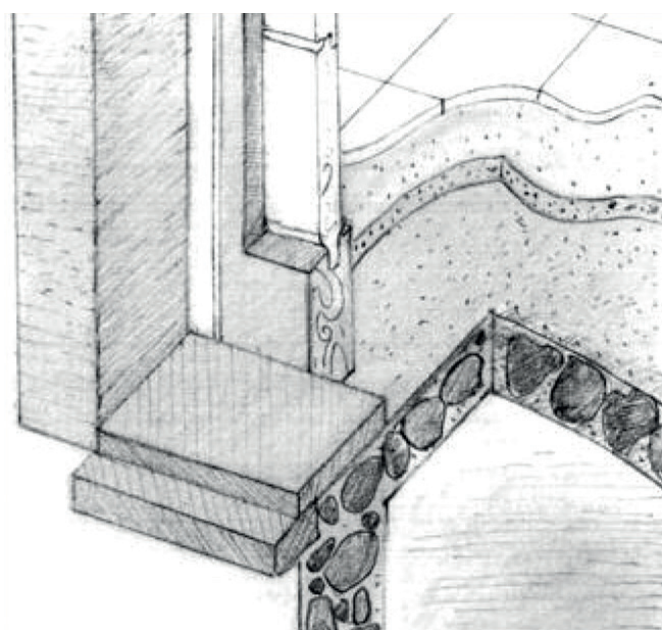

Detail of the threshold

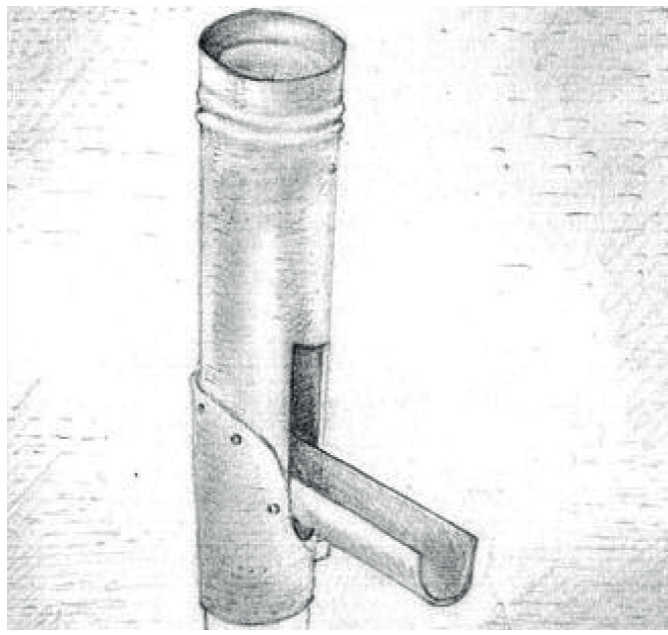

Detail of the flop of the pipe

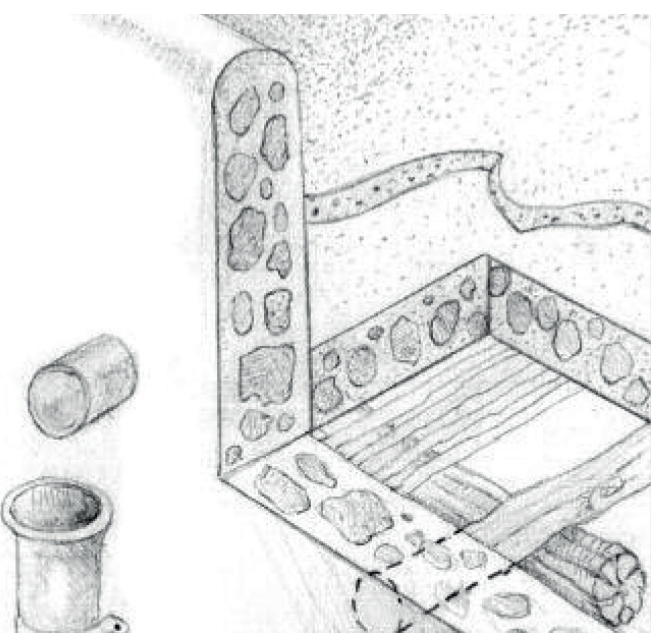

Detail of the terrace 


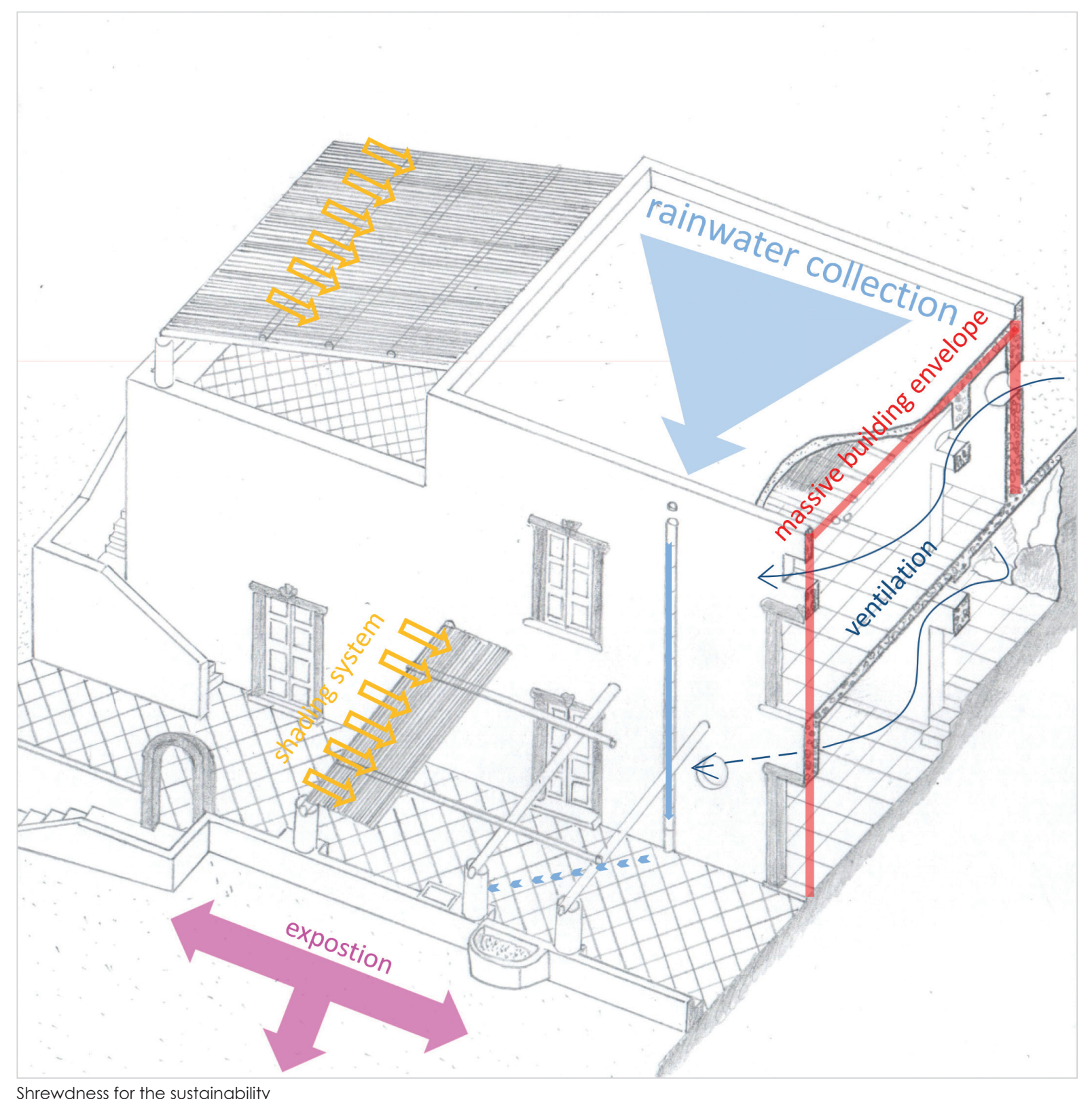




\section{ENERGY BEHAVIOR}

The indoor living quality of the Filicudian houses is so plain to see that any quantitative measurement should not be necessary. During the hot summer season, you can stay there comfortably, without cooling plants or other kinds of aid. Their health quality makes them an architectonic element which is very appreciated by temporary or permanent users. However, it is a good rule to transform pragmatic knowledge into scientific expertise through measurement of the most significant thermotechnical parameters.

The computation was carried out on a typical building with Master Clima [18], an open source software; it is designed by 'Aermec' and is based on the actual standard. The characteristics of the materials have been assumed by the data bank of the same software, but their values have reviewed by considering the outputs of others research on other masonry and local buildings [16]. The Energy Performance Index (EPI) is certainly the most important of these [19]. It is possible to calculate it for a specific Filicudian house, chosen as the case study, obtaining values rounding to $17 \mathrm{KWh} / \mathrm{m}^{2} \cdot \mathrm{y}$, restricting the time to the summer season. This limitation is correct because, as you can well understand, these types of houses are used primarily during this period. Therefore, it is very close to the Passive House standard, especially in the versions studied for southern European countries [20].

This very high performance is not a surprise because, as you know, this value is strictly influenced by the following aspects [6]:

- the orientation of the windows;

- the type of building envelope;

- the existence of shading systems;

- the possibility of natural ventilation.

All these are qualifying characteristics of Filicudian houses.

You must consider also that the values of the temperature offset and attenuation of its peak are very positive; in fact, they move around more than 15 hours and 5\% for vertical elements and less than 10 hours and $15 \%$ for horizontal ones.

Therefore, the mathematic approach has confirmed the intuitive observations.

\begin{tabular}{|c|c|c|}
\hline \multicolumn{3}{|c|}{$\begin{array}{l}\text { Energy Performance evaluated with Masterclima } \\
\qquad\left[\begin{array}{ll}1 & 1\end{array}\right]\end{array}$} \\
\hline \multicolumn{3}{|c|}{ GENERAL INPUTS } \\
\hline Climatic area (A-F) & & B \\
\hline Daily Degree & & 758 \\
\hline Type of the building & & residential \\
\hline Volumes & $m^{3}$ & 954,00 \\
\hline \multicolumn{3}{|c|}{ COOLING } \\
\hline $\begin{array}{l}\text { Energy requirement for } \\
\text { cooling the building }\end{array}$ & kWh & 2818,141 \\
\hline Floor area & $m^{2}$ & 159,00 \\
\hline Quality judgment & & very good \\
\hline $\begin{array}{l}\text { Class of the envelope } \\
\text { (I-IV) }\end{array}$ & & $\|$ \\
\hline EPI & $\mathrm{kWh} /\left(\mathrm{m}^{2} \cdot \mathrm{a}\right)$ & 17,724 \\
\hline
\end{tabular}




\begin{tabular}{|c|c|c|c|}
\hline \multicolumn{4}{|c|}{ Thermotechnical characteristics of the building envelope of the Aeolian house [47] } \\
\hline \multicolumn{4}{|c|}{ COVERING ROOF } \\
\hline \multirow[t]{2}{*}{ STRATIGRAPHY (from bottom) } & Thickness & $\mathrm{cm}$ & 26 \\
\hline & Surface weight & $\mathrm{kg} / \mathrm{m}^{2}$ & 380,300 \\
\hline Plaster of lime & Thermal capacity & $\mathrm{kJ} /\left(\mathrm{m}^{2} \cdot \mathrm{K}\right)$ & 77.82 \\
\hline Cane & Thermal resistance & $m^{2} \cdot K / W$ & 1.425 \\
\hline Dry sand & Thermal transmittance & $W /\left(m^{2} \cdot K\right)$ & 0.702 \\
\hline Cast of lime, water and volcanic inert & Periodic thermal transmittance & $W /\left(m^{2} \cdot K\right)$ & 0.116 \\
\hline Insulation & Attenuation & & 0.165 \\
\hline Exterior finish & temperature offset & [h] & -8.53 \\
\hline \multicolumn{4}{|c|}{ MASONRY VAULT } \\
\hline \multirow[t]{2}{*}{ STRATIGRAPHY (from bottom) } & Thickness & $\mathrm{cm}$ & 35 \\
\hline & Surface weight & $\mathrm{kg} / \mathrm{m}^{2}$ & 617,400 \\
\hline Plaster of lime & Thermal capacity & $\mathrm{kJ} /\left(\mathrm{m}^{2} \cdot \mathrm{K}\right)$ & 78.00 \\
\hline Lava stones & Thermal resistance & $m^{2} \cdot K / W$ & 1.236 \\
\hline Cast of lime, water and volcanic inert & Thermal transmittance & $W /\left(m^{2} \cdot k\right)$ & 0.809 \\
\hline Insulation & Periodic thermal transmittance & $W /\left(m^{2} \cdot k\right)$ & 0.145 \\
\hline \multirow[t]{2}{*}{ Exterior finish } & Attenuation & & 0.179 \\
\hline & Temperature offset & {$[\mathrm{h}]$} & -9.3 \\
\hline \multicolumn{4}{|c|}{ EXTERNAL VERTICAL MASONRY } \\
\hline \multirow[t]{2}{*}{ STRATIGRAPHY (from extern) } & Thickness & $\mathrm{cm}$ & 70 \\
\hline & Surface weight & $\mathrm{kg} / \mathrm{m}^{2}$ & $1,320,000$ \\
\hline Plaster of lime & Thermal capacity & $\mathrm{kJ} /\left(\mathrm{m}^{2} \cdot \mathrm{K}\right)$ & 115.08 \\
\hline Lava stones and lime & Thermal resistance & $\mathrm{m}^{2} \cdot \mathrm{K} / \mathrm{W}$ & 0.502 \\
\hline \multirow[t]{4}{*}{ Plaster of lime } & Thermal transmittance & $\mathrm{W} /\left(\mathrm{m}^{2} \cdot \mathrm{K}\right)$ & 1.992 \\
\hline & Periodic thermal transmittance & $\mathrm{W} /\left(\mathrm{m}^{2} \cdot \mathrm{K}\right)$ & 0.105 \\
\hline & Attenuation & & 0.053 \\
\hline & temperature offset & [h] & -15.25 \\
\hline
\end{tabular}


The analysis carried out shows clearly the perfect correspondence between the Filicudian houses and the rules of the Energy saving standards; therefore it is a sustainable building ante litteram.

You can also consider the Filicudian houses as an example of an environmentally friendly building, according to local building regulations [21,22], which define several items of sustainability. By respecting them, in the refurbishment building works, it is possible to obtain a prize, a bonus to increase the volume of the house [22]. This approach is similar in other Italian Regions. These items, defined bio-architectonic items [23], are grouped in five thematic areas: energy, water, materials, waste, and health. The Filicudian houses respect numerous points in the list: regarding summer cooling (art. 2, area $1^{\circ}$, point 7 ), rain water recovery (art. 2 , area $2^{\circ}$, point 1 ), use of local material (art. 2, area $3^{\circ}$, point 2), and high acoustic insulation of the opaque building envelope (art. 2, area $5^{\circ}$, point 3).
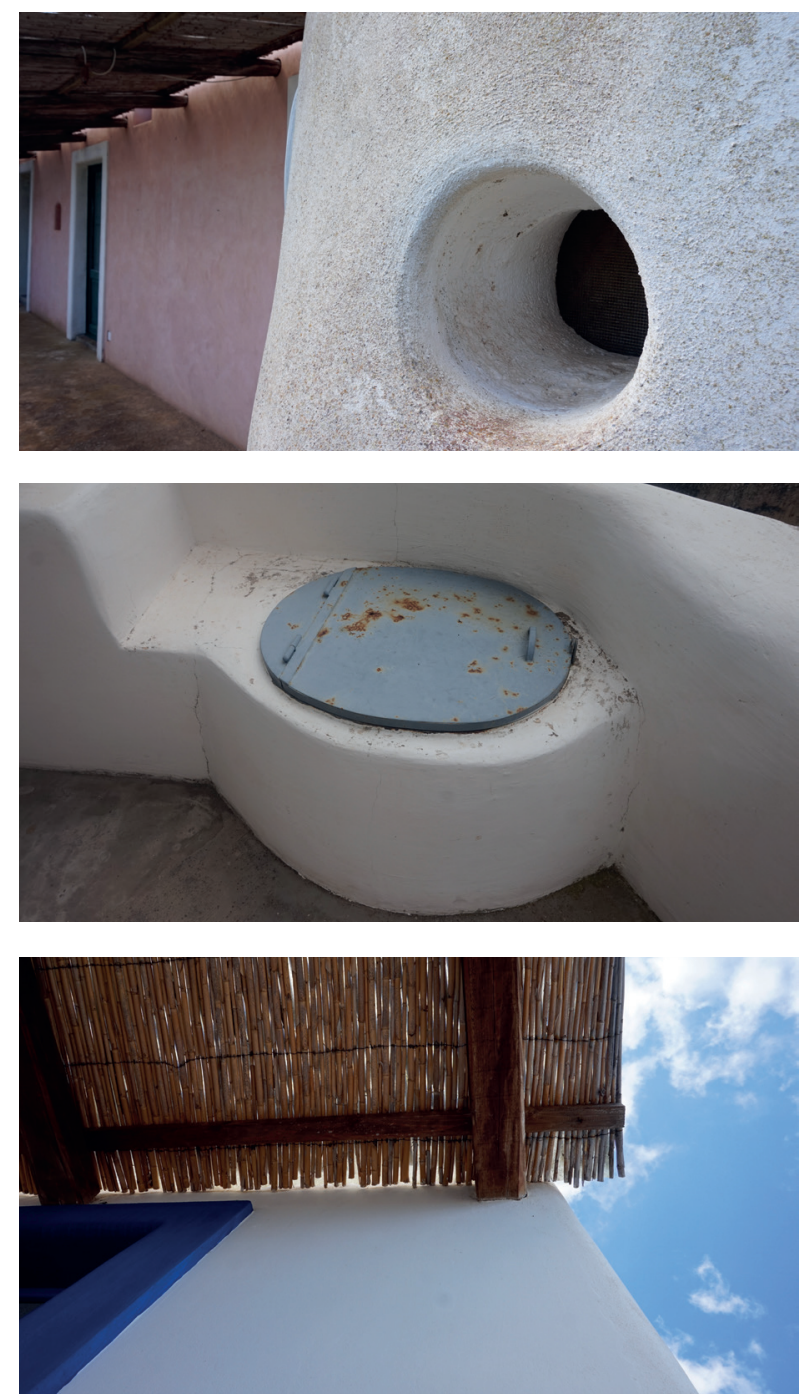


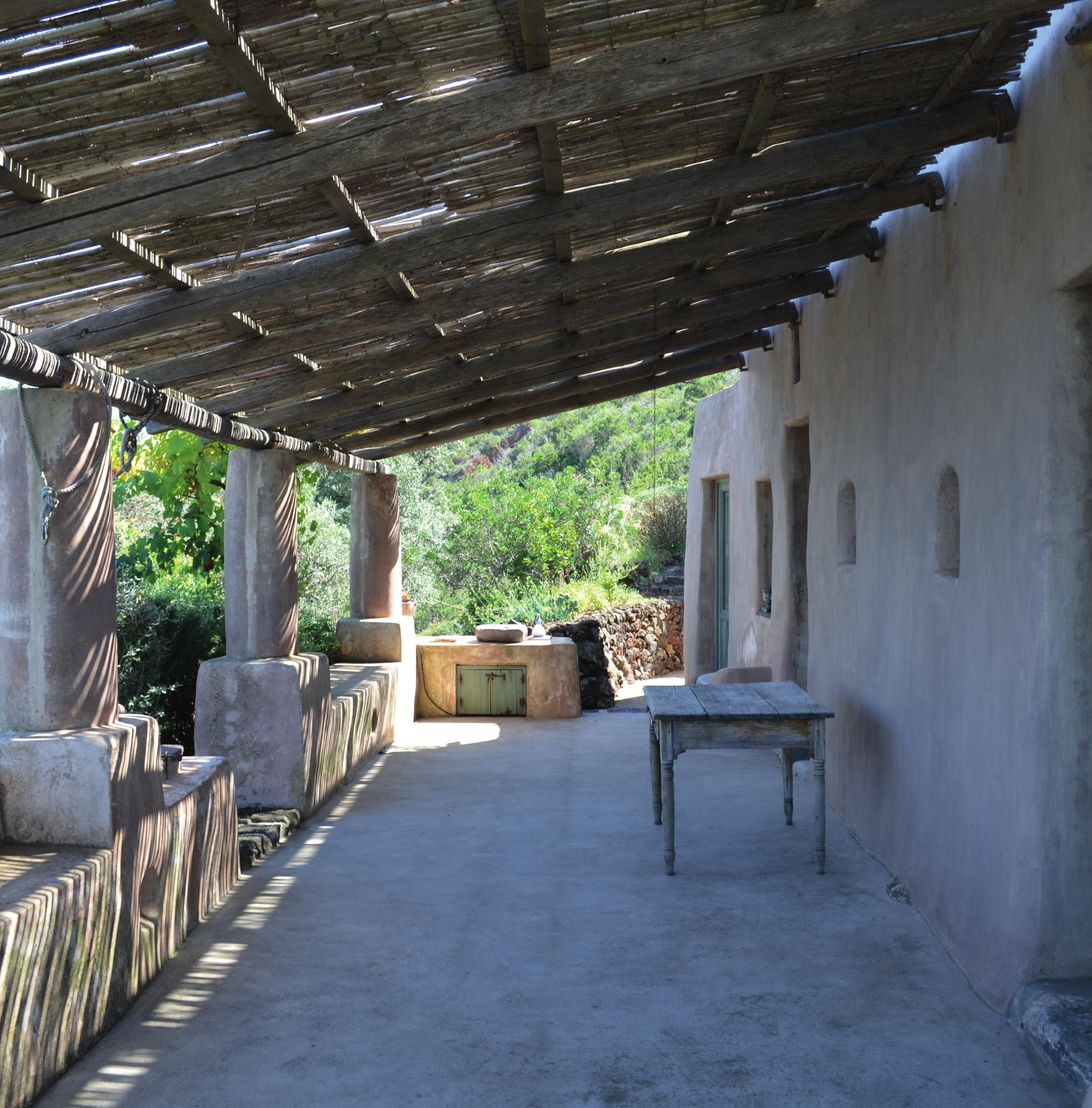




\section{AEOLIAN INTENSIVE PERIOD}

\section{LEARNING OUTCOMES}

As already mentioned, the Italian teaching module of the VVITA project is called the ATM; it is focused on topics that can be useful to deeply understand the wisdom of the vernacular architecture of the Aeolian Islands and to define principles and strategies to reactivate it in order to revitalize the local built heritage.

At the basis of this, there is the knowledge of the characteristics of traditional Mediterranean architecture, from a typological, historical-cultural, and technical-constructive point of view. Particular attention is paid to the anchoring of the building artefacts to the context and to the consequent formal, functional, and constructive relationships between Aeolian architecture and the environment. Belonging to the forms and cultures of Mediterranean life is considered the starting point for the identification of features, parameters, and typologies to be taken into consideration in the interventions of refurbishment of the existing built heritage and in the construction of new facilities.

The architectural characterization goes beyond the knowledge of the historical-cultural, landscape, and technical constructive issues, going as far as a thermophysical and mechanical modelling of the built heritage. For this purpose, the ATM is structured to transfer notions and knowledge related to the basics of thermodynamics and heat transmission, as well as to the thermophysical properties of traditional building materials in the Mediterranean environment and more generally, to the energy behav- ior of historical buildings. Knowledge of the climate data of the Aeolian Islands is also foreseen, in order to build a dynamic characterization of the thermophysical behavior of the analyzed buildings.

Likewise, in order to be able to carry out a mechanical modelling of the buildings which are the object of analysis, the knowledge provided by the ATM concerns the structural behavior of the historical buildings in the seismic area, with particular attention to seismic actions and to the relationships between the geometry and seismic response of the structures.

With the aim of creating an innovative tool (geodatabase) for the management of the built heritage quality, able to integrate the acquired multidisciplinary data with their geographical location, the ATM also provides basics of topography and informatics, in particular with regard to data automatic structuring, data storage and management systems, and georeferencing systems.

The skills developed during the ATM activities concern above all the use of Rapid Evaluation Methods (REM) [24] in order to achieve a rapid evaluation of the architectural, thermophysical, and mechanical quality of the analyzed buildings. With the help of thematic checklists, drawn based on models such as the ITACA Protocol [25] or the Leadership in Energy and Environmental Design (LEED) method [26], it was possible to establish the features and parameters to be analyzed, in order to compare the different case studies and set, for 


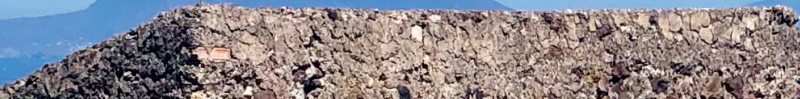

1.1.2.

6.

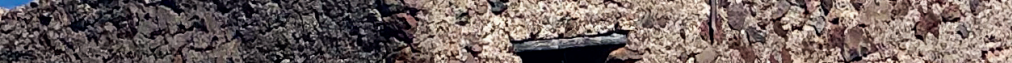

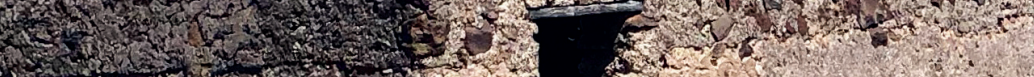

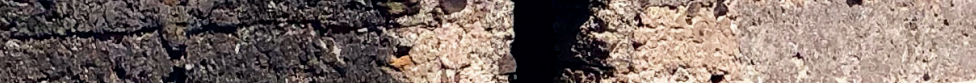

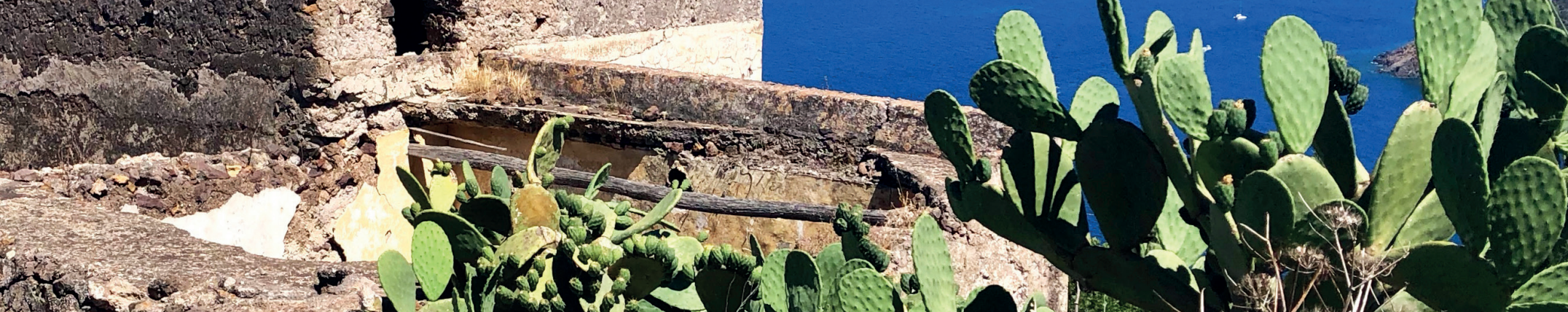

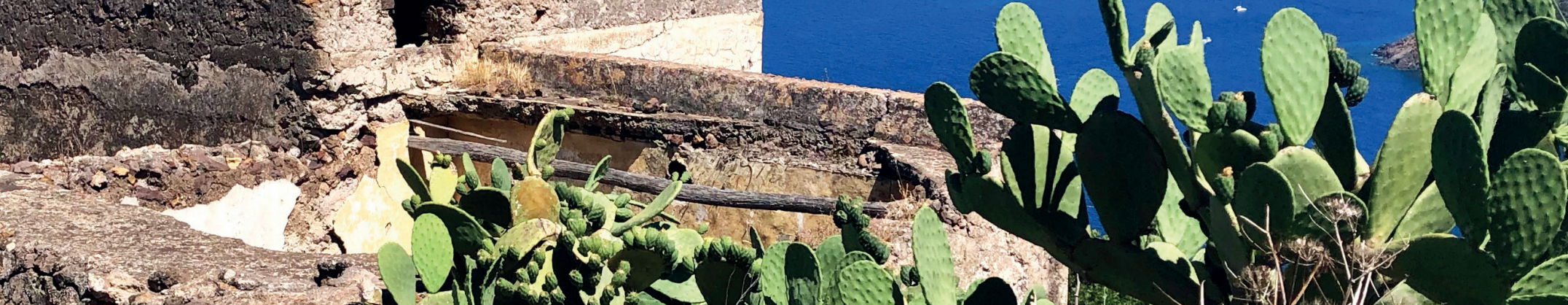

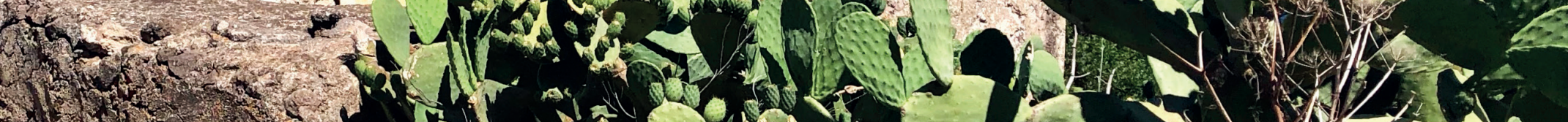
D.

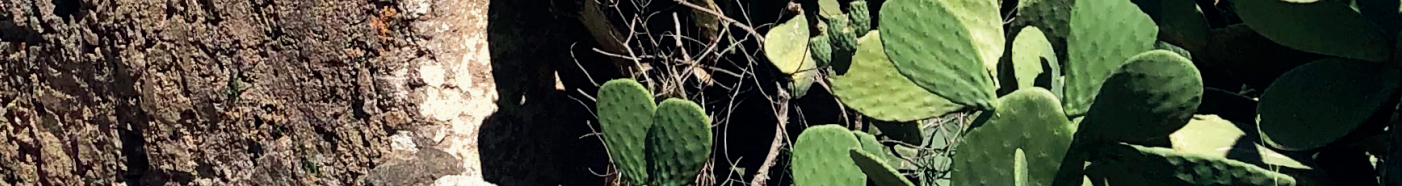

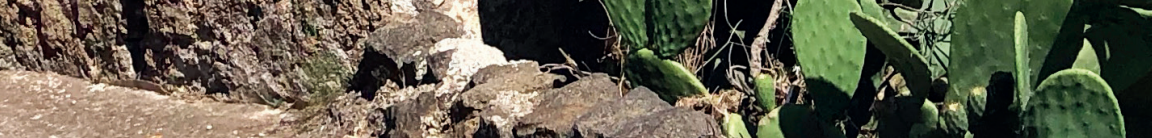

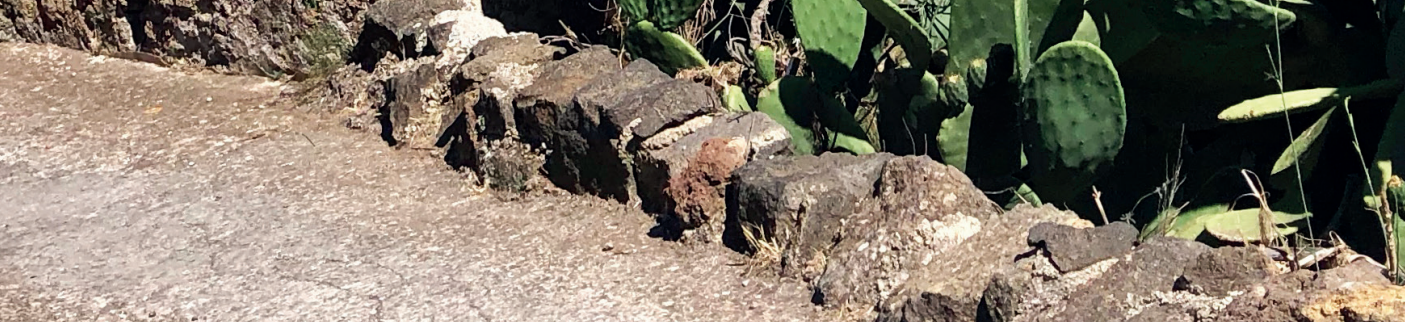

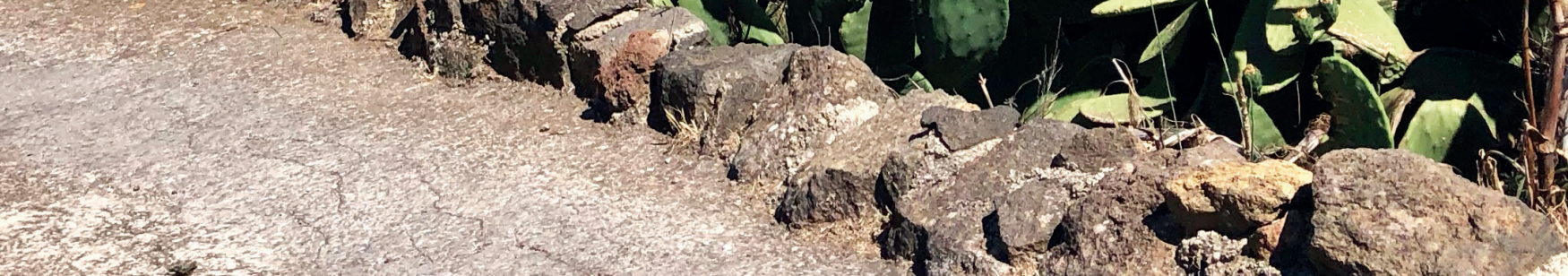


each of them, quality levels with respect to a fixed grid.

The fieldwork relies on Geographic Information System (GIS) technology [27], implementing the information collected in the field within a georeferenced data system. Therefore, the skills that the students can develop are the following:

- use and management of thematic maps at different scales;

- construction, in a guided way, of a georeferenced data system (geodatabase);

- data-entry and data-editing in a novel geodatabase (association of geometry, topography and data);

- measurements of internal thermo-hygrometric comfort and ventilation, calculation of transmittance and attenuation;

- leading a refurbishment design process - with the possibility of introducing new small facilities - in which architectural, energy balance and anti-seismic issues are integrated.

The main characteristic of vernacular architecture is to be contextual. This takes place in the construction and arises out of what is permanent rather than from a given event [28]. Starting from this statement, the students can have an immersive experience, applying the acquired knowledge

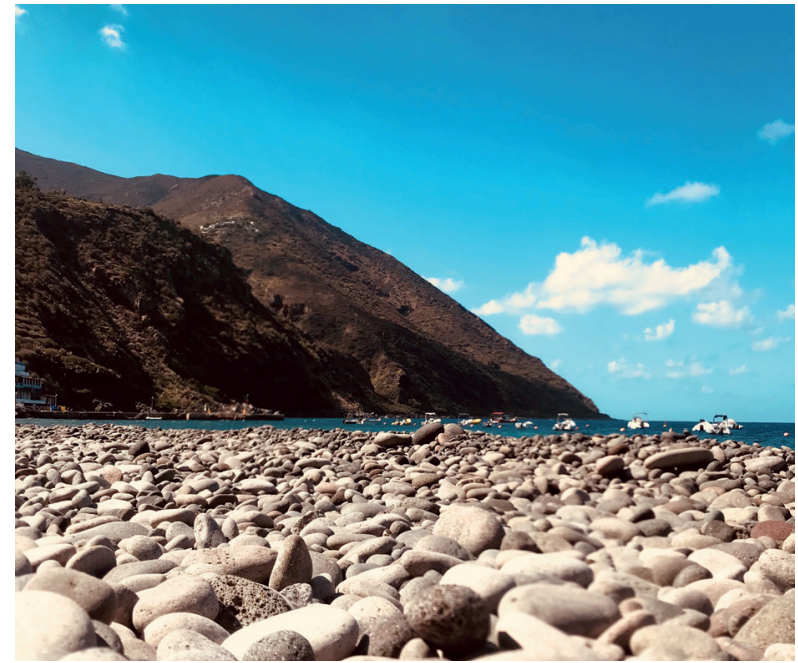

and skills on the Aeolian environment. More specifically, they can develop the competences of:

- work in a multidisciplinary and multicultural team;

- manage a novel software tool, based on GIS technology;

- make a multidisciplinary assessment of the quality of Aeolian vernacular architecture;

- make a synthesis of the three themes analyzed (architecture, energy balance and seismic restraint) in an integrated design process; 
- experiment with a site-specific design process.

The educational approach of the ATM is based on multidisciplinarity. Many topics are involved both in the data-entry/editing activities of the novel geodatabase and in the design simulation activities.

History, History of Architecture, and History of Construction are important to understand the Aeolian vernacular architecture in the wider perspective of the Mediterranean historical buildings.

Landscape Analysis and Design are useful to see the relationships between architecture, people, and places.

Building Technology and Building Science provide the tools to understand and improve the material quality of the buildings, paying attention to construction processes. Technical Physics is involved in the activities related to the energy balance assessment. Topography is concerned with the activities of managing the thematic maps and of realizing the novel geodatabase.

In addition to this knowledge, participants have to show interest in new places and new challenges. In fact, the relationship with the location is the best strength of the ITM and therefore, it is very important to take advantage of the full immersion in it. On the other hand, the participants are called to work in very particular conditions, sometimes difficult to access and manage.

\begin{tabular}{|c|c|c|}
\hline \multicolumn{3}{|c|}{ Main learning outcomes of the AMT } \\
\hline knowledge & skills & competences \\
\hline \multirow{3}{*}{$\begin{array}{c}\text { characters of traditional Mediterranean } \\
\text { architecture }\end{array}$} & use of REM & ability to synthesize \\
\hline & use of thematic maps & working in a multicultural team \\
\hline & construction of a geodatabase & managing a novel software tool \\
\hline \multirow{2}{*}{$\begin{array}{l}\text { thermo-physical and mechanical } \\
\text { modelling of the built heritage }\end{array}$} & data-entry and data-editing & $\begin{array}{c}\text { assessment of the quality of Aeolian } \\
\text { vernacular architecture }\end{array}$ \\
\hline & $\begin{array}{l}\text { measurements of thermo-physic } \\
\text { parameters }\end{array}$ & integrated design process \\
\hline data automatic structuring & \multirow{3}{*}{ refurbishment design process } & \multirow{3}{*}{ site-specific design } \\
\hline data storage and management systems & & \\
\hline georeferencing systems & & \\
\hline
\end{tabular}




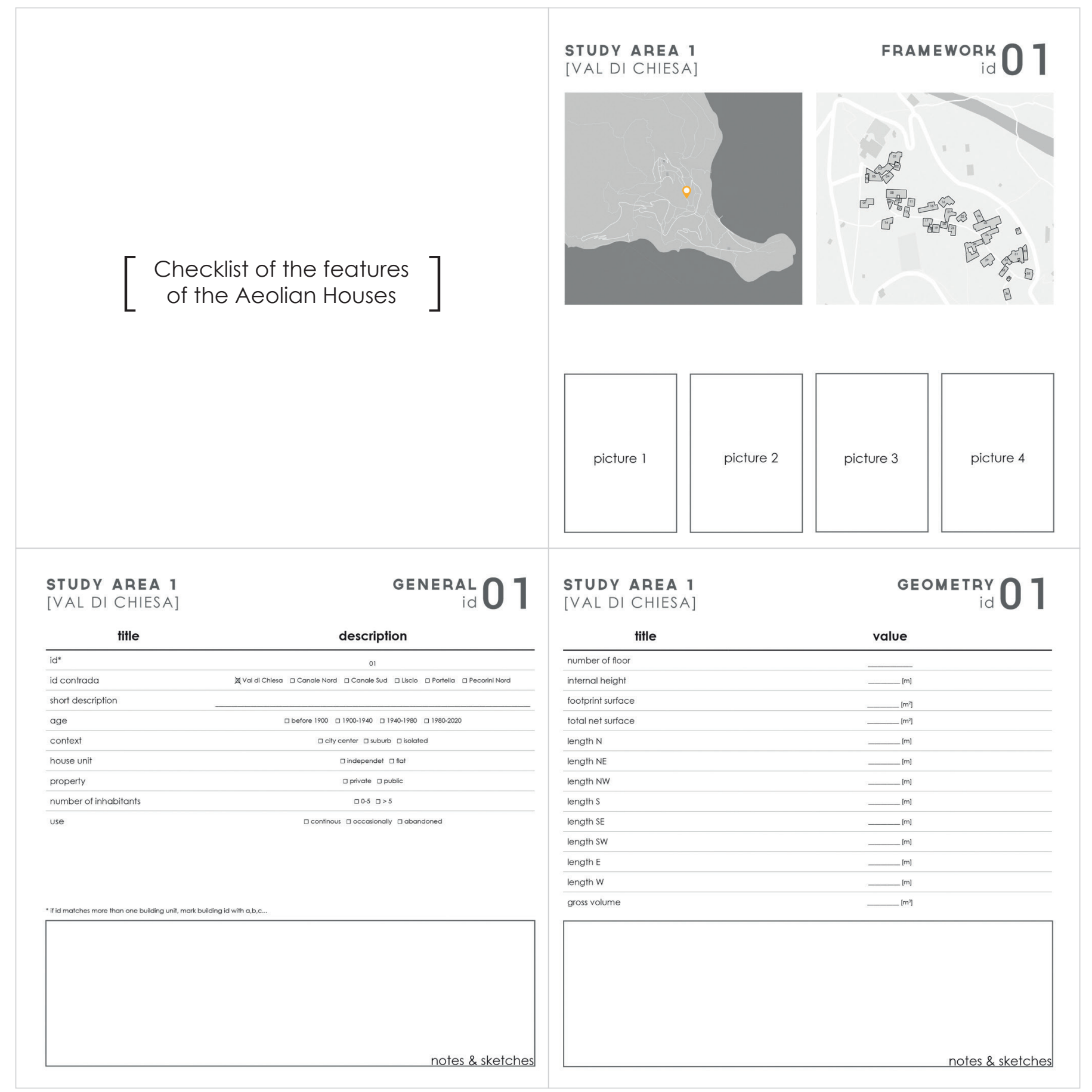


STUDY AREA 1

[VAL DI CHIESA]

\begin{tabular}{|c|c|}
\hline title & value/description \\
\hline \multicolumn{2}{|l|}{ wall description } \\
\hline \multicolumn{2}{|l|}{ roof description } \\
\hline \multicolumn{2}{|l|}{ ground floor description } \\
\hline \multicolumn{2}{|l|}{ other descriptions } \\
\hline wall thickness & $\longrightarrow_{[m]}$ \\
\hline roof thickness & $\underbrace{[m]}$ \\
\hline ground floor thickness & $\underbrace{}_{[\mathrm{m}]}$ \\
\hline other thicknesses & $\chi_{[m]}^{[m]}$ \\
\hline glass windows & asingle $\square$ double $\square$ double-glozed \\
\hline glass windows U & {$\left[{ }_{[\mathrm{W} /(\mathrm{m} *))]}\right.$} \\
\hline frame windows & $\square$ aluminium $\square$ pre $\square$ wood \\
\hline frame windows $U$ & ]$_{[\mathrm{W} /(\mathrm{m} * \mathrm{*})]}$ \\
\hline \multicolumn{2}{|l|}{ cooling system description } \\
\hline \multicolumn{2}{|l|}{ heating system description } \\
\hline \multicolumn{2}{|l|}{ heating terminal units description } \\
\hline \multicolumn{2}{|l|}{ control system description } \\
\hline \multicolumn{2}{|l|}{ not conditioned ambient ground floor } \\
\hline \multicolumn{2}{|l|}{ not conditioned ambient ceiling } \\
\hline not conditioned ambient attic & \\
\hline not conditioned ambient room & \\
\hline
\end{tabular}

STUDY AREA 1

[VAL DI CHIESA]

Structure
id

\begin{tabular}{|c|c|c|c|c|}
\hline title & value & \multicolumn{3}{|c|}{ description (score) } \\
\hline construction features & , & \multicolumn{3}{|c|}{$\begin{array}{ll}\begin{array}{l}\text { areinforced concrete } \\
+2.0\end{array} & \begin{array}{l}\text { a masony wal } \\
+1.0\end{array}\end{array}$} \\
\hline foundation & , & \multicolumn{3}{|c|}{$\begin{array}{l}\text { Dhorizontal } \quad \begin{array}{l}\square \text { slope } \\
+1.0\end{array} \\
+2.0\end{array}$} \\
\hline type of soil & , & \multicolumn{3}{|c|}{$\begin{array}{l}\text { arock } \\
+3.0\end{array} \quad \begin{array}{c}\text { asoft } \\
+1.0\end{array}$} \\
\hline layout organization & ' & \multicolumn{3}{|c|}{ 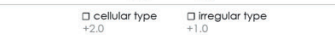 } \\
\hline plan regularity & , & \multicolumn{3}{|c|}{ 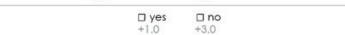 } \\
\hline height regularity & , & \multicolumn{3}{|c|}{$\begin{array}{l}\text { ayes } \\
+1.0\end{array}$} \\
\hline height of the first floor & $\ldots^{[m]}$ & \multicolumn{2}{|c|}{$\begin{array}{l}7>0 \text { height of the } 2 \text { nd floor } \\
0\end{array}$} & $\begin{array}{c}a<\text { height of the 2nd lloor } \\
-1.0\end{array}$ \\
\hline height of the second floor & $\underbrace{[m]}_{[m]}$ & \multicolumn{2}{|c|}{$\begin{array}{l}\square<\text { height of the lst floor } \\
0.0\end{array}$} & $\begin{array}{l}9>\text { height of the Ist floor } \\
-1.0\end{array}$ \\
\hline wall thickness at the first floor & $\ldots_{[m]}^{[m]}$ & \multicolumn{2}{|c|}{$\begin{array}{l}\mathrm{g}>\mathrm{>} \text { wall thicknoss at } 2 \text { 2nd fioor } \\
0.0\end{array}$} & $\begin{array}{l}0<\text { wall thicknoss at } 2 \text { nd floor } \\
-1.0\end{array}$ \\
\hline wall thickness at the second floor & $\ldots^{[m]}$ & \multicolumn{2}{|c|}{$\begin{array}{l}0<\text { wall thickness of is ffoor } \\
0.0\end{array}$} & $\begin{array}{l}9>\text { wall thickness a } 1 \text { 1st floor } \\
-1.0\end{array}$ \\
\hline number of openings for each cell & - & \multicolumn{2}{|c|}{$\begin{array}{l}a \leq 2 \\
0.0\end{array}$} & $a>2$ \\
\hline presence of large arches & , & \multicolumn{2}{|r|}{ ayes } & $\begin{array}{c}\not \mathrm{no} \\
+2.0\end{array}$ \\
\hline presence of damages or cracks & , & \multicolumn{2}{|r|}{$\begin{array}{l}\text { ayes } \\
+1.0\end{array}$} & $\begin{array}{c}7 \mathrm{no} \\
+3.0\end{array}$ \\
\hline presence of walls on slope & ' & \multicolumn{2}{|r|}{$\begin{array}{c}\text { ayos } \\
+1.0\end{array}$} & $\begin{array}{c}\square \mathrm{no} \\
+3.0\end{array}$ \\
\hline staircase & , & \multicolumn{2}{|r|}{$\begin{array}{l}\text { Dinside } \\
+1.0\end{array}$} & $\begin{array}{l}\square \\
+3.0 \\
+3 \text { oside }\end{array}$ \\
\hline dimension of the largest cell & $L_{\left[m^{2}\right]}$ & \multicolumn{2}{|r|}{$\begin{array}{l}0 \leq 25 \mathrm{~m}^{2} \\
0.0\end{array}$} & $\begin{array}{l}a>25.1 \mathrm{~m}^{2} \\
+30.0\end{array}$ \\
\hline
\end{tabular}

STUDY AREA 1

[VAL DI CHIESA]

BUILDING
id

\begin{tabular}{|c|c|c|}
\hline title & value & description (score) \\
\hline cellar aggregation & 1 & 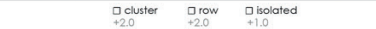 \\
\hline relation with the slope & 1 & $\begin{array}{ll}\square \text { algned } \\
+2.0 \\
t_{2} .0\end{array}$ \\
\hline facade color & 1 & 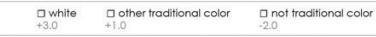 \\
\hline door jambs and lintel & 1 & $\begin{array}{l}\square \text { trodilitional color } \quad \square \text { not tradilional color } \\
-20\end{array}$ \\
\hline volume addiction & ${ }^{\left[\mathrm{m}^{3}\right]}$ & $\begin{array}{l}\text { Dless than } 10 \% \quad \text { less than } 40 \% \quad \square \text { more than } 40 \% \\
+1.0\end{array}$ \\
\hline puleri & 1 & $\underset{+4.0}{\substack{\text { Iin use } \\
+4.0}} \underset{+2.0}{\square \text { notin use }}$ \\
\hline bagghio & 1 & $\begin{array}{cc}\square \text { yes } & \square .0 \\
+4.0 & 0.0\end{array}$ \\
\hline rainwater collection systems & I & 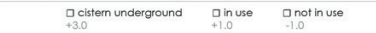 \\
\hline green essences & 1 & $\begin{array}{ll}\substack{\square \\
+30} \\
+30 \text { ditional } \\
\substack{+20 \\
+20}\end{array}$ \\
\hline perimeter walls & 1 & 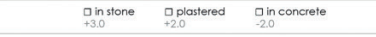 \\
\hline enclosure & I & $\begin{array}{ll}\square \\
+3.0\end{array}$ \\
\hline not congruent pavements & 1 & $\begin{array}{ll}a_{2} y e s & \square_{0.0} \\
2.0\end{array}$ \\
\hline not congruent roofs & 1 & $\begin{array}{ll}\square \text { yes } & \square \text { no } \\
2.0 & 0.0\end{array}$ \\
\hline not congruent windows shape & , & 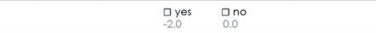 \\
\hline not congruent windows frame & i & $\begin{array}{l}\text { ayes } \\
-20\end{array}$ \\
\hline not congruent shutters & 1 & $\begin{array}{ll}\square \\
-2.0 & \square \text { no } \\
0.0\end{array}$ \\
\hline not congruent horizontal shading systems & 1 & $\begin{array}{l}\text { ayes } \\
-2.0\end{array}$ \\
\hline not congruent pluvials & 1 & 2 yos \\
\hline
\end{tabular}

STUDY AREA 1

[VAL DI CHIESA]

ENERGY
id

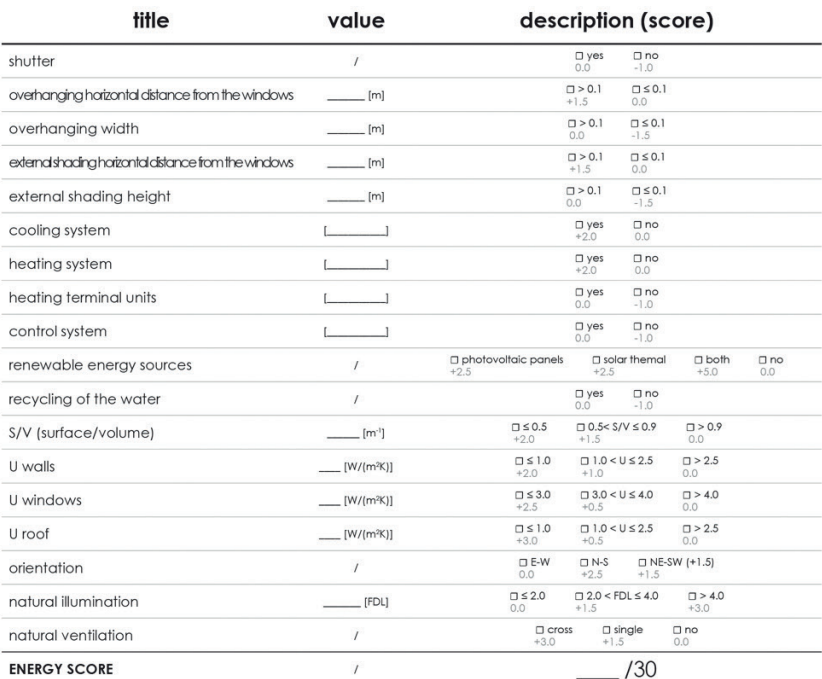




\section{METHODOLOGY}

The ATM is composed of different moments with different teaching/learning activities, all connected among them.

- THEORY: The lectures form a corpus to support the development of the workshop. They are focused on the knowledge of the historical-cultural, landscape, and construction issues of Aeolian vernacular architecture. The courses are also oriented to provide the necessary technical tools and to facilitate the inclusion of all students in the new context of study. The lectures are mostly scheduled in the first two days, in Catania and Lipari.

- PRACTICE: The second activity is practice and is addressed to contextualize the knowledge of the Mediterranean and Aeolian area provided in the previous step, through concrete cases in which to quantitatively verify paradigms and parameters introduced. It consists of both solving concrete problems and of practical activities, such as guided tours, meeting with local experts, and film watching.

Practice is also connected with technological issues. For instance, as with the GIS tool, the students are asked to realize the platform in which they have to upload and manage the data about buildings. It is developed by the students within a guided activity, using an innovative open source GIS software tool.

- WORKSHOP: The third activity takes place in the field and consists of the workshop. In it, the students are called to carry out two tasks: field surveys and design simulations. The two tasks are directly connected: the analysis on the building heritage, carried out with the help of the REM, is implemented in the GIS software tool. Subsequently, a design exercise based on the elaborated assessment is carried out, with the aim of resolving the weakness and enhancing the potentials of the case studies.

Students are divided into heterogeneous work groups and to each of them is assigned a larger study area for analysis (task 1), which is smaller for the design simulation (task 2).

- TASK 1. IMMERSIVE DATA-ENTRY/EDITING ACTIVITY IN GIS ENVIRONMENT: The settlement in Filicudi consists of small scattered groups of buildings, mostly residential, located in the south-eastern side of the island. They are connected to each other by a dense network of mule tracks and a recently constructed driveway. The study areas assigned to each group are analyzed from different points of view (architectural, thermo-physical, mechanical) following these phases:

a) On-site surveys (visual analysis, empirical deductive evaluation, thermophysical measurements);

b) Systematization of information, through the use of known databases;

c) Data-entry/editing in the GIS environment; 


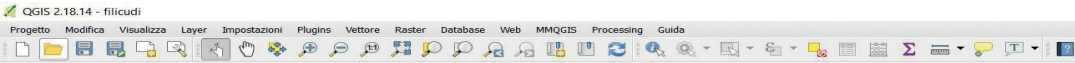
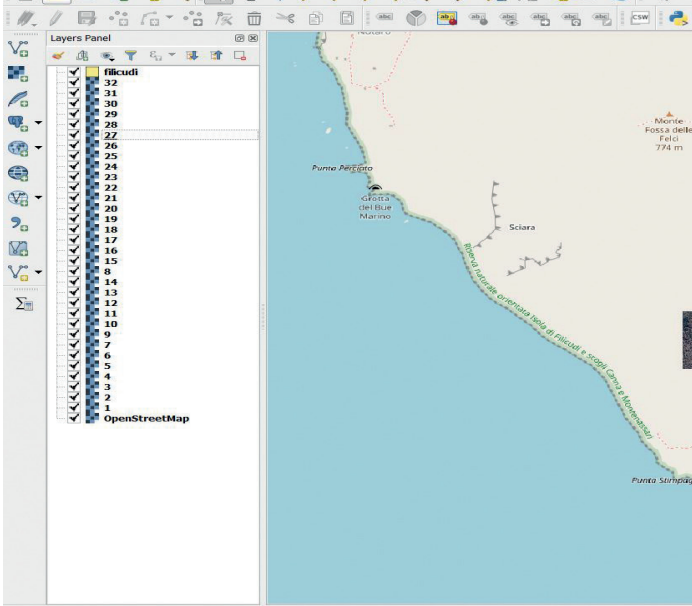


\begin{tabular}{|c|c|c|}
\hline \multicolumn{3}{|c|}{ Didactic activities in ATM } \\
\hline Theory & Practices & Workshop \\
\hline \multirow[t]{3}{*}{$\begin{array}{l}\text { Mediterranean living forms and cultures } \\
\text { [V. Sapienza] } \\
\text { [G. Giusso] }\end{array}$} & & \multirow{7}{*}{$\begin{array}{l}\text { Task 1 } \\
\text { Immersive data-entry/editing } \\
\text { activity in GIS environment } \\
\text { [staff] }\end{array}$} \\
\hline & $\begin{array}{l}\text { Visit to the Botanical Garden of } \\
\text { Catania } \\
\text { [G. Giusso] }\end{array}$ & \\
\hline & Visit of the Lachea Island & \\
\hline $\begin{array}{l}\text { Thermophysical properties of traditional } \\
\text { building materials in the Mediterranean } \\
\text { environment } \\
\text { [A. Gagliano] }\end{array}$ & & \\
\hline $\begin{array}{l}\text { REM } \\
\text { [R. Caponetto] }\end{array}$ & & \\
\hline $\begin{array}{l}\text { Structural behavior of historical buildings in } \\
\text { seismic area } \\
\text { [I. Caliò] }\end{array}$ & & \\
\hline \multirow[t]{2}{*}{$\begin{array}{l}\text { Basics of topography and GIS } \\
\text { [M. Mangiameli] }\end{array}$} & & \\
\hline & $\begin{array}{l}\text { Data automatic structuring, data } \\
\text { storage and management systems and } \\
\text { georeferencing systems } \\
\text { [M. Manggiameli] }\end{array}$ & \multirow{7}{*}{$\begin{array}{l}\text { Task } 2 \\
\text { Design simulation of local } \\
\text { architecture revitalization } \\
\text { [staff] }\end{array}$} \\
\hline \multirow{3}{*}{$\begin{array}{l}\text { History of Aeolian Islands } \\
\text { [R. Vilardo] } \\
\text { [M. Martinelli] }\end{array}$} & & \\
\hline & Visit to the Lipari Museum & \\
\hline & $\begin{array}{l}\text { Visit to Filobraccio and Capo Graziano } \\
\text { [V. Sapienza] }\end{array}$ & \\
\hline \multirow{3}{*}{$\begin{array}{l}\text { Ancient terraces of Filicudi Island } \\
\text { [A. Bonazza] } \\
\text { [A. Sardella] }\end{array}$} & & \\
\hline & $\begin{array}{l}\text { Visit to the Pumice-stone Quarries } \\
\text { [E. Carnevale] }\end{array}$ & \\
\hline & Visit to Zucco Grande & \\
\hline
\end{tabular}


d) Summary evaluation and attribution of a quality label to each analyzed building.

The use of checklists, prepared by the teaching staff, makes the data collection easy.

Through a REM methodology, the system provides three indexes for each one of the topics covered:

1) Typological/landscape/constructive aspects;

2) Energy behavior;

3) Mechanical behavior.

The sum of them forms a global index that measures the quality of the surveyed buildings.

The implemented virtual platform can be queried to give aggregated data. The sum of the results of all study areas allows the obtaining of information on a significant portion of the whole island.
- TASK 2. DESIGN SIMULATION OF LOCAL ARCHITECTURE REVITALISATION: The working groups have to deepen their reflections on an assigned building located within the study area, in order to reach a more precise assessment of the architectural quality that takes into account the different relevant issues. The architectural parameters to be evaluated concern the coherence of the construction elements with the traditional building models and landscape characteristics, with particular attention to:

- Relations between architecture and context;

- Materials used in the construction process;

- Water and waste systems;

- Natural ventilation;

- Daylighting.

\begin{tabular}{|c|c|c|}
\hline & & Inputs of the Task 2 \\
\hline Area of study & Destination of the revitalized buildings \\
\hline Valdichiesa & winter & summer \\
\hline Canale Nord & municipal office & typical products shop \\
\hline Canale Sud & bike rental & infopoint \\
\hline Liscio & wellness center & electric bike station \\
\hline Portella & university center & medical center \\
\hline Pecorini nord & art center & observation point \\
\hline
\end{tabular}




\begin{tabular}{|c|c|c|}
\hline \multicolumn{3}{|c|}{ List of the Aeolian Teaching Module participants } \\
\hline $\begin{array}{c}\text { UNICT } \\
\text { HOST PARTNER }\end{array}$ & NTNU & UAUIM \\
\hline \multicolumn{3}{|c|}{ TEACHING STAFF } \\
\hline Vincenzo Sapienza & Luca Finocchiaro & Marius Voica \\
\hline Ivo Caliò & Chiara Bertolin & Mihaela Hărmănescu \\
\hline Antonio Gagliano & Markus Schwai & Elena Cristina Mândrescu \\
\hline Simona Calvagna & & Marina Mihăilă \\
\hline Gianluca Rodonò & & Adrian Moleavin \\
\hline \multicolumn{3}{|c|}{ STUDENTS } \\
\hline Antonino Artino & Florian Betat & Ioana Capotă \\
\hline Ivan Attardo & Ilya Pugachenko & Iulia Panait \\
\hline Jessica Caruso & Marija Katrina Dambe & Alexandru-Marian Mărginean \\
\hline Noemi D'Amico & Irhana Sehovic & Ana Maria Petrescu \\
\hline Giulia Fiore & Jingjing Zhou & Diana Neagu \\
\hline Sharon Gibilras & Alla Aniskova & Corina Șerban \\
\hline Sebastiano Greco & Stefanie Katharina Stanke & Alexandra Ivănescu \\
\hline Agata Lipari Galvagno & Filipova-Jeni Nankova & Maria luca \\
\hline Angelo Monteleone & & Andrei-Mihai Bosnyak \\
\hline Anna Scandura & & Adina Popa \\
\hline \multirow[t]{5}{*}{ Claudio Torre } & & Diana-Nicole Șerban \\
\hline & & Oana-Maria Anghel \\
\hline & & Ioana-Mihaela Iordache \\
\hline & & Diana Bădicu \\
\hline & & Theodora Bratu \\
\hline
\end{tabular}


From the point of view of energy balance, the evaluation of the building's thermophysical performance is deepened by introducing the collected data within an easy-to-use software [29], able to return a qualification of the studied buildings for a subsequent comparison between the differ-
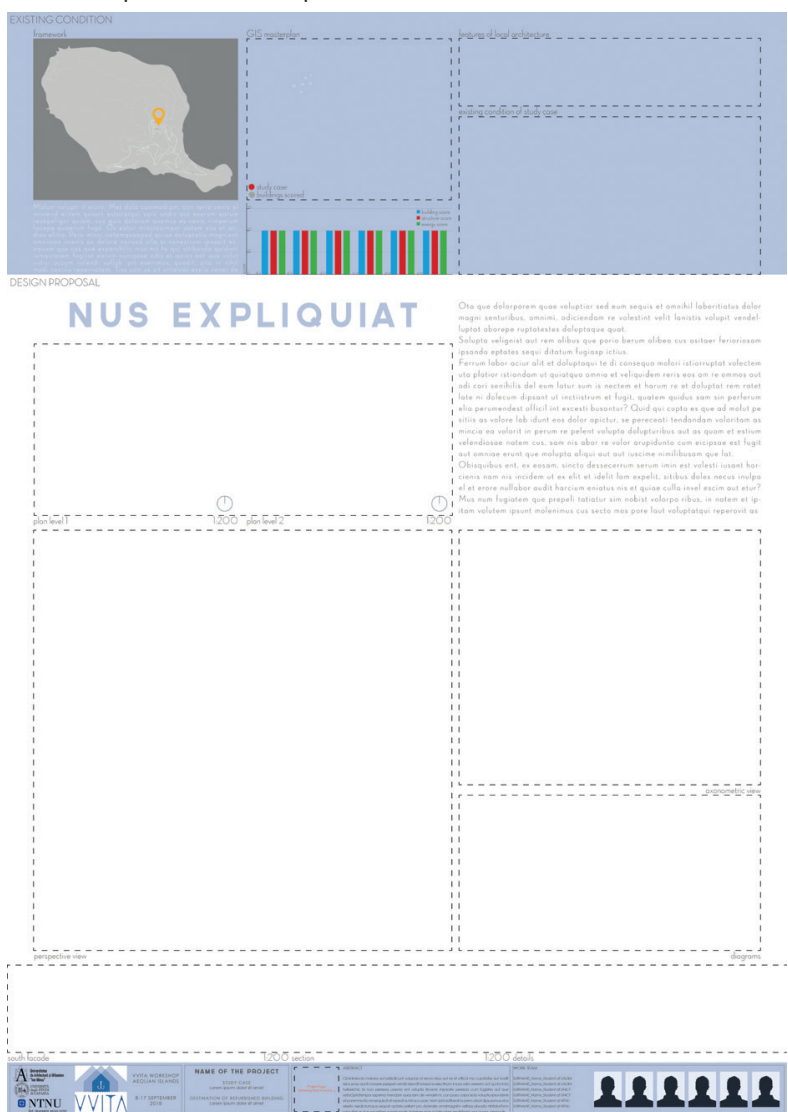

ent case studies. From a mechanical point of view, a visual analysis of the cracks, accompanied by a guided assessment of the structural features of the buildings, makes it possible to establish a quality label related to the response to the seismic action of each building.
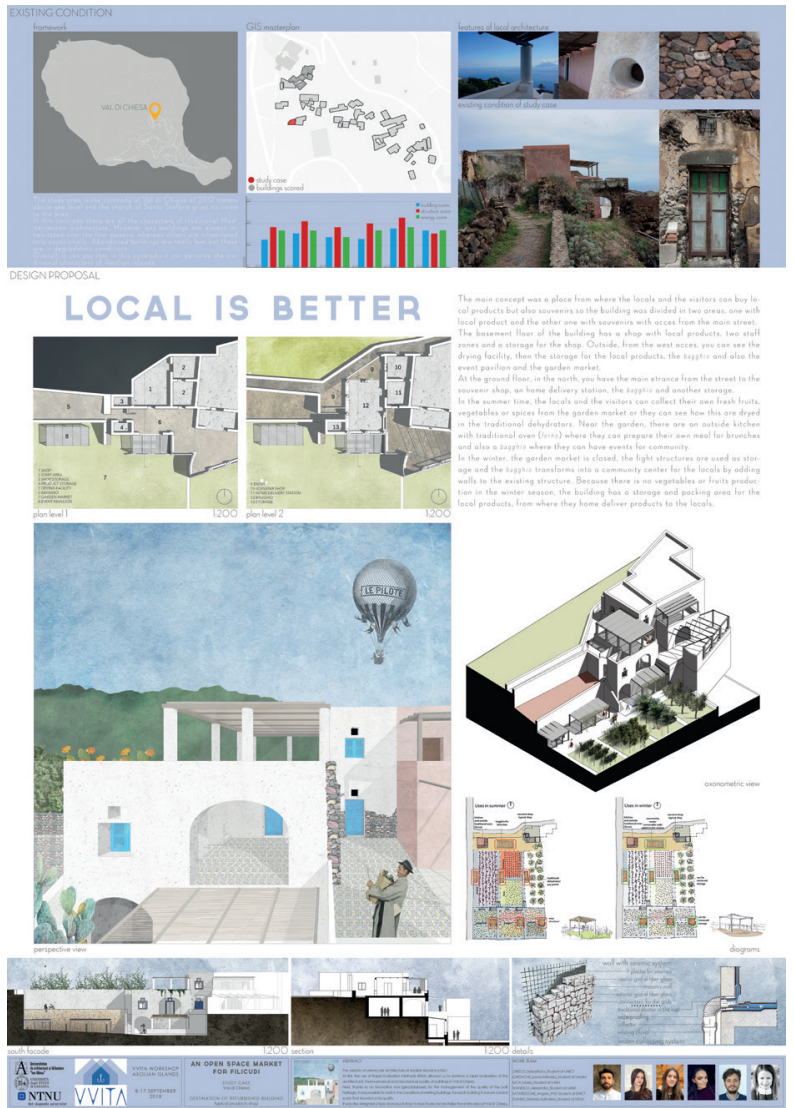
The design simulation for the revitalization of the built heritage starts from this point. The design choices therefore derive from parametric assessments attentive to the sustainability and coherence of the interventions, to the peculiar characteristics of landscape and traditional architecture, and to the use of renewable energies. This applies both to refurbishment and to possible completion volumes.

The designs are addressed to ruined buildings which, unfortunately, are quite frequent in Filicudi. This fact leaves the students quite free and stimulates their creativity and invention.

The teaching staff provides the new destinations for each building. The projects have to foresee an elevated grade of flexibility, according with the difference in use in different seasons. In winter, the functions must be developed in the masonry cells. In summer, according with the increasing number of inhabitants, some additions, i.e., kinetic or removable structures, can be considered.

In the GIS platform it is also possible to simulate some refurbishment actions, in order to understand their impact on the building.
TIMING: The typical workday is organized according to the following timetable.

A.M.: Field surveys and excursions.

P.M.: Data processing and design and planning.

18.00: 5 minutes per group presentation of the work done during the day, in a few slides. This follows with a debate with the staff members to address the activities of the following days.

The evaluation of the outputs is carried out by the staff in three periods.

One or two days after the start of the workshop, an intermediate presentation is made, to check the outputs of task 1 and the concept of task 2.

The last day is reserved for the oral presentation of the work.

The students are also invited to present a final report and a poster within three months after the end of the ATM. The final report is included in the final book of VVITA. The posters are used to realize an exhibition of the works in the common spaces of the University of Catania. 


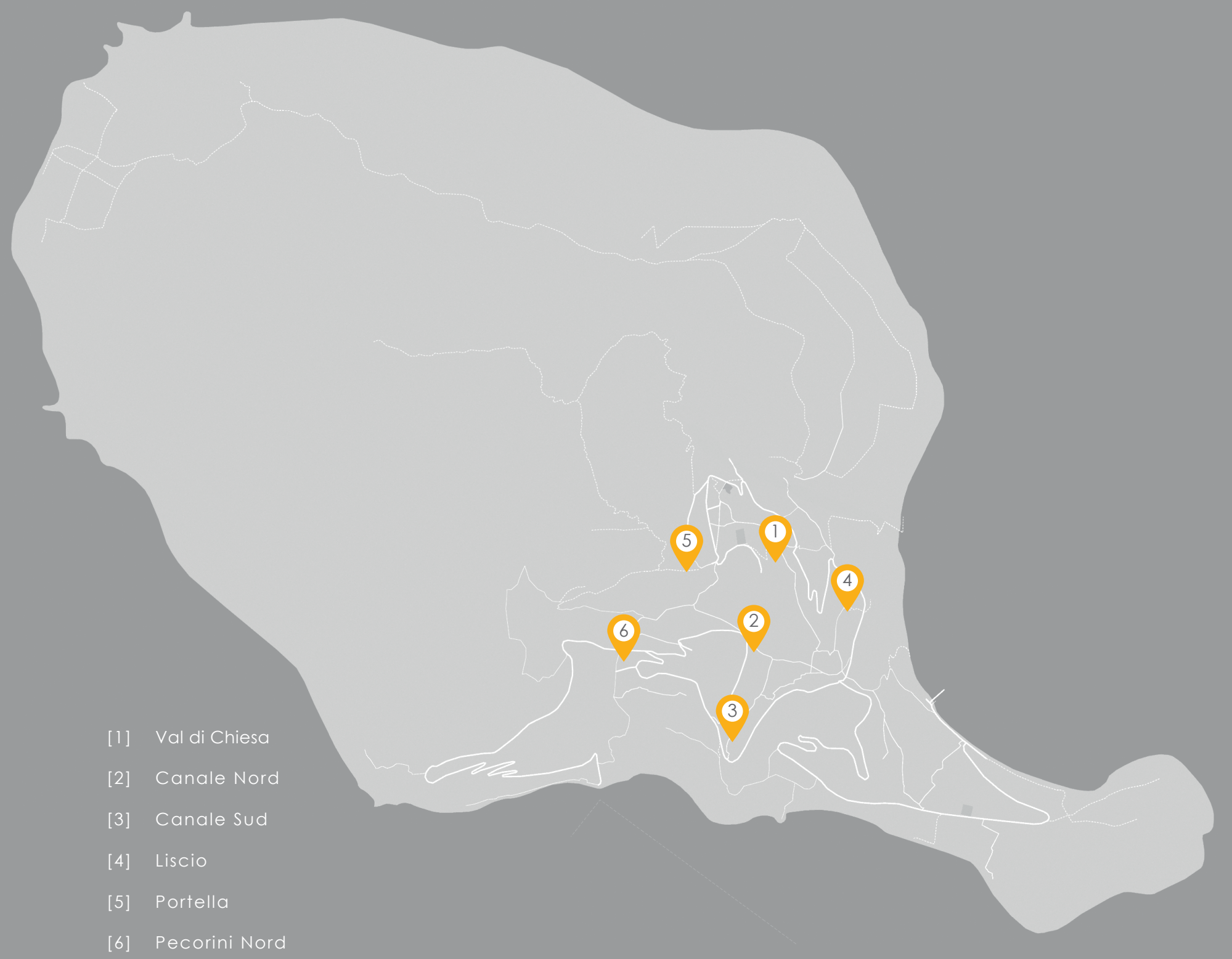




\section{REFERENCES}

[1] Finley M. I., Mack Smith D., Duggan C.; Breve storia della Sicilia, Laterza: Bari, 1992 (in Italian).

[2] "Aeolian Islands - UNESCO World Heritage Centre" [Online]. Available: https://whc.unesco.org/en/list/908.

[3] "Clima - Isole Eolie" [Online]. Available: http://www.eOlie.it/clima.htm (in Italian), (accessed on October, 2019).

[4] Trovato C. S., Tropea G., Piccitto G., Vocabolario siciliano, Centro di Studi Filologici e Linguistici Siciliani: Palermo, 1985-2002 (in Italian).

[5] Perricone M., Oliva A., Tecniche costruttive tradizionali negli insediamenti abitativi di Stromboli, Proceedings of the International symposium: The project in the space of memory: signs, ideas and future development. Naples, 1995 (in Italian).

[6] Calvagna S., Gagliano A., Greco S., Rodonò G., Sapienza V.; Innovative Multidisciplinary Methodology for the Analysis of Traditional Marginal Architecture, Sustainability vol. 12 (4), 2020.

[7] Polverino F., Tra lastrici e terrazzi. CUEN: Neaples, 1999 (in Italian).

[8] Polverino F., Ischia: architettura e terremoto. Clean Edizioni: Neaples, 1998 (in Italian).

[9] Maresca R., Seismicity of the Aeolian Islands, Southern Italy, In: Annales Geophysicae, 1984.

[10] Lucchi F., Peccerillo A., Keller J., Tranne C. A., Rossi P. L., The Aeolian Island Volcanoes, Geological Society, London.

[1 1] Georgescu E. S., Georgescu M. S., Macri Z., Marino E. M., Margani G., Meita V., Pana R., Cascone S. M., Petran H., Rossi P. P., Sapienza V., Voica M.. Seismic and Energy Renovation: A Review of the Code Requirements and Solutions in Italy and Romania, In: Sustainability, No. 10(5), 1561, 2018

[12] Sapienza V., Le murature tradizionali nell'area etnea: Modi costruttivi e consistenza materica. Recupero Conservazione, 84, 2008 (in Italian).

[13] Giuffrè A., Sicurezza e conservazione dei centri storici. Il caso Ortigia, Laterza, Rome, 1983 (in Italian).

[14] Gavarini, C., Giuffrè, A., Longhi, G., Ingegneria Antisismica, ESA: Milan, 1991 (in Italian).

[15] Cascone S. M., Sapienza V., Porto S. M., Lionti l., Fiber-Reinforced Polymer Nets for Strengthening Lava Stone Masonries in Historical Buildings. SUSTAINABILITY No. 8, 394, 2016.

[16] Sapienza V., The Aeolian houses of Filicudi: an example of spontaneous sustainable architecture. II Progetto Sostenibile, No. 34, 2014, (in Italian).

[17] Sapienza V., Spontaneous architecture and energetic sustainability: the Aeolian homes of Filicudi Isle. In: Noguchi M., 
ZEMCH-12, ZEMCH Network: Glasgow, 2012.

[18] "Masterclima" [Online]. Available: http://www.masterclima.info/page/Software.asp (accessed on October, 2019).

[19] Sapienza, V., Salemi, A., Patania, F., Cascone, S., Gagliano, G., Lo Faro, A., Lombardo, G., Moschella, A.; Thermal performance of existing buildings in Mediterranean climate area. In: Changing needs, adaptive buildings, smart cities. vol. 1, p. 1017-1024, Milan:Poliscript, 2013.

[20] "Passive-On Project" [Online]. Available: http://www.eerg.it/passive-on.org/en/index.php (accessed on October, 2019).

[21] Sapienza, V., Gagliano, A., Chiaramonte, R.; Energetic sustainability of the building substitution: the rewards and the facilitations of the Italian Piano Casa. In: Renewable Energy \& Power Quality Journal, No. 11, 2013.

[22] Sicilian Authority Law No. 6 - 23/03/2010, Norme per il sostegno dell'attività edilizia e la riqualificazione del patrimonio edilizio; Gazzetta Ufficiale della Regione Siciliana No. 14 in 26-3-2010; Regione Siciliana: Palermo, 2010 (in Italian).

[23] Sicilian Infrastructure Council Decree 07/07/2010, Bioedilizia; Gazzetta Ufficiale della Regione Siciliana No. 33 in 23 7-2010; Regione Siciliana: Palermo, 2010 (in Italian).

[24] Kalman H. D., The Evaluation of Historic Buildings, Parks Canada, 1980.

[25] "ITACA. Istituto per l'Innovazione e Trasparenza degli Appalti e la Compatibilità Ambientale" [Online]. Avialbale: http://itaca.org/valutazione_sostenibilita.asp

[26] "LEED rating system - U.S. Green Building Council" [Online]. Available: https://new.usgbc.org/leed (accessed on October, 2019).

[27] "QGIS - A Free and Open Source Geographic Information System" [Online]. Available: https://www.qgis.org/en/ site/ (accessed on October, 2019).

[28] Frey P., Learning from Vernacular. Towards a new vernacular architecture, Actes Sud: Arles, 2010.

[29] "Docet - CNR" [Online]. Available: http://www.docet.itc.cnr.it/ (accessed on October, 2019).

\section{Vincenzo Sapienzo}

Department of Civil Engineering and Architecture, University of Catania, Italy

Mail: vincenzo.sapienza@unict.it

\section{Simona Calvagna}

Department of Civil Engineering and Architecture, University of Catania, Italy.

Mail: simona.calvagna@unict.it 

PART III AEOLIAN TEACHING MODULE CONTRIBUTIONS

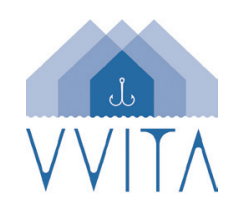



STAFF CONTRIBUTIONS 


\section{CONSTRUCTIVE CHARACTERISTICS OF TYPICAL AEOLIAN ARCHITECTURE AND METHODS FOR EVALUATION OF SUSTAINABILITY}

\section{INTRODUCTION}

This session aims to identify the main characteristics of the typical Aeolian architecture and to indicate the most appropriate systems to assess its sustainability. In this peculiar context, the sustainability assessment is particularly complex because the Aeolian architecture denotes a homogenous and specific housing style, which is intrinsically linked to local culture. It is characterized by a construction code, which is a direct expression of necessities, that is linked to environmental conditions and to locally available resources. The archipelago is protected by a Territorial Landscape Plan and is included in the list of the Intangible Cultural Heritage of Humanity (in 2000, UNESCO placed the Aeolian Archipelago among the 691 sites in the world protected by virtue of their "environment and/ or cultural characteristics").

\section{TYPICAL AEOLIAN ARCHITECTURE}

To carry out the analysis on a building's sustainability, it is important to know the functional and construction characteristics that distinguish it. Therefore, the first part of the session concerns just the characteristics of typical Aeolian architecture. In particular, we will start with the typical architectural elements and then, we will describe the specific technical solutions.

Aeolian architecture is the result of objective and contextual necessities due to en- vironmental conditions and the historical genesis. The geomorphological characteristics of places of volcanic nature, the climatic factors (characterized by a high level of sunshine, minimum temperature range, and low amounts of rain), and the limited quantity of available resources (economical, material) have strongly influenced the construction of traditional types of buildings [1].

\subsection{TYPOLOGICAL CHARACTERISTICS}

Aeolian architecture was strongly influenced by the architecture of the sixteenth century Campania region, which, after migration, was grafted onto a previously Greek-Roman and Islamic architecture. In reality, the first settlements occurred as far back as the Neolithic age between 5500 and $4000 \mathrm{BC}$. During the following centuries, the archipelago was populated by Etruscans, Carthaginians, Greeks, and Romans, then, Arabs and Normans, followed by the Spaniards; but, most of the current villages were built in the nineteenth century. The original element of the typical architecture is a single cubic or parallelepiped shaped cell, with only one entrance door and two possible round windows. The building mainly responded to the needs of defence from external dangers, in particular possible invasions or raids by enemies coming from the sea. Inside the houses, there was the kitchenette (cufularu) on one side and the beds on the other. Nowadays, on the Aeoli- 
an archipelago, it is possible to identify two different types of buildings: the vertical one (in steep areas), and, most frequently, the horizontal one (in flat areas). Both types are generated using a "cellular" construction, through the superimposition or combination of cubic elements (rooms), and have similar building characteristics, which are reflected in the most recurrent pathologies and on the life cycle of the various components and of the entire building. The other traditional buildings are a combination of these two types. Figure 4 shows the combination of cubic elements for the "horizontal type"; originally, only a single cubic "cell" and a terrace composed the house (fig.1). Subsequently, another "cell" was put beside the first, in place of the patio. This one rotated and adapted to everyday life with functional elements. The typical elements of the traditional building are the following.

- The bagghiu (baglio), a large terrace a the front of the house.

- The bisòlu, small stone walls that delimit

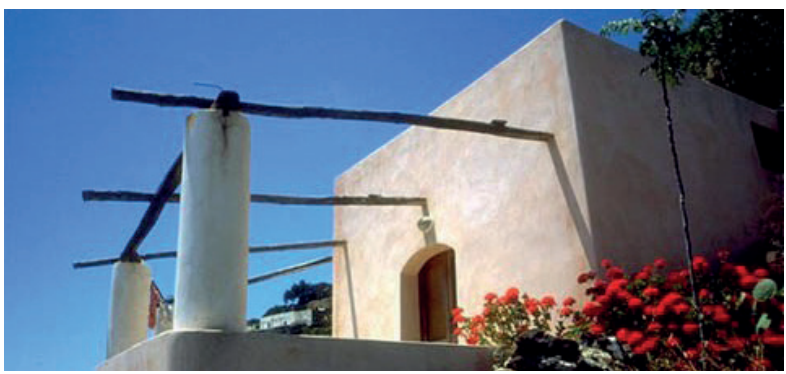

Figure 1. Single cell house

the terrace and are sometimes decorated with majolica tiles.

- The loggia, a trellis of wooden beams covered with cane, the roof of the terrace.

- The pulèra, columns that support the loggia.

- The princu, a stone washbowl that restson the pila, an outdoor tub used to do the laundry.

- The furnu, the oven, which is domeshaped, positioned to the side of the terrace above a base used to store firewood.

- The astricu, the horizontal roof. It has animportant function: to isolate the house from the cold in winter and from the heat in summer; but in the past, it was normally used for collecting rainwater (the raised edge of the terrace, called "petto di colomba" - "dove's breast" - enabled the collection of rainwater in order to convey it to an underground cistern).

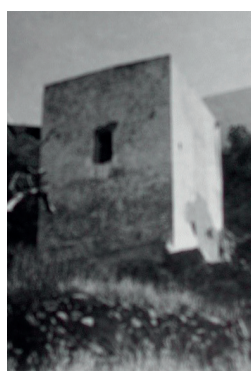

Figure 2. Two-cell house (vertical type)

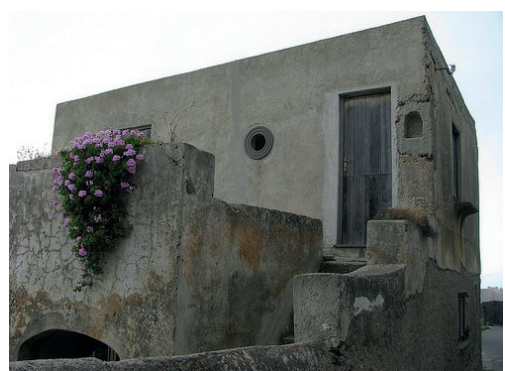

Figure 3. Two-cell house (horizontal type) 

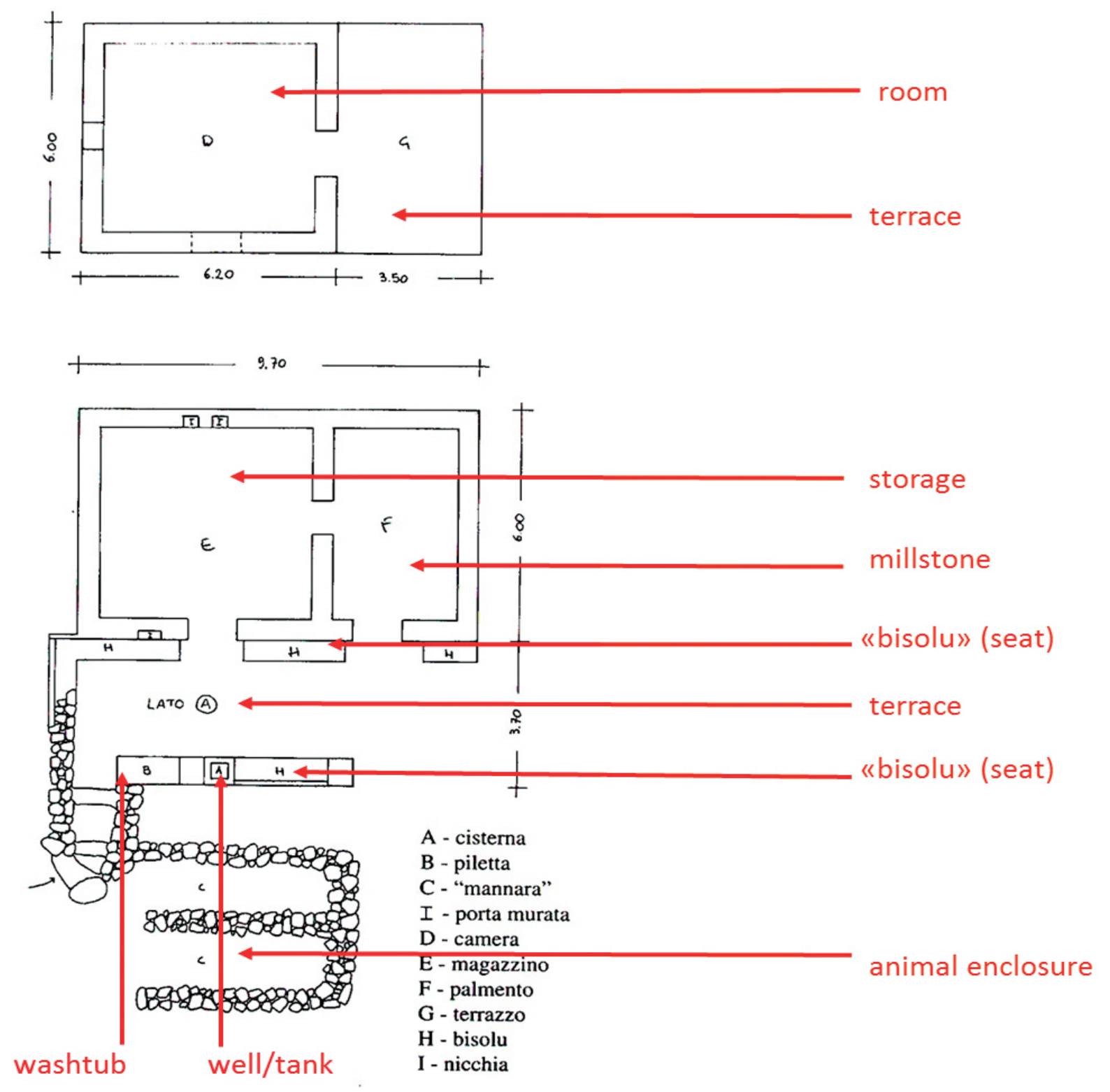

Figure 4. Combination of two "cells" in a "horizontal type" house 


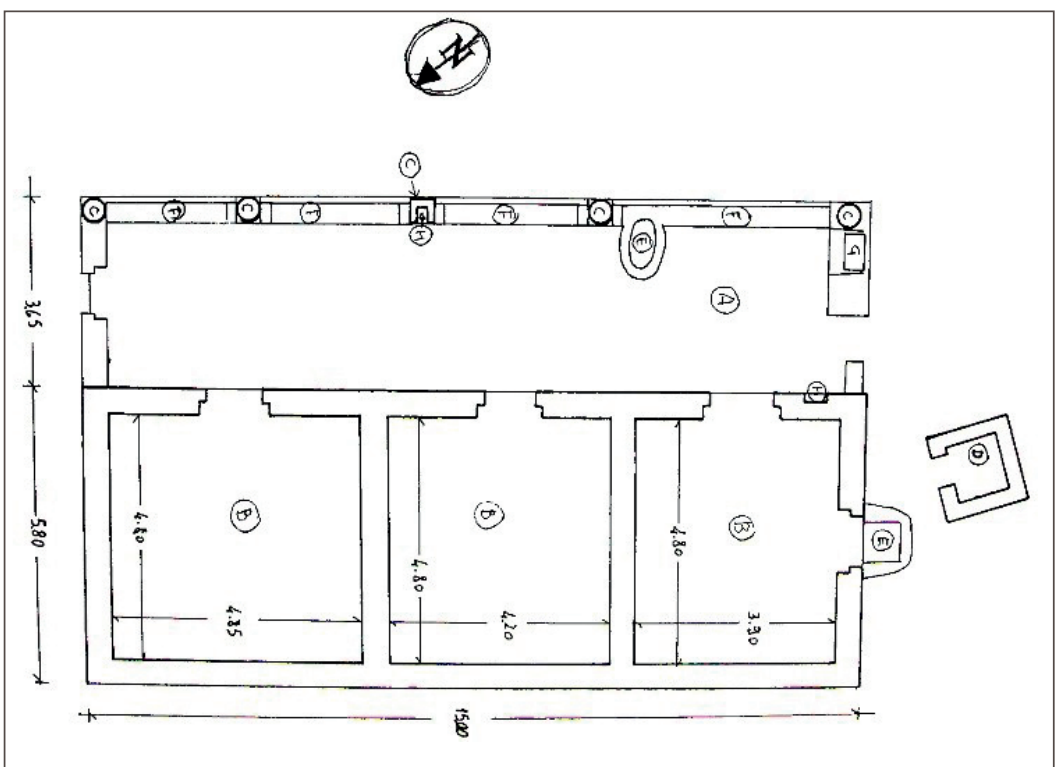

Figure 5. Layout of a typical house

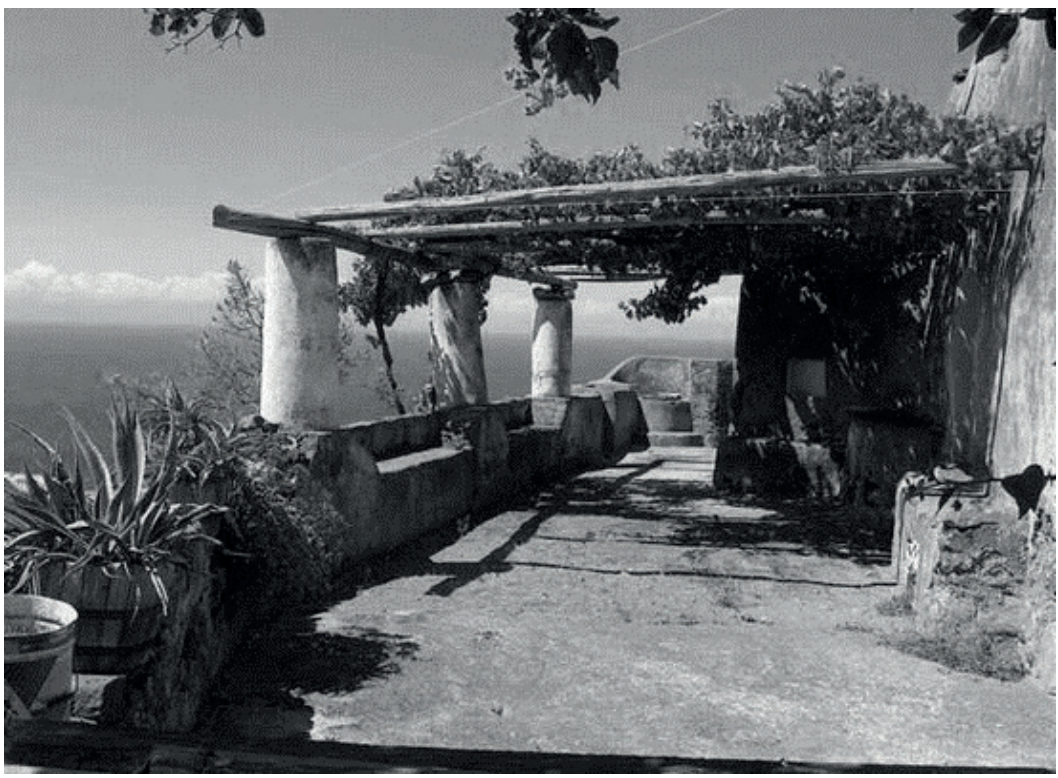

Figure 6. "Bagghiu"

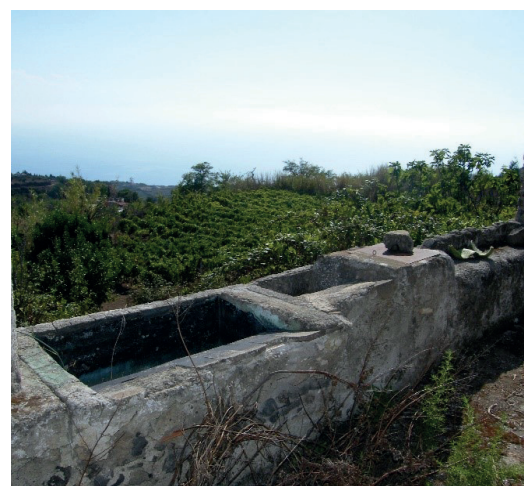

Figure 7. "Pila" and "princu"

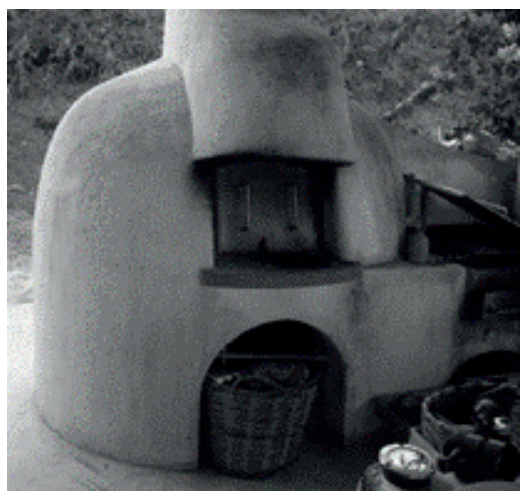

Figure 8. "Furnu"

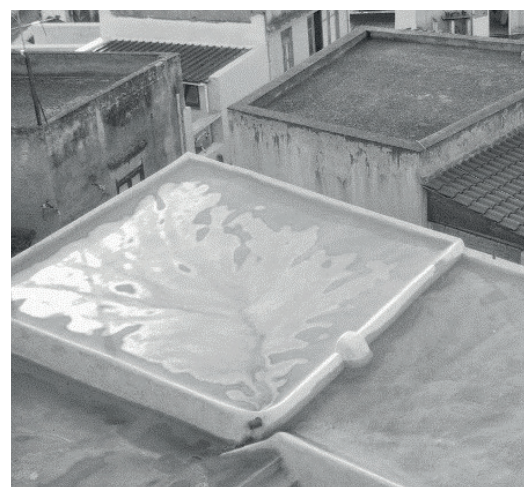

Figure 9. "Astricu" 


\subsection{ANALYSIS OF THE "TRADITIONAL" BUILDING SOLUTIONS AND SOME REFERENCES ON NEW TECHNOLOGIES}

As mentioned above, the typical architecture of the Aeolian Islands is strictly linked to the environmental conditions and to the locally available resources. The geo-morphological characteristics of the locations and the climatic factors have strongly limited the local "modus aedificandi"; however, simultaneously, the architectonic and technological choices have delivered unique places and cultural facts of the Mediterranean area.

Throughout time, several factors have influenced the building procedure (availability of raw materials, costs of materials and skilled workers, the ease and speed of the work carried out, the elements' durability, etc.). This has led to a progressive technological transformation extraneous to the local culture.

Starting from the nineteenth century, Aeolian construction practices were characterized as follows:

\section{FOUNDATIONS AND WALLS}

- foundations made of lava stone, with limeand pumice mortar;

- very shallow ( $h=l e s s$ than $40 \mathrm{~cm}$ ) foraone-storey house:

- no taller than $70 \mathrm{~cm}$ tall, for multi-storeybuildings:

- walls usually made of shapeless stone (quarried in the islands) and mortar (rich in lime and coarse pumice called "rupiddu", lava lapillus). Subsequent to the Messina earthquake (1908), rough-hewn stone masonry was used, with horizontal mortar courses (distance $=70 \mathrm{~cm}$ );

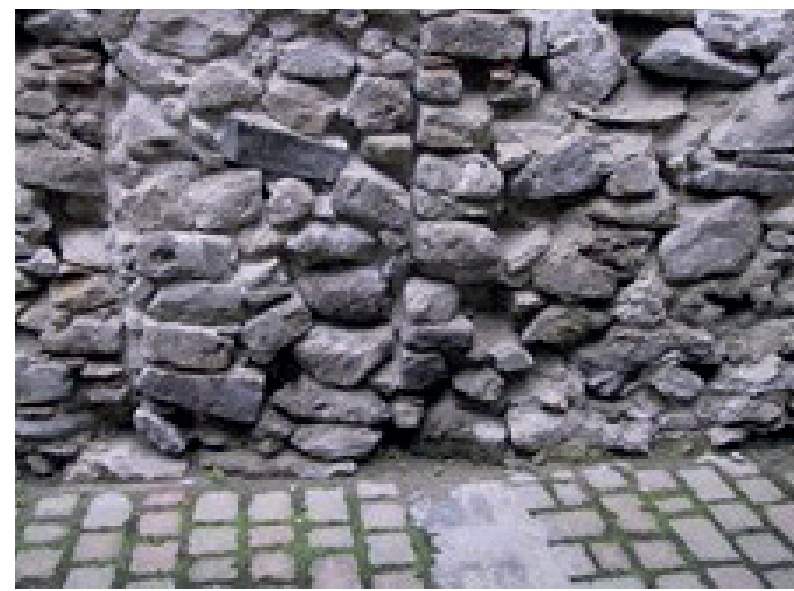

Figure 10. Shapeless stones wall

Masonry made of shapeless local stones and lime mortar (with coarse pumice called "rupiddu"). The lava stones are heaped together almost without mortar and the masonry corners do not have capstones.

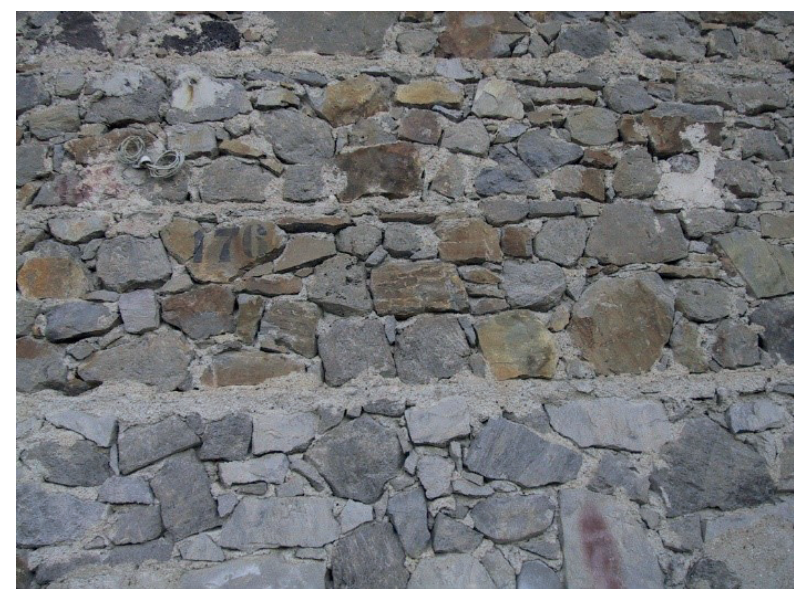

Figure 11. Rough-hewn stones and horizontal "courses" of lime mortar

Masonry made of rough-hewn stones and lime mortar with coarse pumice. Mortar courses are present (at a distance of $70 \mathrm{~cm}$ ) giving stability to the wall in opposition to horizontal forces (see construction standards in seismic area). 
- for the internal partitions, either tuff or lava stone were often used.

\section{HORIZONTAL FLOORS}

The solid ground floor was made of lime and pumice stone (sometimes there was a crawl space). The traditional intermediate floor was made of wood and conglomerate: there was a double system of beams (main and secondary unhewn logs) on which a reed mat was laid; a special conglomerate (made of volcanic lapilli, lime mortar, and fine pumice) was casted. The flat roof (called "astricu", thickness 12-15 $\mathrm{cm}$ ) had a screed made of lime mortar, volcanic lapilli, and fine pumice, laid on a layer of broken stones, whose flat side rests on a layer of canes, the entirety supported by beams made of local chestnut wood. The astricu collects the meteoric waters, which are channelled/transported into the cistern
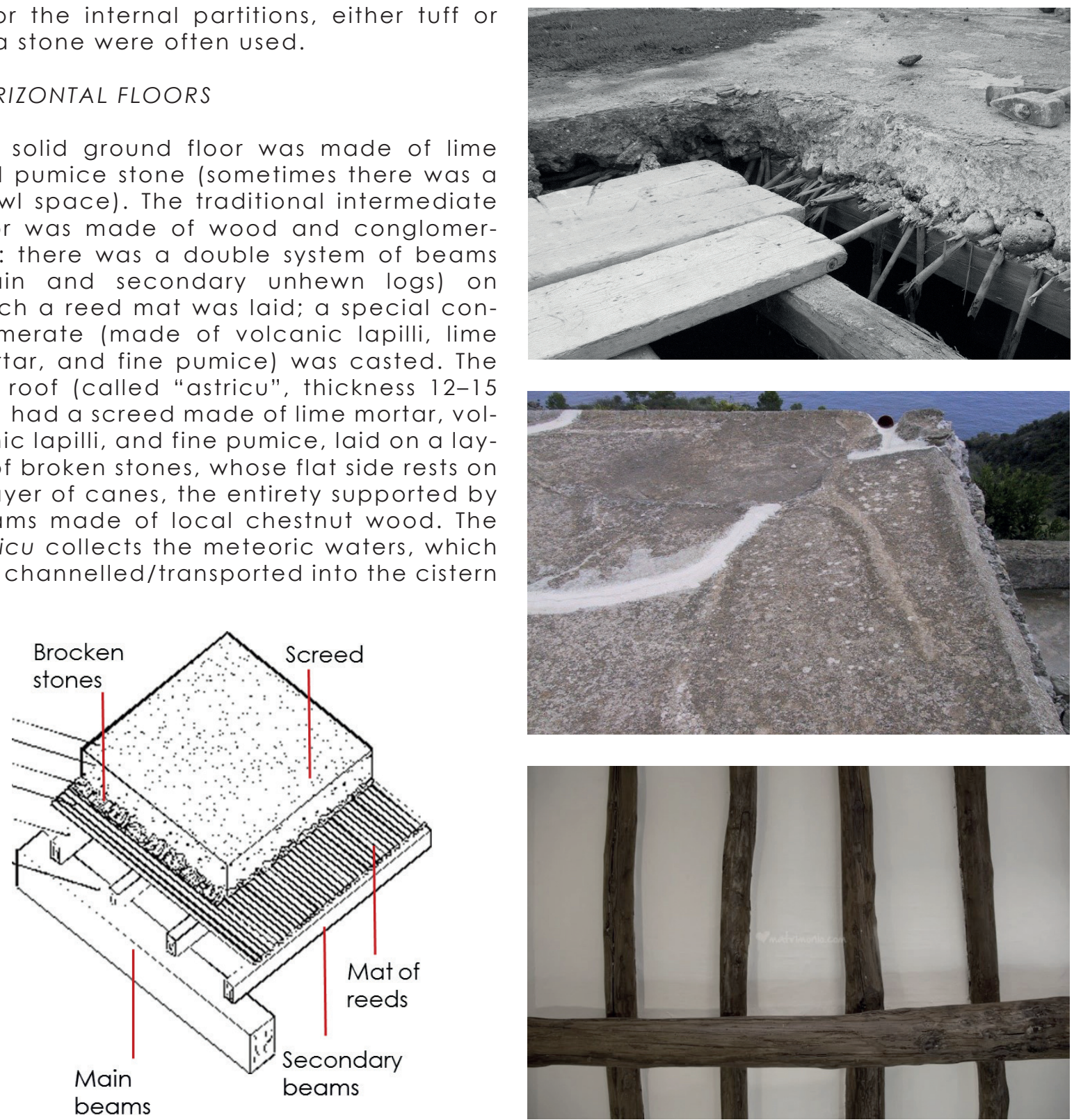

Figure 12. Some images of the "astricu" 
(generally located under the house), through the drainpipe, made of terracotta elements. A careful processing by beating the surface layer, still fresh (in order to completely saturate the voids and therefore, the porosity), ensured the water tightness of the terrace.

\section{VERTICAL CONNECTIONS}

The external staircases and the internal stairs connecting the ground floor with the first generally consisted of solid basalt steps laid on a rampant masonry arch; inside, wooden stairs were used for all other floors.

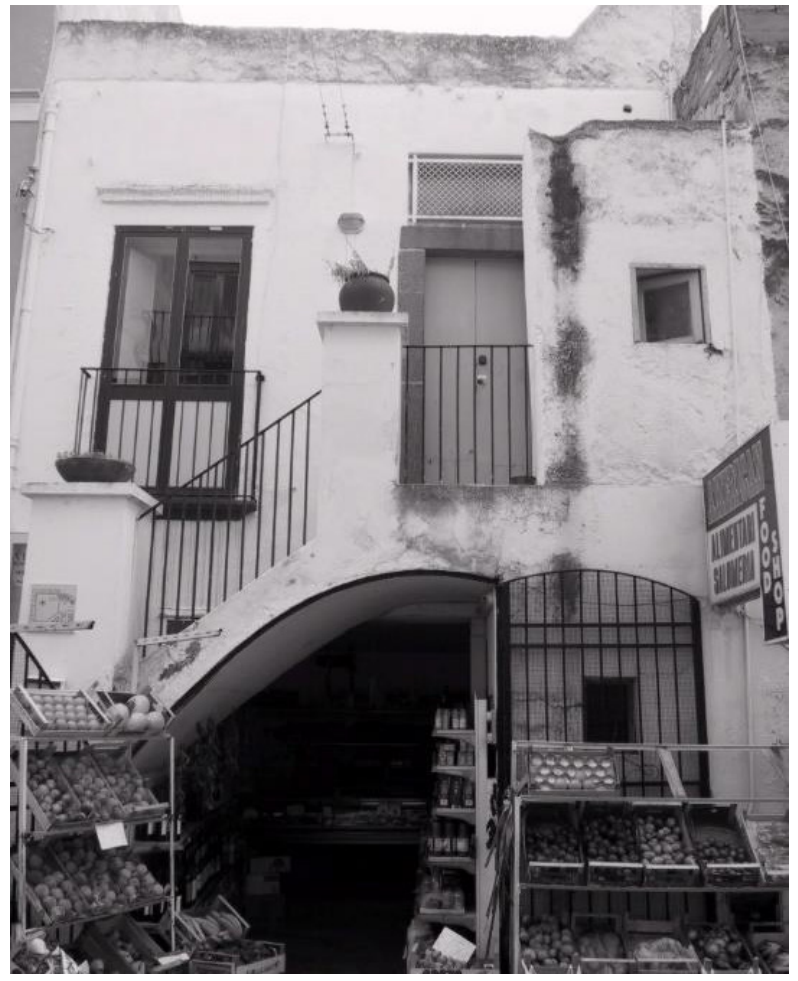

Figure 13. Typical staircase (exterior and internal)

\section{FINISHES}

The traditional plaster (in two layers) was made of lime mortar with very fine lapilli. Often there was lime-based painting, which was used until the 1970s. As for the flooring, for both interiors and exteriors, coloured ceramic tiles (coming from S. Stefano di Camastra) or pressed cement tiles (sometimes with marble flakes) were used. The external floors (for storage rooms and terraces) are made of lime, and pumice (after cement, lime, and pumice). Traditional doors and windows are made of chestnut wood with oil paint.

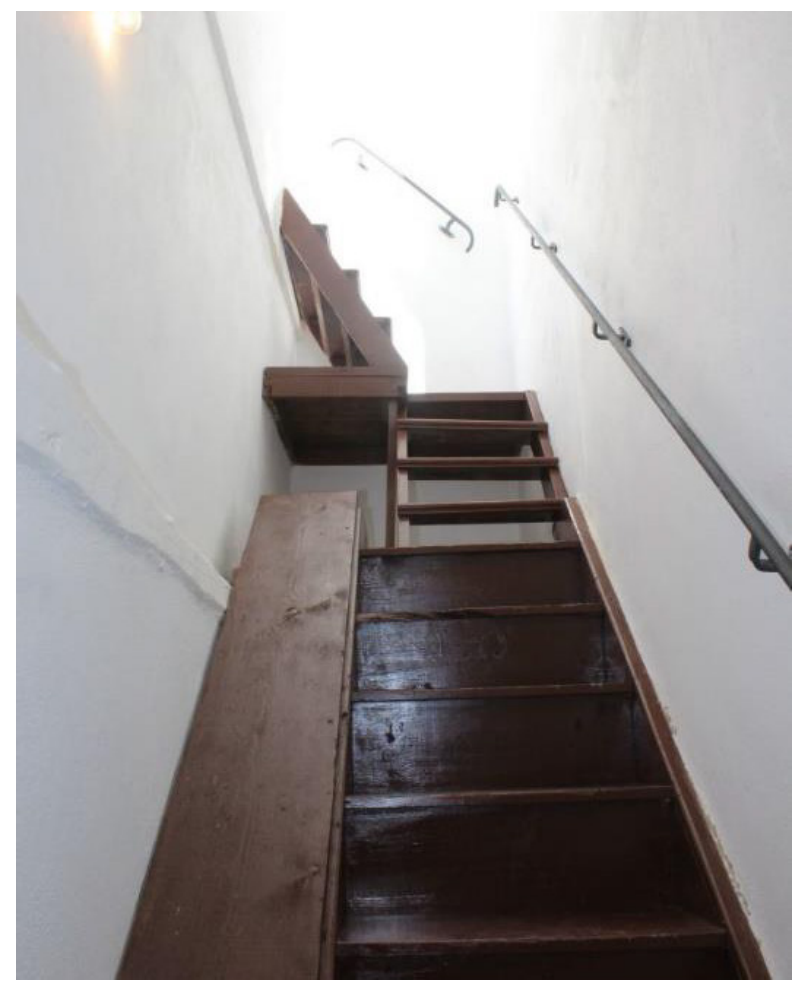




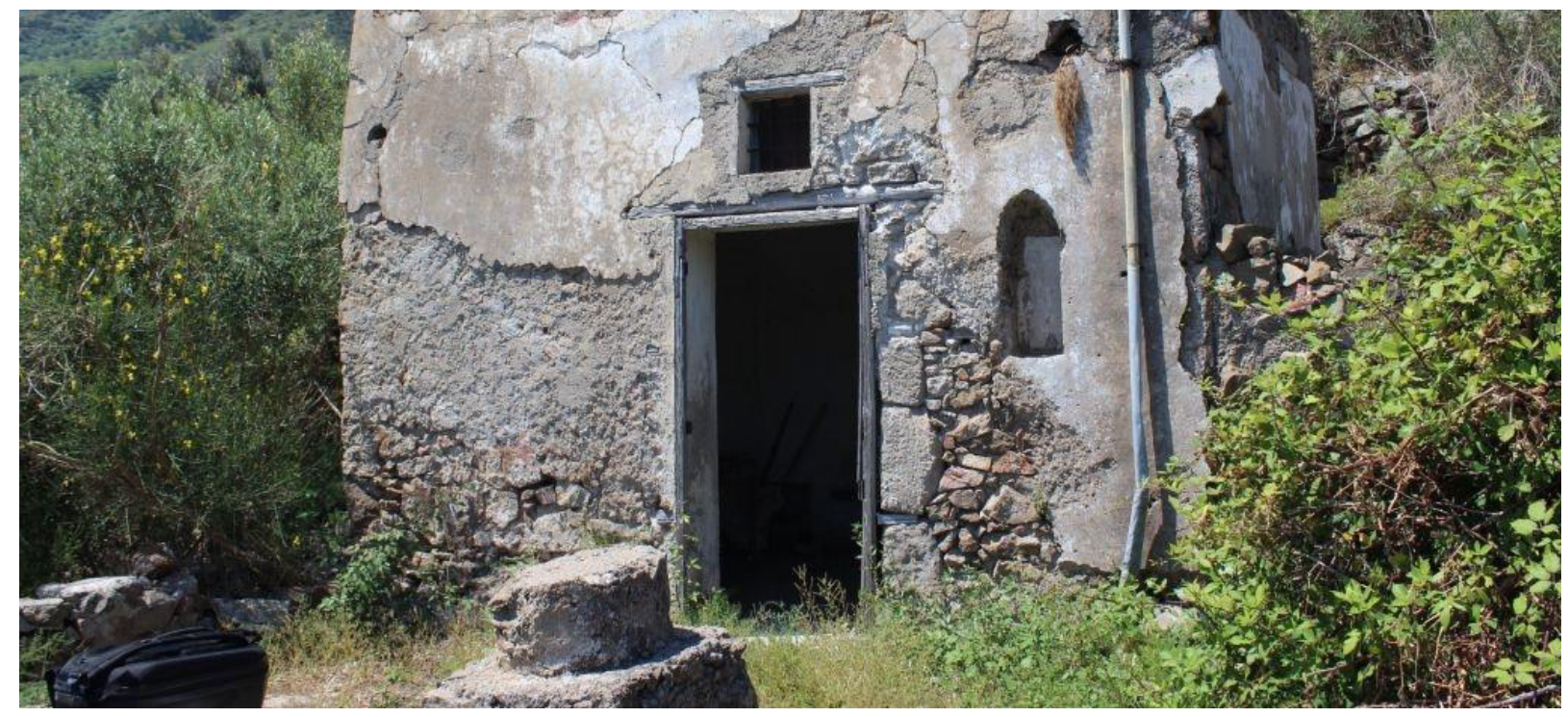

Figure 14. The traditional plaster: lime mortar and fine lapilli

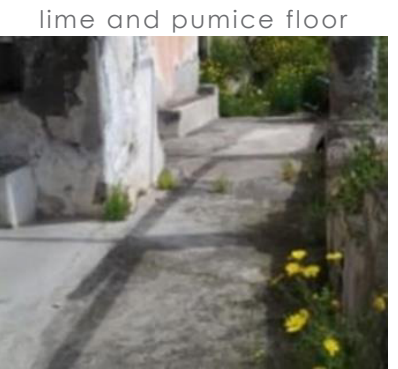

colored ceramic tiles

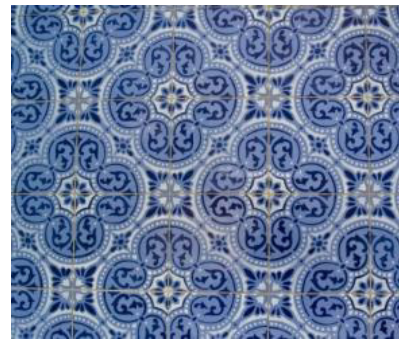

pressed cement tiles

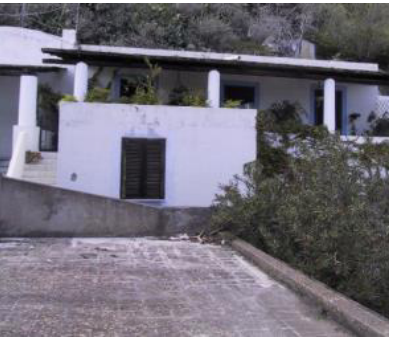

pressed cement tiles

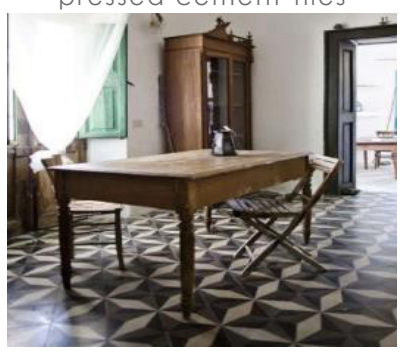

Figure 15. Typical floors
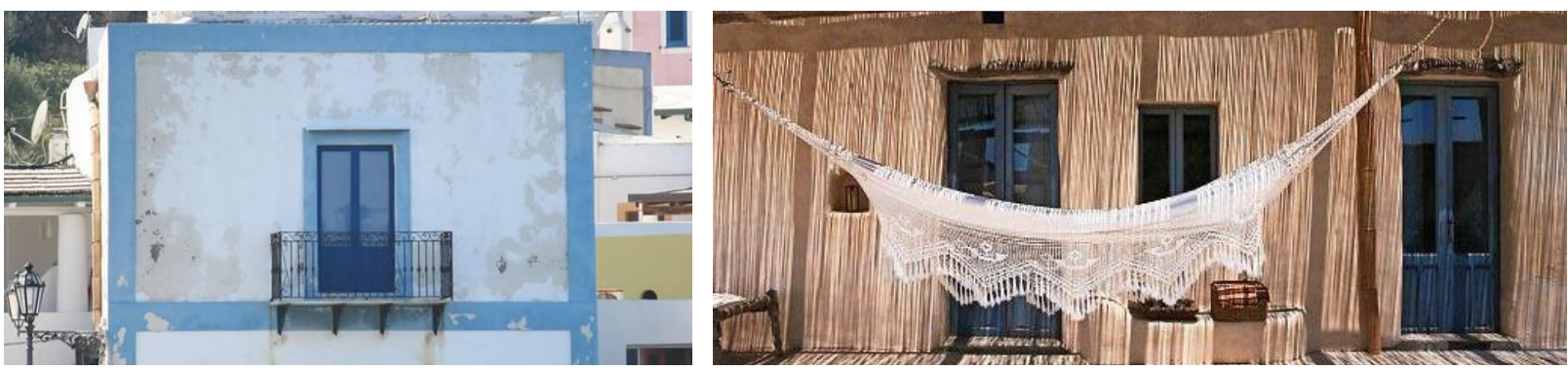

Figure 16. Colourful wooden windows and doors 


\section{RECENT TECHNIQUES}

Over time, different factors have strongly influenced local building procedures: the exhaustion of several natural resources, the closure of stone quarries, and the consequent use of artificial materials, sourced from other places (Sicily and south Italy); the consequent higher cost of materials, due to maritime transport; the scarce availability of workers with consolidated experience; the research and application of building procedures considered appropriate for the swift execution of the work, but lacking in assimilation and elaboration processes that aim at a long-lasting maintenance of the specific performances of each individual technological unit. All of these factors have determined a progressive transformation of the built environment. Building technologies and typological models foreign to the local culture have sometimes been passively imported, determining a relevant and diffused technological and environmental decay. For example, starting from the 1920s, the "pomicemento" blocks (for load-bearing walls and partitions) made of pumice and cement mixtures were produced in Lipari and exported. In the 1960s, the reinforced concrete conglomerate (cast in place) was introduced, for bearing frames and for ribbed hollow block floors. From 1970 onwards, the floors have been made of prefabricated joists and lightening bricks. For the exterior surfaces, in the 1970s, a plaster made of "marble powders" with a new finishing in lime paste and white cement was used. The last decade saw the introduction of "Terranova" plaster. Since the mid-1980s and up to the early 1990s, colored plastic paints (absolutely not recommended) were introduced onto the is- lands, but they are no longer utilized. The use of asphaltic and bituminous sheaths for the waterproofing of flat roofs began in recent decades.

\section{BUILDING SUSTAINABILITY IN SPECIAL CONTEXTS}

This section also concerns the sustainability of Aeolian architecture. The aim of these notes is to give basic information to evaluate, quickly, the effective sustainability of local buildings.

Aeolian architecture, like all types of vernacular architecture, represents the result of a stratification of empirical knowledge, linked to the socio economic, cultural, and environmental needs of a specific community. Local communities were normally in charge of maintaining their own traditional construction processes, or system of knowledge. These are very "fragile", since the processes of transmission of experience are especially sensitive to social, economic, and environmental change. However, they are considered key elements for a sustainable development of our built environments, because they are an expression of social diversity and sources of practical and technological culture strongly connected to the environmental, economic, and social needs of any location.

Among the negative effects of globalization and industrialization is the tendency toward cultural homogenization, which in architectural terms translates into the use of standard project solutions, which in many cases require a high consumption of environmental and energy resources and present scarce references to the cultural heritage of the places where they are used 

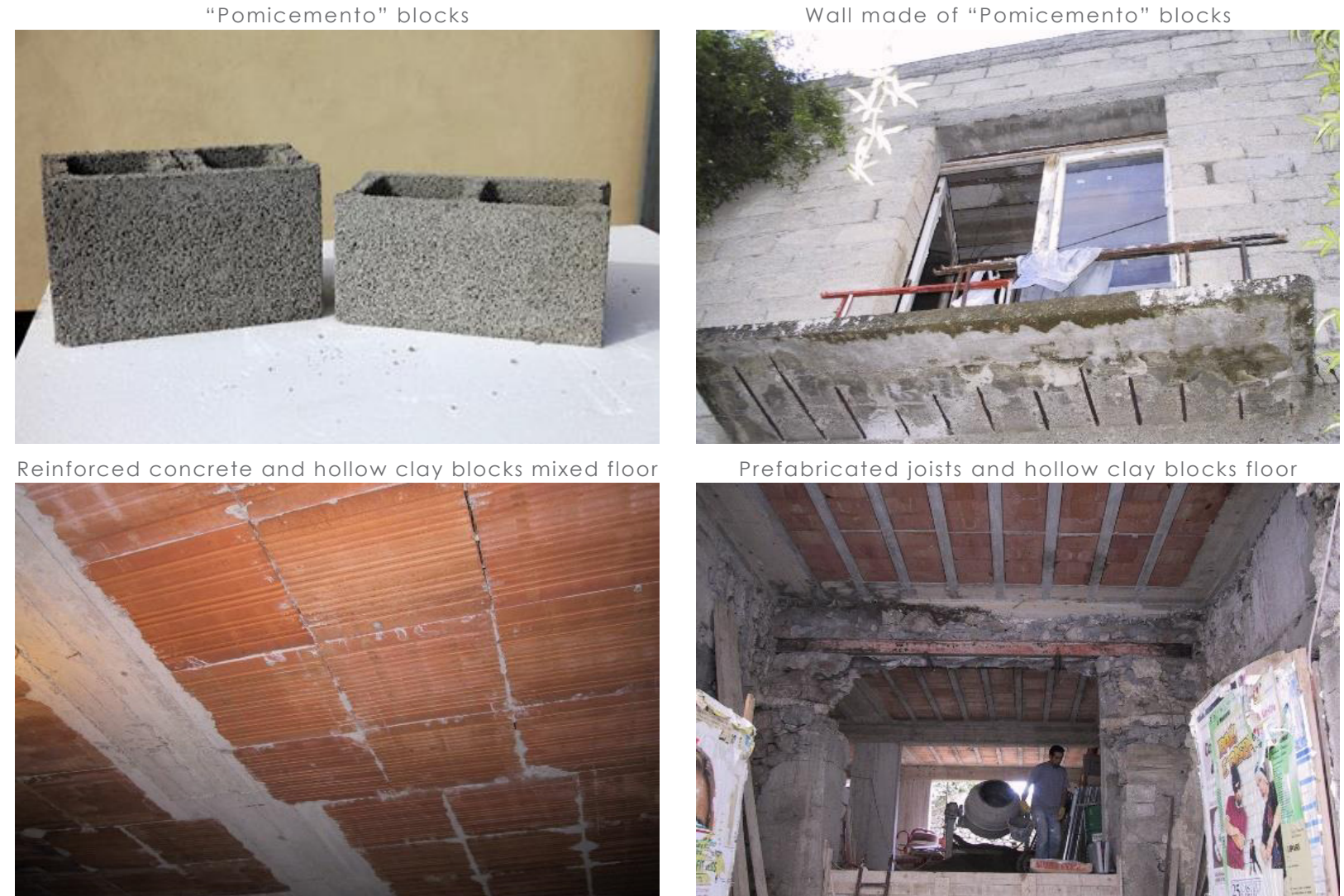

Prefabricated joists and hollow clay blocks floor

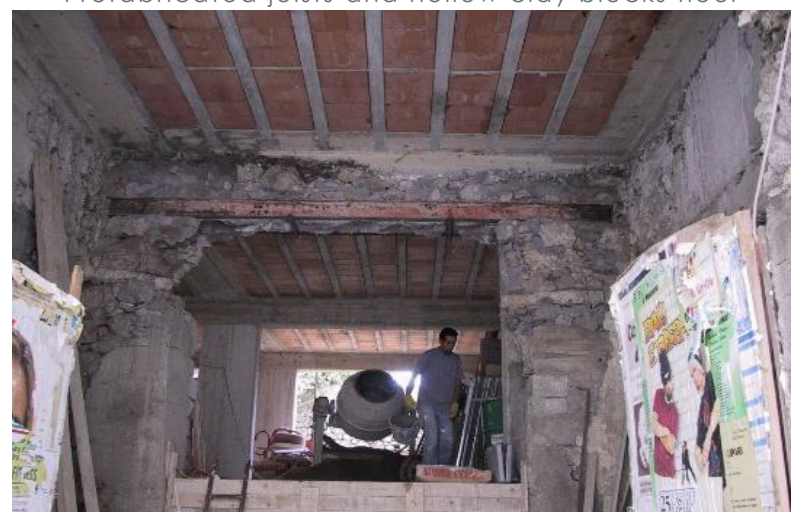

"Marble powders" plaster
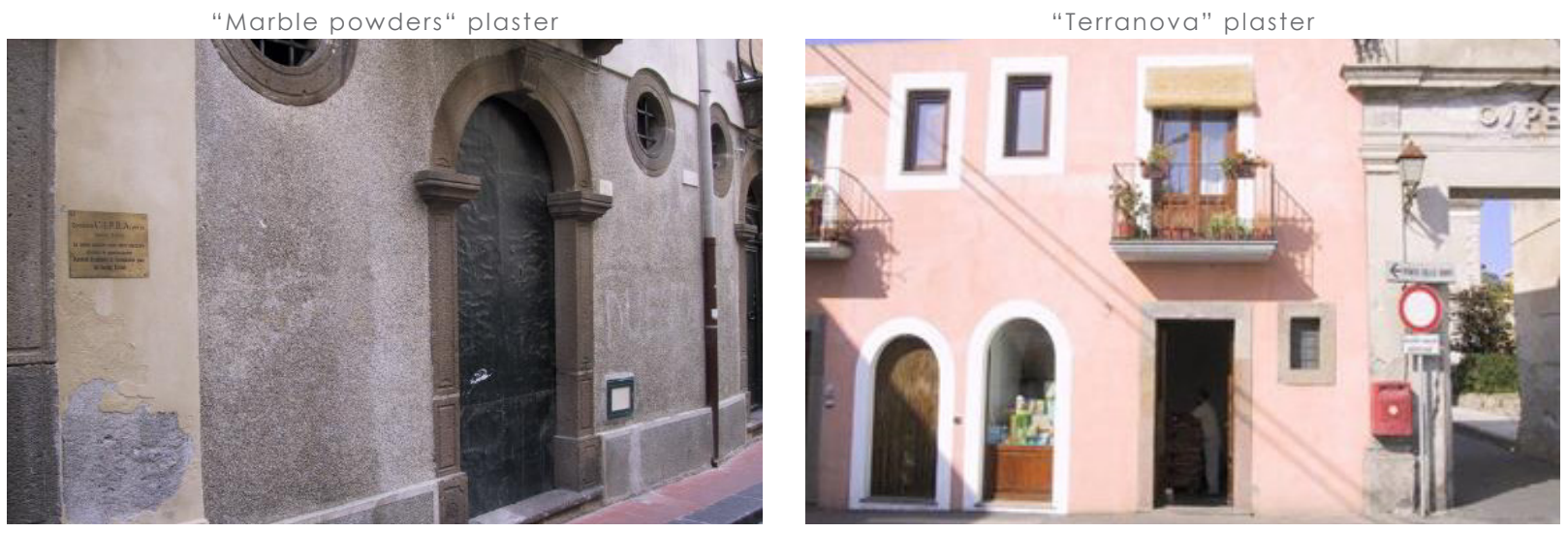

Figure 17. Some recent technologies used in the islands 
[2]. Contrary to what happens to monumental architecture, which usually survives more easily to substitutions and alterations over time, the ordinary traditional home requires periodic modifications to adapt it to new standards of living space and safety. There are several risks during an intervention on a minor building and they can be mainly due to the replacement of existing materials and the contrast between industrial and craft production; a fragility that occurs in areas related to several architectural elements such as the replacement of inappropriate consolidation of horizontal structures, or the insertion of systems performed with inappropriate methods. Generally, the aim of the project must be to achieve a balanced compromise between the preservation of the traditional building and its necessary adaptation to functional needs [3].

Additionally, in the case of the Aeolian Islands, the traditional architectonic signs and the expression of a naturally sustainable construction technique are today undermined by a saturation of the empty spaces and from a progressive typological transformation, foreign to the local culture, that, while taking advantage of new (not truly compatible) technologies, has caused a generalized degradation.

It is necessary to guarantee the possibility of carrying out the necessary adjustments, avoiding, as far as possible, the mutation of the character and materiality of these buildings.

This is why it is exceptionally important to evaluate the sustainability of such peculiar contexts. If, on the one hand, the energy consumption needs to be reduced with more thermally performing building solutions and components, and the seismic re- sponse of these buildings must be improved to prevent collapse due to an earthquake (a highly plausible risk in an area such as the Aeolian one), on the other hand, the characteristics of such unique places can not be ignored. In this sense, as we will see, many of the rating systems for the evaluation of sustainability have the limit of giving little weight to the component of local specificity. However, this will be further discussed in the next paragraph.

\section{SUSTAINABILITY AND ASSESSMENT SYSTEMS}

Before understanding how to assess the sustainability of buildings in a specific context, we need to take a step back and recall the concept of sustainability, which has gradually undergone a transformation in relation to the different needs that have arisen over time and which have caused a transformation in the way of conceiving sustainability. After the oil crisis of the 1970s, all nations promoted measures and regulations against energy consumption from real estate. The energy consumption assessment became the criterion to evaluate the sustainability of buildings. Subsequently, the concept of sustainability evolved and nowadays, energy consumption is assumed only as one of the parameters by which sustainability is assessed. This is why a multidisciplinary approach to sustainability is preferred today [6].

Continued economic growth has led to an overuse of environmental resources, but also an increase in greenhouse gas emissions. Today, all economic sectors have to ensure a long-term ecological balance, reducing the consumption of natural resources according to the restoring capacity of 


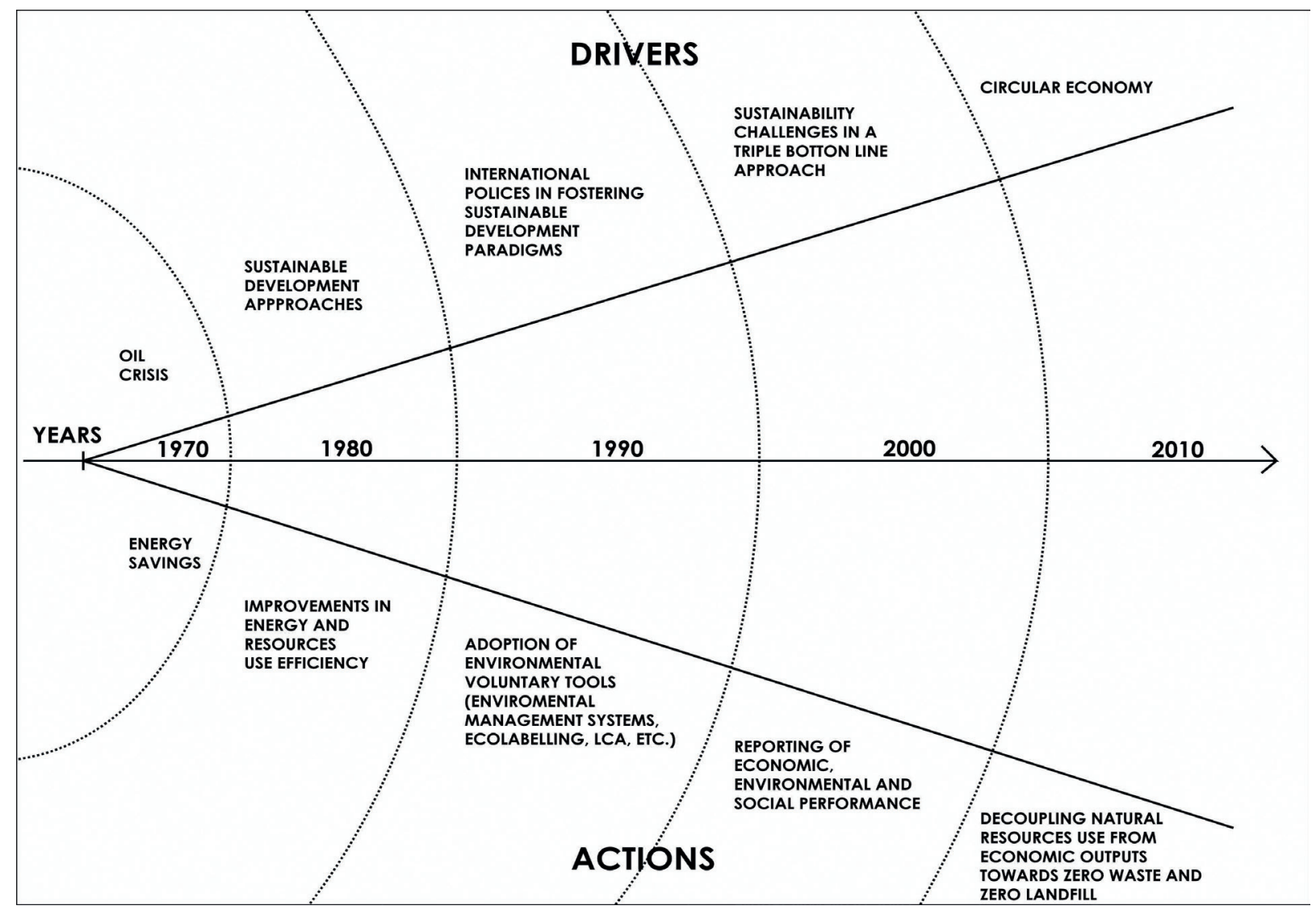

Figure 18. The approach to "sustainability" over time

the planet [5].

As is known, nowadays, sustainability (according to ISO 15392-2008) is commonly examined through three dimensions: the effect of a phenomenon or system on society (often referred to as social sustainability), its impact on the environment (often referred to as environmental sustainability), and its economic implications (often referred to as economic sustainability).

The need to evaluate sustainability in order to classify/label buildings has arisen, and so has the need to guide the design, moving towards a more sustainable approach. Public disclosure of results encourages stakeholders (property owners, planners, and local administrations) to design and build cities and buildings with superior environmental, social, and economic performance.

However, the question is: how does one exactly evaluate sustainability? 
More than 600 sustainability assessment rating systems are available worldwide. New systems are continually proposed and the most diffused ones receive a yearly update. This evolving situation has led to the release of the standards "Sustainability in Building Construction - Framework for Methods of Assessment of the Environmental Performance of Construction Works - Part 1: Buildings" (ISO 21931-1, 2010) and "Sustainability of Construction Works - Sustainability Assessment of Buildings - General Framework" (ISO 15643-1, 2010) [6]. Systems for sustainability assessment have various subjects - from energy performance evaluation to multidimensional quality assessment.

Berardi [6] groups them into:

- CED: cumulative energy demand systems (on energy consumption);

- LCA: life cycle analysis systems (on environmental aspects);

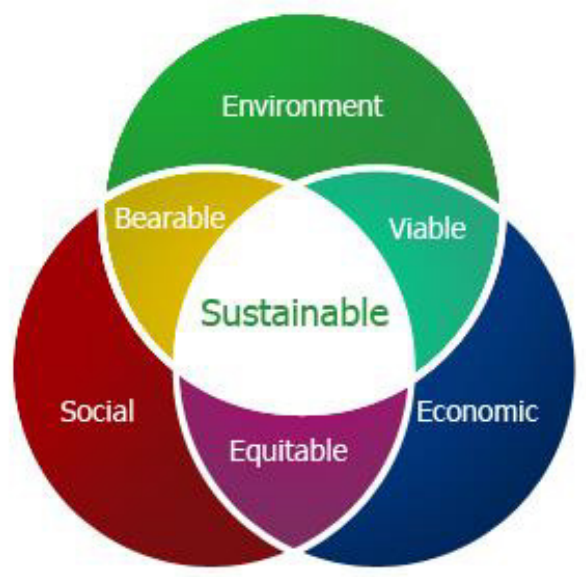

Figure 19. The three dimensions of sustainability
- TQA total quality assessment systems (ecological, economic, and social aspects). However, many systems can not exclusively be included in one of the abovementioned categories. CED systems, generally monodimensional, evaluate the sustainability of a building through energy-related measurements. LCA systems measure the impact of a building on the environment by assessing the emission of substances related to the building's construction and operation. LCA can have one or more evaluation parameters, while TQA systems are multidimensional because they evaluate different parameters.

The first two systems have a quantitative approach, while the TQA system is qualitative or quantitative in relation to different criteria [6].

While assessment systems have been giving value to the environmental characteristics, the surge in importance of economic and social evaluations has manifested in systems tailored to developing countries, where evaluating the environment alone is insufficient. In turn, this should shift the assessment systems toward a new perspective of sustainability. Owing to the evaluations' thorough approach, systems demanding considerable detailed information have been developed. The criteria's intricacy is reported as being the restricting factor for the promulgation of rating systems, and even sustainability, within building stakeholders who would be slow to endorse sustainability practices. Therefore, to promote sustainable building assessment systems, it is crucial tocompromise between ease of use and thoroughness of analysis. The fact that multi-criterion TQA systems are more widely used than their LCA counterparts can be attributed to their simplicity 


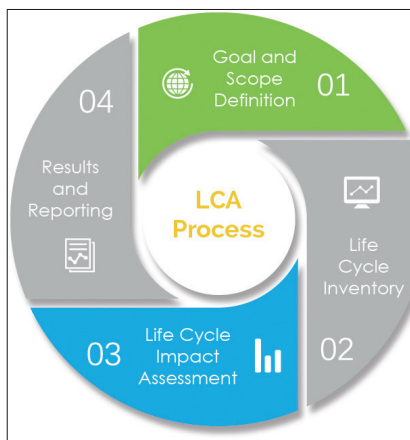

The system boundaries of the building's LCA can be of three types: cradle-to-grave, cradle-to-gate, and gate-to-gate. The cradle-to-gate approach is an assessment of a partial life cycle of a product, from resource extraction to the factory gate, before the product is transported to the consumer. It is usually used as a basis for environmental product declaration. The gate-to-gate approach is a partial analysis that looks at only one process in the entire production chain. Information about each gate-to-gate module can be linked accordingly in a product chain, including information about the extraction of raw materials, transportation, disposal, and reuse, to provide a full cradle-togate evaluation. The cradle-to-grave approach is the most used because it starts from the pre-use phase, including raw material acquisition, goes through manufacturing and transportation to site, and terminates with the end-of-life phase, which includes demolition, recycling potential, landfill, and reuse [5].

LCA assessments consist of four phases (ISO 14040, 2006): the goal and definition phase, the life cycle inventory, the life cycle impact assessment and the improvement assessment phase. LCA diffusion in the building sector is limited by a lack of information. In fact, the specificities of the construction processes require data for every building material in any region. This lack of information on building materials is especially frequent for the existing buildings. Databases have been created for LCA evaluations and implemented in specifically designed software in several geographic areas: BEES in the US, BOUSTEAD and ENVEST in England, SIMAPRO and EcoQuantum in the Netherlands, Ecoinvent in Switzerland, and GaBi in Germany. However, these databases are only valid for assessments in a specific region. Another obstacle for LCA diffusion is its specialist structure: outputs of LCA systems are represented by environmental impacts expressed through chemical substances, which are not easily understood by construction sector actors. LCA systems assess the environmental paradigm of sustainability without considering social and economic impacts. To fit this limit, some studies relate the disaggregation analysis necessary for an LCA to an evaluation of economic costs. For example, BEES and GaBi systems already permit the selection of cost-effective environmentally preferable products [6].

Figure 20. The LCA process: definition and limits

and checklist structure. Nevertheless, LCA system analyses can be more exhaustive compared to multi-criterion systems but still hard to understand, with their use limited to a number of specialists [5].

For these reasons (according to which multidimensional, quicker methods are preferable), the topic of TQA will be analyzed in the next paragraphs.

\subsection{RATING SYSTEM FOR ASSESSING SUSTAINABILITY}

To establish an objective and comprehensive method of assessment on the wide range of environmental performances of a building is the goal of the rating systems used to evaluate them. They aim to measure a building's performance with a system that is consistent and harmonized with respect to pre-established standards, guidelines, factors, or criteria.
In order to produce rating systems for the evaluation of a building's environmental sustainability, scoring methods established on the following four major components have been employed most often:

- Categories: a certain set of environmental performance-related items to be accounted for in the evaluation;

- Scoring system: a performance measurement system combining points, or credits, earned through the achievement of a performance level set for each point of assessment;

- Weighting system: the importance that each point pertaining the scoring system is given;

- Output: a result produced to demonstrate the environmental performance attained 


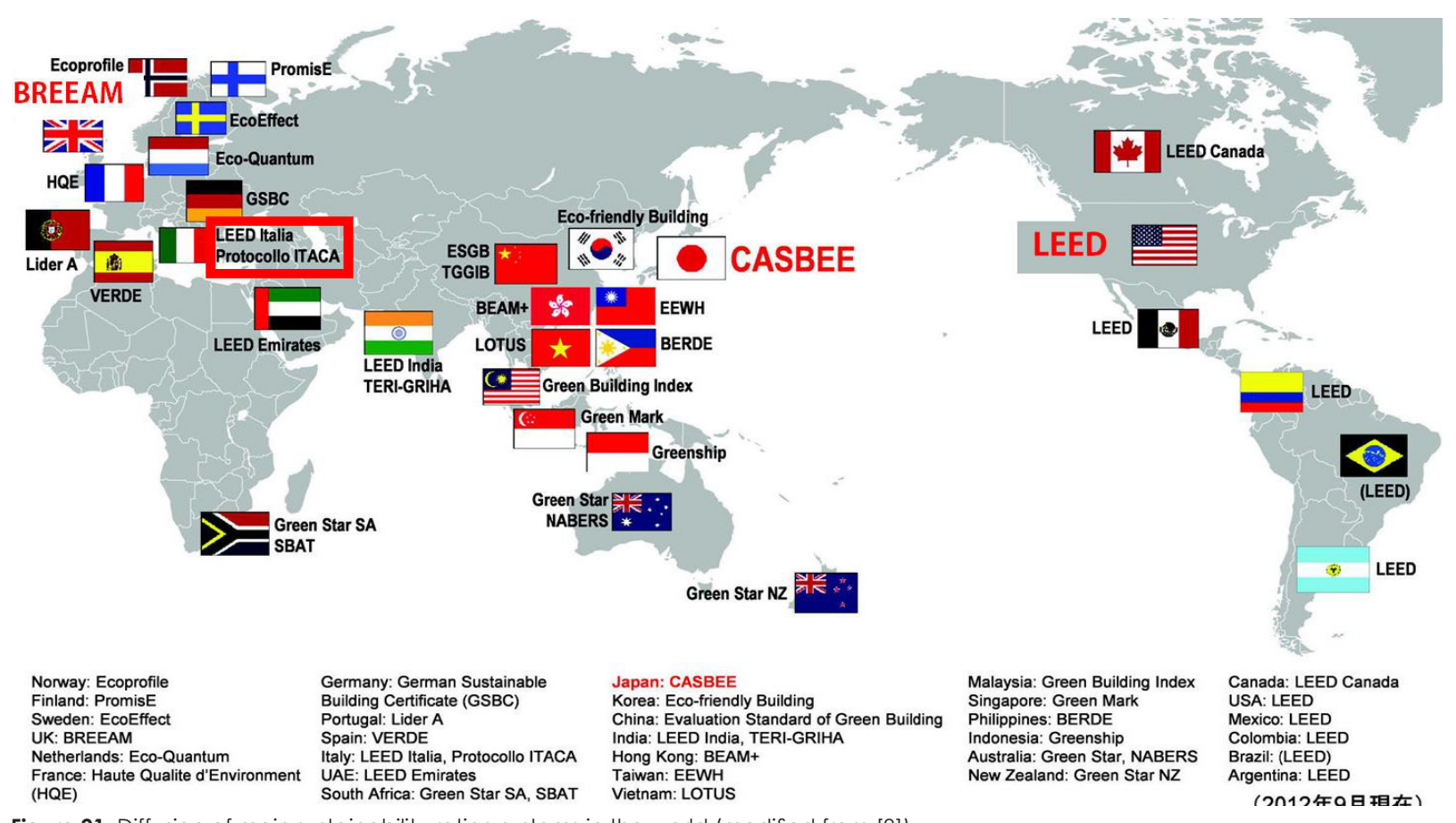

Figure 21. Diffusion of main sustainability rating systems in the world (modified from [8])

throughout the scoring phase through an extensive, direct approach.

This is the structure that each rating system employed in the assessment of a building's environmental impact is built upon; however, a number of significant parts prove different after a study of the details [5].

Different scopes are examined in all the systems, with different levels of detail.

In Table 1, the scopes' distribution among the schemes/systems is presented graphically. Some of the most diffused systems (BREEAM, CASBEE, LEED, SBTool) were presented in detail during the lesson, though for the scope of the present document they were only mentioned and compared. A broader understanding may be obtained by con- sulting the respective websites and specific manuals.

Other important European systems are DGNB (Deutsche Gesellschaft für Nachhaltiges Baven, Germany) and HQETM (Haute Qualité Environnementale, France), but they are not as common and are not covered in this lesson.

BREEAM (BUILDING RESEARCH ESTABLISHMENT ENVIRONMENTAL ASSESSMENT METHODOLOGY)

BREEAM, published by the Building Research Establishment (BRE) in 1990, is the world's oldest established method of assessing, rating, and certifying the sustainability of buildings. 


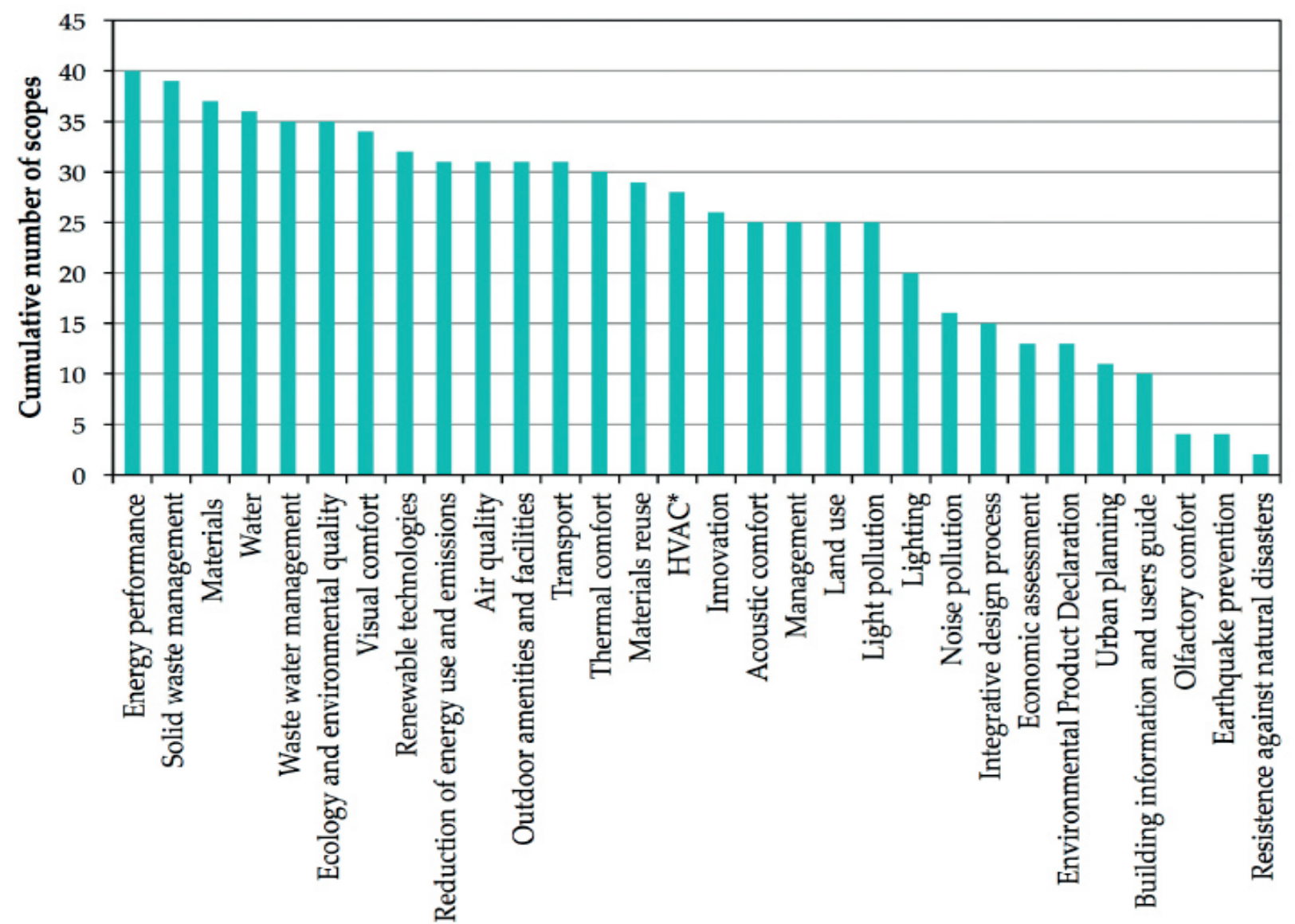

Table 1. Scopes' distribution among the analyzed rating schemes (*HVAC: heating, ventilation, and airconditioning) [5]

There are different types of schemes, applied to different types of building or situation, as shown in the next page, regarding Refurbishment and Fit-Out Technical Standards, In use, New Construction, and Infrastructure. They are all defined in 11 .

The scheme's ten categories and 71 criteria allow for the description of the sustainability.
For each category, a percentage-weighting factor and a totalof 112 credits are assigned commensurably, although the latter feature the following conditions: the categories "Energy and CO2" and "Water and Waste" have a set minimum achievement listed in Table 2, along with the schemes' categories [5]. 


\begin{abstract}
Refurbishment and Fit-Out Technical Standard. Through the assessment and certification process, the standard recognizes and reflects the performance of the building once improvements have been made to the external envelope, structure, core services, local services, or interior design of a building. The standard can be used to assess the refurbishment and fit-out of most types and uses of existing buildings, including homes (note: in the UK, there are separate standalone technical standards for non-domestic and domestic projects). The standard includes specific assessment criteria for heritage buildings that take into account the constraints on these types of projects.

In-Use. The standard can be used for all existing non-domestic buildings. It is a scheme to help building managers reduce the running costs and improve the environmental performance of existing buildings. It has three parts - Parts 1 (building asset) and 2 (building management) are relevant to all non-domestic, commercial, industrial, retail, and institutional buildings. Part 3 (occupier management) of the BREEAM In-Use certification scheme is currently restricted to offices. BREEAM In-Use is widely used by members of the International Sustainability Alliance (ISA), which provides a platform for certification against the scheme.

New Construction Homes and Commercial Buildings. The New Construction standards can be used to assess the design, construction, intended use, and future-proofing of new building developments, including the local, natural, or manmade environment surrounding the building. The standards can be used to assess most types of new buildings, including new homes and additions to existing buildings. Each one uses a common framework that is adaptable, depending upon the type and location of the building.

Infrastructure - Civil Engineering and Public Realm. In the short term, a new CEEQUAL will be launched as the successor to CEEQUAL Version 5.2 and BREEAM Infrastructure (Pilot). This will bring together the best of both schemes into a new best practice approach to challenge projects to deliver better outcomes in infrastructure sustainability. It will combine the legacy and track record of CEEQUAL with the new thinking from BREEAM. For now, new projects have two options: register with CEEQUAL Version 5 or pre-register for CEEQUAL (2018).

Communities. This standard focuses on the master-planning of whole communities. It is aimed at helping construction industry professionals design places that people want to live and work in, that are good for the environment, and that are economically successful.
\end{abstract}

CASBEE (COMPREHENSIVE ASSESSMENT SYSTEM FOR BUILT ENVIRONMENT EFFICIENCY)

The CASBEE is the Japanese sustainability rating system for buildings. It was developed by a research committee established in 2001 through the collaboration of academia, industry and national and local governments, which established the Japan Sustainable Building Consortium (JSBC) under the auspice of the Ministry of Land, In- frastructure, Transport, and Tourism (MLIT) [12]. The launch occurred in 2005 for the international market, then it became compulsory in 24 municipalities of Japan, where it was made mandatory that the results of an assessment performed through CASBEE be attached to the building permits' application. The dimensions of a building are the basis for the schemes allowed by CASBEE, which address the four main building life phases [5]: 


\begin{tabular}{|c|c|c|c|c|c|c|c|c|c|c|c|c|c|c|c|c|c|c|c|}
\hline Rating System & & & & & & & & & Cate & ego & ries & & & & & & & & \\
\hline & 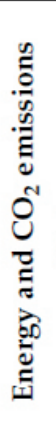 & $\frac{\grave{d}}{3}$ & $\frac{\frac{n}{\pi}}{\stackrel{0}{\frac{\pi}{0}}}$ & 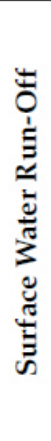 & 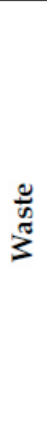 & $\underset{0}{0}$ & 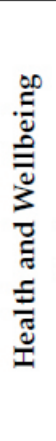 & $\frac{\text { 해 }}{\frac{0}{8}}$ & 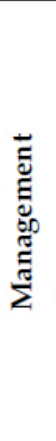 & 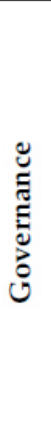 & 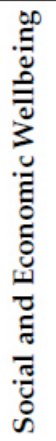 & 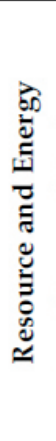 & 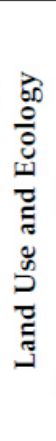 & 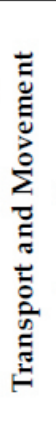 & 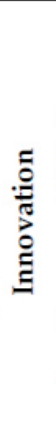 & 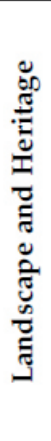 & 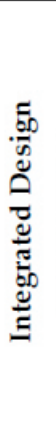 & 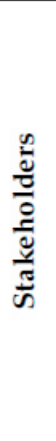 & 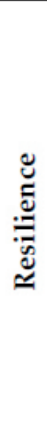 \\
\hline $\begin{array}{c}\text { BREEAM Communities } 2012 \\
\text { BREEAM New construction } 2016 \\
\text { BREEAM In-use } 2015 \\
\text { BREEAM Infrastructure } 2016 \\
\text { BREEAM Nondomestic refurbishment } 2015 \\
\text { EcoHomes } \\
\text { Code for sustainable homes }\end{array}$ & $\begin{array}{l}\bullet \\
\bullet \\
\bullet \\
\bullet \\
\bullet \\
\bullet\end{array}$ & $\begin{array}{l}\bullet \\
\bullet \\
\bullet \\
\bullet \\
\bullet \\
\bullet\end{array}$ & $\begin{array}{l}\bullet \\
\bullet \\
\bullet \\
\bullet \\
\bullet \\
\bullet\end{array}$ & & $\begin{array}{l}\bullet \\
\bullet \\
\bullet \\
\bullet \\
\bullet \\
\bullet\end{array}$ & $\begin{array}{l}\bullet \\
\bullet \\
\bullet \\
\bullet \\
\bullet \\
\bullet\end{array}$ & $\begin{array}{l}\bullet \\
\bullet \\
\bullet \\
\bullet \\
\bullet \\
\bullet \\
\bullet\end{array}$ & & $\begin{array}{l}\bullet \\
\bullet \\
\bullet\end{array}$ & & & $\bullet$ & $\begin{array}{l}\bullet \\
\bullet \\
\bullet \\
\bullet \\
\bullet\end{array}$ & $\begin{array}{l}\bullet \\
\bullet \\
\bullet \\
\bullet \\
\bullet \\
\bullet\end{array}$ & $\begin{array}{l}\bullet \\
\bullet \\
\bullet\end{array}$ & & $\bullet$ & $\bullet$ & $\bullet$ \\
\hline
\end{tabular}

Table 2. BREEAM, categories for each scheme [5]

- CASBEE for Predesign, used in site selection and building planning;

- CASBEE for New Construction, used in the first three years following the building's completion:

- CASBEE for Existing Buildings, used no earlier than one year of operation;

- CASBEE for Renovation, whose purpose is to support a building refurbishment.

With the intention of attaining the specific purposes, a vast number of ancillary rating systems are available to CASBEE when the base system is insufficient, for instance for detached houses, temporary constructions, heat island effect, urban development, or cities and market promotions.

Under CASBEE [12], there are two spaces: internal and external, divided by the virtual enclosed space boundary, which is defined by the site boundary and other elements, with two factors related to the two spaces. Thus, we have put forward CASBEE, in which the "negative aspects of environmental impact which go beyond the virtual enclosed space to the outside (the public property)" and "improving living amenity for the building users" are considered side by side.

Under CASBEE, these two factors are defined below as $Q$ and $L$, the main assessment categories, and are evaluated separately. $Q$ 
(Quality) - Built Environment Quality: Evaluates "improvement in living amenity for the building users, within the virtual enclosed space (the private property)".

L (Load) - Built Environment Load: Evaluates "negative aspects of environmental impact which go beyond the virtual enclosed space to the outside (the public property)".

The core concept of CASBEE is called BEE (Built Environment Efficiency). BEE is an indicator calculated by using $Q$ as the numerator and $L$ as the denominator.

Built Environment Efficiency (BEE) $=\frac{Q \text { (Built environment quality) }}{L \text { (Built environment load) }}$

With three subcategories from which to base the values' calculations, as reported by the score sheet in Table 3, Q and LR can range between 0 and 100 . With the $Q$ and $L R$ values on the $y$-axis and $x$-axis, respectively, BEE is expressed as the gradient of the line on the graph. The BEE value is used to assign a level of performance ranging from $C$ through $B-, B+$ and $A$, up to $S$ to the project in question. Applying the $Q$ and $L R$ values and the coefficients of every item, the assessment results sheet analyzes and sets weights, then produces a final BEE index score in its last step.

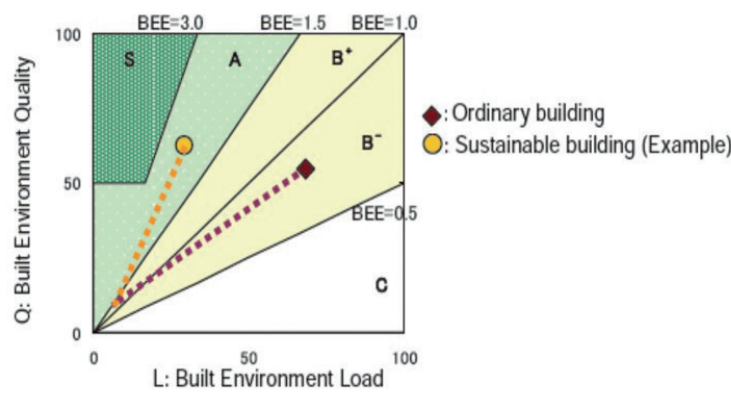

Figure 22. Environmental labeling based on Built Environment Efficiency (BEE) $[9,12]$

\section{LEED (LEADERSHIP IN ENERGY AND ENVIRON- MENTAL DESIGN)}

The US Green Building Council (USGB), a nongovernmental organization with representatives from industry, academia, and government, first launched the Leadership in Energy and Environmental Design Pilot Project Program, referred to as LEED $\AA$ Version 1.0, in the USA in 1998. This program has since been subject to revisions, integrations, and national customizations. In 2016, the last complete version (4.0) was released but in 2018, a beta version of the 4.1 version was introduced, starting with Existing Buildings.

The LEED ${ }^{\circledR}$ Green Building Rating System is one of the most widespread systems in the world (the most used according to the U.S. Green Building Council). It is a voluntary

\begin{tabular}{ll}
\multicolumn{1}{c}{ Scoring for $\mathbf{Q}$} & \multicolumn{1}{c}{ Scoring for LR } \\
\hline Q1: Indoor environment & LR1: Energy \\
Q2: Quality service & LR2: Resources and materials \\
Q3: Outdoor environment on site & LR3: Off-site environment \\
\hline
\end{tabular}

Table 3. CASBEE's score sheet [5] 


\begin{tabular}{|l|l|}
\hline $\begin{array}{l}\text { BD+C } \\
\text { Building Design and } \\
\text { Construction }\end{array}$ & $\begin{array}{l}\text { Applies to buildings that are being newly constructed or going through } \\
\text { a major renovation; includes New Construction, Core and Shell, Schools, } \\
\text { Retail, Hospitality, Data Centers, Warehouses and Distribution Centers, } \\
\text { and Healthcare. }\end{array}$ \\
\hline $\begin{array}{l}\text { ID+C } \\
\text { Interior Design and } \\
\text { Construction }\end{array}$ & $\begin{array}{l}\text { Applies to projects that are a complete interior fit-out; includes } \\
\text { Commercial Interiors, Retail, and Hospitality. }\end{array}$ \\
\hline $\begin{array}{l}\text { O+M } \\
\text { Building Operations } \\
\text { and Maintenance }\end{array}$ & $\begin{array}{l}\text { Applies to existing buildings that are undergoing improvement work } \\
\text { or little to no construction; includes Existing Buildings, Schools, Retail, } \\
\text { Hospitality, Data Centers, and Warehouses and Distribution Centers. }\end{array}$ \\
\hline $\begin{array}{l}\text { ND } \\
\text { Neighborhood } \\
\text { Development }\end{array}$ & $\begin{array}{l}\text { Applies to new land development projects or redevelopment projects } \\
\text { containing residential uses, nonresidential uses, or a mix. Projects can be } \\
\text { at any stage of the development process, from conceptual planning to } \\
\text { construction; includes Plan and Built Project. }\end{array}$ \\
\hline Homes & $\begin{array}{l}\text { Applies to single family homes, low-rise multifamily (one to three stories), } \\
\text { or mid-rise multifamily (four to six stories); includes Homes and Multifamily } \\
\text { Low-rise and Multifamily Mid-rise. }\end{array}$ \\
\hline Cities and \\
communities
\end{tabular}

Table 4. Different schemes of LEED (modified from [10])

system. Numerous schemes are developed to rate new and existing commercial, institutional, and residential buildings (Table $4)$. Five categories are included in every scheme, containing the same list of performance requirements. Those which change substantially in accordance with the specific area of interest and building type are the number of credits, prerequisites, and points available.

Table 5 provides a description of the categories included in the LEED $\circledast$ environmental rating schemes.
The majority of the schemes contain mandatory prerequisites and non-compulsory credits, which can be selected observing the objectives that are to be achieved. The summation of points for each credit generates the evaluation outcome. A sole weight is allotted to each credit according to a strictly established scoring system that conceives a maximum score of 100 points, in addition of 10 bonus points awarded for the compliance with two special categories. A score of 40 points is the minimum requirement for passing the basic evaluation. 


\begin{tabular}{cl}
\hline Category & \multicolumn{1}{c}{ Description } \\
\hline Sustainable sites & $\begin{array}{l}\text { This section examines the environmental aspects linked to the building site. The goal is to } \\
\text { limit the construction impact and verify meteoric water outflow. }\end{array}$ \\
\hline Water efficiency & $\begin{array}{l}\text { The section is linked to the water use, management and disposal in the buildings. } \\
\text { The reduction of water consumption and meteoric water reuse are promoted. }\end{array}$ \\
\hline Energy and atmosphere & $\begin{array}{l}\text { In this section building energy performance improvement, the use of renewable sources } \\
\text { and the energy building performance control are promoted. }\end{array}$ \\
\hline Materials and resources & $\begin{array}{l}\text { In this area the environmental subjects associated to the material selection, the reduction of } \\
\text { virgin material use, the garbage disposal and the environmental impact due to transport } \\
\text { are considered. }\end{array}$ \\
\hline Indoor environmental quality & $\begin{array}{l}\text { The themes considered in this section cover indoor environmental quality, taking into } \\
\text { account for example healthiness, comfort, air renewal and air pollution control. }\end{array}$ \\
\hline Innovation in design & $\begin{array}{l}\text { The aim of this section is to identify the design aspects that improve on the sustainability } \\
\text { operations in the building construction. }\end{array}$ \\
\hline Regional priority & $\begin{array}{l}\text { This area has the objective of encouraging the design groups to focus the attention on the } \\
\text { local characteristics of the environment. }\end{array}$ \\
\hline
\end{tabular}

Table 5. LEED's categories and description [5]

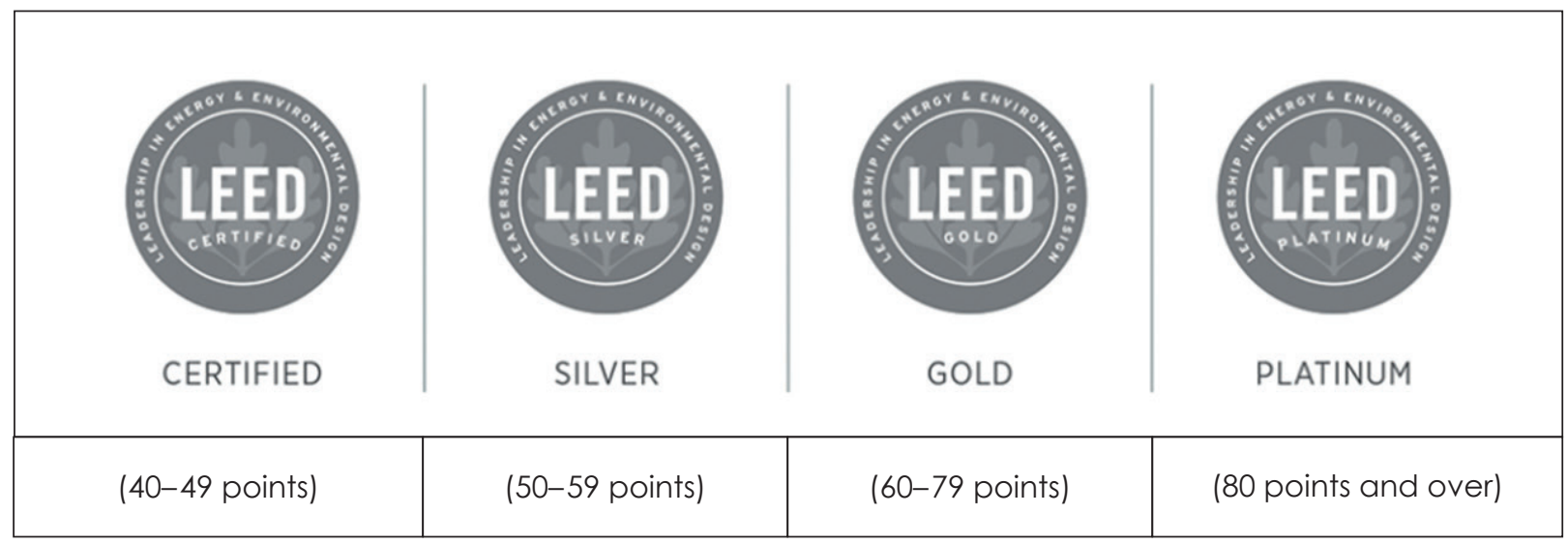

Table 6. Based on the number of points achieved, a project earns one of these four LEED rating levels (modified from: [10]) 
The Sustainable Building Challenge, previously known as the Green Building Challenge, is an international initiative conceived in 1996 that set the goal of identifying standards for energy and environmental performance suitable for international and national conditions. More specifically, the aim of the Green Building Challenge was to develop and constantly update a methodology able to combine the advantage of using a common international standard with the possibility of its complete contextualization with respect to the single national application areas.

Thus, it was necessary to determine evaluation tools suitable for the objective assessment of a building's environmental, economic, and social impact throughout its life cycle by means of various methodological bases. The combined efforts of 20 countries' representatives led to the development of the SB method. In addition to a common international standard, another feature of this method is the ease of customization for each national context. The International Initiative for a Sustainable Built Environment (iiSBE) manages a technical committee tasked with updating the SB method, which is used in the evaluation of all design concepts or existing buildings, regardless of their prevalent use and geometrical extension, according to the four stages: predesign, design, construction, and operation.

The SB method is the base of origin of the Green Building Tool (GBTool), thereafter modified to be named the Sustainable Building Tool (SBTOol). Four levels characterize the performance framework of the SBTool: performance issues, performance categories, performance criteria, and performance subcriteria. Table 7 demonstrates SBTool's issue areas, in which it is expressed per each phase of a building's life cycle $[5,7]$.

\subsection{COMPARISONS BETWEEN THE DIFFERENT SYS- TEMS}

It is normally difficult to compare the various systems, at times prohibitive. As the purposes targeted by every rating scheme are different, an accurate comparison between categories and subcategories is frequently unattainable.

However, below, we will briefly present some comparison tables in relation to different aspects [7].

\begin{tabular}{|c|c|c|c|c|}
\hline Issue area & Predesign & Design & Construction & Operation \\
\hline Site location, available services and site characteristics & $\bullet$ & & & \\
\hline Site regeneration and development. Urban design and infrastructure & & $\bullet$ & & $\bullet$ \\
\hline Energy and resource consumption & & $\bullet$ & $\bullet$ & $\bullet$ \\
\hline Environmental loadings & & $\bullet$ & • & • \\
\hline Indoor environmental quality & & $\bullet$ & & - \\
\hline Service quality & & $\bullet$ & $\bullet$ & • \\
\hline Social, cultural and perceptual aspects & & $\bullet$ & • & • \\
\hline Cost and economic aspects & & • & • & • \\
\hline
\end{tabular}

Table 7. Analysis of the SBTool's issue areas expressed per each phase of a building's life cycle [5] 


\begin{tabular}{|c|c|c|c|c|c|c|}
\hline Rating System & Launch Year & Launch Country & Certification Body & International Versions and National Adaptations & Weighting System & Rating Levels \\
\hline BREEAM & 1990 & UK & BRE & 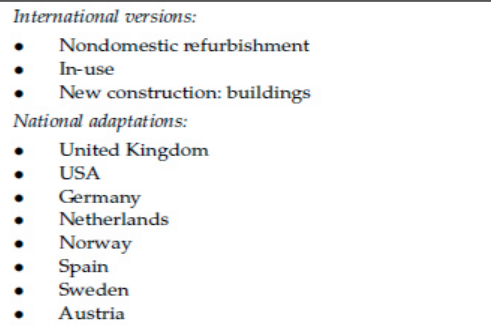 & Applied to each category & $\begin{array}{ll}\text { - } & \text { Unclassified } \\
\text { - } & \text { Pass } \\
\text { - } & \text { Good } \\
\text { - } & \text { Excellent } \\
\text { - } & \text { Outstanding }\end{array}$ \\
\hline CASBEE & 2004 & Japan & JSBC & N/A & $\begin{array}{l}\text { Complex weighting system } \\
\text { applied at every level }\end{array}$ & $\begin{array}{ll}: & \mathrm{S} \\
: & \mathrm{A} \\
: & \mathrm{B}+ \\
& \mathrm{B}- \\
& \mathrm{C}\end{array}$ \\
\hline LEED v.4 & 1998 & USA & USGBC & $\begin{array}{l}\text { - LEED v3.0 for new construction and } \\
\text { major renovations } \\
\text { - LEED for homes } \\
\text { - LEED for core and shell } \\
\text { and maintenance } \\
\text { - LEED for commercial interiors } \\
\text { - LEED for schools } \\
\text { - LEED for retail } \\
\text { - LEED for healthcare } \\
\text { pational adaptations: } \\
\text { - Argentina } \\
\text { - Cazil } \\
\text { - Italy }\end{array}$ & $\begin{array}{l}\text { All credits are equally } \\
\text { weighted, but the number } \\
\text { of credits related to each } \\
\text { issue is different }\end{array}$ & $\begin{array}{ll}\text { - } & \text { Certified } \\
\text { - } & \text { Silver } \\
\text { - } & \text { Gold } \\
\text { - } & \text { Platinum }\end{array}$ \\
\hline SBTool 2016 & 2002 & International & iiSBE & $\begin{array}{l}\text { National adaptations: } \\
\text { • } \quad \text { Czech Republic (SBToolCZ) } \\
\text { : } \quad \text { Portugal (SBToolPT) } \\
\text { - } \quad \text { Italy (Protocollo Itaca) } \\
\quad \text { Spain (Verde) }\end{array}$ & Applied to each category & $\begin{array}{ll}: & -1 \\
: & 0 \\
: & 1 \\
: & 3\end{array}$ \\
\hline
\end{tabular}

Table 8. Summary of the main features of some rating systems (modified from [5])

\begin{tabular}{|c|c|c|c|c|}
\hline Rating System & New Buildings & Existing Buildings & Buildings under & Urban Planning Projects \\
\hline BREEAM & - & - & - & - \\
\hline CASBEE & - & - & • & • \\
\hline LEED & - & - & • & - \\
\hline
\end{tabular}

Table 9. Type of intervention covered by the selected schemes (modified from [5])

\begin{tabular}{|c|c|c|c|c|c|c|c|}
\hline Rating & Residential & Office & Commercial & Industrial & Educational & Other type of & Urban \\
\hline BREEAM & - & - & - & $\cdot$ & - & • & $\cdot$ \\
\hline CASBEE & - & - & - & - & - & - & - \\
\hline LEED & - & - & - & N/A & - & - & • \\
\hline SBTool & • & - & • & N/A & - & N/A & N/A \\
\hline
\end{tabular}

Table 10. Building type assessed by the selected schemes (modified from [5]) 


\begin{tabular}{|c|c|c|c|c|}
\hline Rating System & Predesign and Design & Construction & Post-Construction & Use/Maintenance \\
\hline BREEAM & - & - & • & • \\
\hline CASBEE & • & • & • & • \\
\hline LEED & N/A & - & • & - \\
\hline SBTool & $\bullet$ & • & $\bullet$ & N/A \\
\hline
\end{tabular}

Table 11. Life cycle phase of the building assessed by the selected schemes

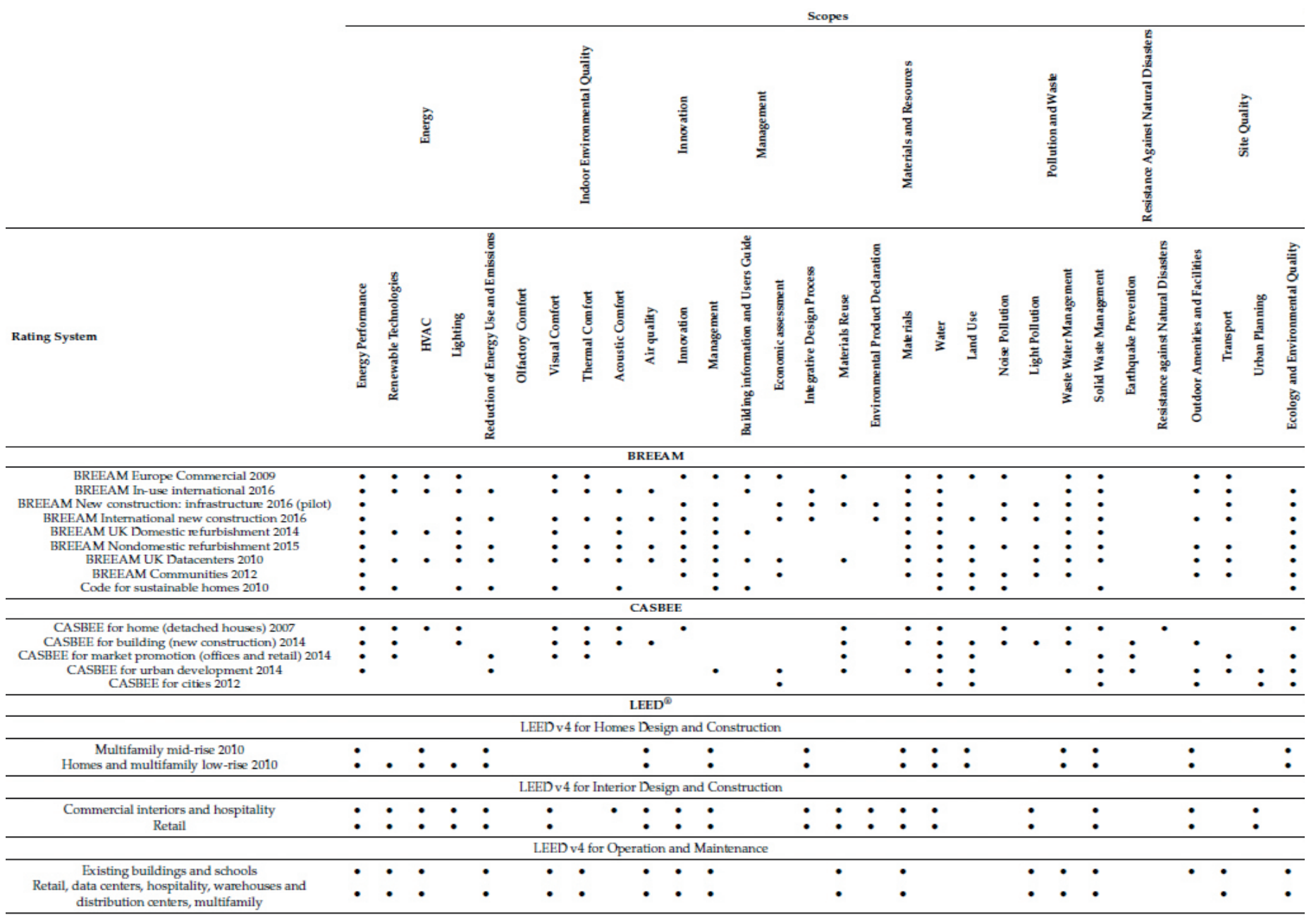

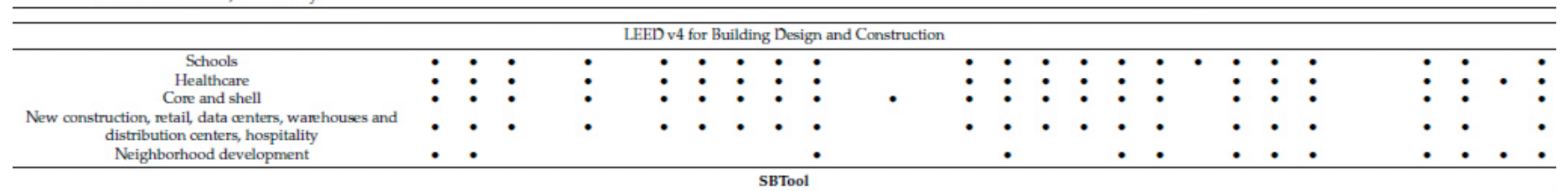

Table 12. Comparison of the scopes and criteria of some rating schemes (modified from [5]) 
Energy performance and solid waste management are the main categories to be evaluated; however, the great majority of schemes also assess the following important categories: materials, water, waste, water management, and ecology and environmental quality. The least assessed scopes concern resistance to natural disasters, as they are taken into consideration exclusively by CASBEE (though, in reality, also by two other systems, that are not considered in this discussion - German Sustainable Building Council (DGNB) and Haute Qualité Environnement (HQETM). Instead, this factor should be introduced in all countries with high seismic/hydrogeological risk etc. (such as Italy).

\subsection{OTHER TWO SYSTEMS FOR SPECIAL CONTEXT}

Moreover, although they are not especially widespread, two other systems have been examined: the ITACA Protocol (owing to it being an Italian Assessment System) and GBC Historic Building (because it is particularly suitable for historical buildings). These two systems are more suitable for the peculiarities of a context such as the Aeolian one.

ITACA

The ITACA Protocol [13] is based on the SB method of IISBE, chosen in 2002 as a reference by the Italian regions (the first version of the Italian SBTool is from 2002 and was presented at the World Sustainable Building conference in Oslo. The Residential SBTool 2002 can be considered the matrix of the ITACA Protocol). The ITACA Protocol system is configured as a federation of regional evaluation protocols characterized by a common methodology and technical scientific requirements. The idea is to share a common standard while allowing it to be declined locally.

The ITACA Protocol, as a result of the characteristics of the SB Method, allows for contextualization to the territorial peculiarities of the regions, while maintaining the same structure, scoring, and weighting system. This quality is particularly important for Italy as it is characterized by different climatic profiles and construction practices.

To date, many Italian Regions have adopted the ITACA Protocol as a tool to support their local policies. There are regional versions of the protocol in Piedmont, Liguria, Marche, Tuscany, Lazio, and Puglia.

The ITACA Protocol (version 2011) is composed of 34 evaluation criteria, through which the level of sustainability of a building can be objectively analyzed.

The criteria are organized into five thematic areas:

- site quality;

- consumption of resources;

- environmental loads;

- indoor environmental quality;

- service quality;

For each criterion, depending on the level of performance achieved, the building receives a score ranging from -1 to +5 (where zero is the standard construction practice. 3 the best current practice and 5 excellence).

Each criterion has a weight, based on the SBTool methodology, which determines its importance compared to the others.

The weighted sum of the scores from each of the 34 criteria determines the overall sustainability score of the building. 
The Green Building Council Italia has developed a new rating system for the certification of buildings subject to restoration or refurbishment. It is called GBC Historic Building ${ }^{\circledR}$, based on the LEED ${ }^{\circledR}$ system matrix and, in particular, on the LEED ${ }^{\circledR}$ Italia 2009 New Construction and Restructuring version. It is quite recent: the first building project was certified in 2018.

The GBC Historic Building ${ }^{\circledR}$ protocol can be used for buildings constructed before 1945 (pre-industrialization). However, for buildings built after 1945 with a preindustrial building process, in the presence of historical testimonial or cultural values, linked to the formal, typological and/or constructive characteristics, it is possible to apply the GBC Historic Building ${ }^{\circledR}$ protocol.

Compared to LEED®/GBC, this protocol adds a thematic area related to sustainable intervention in the conservation field, named "Historic Valence" (VS). It has the ultimate goal of preserving all that is "testimony with the value of civilization".

As in existing LEED®/GBC systems, in GBC Historic Building ${ }^{\circledR}$, the distribution of points is based on the effects of actions related to the design, construction, use, and maintenance of the building (for example, greenhouse gases, the use of fossil fuels, toxic and carcinogenic agents, air and water pollution, and internal conditions) on the environment and on human health.

All requirements are grouped within the following thematic areas:

- Historic Valence (VS);

- Site Sustainability (SS);

- Water Management (GA)

- Energy and Atmosphere (EA);

- Materials and Resources (MR);
- Internal Environmental Quality (IQ);

- Innovation in Design (IP);

- Regional Priority (PR).

The points system associated with credits is based on the following rules:

- the prerequisites are mandatory and do not give a score;

- all credits are worth at least 1 point;

- all credits have a positive integer value (there are no fractional or negative numbers).

The maximum score achievable is 110 , divided into 100 points distributed between the VS, SS, GA, EA, MR, and QI areas and in 10 points for the IP and PR areas.

\subsection{CRITICAL ISSUES}

The public receives an easily comprehensible report of how "green" a building may be due to assessment methods producing quantifiable results. This is not to say that scoring systems are impervious to negative issues.

Firstly, the building is awarded a level of certification that does not directly or extensively report its performance within specific categories of sustainable design and they are also not reliably congruous to the total reduction in realized environmental impact. Points awarded to more positively impacting categories of a rating system are identical to others and, at times, building teams work toward accumulating points where they are most affordable, not by employing methods more beneficial to the environment. This is an issue present in all major sustainability rating systems that there are inconsistencies between the impact on the environment of a specific inclusion and its designer's reward. 
The discrepancy of the difficulty to fulfil various metrics compounds the problem, as certain requirements are easily attainable in one context whereas they might be unfeasible in others. Promoting the use of bicycles and public transport award points in the LEED, BREEAM, Green Globes, and Green Star systems, for instance, though implementing this metric ranges from easy to near impossible whether the context is more or less urban.

Furthermore, the costs relative to the fulfilment of certain credits are higher than others; for example, the same credit is attributed to the use of highly refletive colors for a building's roof and the installation of a green roof system. Additionally, owners are not guaranteed direct lifecycle payback costs by employing some of the more environmentally positive credits, although they are a concrete incentive.

The result is that owners and developers tend to decide on the inclusion of credits not by their impact on the environment, but their potential economic benefit [9].

In summary, the evaluation a building's performance on the basis of a score inevitably involves simplifications that are occasionally excessive. In general, scoring methods have these other limitations:

- Each indicator is associated with a different score, weighted, and decided arbitrarily by an external commission, regardless of the context and the specific case.

- There is a risk of standardizing design solutions. Many criteria tend to provide repetitive solutions that are not valid everywhere. In this sense, many systems are trying to overcome these shortcomings. Sustainability is global, but the same cannot be said about the methods to establish a building's level of environmental sustainability. Though in a number of rating systems, the point system varies, displaying a geographic and cultural singularity, any specific system lacks variation regarding climate or cultural differences.

- There is no database to obtain detailed information on the materials and products with which buildings are made. Many products have ecofriendly labels even in cases where the origin is not clear - often the methods overlook economic and social sustainability.

- The lack of a unified regulatory framework and unequivocal political choices have led to the definition of a high number of certification systems that are difficult to compare.

The importance of harmonization has also been implemented at the European level (Communication No. $445-01.07 .2014$ which highlights the need to create shared and comparable assessment tools to facilitate better use of resources in the construction sector). The Common European sustainable Built Environment Assessment (CESBA) initiative (2014, 13 European countries) provides a common framework. The mission of CESBA is promoting the promulgation and endorsement of principles of sustainable built environments by way of harmonized assessment systems throughout the built environment's life cycle. For this reason, it is CESBA's aim to be Europe's paramount organization, leading the harmonization of current and future built environment assessment systems [14].

The findings from the various systems' comparison [5] are reported below. 
- The rating systems for the evaluation of a building's environmental impact are all appropriate for current and new buildings, also dealing with the refurbishment of buildings with the exception of the SBTool.

- BREEAM and CASBEE are able to assess all types of buildings, unlike LEED ${ }^{\circledR}$, which does not concern industrial buildings. The most restricted is the SBTool, as urban planning projects are not covered by it, in addition to any building type different from residential, office, commercial, and educational buildings.

\section{- BREEAM and CASBEE deal with a building's} entire life cycle phases.

- The SBTool system has solely been designed for certifying a building's low performance level.

- Quantitively speaking, the categories most considered by the schemes are energy performance, solid waste management, material, and water.

- The least considered categories are "resistance against natural disasters", "earthquake prevention", and "olfactory comfort". The lack of attention to the issues such as "resistance against natural disasters" and "earthquake prevention" is a serious deficiency when we operate in a highrisk territory (hydrogeological or seismic) like the Italian one.

- Only the new GBC Historic Building ${ }^{\circledR}$ gives a specific answer for the certification of historic buildings subject to restoration or refurbishment.
In conclusion, regarding the further development of these schemes, beneficial features would be as follows:

- Completeness, indicating the appropriate analysis of all the elements denoting a building and its life cycle;

- A clear representation of the weighting system, with reliable evidence to support the scoring system;

- Greater harmonization at the international level would be desirable, while respecting the specificities of places. 
Rosa Caponetto

Department of Civil Engineering and Architecture, University of Catania, Italy Mail: rosa.caponetto@darc.unict.it 


\section{REFERENCES}

[1] Caponetto R., Ferro V., Rodonò U., Architettura tipica eoliana: note per una metodologia di intervento sostenibile, in Atti Convegno "La riqualificazione delle coste del Mediterraneo fra tradizione, sviluppo e interventi sostenibili", editore, Napoli, 2003 (in Italian).

[2] Todesco S. (a cura di), Atlante dei Beni Etno-antropologici eoliani, EDAS, Messina 1995 (in Italian).

[3] Dipasquale L., Mecca I.,Vernacural architecture as codified model for the contemporary sustainable project. In: TECHNE n. 12, 2016.

[4] Mileto C., Vegas López-Manzanares, F., Diodato M., Tecniche costruttive tradizionali a Valencia. Metodo e risultati dallo studio materiale dell'architettura. In: Materiali e Strutture. Problemi di conservazione II (4): $95-111$. Edizioni Quasar, ISSN 1121-2373, http://hdl.handle.net/10251/60837 (2013) (in Italian).

[5] Bernardi E., Carlucci S., Cornaro C. and Bohne R. A., An Analysis of the Most Adopted Rating Systems for Assessing the Environmental Impact of Buildings, Sustainability 9 (7), 1226, 2017.

[6] Berardi U., Sustainability Assessment in the Construction Sector: Rating Systems and Rated Buildings. Sustainable Development, Volume 20, Issue 6, 2011.

[7] Nguyen B. K., Altana H. Comparative review of five sustainable rating systems, in: 2011 International Conference on Green Buildings and Sustainable Cities, Procedia Engineering Volume 21, Volume 1 of 2, Elsevier B.V., Bologna, Italy, 2011

[8] Shuzo Murakami II contesto di sviluppo del sistema CASBEE (Comprehensive Assessment System for Building Environmental Efficiency) DOI: 10.14609/Ti_1_14_2i

[9] Say C., Wood A., Sustainable Rating Systems Around the World, CTBUH Journal, Issue II, 2008, http://ctbuh.org/paper

[10] "LEED rating system - U.S. Green Building Council" [Online]. Available: https://www.usgbc.org/leed (accessed on October, 2019).

[1 1] "Technical Standards - BREEAM" [Online]. Available: https://www.breeam.com/discover/technical-standards/ (accessed on October, 2019).

[12] "CASBEE - Comprehensive Assessment System for Built Environment Efficiency"[Online]. Available: http://www.ibec. or.jp/CASBEE/english/ (accessed on October, 2019).

[13] "iiSBE Italia" [Online]. Available: http://www.iisbeitalia.org/sbmethod/protocollo-itaca (accessed on October, 2019).

[14] "CESBA - Common European Sustainable Built Environment Assessment" [Online]. Available: https://www.cesba. eu/ (accessed on October, 2019). 


\section{Antonio Gagliano \\ ASSESSMENT OF ENERGY PERFORMANCE OF A TYPICAL AEOLIAN BUILDING IN THE FRAMEWORK OF THE ITALIAN ENERGY CERTIFICATION PROCEDURE}

\section{INTRODUCTION}

The building sector, which is approximately responsible for $40 \%$ of energy consumption and $36 \%$ of $\mathrm{CO}_{2}$ emissions, has huge potential energy savings that impose to reduce drastically their energy consumptions and environmental effects [1,2].

To attain the goal of reducing fossil fuel dependency, the European Union has wisely considered the best courses of action for reducing overall energy consumption and greenhouse gas emissions.

Along with thorough and necessary modernization and adjustment to current building requirements and life standards, energy efficiency improvements realized during the refurbishment of heritage buildings extend the buildings' life expectancy. In a long period, from this point of view, it also decreases expenses for the buildings' owners and users, increases the occupants' comfort and quality of life while positively affecting the environment and the buildings' value.

In this context, the Energy Performance Certification (EPC) was revealed to be an effective tool for evaluating the energy efficiency in buildings, as well as for providing useful recommendations for upgrading the building energy performance in light of a cost-effective perspective [3].

In 2002, the Energy Performance of Buildings Directive (EPBD) [1] introduced a simplified tool for the energy performance assessment of residential buildings EPCs.

In 2010, the EPBD recast has introduced new requirements to expand the quality, usabili- ty, and public acceptance of EPCs [2]. To date, all 28 Member States (MS) formally implemented the EPBD requirements in their national legislation (fig. 1).

The building energy assessment is evaluated through different methodologies, which have to satisfy the obligations of the European Performance of Buildings Directives $[1,2]$.

However, the estimation of the building's energy performance requires specific information which allows describing of the energy performance of the building envelope as well as the building services.

Although for all the European Countries, the assembly of the EPC is mandatory, different procedures must be followed for making it. In Italy, the energy certification of buildings follows the "asset rating" procedure, which requires the following assumptions.

Data may be obtained from the building inspection or design data.

Standard weather conditions, occupancy schedules, and HVAC systems management are used for calculating the energy performance.

The certification procedure allows the determination of several energy performance indicators, and subsequently, the attainment of the performance class for the building.

such energy performance indicators, defined by the UNITS 11300 Sections 1 to 6 [5], are the following:

- heating and cooling energy needs; 


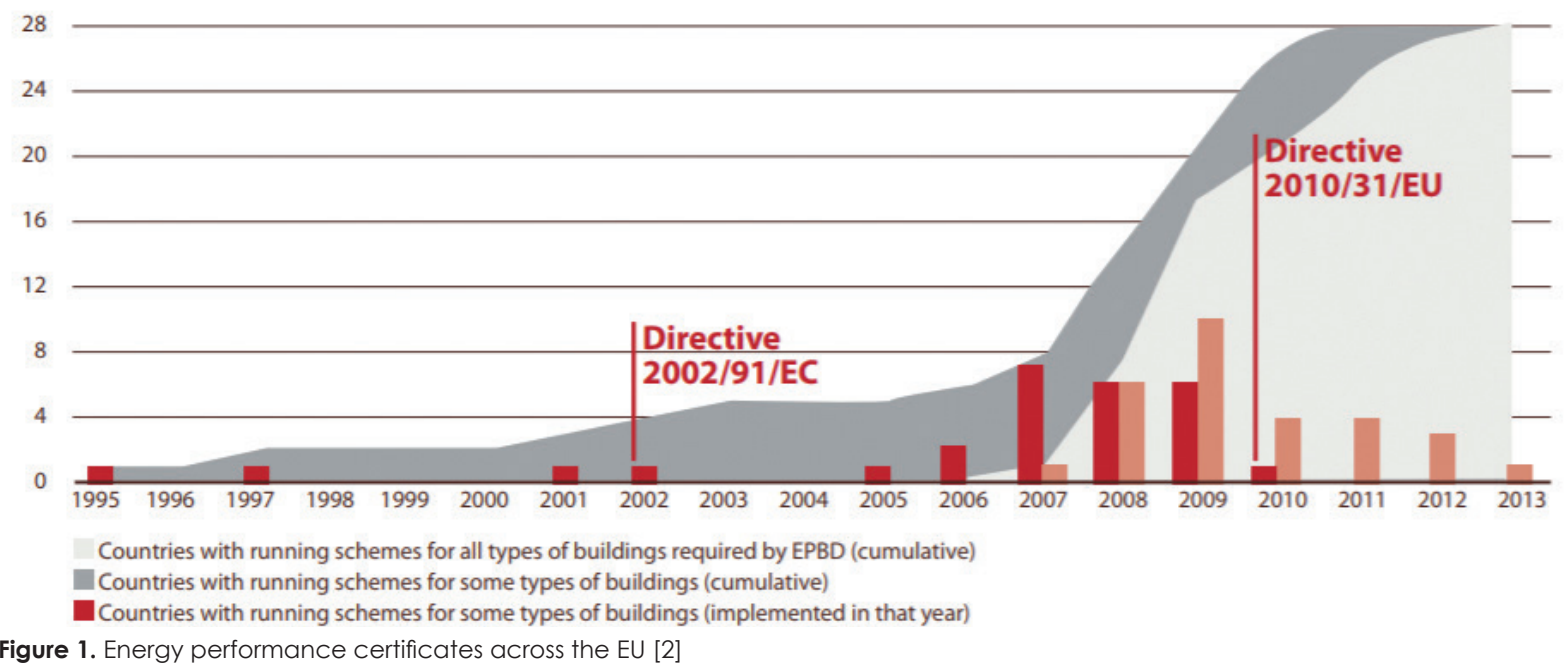

- primary Energy consumptions for heating $\left(P E_{H}\right)$, ventilation $\left(P E_{v}\right)$, domestic hot water $\left(P E_{D H W}\right)$, and lighting $\left(P_{E L}\right)$;

- primary consumptions for cooling $\left(\mathrm{PE}_{\mathrm{C}}\right)$;

- energy produced through renewable sources $\left(P E_{r e n}\right)$ (e.g., thermal solar, photovoltaic, biomass);

- renewable and non-renewable energy sources and internal or external energy carriers on the border of buildings;

- energy needs for transport things or people by elevators and escalators.

The building energy performance is assessed through comparison with a reference building (identical to the real one as for geometry, orientation, location in the climatic zone, use, and so on ), which has predefined thermal characteristics and energy parameters.

The rating system is based on 10 adaptable classes $\left(A_{4}, A_{3}, A_{2}, A, B, C, D, E, F, G\right)$, based on a range proportional between the Energy Performance (EP) of the investigated building and the EP of a virtual reference building as described in the Italian Ministerial Decree 26 June 2015 [6].

The present lecture aims to illustrate the main features of the DOCET software, developed by the Italian National Agency for New Technologies, Energy, and Sustainable Economic Development (ENEA) and the National Research Council of Italy (CNR) [7]. This software, which implements the algorithms defined by the UNITS 11300 , allows achievement of the EPC for single buildings, e.g., row or single-family houses, or lone apartments. Only a single thermal zone may be taken into account. Due to the simplification assumed, the EPC developed by DOCET may be used only for residential buildings with net area lower than $200 \mathrm{~m}^{2}$. 


\section{BUILDINGS' ENERGY PERFORMANCE} INDICATORS

The building energy performances (EP) are presented as final specific annual energy needs ( $\mathrm{kWh} / \mathrm{m}^{2}$ year), including all the specific energy consumptions for heating, cooling, ventilation, domestic hot water, lighting, and mobility; these last are included only for non-residential buildings, under a building's normal operations.

The energy performance index for winter air conditioning $E P_{H}$ is calculated by the ratio of the energy requirements for space heating $Q_{H, n d}$ and the average seasonal efficiency of the heating system, $\left(\eta_{H}\right)$ :

$E P_{H}=\frac{Q_{H, n d}}{\eta_{H}}$

The energy performance index for summer air conditioning, EPC, is calculated by the ratio of the energy requirements for cooling $Q_{C, n d}$ and the efficiency of the cooling system, $\left(n_{C}\right)$ :

$\mathrm{EP}_{\mathrm{C}}=\frac{\mathrm{Q}_{\mathrm{C,nd}}}{\eta_{\mathrm{C}}}$

The energy performance index for domestic hot water (DHW), EP $w^{\prime}$ is calculated by the ratio of the energy requirements for DHW production $Q_{w}$, and the efficiency of the Water Heating System, $\left(n_{w}\right)$ :

$$
\mathrm{EP}_{\mathrm{w}}=\frac{\mathrm{Q}_{\mathrm{w}, \mathrm{nd}}}{\eta_{\mathrm{w}}}
$$

The global annual energy requirement is calculated by the sum of the primary energy needs for each energy service, (hot water heating, air conditioning, and lighting) considering a semi-stationary approach and monthly calculation interval.

The energy performance of the building is expressed through the global non-renewable energy performance index EPgl, nren, concerning the net area $\left[\mathrm{kWh} / \mathrm{m}^{2} / \mathrm{year}\right.$.

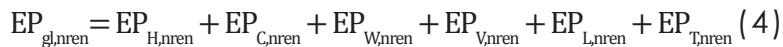

$\mathrm{EP}_{\mathrm{H}, \mathrm{nren}}=$ energy performance index for winter air conditioning:

$\mathrm{EP}_{\mathrm{C}, \mathrm{nren}}=$ energy performance index for summer air conditioning:

$\mathrm{EP}_{\mathrm{w}, \mathrm{nren}}=$ energy performance index for DHW energy demand;

$\mathrm{EP}_{\mathrm{V}, \mathrm{nren}}=$ energy performance index for mechanical ventilation $M$ :

$\mathrm{EP}_{\mathrm{L}, \mathrm{nren}}=$ energy performance index for lighting interior;

$\mathrm{EP}_{\mathrm{T}, \mathrm{nren}}=$ energy performance index for mobility.

The terms $E P_{L, \text { nre }}$ and $E P_{T, n r e n}$ have to be taken into account only for non-residential buildings.

The energy requirement satisfied by a renewable source allows compensating of the energy requirements for the same energy carrier and up to the full coverage of such requirements.

The energy performance class is obtained by positioning the EP index in a predefined scale of classes, each one representing a performance level, as shown in Table 1 [6]. 


\begin{tabular}{|c|c|c|}
\hline $\operatorname{EP}_{\text {gl, ren i.itstandard }}(2019 / 21)$ & Class & $\operatorname{EP}_{\text {glimenifistandard }}(2019 / 21)$ \\
\hline & A4 & $\leq 0.40$ \\
\hline $0.40<$ & A3 & $\leq 0.60$ \\
\hline $0.60<$ & A2 & $\leq 0.80$ \\
\hline $0.80<$ & A1 & $\leq 1.00$ \\
\hline $1.00<$ & B & $\leq 1.20$ \\
\hline $1.20<$ & C & $\leq 1.50$ \\
\hline $1.50<$ & D & $\leq 2.00$ \\
\hline $2.00<$ & E & $\leq 2.60$ \\
\hline \multirow[t]{2}{*}{$2.60<$} & $\mathbf{F}$ & $\leq 3.50$ \\
\hline & $\mathbf{G}$ & $>3.50$ \\
\hline
\end{tabular}

Table 1. Scale of the energy performance class

\subsection{THERMAL ENERGY NEEDS FOR HEATING AND COOLING}

Figure 2 depicts the heat fluxes that contribute to the building energy balance.

Equations 5 and 6 allow calculating of the thermal energy needs for heating " $Q_{H, n d}$ " and cooling " $Q_{c, n d}$ " by applying a monthly steady-state balance between the energy losses due to transmission and ventilation and the energy gains due both to the solar radiation and internal source, corrected through the gain or loss utilization factors,

$$
\begin{aligned}
& Q_{H, \text { nd }}=\left(Q_{H, \text { rr }}+Q_{H, v e}\right)-\eta_{H} \cdot\left(Q_{\text {sol }}+Q_{\text {int }}\right) \\
& Q_{C, \text { nd }}=\left(Q_{s o l}+Q_{\text {int }}\right)-\eta_{C} \cdot\left(Q_{C, \text { rr }}+Q_{C, v e}\right)
\end{aligned}
$$

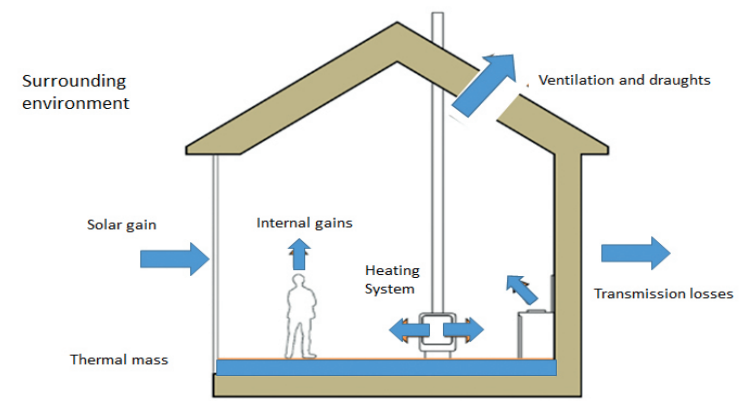

Figure 2. Building energy balance

$Q_{\mathrm{tr}}=$ transmission energy losses:

$Q_{v e}=$ ventilation energy losses:

$Q_{\text {sol }}=$ solar gains:

$Q_{\text {int }}=$ internal gains:

$\eta_{H^{\prime}} \eta_{C}=$ the gain and loss utilization factors, respectively.

Since a building may be subdivided into different air-conditioned zones, the thermal exchanges are calculated for each air-conditioned zone and each month [8,9]. The heat losses for transmission and ventilation heat fluxes to the outdoor environment during the heating period are calculated by Equations 7 and 8 ,

$\mathrm{Q}_{\mathrm{H}, \mathrm{tr}}=\mathrm{H}_{\mathrm{tr}, \mathrm{adj}} \cdot\left(\theta_{\mathrm{int}, \mathrm{H}^{\mathrm{H}}}-\theta_{\mathrm{e}}\right) \cdot \mathrm{t}+\left\{\sum_{\mathrm{k}} \mathrm{F}_{\mathrm{r}, \mathrm{k}} \Phi_{\mathrm{r}, \mathrm{mn}, \mathrm{k}}\right\} \cdot \mathrm{t}$

$\mathrm{Q}_{\mathrm{H}, \mathrm{ve}}=\mathrm{H}_{\mathrm{ve}, \mathrm{adj}} \cdot\left(\theta_{\mathrm{int}, \mathrm{H}}-\theta_{\mathrm{e}}\right) \cdot \mathrm{t}$

The heat gains during the cooling period are calculated by Equations 9 and 10

$\mathrm{Q}_{\mathrm{c}, \mathrm{tr}}=\mathrm{H}_{\mathrm{tr}, \mathrm{adj}} \cdot\left(\theta_{\mathrm{int,H}}-\theta_{\mathrm{e}}\right) \cdot \mathrm{t}+\left\{\sum_{\mathrm{k}} \mathrm{F}_{\mathrm{r}, \mathrm{k}} \Phi_{\mathrm{r}, \mathrm{mn}, \mathrm{k}}\right\} \cdot \mathrm{t}$

$\mathrm{Q}_{\mathrm{C}, \mathrm{ve}}=\mathrm{H}_{\mathrm{ve}, \mathrm{adj}} \cdot\left(\theta_{\mathrm{int}, \mathrm{H}}-\theta_{\mathrm{e}}\right) \cdot \mathrm{t}$ 
$\mathrm{H}_{\text {tr,adj }}=$ global coefficient of heat exchange due totransmission from each zone, (W/K); $\mathrm{H}_{\text {ve,adj }}=$ global coefficient of heat exchange due to the ventilation of the considered zone, $(\mathrm{W} / \mathrm{K})$;

$\theta_{\text {int, H }}=$ internal temperature for the zone, being $20{ }^{\circ} \mathrm{C}$ during the heating period;

$\theta_{\text {int. }}=$ internal temperature for the zone, being $26^{\circ} \mathrm{C}$ during the cooling period;

$\theta_{e}=$ average monthly temperature of the external environment, $\left({ }^{\circ} \mathrm{C}\right)$;

$\mathrm{F}_{r, \mathrm{k}}=$ form factor between the $\mathrm{k}$ building component and the sky vault;

$\Phi_{r, m n, k}=$ extra thermal flux due to the infrared radiation towards the celestial vault from the building component k, mediated over time $(\mathrm{W})$;

$\dagger=$ length of the month (sec).

\subsection{GLOBAL COEFFICIENT OF HEAT EXCHANGE}

The transmission of heat from a thermal zone takes place towards the external environment, the ground, and other air-conditioned and non-air-conditioned zones. The global coefficient of heat exchange is given by the sum of all the transmission coefficients

$\mathrm{H}_{\mathrm{tr}, \mathrm{adj}}=\mathrm{H}_{\mathrm{D}}+\mathrm{H}_{\mathrm{G}}+\mathrm{H}_{\mathrm{U}}+\mathrm{H}_{\mathrm{A}}$

$H_{D}=$ transmission heat transfer coefficient to the outdoor environment (W/K);

$H_{G}=$ transmission heat transfer coefficient to the ground $(\mathrm{W} / \mathrm{K})$;

$\mathrm{H}_{u}=$ transmission heat transfer coefficient to not air-conditioned room's (W/K);

$\mathrm{H}_{\mathrm{A}}=$ transmission heat transfer coefficient to air-conditioned areas with a different set-point temperature (W/K).
These transmission coefficients are determined by the heat flow rate due to thermal transmission, divided by the difference between the environment temperatures on either side of the construction.

TRANSMISSION COEFFICIENT TO THE EXTERNAL ENVIRONMENT

The transmission coefficient via the external environment is given by

$\mathrm{H}_{\mathrm{D}}=\sum_{\mathrm{i}} \mathrm{U}_{\mathrm{c}, \mathrm{i}} \mathrm{A}_{\mathrm{c}, \mathrm{i}}+\sum_{\mathrm{k}} \Psi_{\mathrm{k}} \mathrm{l}_{\mathrm{k}}+\sum_{\mathrm{j}} \mathrm{X}_{\mathrm{j}}$

being:

$A_{c, i}=$ area of the opaque component $\left(m^{2}\right)$; $U_{c, i}=$ transmittance of the component, (W/ $\left.m^{2} \mathrm{~K}\right)$;

$\Psi_{k}=$ linear thermal transmittance of the $k$ linear thermal bridge (W/ $\mathrm{m} \cdot \mathrm{K})$;

$I_{k}=$ length, along which $\psi_{k}(\mathrm{~m})$ is applied;

$x=$ thermal transmittance of the $j$ punctual thermal bridge (W/K);

The summation of the products $A_{c, i}$ and $U_{c, i}$ is obtained by:

$$
\sum_{\mathrm{i}} \mathrm{U}_{\mathrm{c}, \mathrm{i}} \mathrm{A}_{\mathrm{c}, \mathrm{i}}=\sum_{\mathrm{i}} \mathrm{U}_{\mathrm{EW}, \mathrm{i}} \mathrm{A}_{\mathrm{EW}, \mathrm{i}}+\sum_{\mathrm{i}} \mathrm{U}_{\mathrm{F}, \mathrm{i}} \mathrm{A}_{\mathrm{F}, \mathrm{i}}+\sum_{\mathrm{i}} \mathrm{U}_{\mathrm{R}, \mathrm{i}} \mathrm{A}_{\mathrm{R}, \mathrm{i}}+\sum_{\mathrm{i}} \mathrm{U}_{\mathrm{w}, \mathrm{i}} \mathrm{S}_{\mathrm{W}_{\mathrm{i}} \mathrm{i}}
$$

The subscript stands for the external walls "EW", for floor " $F$ ", roof " ${ }_{R}$ ", and windows " w". For each opaque element of the building envelope (wall, floor, basement, roof, etc.), the value of thermal transmittance $U$ is calculated by

$$
\mathrm{U}=\frac{1}{\mathrm{R}_{\mathrm{si}}+\sum_{\mathrm{j}}\left(\mathrm{s}_{\mathrm{j}} / \lambda_{\mathrm{j}}\right)+\mathrm{R}_{\mathrm{se}}}
$$



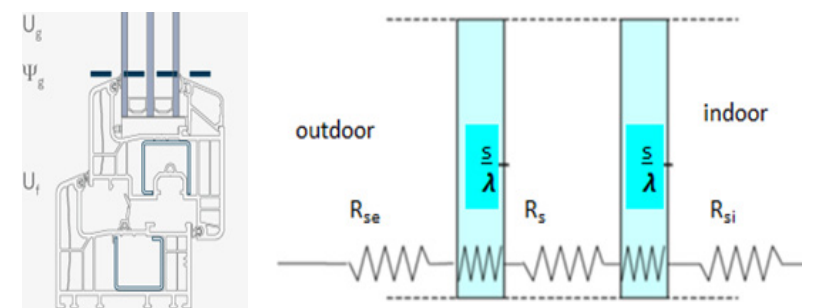

Figure 3. View of a window's section

$R_{s i}=$ internal surface resistance, $\left(m^{2} \mathrm{~K} / \mathrm{W}\right)$; $R_{\mathrm{se}}=$ external surface resistance, $\left(\mathrm{m}^{2} \mathrm{~K} / \mathrm{W}\right)$;

$s=$ thickness of the material $(\mathrm{m})$;

$\lambda=$ heat conductivity of the material (W/ $\mathrm{mK})$.

Figure 3 shows the different elements that contribute to determine the UW and Ug values.

The window's thermal transmittance is calculated by:

$U=\frac{U_{g} \cdot A_{g}+U_{f} \cdot A_{f}+\Psi_{g} \cdot L_{g}}{A_{w}}$

being:

$\mathrm{U}_{\mathrm{g}}=$ the $\mathrm{U}$-value of the glass $\left(\mathrm{W} / \mathrm{m}^{2} \mathrm{~K}\right)$;

$A_{g}^{g}=$ the area of the glass $\left(m^{2}\right)$;

$U_{f}=$ the $U$-value of the frame $\left(\mathrm{W} / \mathrm{m}^{2} \mathrm{~K}\right)$ :

$A_{f}=$ the area of the frame $\left(m^{2}\right)$;

$\psi_{\mathrm{g}}=$ heat loss per meter of glass edge (W/ $\mathrm{mK})$;

$L_{g}=$ is the perimeter of the glass $(m)$;

$A_{w}=$ is the area of the window $\left(\mathrm{m}^{2}\right)$.
The $U_{\text {value }}$ of the glass is calculated by

$U=\frac{1}{R_{s i}+\sum_{j}\left(s_{j} / \lambda_{j}\right)+\sum_{j} R_{s, j}+R_{s e}}$

\section{GROUND HEAT TRANSFER COEFFICIENT}

The heat transfer via the ground is calculated by

$\mathrm{H}_{\mathrm{G}}=\mathrm{A} \cdot \mathrm{U}_{\mathrm{G}} \cdot \mathrm{b}_{\mathrm{tr}, \mathrm{g}}$

$A=$ area of the element $\left(\mathrm{m}^{2}\right)$;

$U_{g}=$ thermal transmittance of the suspended part of the floor (between the internal environment and the underfloor space) (W/ $\left.\mathrm{m}^{2} \mathrm{~K}\right)$;

$b_{t r, g}$ is given in the UNI/TS $11300-1$ standard.

\section{NOT AIR-CONDITIONED ROOMS HEAT TRANS- FER COEFFICIENT}

To consider thermal transmission and solar gains from the conditioned zone towards unconditioned thermal zones (UTZ) a tuning factor, smaller than 1, is introduced

$\mathrm{H}_{\mathrm{U}}=\mathrm{H}_{\mathrm{iu}} \cdot \mathrm{b}_{\mathrm{tr}, \mathrm{x}}$

$H_{i u}=$ global coefficient of heat exchange between the unconditioned and the conditioned zones;

$\mathrm{b}_{\mathrm{tr} \mathrm{x}}=$ tuning factor

For existing buildings, the values of the btr, x factor can be assumed by the UNI/TS 11300-1 standard 
$\mathrm{H}_{\mathrm{iu}}=\mathrm{A}_{\mathrm{iu}} \cdot \mathrm{U}_{\mathrm{s}, \mathrm{iu}}$

$\mathrm{A}_{\mathrm{iu}}=$ area of the building component facing the non-air-conditioned environment $\left(\mathrm{m}^{2}\right)$; $U_{s, i u}=$ thermal transmittance of the building component facing the unconditioned zone $\left(\mathrm{W} / \mathrm{m}^{2} \mathrm{~K}\right)$.

\subsection{THERMAL BRIDGES}

The contribution due to the thermal bridges has to be taken into account for calculating the transmission heat transfer coefficient HD (eq. 12).

The UNI EN ISO 14683:2018 allows the use of fixed values for the linear thermal transmittance of the thermal bridges. Such values vary according to the characteristics of the technical element and as a function of the thermal insulation of the single element. Table 2 shows the default values utilized by DOCET.

In existing buildings and with a lack of reliable design data, the thermal exchange through thermal bridges can be determined at a flat rate, applying an increase of $5 \%$.

\begin{tabular}{|c|c|c|}
\hline Technical element & Insulated (W/mK) & Not insulated (W/mK) \\
\hline Pillar & 0.15 & 0.90 \\
\hline Internal wall & 0.20 & 0.10 \\
\hline Corner & 0.10 & 0.15 \\
\hline Window & 0.15 & 0.45 \\
\hline Ground floor & 0.80 & 0.65 \\
\hline Internal floor & 0.65 & 0.80 \\
\hline Roof & 0.75 & 0.65 \\
\hline
\end{tabular}

Table 2. Thermal bridge thermal transmittance

\subsection{INFRARED RADIATION TOWARDS THE CE- LESTIAL VAULT}

The thermal flux towards the celestial vault is given by the infrared radiation towards the celestial vault " $\phi_{r, k}$ " per the form factor between the k building component and the sky vault $F_{r, k}$, which is determined by the presence of obstruction.

$\Phi_{\mathrm{r}, \mathrm{k}}=\mathrm{R}_{\mathrm{se}} \cdot \mathrm{U}_{\mathrm{k}} \cdot \mathrm{A}_{\mathrm{k}} \cdot \mathrm{h}_{\mathrm{r}} \cdot \Delta \theta_{\mathrm{er}}$

$A_{k}=$ area of the opaque component $\left(\mathrm{m}^{2}\right)$; $U_{k}=$ transmittance of the $k^{\text {th }}$ component, $\left(\mathrm{W} / \mathrm{m}^{2} \mathrm{~K}\right)$;

$\mathrm{R}_{\mathrm{se}}=$ external surface resistance $\left(\mathrm{m}^{2} / \mathrm{W} \cdot \mathrm{K}\right)$; $h_{r}=$ radiative coefficient, $\left(W / m^{2} K\right)$, calculated by:

$\mathrm{h}_{\mathrm{r}}=5 \varepsilon$

$\Delta \theta_{\text {er }}=$ difference between outdoor air temperature and apparent sky temperature, which can be assumed of $11 \mathrm{~K}$;

$\mathrm{F}_{\mathrm{r}, \mathrm{k}}=$ sky view factor between a building component and the sky vault, it is calculated by:

$\mathrm{F}_{\mathrm{r}, \mathrm{k}}=\mathrm{F}_{\mathrm{sh}, \mathrm{ob}, \mathrm{dif}}(1+\cos \beta) / 2$

$(1+\cos \beta) / 2=$ unshaded value of the view factor from the surface to the sky;

$\beta=$ angle of inclination of the component on the horizon;

$\beta=0^{\circ}$ for horizontal roofing, $\beta=90^{\circ}$ for vertical walls. 
$\mathrm{F}_{\text {sh,ob,dif }}=$ diffuse shading coefficient. This is calculated by the ratio of the diffuse sky irradiances with and without shading; it is 1.0 in deficiency of shading from external elements.

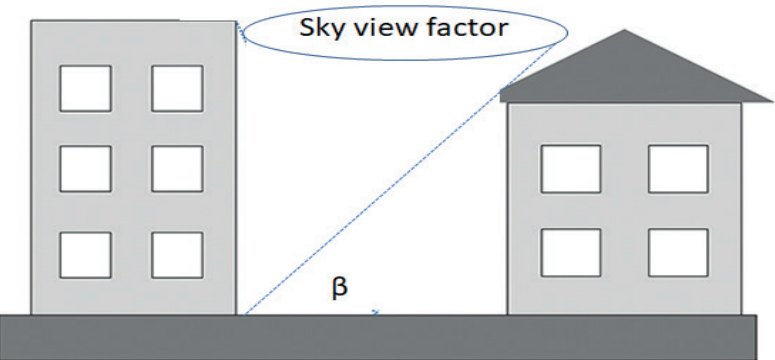

Figure 4. Sky view factor

\subsection{SOLAR GAINS}

The hourly heat flow rate from solar gains is calculated by

$\mathrm{Q}_{\mathrm{sol}}=\sum_{\mathrm{k}} \Phi_{\mathrm{sol}, \mathrm{k}} \cdot \mathrm{t}$

$\Phi_{\text {sol, } \mathrm{k}}=$ solar gains through glazing $(\mathrm{MJ})$.
It depends, besides the type of glass, on the structure of the component and the effectiveness of any shielding (e.g., curtains, shutters).

$\Phi_{\text {sol,k }}=\mathrm{F}_{\mathrm{sh}, \mathrm{ob}, \mathrm{k}} \cdot \mathrm{A}_{\mathrm{sol}, \mathrm{k}} \cdot \mathrm{I}_{\mathrm{sol}, \mathrm{k}}$

$\mathrm{A}_{\text {sol, } \mathrm{k}}=$ effective solar area of the $\mathrm{k}^{\text {th }}$ surface, $\left(m^{2}\right)$.

$\mathrm{I}_{\text {sol, } \mathrm{k}}=$ average monthly solar irradiance on the $k^{\text {th }}$ surface, $\left(\mathrm{W} / \mathrm{m}^{2}\right)$.

$\mathrm{F}_{\text {sh,ob,k}}=$ shading reduction factor on the $\mathrm{k}^{\text {th }}$ surface, which is in turn calculated by

$\mathrm{F}_{\text {sh,ob,k }}=\mathrm{F}_{\text {hor }} \cdot \mathrm{F}_{\text {ov }} \cdot \mathrm{F}_{\text {fin }}$

$\mathrm{F}_{\text {hor }}=$ shading factor due to external obstructions (fig. 5a);

$\mathrm{F}_{\text {ov }}=$ shading factor due to horizontal projections (fig. 5b);

$\mathrm{F}_{\text {fin }}$ = shading factor due to vertical projections (fig. 5c).

The three shading factors, which depend on the orientation and the heating period,

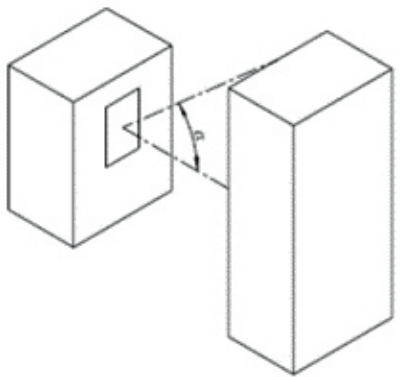

a) external obstructions

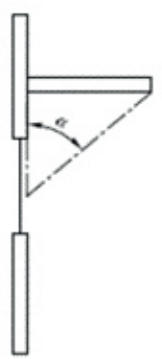

b) horizontal projections

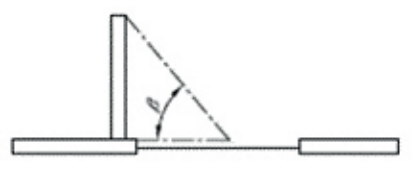

c) vertical projections

Figure 5. Shading factors for external obstruction, horizontal, and vertical projections 
can be calculated by linear interpolation of the tabulated data in Appendix D of the UNI/TS11300-1 standard, as a function of the angles $a$ and $\beta$ shown in Figure 5.

\section{THE EFFECTIVE SOLAR AREA}

The effective solar area is calculated in a different way for opaque and transparent surfaces.

For opaque surfaces,

$$
\mathrm{A}_{\mathrm{sol}, \mathrm{k}}=\alpha_{\mathrm{S}, \mathrm{c}} \cdot \mathrm{R}_{\mathrm{se}} \cdot \mathrm{U}_{\mathrm{k}} \cdot \mathrm{A}_{\mathrm{k}}
$$

$a_{s, c}=$ coefficient of absorbance;

$R_{s e}^{S, c}=$ external surface resistance $\left(\mathrm{m}^{2} / \mathrm{W} \cdot \mathrm{K}\right)$.

For transparent surfaces, an equivalent surface called actual solar collecting area $\mathrm{A}_{\text {sol }}$ is calculated as:

$\mathrm{A}_{\mathrm{sol}}=\mathrm{F}_{\mathrm{sh}, \mathrm{gl}} \cdot \mathrm{g}_{\mathrm{gl}} \cdot(1-\mathrm{FF}) \cdot \mathrm{A}_{\mathrm{w}, \mathrm{p}}$

$F_{\text {sh,gl }}=$ factor of reduction in solar gains related to the use of mobile shielding (e.g., curtains).

$g_{g l}=$ total solar energy transmittance of the window when solar shading is not used, which is in turn calculated by:

$\mathrm{g}_{\mathrm{gl}}=\mathrm{F}_{\mathrm{w}} \cdot \mathrm{gg}_{\mathrm{l}, \mathrm{n}}$

$F_{w}=$ exposure factor and $g_{1, n}$ is the transmittance of total solar energy for an angle of incidence of the solar irradiance orthogonal to the surface.

$F_{F}=$ fraction of area relative to the frame.
This is calculated by the ratio between the projected area of the frame and the total projected area of the window component. $\mathrm{A}_{w .0}=$ total projected area of the glazed component (area of the window compartment).

\subsection{INTERNAL GAINS}

The internal heat source (Qint) includes all the energy generated inside the building, which comes from cooking use, plant systems, lighting, electrical plants, household appliances, and so on [11].

$\mathrm{Q}_{\mathrm{int}}=\sum_{\mathrm{k}} \Phi_{\mathrm{int}, \mathrm{k}} \cdot \mathrm{t}$

$\Phi_{\text {int, }}(W)=$ hourly heat flow rate from each internal heat source k (occupancy, domestic appliance, artificial light, computers). They can be determined in a real case or provided by norms or tables. $\dagger=$ time period

\subsection{VENTILATION HEAT TRANSFER COEFFICIENT}

The ventilation heat transfer coefficient is calculated by

$\mathrm{H}_{\mathrm{ve}, \mathrm{adj}}=\rho_{\mathrm{a}} \cdot \mathrm{C}_{\mathrm{pa}} \cdot\left(\sum_{\mathrm{k}} \mathrm{b}_{\mathrm{ve}, \mathrm{k}} \cdot \mathrm{q}_{\mathrm{ve}, \mathrm{k}, \mathrm{mn}}\right)$

being

$\mathrm{q}_{\mathrm{ve}, \mathrm{k}, \mathrm{mn}}=\mathrm{f}_{\mathrm{ve}, \mathrm{t}, \mathrm{k}} \cdot \mathrm{q}_{\mathrm{ve}, \mathrm{k}}$

$\mathrm{q}_{\mathrm{ve}, \mathrm{k}, \mathrm{mn}}=\mathrm{f}_{\mathrm{ve}, \mathrm{t}, \mathrm{k}} \cdot \mathrm{q}_{\mathrm{ve}, \mathrm{k}}$

$\rho_{a} \cdot C_{p a}=$ air thermal volumetric capacity. 
$\rho_{a} \cdot C_{p a}=1,200 \mathrm{~J} /\left(\mathrm{m}^{3} \cdot \mathrm{k}\right)$ or $=0.34 \mathrm{Wh} /\left(\mathrm{m}^{3} \cdot \mathrm{k}\right)$. $q_{v e, k, m n}=$ time-averaged flow rate of $k^{\text {th }}$ airflow.

$b_{\text {ve }, k}=$ temperature correction factor for the $\mathrm{k}^{\text {th }}$ airflow. It is 1 in the case of natural ventilation, less than 1 when the air ventilation temperature is different from the external environment (e.g., adoption of pre-heating/cooling or heat recovery system).

$f_{v e, t, k}=$ fraction of time in which the flow of $\mathrm{k}^{\text {th }}$ air occurs; for a permanent situation, it is equal to 1.00 .

$q_{v e, k}=$ flow rate of $k^{\text {th }}$ airflow $\left(m^{3} / h\right)$.

\subsection{BUILDING HEAT TRANSFER COEFFICIENT}

The building heat transfer coefficient is obtained by the sum of transmission and ventilation heat transfer coefficients

$\mathrm{H}=\mathrm{H}_{\mathrm{T}}+\mathrm{H}_{\mathrm{ve}}$

Figure 6 shows the flow chart of the procedure followed for determining the energy flux through the building envelope.

\subsection{THERMAL DYNAMIC BEHAVIOR}

The dynamic effects due to the thermal inertia of the fabric are taken into account, introducing a utilizing factor for the gain "n" (Equations 5 and 6).

This factor is a function of the ratio between gain and losses " $Y$ ",

- $\gamma=\mathrm{Q}_{\text {gain }} / \mathrm{Q}_{\text {losses }}$

The time constant $T$ [hour] in conjunction with the gain/loss ratio characterizes the fabric's ability to use the solar and the internal gains.

$\tau=\frac{\mathrm{C}_{\mathrm{m}} / 3600}{\mathrm{H}_{\mathrm{tr}, \mathrm{adj}}+\mathrm{H}_{\mathrm{ve}, \mathrm{adj}}}$

$\mathrm{C}_{\mathrm{m}}=$ internal capacity factor of the fabric $(24 \mathrm{~h})(\mathrm{J} / \mathrm{K})$,

$\mathrm{H}_{\text {tradi }}+\mathrm{H}_{\text {ve adj }}=$ coefficient of thermal disper$\operatorname{sion}(W / K)$.

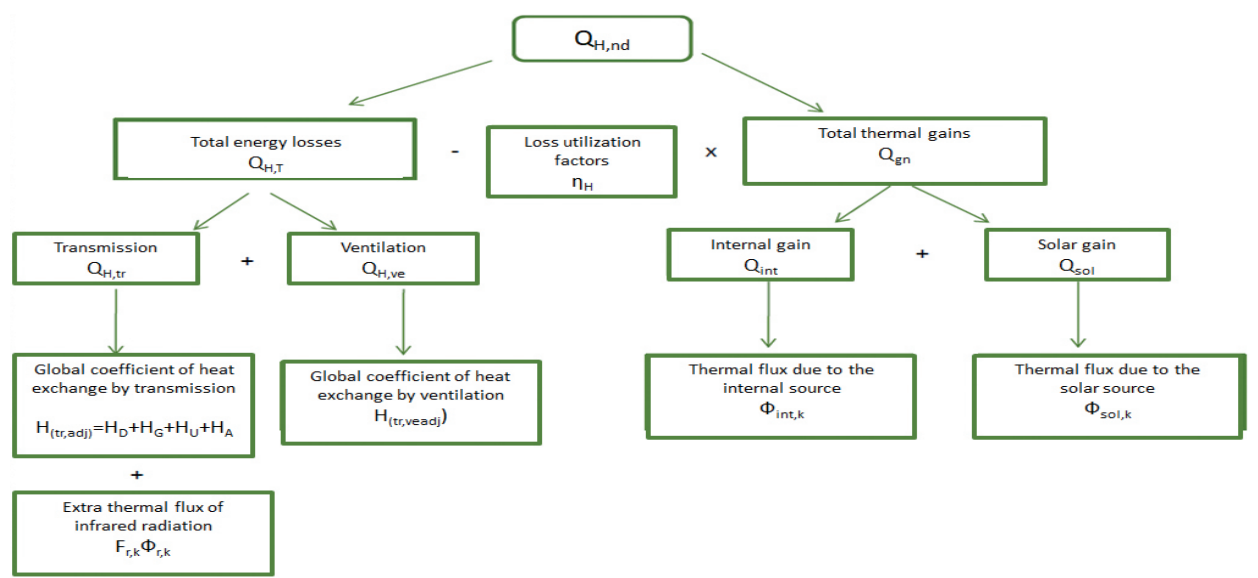

Figure 6. Summary of procedure of the calculation of $Q_{H, n d}$ 


\subsection{HEATING AND COOLING SYSTEM}

The delivered primary energy for space heating is calculated, starting from the energy needs for space heating considering pre-defined efficiency factors, ngl, as a function of the characteristics of the system.

$\mathrm{Q}_{\mathrm{p}, \mathrm{H}}=\mathrm{Q}_{\mathrm{H}, \mathrm{nd}} / \eta_{\mathrm{gl}}$

$Q_{p, H}=$ total primary energy needs for heating space.
They take into account both the primary energy supplied by the heating generator " $Q_{\text {gn,IN" }}$ and the primary energy used by the auxiliary systems (e.g., electrical pump, ventilator) " $Q_{\text {aux }, p}$ ".

$Q_{p, H}=Q_{g n, I N}+Q_{a u x, p}$

$Q_{\mathrm{gn}, \mathrm{IN}}=\mathrm{Q}_{\mathrm{l,gn}}+\mathrm{Q}_{\mathrm{l}, \mathrm{d}}+\mathrm{Q}_{\mathrm{l,c}}+\mathrm{Q}_{\mathrm{l,e}}$

$Q_{1, g n}=$ generation system's energy losses:

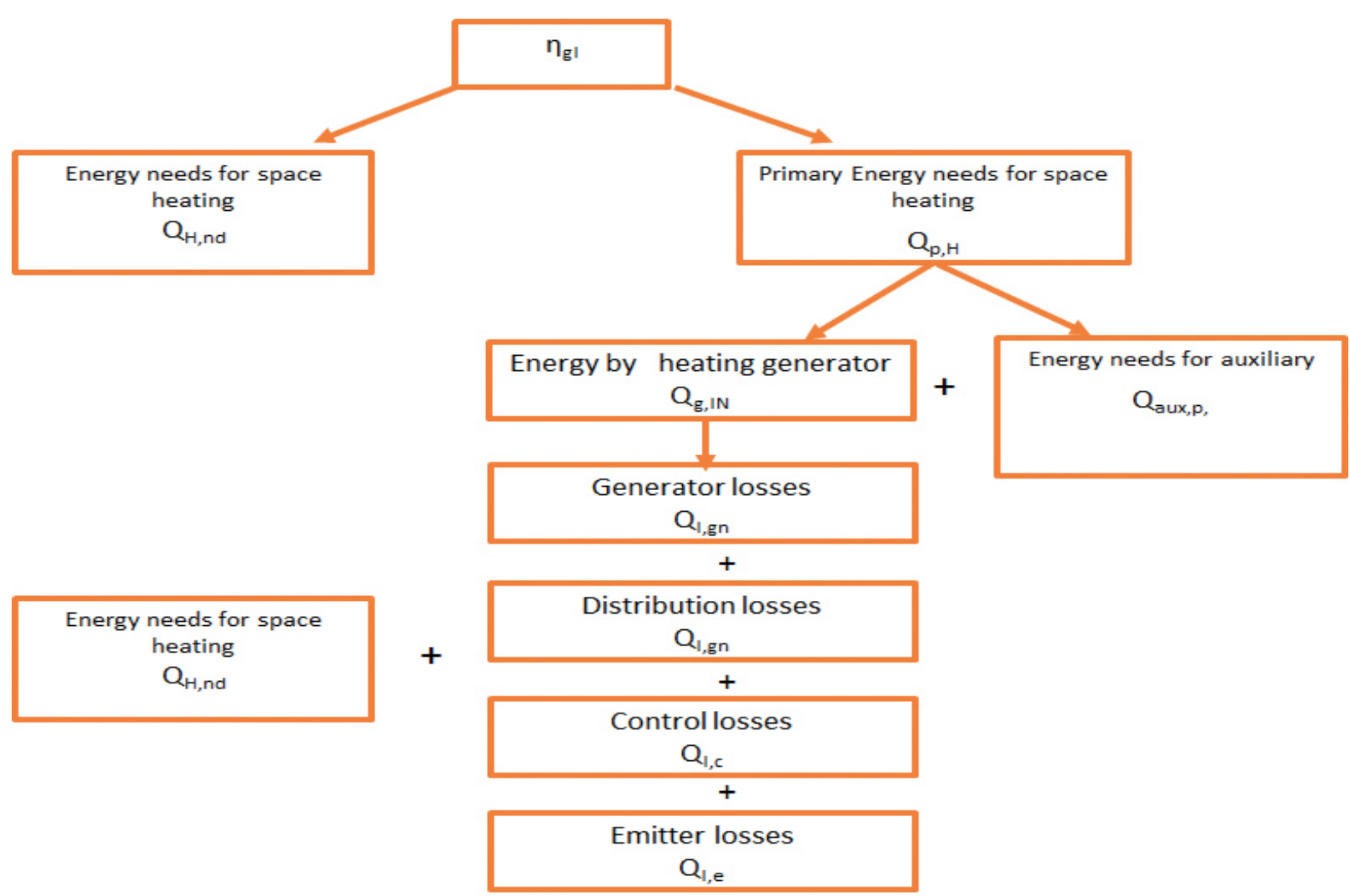

Figure 7. Summary of the procedure of the calculation of $n_{g l}$ 
$Q_{1, d}=$ piping distribution system's energy losses:

$Q_{1, c}=$ heating control system's energy losses; $Q_{1, e}=$ emitters' energy losses.

These energy losses can be calculated through the efficiencies of the emission system $\eta_{e}$, regulation system $\eta_{c^{\prime}}$ distribution system $\eta_{d}$ and generation system $\eta_{g n}$.

Figure 7 illustrates the steps followed for determining the total primary energy needs.

\section{UNSTEADY STATE ANALYSIS}

The thermal behavior of masonry under dynamic boundary conditions is characterized through periodic thermal transmittance (Yie) [10], which expresses the heat flux through the internal surface of a facade when the outdoor temperature follows a sinusoidal function. The periodic thermal transmittance also gives the evidence on the capability of an opaque wall to shift and attenuate thermal flux, which crosses
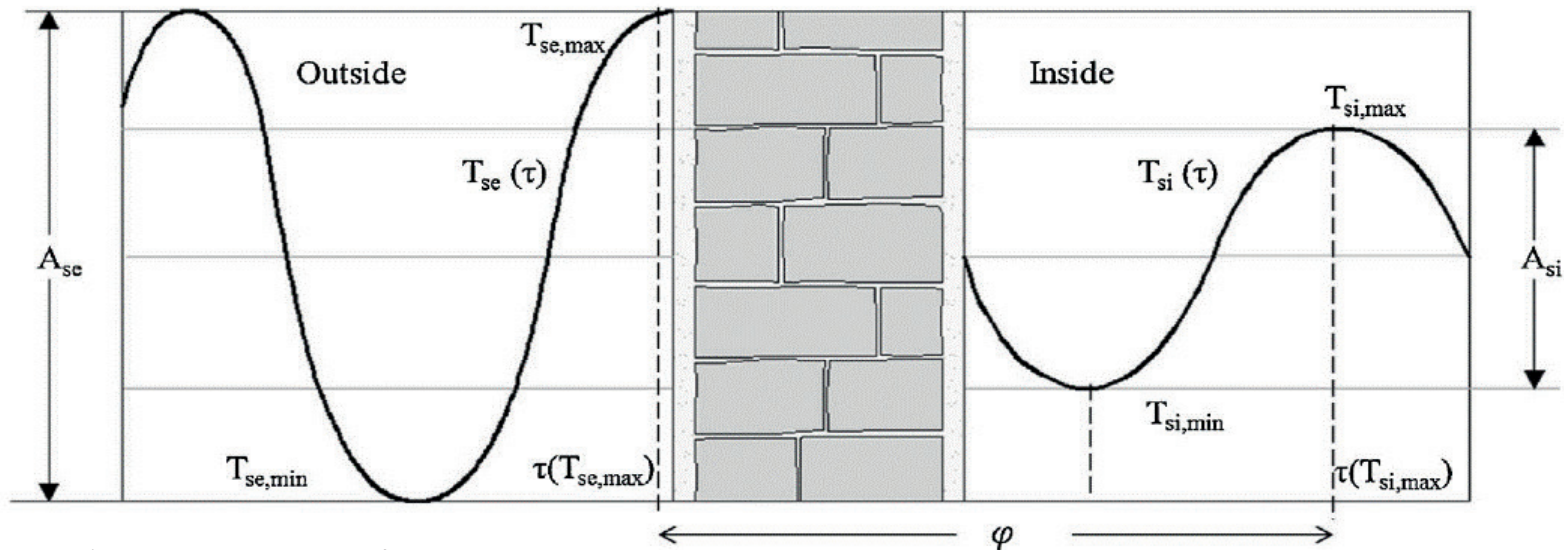

Figure 8. Time lag and decrement factor [6]

\begin{tabular}{|c|c|c|}
\hline Time shift & Decrement factor & Rating \\
\hline$\varphi>12$ & $f<0.15$ & Excellent \\
$12 \geq \varphi>10$ & $0.15 \leq f<0.30$ & Good \\
$10 \geq \varphi>8$ & $0.30 \leq f<0.40$ & Sufficient \\
$8 \geq \varphi>6$ & $0.40 \leq f<0.60$ & Bad \\
\hline
\end{tabular}

Table 3. Rating for time shift and decrement factor based on Italian regulation. 
it over $24 \mathrm{~h}$. As a general rule, the lower the value of the thermal transmittance is, the better the thermal behavior of the component is.

Italian legislation on the energy performance of buildings prescribes specific requirements for thermal dynamic behavior during the summer period. In particular, vertical walls facing from East to West must have either a superficial thermal mass higher than $230 \mathrm{~kg} \mathrm{~m}^{-2}$ or a periodic thermal transmittance lower than $0.12 \mathrm{~W} \mathrm{~m}^{-2} \mathrm{~K}$.

The dynamic behavior of the building envelope is also described using two dynamic factors - time lag (TL) and the decrement factor (f) $[12,13]$. The time lag indicates the time shift between the maximum outer and inner surface temperature occurrence:

$\mathrm{TL}=\tau_{\text {Tso,max }}-\tau_{\text {Tsi,max }}$

The decrement factor (DF) is defined as the ratio of the amplitude of the inner surface temperature fluctuations to the amplitude of the outer surface temperature fluctuations:

$$
\mathrm{DF}=\frac{\mathrm{A}_{\mathrm{si}}}{\mathrm{A}_{\text {so }}}=\frac{\mathrm{T}_{\text {si,max }}-\mathrm{T}_{\text {si,min }}}{\mathrm{T}_{\text {so,max }}-\mathrm{T}_{\text {so, min }}}
$$

\section{being}

$\mathrm{T}_{\text {si,max }}$ and $\mathrm{T}_{\text {si,min }}=$ the maximum and minimum temperature on the inner surface;

$\mathrm{T}_{\text {so, } \max }$ and $\mathrm{T}_{\text {so,min }}=$ the maximum and minimum temperature on the outdoor surface. The DF factor measures the decreasing ratio of the amplitude of the heatwave that propagates from the outer surface to the inner surface of a wall [6].
Figure 8 illustrates the time lag and decrement factor for a building façade.

In Table 3, time lag and decrement factors are correlated with the dynamic behavior of the building envelope [6].

\section{CASE STUDY}

This section of this report illustrates the application of the EPC procedure on a typical Aeolian building carried out using the DOCET software.

Figure 9 shows a typical Aeolian building used as a case study.

The island of Filicudi is included in the Italian climatic zone $B$, which is characterized by the heating degree day (HDD) number of 75 . The period allowed for space heating is from 1st December to 31 March.

\subsection{BUILDING ENVELOPE}

Preliminary to proceed to the elaboration of the EPC, it is necessary to recover all the data necessary for defining the typological characteristics as well as the thermophysical property of the building envelope, as well as on the features of the air conditioning system.

Figure 10 depicts the first input window of the DOCET software, where general information on the building has to be definite. In particular, it is requested to indicate the year of construction, the color of the building envelope, the type of urban context, the geometric characteristics of the external buildings that could shade the analyed house, as well as the main house's dimensions. 

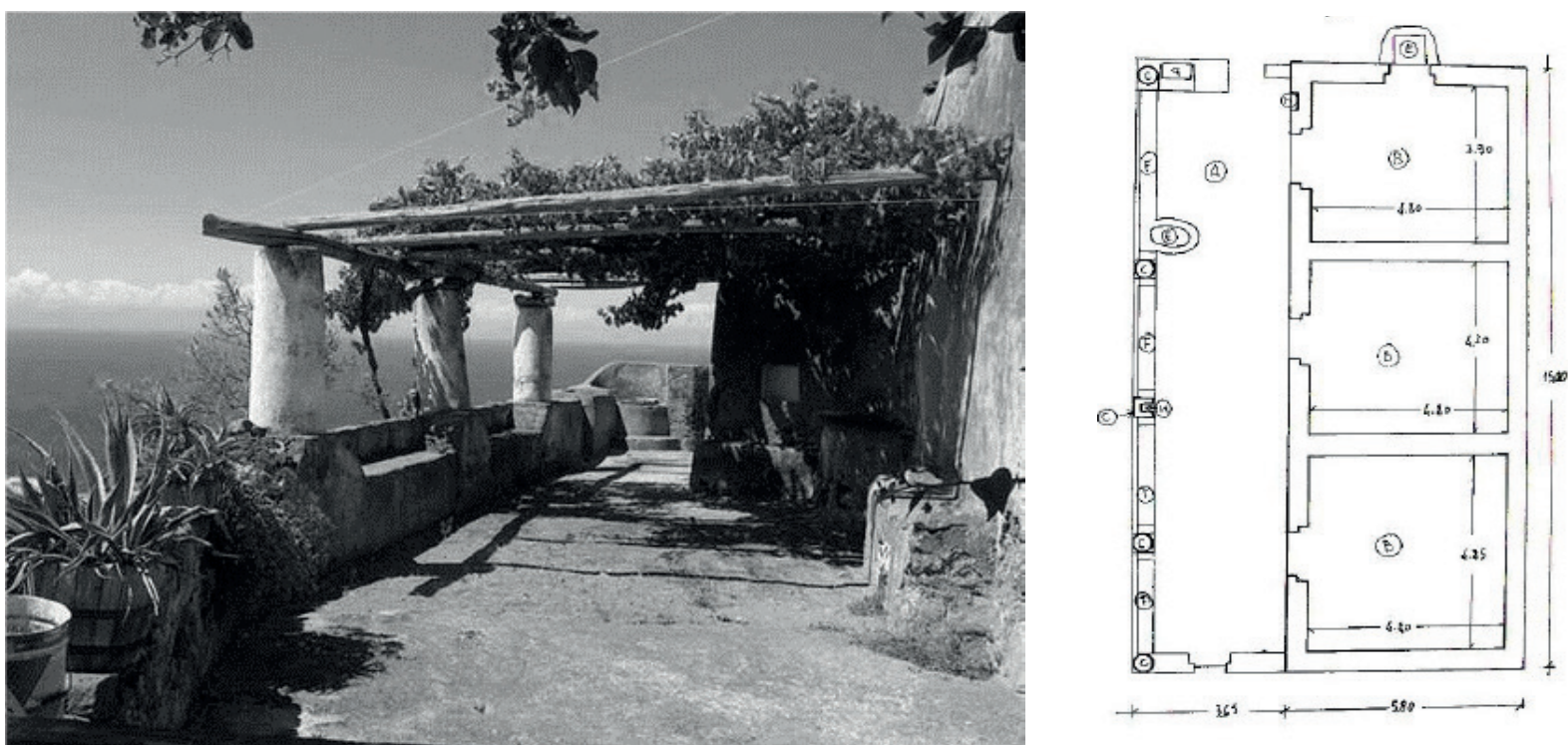

Figure 9. View and plan of a typical Aeolian building

As regards the building's general data, the internal height, the number of floors, gross surface of the air-conditioned environment, and the useful (or net) floor area of the air-conditioned environment, as well as the linear dimensions of the facades for each orientation, have to be defined.

The thermal transmittance of $r$, the opaque component of the building envelope (external wall, roof, basement floor), may be selected, among a predefined set of alternatives, as a function of the year of construction, location, actual requirements, etc. These default values of the thermal transmittance are derived by the UNI/TR 11552:2014 technical standard [7].

The shape of the building unit is described by the surface of each external wall considering their cardinal orientations (fig. 11), as well as the surface of the floor, roof, and unconditioned zone.

The thermal transmittance of the windows is determined as a function of the frame and glass typologies.

Simplified fixed values of linear thermal transmittance are used according to the characteristics of the technical element and the presence of thermal insulation [7]. Shading systems such as internal white curtains, fixed external overhangs, or fixed vertical fins can be selected and solar gains through the windows are reduced consequently.

Only natural ventilation with an air exchange rate equal to $0.3(\mathrm{vol} / \mathrm{h}) \mathrm{can}$ be taken into account.

At the end of the phase of input data, the software performs a check on these data and provides as the first output the ratio S/V between the gross volume of the air-conditioned environment ( $V$ ) and the gross surface of the air-conditioned environment (S). 


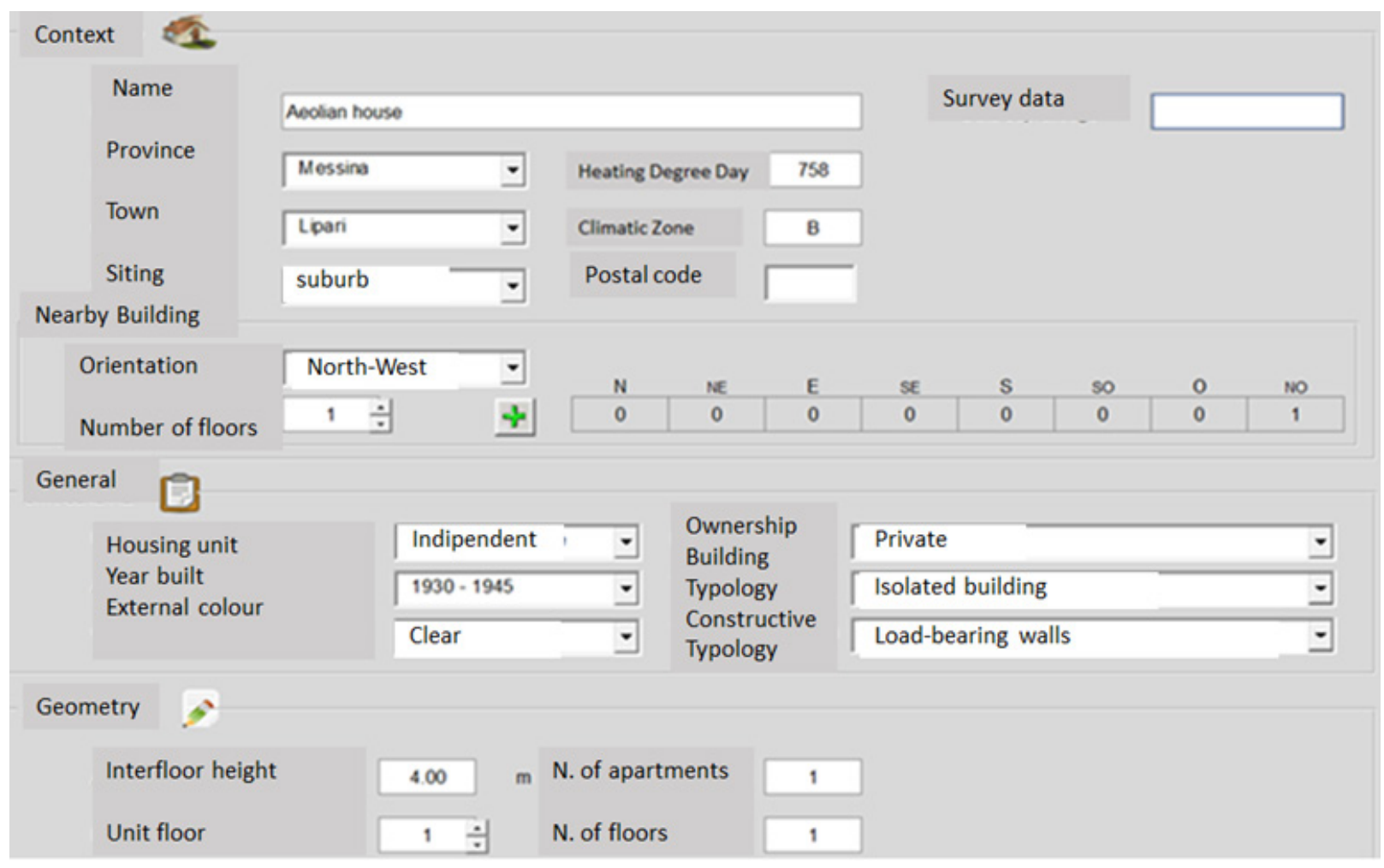

Figure 10. Building's general data

Thus, the different terms that determine the building's energy balance are calculated. Figure 12 shows the calculated values for $\mathrm{H}_{\mathrm{T}}$ and $H_{v}(W / K), T(h)$, the monthly values of $Q_{H, n d^{\prime}}$ and $Q_{C, n d}(k W h)$, and $E P_{H, n d}$ and $E P_{C, n d}$ $\left(\mathrm{kWh} / \mathrm{m}^{2}\right)$.

It is possible to observe that energy needs for heating spaces are $\mathrm{EP}_{\mathrm{H}, \mathrm{nd}}=250.53 \mathrm{kWh} /$ $\mathrm{m}^{2}$ year, which are remarkably higher than the primary energy allowable for new buildings ( $E P_{\mathrm{H}, \mathrm{nd}}=49.23 \mathrm{kWh} / \mathrm{m}^{2}$ year) built in the same climatic zone. This finding indicates a modest performance of the building enve- lope of the investigated reference building during the heating period, in accordance with the current Italian EPC procedure.

Otherwise, the energy needs calculated for the cooling period are rather low, EP $\mathrm{c}$, nd $=18.40 \mathrm{kWh} / \mathrm{m}^{2}$ year. This finding indicates a good thermal behavior of the Aeolian building during the summer period.

As a result, it is possible to assert that the Aeolian buildings were built with the aim to optimize their performance during the summer period in concordance to the hot weather climate that characterizes the Aeolian Islands. 


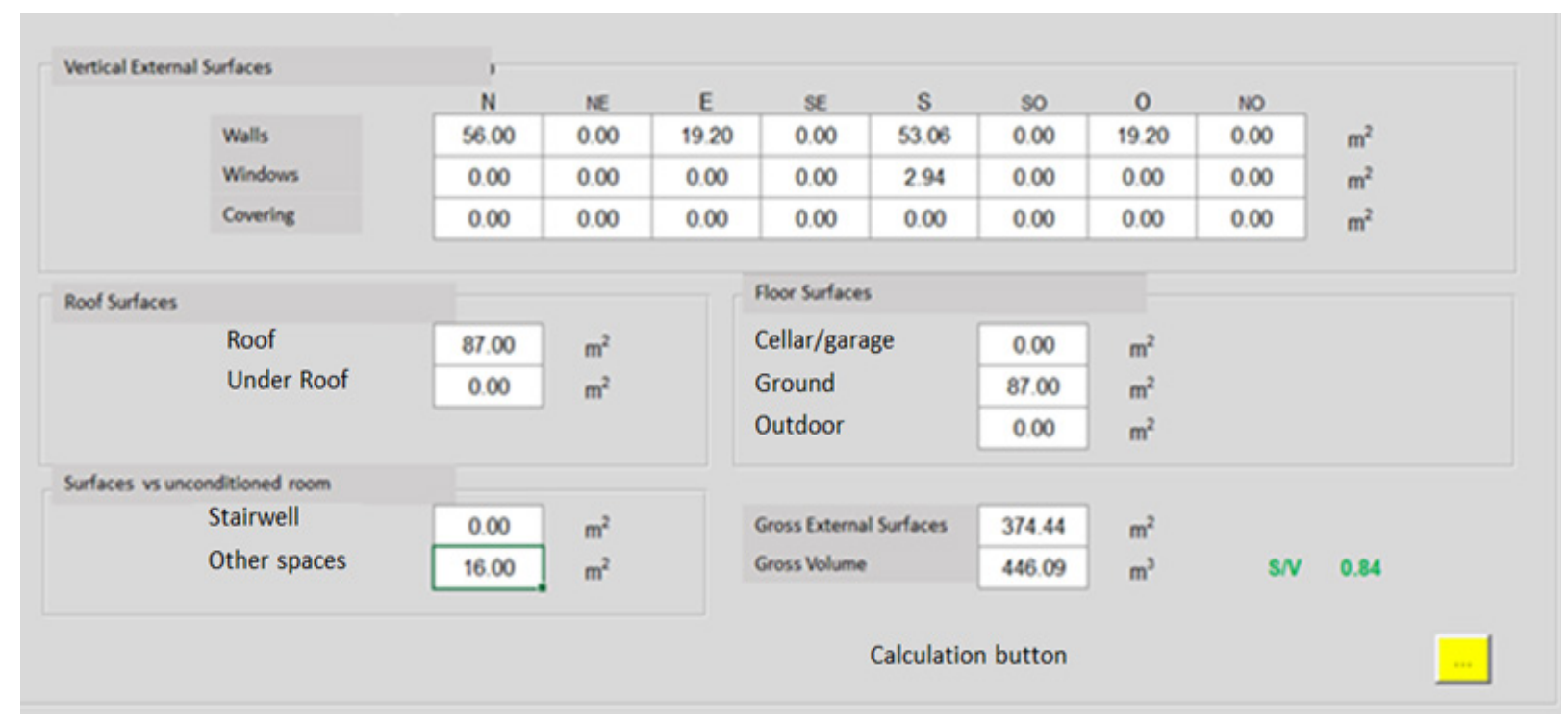

Figure 11. Dimensions of the building envelope surface

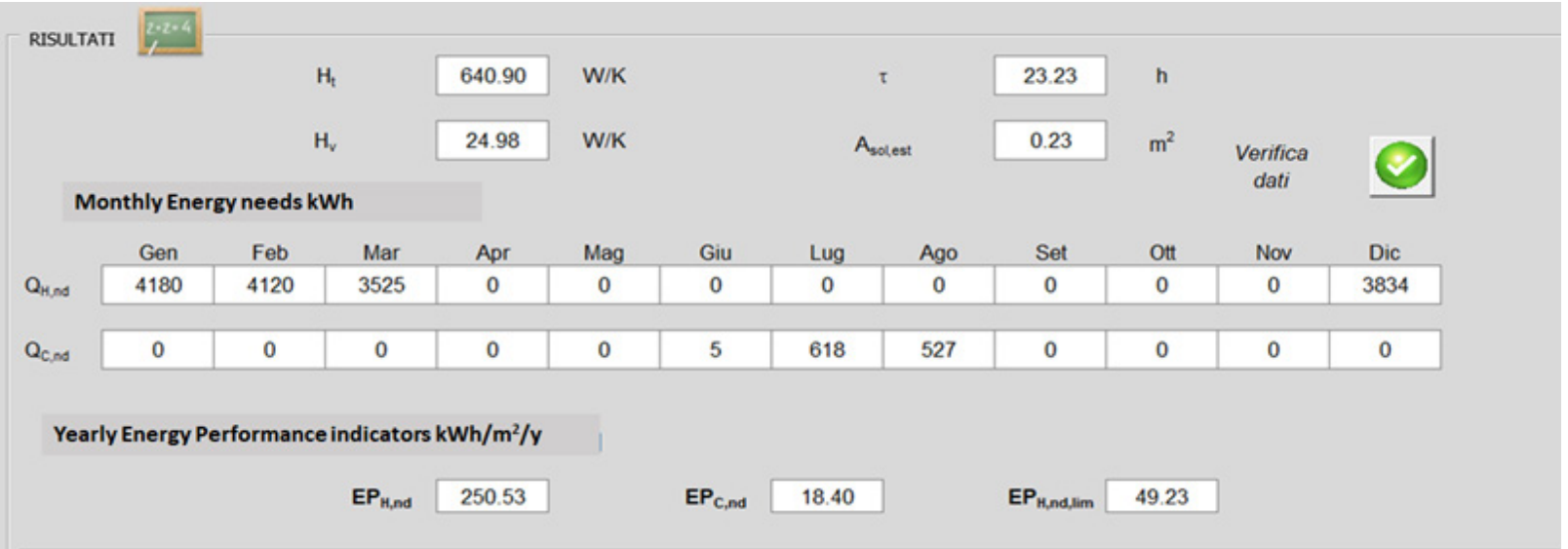

Figure 12. Dimensions of the building envelope surface 


\subsection{HEATING SYSTEM}

As regards the generation system, DOCET allows selection of the following options: Combustion systems; Biomass systems; Heat pumps; District heating. Since, currently, many of the Aeolian buildings are not equipped with a heating system, a conventional gas boiler is selected as a heating generator. Moreover, a solar thermal system of $2.00 \mathrm{~m}^{2}$ is included in this analysis. Figure 13 shows the non-renewable primary energy needs calculated for the heating, cooling and domestic hot water systems, respectively.

These results indicate that the non-renewable primary energy needs, EP ${ }_{\text {gl, nren' }}$ are $406.15 \mathrm{kWh} / \mathrm{m}^{2}$, while the non-renewable primary energy needs of the reference building, $\mathrm{EP}_{\text {gl,nren }}(\mathrm{ref})$, are $107.23 \mathrm{kWh} / \mathrm{m}^{2}$. Thus, this building has energy consumptions that are four times greater than a new building with the same shape. Since a solar thermal system $\left(2.00 \mathrm{~m}^{2}\right)$ for DHW production has been included, the EPC indicates also the amount of renewable primary energy (fig. 14).

The primary energy is obtained by the summation of both the non-renewable "nren" sources, which come from a fossil fuel source, and renewable energy sources "ren". Both renewable and non-renewable energies are converted in primary energy, utilizing the primary energy conversion factors $f P$, nren and $f P$, ren. These factors include the delivered energy plus a contribution for taking into account the energy "overhead" necessary to extract, process, and transport the energy carrier to the dwelling.

\begin{tabular}{|c|c|c|c|c|c|c|c|c|c|c|c|c|}
\hline RISULTATI & \multicolumn{12}{|l|}{$\sqrt{2 \cdot 2 \cdot 4}$} \\
\hline \multicolumn{5}{|c|}{ Not renewable primary energy [kWh] } & \multirow[b]{2}{*}{ Mag } & \multirow[b]{2}{*}{ Giu } & \multirow[b]{2}{*}{ Lug } & \multirow[b]{2}{*}{ Ago } & \multirow[b]{2}{*}{ Set } & \multirow[b]{2}{*}{ Ott } & \multirow[b]{2}{*}{ Nov } & \multirow{2}{*}{ Dic } \\
\hline & Gen & Feb & Mar & Apr & & & & & & & & \\
\hline $\mathbf{Q}_{\mathrm{p}, \mathrm{H}}$ & 6231 & 6138 & 5260 & 0 & 0 & 0 & 0 & 0 & 0 & 0 & 0 & 5719 \\
\hline $\mathbf{Q}_{\mathrm{p}, \mathrm{C}}$ & 0 & 0 & 0 & 0 & 0 & 0 & 0 & 0 & 0 & 0 & 0 & 0 \\
\hline$Q_{p, w}$ & 216 & 190 & 180 & 157 & 142 & 132 & 132 & 135 & 153 & 175 & 194 & 231 \\
\hline \multirow[t]{2}{*}{$\mathbf{Q}_{p}$} & 6448 & 6328 & 5440 & 157 & 142 & 132 & 132 & 135 & 153 & 175 & 194 & 5950 \\
\hline & \multicolumn{4}{|c|}{ Yearly primary energy } & & & & & & & & \\
\hline $\mathbf{Q}_{\mathrm{gn}, \mathrm{out}, \mathrm{H}}$ & 17805.35 & $\mathrm{kWh}$ & $\mathbf{E} \mathbf{P}_{\mathrm{H}, \mathrm{nd}}$ & 250.53 & $\mathrm{kWh} / \mathrm{m}^{2} \mathrm{a}$ & $\mathbf{E P}_{\mathrm{C}, \mathrm{nd}}$ & 18.40 & $\mathrm{kWh} / \mathrm{m}^{2} \mathrm{a}$ & $\mathbf{E P}_{\mathrm{W}, \mathrm{nd}}$ & 15.68 & $\mathrm{kWh} / \mathrm{m}^{2} \mathrm{a}$ & \\
\hline \multirow[t]{3}{*}{$\mathbf{Q}_{\mathrm{gn}, \mathrm{out}, \mathbf{W}}$} & 1440.93 & $\mathrm{kWh}$ & $\eta_{\mathrm{H}}$ & 0.67 & - & $\eta_{\mathrm{c}}$ & 0.00 & - & $\eta_{w}$ & 0.32 & - & \\
\hline & & & $\mathbf{E P}_{\mathrm{H}, \text { nren }}$ & 373.56 & $\mathrm{kWh} / \mathrm{m}^{2} \mathrm{a}$ & $\mathbf{E P}_{\mathrm{C}, \text { nren }}$ & 0.00 & $\mathrm{kWh} / \mathrm{m}^{2} \mathrm{a}$ & $E P_{W, \text { nren }}$ & 32.59 & $\mathrm{kWh} / \mathrm{m}^{2} \mathrm{a}$ & \\
\hline & & & $\mathbf{E P}_{\text {gl,nren }}$ & 406.15 & $\mathrm{kWh} / \mathrm{m}^{2} \mathrm{a}$ & Classe & G & & $\mathbf{E P}_{\mathrm{gl}, \mathrm{nren}, \text { rif }}$ & 107.23 & $\mathrm{kWh} / \mathrm{m}^{2} \mathrm{a}$ & 20192021 \\
\hline
\end{tabular}

Figure 13. Not renewable primary energy need 


\begin{tabular}{|c|c|c|c|c|c|c|c|c|c|c|c|c|}
\hline \multicolumn{13}{|c|}{ Renewable primary energy [kWh] } \\
\hline & Gen & Feb & Mar & Apr & Mag & Giu & Lug & Ago & Set & Ott & Nov & Dic \\
\hline$Q_{p, H}$ & 53 & 51 & 46 & 0 & 0 & 0 & 0 & 0 & 0 & 0 & 0 & 49 \\
\hline & & & & & & & & & & & & \\
\hline $\mathbf{Q}_{\mathrm{p}, \mathrm{C}}$ & 0 & 0 & 0 & 0 & 0 & 0 & 0 & 0 & 0 & 0 & 0 & 0 \\
\hline & & & & & & & & & & & & \\
\hline$Q_{p, w}$ & 41 & 44 & 86 & 98 & 129 & 131 & 139 & 135 & 100 & 82 & 50 & 24 \\
\hline & & & & & & & & & & & & \\
\hline $\mathbf{Q}_{p}$ & 94 & 95 & 132 & 98 & 129 & 131 & 139 & 135 & 100 & 82 & 50 & 73 \\
\hline \multicolumn{13}{|c|}{ Yearly Primary Energy $\left[\mathrm{kWh} / \mathrm{m}^{2} / \mathrm{y}\right]$} \\
\hline & & & $\mathbf{E P}_{\mathrm{H}, \text { ren }}$ & 3.17 & & $\mathbf{E P}_{\mathrm{C}, \text { ren }}$ & 0.00 & & $E P_{W, \text { ren }}$ & 16.95 & & \\
\hline & & & $\mathbf{E P}_{\text {gl,ren }}$ & 20.12 & & $\mathbf{E P}_{\mathrm{gl}, \text { ren, rif }}$ & 0.00 & & & & & \\
\hline
\end{tabular}

Figure 14. Renewable primary energy

The non-renewable primary energy related to electricity consumption depends on the energy mix (coal, oil, gas, biomass) and the process efficiency in each country. The conversion from a primary energy resource to delivered energy is calculated through standard weighting factors.
The total primary energy EPgl, tot is determined by the sum of EPgl,nren, and EPgl,ren (fig. 15). As an output, the software provides also the monthly variation of the not renewable, renewable, and total primary energy (fig. 16).

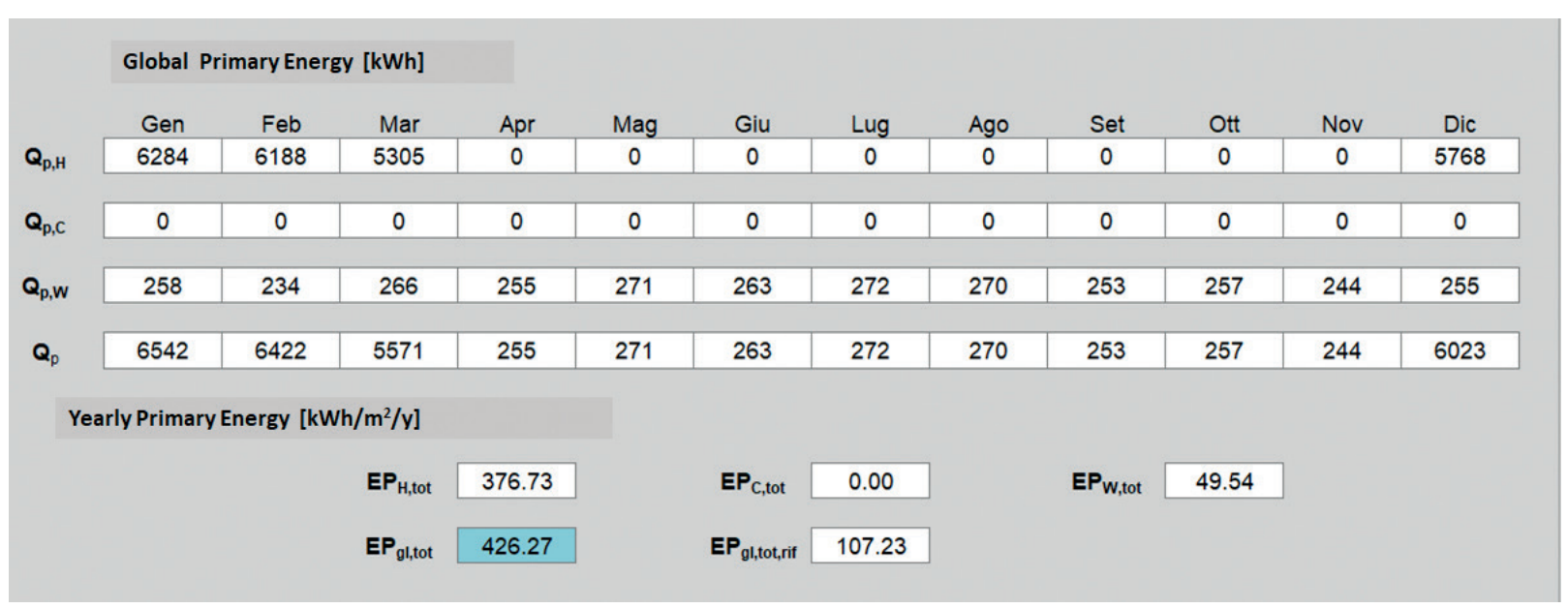

Figure 15. Total primary energy need 

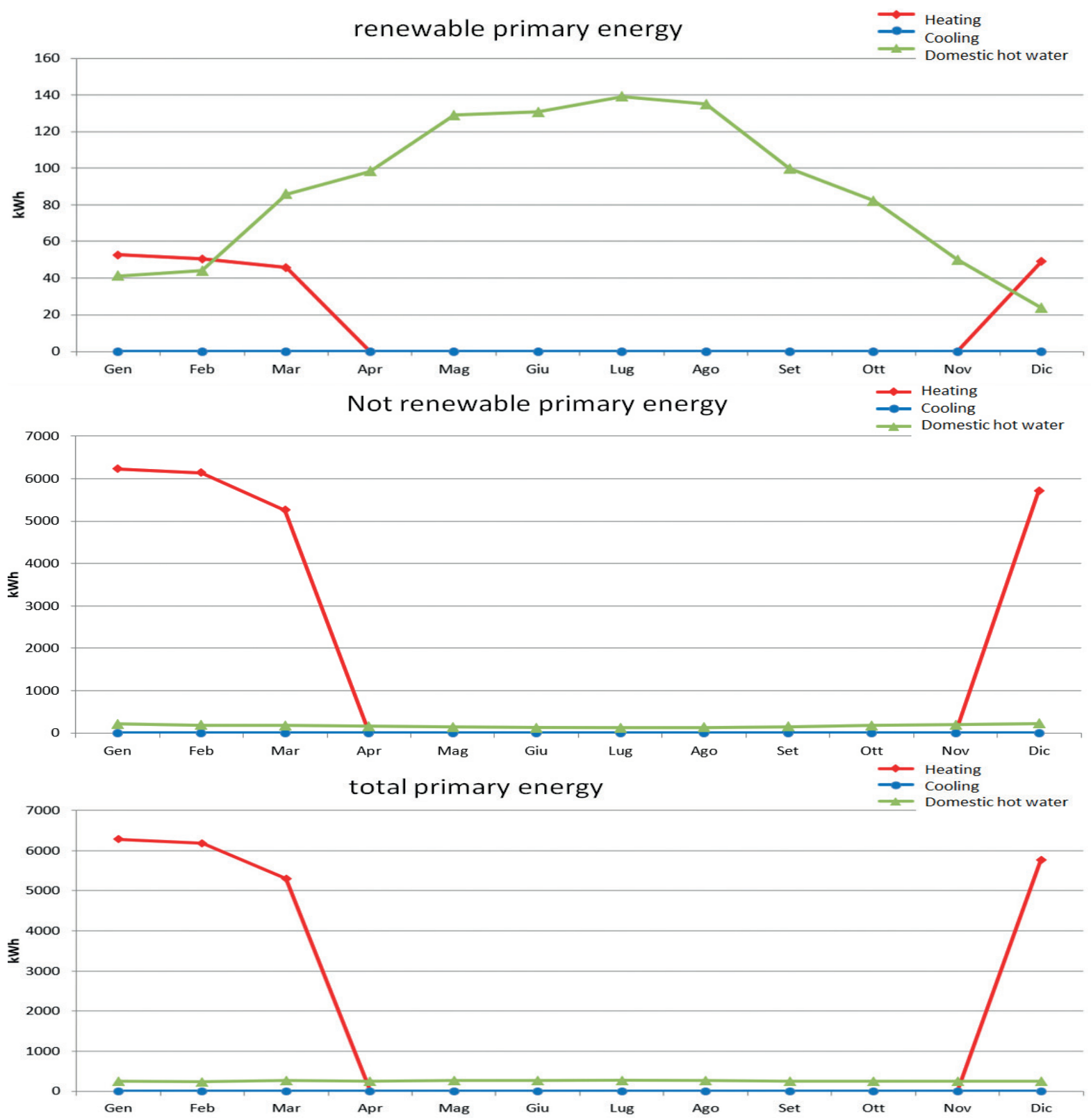

Figure 16. A yearly variation of the primary energy needs 


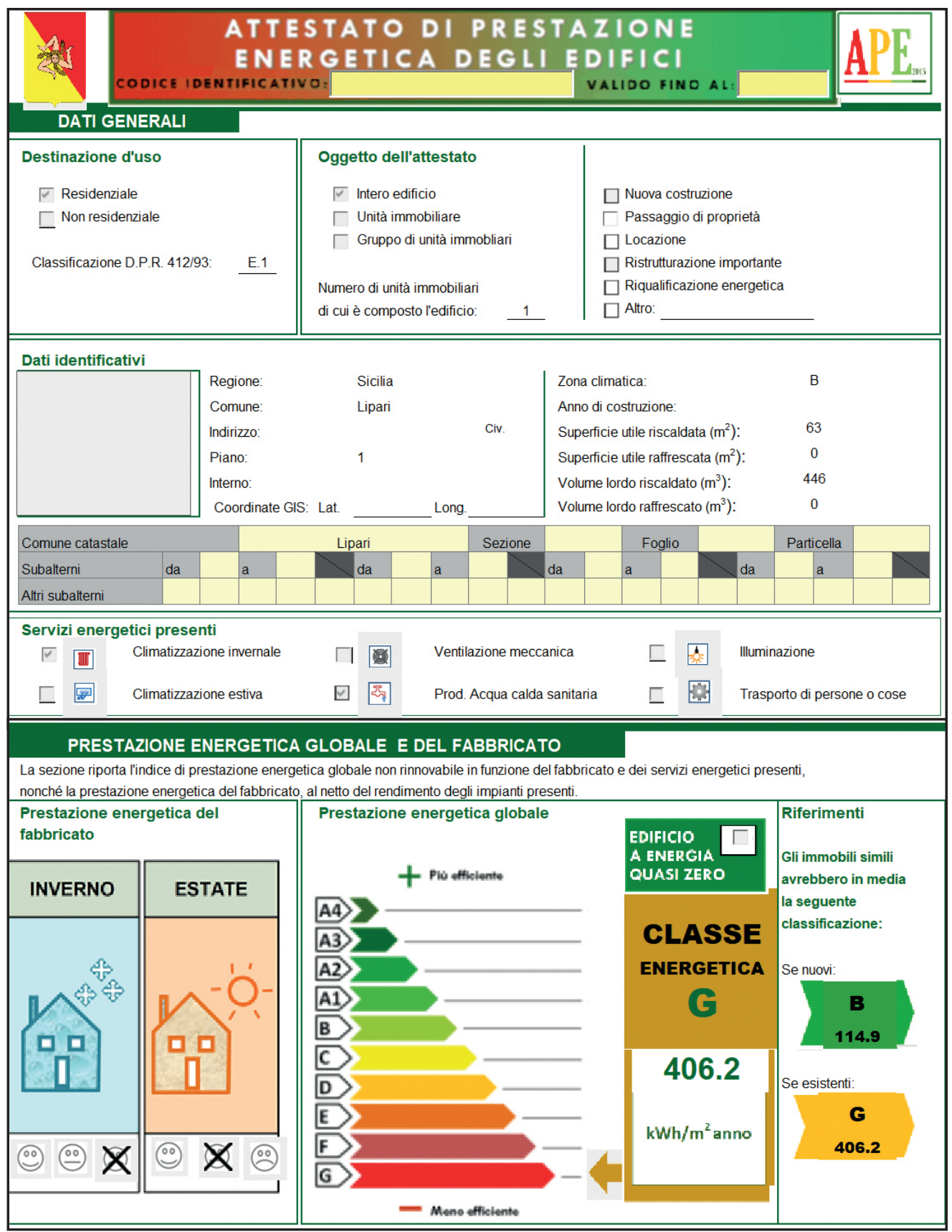

Figure 17. A portion of the Energy Performance Certificate 
Finally, Figure 17 shows a section of the Energy performance certificate, which is written in Italian, where the main results of the building energy consumption and its classification are showed.

This EPC illustrates the main characteristic of the analyzed building, such as the toponomastic and the geometric data, the gross heated volume and net surface lleft part), and the energetic class and the EPgl, nren, which are respectively $G$ and 406.2 $\mathrm{kWh} / \mathrm{m}^{2}$. The energy performance certificate has also defined some solutions to reduce building's energy consumption. In the specific context, an interesting opportunity is represented by the installation of a photovoltaic thermal plant, which allows the contemporary generation of both thermal energy and power [14].

\section{CONCLUSIONS}

This article summarizes the lecture proposed in the context of the intensive school of the projects VVITA Erasmus+ held in Filicudi in September 2018. The arguments had the aim to illustrate the procedures and the methodologies that allowed the evaluation of energy consumption in the framework of the EPC. An example of EPC, having as reference a typical Aeolian building, has been developed.

Such analyses have highlighted some interesting outcomes. In particular, it was evidenced that the energy needs for heating spaces are $250.53 \mathrm{kWh} / \mathrm{m}^{2}$ year, which is almost five times higher than the values required for a new building $\left(49.23 \mathrm{kWh} / \mathrm{m}^{2}\right.$ year).

This result indicates the poor performance of the building envelope during the heating period.

Otherwise, since energy needs during the cooling period are modest, $18.40 \mathrm{kWh} / \mathrm{m}^{2}$ year, it is possible to highlight that such typology of building fabric has the best performance during the summer period in concordance to the weather and climate of the Aeolian Islands.

The performance of this building has a further decrease when the efficiencies of the energy generation systems are included; a yearly energy need of $406.2 \mathrm{kWh} / \mathrm{m}^{2}$ is reached.

In light of the coarse analysis carried out, it is mandatory to improve significantly the efficiencies of the energy generation systems, as well as to increase the energy produced by the renewable energy system.

\section{Antonio Gagliano}

Department of Electric Electronic and Computer Engineering, University of Catania, Italy Mail: antonio.gagliano@unict.it 


\section{REFERENCES}

[1] "Energy Performance of Building Directive 2002" [Online]. Available: Energy Performance of Buildings Directive),2002/91/CE-EPBD, https://eur-lex.europa.eu/LexUriServ/LexUriServ.do? uri=OJ:L:2003:001:0065:0071:EN:PDF (accessed on October, 2019).

[2] "Energy Performance of Building Directive 2010" [Online]. Available: Energy Performance of Buildings Directive 2010/31/EU (EPBD), https://eur-lex.europa.eu/LexUriServ/LexUriServ.do?uri=OJ:L:2010:153:0013:0035:EN:PDF (accessed on October, 2019).

[3] Belussi L., Danza L., Meroni I., Salamone F., Minutoli S., Romeo C. , Simplified tool for the energy performance assessment of residential buildings. Modelling, Measurement and Control B 87, (3), pp. 122-128, 2018.

[4] "Energy performance certificates across the EU" [Online]. Available: http://bpie.eu/publication/energyperformance-certificates-across-the-eu/ (accessed on October, 2019).

[5] UNITS 11300 Sections 1 to 6 , https://www.cti2000.eu/la-uni-ts-11300/

[6] Ministry of Economic Development (Italy), Inter-Ministerial Decree 26 June 2015. https://www.iea.org/beep/italy/ codes/decree-for-energy-efficiency-requirements-in-buildings-2015.html

[7] "DOCET software" [Online]. Available: http://www.docet.itc.cnr.it/ (accessed on October, 2019).

[8] Gagliano A., Giuffrida S., Nocera F., Detommaso M., Energy efficient measure to upgrade a multistory residential in a nZEB, AIMS Energy 5 (4), pp.601-624, 2017.

[9] Gagliano A., Nocera F., Patania F, Detommaso M., Sapienza V., Deploy energy-efficient technologies in the restoration of a traditional building in the historical center of Catania (Italy), Energy Procedia 62, pp. 62-71, 2014.

[10] ISO 6946:2017 Building components and building elements, Thermal resistance and thermal transmittance, Calculation methods, https://www.iso.org/standard/65708.html (accessed on October, 2019).

[11] Tronchin, L. "Energy performance building evaluation in Mediterranean countries: Comparison between software simulations and operating rating simulation", Energy \& Buildings, 2008.

[12] Moschella A., Gagliano, Lo Faro A., Mondello A., Salemi A., Sanfilippo G. , "A Methodology for an Integrated Approach for Seismic and Energy Refurbishment of Historic Buildings in Mediterranean Area", Sustainability, 2018.

[13] Gagliano A., Patania F., Nocera F., Signorello C., Assessment of the dynamic thermal performance of massive buildings Energy and buildings 72, pp. 361-370, 2014.

[14] Gagliano A., Tina G.M., Aneli S., Nižetić S., Comparative assessments of the performances of PV/T and conventional solar plants, Journal of cleaner production 219, pp. 304-315, 2019. 


\section{GIS CONTRIBUTION TO BUILDING MANAGEMENT}

\section{GIS TECHNOLOGY}

Geographic Information System (GIS) is a technology that has transformed the way to manage and use all geographic data necessary for all human activities [1].

All human activities need to place information in a geographical context. Many of these activities concern with the recording and planning of human-made environments, with the monitoring and managing of natural environments, with monitoring and managing transport, services, network, and navigation systems, and with understanding social structures.

To this aim, GIS technology can be used as Digital Data Service (DDS) for the management of environmental risks, such as the hydrogeological risk [2,3] and the management of renewable energy [4].
The GIS technology can be considered an engineering work, well defined by an architecture (fig. 1) that is designed, built, and tested in all its components.

The hardware components of a GIS application are computers, servers, display devices such as monitors, printing devices, satellite positioning sensors such as GPS, computer networks, etc. (fig. 2) and allow for the analysis, visualization, and sharing of the spatial information.

The software components used in GIS technology allows the managing of all information concerning all GIS components. The software components can be divided into three categories (fig. 3): base software, GIS software, and software for spatial applications.

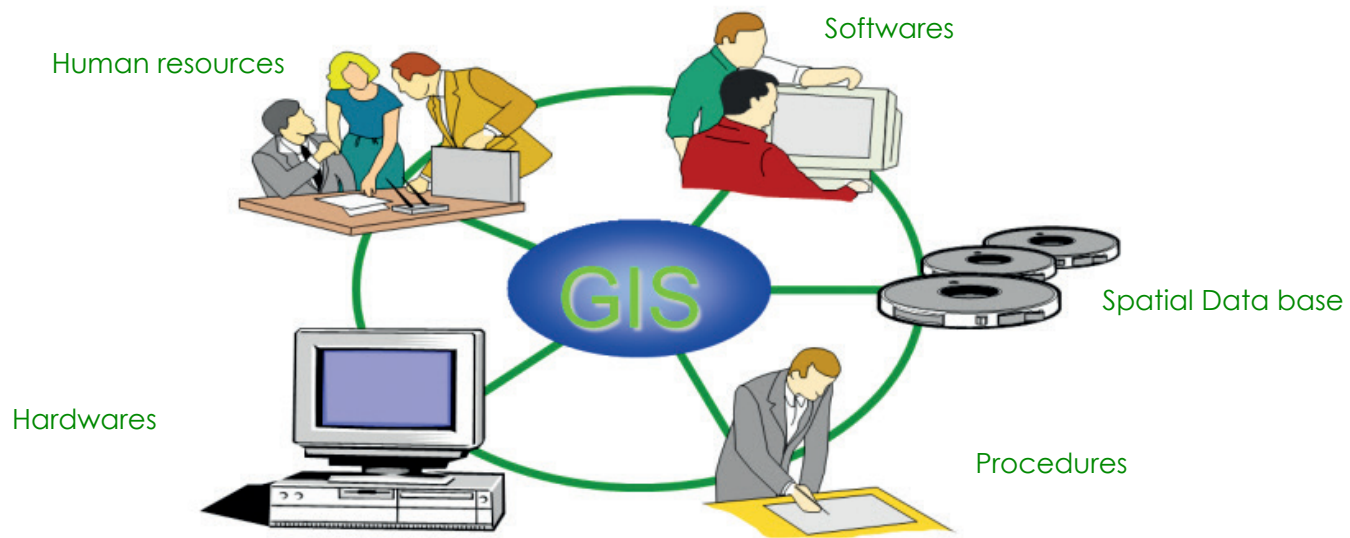

Figure 1. Components of GIS application 


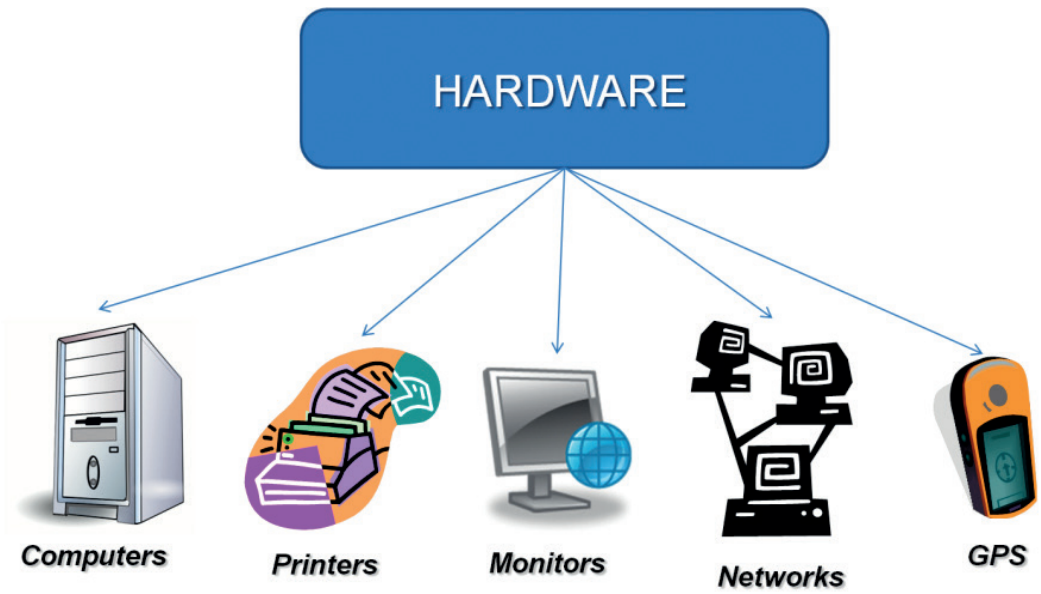

Figure 2. Hardware Components of GIS application

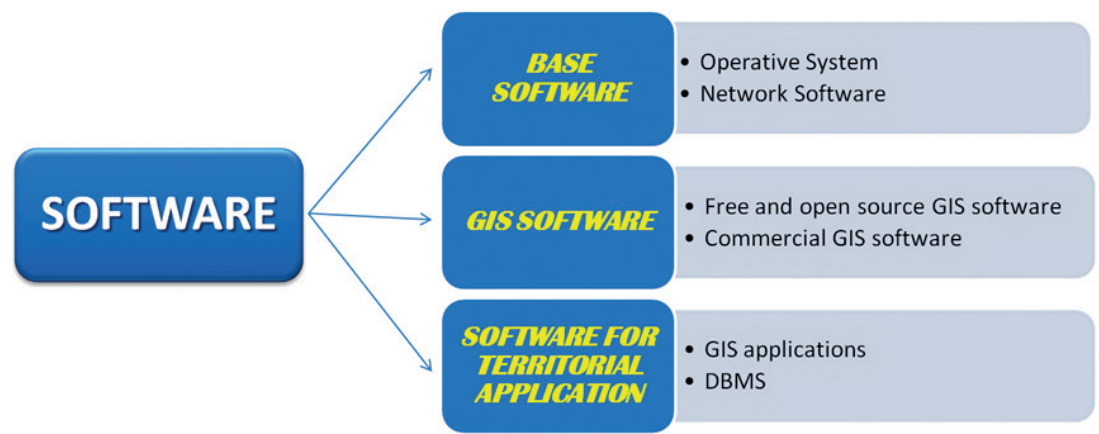

Figure 3. Software Components of GIS application 
The base software manages the individual hardware components that compose the GIS architecture, i.e., operating systems, networking software, driver for printers, scanners, topographic instruments, etc. [1]. The GIS software allows one to use typical GIS tools on the spatial data and they are divided into free and open source GIS software and commercial GIS software [5].

The first is identified by the acronym FOSS (Free and Open Source Software) and is licensed under the GPL (General Public License). This license grants the recipients of a computer program the rights of the free software definition and uses copyleft to ensure the freedoms are preserved, even when the work is changed or added to.

This technology is popular amon GIS software, so much that a community called OSGEO [http://www.osgeo.org/] has been created for supporting the collaborative development of open source geospatial software, and promoting its widespread use. The second is payment software typically with closed source codes.

The software for spatial applications deals with data enriched by spatial information and software for the development of GIS applications.

The data managed and used within the GIS applications are enriched by spatial characteristics, then georeferenced using topography approaches.

These data can be divided into two main categories - raster and vector data.
The raster data represent the cartographic support used in the GIS environment, and includes satellite images, orthophotos, DEM, etc.

The vector data allow the computerizing, interconnecting, and representing of every element of the territory, using as geometric primitive points, lines and polylines.

Vector data are called a "shape file" and this is a proprietary format for the GIS environment.

All types of data within the GIS platform are handled, displayed, and shown with a structure of overlapping layers (fig. 4), in which each layer can be used and represented separately.

GIS technologies allow the acquisition, analysis, representation, and exportation of the georeferenced spatial data with rigorous topographic approaches.

For this aim, it is evident that the GIS environment is much more advanced compared to a CAD (Computer Aided Design) and is suitable for the analysis of many local resources such as technological networks, land use, transport infrastructures, environmental assessments, and social factors; therefore it can be considered a valuable tool for decision support.

Therefore, GIS can be used as an environment to manage spatial databases (also external to the GIS software), providing a valid tool to carry out simulations with georeferenced data and to simulate risk scenarios through real-time spatial data $[6,9]$. 


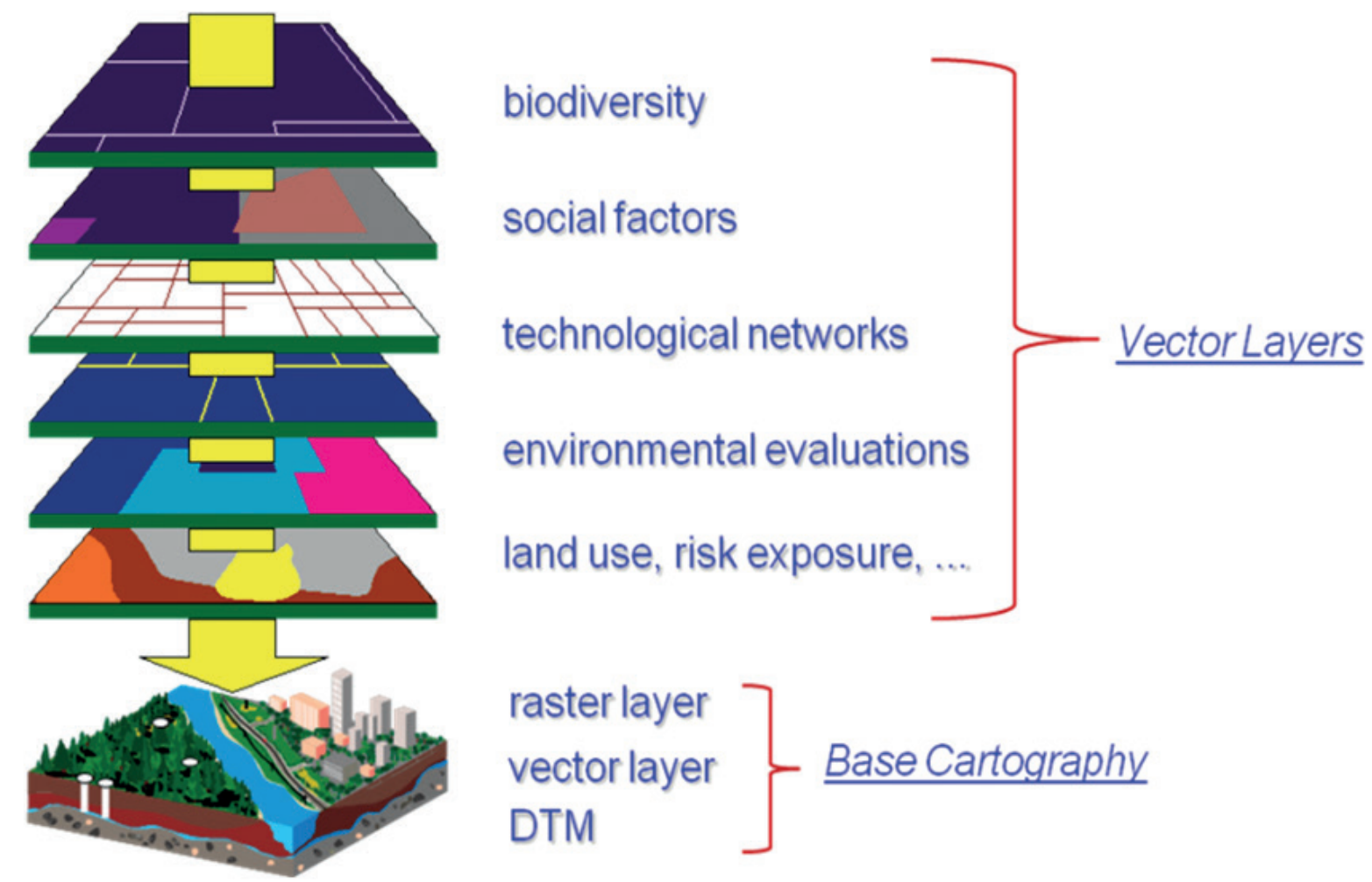

Figure 4. Types of data used in a GIS application 


\section{GIS APPLICATION TO VVITA PROJECT}

In the framework of the VVITA project, GIS technology has been used to analyze the architectural, structural, and energy characteristics of some buildings falling within the territory of Filicudi (Aeolian Islands, Sicily, Italy).

The GIS application has been developed using the free and open source geographic information system QGIS, version 2.18 [10]. As cartographic support, an orthophoto with a Datum WGS84/Pseudo Mercator was managed in the GIS environment as a Web Map Service (WMS) layer downloaded from the Cartographic Portal of the Sicily Region (fig. 5).

The different structures present in the orthophoto have been digitized as vector layers, associating a spatial database with the architectural, structural, and energetic characteristics of the buildings under examination (fig. 6).

To determine the quality indexes of the buildings digitized, we used the field calculator available in QGIS, which allows the performance of mathematical operations on the attributes related to the digitized buildings and the generatation of new fields with the calculated indices (fig. 7). Finally, the "evis_tool" QGIS plugin was used to associate photos of the digitized buildings in order to enrich the spatial database with information regarding their actual state. Indeed, the plugin allows one to insert the folder path of the images in the attribute table of each element, i.e., each record of the "buildings" table.

Therefore, once a building is queried in the GIS environment, the user can view the image relating to the actual state of the building in addition to all other information stored in the associated table.

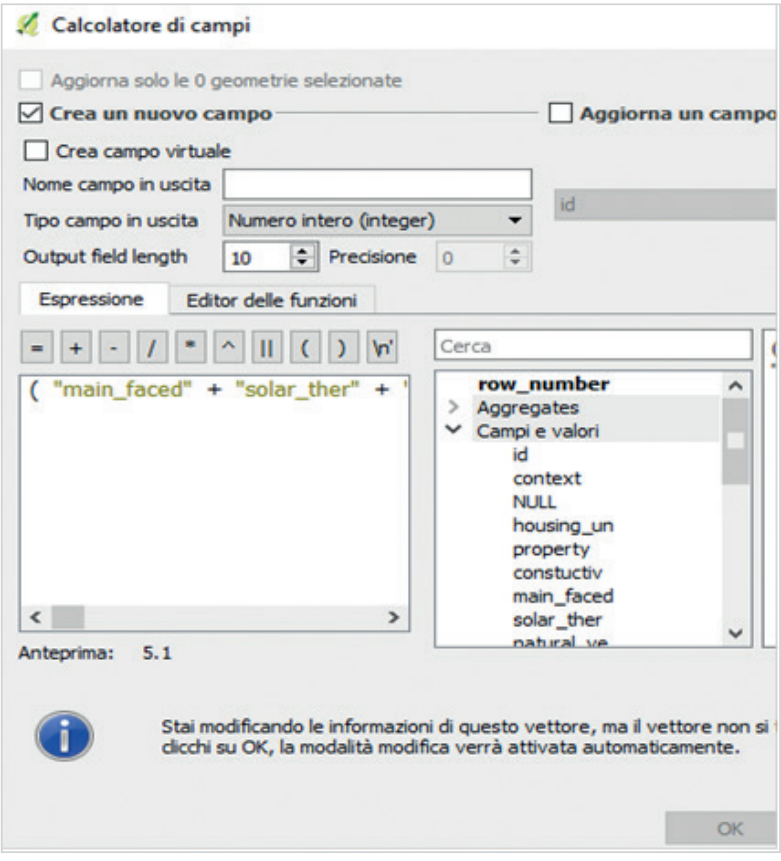

Figure 7. Fields calculator 


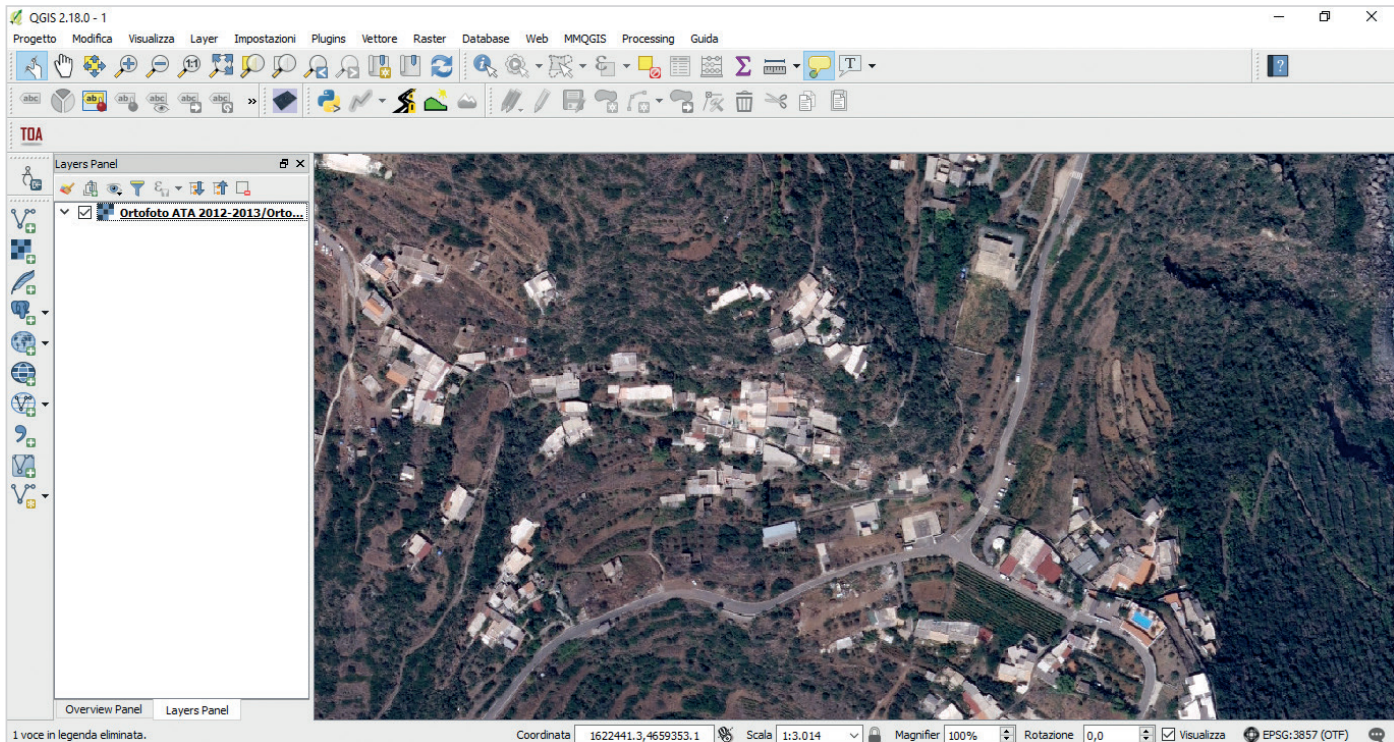

Figure 5. Orthophotos used in a GIS application

7 QGIS 2.18.0- 6.prlibro

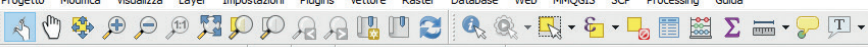

a

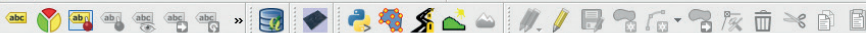

?

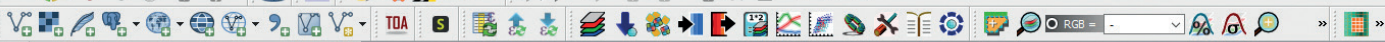
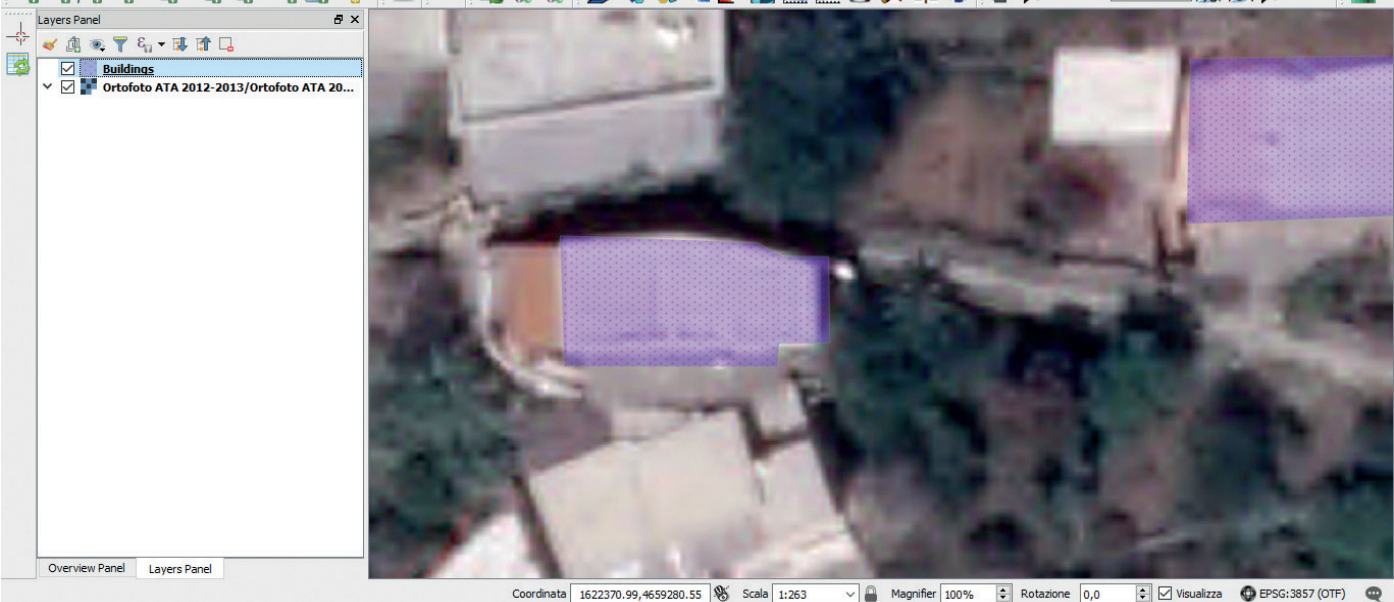

Figure 6. Building digitalized as vector layer in the GIS application 
Michele Mangiameli

Department of Civil Engineering and Architecture, University of Catania, Italy Mail: michele.mangiameli@unict.it

\section{Giuseppe Mussumeci}

Department of Civil Engineering and Architecture, University of Catania, Italy Mail: giuseppe.mussumeci@unict.it 


\section{REFERENCES}

[1] Mussumeci G. - Remote sensing and GIS notes - UNICT-DICAr

[2] Mangiameli M, Mussumeci G. GIS approach for preventive evaluation of roads loss of efficiency in hydrogeological emergencies. International Archives of the Photogrammetry, Remote Sensing and Spatial Information Sciences - ISPRS Archives. https://doi.org/10.5194/isprsarchives-XL-5-W3-79-2013, 2013.

[3] Mangiameli M, Mussumeci G. Real time integration of field data into a GIS platform for the management of hydrological emergencies. International Archives of the Photogrammetry, Remote Sensing and Spatial Information Sciences - ISPRS Archives. https://doi.org/10.5194/isprsarchives-XL-5-W3-153-2013, 2013.

[4] Mangiameli M., Mussumeci G., Roccaro P., Vagliasindi F. G. A. Free and open-source GIS technologies for the management of woody biomass. APPLIED GEOMATICS, vol. 11, p. 309-315, ISSN: 1866-9298, doi: 10.1007/s12518-01900265-8, 2019

[5] Arnulf Christl. "Free Software and Open Source Business Models", Advances in Geographic Information Science, 2008.

[6] Mangiameli M, Mussumeci G, "Real Time Transferring of Field Data into a Spatial DBMS for Management of Emergencies with a Dedicated GIS Platform". In Proceedings of the International Conference on Numerical Analysis and Applied Mathematics 2014 (ICNAAM 2014), 22-28 September 2014, Rhodes, Greece, http://dx.doi. org/10.1063/1.4912992, 2015.

[7] Mangiameli M, Mussumeci G, "A spatial DB model to simulate the road network efficiency in hydrogeological emergency". In Proceedings of the 11 TH INTERNATIONAL CONFERENCE OF COMPUTATIONAL METHODS IN SCIENCES AND ENGINEERING 2015 (ICCMSE 2015), 20-23 March 2015, Metropolitan Hotel, Athens, Greece, 2015.

[8] Mangiameli, M., Mussumeci, G., Oliva, S., "Free and Open Source GIS Technologies for the Assessment of Tsunami Hazards in the Ionic Sea ".In Proceedings of 19th International Conference on Computational Science and Its Applications, ICCSA 2019; Saint Petersburg, Russia, July 1-4, 2019, Part of the Lecture Notes in Computer Science book series (LNCS, volume 11622), pp 216-224, 2019.

[9] Mangiameli M, Muscato G, Mussumeci G, "Road network modeling in open source GIS to manage the navigation of autonomous robots". In Proceedings of the International Conference on Numerical Analysis and Applied Mathematics 2013 (ICNAAM 2013), 21-27 September 2013, Rhodes, Greece, http://dx.doi.org/10.1063/1.4825731, 2013.

[10] Lipenbergs, E., Stafecka, A., Ivanovs, G., Smirnova, I. "Quality of service measurements and service mapping for the mobile internet access",2017 Progress In Electromagnetics Research Symposium - Spring (PIERS), 2017. 


\section{Alessandro Sardella, Alessandra Bonazza}

\section{THE HERITAGE OF HAND-BUILT TERRACES IN THE AEOLIAN ISLANDS: SHARING BEST PRACTICES FOR RESILIENCE IMPROVEMENT AND CULTURAL HERITAGE PRESERVATION IN A CHANGING ENVIRONMENT}

\section{INTRODUCTION}

In recent decades, land abandonment and tourism pressure has caused a serious threat to functions and integrity of the Aeolian Islands' rural heritage landscape. Almost entirely abandoned after the second world war and extremely deteriorated because of lack of use and maintenance, terraces in the Aeolian Archipelago and their traditional techniques of cultivation represent a significant resource for strengthening the resilience of the communities of small islands to climate change impact. It is widely recognized, in fact, that the Mediterranean area is a hot spot likely to experience in the future an increase in prolonged drought periods and in frequency and intensity of events of heavy rain. Knowledge-based strategies for sustainable management in a changing environment are therefore necessary in order to improve landscape benefits in the face of increasing risks.

The present contribution aims at illustrating the activities carried out in the Aeolian Islands for recovering the historic construction techniques of dry-stone walls typical of the Aeolian terraces as a best practice of landscape maintenance to be undertaken, for strengthening its resilience to extreme events linked to climate change. These training activities follow the recommendation included in the strategic document "Elements for a National Strategy for Adaptation to Climate Change". In this framework, the first "Introductory course, theoretical and practical, for the construction of dry- stone walls typical of the Aeolian terraced landscape", organized in the Island of Lipari with the major objective of training local people on traditional techniques for the construction of dry-stone walls typical of the Aeolian landscape, is presented with reference also to geological and environmental aspects that may have an influence on the final features of the terraced landscape in small islands of volcanic origin in the Mediterranean Basin.

\section{CLIMATE CHANGE IMPACT ON CULTURAL HER- ITAGE. THE ITALIAN NATIONAL STRATEGY FOR ADAPTATION TO CLIMATE CHANGE}

In spite of the efforts addressed at the European level from the perspective of research and policy for enhancing the resilience of cultural heritage, including landscape, in a changing environment, it is widely recognized that still, further actions are necessary in order to guarantee the sustainable management and protection of built and natural environments [1]. It is widely recognized that extreme climate events cause risks to heritage assets, impacting on the preservation and conservation of their cultural, historic and artistic values, and on the safety of visitors, staff, and local communities, implying undoubtedly negative consequences for the local economies due to loss of tourism incomes. The danger is augmented in "hot spot" regions with built 
and natural environments exposed, like coastal areas and small islands in the Mediterranean Basin that are considered at a high level of risk.

It should be considered that as a consequence of climate change, an increased intensity and frequency of hydrometeorological events, such as heavy rainfall, wind storms, heat waves, and droughts, is experienced; these phenomena are driving factors in causing flooding, fires, and landslides. Our landscape is unfortunately at risk not only from a high probability of a disaster occurring, but in the majority of cases, severe damage is mainly due to the lack of preparedness in emergency situations. Particularly, abandonment and lack of maintenance are among the major causes of its vulnerability.

In addition, it should be evidenced that generally, national adopted plans on climate change adaptation still do not include specific measures for safeguarding cultural heritage and landscapes. In Europe, at the national level, only France, Italy, and recently, Ireland integrated strategies for the protection of built and natural environments into plans for adaptation to climate change. Specifically, the Italian National Strategy for Adaptation to Climate Change consists of three technical-scientific documents published in 2014, providing an updated knowledge of the impact of climate change and a strategic evaluation on the adaptation, here listed:
- Strategic document "Elements for a National Strategy for Adaptation to Climate Change" [2];

- Technical-scientific Report "State of scientific knowledge on impacts, vulnerability and adaptation to climate change in Italy" [3];

- Technical-legal Report "Analysis the EU National legislation relevant to impacts, vulnerability and adaptation to climate change" [4].

A multidisciplinary and coordinated approach has been applied for strategy development including the collaboration of different targeted stakeholders, such as the scientific community, rescue bodies (Civil Protection, Fire Brigades), and public authorities at different levels.

The process, started in July 2012 and coordinated by the Italian Ministry of the Environment and Protection of Land and Sea with the technical and scientific support of the Euro-Mediterranean Centre on Climate Change (CMCC), was supported by 232 experts and foresaw the involvement of stakeholders since the very beginning with ad hoc consultations with ministries and regions and an online public consultation with citizens from 30 October 2013 to 20 January 2014. 
The principal objectives of the strategy are as follows:

- evaluation of climate change impact on different social-economic sectors and natural systems.

- risk reduction caused by climate change.

- identification of actions for adaption.

- enhancement of the adaptation capacities of natural, social, and economic sectors.

Cultural Heritage and landscapes are taken into consideration as sectors at risk.

\subsection{ELEMENTS FOR A NATIONAL STRATEGY FOR ADAPTATION TO CLIMATE CHANGE - CULTURAL LANDSCAPE.}

The integration of existing risk management plans with preparedness strategies and evacuation plans specifically dedicated to cultural and natural heritage safeguarding, represents the principal action to be undertaken in view of a sustainable protection of heritage assets, including landscape, exposed to climate change. This can be obtained either by reviewing and tailoring the directives and plans already adopted or proposing the inclusion of new sections specifically addressed to the topic.

In the strategic document "Elements for a National Strategy for Adaptation to Climate Change", general short (by 2020) and long (over 2020) term "soft" recommendations are given for awareness raising on climate change impacts, cultural heritage vulnerability and adaptation strategies to be adopted:
- existing knowledge transferring (by 2020);

- implementation of continuous environmental monitoring of prioritized climate parameters in proximity of the heritage site at risk (by 2020);

- database creation in support of decision and policy makers at the national and regional level (by 2020);

- foster routine maintenance avoiding as much as possible invasive interventions (by 2020).

- comprehension of the environmental, economic and social context (by 2020);

- promotion of long-term financing for maintenance actions (over 2020).

Concerning landscaping assets, the safeguarding of terraced landscapes by the recovery of dry-stone walling technique is recommended as an adaptation strategy to strengthen the resilience to climate change by preventing hydrogeological instability and desertification.

Within this framework, the present contribution aims at illustrating the first "Introductory course, theoretical and practical, for the construction of dry-stone walls typical of the Aeolian terraced landscape" organized in the Island of Lipari, with the major objective of training local people on traditional techniques for the construction of dry-stone walls typical of the Aeolian landscape. 


\section{THE ENVIRONMENTAL FRAMEWORK OF THE AEOLIAN ISLANDS}

The Aeolian Islands Archipelago, also known as the Lipari Archipelago or Lipari Islands, is located in the Southern Tyrrhenian Sea at the North of Sicily and consists of seven main islands and several uninhabited islets. Lipari, Vulcano, Filicudi, Alicudi, Panarea, and Stromboli belong to the Municipality of Lipari, the largest island of the Archipelago, whereas Salina comprises the Municipalities of Santa Marina, Leni, and Malfa.

The current shape of the Aeolian Islands landscape is due to the succession of eruptive activity over 250,000 years. From a geological point of view, the Aeolian Islands are defined as a Volcanic Arc and represent the most active volcanic structure in the Mediterranean area, including active (Stromboli and Vulcano) and dor- mant (Panarea and Lipari) volcanoes, together with extinct ones. Active/dormant volcanoes are in the central (Vulcano and Lipari) and eastern (Stromboli and Panarea) sector of the archipelago. By contrast, no historical eruptions are recorded in the western side of the archipelago [5]. The islands of the archipelago exhibit strong structural, volcanological, and petrological variations. Lava flows, lava domes, scoriaceous deposits, and hydromagmatic pyroclastic products characterize the volcanic activity of the islands.

Products are extremely variable from a compositional point of view from basalt to rhyolite. Providing an outstanding field for volcanological studies of ongoing geological processes in the development of volcanic landforms, the Aeolian Archipelago has been listed in the World Heritage List of UNESCO since 2002.

The islands have been well known since the

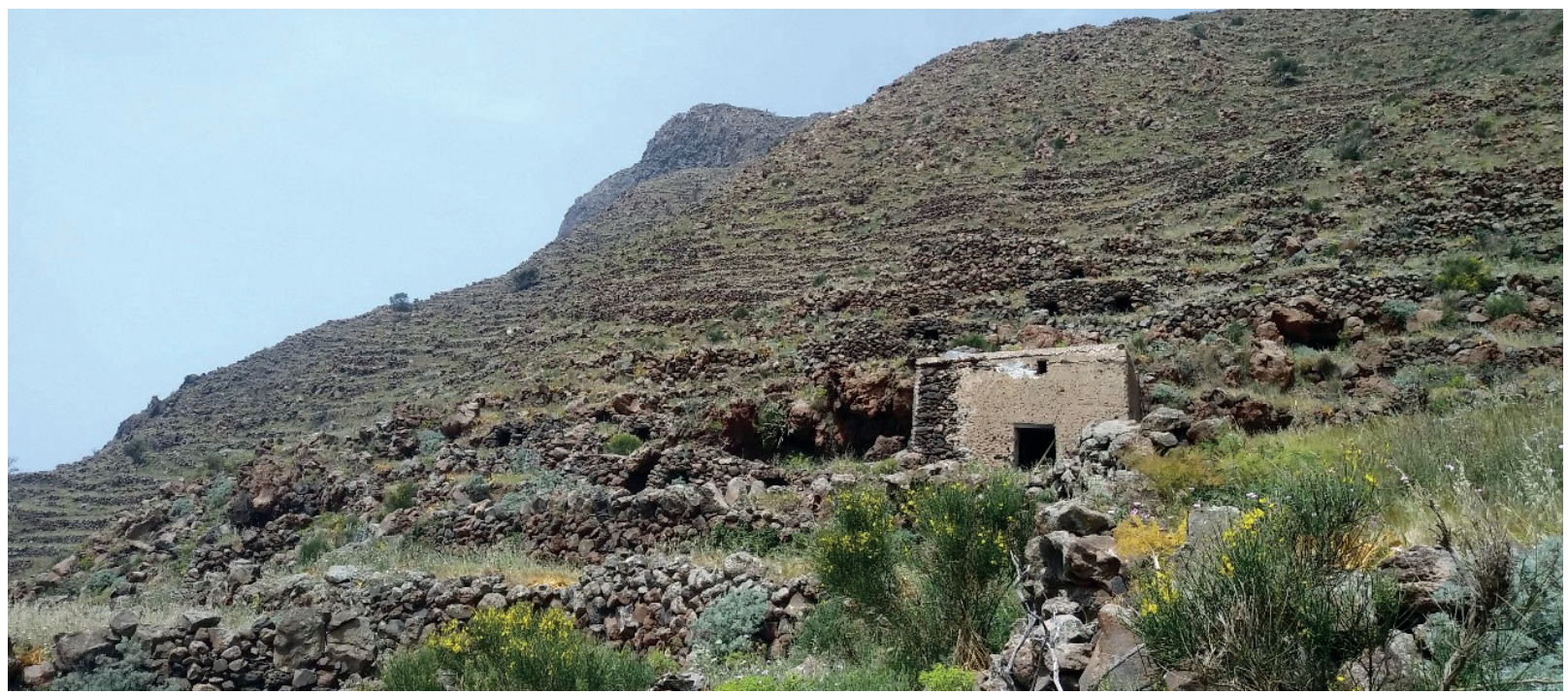

Figure 1. The typical historic terraced landscape of the Aeolian territory: an example of agriculture dry-stone walls system in Alicudi Island (Photo by A. Sardella) 
prehistoric time (4.000 B.C.), thanks to its strategic geographical position in the Mediterranean and also to the presence of obsidian, a volcanic glass from lava flow enriched in silica erupted in Lipari [6].

The human presence on the islands determined the start of the use of land for subsistence with the practice of agriculture and pastoralism. The first builders of dry-stone walls, named Eoli, arrived on the Aeolian Islands from Aegean.

They constructed artificial terraces to create arable areas supported by high stone walls. The new technique of wall construction in dry-stone replaced the fragile huts made of reeds. Remains of prehistorical huts, dry-stone built, are present in the archaeological sites of Stromboli, Salina, Filicudi, and Panarea [7].

Actually, terraces are distributed in almost all the islands, with the exception of Vulcano [8]. Terraced areas in Lipari are distributed patchier and the islands of Alicudi, Filicudi, Salina, and Panarea are almost entirely terraced with the exception of land composed of loose substrates (skiing) and cliffs (Fig. 1). In Vulcano, the almost total absence of terraces is due to the last eruption in 1888-1890, which determined the abandonment of large parts of cultivated terraces.

Highly inhabited and extensively cultivated (olive tree, wheat, barley, caper plant, legumes, citrus tree, vegetables, etc.) since the middle of the XX century, terraced cultivated areas were almost abandoned in 1950-1960, reaching currently 90\% [8]. The progressive abandonment of agricultural activity and the lack of maintenance of dry-stone walls implied consequently a severe damage to the landscape [9].

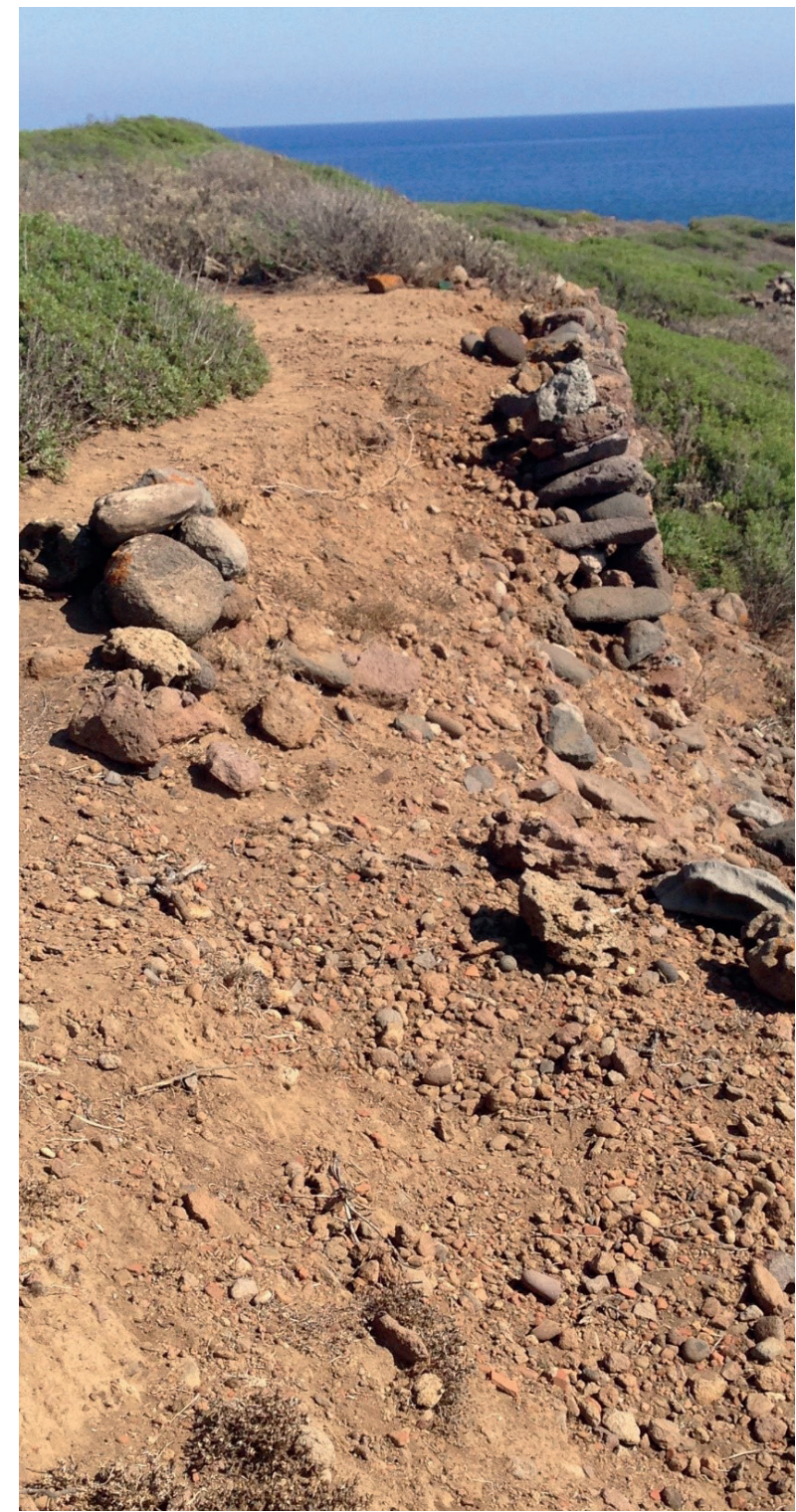

Figure 2. An example of collapsed dry-stone wall in the Island of Filicudi. (Photo by A. Sardella) 
Deterioration of dry-stone walls, as a consequence of abandonment, in the islands is mainly determined by:

- increase in spontaneous growth of vegetation that causes destabilization of the wall (dislodging and collapsing of single stones);

- dislodging of top stones by the action of large animals;

- erosion by rain and wind, particularly during extreme events of rain;

- fire, particularly during prolonged drought periods.

Figure 2 shows an example of a dry-stone wall collapsed in the island of Filicudi.

\section{INTRODUCTORY COURSE, THEORETICAL, AND PRACTICAL FOR THE CONSTRUCTION OF DRY - STONE WALLS TYPICAL OF THE AEOLIAN TER- RACED LANDSCAPE}

The course, funded by the Aeolian Island Preservation Fund (AIPF), took place in Lipari from 17 to 21 April 2018 and consisted of theoretical and practical sessions, including the construction of a real dry-stone wall in situ, conducted under the coordination of professionals in environmental science, building technologies, biodiversity, geology, archaeology, and craftsmen expert in traditional building techniques. It was structured to allow the participants to take advantage of an action learning process on significant and peculiar aspects of territorial identity.

The exchange of knowledge and experience was addressed mainly to recover in- tangible aspects of rural heritage and contribute to the sustainable maintenance and environmental protection of landscape from the environmental, social, and economic point of view.

The course aimed to train artisans capable of carrying out the important work of ordinary and extraordinary maintenance of existing ruined masonry or to build ex novo dry-stone walls following traditional construction techniques, researching and choosing the equipment, the materials, and the products needed.

The activities and the results of the project interested local residents, farmers, craftsmen, unemployed persons, voluntary associations, and experts of the academic and scientific community. A total number of fifteen participants (fourteen males and one female) with ages ranging from 20 to 80 attended the course. Almost $50 \%$ of the participants were unemployed, while the rest of the members came from the tourism, research, and agriculture sectors.

The course lasted 5 days, with classroom lectures and practical sessions. Classroom lectures focused on the environmental, rural, and cultural values of the dry-stone walls of the terraces in the Aeolian Archipelago; landscape protection and conservation; climate change and related risks on the natural environment; building construction techniques of dry-stone walls (basics of static and stability of walls, analysis of materials and their application, sizing site, types of building materials and equipment); management of safety in situ.

Guided excursions on historic terraces in the Islands, where the construction technique of the traditional dry-stone walls is particularly representative, were a fundamental part of the course, as well as the visits on 
the Island of Filicudi to: 1) the archaeological sites of Filo Braccio and Capo Graziano and 2) the areas of "Monte Torrione" and "Filicudi Porto", considered examples of "Best Practices" [10]. These areas underwent, in 2015, a significant intervention of recovery of damaged dry-stone walls by the use of traditional building techniques, thanks to the support of the Regional Rural Development Plan of the Sicily Region.

The practical activity was based on the restoration and construction of a dry-stone wall in an area in Lipari through the following activities under the guide of experienced craftsmen: setting the work, preparation of the site area, selection of suitable stone, stone working with traditional tools, and method of laying the stones.

The main phases of work conducted during the practical session of dry-stone wall building are listed below:

- cleaning and preparation of the reconstruction area with movement of the crumbled stones to the recovery area and separation of the big stones from the small ones to facilitate the reconstruction of the new wall;

- preparation of guides to regulate the slope of the wall (10-15\%), as shown in Figure 3;

- excavation of the foundation trench, basement compaction, and realization of the first layer positioning the larger stones;

- placement and embedding of stones following their natural shape;

- internal filling with small-sized stones, Iocally named minutame (Fig. 4);

- layering and leveling (Fig. 5).

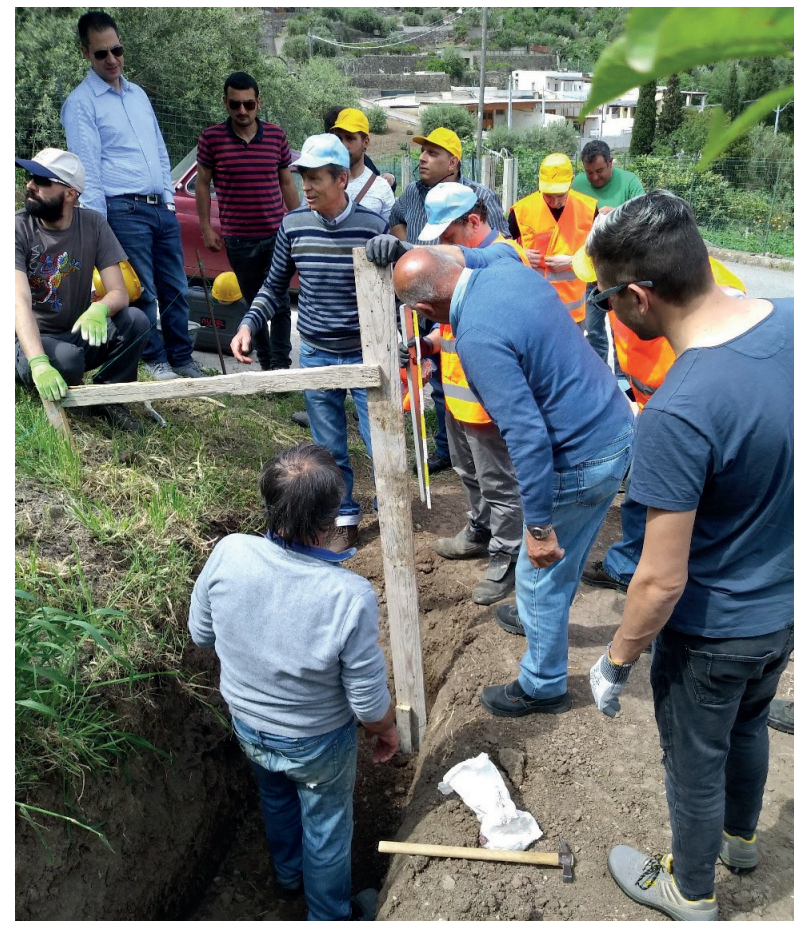

Figure 3. Master builders showing how to prepare guides for regulating the slope of the wall before its construction (Photo by A. Sardella)

The equipment utilized consisted of pickaxes, shovels, iron poles, buckets, wheelbarrows, lines, and planks.

\section{CONCLUDING REMARKS AND FUTURE PERSPECTIVES}

Geomorphological features of the Aeolian Islands determined over time the distribution of human settlements, empowering better use of landscape for the survival of the community. One of these landscape modelling techniques was, since ancient 


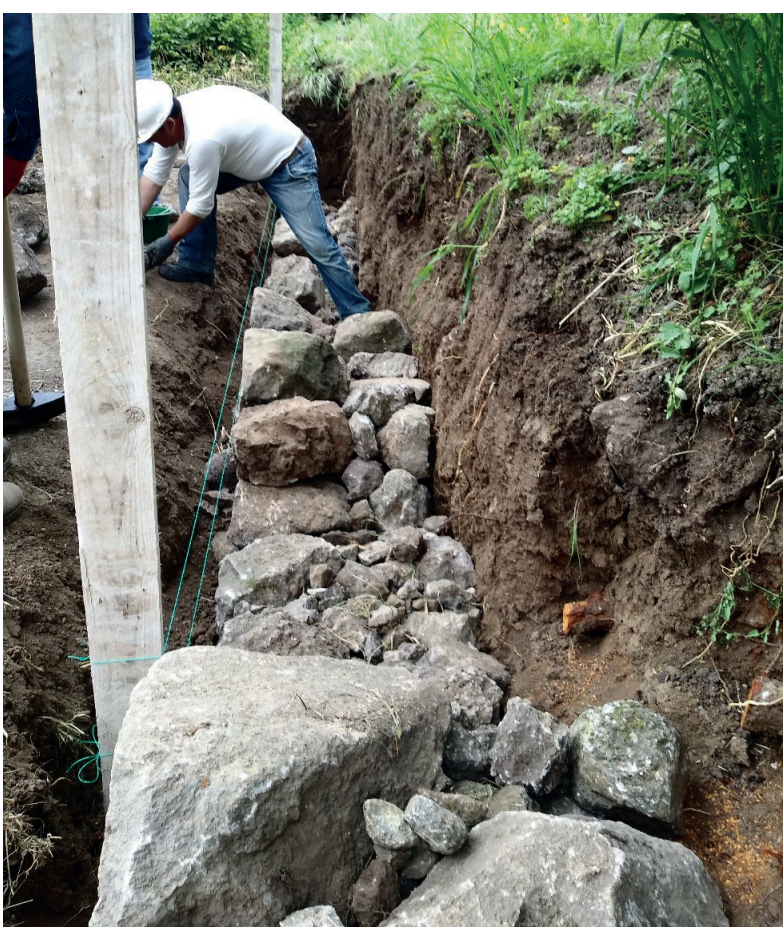

Figure 4. Practitioners positioning the drainage internal filling of the wall with smaller stones. (Photo by A. Sardella)

times, the construction of terraces on these inhospitable volcanic lands by realizing dry-stone walls to contain soil and obtain arable lands. Terraces are recognized of primary importance for the strengthening of landscape resilience to climate change, playing a key role in preventing landslides and floods, improving slope stability, striving against land erosion and desertification, heightening biodiversity, and generating adequate microclimatic conditions for agriculture. This is the leading reason of the recent inscription (2018) in the List of Intangible Cultural Heritage of UNESCO of

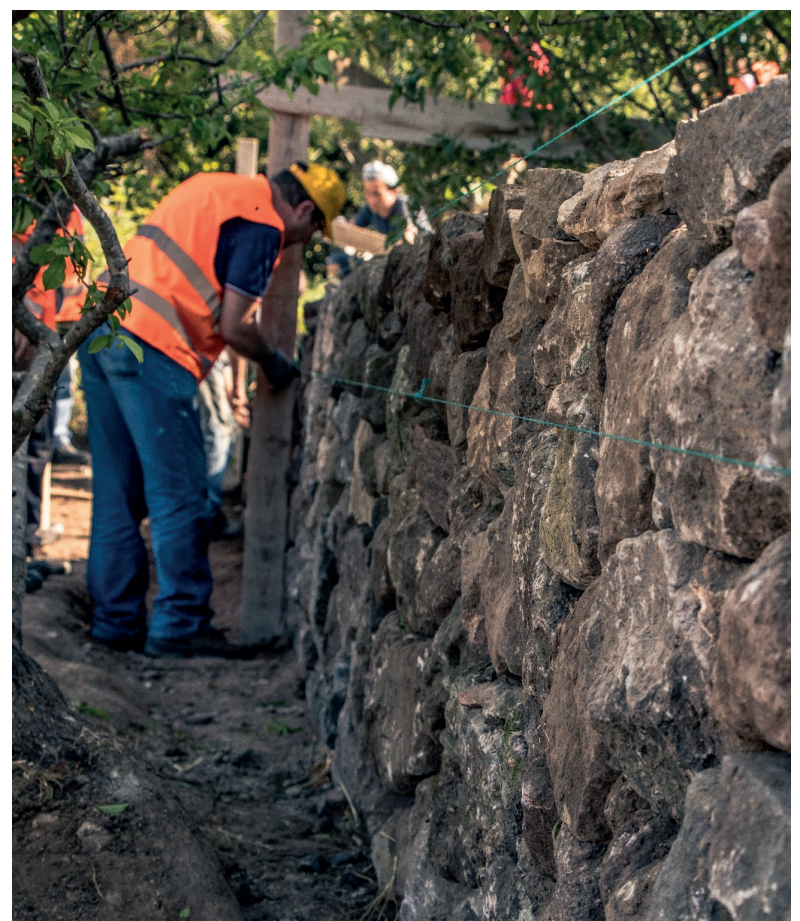

Figure 5. Final phase: layering and levelling phases. (Photo by G. Taranto)

the art of dry-stone walling knowledge and technique, which should kept alive and transmitted to future generations also by performing courses like the one described within the present contribution.

Such courses will contribute either to boost agricultural activity by recovering the cultivation of the products of the past, as a potential resource for the social and economic development of the Aeolian territory, and to protect the territory and the cultural landscape by creating new professional skills and the retraining of craftsmanship in danger of extinction. In addition, they will 
facilitate the promotion of maintenance of the existing terracing, improving consequently the resilience of the Aeolian landscape to climate change.

The overall objective is to create a continuous activity of training and capacity of building over time involving local stakeholders aiming at:

- keeping alive a traditional craft in danger of extinction, characterized by high professionalism and quality of the products;

- encouraging generational turnover, through the transfer of skills acquired by craftsmen during their professional experience;

- giving participants the opportunity to obtain placements, ensuring the necessary tools and theoretical and practical skills;

- encouraging the creation of craftsmen small enterprises (SMEs);
- providing more cultivable land surfaces for the development of sustainable agriculture:

- protecting and enhancing the rural landscape as a leading resource for the promotion and improvement of local economic development;

- improving the hydrogeological features of the area.

A future step is to create the necessary expertise that will be acquired for the creation of an Aeolian Rescue Team for the recovery and maintenance of dry-stone walls on abandoned terraces with a high degree of deterioration. Educational initiatives for scholarships and citizens are also planned in order to increase awareness of the significance and value of cultural landscapes.

\section{Alessandro Sardella \\ Institute of Atmospheric Sciences and Climate, National Research Council, Italy Mail: a.sardella@isac.cnr.it}

\section{Alessandra Bonazza}

Institute of Atmospheric Sciences and Climate, National Research Council, Italy Mail: a.bonazza@isac.cnr.it 


\section{REFERENCES}

[1] Bonazza A., Maxwell I., M. Drdácký, Vintzileou E., Hanus C., Ciantelli C., De Nuntiis P., Oikonomopoulou E., Nikolopoulou V., Pospísil S., Sabbioni C., Strasser P., Safeguarding Cultural Heritage from Natural and Man-Made Disasters - A comparative analysis of risk management in the EU. Corporate Author(s): Directorate-General for Education, Youth, Sport and Culture (European Commission). ISBN 978-92-79-73945-3, (catalogue) NC-05-17-059-EN-N. DOI:10.2766/224310. 2018.

[2] Castellari S. et al., Elementi per una Strategia Nazionale di Adattamento ai Cambiamenti Climatici. Ministero dell'Ambiente e della Tutela del Territorio e del Mare, Roma, 2014a, 239 p. ISBN 9788887728071, 2014, (in Italian).

[3] Castellari S. et al., Rapporto sullo stato delle conoscenze scientifiche su impatti, vulnerabilità ed adattamento ai cambiamenti climatici in Italia. Ministero dell'Ambiente e della Tutela del Territorio e del Mare, Roma, $2014 \mathrm{~b}, 878$ p. ISBN 9788887728095, 2014, (in Italian).

[4] Castellari S. et al., Analisi delle normative comunitaria e nazionale rilevante per gli impatti, la vulnerabilità e l'adattamento ai cambiamenti climatici. Ministero dell'Ambiente e della Tutela del Territorio e del Mare, Roma, 2014c, 155 p. ISBN 9788887728088. 2014, (in Italian).

[5] Lucchi F., Peccerillo A., Keller J., Tranne C.A., Rossi P.L. (eds.), The Aeolian Islands Volcanoes, Geological Society Memoir No. 37, The Geological Society, London (UK), 2013.

[6] Martinelli M.C., Le isole Eolie al centro del Mediterraneo 4000 anni fa, in Eolie Arcipelago Unesco, collana Le Sicilie, Erre produzioni ed., Siracusa, 2016, (in Italian).

[7] Martinelli M.C., Isole Eolie. Filicudi nell'età del Bronzo, Assessorato beni Culturali e dell'Identità siciliana, Palermo. 2015, (in Italian).

[8] Barbera G., Cullotta S., Rossi-Doria I., Ruhl J., Rossi Doria B., I paesaggi a Terrazze in Sicilia: metodologie per l'analisi, la tutela e la valorizzazione, Collana di Studi dell'Agenzia Regionale per la Protezione dell'Ambiente V. 7, Regione Sicilia, Palermo, 2009, (in Italian).

[9] Tarolli P., Rizzo D., Brancucci G., Terraced Landscapes: Land Abandonment, Soil Degradation, and Suitable Management, in World Terraced Landscapes: History, Environment, Quality of Life, Springer, 2019.

[10] Sardella A., Bonazza A., Dalla lava ai muri in pietra a secco: il paesaggio terrazzato delle isole eolie. In "Paesaggi Terrazzati: scelte per il futuro. Terraced Landscapes: choosing the future". Ed. Regione del Veneto. PP 164-170. ISBN: 9788890880551, 2018, (in Italian).

[11] "Art of dry stone walling, knowledge and techniques " [Online]. Available: https://ich.unesco.org/en/RL/art-of-drystone-walling-knowledge-and-techniques-01393

[12] "Aeolian Islands - UNESCO World Heritage Centre" [Online]. Available: https://whc.unesco.org/en/list/908

[13] "Elementi per una Strategia Nazionale di Adattamento a Cambiamenti Climatici" [Online]. Available: http://www. minambiente.it/sites/default/files/archivio/allegati/clima/snacc_2014_elementi.pdf (in Italian). 

STUDENT CONTRIBUTIONS 


\section{THE "CONTROLLED TRANSFORMATION" OF VERNACULAR ARCHITECTURE}

Students, divided into six groups, were called to carry out a design intervention on one or more abandoned buildings, in six different contrada of the island of Filicudi. Each of these buildings was revitalized by assigning different functions at the service of both the local and touristic community. The functions are the following:

- typical agri-food products shop;

- art center and art gallery;

- Infopoint;

- research laboratory and observation point; - public library and community center;

- wellness and medical center.

The methodological approach suggested by the staff team has addressed the students towards multidisciplinary analyses aimed at understanding the features of the island's architecture.

Students focused on landscape and morphological aspects, on materials and their mechanical performance, on energy performance, and on passive building behavior.

As showed before, these data were uploaded in an innovative tool to achieve a quantitative measure of the quality of local building heritage.

This approach has certainly generated a conscious reading of the deep bond between Aeolian landscape and vernacular architecture. Here, over the centuries, building materials have been not only lava stones, wood, and the Arundo Donax (local river reeds), but also what Hiroshi Sambuichi calls "moving materials" [1], i.e., wind, solar radiation, rain, and all the natural phenom- ena that make each landscape unique.

One of the main goals of all the projects has been the insertion of flexible community functions linked to the fact that the inhabitants living on the island in winter are not the same as those living there in the summer. The inhabitants of the island change not only in number but also in needs, ways of life, and employment. Therefore, the agri-food shop, in winter, becomes a grocery; the Infopoint becomes a municipal delegation, and so on. The seasonality of use of the spaces allows the inclusion of users among the moving materials, with their presence and changing needs as the seasons change.

Students' projects have accurately used these "moving materials" for the new interventions, integrating them into the following different design approaches:

- consolidation of the ruins in order to preserve their testimonial value;

- reconstruction of the ruins by proposing traditional volumes and construction processes;

- reconstruction or addition with contemporary languages and technologies.

In any case, they are based on "controlled transformation" [2], i.e., an approach that seeks to find the right balance between the need to reconfigure the building to adapt it to contemporary performance standards 
and the need to preserve the shape and materials of the existing buildings. In the three design approaches, the aesthetic morphological designs vary between the extremes of "continuity" and "contrast" with the existing building, in relation to the critical analysis that is carried out on the pre-existence, the overall design vision, and the sensitivity of the design choice [3]. In new designed interventions, the use of contemporary materials in contrast with those of the building tradition is generally preferred to mark the recognition of the intervention. The technologies used for the construction of new components are characterized by characteristics of lightness and reversibility, in order to create appropriate construction systems compatible with the existing one.

The typological element that most stimulated the project ideas was definitely the baggio, an open shaded space in front of the buildings, traditionally used as the main work and convivial space. This characteristic of flexibility and representativeness has been reinterpreted by the students by creating lightweight steel structures, seasonal temporary pavilions, and kinetic shading devices. All solutions have combined maximum flexibility with adaptability of use and reversibility of intervention.

These projects demonstrate how vernacular architectures can still meet the needs of contemporary living with the inclusion of a few controlled design interventions, while maintaining their character of testimonial value of the place where they arise. The didactic activities have been communicated by an exhibition and some videos posted in the Social [4-6].

\section{REFERENCES}

[1] Sambuichi H., Architecture of the Inland Sea, Tokyo: Toto; 2016.

[2] Malighetti L.E., Methodologies and strategies for small town centres regeneration. Architecture between tradition and innovation: the Swiss architects case study of Wespi de Mueron Romeo Architetti. TECHNE 2016; 12: 112-121.

[3] Zordan L., Tipo, Tecnica e progetto nella conservazione dei tessuti storici. In: AA.VV. Le tradizioni del costruire in pietra: materiali, tecniche, modelli e sperimentazioni. L'Aquila: Gruppo Tipografico Editoriale; 2002, (in Italian).

[4] VVITA - ATM [program] https://www.youtube.com watch? $v=m S U Q c x a F 93 g \&$ feature=youtu.be

[5] VVITA - ATM [students] https://www.youtube.com/ watch? $v=+$ DeQOPIzB7o\&feature=youtu.be

[6] VVITA - ATM [academic staff]

https://www.youtube.com/

watch? $v=$ XixrdDOxU2s\&feature=youtu.be 


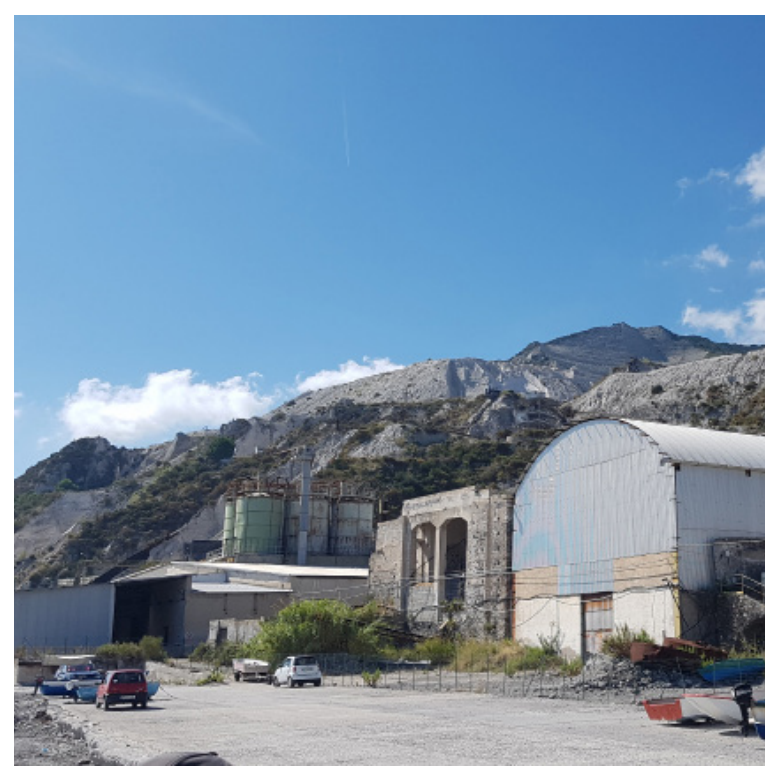


INTRODUCTION TO THE ARCHIPELAGO

THE PUMICE QUARRIES OF LIPARI

MONTELEONE_Angelo_PhD Student at UNICT

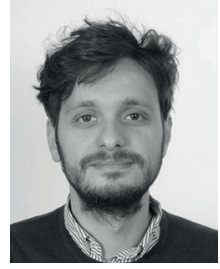

\begin{abstract}
The Aeolian Islands, due to their volcanic origin, are rich in obsidian and pumice stone. This immense geomorphological heritage has for years been seriously threatened by the effects of human activity, to the point of altering the delicate natural balance of the island. In fact, during the nineteenth century, Lipari was the protagonist of an important industrial development process linked to the extraction of pumice stone. In the 2000s, however, the peculiarities of flora, fauna, and landscape determined the recognition of the Aeolian Islands as a world heritage site. With the blocking of every form of mining activity, the reuse of buildings destined in ancient times for mining and production activities would be an opportunity for development and development for the island.
\end{abstract}




\section{INDUSTRIAL ARCHAEOLOGY}

Industrial Archaeology (IA) was born in England about sixty years ago thanks to a statement by Michael Rix, with which he tried to address attention to industrial abandoned areas. Between 1950 and 1960 , the interest in this subject grew, starting from the case of the demolition of Euston station in London. Thanks to this, the importance of the recovery and revaluation of IA, to be considered historical heritage of the period relative to the first English industrial revolution, has emerged. Some cases followed, such as the Iron Bridge over the River Seven, which was declared a national monument and is now included in the UNESCO World Heritage List. However, the $B B C$ journalist Kenneth Hudson was one of the first to make a significant contribution, spreading the culture of IA with his work, as a real discipline [1].

Twenty years later, the movement became a subject of interest also in Italy, having been introduced to the International Congress held at the Rotonda della Besana (Milan), in the San Leucio exhibition: Archaeology, History, and Project. Moreover the birth of the Italian Society for Industrial Archaeology followed, with the aim of census cultural assets and industrial heritage [2]. IA could be considered a complex discipline, which starts from the interest in buildings that are protagonists of the Industrial
Revolution. In Italy, IA is more articulated because the development in production processes, especially in southern Italy, was linked to obsolete methods.

Large factories, processing plants, and buildings connected to mining activities and to the production process, still in use until the 1990s, are evidence of fundamental importance of the industrial era. The slow process of modernization involved in the southern regions and Sicily made these areas protagonists in the production and export of raw materials, closely related to the specificities of the places. However, the appearance of areas was considerably conditioned by the activity of the large plants linked to mining activities, characterized by a low level of mechanization. These are likewise comparable to the great industries of northern Europe and how they take on a significant importance within a cultural and historical path of a territory. One of these is the case of the pumice quarries and mills of Lipari, which in the last two hundred years have represented a fundamental piece for the economy and the appearance of the island. A few decades after their divestment, they have become opportunities for the development of the territory. 


\section{THE AEOLIAN ISLANDS}

Located about $90 \mathrm{~km}$ from the northeast coast of Sicily, less than 12 miles from Capo Milazzo, the Aeolian archipelago has seven large islands (Lipari, Vulcano, Salina, Stromboli, Filicudi, Alicudi, and Panarea) and five minor ones ( Basiluzzo, Dattilo, Lisca Nera, Bottaro, and Lisca Bianca), born from the succession of 12 eruptive vents referable to the same geological history [3]. Administratively, the archipelago belongs to the province of Messina and is divided into four municipalities - Lipari, Santa Marina Salina, Leni, and Malfa - counting a total population of 15,000 inhabitants spread over an area of about 115 square kilometers (11,500 ha). Lipari, formerly known as "Meligunis", is the largest and most populous with an area of 376 square kilometers, almost a quarter of the extension of the entire archipelago. Since the Neolithic period, the Sicilian islands have always been inhabited and nowadays, they represent very important evidence of the evolution of prehistoric populations. In fact, over the years, the same geographical position of the Aeolian archipelago allowed their population by several peoples who, animating the routes of the Mediterranean Sea, used them as a landing place or as a basis for trade in materials. Therefore, they played a strategic role until the first Punic war. After centuries of growth, alternated with cours- es of domination by settlers, in the last 200 years, the entire archipelago experienced a long period of development, closely connected to the economy that affected its fate. However, repopulation and economic development do not always coincide with the enhancement of the territories. After the Italian unification, governments that succeeded until 1945 had little interest in the economic progress of the smaller sicilian islands, experimenting in some of these new forms of imprisonment.

Meanwhile, the uncontrolled exploitation of territories for the excavation of minerals has led to an accelerated process of natural degradation, defacing the lands of every form of rare living species and completely gutting the landscape of every extractable and marketable material.

Lipari is divided between the urban center of Lipari and the hamlets, extending administratively over five of the seven islands of the archipelago: Alicudi, Filicudi, Vulcano, Panarea, and Stromboli. The urban center extends between the small flat areas close to the two main peaks and into two wonderful inlets on the sea, "Marina Lunga" and "Marina Corta". 
The island, like the rest of the archipelago, has volcanic origins and its morphology derives from the activity of twelve volcanoes over a million and a half years. The territory, rich in obsidian and pumice stone, a characterizing element of its geomorphological heritage, has for years been seriously endangered by the effects of human activity, to the point of distorting the delicate natural balance of the island [4]. Precisely, the extraction of minerals has characterized the history of the island since the 5th millennium BC, when the initial documented activities had already begun. At the time, pumice stone found considerable use in the abrasion of axes and fishing tools, while obsidian was used to make cutting tools. In later centuries, especially in Roman times, pumice was used mainly in construction as a light material for vault construction. During the sixteenth century, the exploitation activities of the pumice quarries grew to a real business, encouraging the start of small exports to Tuscany, Campania, and Marseille. In the eighteenth century, the opportunities offered by the growing market soon attracted the interest of investors from all over Europe, leading to a significant increase in exports from 500 to 700 tons per year. Despite the important commercial volumes of the island, so much to be defined by Deodat De Dolomieu in 1781 as "the immense warehouse that supplies the pumice to all of Europe", the main source of livelihood was still based on agriculture, for the production of Malvasia and raisin wines, capers, and dried figs [5].
The industrial pumice exploitation developed in 1825, when the Marquis Vito Nunziante, owner of a concession for sulfur, alum, and boric acid mines at Vulcano, received an authorization for the exclusive exploitation of pumice quarries from Lipari, a product destined for the markets of England, the United States, and Russia. Despite this, in the first years of exploitation, the extraction process was mainly characterized by rudimentary methods and the excavators used to sell the material to the captains of the sailing ships, who subsequently resold it in various ports of Italy and France. Towards the end of the century, some foreign companies promoted the construction industrial production facilities. Therefore, in 1884, an effective regulation was drawn up for a fee on the pumice stone that was extracted from the quarries of the state property. Unfortunately, the regularized activity slowed down due to the impracticability of state property being usurped. Moreover, the monopoly request for the excavation firstly by Barthe, later by the Eolia Society, and afterwards by Theodor Haan of Dresden, proved to be unsuccessful also because of continuous disputes with the municipality [6].

With the crisis of 1929, the Liparese market also suffered a severe blow, with a great reduction in exports. In 1935, a new danger emerged due to the choice of some Aeolian industrialists to concentrate their investments in the Yali pumice quarries in Greece, where greater product purity and lower labor costs ensured higher profit margins. 


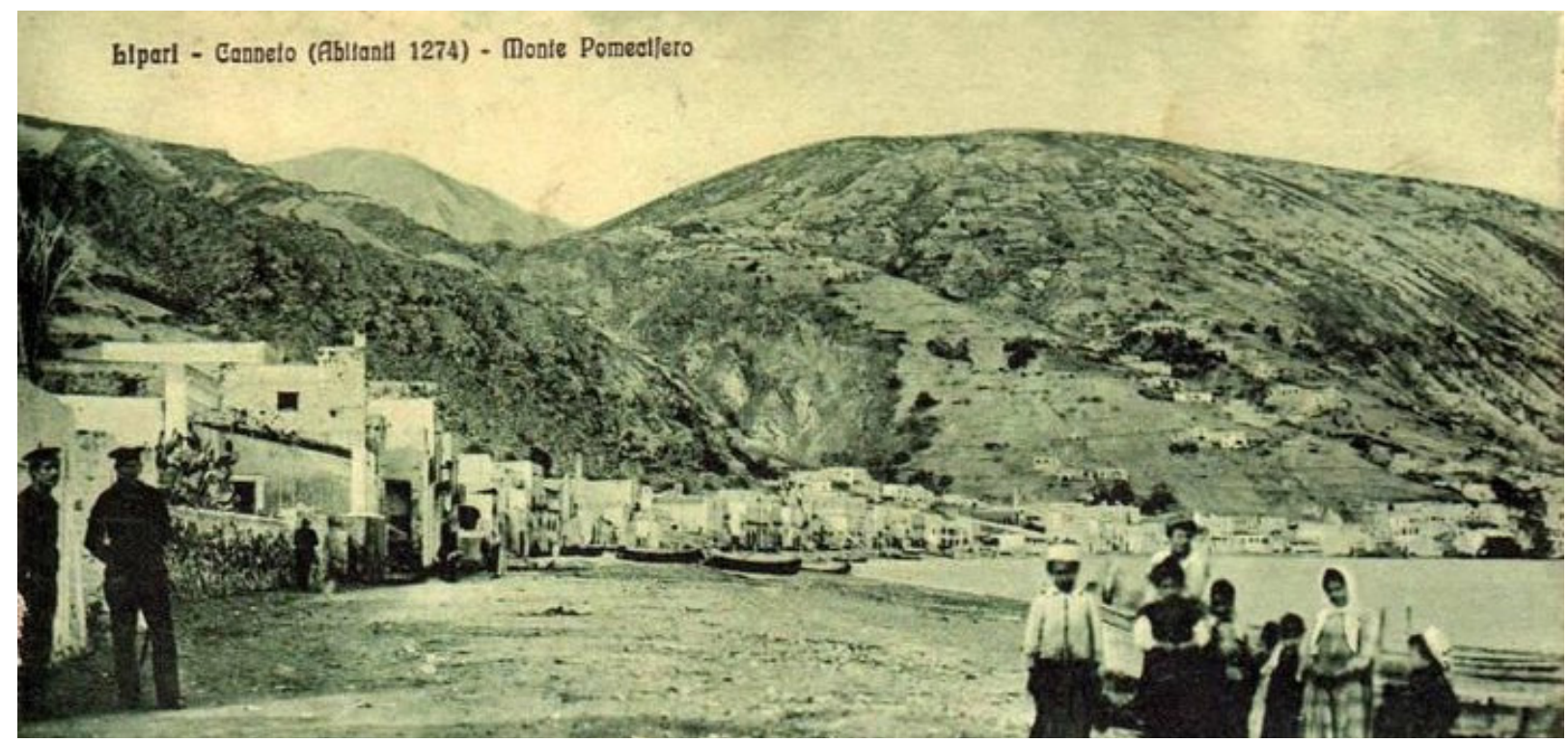

Figure 1. UNESCO - Canneto, Lipari. 1924 [6]

Table 1. Main companies related to the extraction and trade of pumice of the XX century [7], [8] COMPANY NAME

SALTALAMACCHIA DIETRICH COMPANY ACTIVITY

GEOFFRAY E JACQUET COMPANY

Pumice industry

CARBONE GIOV. COMPANY Pumice trade

RHODES H. JAMESS E C. Pumice industry

RODRIQUEZ FERDINANDO

Pumice industry

TH. FERLAZZO COMPANY

Connected to pumice quarries

ANGELO D'AMBRA COMPANY

Pumice trade

SAN CRISTOFORO COOPERATIVE

Pumice industry

ITALPOMICE

EOLPOMICE COMPANY

G. RESTUCCIA \& CO.

Pumice industry

Pumice industry

Pumice industry

Pumice industry

PUMEX SPA

Pumice industry 
The economy of Aeolian pumice stone started again from 1950, with the updating in extraction methods through mechanization. However, the excessive parceling represented a strong limit for real growth, as the island had a total of 40 small individual companies.

The rationalization of industrial processes, starting with the gradual acquisition of all mining activities by Pumex SpA, has allowed it to reach huge growth margins since 1968 , allowing it to gradually acquire all the other companies.

Until the end of the century, the process of extracting pumice has continued to represent the leading sector of the economy of the island. It has been affected by significant changes over time, dictated by the evolution of applicable technologies but also by the socioeconomic conditions of the island, such as influencing the availability of manpower. Primarily, three main types of extraction - quarrying, cutting, and tunneling - could be identified [9]. Instead, before the definitive cessation of the extraction activities, the process took place by using bulldozers for the excavation of the promontory from the top to the bottom, with the definition of horizontal planes. The extracted material was pushed into hoppers made in the body of the mountain itself and from the bottom of which, through special unloading mouths, this precipitated on conveyor belts which conveyed it to the production channels. Finally, here, a first granulometric selection was made of the material (large stones, granules, lapillus pumice). At the excavation and supply of the pumice, it was followed by its grinding and subsequent drying in rotary cylindrical furnaces, the use of cyclones to break down dust, the sieving and the granulometric classification of the material through the use of tumblers, discharging inside the bags, and finally, the boarding and the sale of the finished products. Different types of pumice stones, bastardoni, fiori, alessandrina, rasaglia, limata, pezzame, granules etc., can be defined [9]. The evolution of the industrial facilities and production systems goes from the adoption of old flat plate ovens to modern drum dryers or even complex drum suction equipment introduced later in order to reduce dust and reduce the risks of silicosis. Therefore, intense mining activity has encouraged the growth of human settlements, but it has also caused significant transformations in the areas concerned, specificalIy in the extreme northern and northeastern sector of the island. The human activities, with their high environmental impact, have not only modified the morphology of the places but have altered the layout of the sea and of the beach areas falling within the original sites of the quarries. The rehabilitation of these degraded areas is extremely important, with interventions aimed at preserving and safeguarding the scientific and cultural value of the mineral resources present, as well as evidence of past mining activity and, the recovery of the neighboring beach areas to restore their use. 
All these aspects, together with the integrity of the flora, fauna, and landscape, determined the acknowledgment of the Aeolian Islands as a World Heritage Site, with inclusion in December 2000 to the list of sites recognized and declared by UNESCO. The inscription was strongly influenced by the evaluation carried out by the IUCN International Union for Conservation of $\mathrm{Na}$ ture and Natural Resources:

"The islands' volcanic landforms represent classic features in the continuing study of volcanology world-wide. With their scientific study from at least the 18th Century, the islands have provided two of the types of eruptions (Vulcanian and Strombolian) to volcanology and geology textbooks and so have featured prominently in the education of all geoscientists for over 200 years. They continue to provide a rich field for volcanological studies of on-going geological processes in the development of landforms. The area also has a long history of land use, and subsequent abandonment, which has led to an on-going processes of maquis recovery" [10].

Registration for the World Heritage List was validated by UNESCO on 12/2/2002 in Cairns, Australia. Among the various points of the document, however, great concern emerged for the effects on the territory determined by the extraction of the pumice, as reported in point 4 "Urges the State Party to prohibit expansion of pumice extraction, as it may impact on the values for which the site was inscribed on the World Heritage List" [11], the continuous call, therefore, to save the site from the indiscriminate and unaware use of itself and its precious resources.

Since the nomination for insertion of the archipelago into the World Heritage List, UNESCO has repeatedly invited local authorities and administrations to respect the directives, under penalty of non-compliance with cancellation from the list. The lack of financial resources and of coordination, despite the proposal of a Landscape Territorial Plan with clear clarifications on the proposal of the natural reservation of Lipari (Fig.2), led UNESCO to renew the obligation of the Convention also with the Italian Government. In the document sent on 27 August 2007 by the Italian National Commission for UNESCO, precise guarantees are required for overcoming the critical points that emerged following the examination of the conservation status of the places[12]. Among the nine points reported, urgency is precisely placed on the closure of the mine and the cessation of mining activities, in order to define a final date for the elimination of pumice waste from the beaches facing the processing areas [13].

The closure of the pumice quarries began thanks to the intervention of the Catania judiciary at the end of August 2007, with the seizure of the factories, boarding bridges, and all the machinery owned, as well as the provision for further bans on future extractive initiatives. The sequestration of the assets was followed by the obligation for the municipality of Lipari to ensure the safety of the site, using the Regional Mining 


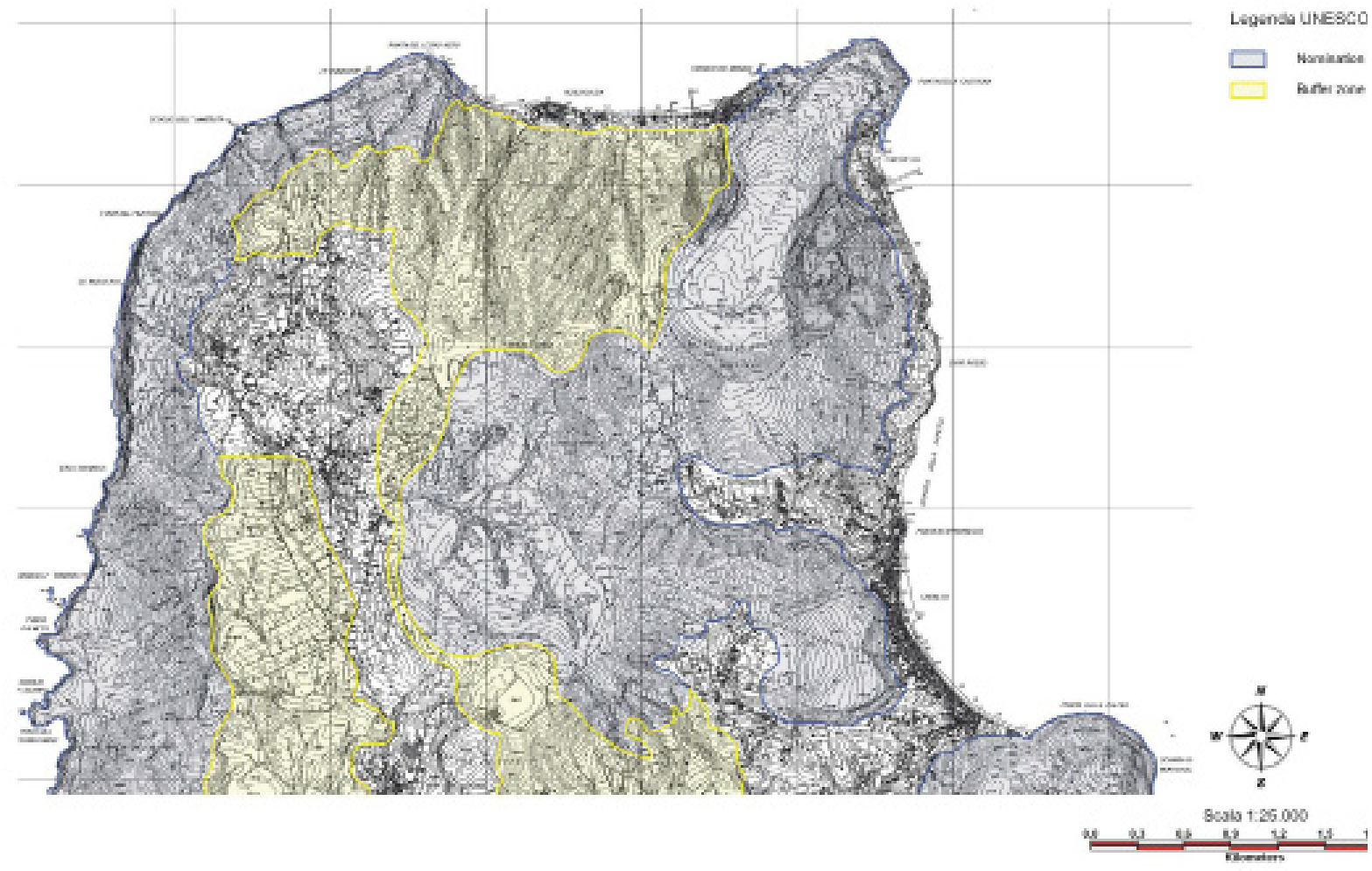

Figure 2. UNESCO - Perimeter of the natural reserve of Lipari [9] 


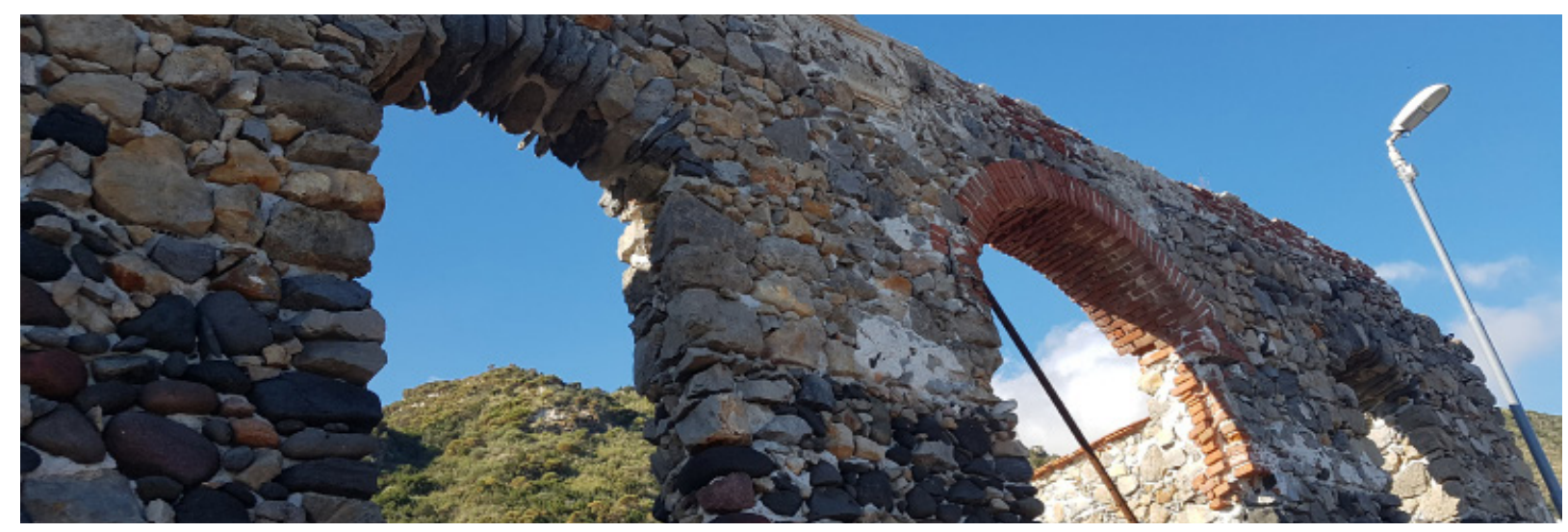

Figure 3. Industrial site of Acquacalda

Corps-Catania Mining District, through the elimination and reuse of existing quarry materials, activities carried out under the supervision of the UNESCO World Heritage Foundation sicily, which is entrusted with the task of supervising all the activities set out in the Management Plan.

The procedure for the closure of the pumice quarries and their disposal was concluded by the Sicilian Region on 24 January 2008, with reintegration by the Regional Department for the work of workers of the former Pumex in the Aeolian Archaeological Museum "Luigi Bernabò Brea". At the same time, the establishment of the terrestrial natural reserve on the island of Lipari and the establishment of the Marine Protected Area wereas launched.

Already in previous years, with a new law[14], the project for a Regional Pumice Museum had been planned. Developed concretely only a few years later, the project idea was integrated into the intervention strategies of the UNESCO Aeolian Islands Management Plan as an "ethno-anthropological enhancement project based on reconversion, conservation and en- hancement aimed at creating a Museum Lipari Regional Pumice". The project involves the conversion of an ancient industrial site placed in Acquacalda [Fig.3], an exceptional testimony of industrial archaeology for the documentation of the extractive and productive phases of pumice [9]

The building is a pumice mill, which was built in the years between the end of the nineteenth century and the beginning of the twentieth as a mill for the processing of pumice; it covers an area of about 600 square meters and a height of 6.90 meters. Since the cessation of activity, it is totally abandoned and ruinous, due to lack of maintenance. The factory, built with load-bearing masonry of lava stones and lime, has a rectangular layout; the main entrance is from Lungomare $S$. Gaetano street and is bordered to the east by an old building and free land, to the south also with free land and to the west with the Cucco stream. A front of drying furnaces in the bottom part gives access to the two back rooms, a larger one in the north originally used as a mill and a second one for storage with independent access in the west; 
it was built with load-bearing masonry of lava stones and lime, and there is also a 15 meter high chimney made of bricks, filled with bricks for the discharge of the fumes produced by the factory and a large part of the coverage of the first body facing the road, characterized by two pitches covered with tiles and a wooden truss structure. Inside, some important elements of the manufacturing process are still visible, such as pumice drying ovens, the loading path, and preparation for processing and transport of pumice products intended for export. The reconversion project developed around the creation of an educational/informative path for the extraction and processing of pumice, with the realization of six different thematic sections, is divided as follows:

- "Archaeological, Mineralogical and Volcanological", dedicated to the exhibition of minerals and the geological history of the archipelago;

- "Traditional pumice cycle", focused on the reconstruction of the extraction and production of pumice;

- "Pumice and history", based on the display of documents and sources on the diachronic aspects of pumice;

- "Pumice and society", concerning the identification and description of the relationship between the pumice industry and the Aeolian society;

- "Technological history", for the reconstruction and display of a complete production plant;

- "Library and multimedia", consisting of archival and documentary material for the use of visitors.

At the base of the initiative proposed by the Superintendency of Cultural and Environmental Heritage of Messina, with the aim of inserting the work within the cultural and museum circuit of Lipari, there is therefore the valorization of the productive activity with the internal museum path, such to allow at the same time the protection and conservation of obsolete disused technological systems. Although more than twenty years have passed since the establishment of the first law, even today, the promoted initiative has not started and currently, the building is still abandoned. Within the plan of reconversion, the preparation of a project for the construction of a Tourist Complex was also integrated, which has not yet been built.

At the same time, several initiatives were promoted within the sustainable redevelopment and recovery program of the quarry areas of the island, aimed at the redevelopment of disused industrial buildings, looking at a masterplan for the Reconversion and Sustainable Recovery Plan of the quarry areas of the Island of Lipari, covering the whole area between Canneto and Acquacalda, starting from the collaboration of universities and research institutions [15].

In 2016, a quarry recovery project was launched, at the same time as the Architecture, Light and Landscape Workshop "Future Lights on a volcanic landscape". In the same year, a second workshop, "Between the wrinkles of an unexpected glacier - Lipari discovering white pumice quarries", was organized by the Politecnico di Milano DASTU Department of Architecture and Urban Studies and by the School of Architecture Urban Planning, Construction Engineering with the collaboration of the Municipality of Lipari [16]. With these latest initiatives, the intent was to pursue new ideas for the conversion of the areas through the active participation of students and teachers of architecture. Despite the start of the activities, the problems related to landslides in the affected areas are not completely contained. 


\section{REFERENCES}

[1] V. Sapienza, RIUSO E CONSERVAZIONE NELL'ARCHEOLOGIA INDUSTRIALE IN SICILIA. Roma, 2015, (in Italian).

[2] E. Celano and S. Chirico, Archeologia industriale, creativita' e gestione integrata . II caso biellese, Tafter J., pp. 1-7, 2011, (in Italian).

[3] G. Racheli, Le isole minori della Sicilia: prospettive di recupero e di sviluppo. Catania: Giuseppe Maimone Editor, 1989, (in Italian).

[4] L. Scimemi, Le linee guida per la valorizzazione del patrimonio UNESCO. Uno studio dei siti siciliani - Tesi di Dottorato in Storia della Cultura e della Tecnica, Università di Palermo, 2013, (in Italian).

[5] D. Stentella, "La storia della pomice a Lipari," 2012. [Online]. Available: http://www.fondazionemicheletti.it/nebbia/ d-stentella-storia-della-pomice-di-lipari/ (in Italian), (accessed on October, 2019).

[6] M. Giacomantonio, "La raccolta e lavorazione della pomice si riorganizza e industrializza," 2015. [Online]. Available: La raccolta e lavorazione della pomice si riorganizza e industrializza, (in Italian).

[7] Società geografica Italiana, Bollettino della Società geografica italiana. Società geografica italiana, 1979, (in Italian).

[8] Ministero delle Finanze - Direzione Generale delle Imposte Dirette, Imposta sui redditi di ricchezza mobile elenco dei contribuenti privati possessori di redditi incerti e variabili delle categorie B e C (esclusa la rivalsa). Libreria dello Stato, 1930, (in Italian).

[9] Regione Siciliana, "Piano di gestione Unesco Isole Eolie," 2008, (in Italian).

[10] IUCN - International Union for Conservation of Nature and Natural Resources, "WORLD HERITAGE NOMINATION IUCN TECHNICAL EVALUATION ISOLE EOLIE ( AEOLIAN ISLANDS ) ( ITALY) ADDENDUM TO 1999 IUCN EVALUATION," 1999.

[1 1] UNESCO, "DECISIONS ADOPTED BY THE 26th SESSION OF THE WORLD HERITAGE COMMITTEE," no. August, 2002.

[12] UNESCO, "Decision: 31 COM 7B.24 'State of conservation of World Heritage Properties - Isole Eolie (Aeolian Islands)"

[13] UNESCO, "World Heritage 31 COM UNITED NATIONS EDUCATIONAL, SCIENTIFIC AND CULTURAL ORGANIZATION CONVENTION CONCERNING THE PROTECTION OF THE WORLD CULTURAL AND NATURAL HERITAGE WORLD HERITAGE COMMITTEE DECISIONS ADOPTED AT THE 31st SESSION OF THE WORLD HERITAGE COM," no. JUly, 2007.

[14] Region of Sicily, Regional Law No. 17 of 15 May 1991.

[15] A. Sidoti, "Realizzazione del programma di riqualificazione e recupero sostenibile delle aree di cava dell'Isola di Lipari. Relazione del 17/01/2017." [Online]. Available: http://www.liparinet.it/realizzazione-del-programma-diriqualificazione-e-recupero-sostenibile-delle-aree-di-cava-dellisola-di-lipari-nuova-relazione-del-consulente-sidoti/, (in Italian) .

[16] "Parco Geominerario Pomice." [Online]. Available: http://parcogeominerariopomice.it/, (in Italian).

[17] Region of Sicily -Department of the Territory and the Environment, "Ordinance n. 14 of 10 June 2019 of the Sicilian Region." (in Italian). 


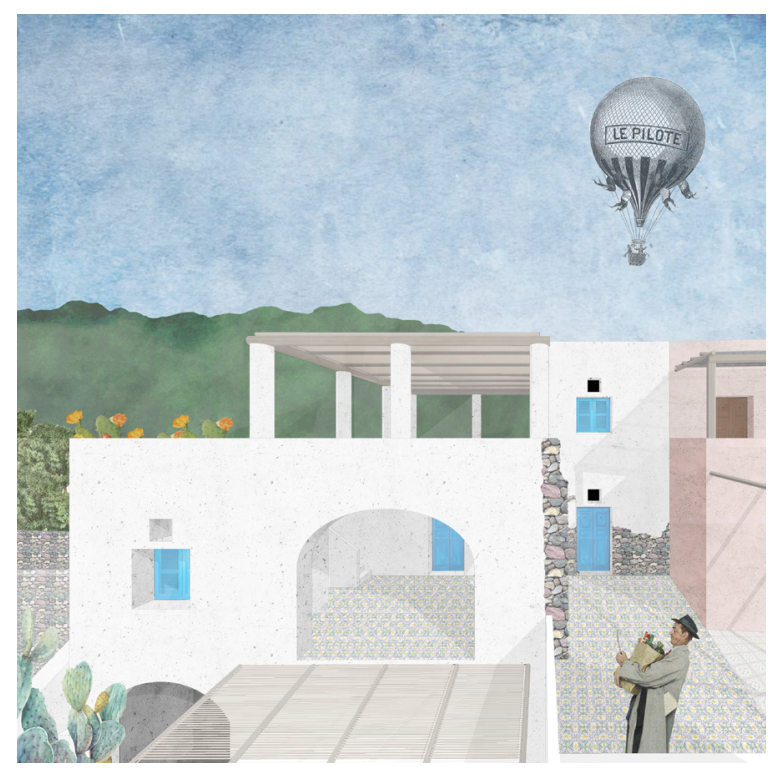




\section{FILICUDI OPEN SPACE}

\section{STUDY CASE}

Val di Chiesa

DESTINATION OF REFURBISHED BUILDING Typical products shop

\section{ABSTRACT}

The wisdom of the vernacular architecture of the Aeolian Islands is a fact.

At first, the use of Rapid Evaluation Methods (REM) allowed us to achieve a rapid evaluation of the architectural, thermophysical, and mechanical quality of the buildings in Val di Chiesa.

Next, thanks to an innovative tool (geodatabase) for the management of the quality of the built heritage, it was possible to match the conditions of existing buildings. For each building, a band score was set that showed us its quality.

A typical products shop was also designed to reactivate and revitalize the entire area of $\mathrm{Val}$ di Chiesa.

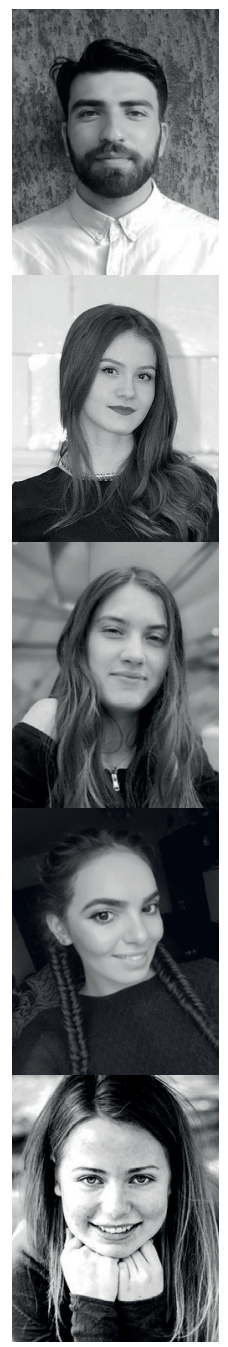

WORK TEAM

GRECO_Sebastiano_Student at UNICT

IORDACHE_loana-Mihaela_Student at UAUIM

IUCA_Maria_Student at UAUIM

IVANESCU_Alexandra_Student at UAUIM

STANKE_Stefanie Katharina_Student at NTNU 


\section{TASK 1 \\ CHECK OF THE AREA}

\author{
VAL DI CHIESA
}

The study area is the contrada of $\mathrm{Val}$ di Chiesa at 290 meters above sea level.

"Valle di Chiesa" is a depression formed by the remains of a gigantic explosion of a volcanic cone. The walls of the mountains outline it and make you feel that you are at the center of a volcano that exploded and extinguished.

The church of Santo Stefano gives its name to the area. Externally, it has a white raised edge and a pyramidal bell tower on the right. Inside, there is a choir above the entrance, two altars on each side, and the central apse niche.

Santo Stefano is the patron saint of the island and a festival is celebrated in the summer around the 3rd of August.

Next to the church stands an ancient cemetery, which testifies to the harshness of life of the past, and in the various epitaphs, the recent history (and not) of the inhabitants of Filicudi can be understood.

The borgo is bordered by the provincial road "porto-valdichiesa-pecorini" to the northeast, while to the southwest, it ends with a great altitude jump that offers a panoramic view. The village is then articulated with secondary non-driveways that lead to various building units.

In this contrada, there are all the characteristics of traditional Mediterranean architecture, from the typological, historical-cultur- al, and technical-constructive point of view. Many buildings are always inhabited over the four seasons, whereas others are inhabitated only occasionally. Abandoned buildings are very few, but these are in degraded conditions.

Overall, it can be said that in this contrada, the traditional characteristics of the Aeolian Islands can be perceived. 


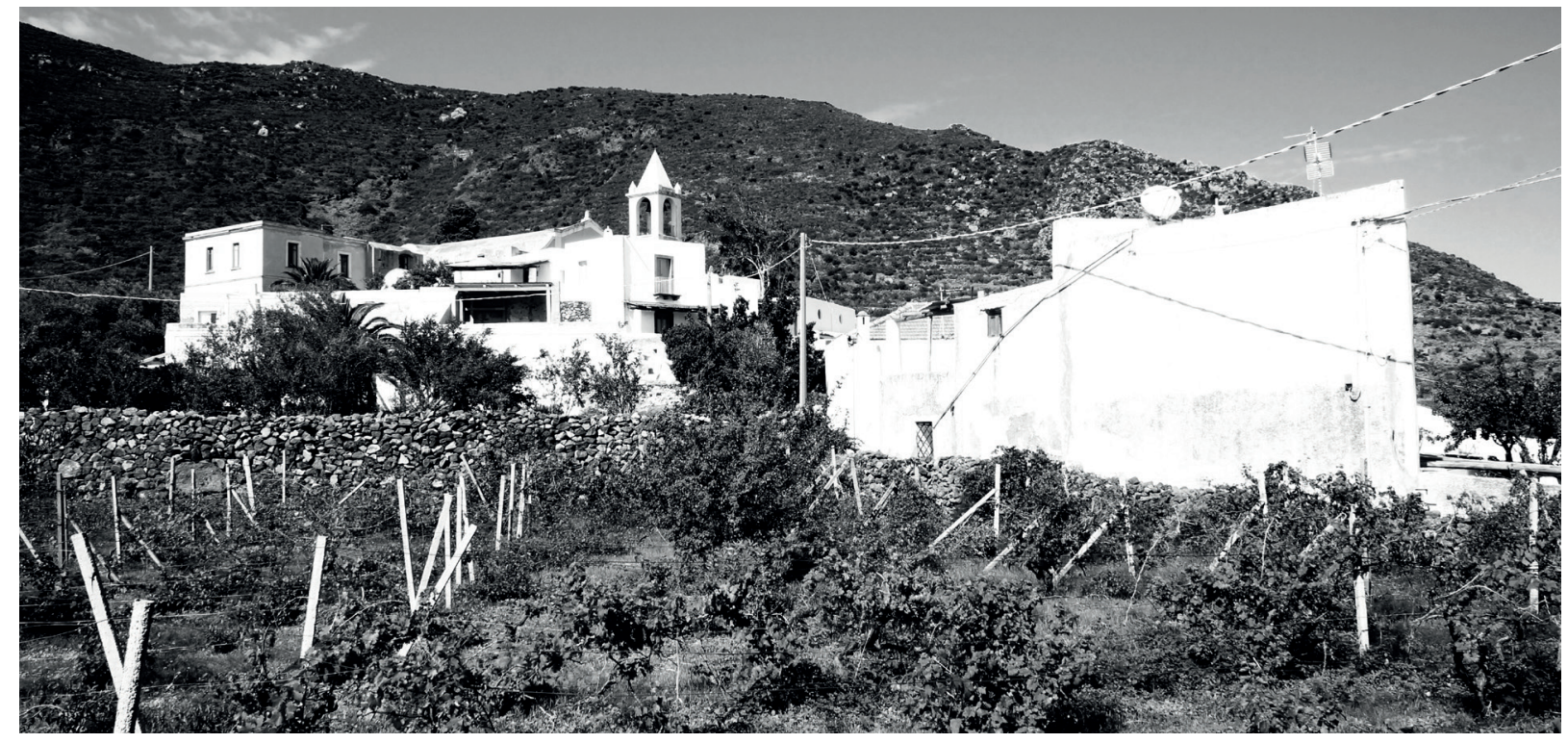

Figure 1. Picture of the study area

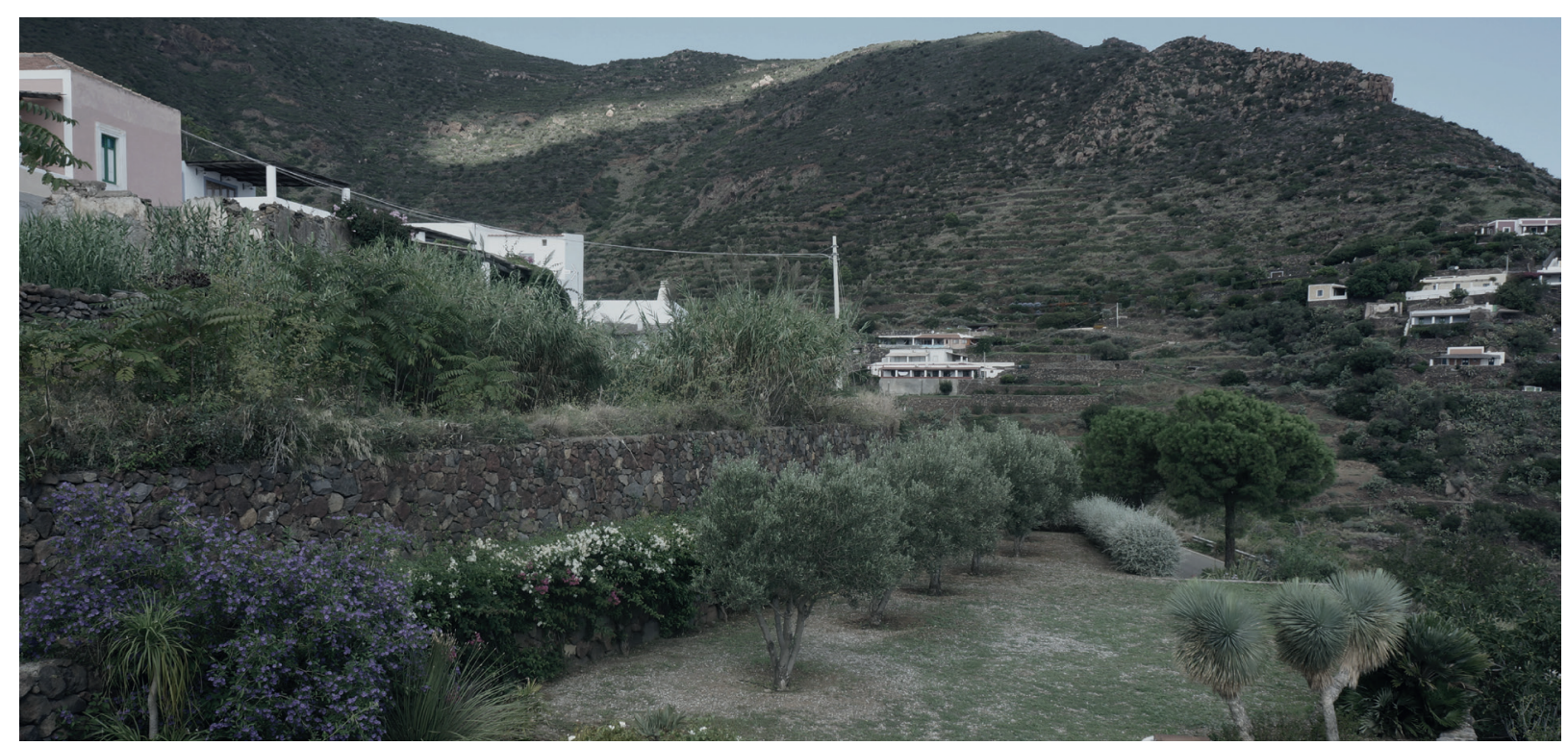

Figure 2. Picture of the study area 


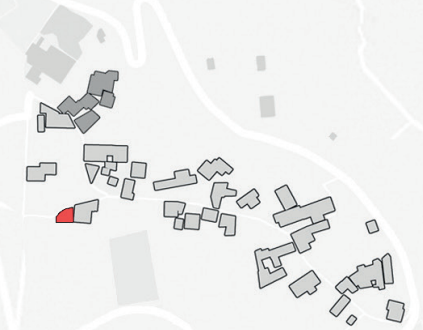

D

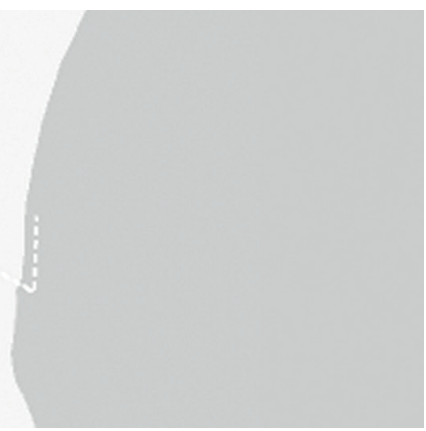

Figure 3. Planimetry of the study area

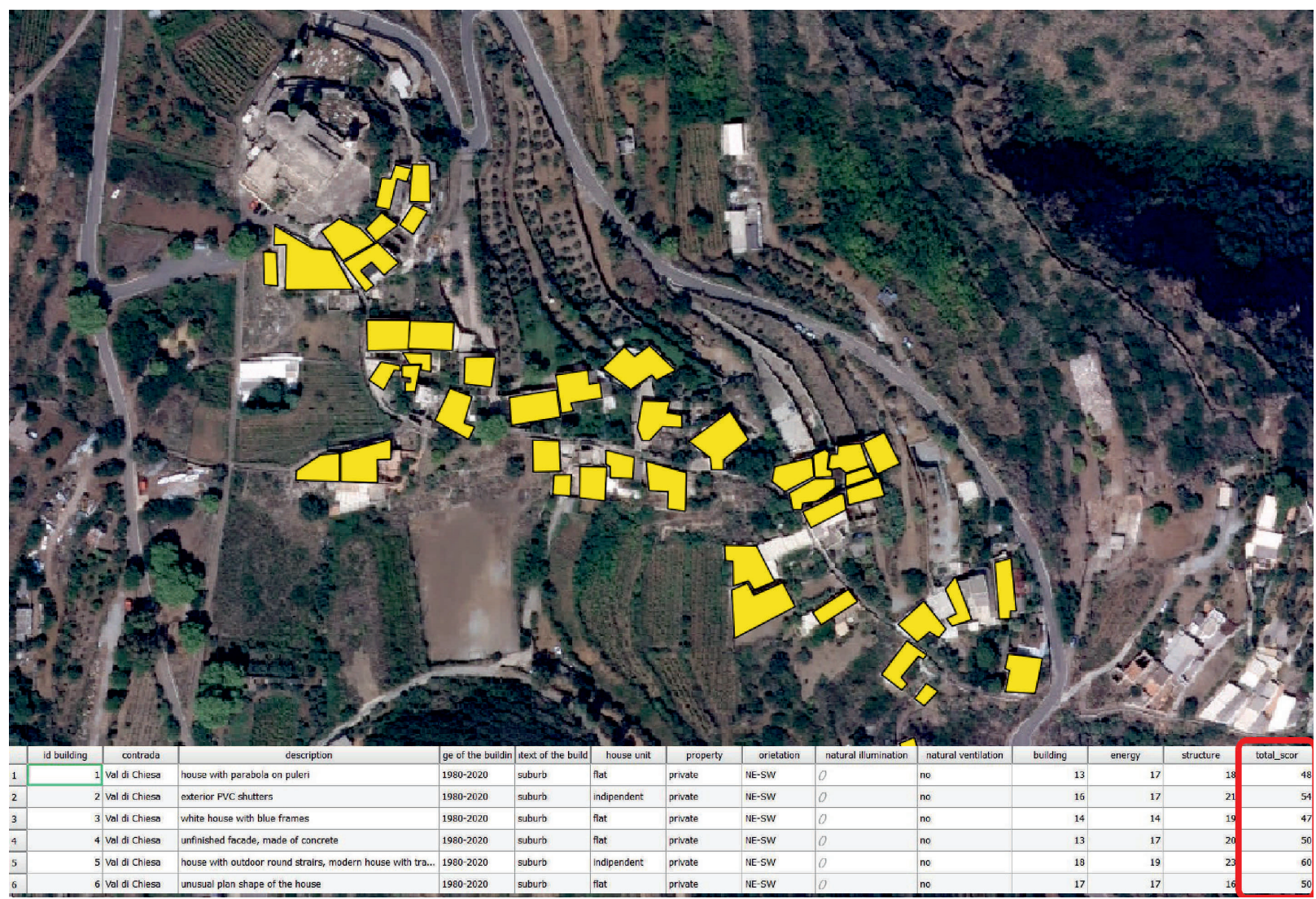

Figure 4. GIS map of the study area 

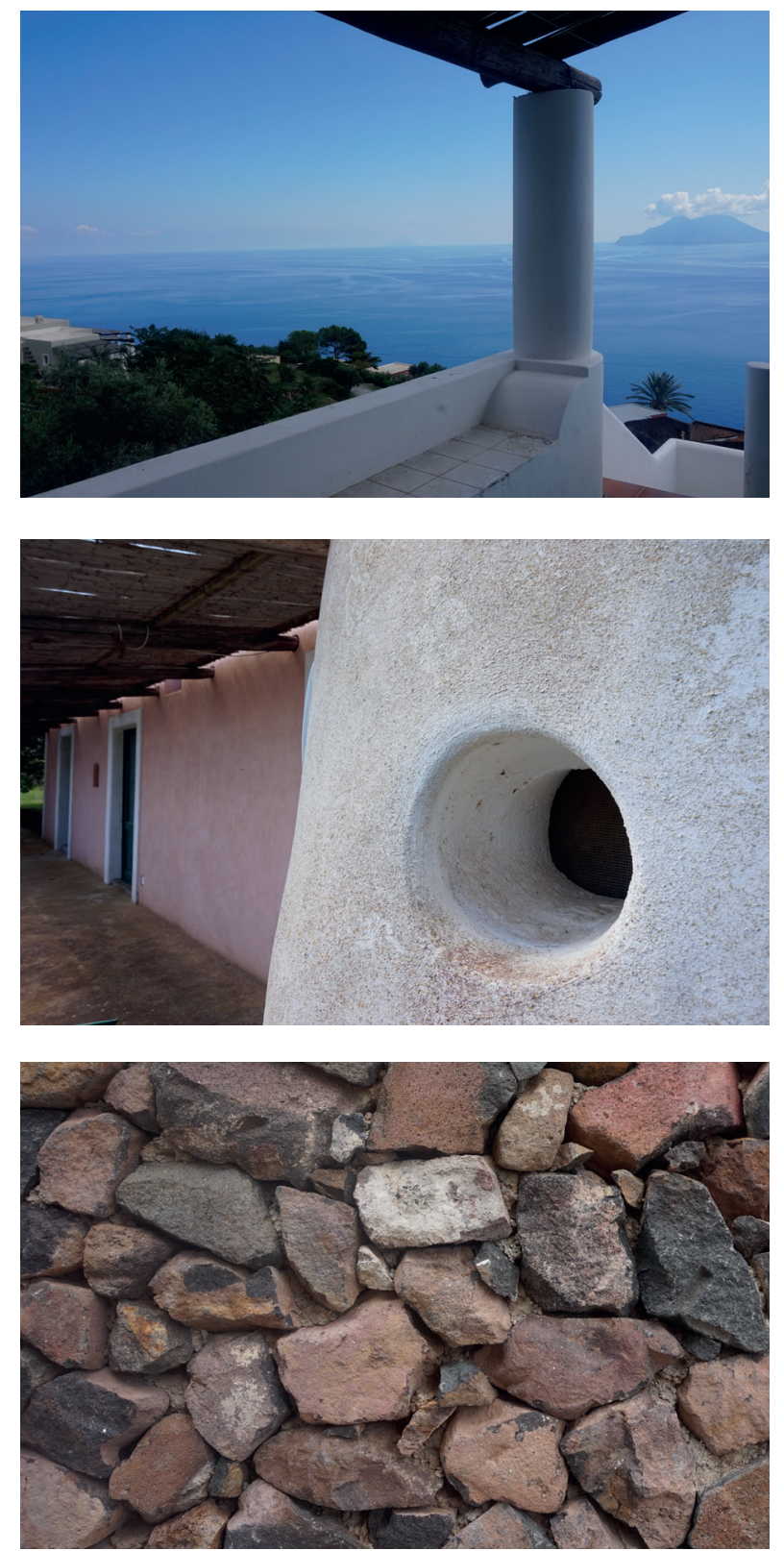

Figure 5. Features of local architecture

\section{FEATURES AND QUALITY OF THE LOCAL ARCHITECTURE}

The architecture of the Aeolian Islands is typically characterized by its focuses on functionality and climate adaptability. The local architecture of $\mathrm{Val}$ di Chiesa is not an exception to this rule. The architecture that was found in the assigned area consisted mostly of traditional Aeolian architecture that was refurbished to be used as holiday homes. The buildings are therefore in good condition and traditional features were mostly kept, even though, not always in use.

The Aeolian house consists of a basic unit, mostly in cube form, which can be combined with a varying number of additional cubes which are either oriented along the slope or stacked vertically in orthogonal direction. Local construction materials are pumice stone (walls) and tuff (paving). A typical element of Aeolian architecture is the "bagghiu", which is a shaded terrace. The roof consists of a wooden construction which is covered by grapevines or other vegetation. Characteristically, cylindrical columns frame the bagghiu. Furthermore, a low stone bench "bisola" surrounds the terrace. Original buildings in addition have a cistern and, in some cases, a wooden stove.

Today, Aeolian architecture is often known for its colorful appearance and indeed, many of the existing buildings in $\mathrm{Val}$ di Chiesa are painted in a range of colors. The windowsill and frame contrast with the wall color. 


\section{TASK 2 \\ DESIGN PROPOSAL}

\author{
EXISTING CONDITION
}

The house is located near the edge of the assigned area, at the intersection of two paths: one which can be taken only by foot (as it is steep and quite tight) and one which is derived from the main road (large enough to be travelled by car).

On a scale from 1 to 10 (1 - none-existent; 10 - walls, roof etc. still in their place), the ruined house can be given a score of 3 regarding its physical condition. Only two walls remained fully undemolished, the rest of them only one-third or just the bottom footprint could be observed (one-third of a door gap, one-third of an arch, one-third of an initial yellow plaster).

From what it seemed, they were using it just to throw some old furniture adrift.

From this point of view, the difficulty to reimagine a layout was what kept our minds busy. As this ruin was clinging next to a well maintained vacation house, we supposed they were somehow twins on the upper level. The only difference was that our house had direct access to one large terrain in front of it by an underground small room. A cistern for collecting rainwater was also still present on the ground floor.

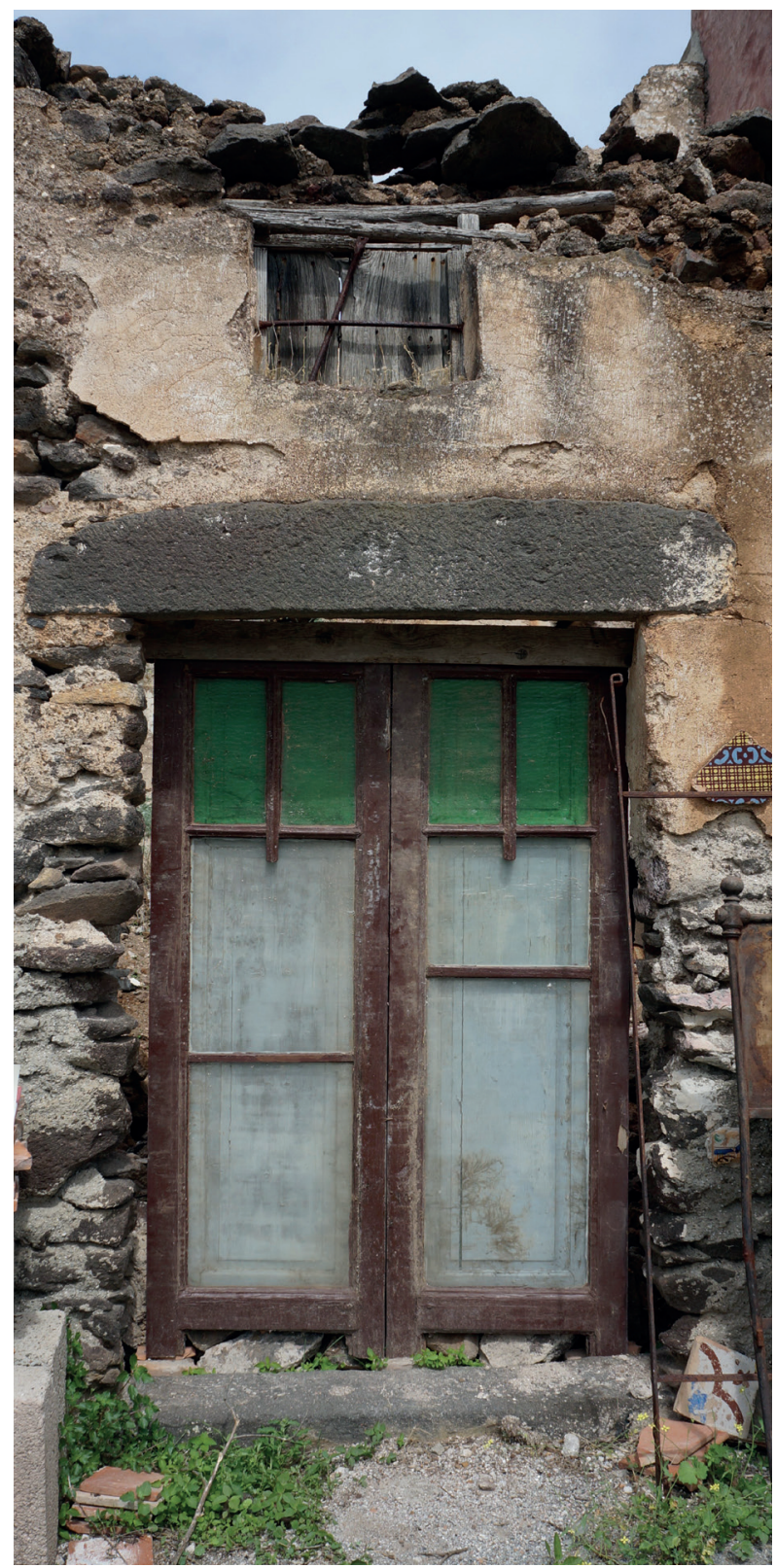

Figure 6. Main entrance of the case study building 


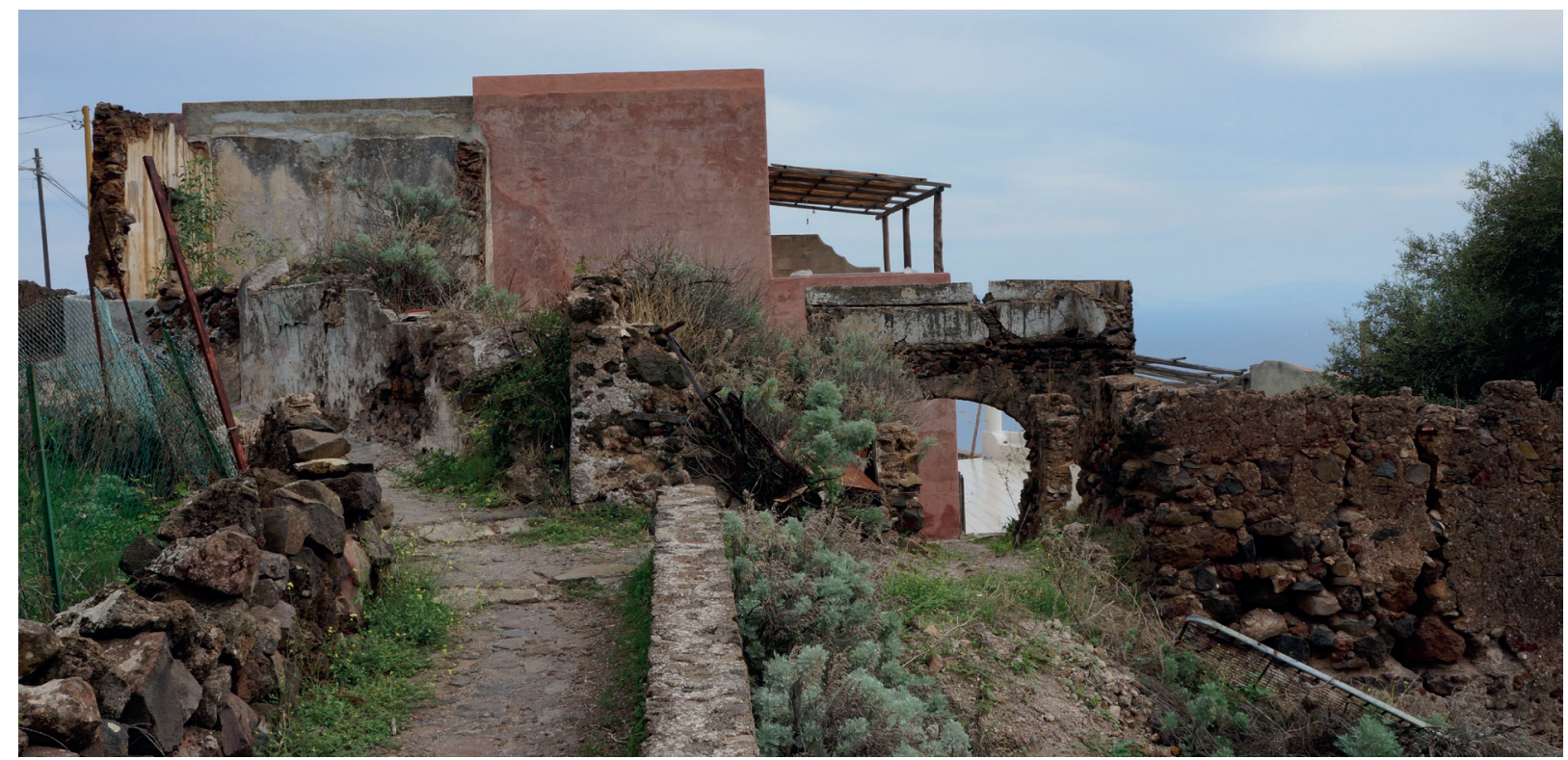

Figure 7. Picture of the case study building (west view)

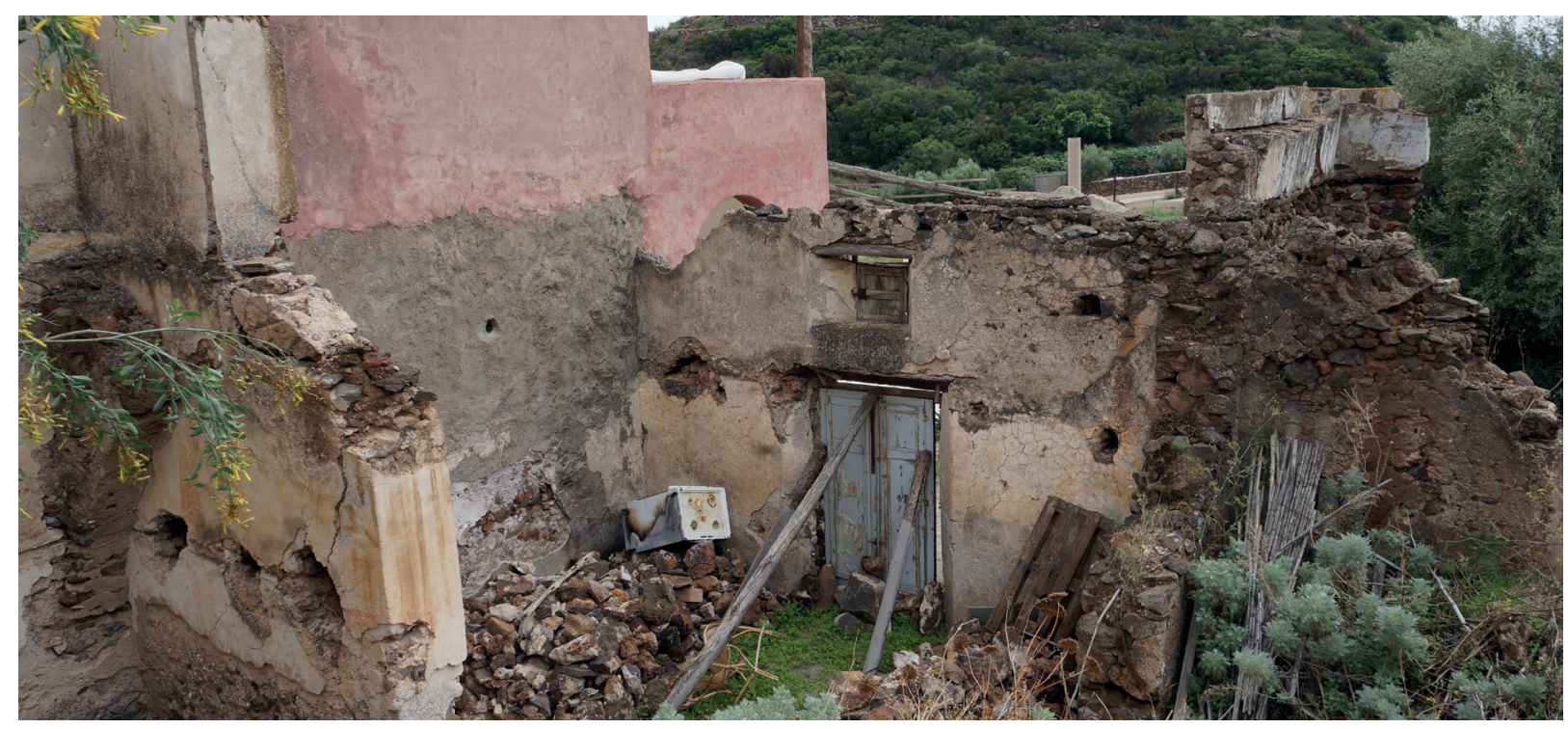

Figure 8. Existing conditions of the case study building 


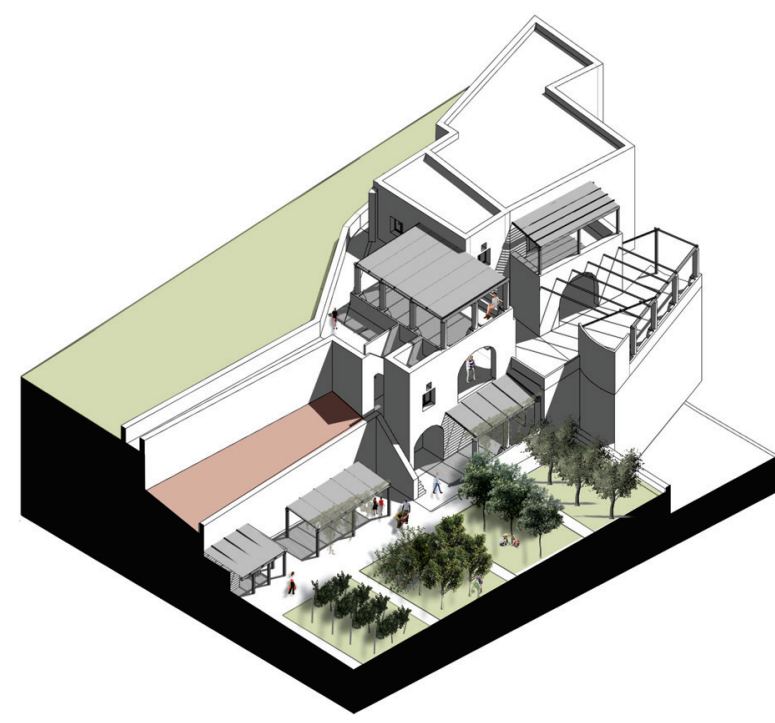

Figure 9. Axonometric view of the new proposal

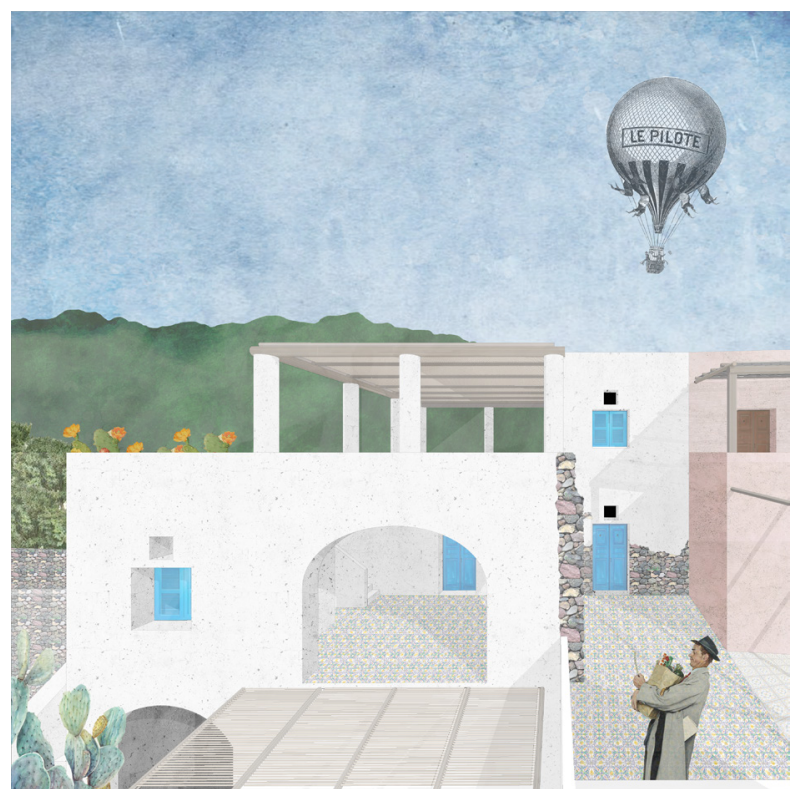

Figure 10. Perspective view of the new proposal

\section{DESIGN PROPOSAL}

The main concept was a place where the locals and visitors could buy local products but also souvenirs, so the building was divided into two areas, one with local products and the other one with souvenirs, with access from the main street.

The basement floor of the building has a shop with local products, two staff zones, and storage for the shop. Outside, from the west access, you can see the drying facility, then the storage for the local products, the bagghiu, and also, the event pavilion and the garden market.

At the ground floor, in the north, you have the main entrance from the street to the souvenir shop, a home delivery station, the bagghiu, and another storage.

In the summer time, the locals and visitors can collect their own fresh fruits, vegetables, or spices from the garden market or they can see how these are dried in the traditional dehydrators. Near the garden, there is an outside kitchen with a traditional oven (furnu) where they can prepare their own meal for brunches and also a bagghiu where they can have events for community. In the winter, the garden market is closed, the light structures are used as storage and the bagghiu transforms into a community center for the locals by adding walls to the existing structure. Because there is no vegetables or fruits production in the winter season, the building has a storage and packing area for local products, from which they home deliver products to the locals. 

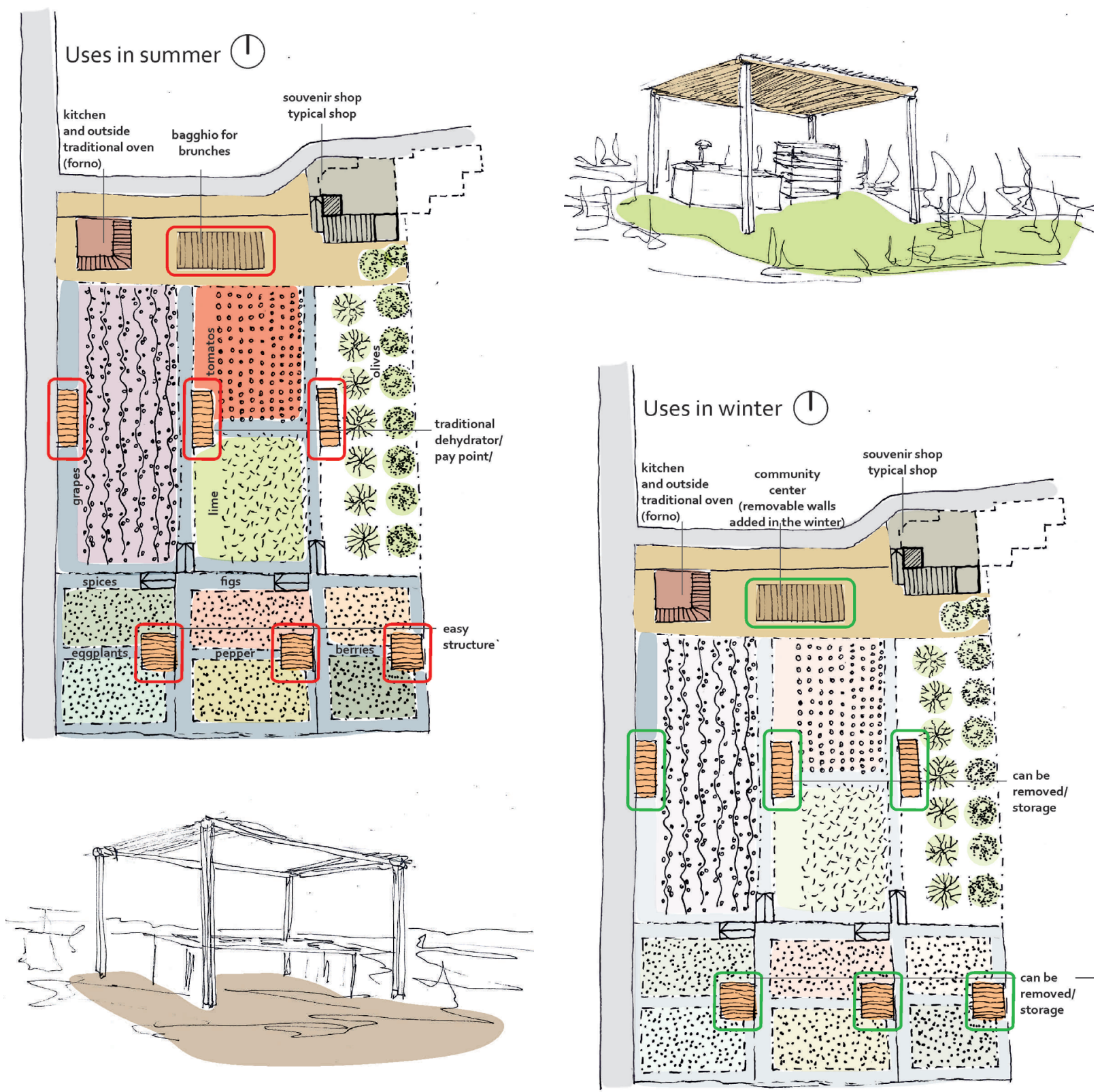

Figure 11. Seasonal uses of the garden market 


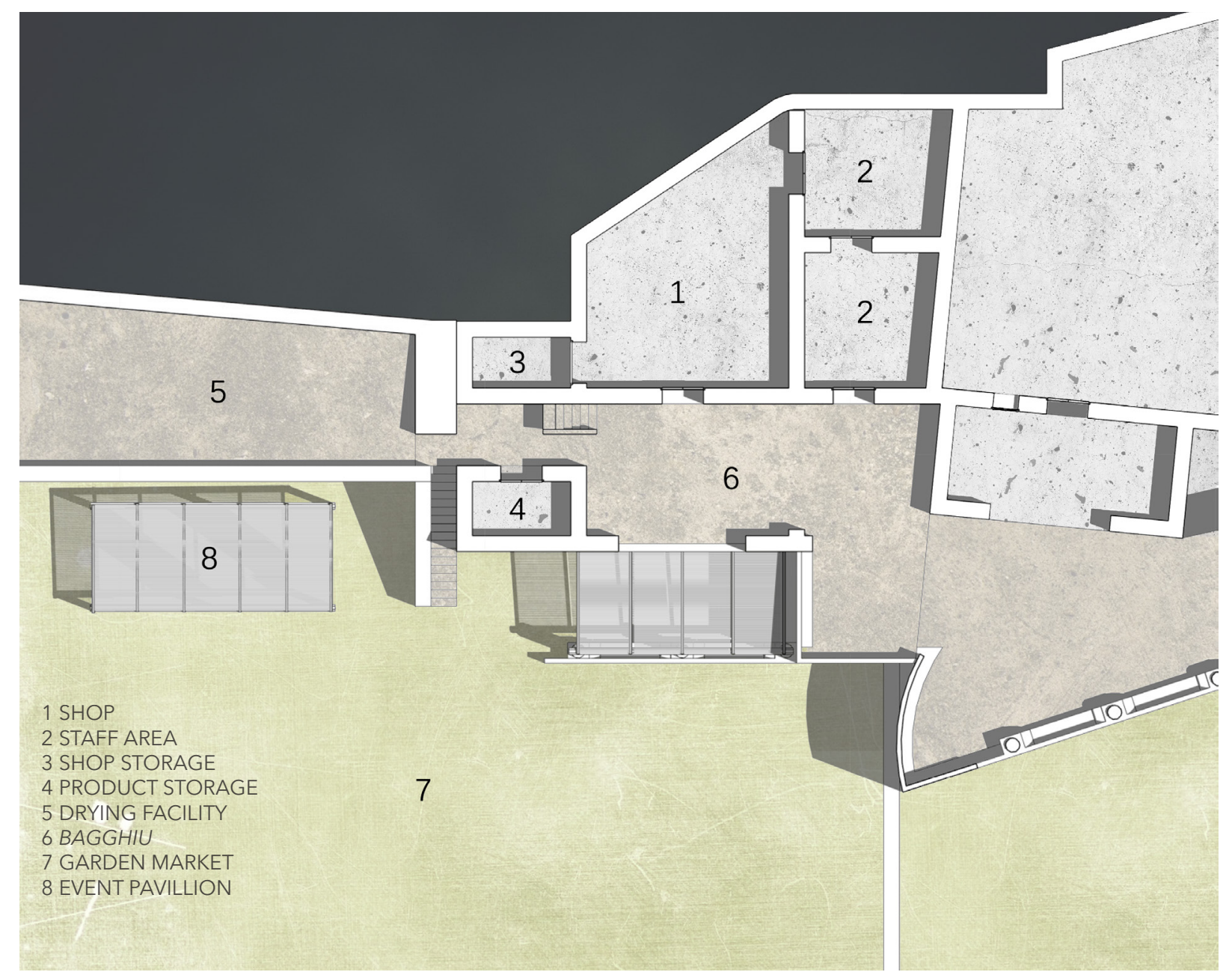

Figure 12. Ground floor plan of the proposal for case study building 


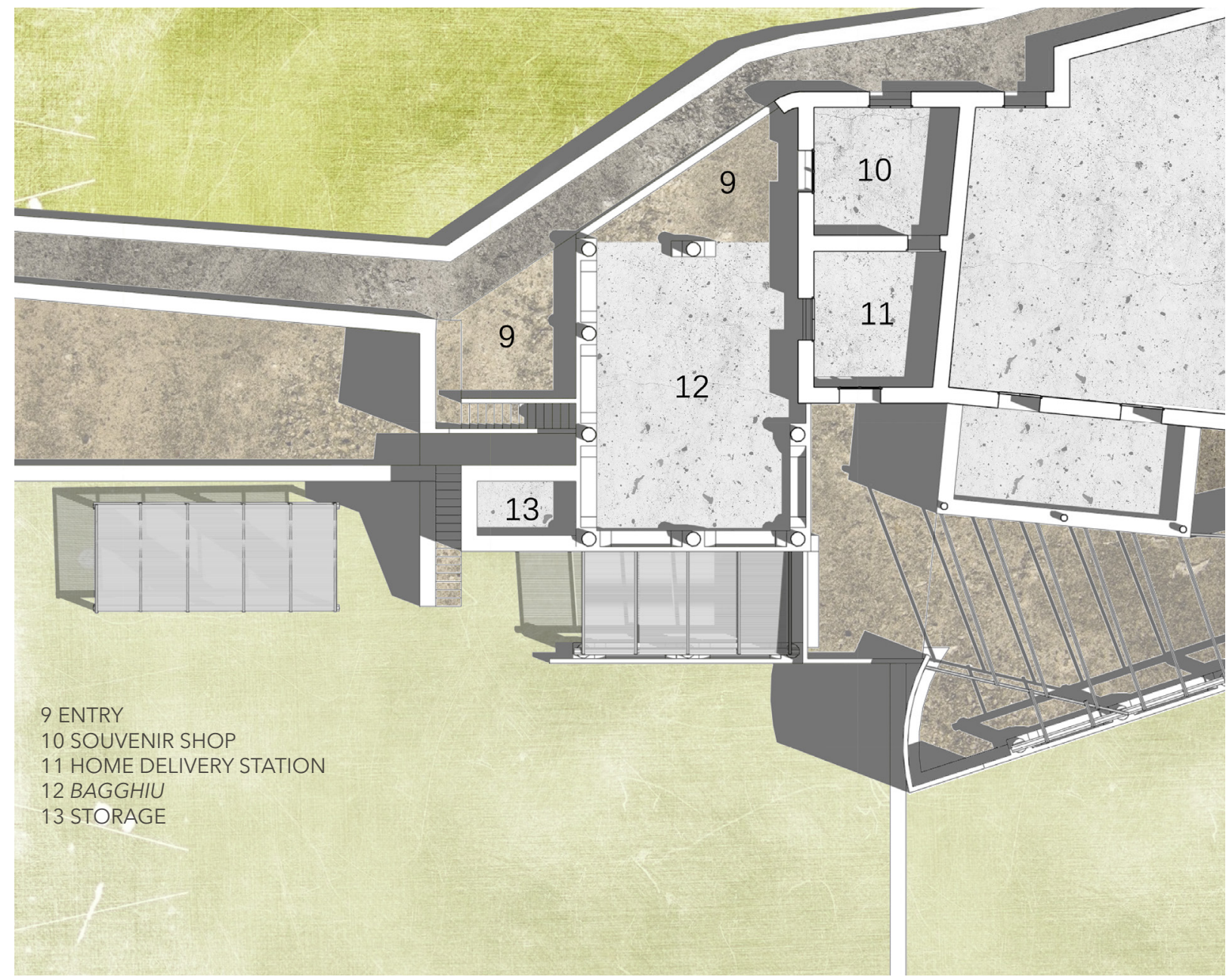

Figure 13. First floor plan of the proposal for case study building 

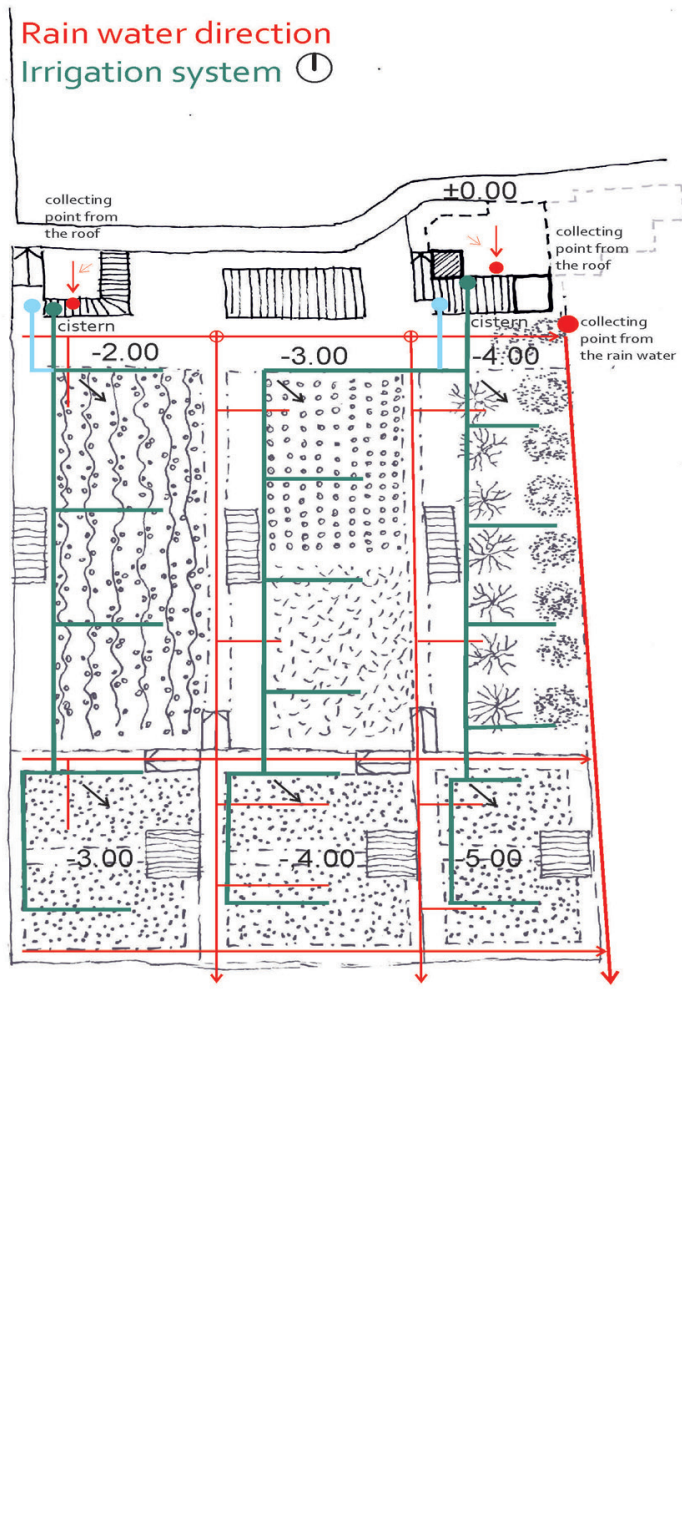

Figure 14. Rainwater collection system for the garden market

\section{DETAIL}

For the building, we used one cistern where the water from the rooftop is collected and used in different ways. Another collecting point for water is located in the garden. The water recycle system is really important for the property because this system helps with the growth of vegetables, fruits, and different species of plants.

For natural ventilation, we used a specific local architectural detail that has two windows oriented from north to south on different levels of height and that let air to cover the entire room.

To maintain the historical wall parts of the old building (genius loci), we created a seismic and structural support. The layers of this system have in the innermost part a concrete wall covered by a mesh. To connect the interior part with the exterior part, some metal rods are used that go through the old rock wall and become caught with a steel net. This type of system aims to let the wall look natural as much as possible. The shading system is used on the bagghiu and also for the light structure in the garden. This system is made from wooden sticks and can be pulled one above the other when more light is needed or be left free for the cistern water collecting system for a fresh shade. 


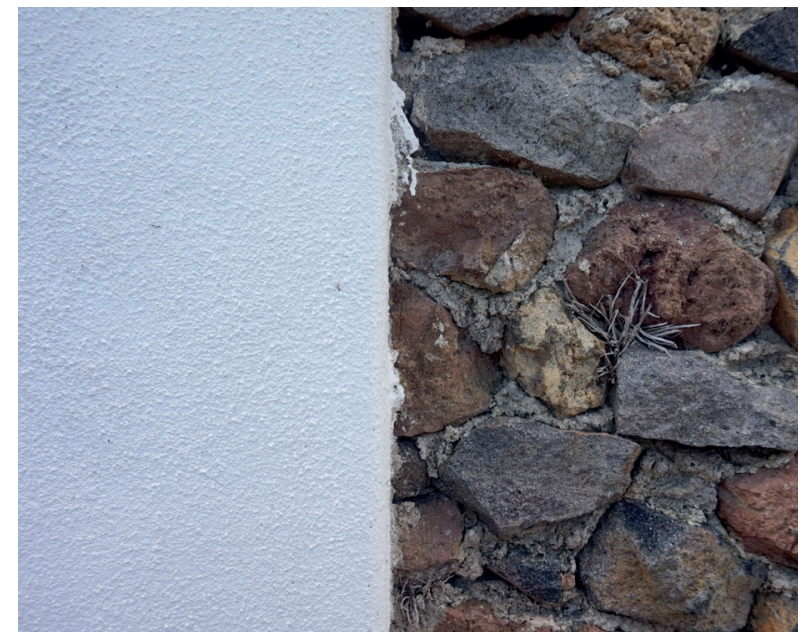

WALL WITH SEISMIC SYSTEM

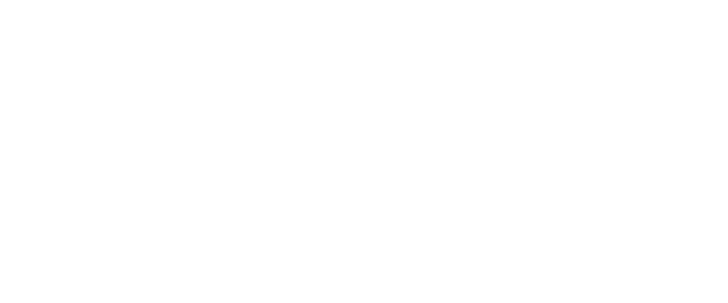

SHADING SYSTEM

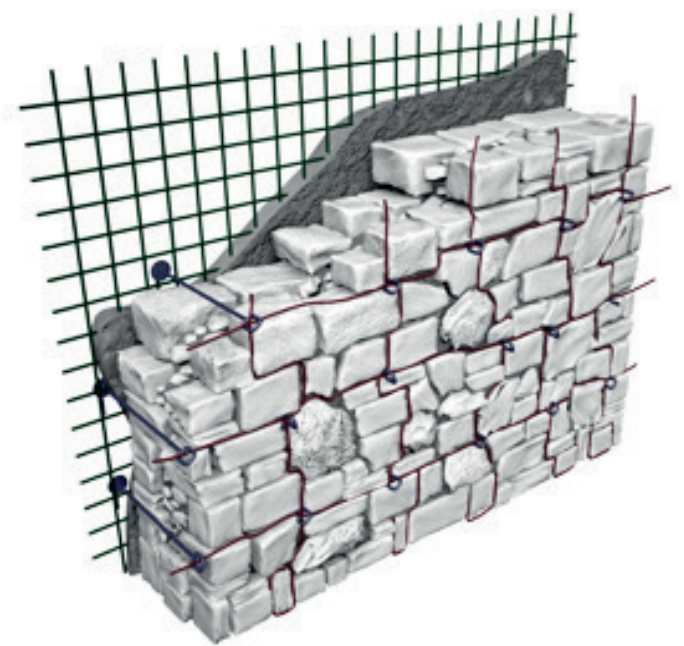

LAYERS OF THE WALL
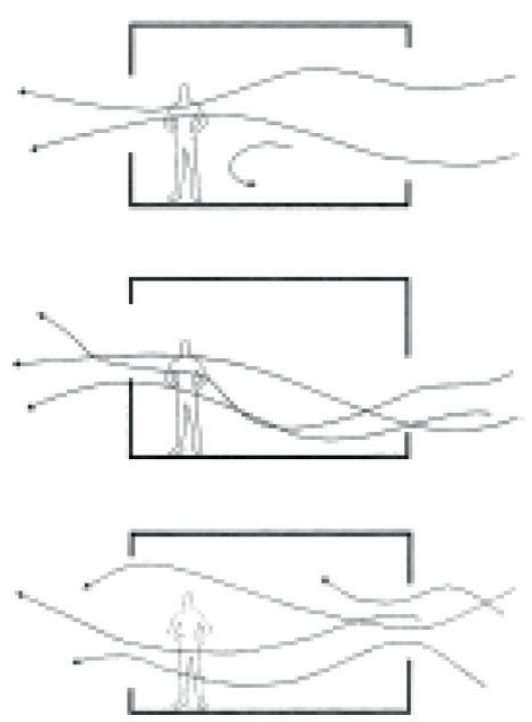

VENTILATION SYSTEM

Figure 15. Other proposed systems 


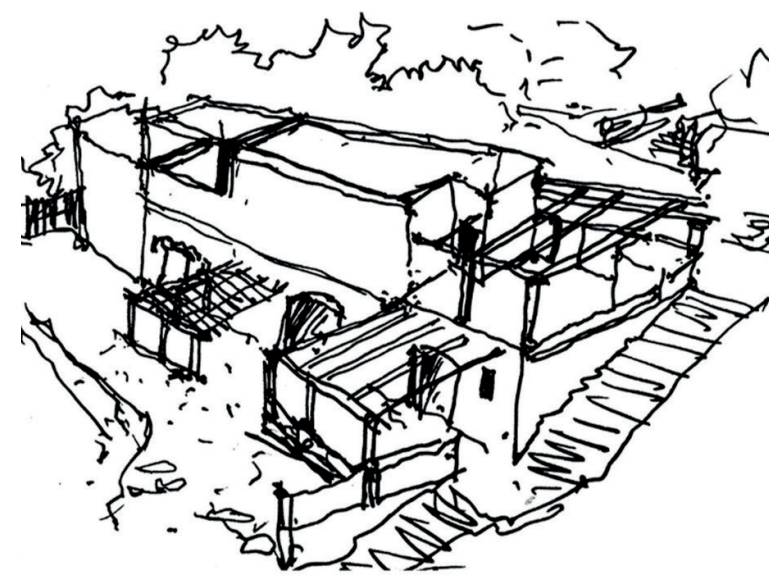




\title{
TRADITIONAL ATMOSPHERE
}

\author{
STUDY CASE \\ Pecorini Nord \\ DESTINATION OF REFURBISHED BUILDING \\ Art center/Art gallery
}

\section{ABSTRACT}

The site is located in the southwest of Filicudi Island, in the Pecorini Nord area. There are some particularities of this area which inspired us for the future designing process, like the building's orientation and its consequences regarding interior zoning.

The position of a building is chosen in relation to seasonal variations in the sun's path and the prevailing wind patterns. Good orientation increases the energy efficiency of the building, making it more comfortable to live in and cheaper to run. This is the reason why the majority of the buildings are facing the southern light.

They open to the landscape through that baggio, a traditional terrace, covered by a vegetal pergola sustained by a structure of wooden beams and massive concrete columns. This baggio is directly connected with the interior, which is separated into different linked functions in row.

Another particular fact of the buildings is the color of the façade and the materials used for the structure. A combination of stone, concrete, and wood is usually used, the facade being covered in cement plaster, eventually varnished in traditional colors (e.g., white). As far as the community is concerned, it is very hospitable and open to discussion about the history and tradition of the place. It is a small population who enjoys conserving its habits and lifestyle, living in small households in relation to the relief of the island.

WORK TEAM

Badicu_Diana_Student at UAUIM Bosnyak_Andrei-Mihai_Student at UAUIM Popa_Adina_Student at UAUIM Lipari Galvagno_Agata_Student at UNICT Scandura_Anna_Student at UNICT Nankova Filipova_Jeni_Student at NTNU

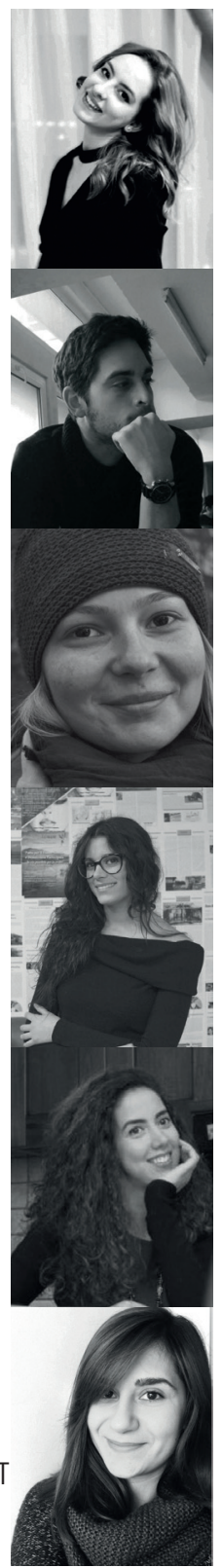




\title{
TASK 1 \\ CHECK OF THE AREA
}

\author{
PECORINI NORD
}

The seven Aeolian Islands are situated on the northern coast of Sicily. Because of the tremendous landscape, they have been recognized by UNESCO as a World Heritage Site and have been listed since 2000. Filicudi island is situated on the west arm, formed by the islands, and next to Alicudi. They are considered as more isolated because they are a considerable detour from the Milazzo-Lipari-Naples route, which was most frequented by merchant ships (in the past) and is by touristic ones (today). However, it has preserved its landscape in a more efficient way. The terrain is terraced; thus, the buildings are situated along the parallel lines, which form the silhouette of the town.

The climate is Mediterranean, characterized by mild weather during the winter and hot dry summers. However, the summer temperatures are extreme with up to $40^{\circ} \mathrm{C}$ and limited to $30 \mathrm{~mm}$ precipitation. There are Western winds.

Our group was focused on the Pecorini Nord area, which is located in the western central part of the island. One of the most important buildings, the landmark of the district, is located in the center of the area - the town's church Chiesa Parrocchiale di San Giuseppe. It functions as a social gathering place for the island's inhabitants, because of its large terrace at the front, which could be seen as a "town square". Therefore, it could be as- sumed as the focal point of the town.

Architecturally, the district could be separated into two semi-areas by the church. The northern part is characterized by isolated private houses on one floor, whereas the southern part could be described as a cluster of two-level houses, with extremely narrow streets between them. There are several common characteristics of the buildings. All of them are situated along the parallel lines, so most of them have quite regular rectangular form. They are always oriented with the terrace facing south and every house has viewing access to the sea, because of the terraced terrain. Moreover, the majority of the buildings have lateral access, directly from the main road. The construction of the buildings is masonry of rough, basaltic stones and $50-60 \mathrm{~cm}$ thickness. The plaster finish is usually in a white, pink, or blue color. All windows are covered with shutters for protection from overheating. Most of the houses have a traditional layout with large transitional living spaces (kitchen, bathroom, living room, bedroom, and storage) and a large terrace "bagghiu" at the front. Most of the terraces floors are covered with decorative mosaic tiles. The canopy construction, positioned over the typical columns, "pulera", is made by wooden beams and is covered with reeds. Most of the houses have preserved the rainwater collection system. 


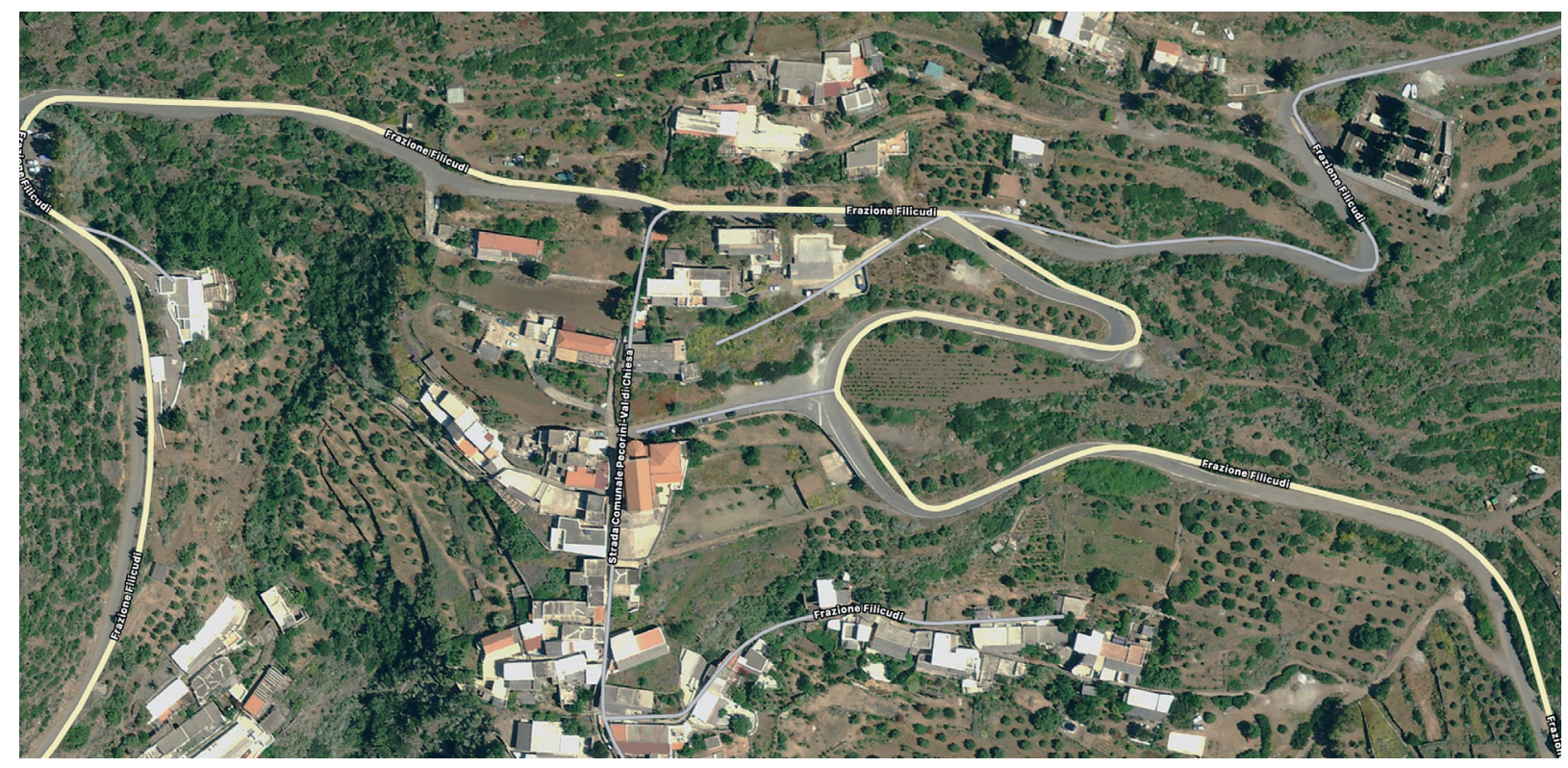

Figure 1. Satellite image of the study area

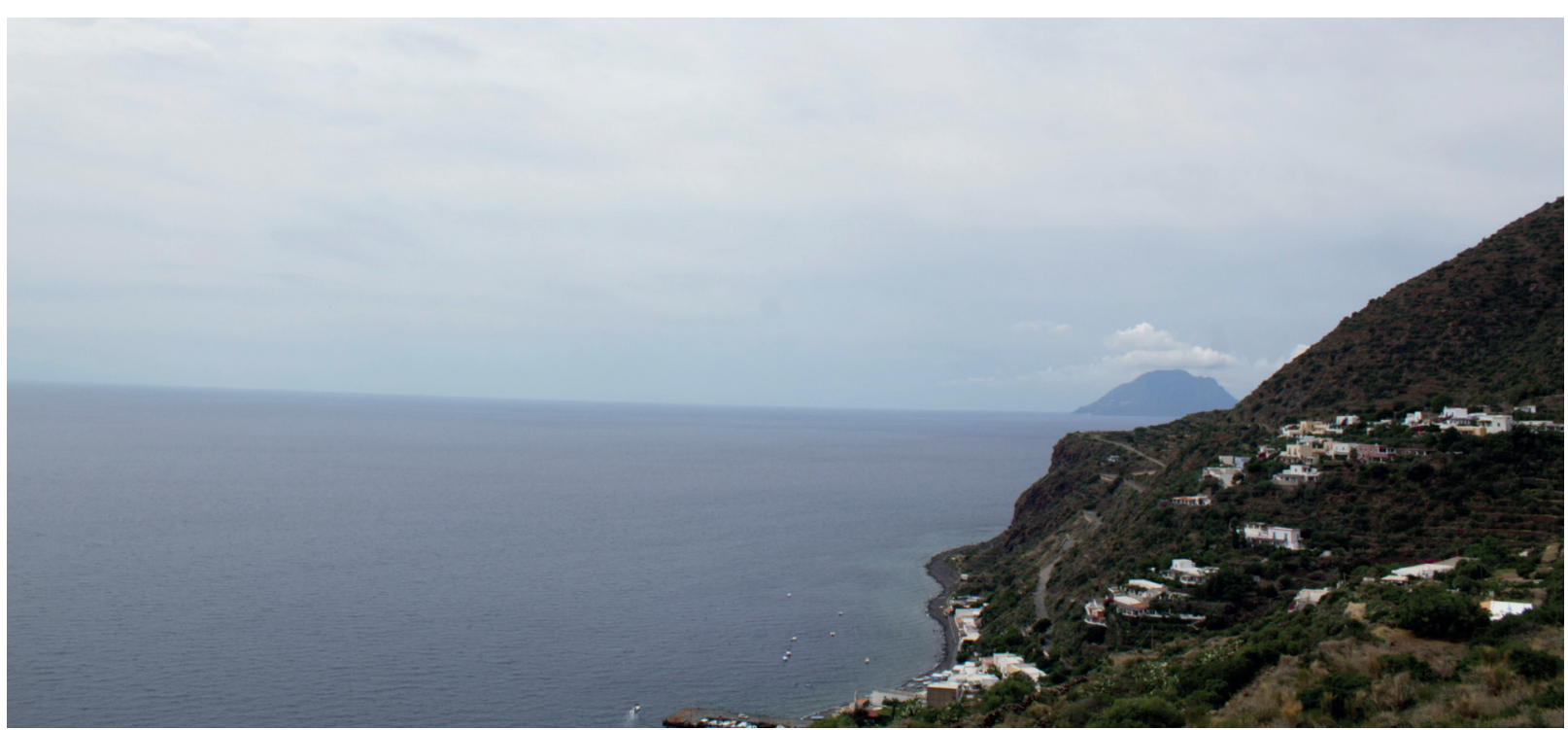

Figure 2. Picture of the study area 


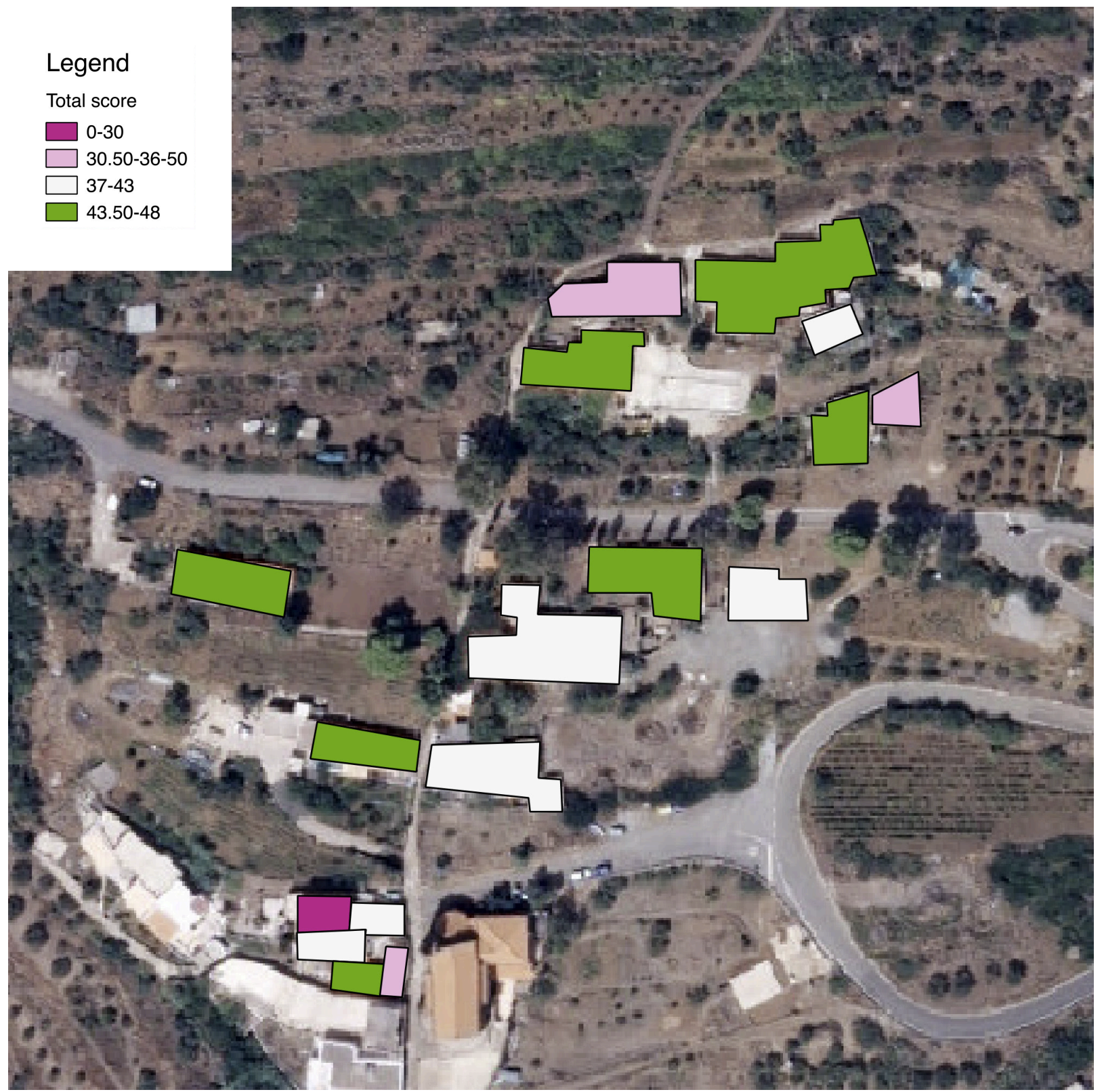

Figure 3. GIS map of the study area 


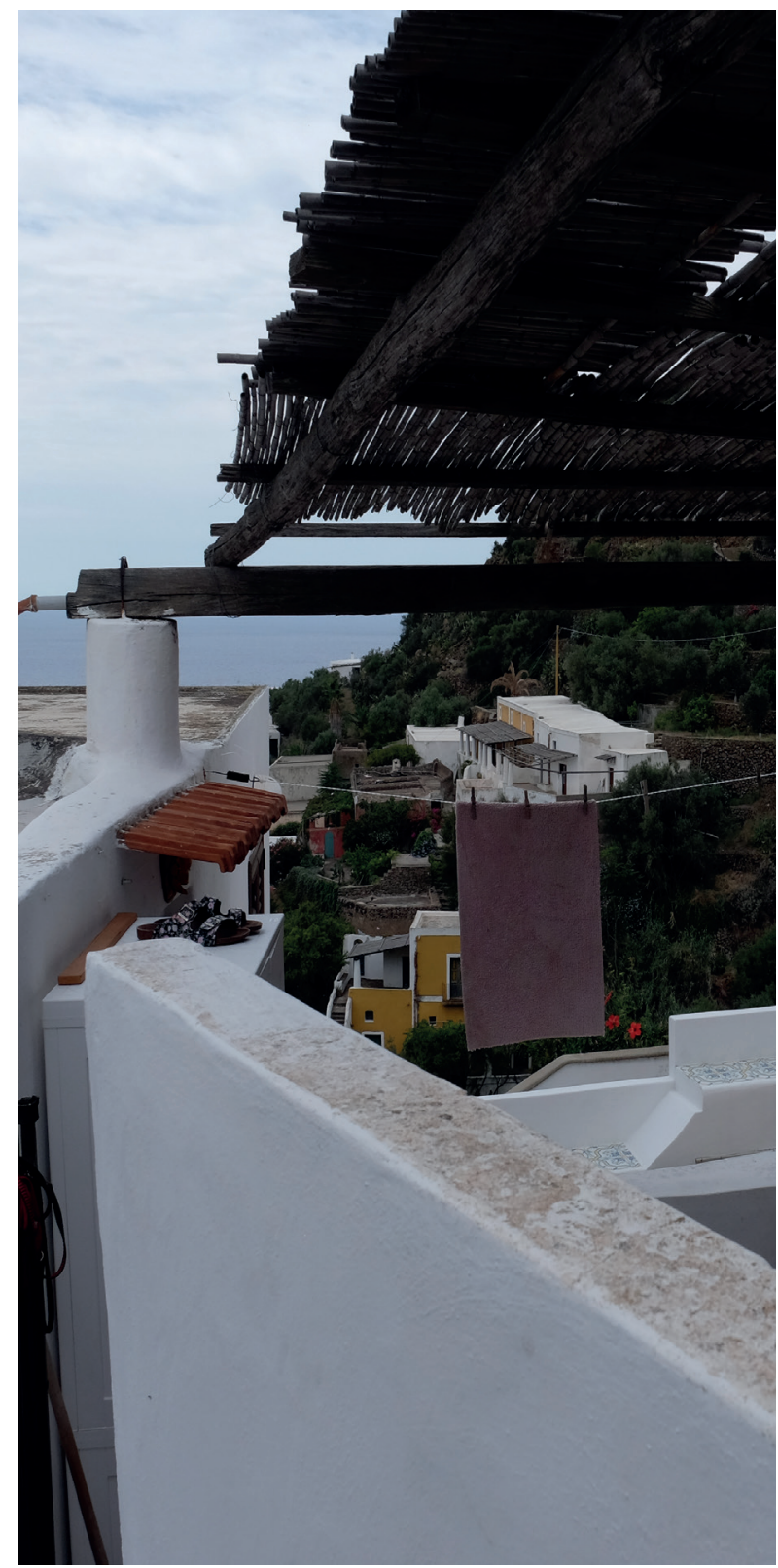

\section{FEATURES AND QUALITY OF THE LOCAL ARCHITECTURE}

The building's architectural aspect is not bad because there are a lot of constructions without traditional plaster color aspect, but most of the buildings have the traditional elements of Aeolian architecture like pulera, bagghiu, etc., that are in use. The architecture is thought to defend its inhabitants from the excessive summer heat. Indeed, the situation about energy requirements is not critical. It is better than what we had thought. The buildings are always oriented along east-west axis, with the terrace facing south. On this terrace, there is a roof that is laid in June and removed in September; in this way, it does not reduce the daylight flow during the winter seasons. The defense from daytime warming depends on the massive nature of the building envelope. It is formed by walls and roofs that have an average weight and are relatively high. A double opening system assures natural ventilation, single or cross. Most of the buildings do not have a heating and cooling system.

The building behavior is good because the type of soil on which the building stands is rock. In addition, the number of openings for each cell is limited, one or two, and no presence of damage or cracks.

Figure 4. Typical bagghiu 


\section{TASK 2 \\ DESIGN PROPOSAL}

\author{
EXISTING CONDITION
}

The building is located in the Pecorini Nord area, near the Catholic Church of Saint Joseph. This has influenced the configuration of the building because it served as the home for the village priest. At the same time, it incorporates, besides the character of the home, a sacred cross. The building consists of two large volumes - the actual building (ground floor and first floor) and the chapel. The whole building is in a state of great degradation and crumbling, the chapel has no cover, and the walls need consolidation because there are alarming cracks in them. At the same time, the main building retains only three walls, and the roof and the floor are destroyed.

The main character of the current building that led to the idea of our concept entails anchoring the building to a very high level. This has led to multiple accesses and entrance platforms at different heights, which is very restorative and has potential for our proposal. The building has three main accesses - east, west, and north - through the first floor.

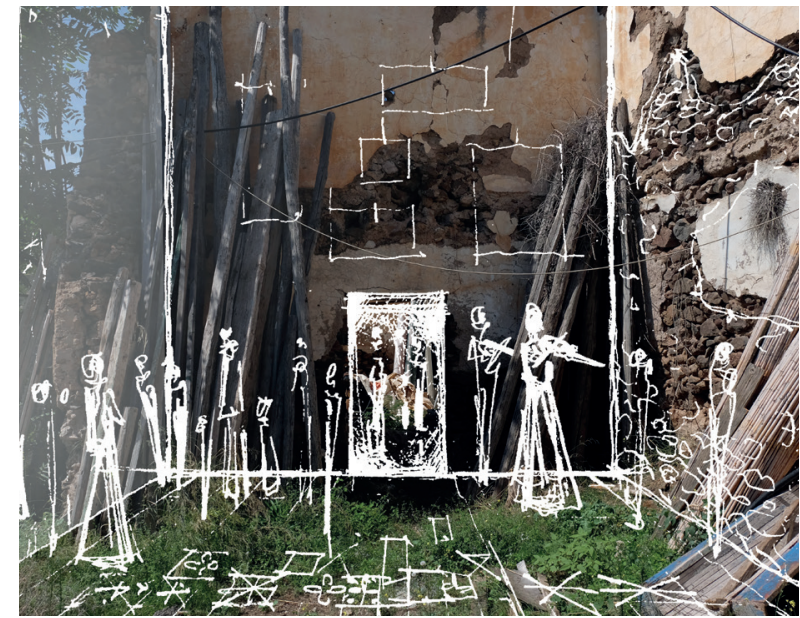

Figure 5. Design sketch of chaptel

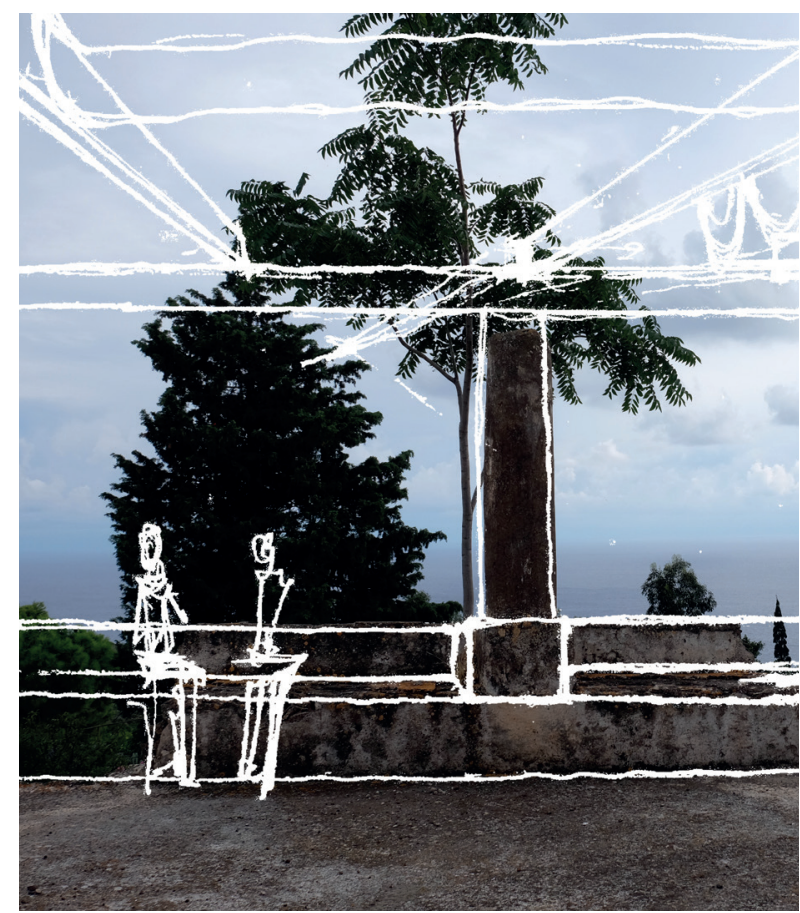

Figure 6. Design sketch of bagghiu 


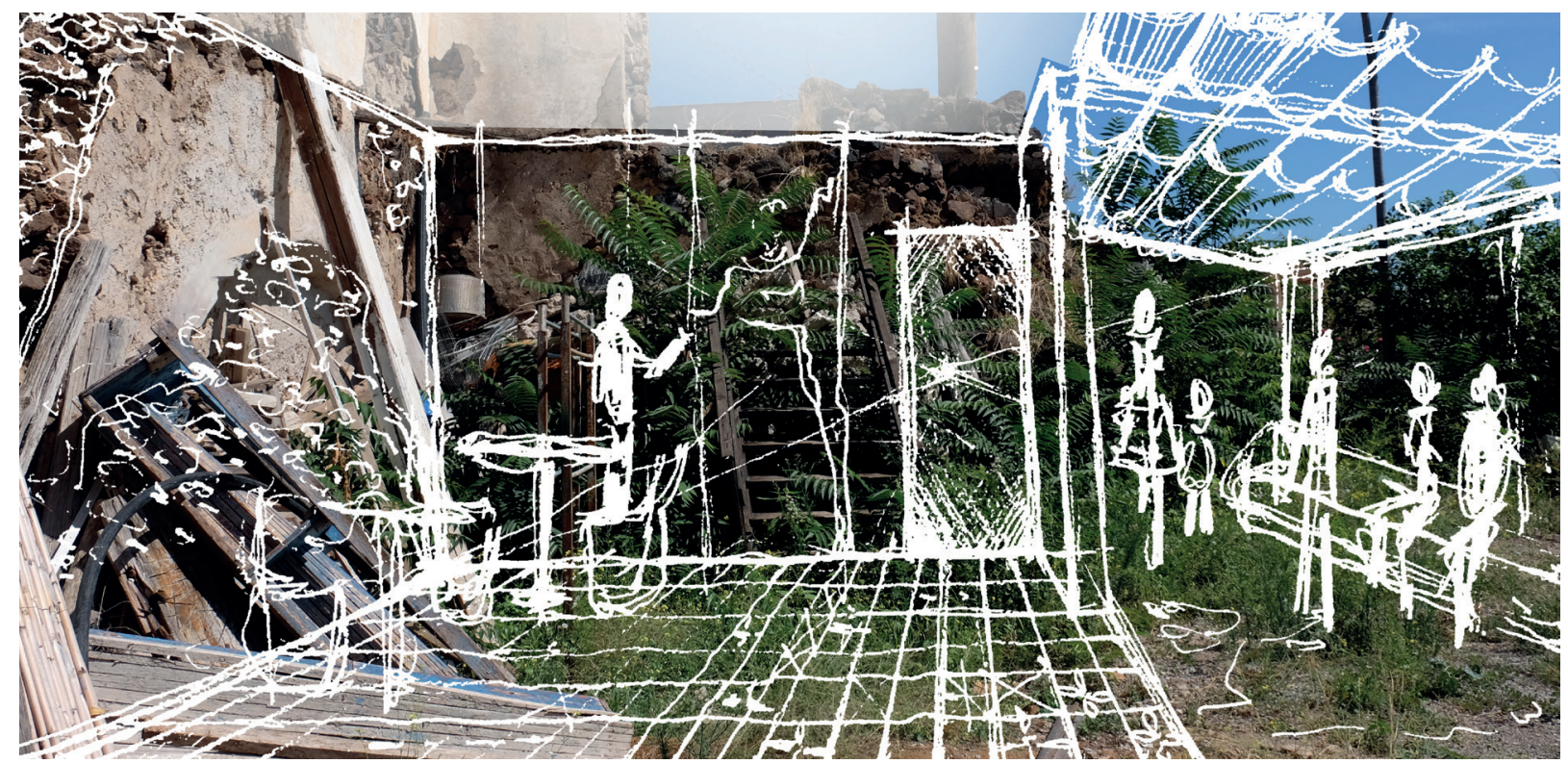

Figure 7. Design sketch of multifunctional space

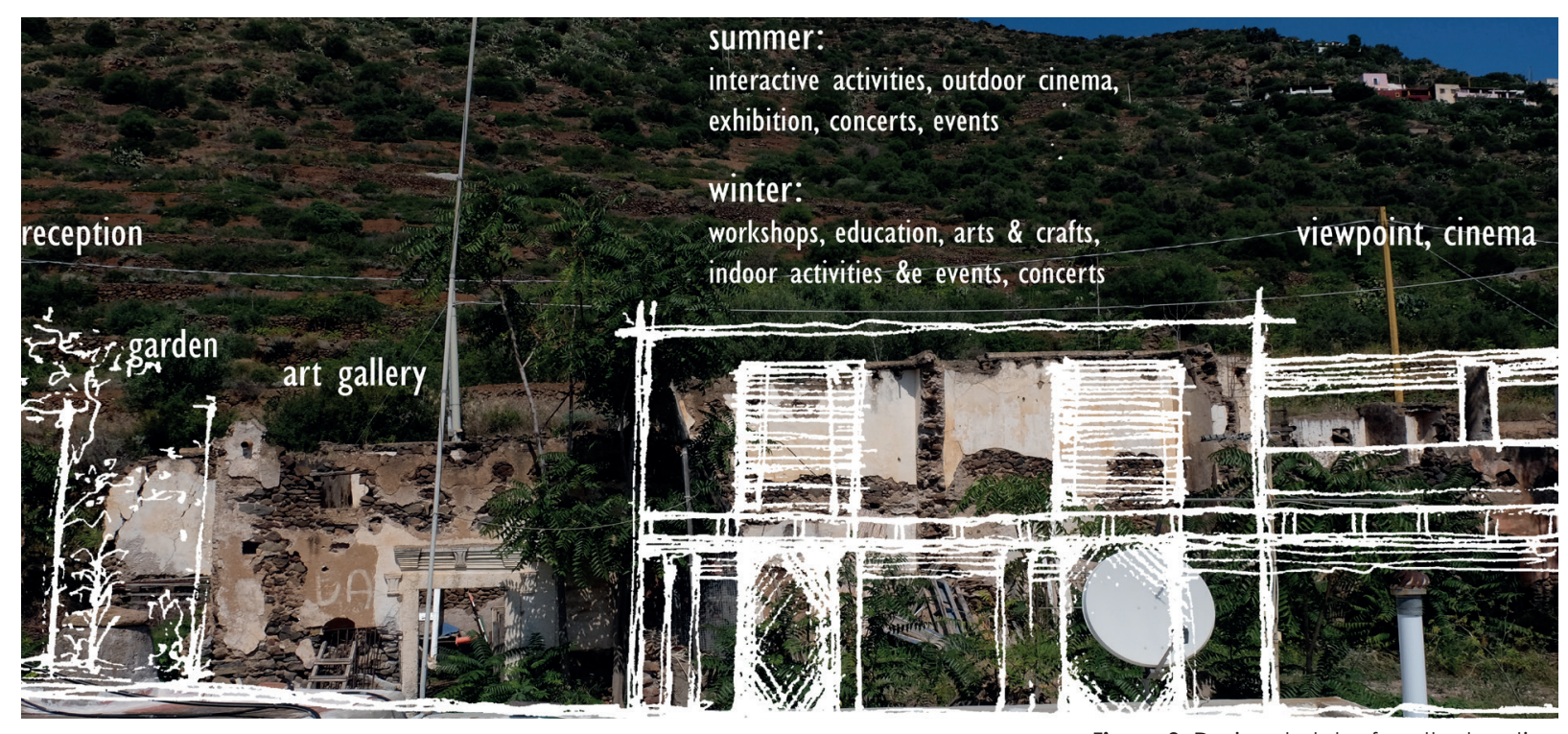

Figure 8. Design sketch of south elevation 


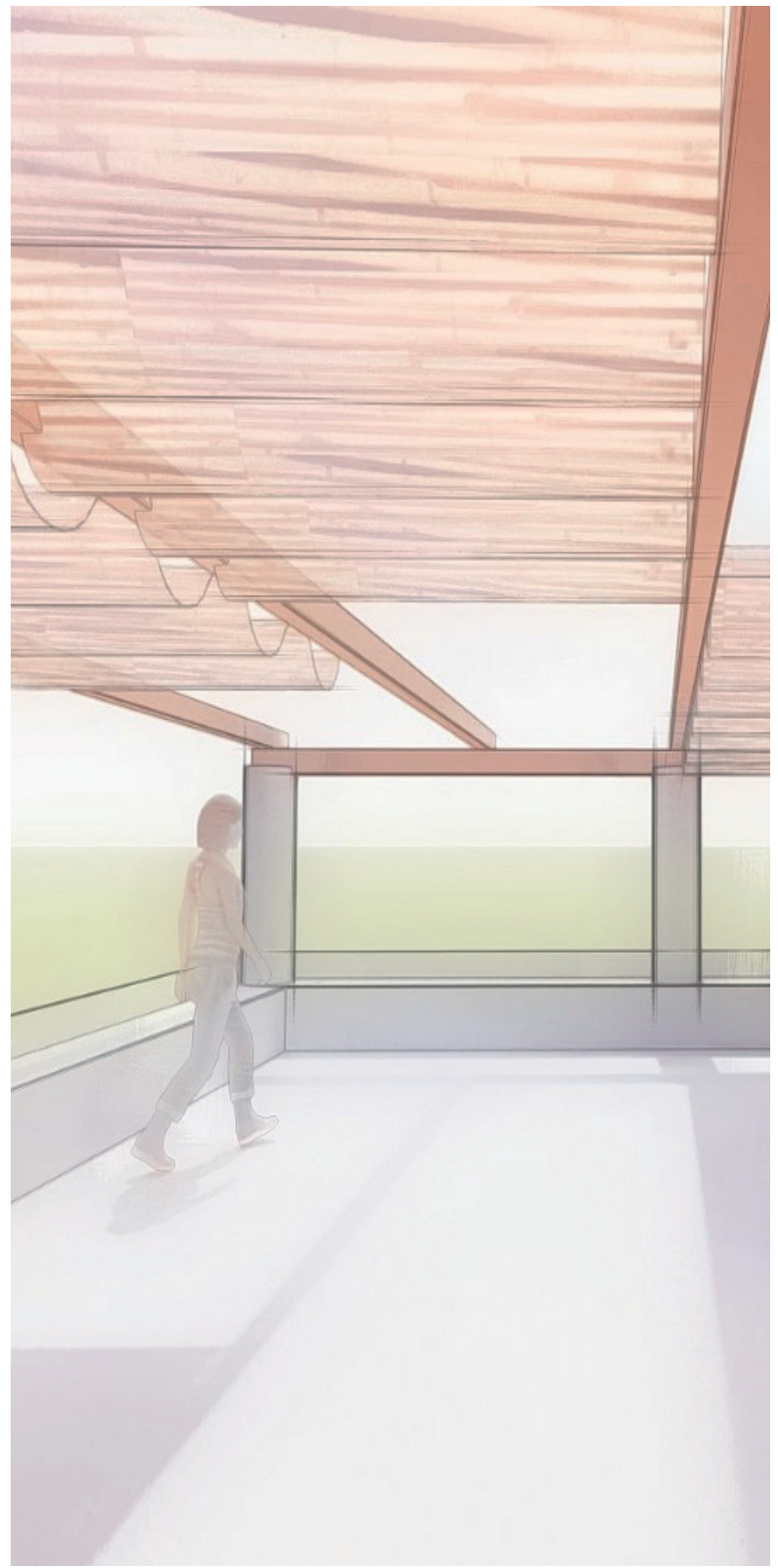

Figure 9. Perspective view of the new proposed bagghiu

\section{DESIGN PROPOSAL}

The first intervention is to strengthen and close the existing building envelope.

We propose the use of local materials and traditional construction techniques; thus, all the terraces of the old buildings, the entire southern wall, and the rest of the walls requiring interventions will be rebuilt. The old "bagghiu" will be rebuilt on its old footprint. New wooden beams will be laid and stabilized by embedding them into the southern wall. The southern wall, the main facade of the building, is destroyed. The second intervention considers the attempt to achieve a facade that respects the old positions of the windows/entrances so that the new addition matches the context, but also to bring a new, modern, image to the building. The chapel will be kept under the current conditions; the only intervention is to cover it with a lightweight structure that will protect the interior from direct sunlight. The element that brings novelty to the project is the coverage of the reconstructed "baggio". It is made of traditional materials (wire-bound reeds) but incorporated into a modern system. We wanted the covers to be easy to mount during summer and disassembly quicker in winter. The system also allows the cover to be opened or closed depending on the sun, maximizing the shading/sunbathing of the building. We also thought about the possibility of this system becoming automated.

By using reeds, the atmosphere created in the "baggio" reminds one of the traditional atmosphere of the houses, but by reinterpreting the volumetry, we bring new qualities, namely that the "baggio"'s cover can be changed as needed. 


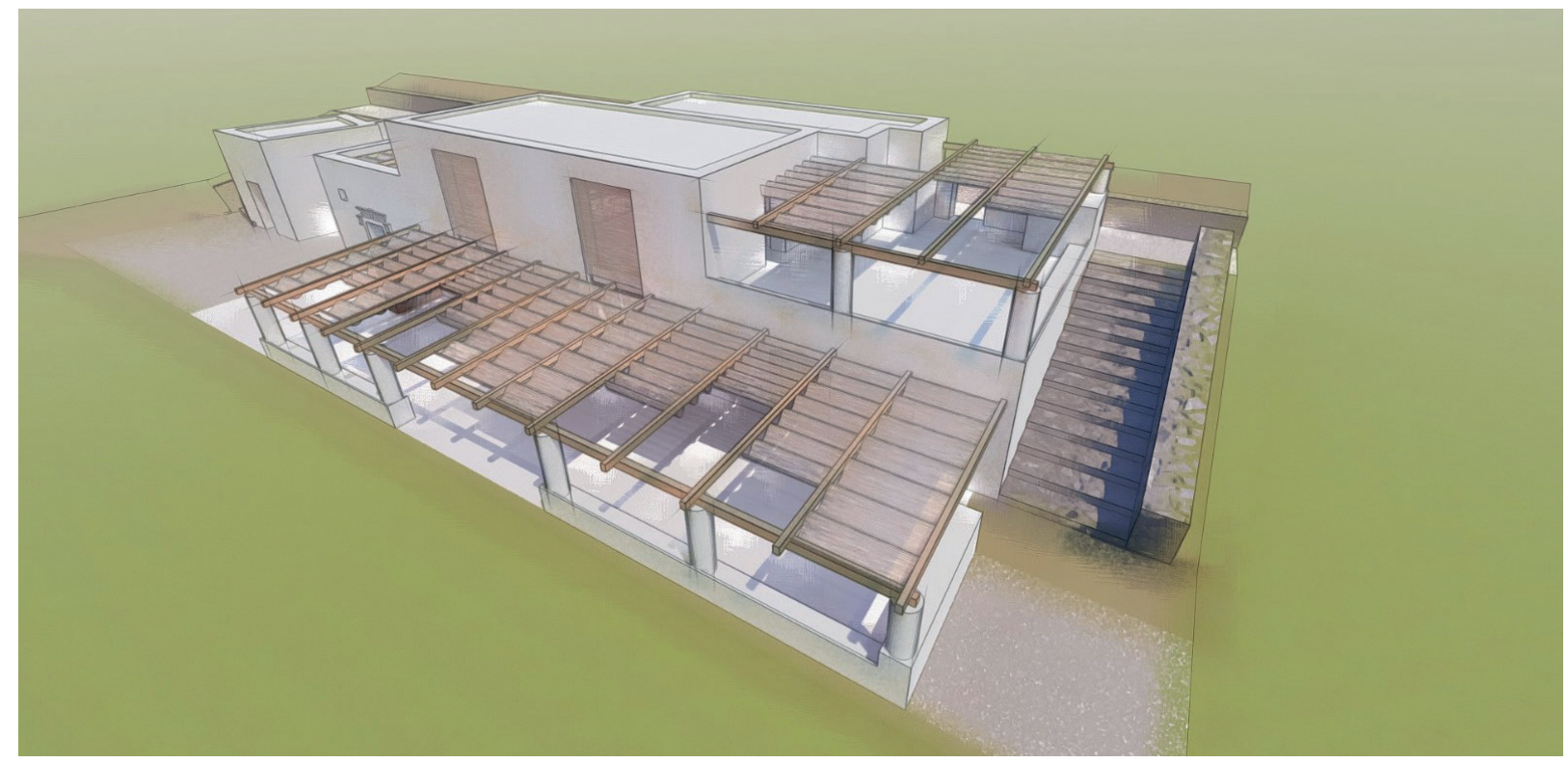

Figure 10. Aerial view of the proposal for case study building

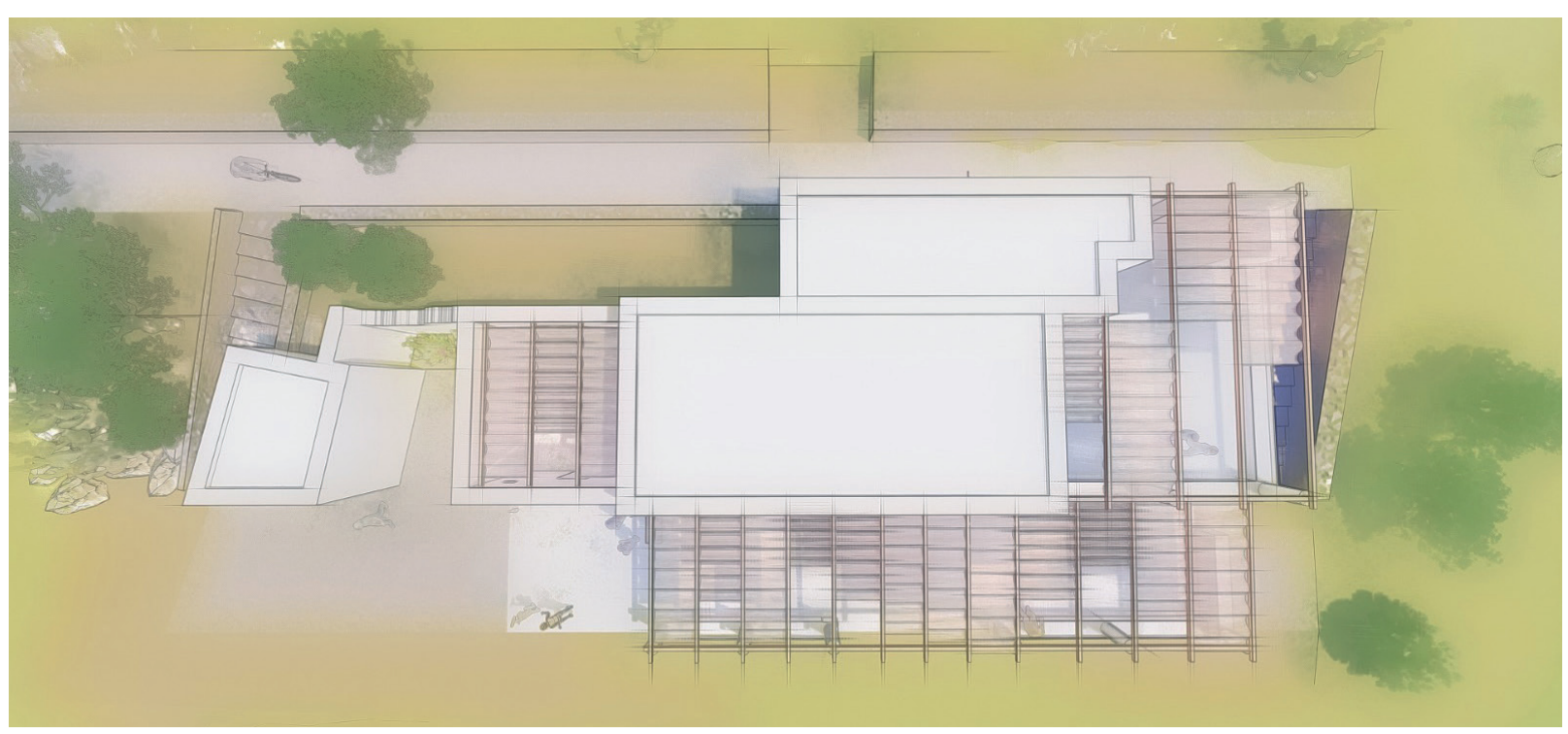

Figure 11. Planimetry of the proposal for case study building 


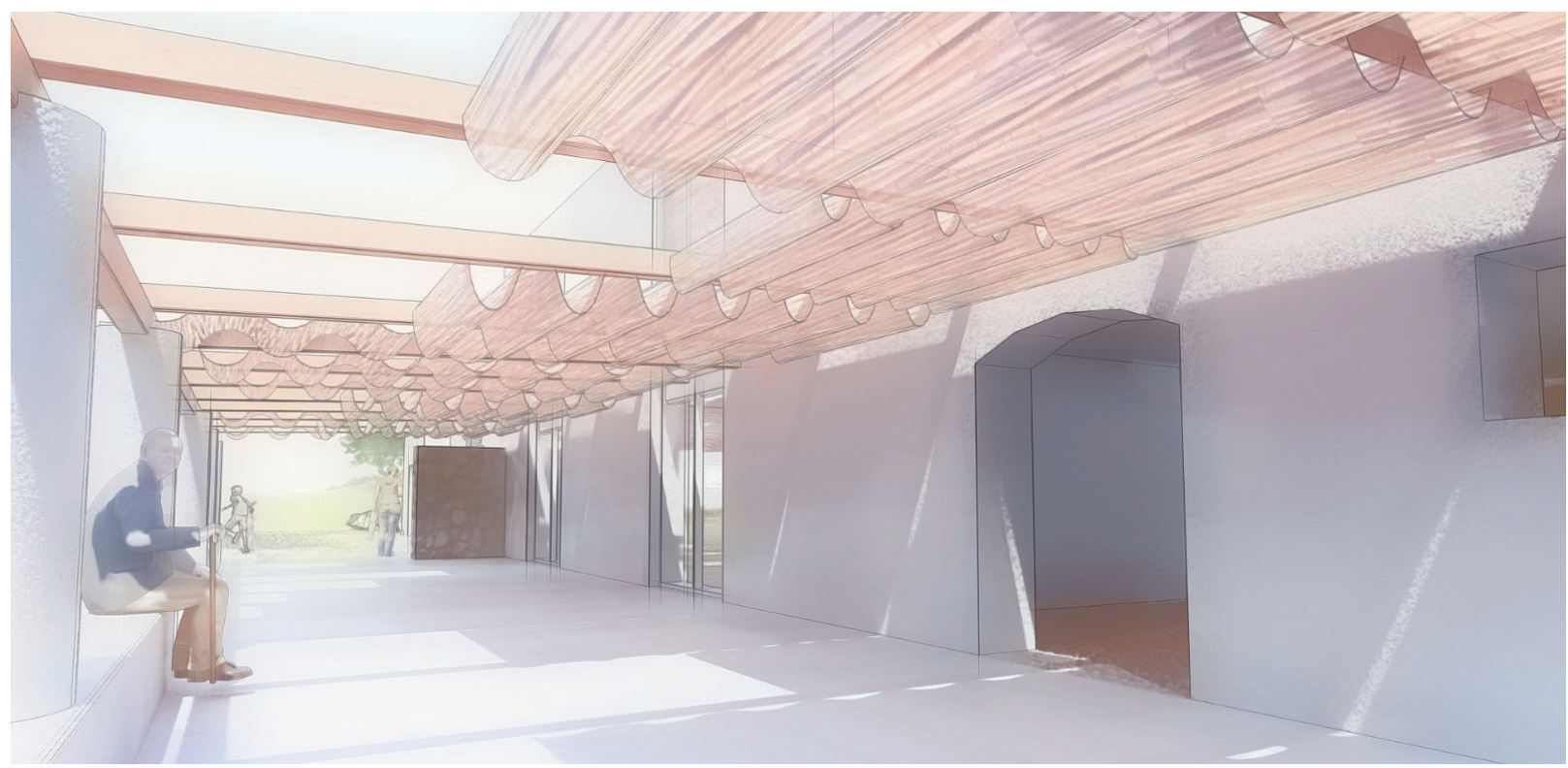

Figure 12. Perspective view of the new bagghiu

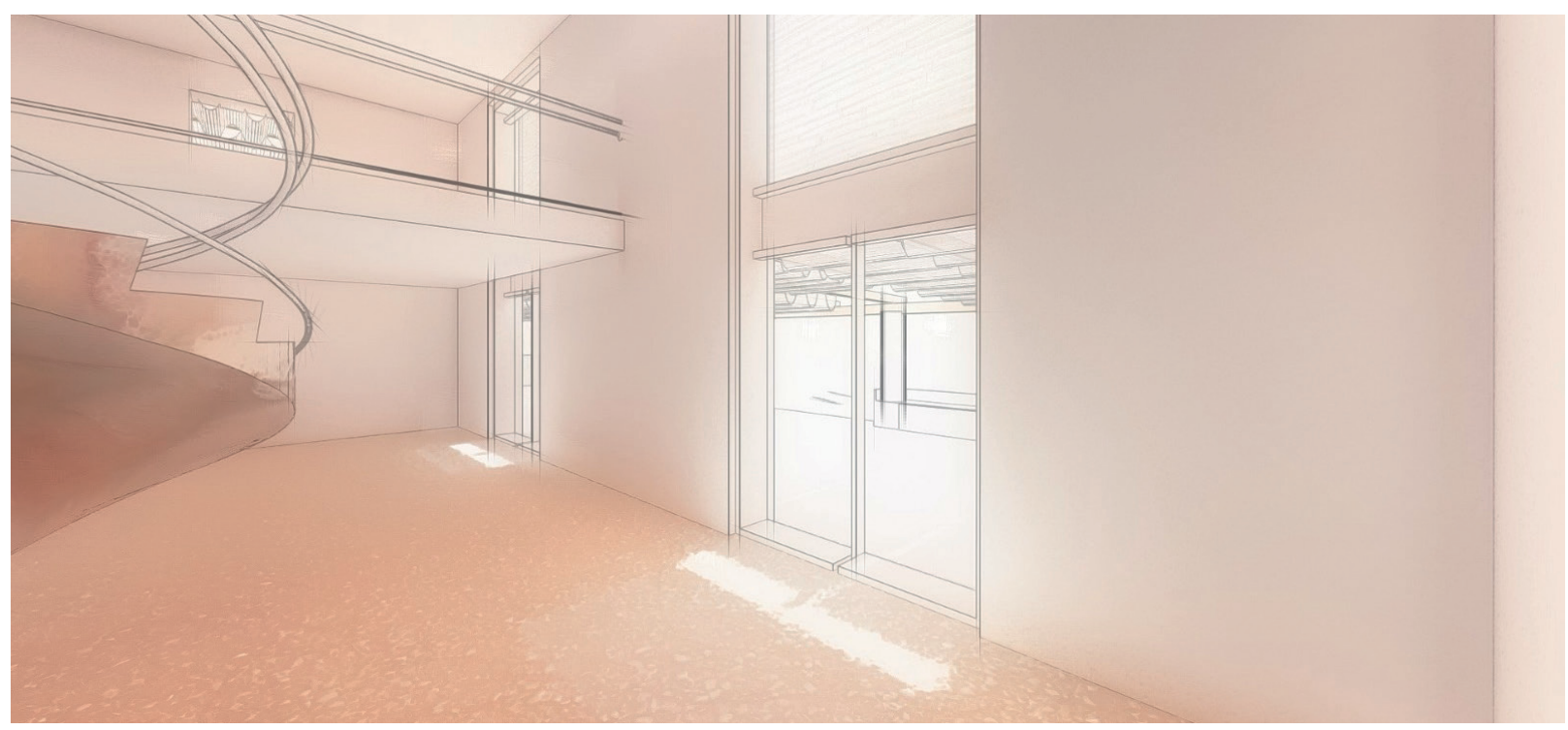

Figure 13. Indoor view of the proposal for case study building 


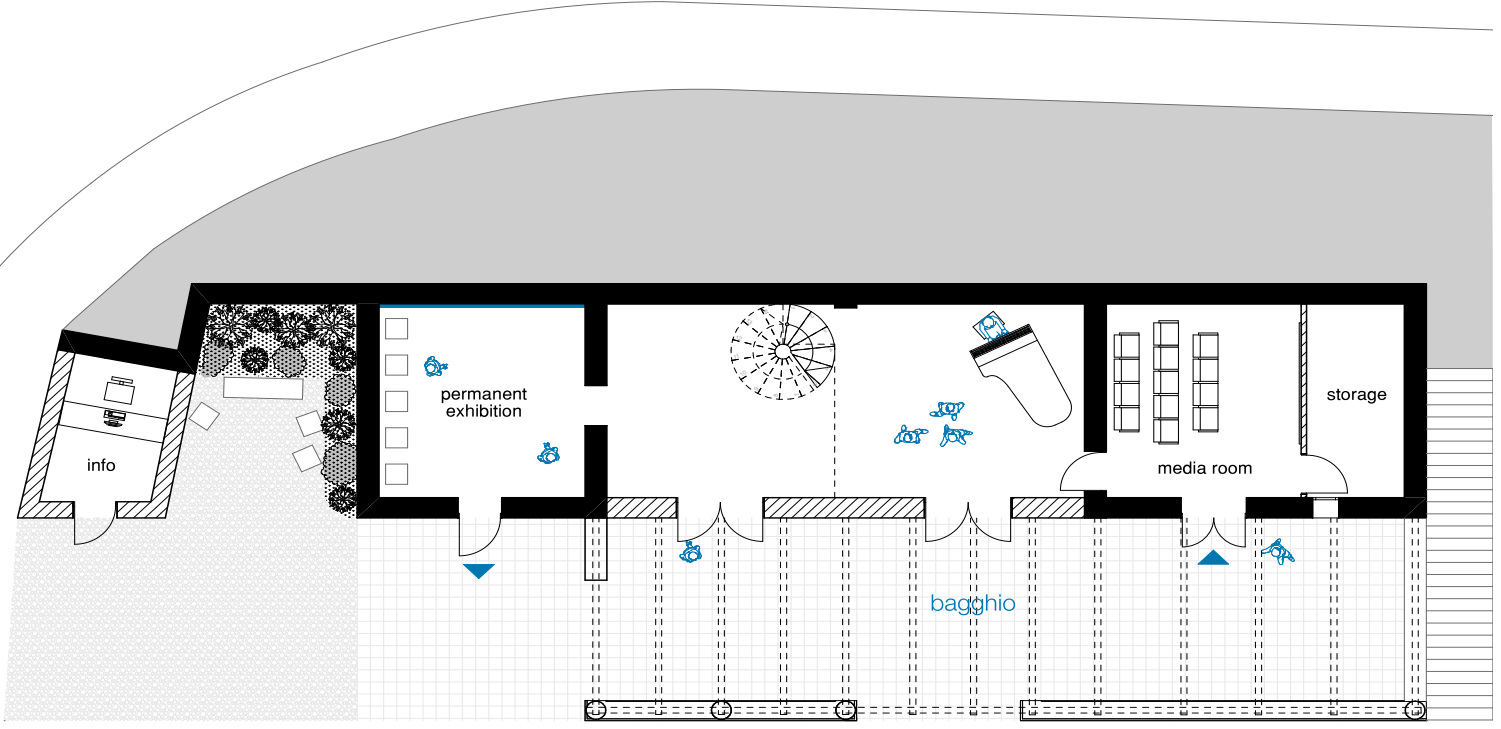

Figure 14. Ground floor plan of the proposal for case study building

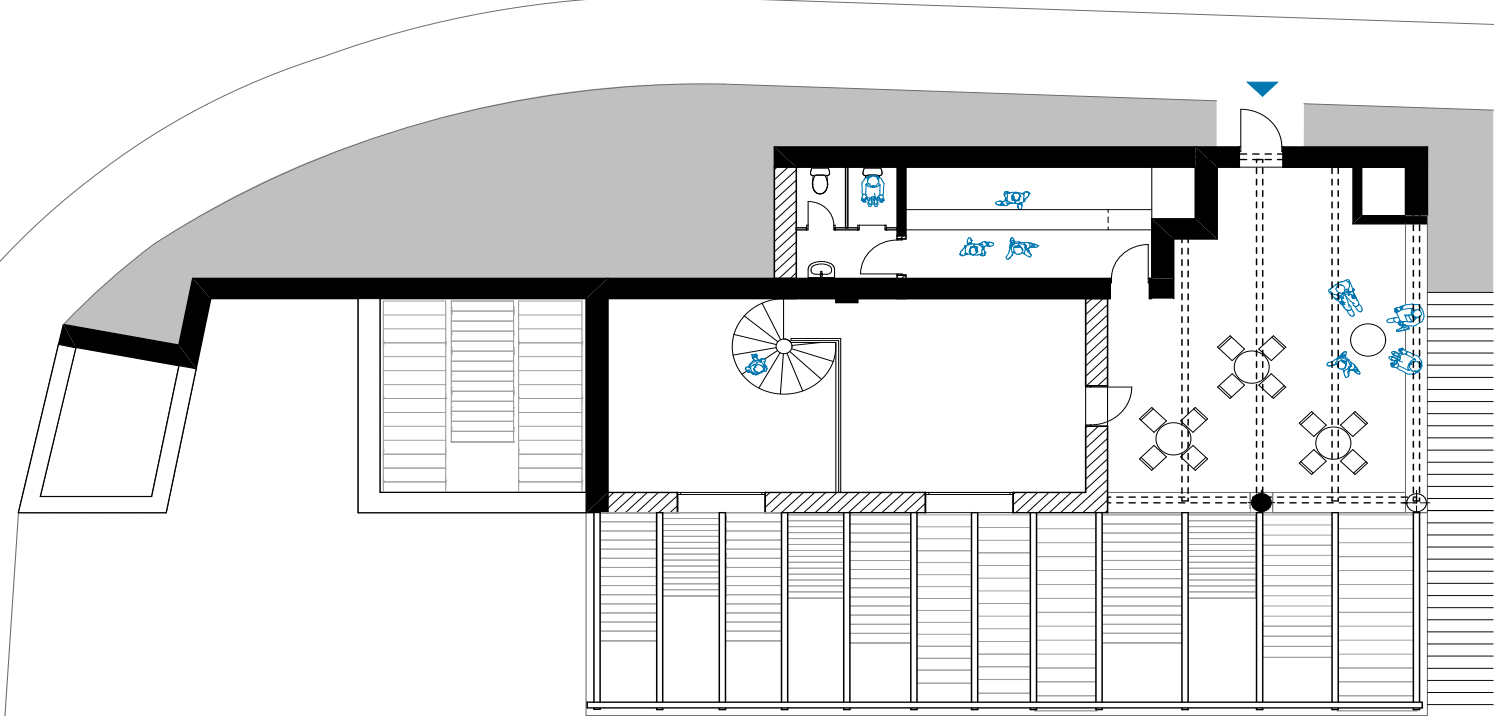

Figure 15. First floor plan of the proposal for case study building 


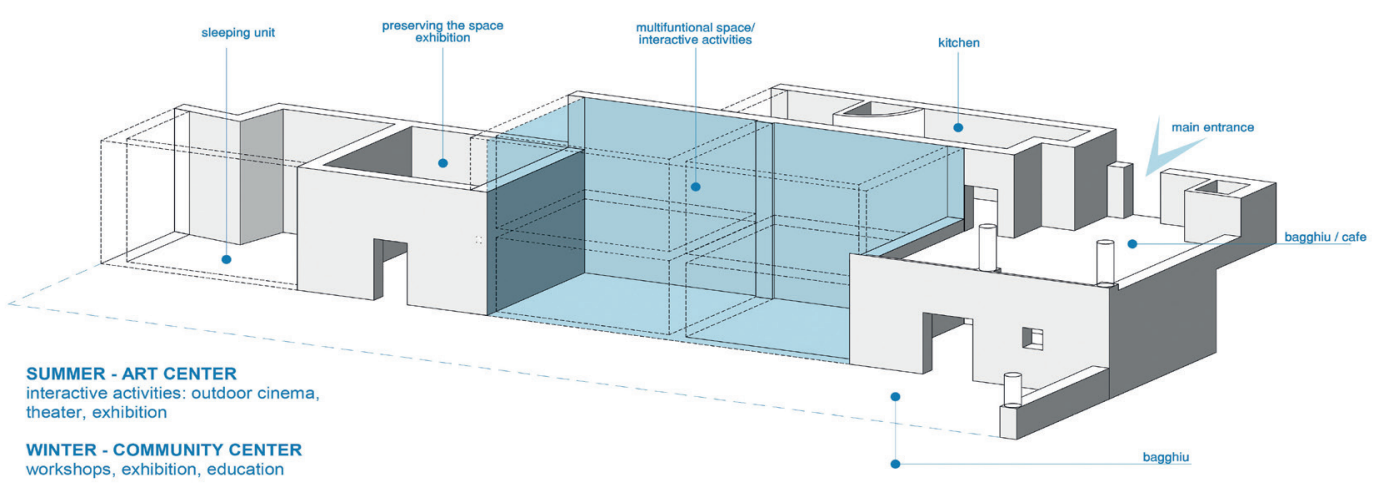

Figure 16. Axonometry diagram with functions of the proposal for case study building
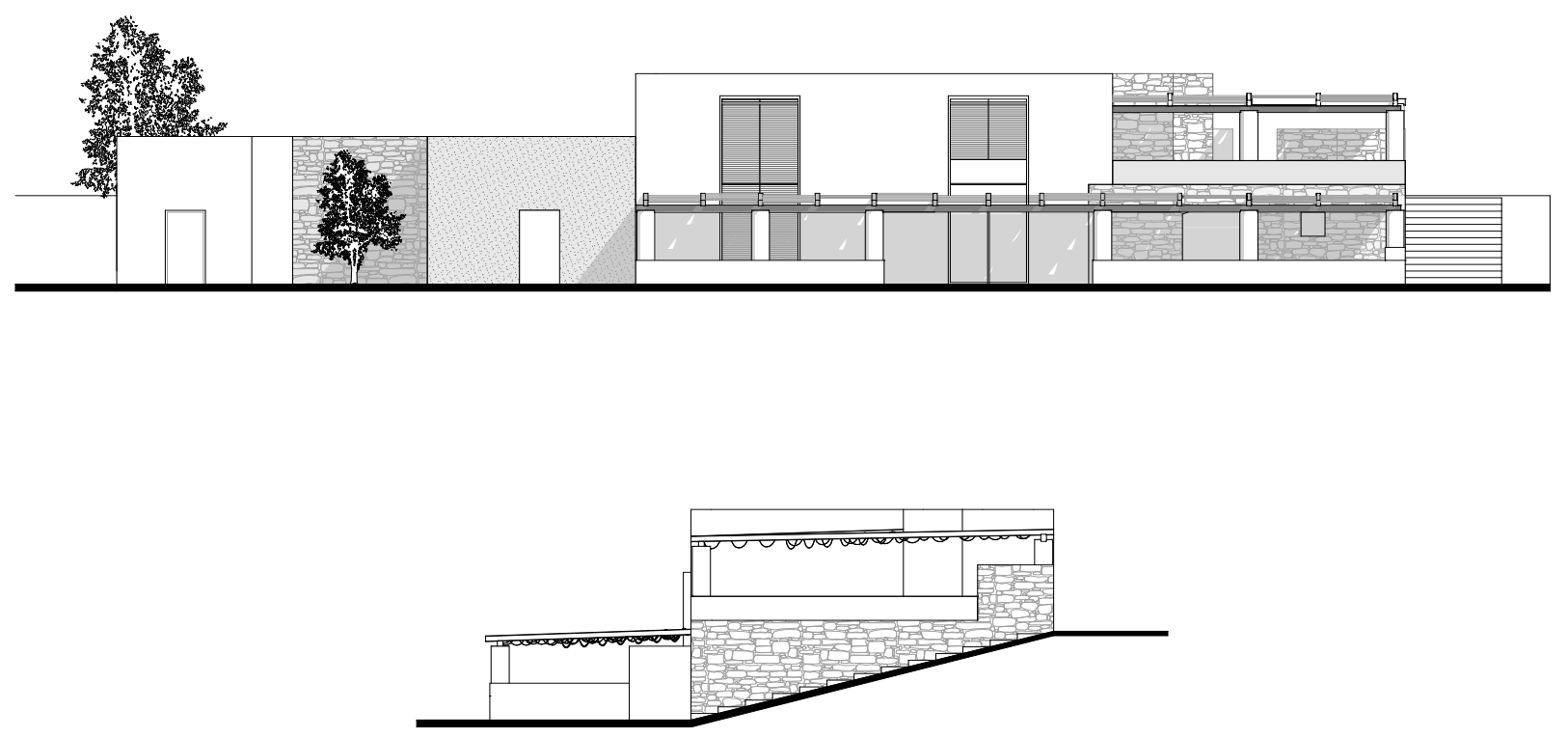

Figure 17. East and south elevations of the proposal for case study building 


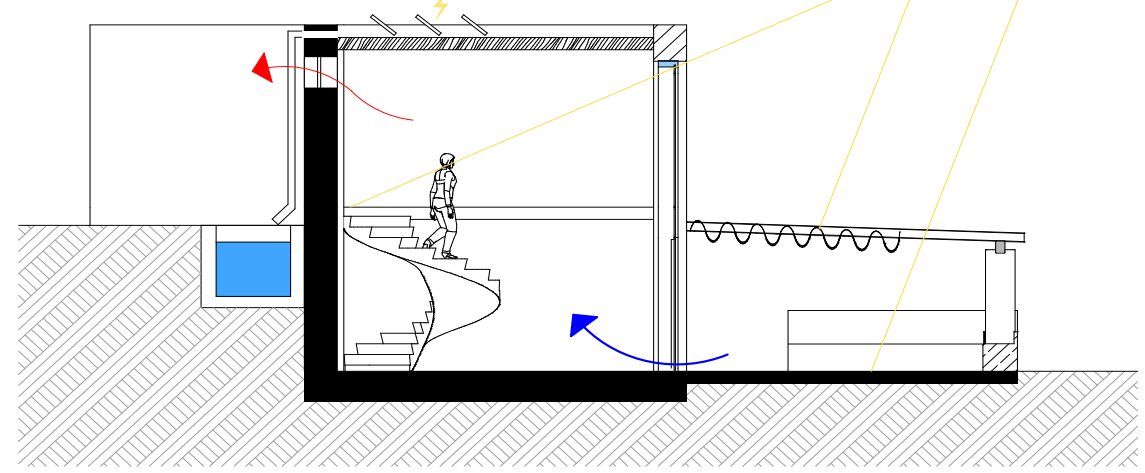

Figure 18. Section of the proposal for case study building

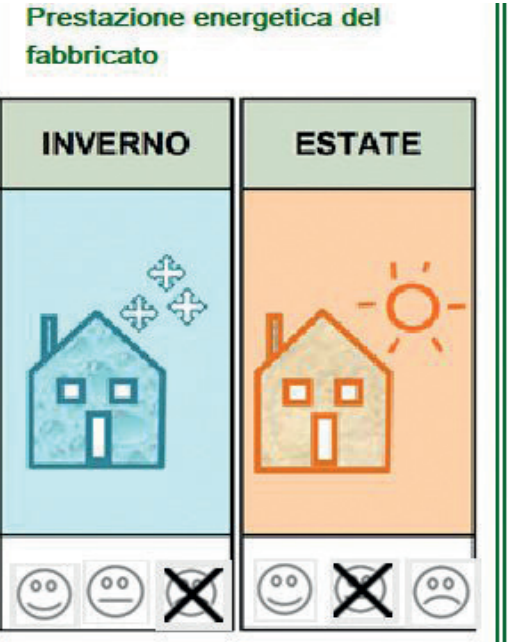

Prestazione energetica de

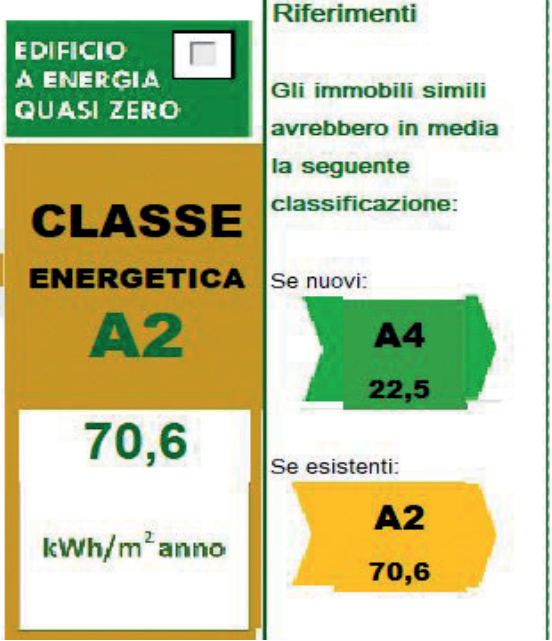

Figure 19. Energy class of the building 

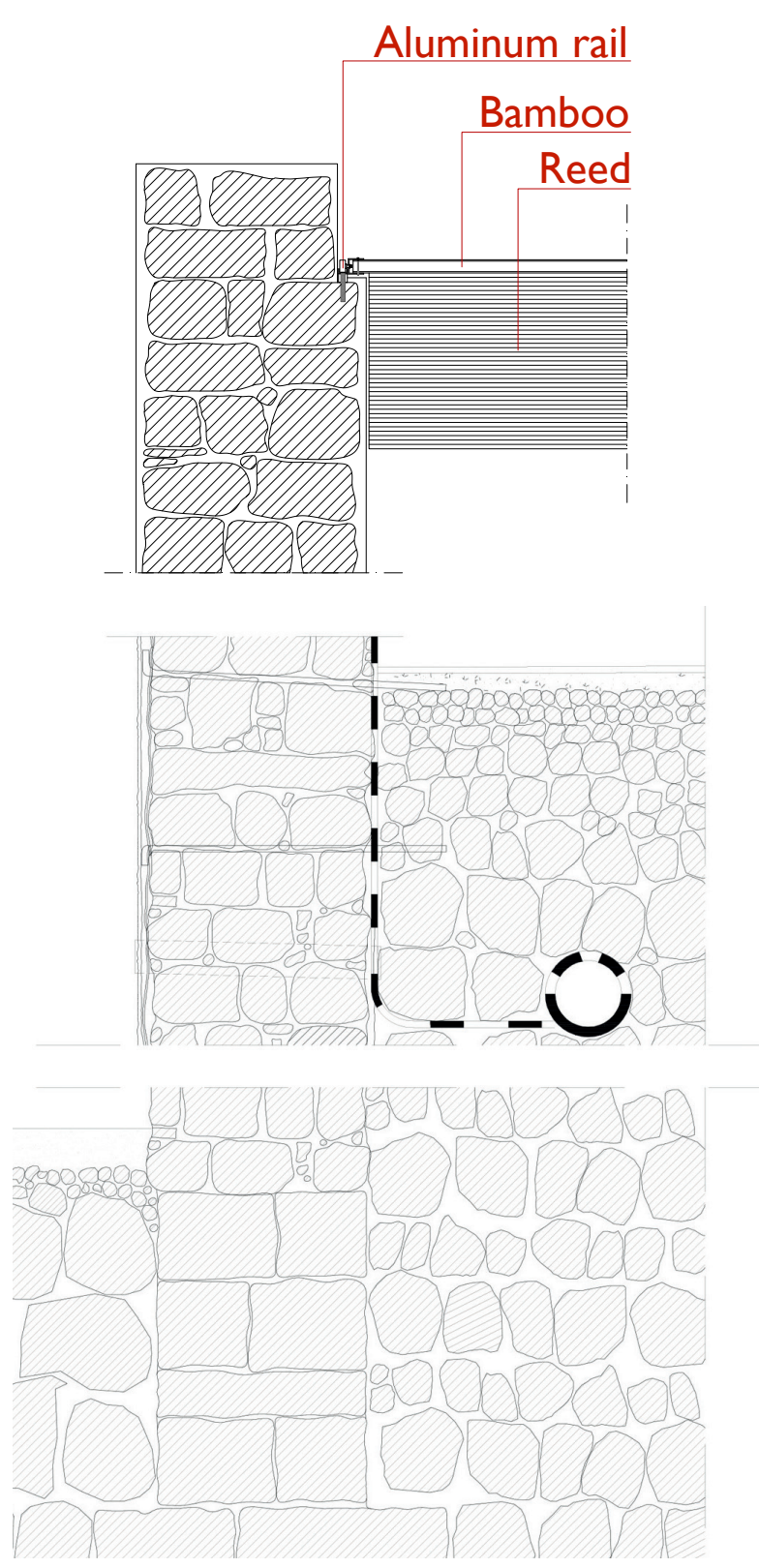

Figure 20. Roof and grounf attack details
DETAIL

The building object of the intervention presents several problems, due to the lack of maintenance of the same parts. For this reason, we decided to intervene mainly in securing the existing masonry and in the creation of new plasters, to safeguard the part of the building that still exists.

The first intervention to be carried out is the securing of the ruin; this is carried out by means of the "reticulatus", which consists of the insertion of steel rods linked together by a steel cable, which gives stability to the masonry.

Once this important procedure has been carried out, the existing plaster is cleaned with low-pressure water and, the plaster's gaps are filled; the joints are repaired and the new plaster is created.

The last procedure is the realization of the last layer of plaster.

Given the excellent location of the site, it was decided to take advantage of the natural ventilation for cooling rooms, accompanied by double glazed windows to prevent overheating of the interior.

Following the local tradition, a water collection system will be built using the flat roof.

Furthermore, given the excellent exposure of the building, photovoltaic panels will be positioned for heating domestic hot water. 


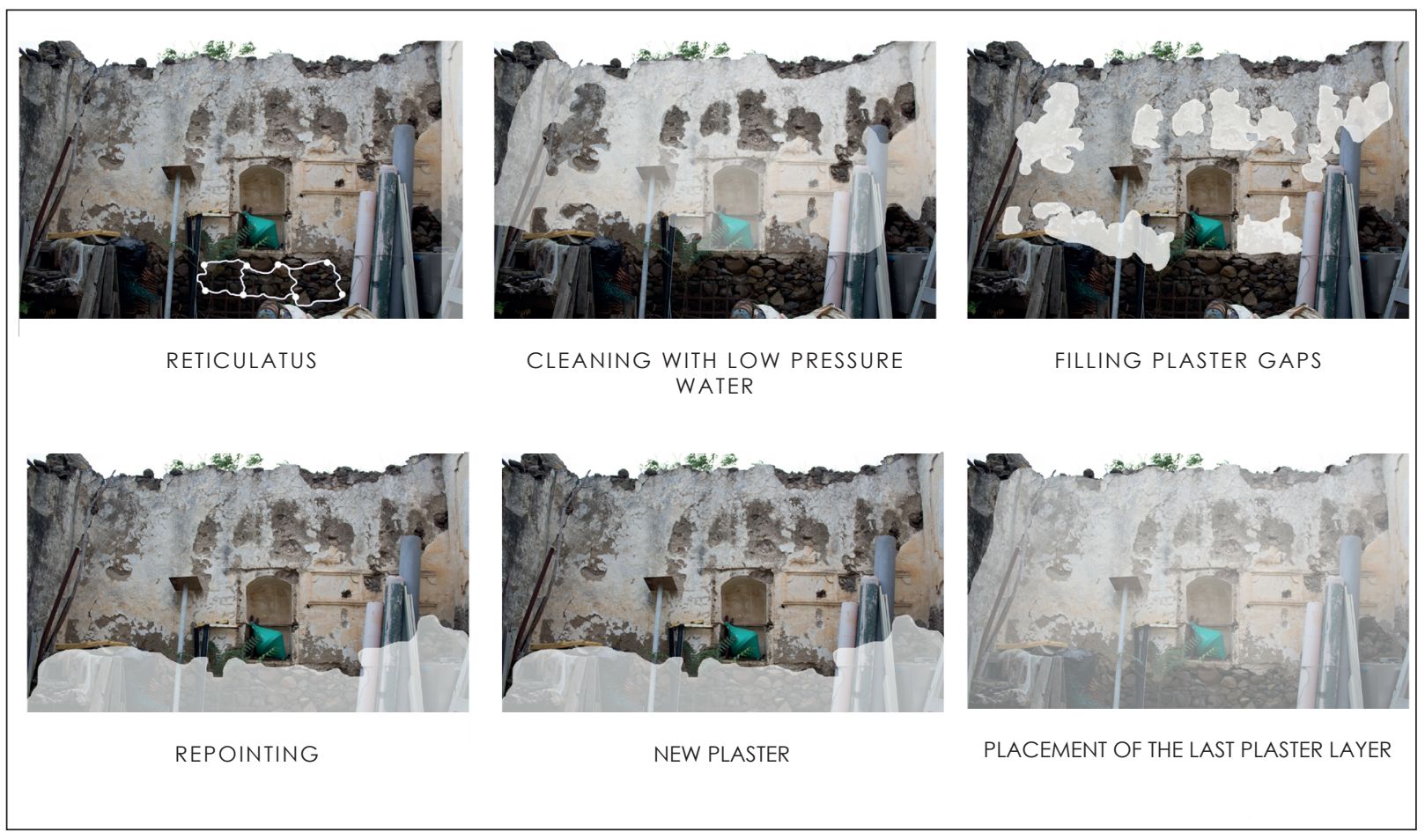

Figure 21. Constructive interventions 


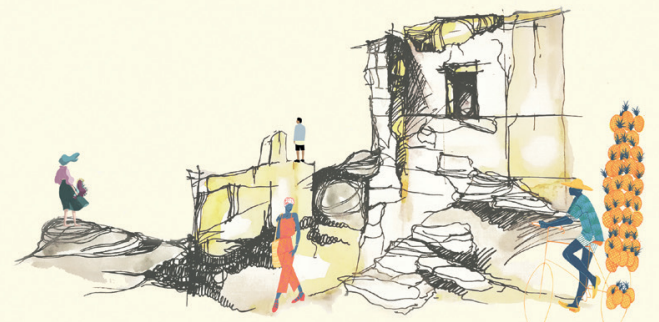

c a nale not 


\section{CANALE NORD SHADING}

\section{STUDY CASE}

Canale Nord

DESTINATION OF REFURBISHED BUILDING Info point

\section{ABSTRACT}

Walking through the in-between of Filicudi, we discovered another sense of "being" in the space, of experiencing a sort of solitude these beautiful vacation houses shared when, free of occupants, they just sat there, bathing in sunlight. Never before have we felt a place so forgotten yet still colorful and lively. There was color and there was whiteness, there was a stillness of the stone thick walls and there was wind, there was movement and there was serenity, where the high cliffs carved by people met the bright blue sea.

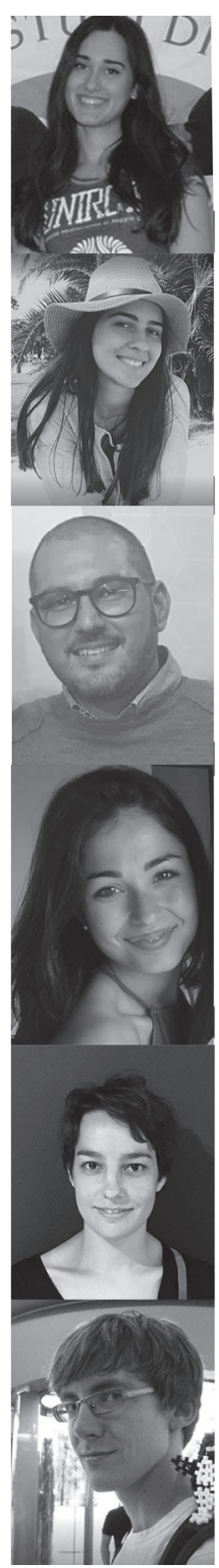




\title{
TASK 1 \\ CHECK OF THE AREA
}

\author{
CANALE NORD
}

Our object of study, the inhabited area entitled Canale Nord, is found at the south east base of the Filicudi isle, at the very point where Provinciale street splits into opposable directions, stretching onward on the coast sides of the island.

Thus, in a somewhat privileged location, closest to the harbor (the main shipping link) yet high enough to peek towards the horizon, the not so dense settlement organizes itself quite uniformly along the two secondary intersected paths derived from the main road (as seen in the site plans).

Both in terms of disposition towards the residential system (marginalized) and state of maintenance (ruins), the constructions we have targeted (pink colored in the general site plan) differ from the homogeneous residential area of Canale Nord. The intervention zone includes the remains of buildings whose past and use we have not been able to discover, an olive orchard and, to our surprise, two dwellings with an important history behind them: the mill where local flour used to be grinded and another where oil was made - with only the walls and the machines standing straight as witnesses, along with a friendly local who was kind enough to reveal to us the ingredients produced there in the past. Naturally, after discovering the nature of the constructions, the mill-orchard-port-house assembly began to make sense and inspired us into finding a contemporary response, a useful transformation plan for the future.

Ultimately, our goal became to let our experience of this place speak through the intervention we proposed, to keep it as light and minimal as possible, and have it generate pathways rather than sheltered. spaces. The shadows would become spaces under the sun, we thought, with a limit as immaterial as the shapes formed on the ground.

We designed a voyage through the landscape, one that would stop only to witness three ultimate experiences offered by the island. That of being in the landscape, and taking the moment to embrace everything around, that of moving through the landscape, and finally, of sitting to watch beyond.

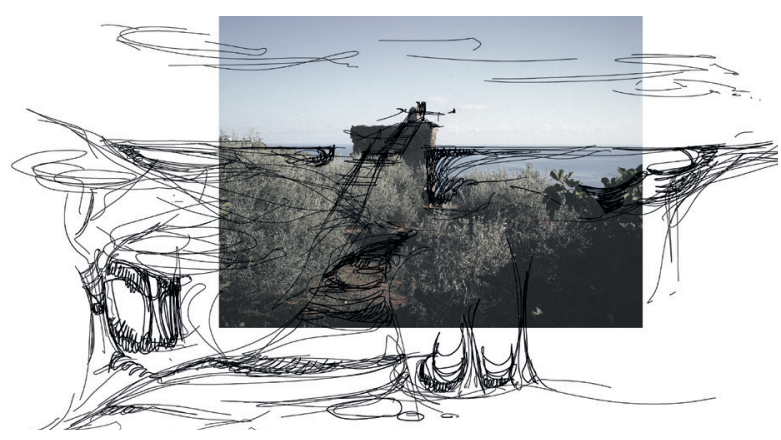




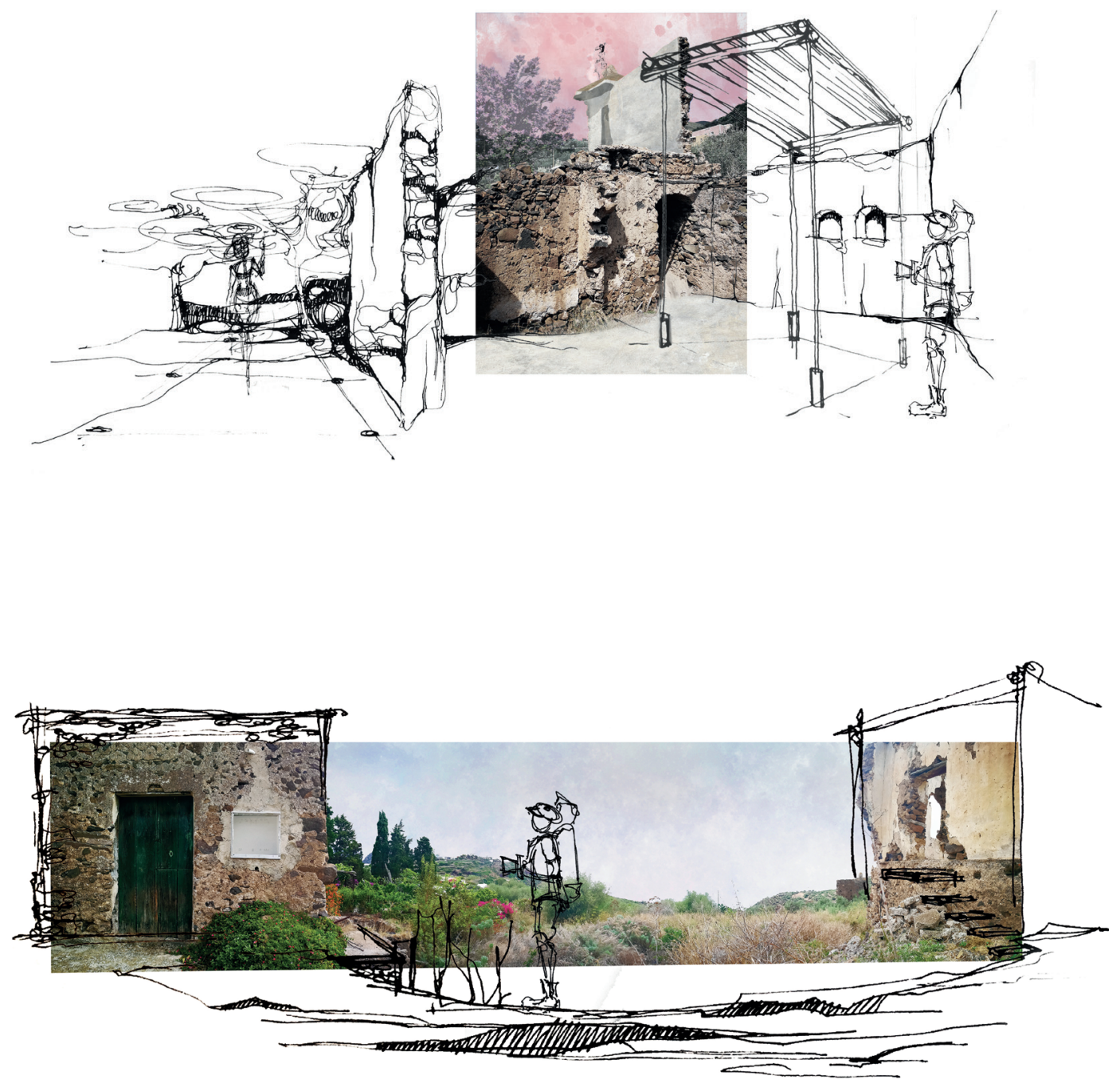


\section{FEATURES AND QUALITY OF THE LOCAL ARCHITECTURE}

Being, we found, should have you hover above ground, as though positioning the subject of our trail of experience in the midst of sky and land.

Moving should happen up and down by climbing through the landscape itself and on the punctual staircases, placed either alongside or perpendicular to the view, having you walk alongside and towards the destination.

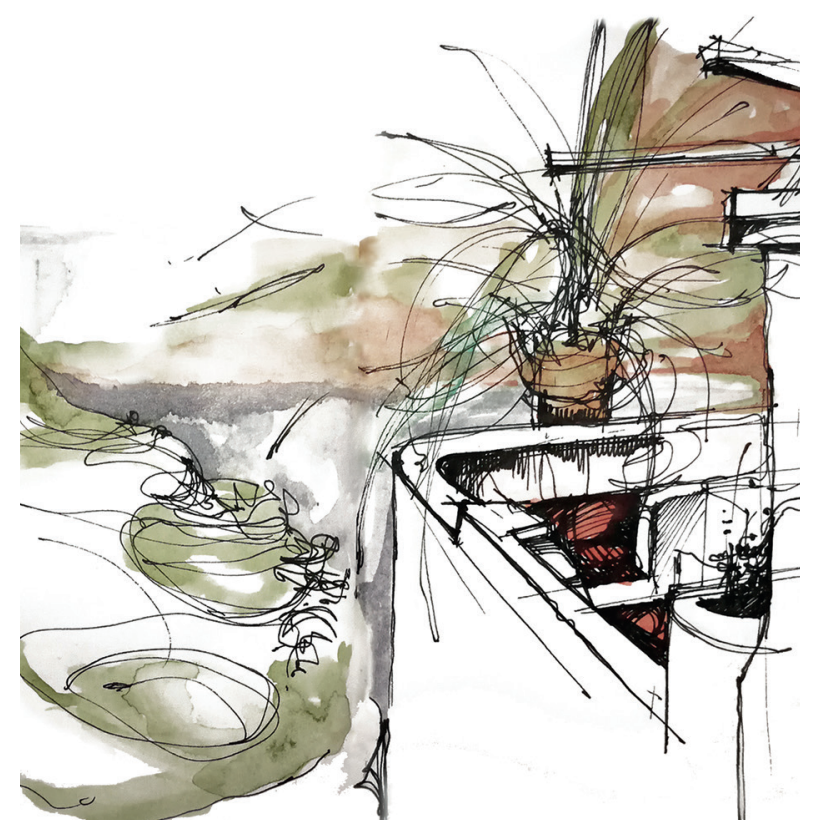

Watching happens in the most intimate of places, through what was once a window frame, a remembrance of past and origin - thus, watching not only with one's eyes but also through an awake consciousness of the place which lies ahead.

The architecture of the island is generated by the utmost primordial need of shelter, through pure and artisanal techniques, therefore resulting in a tectonic hard to replicate today. We tried not replicating but seamlessly joining past and present with two goals in mind: to transform shadow into space and create a sensorial experience based on the moment of meeting between "stranger" and "island".

As has previously been mentioned, the settlement of Canale Nord is, in terms of location, truly privileged; thus, the fact that its buildings are (mostly) still inhabited is no wonder. We were able to notice a state of architectural homogeneity arising from the existence and maintenance of the traditional elements of the Aeolian house. Moreover, modern technological interventions were not numerous lat least as seen from the outside of the homes we were not able to enter). The local architecture of the zone indeed represents a perfect machine à habiter, its components being perfectly suited to the weather conditions, land features, and local lifestyle. 

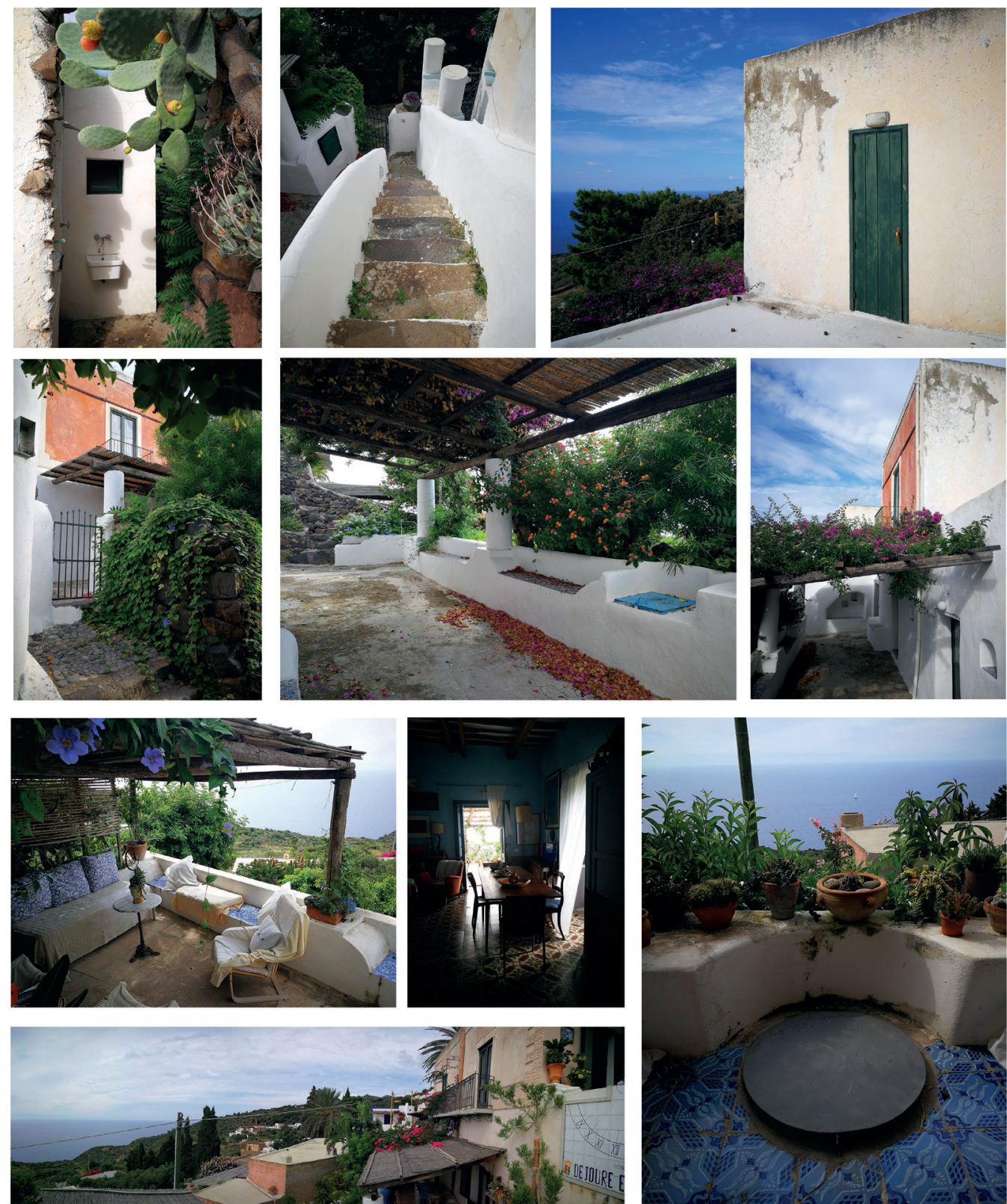

Figure 3. Typical Aeolian features 

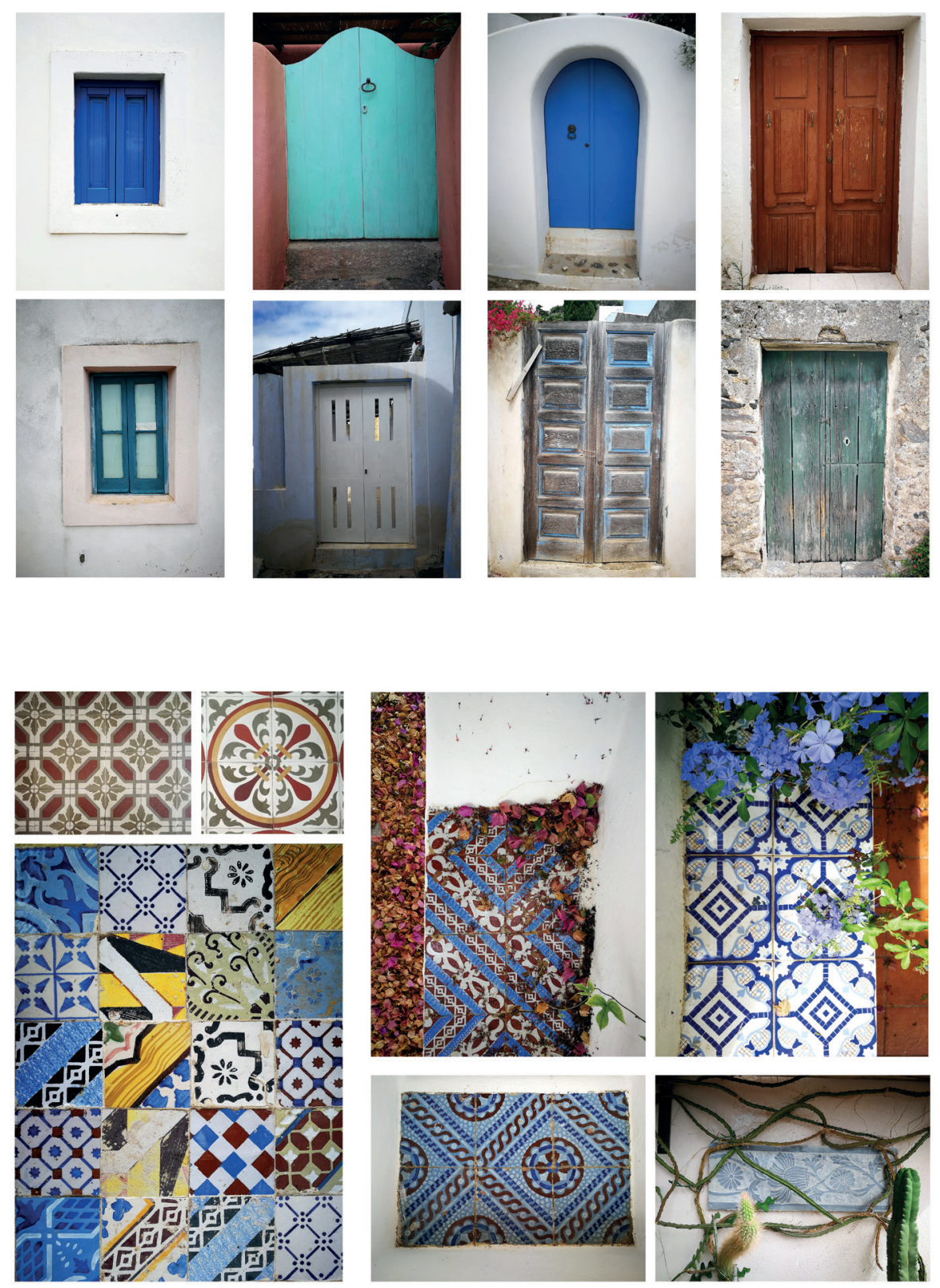

Figure 4. Details: doors and patterns 


\section{GIS THEMATIC MAPS AND SCORES}

The first part of the analysis phase foresees a cognitive inspection for all the buildings of the study area. For each building a survey has been compiled with information of a geometrical, constructive, structural, historical, and energetic nature. Once data collection is complete, the next step is to enter the information into a database. For this phase, we used the GIS tool.

A Geographic Information System is designed to capture, store, manipulate, analyze, manage, and present spatial or geographic data.

\section{Facade Color}

Not original color

Other original color White
The tool allows us to obtain thematic maps, an architectural score, structural score, and energetic score for each building. The processing of the three scores determines a final score on the overall quality of the buildings. The purpose of the analysis is to create a study method, a new tool useful for administrations for planning and design of the territory.
Puleri

Not in use In use 


\section{0-1940 \\ 1940-1980 \\ before 1900}

Age of buildings
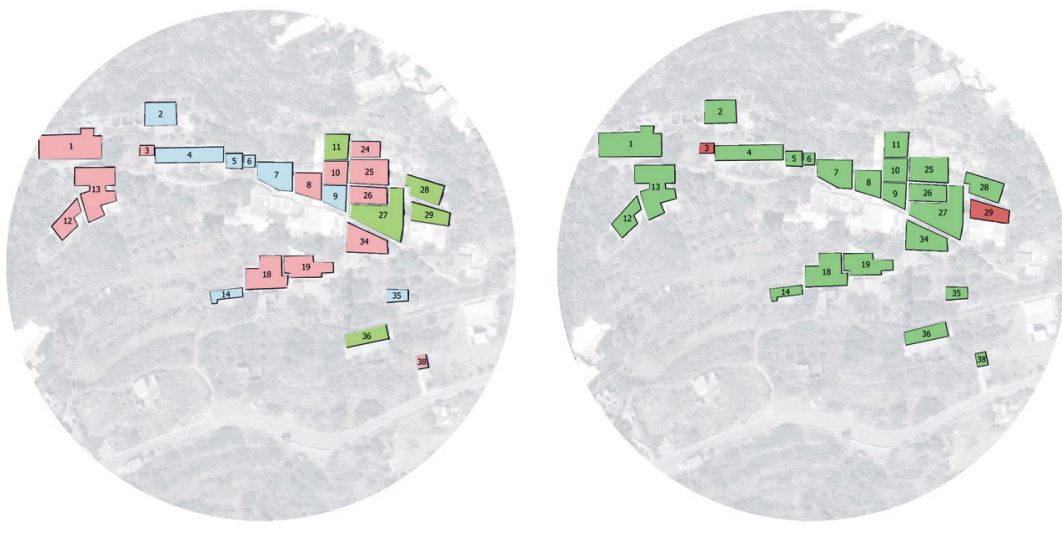

Bagghio

$\square$ Not in use

In use

Layout configuration
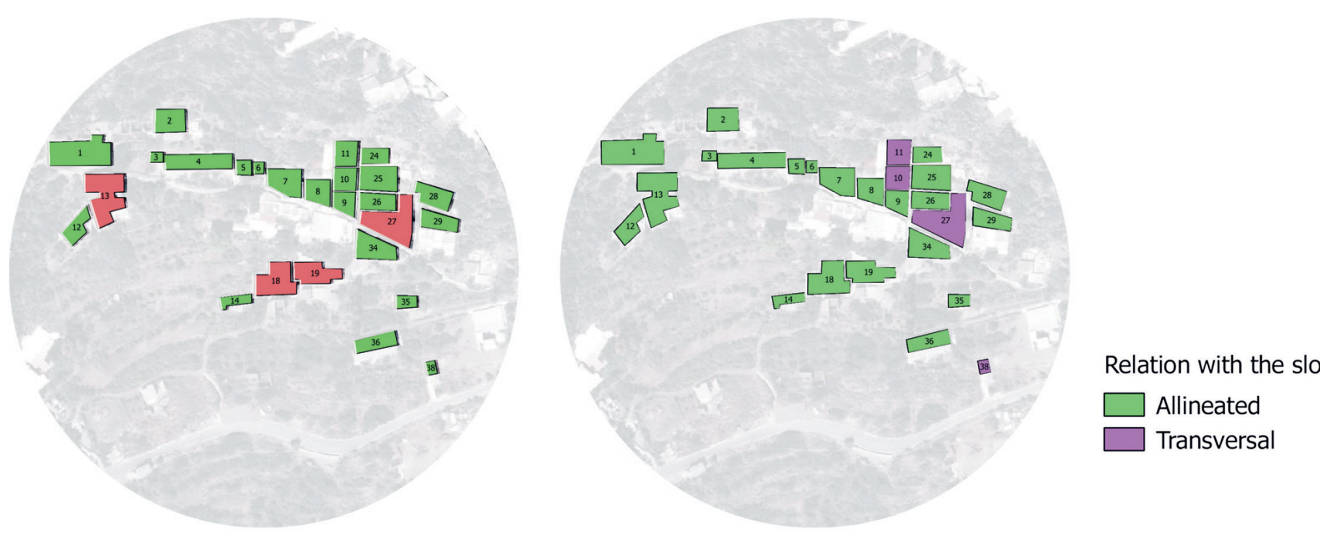

Dimension

$\square>100 \mathrm{~m}^{2}$

Irregular
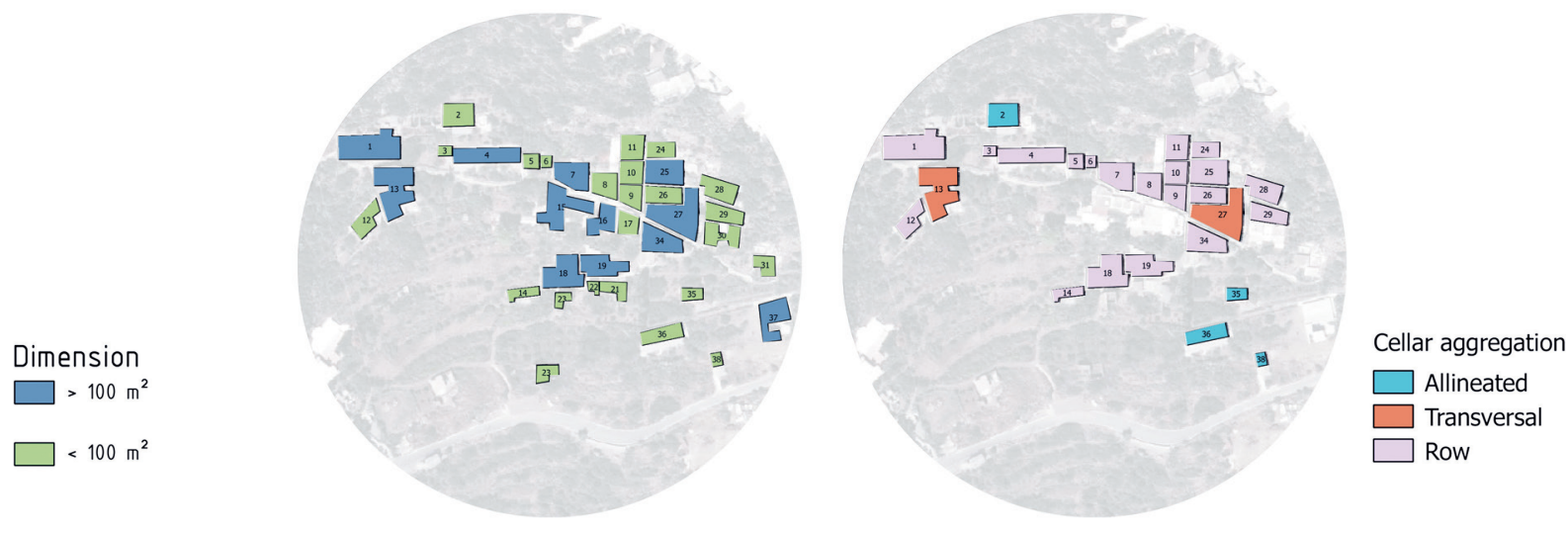

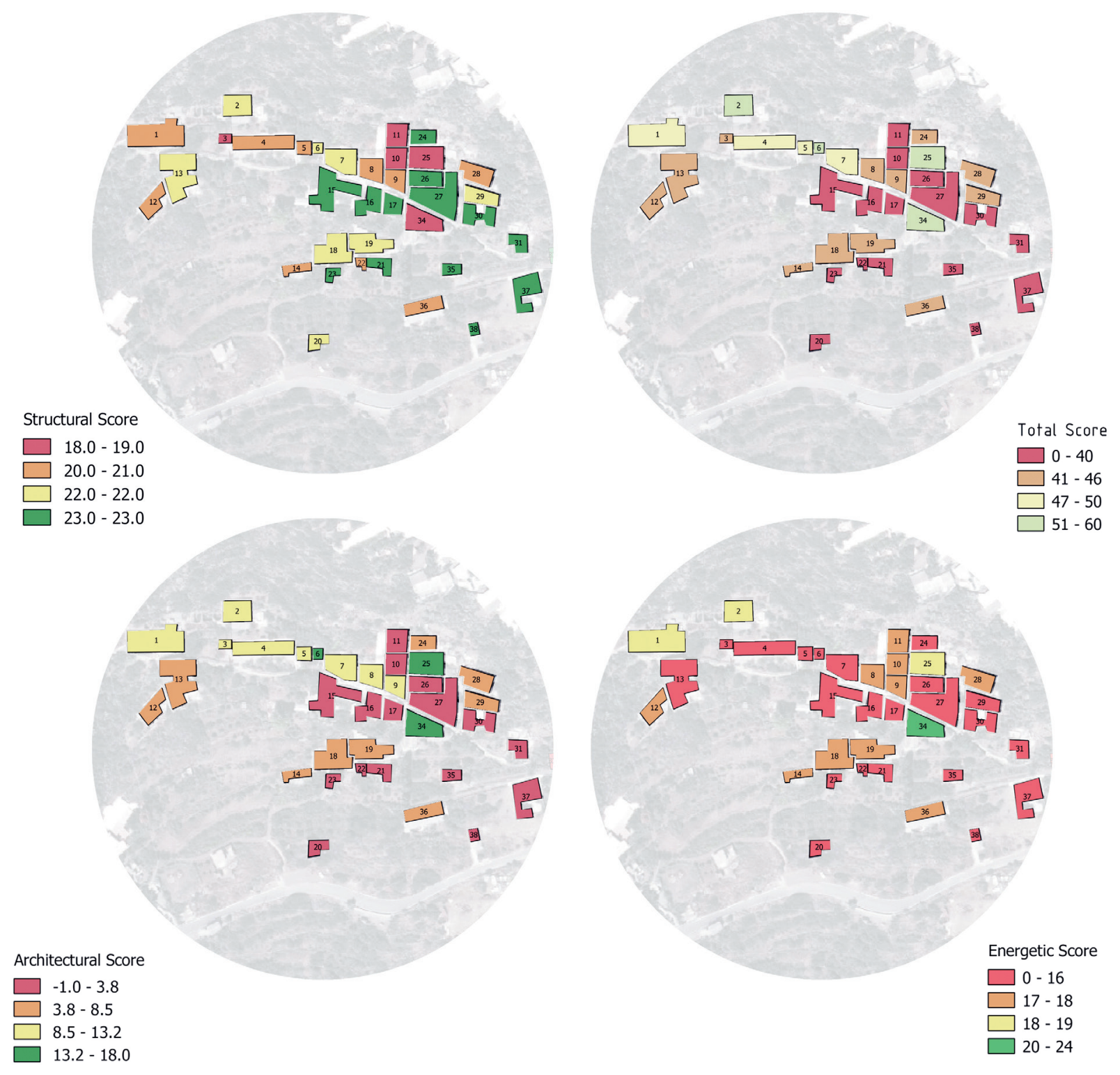


\section{STATE OF FACT}

In our intervention site, there are several buildings. Some of them are in a state of ruin or abandonment, others are better preserved. We have decided to intervene in the structure where we plan to place the municipal office. In this image, we show the actual state of the building. It is a two-elevation building, one of which is underground. The elements of the structure are traditional: from the masonry walls to the structure of the floors, as well for the window and the door. There is only one window in the south facade and a ruined wooden door in the east side.

Before defining the intervention strategy, it was necessary to know the current performance of the building, to be able, in this way, to choose the most suitable interventions for the specific case.

We have conducted an energy analysis with the DOCET software, which allows for the evaluating of energy performance of a building envelope by inserting the thermophysical values of the building components.

The simulation result is that our building belongs to the energy class $\mathrm{F}$.

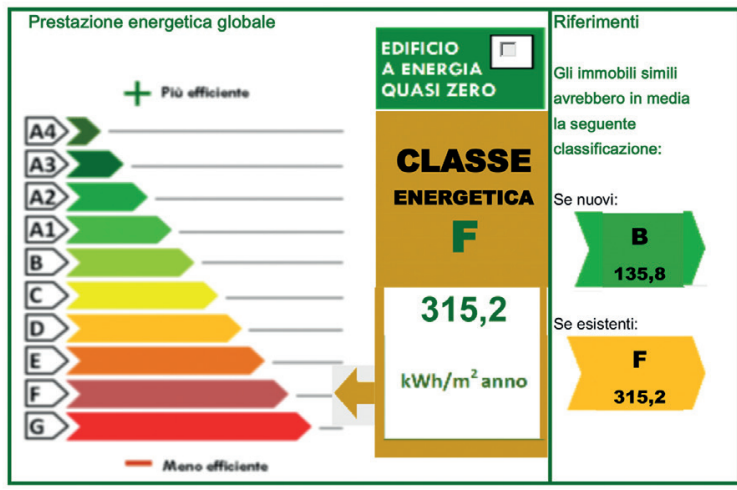

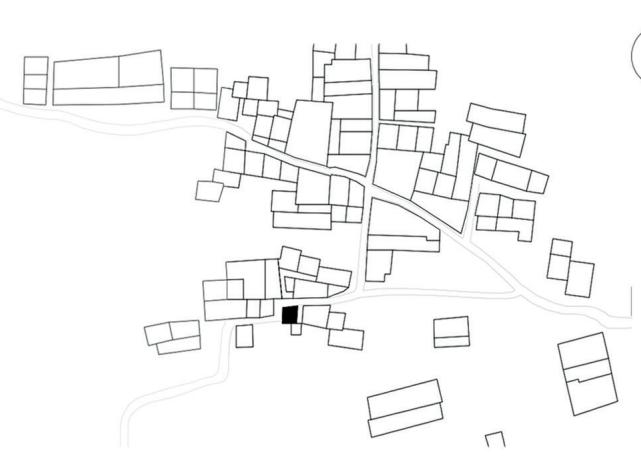
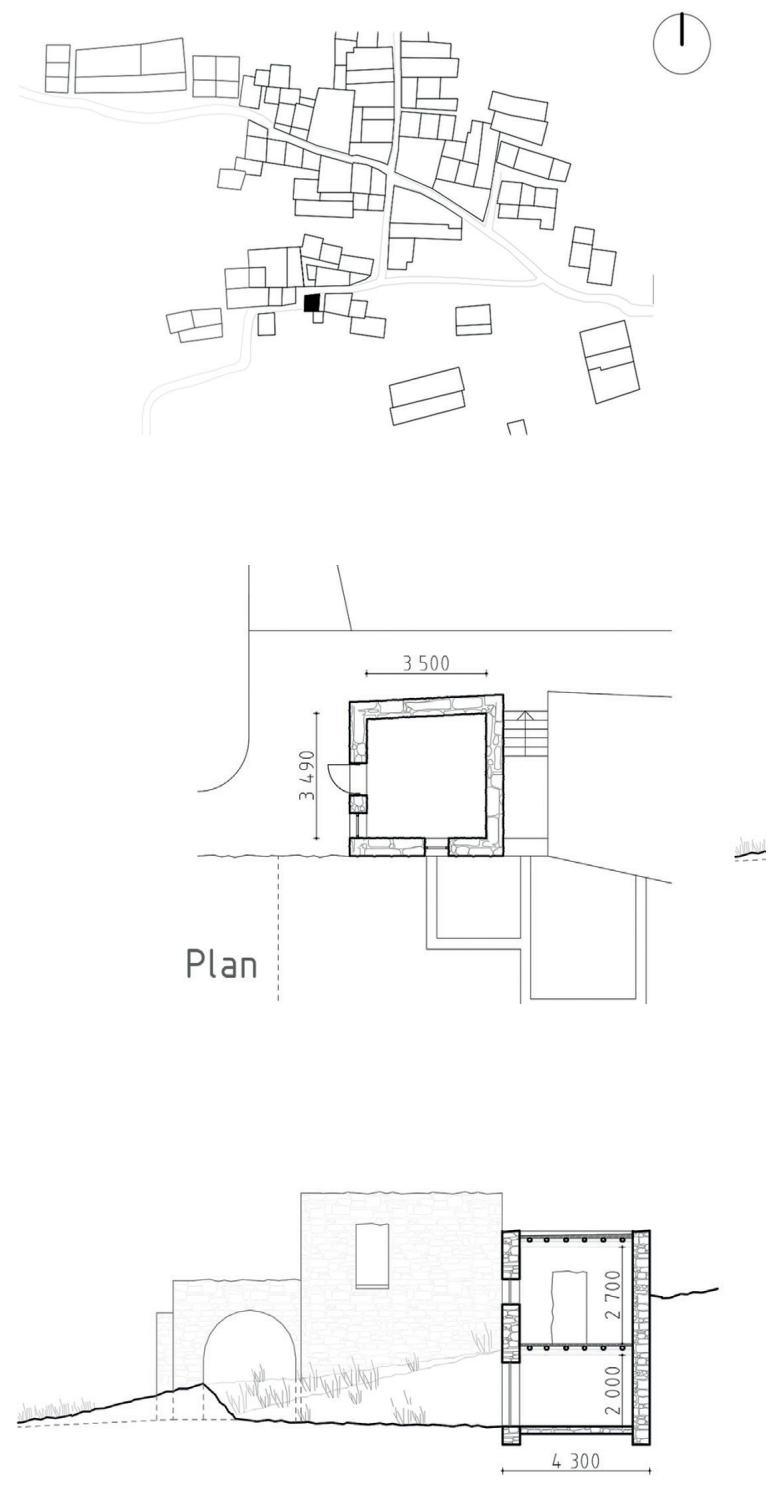

Section

Figure 5. Graphic drawings 


\title{
TASK 2 \\ DESIGN PROPOSAL
}

\author{
EXISTING CONDITION
}

The project location can be described as a rather large area that from one side is limited by the road and from the other side by the pedestrian path. The whole territory is permeated with retaining walls, which prevent landslides. The walls create for natural terraces on the site. On one of the terraces, a splendid olive garden was found. As was mentioned before, there are three remains of buildings on the site. One of them, which is located closer to the road, presumably was a dwelling. Only several parts of the external walls were saved. This building can be considered as the most damaged among all three houses. Regarding its location, the decision to make an entrance, the primary part of the info point in this ruin was made. This building will contain basic information about the island, touristic maps and booklets, descriptions of the most interesting places, and picturesque paths.

The other two buildings were closely connected to the pedestrian route and were located on the highest terrace. In the building for oil production,

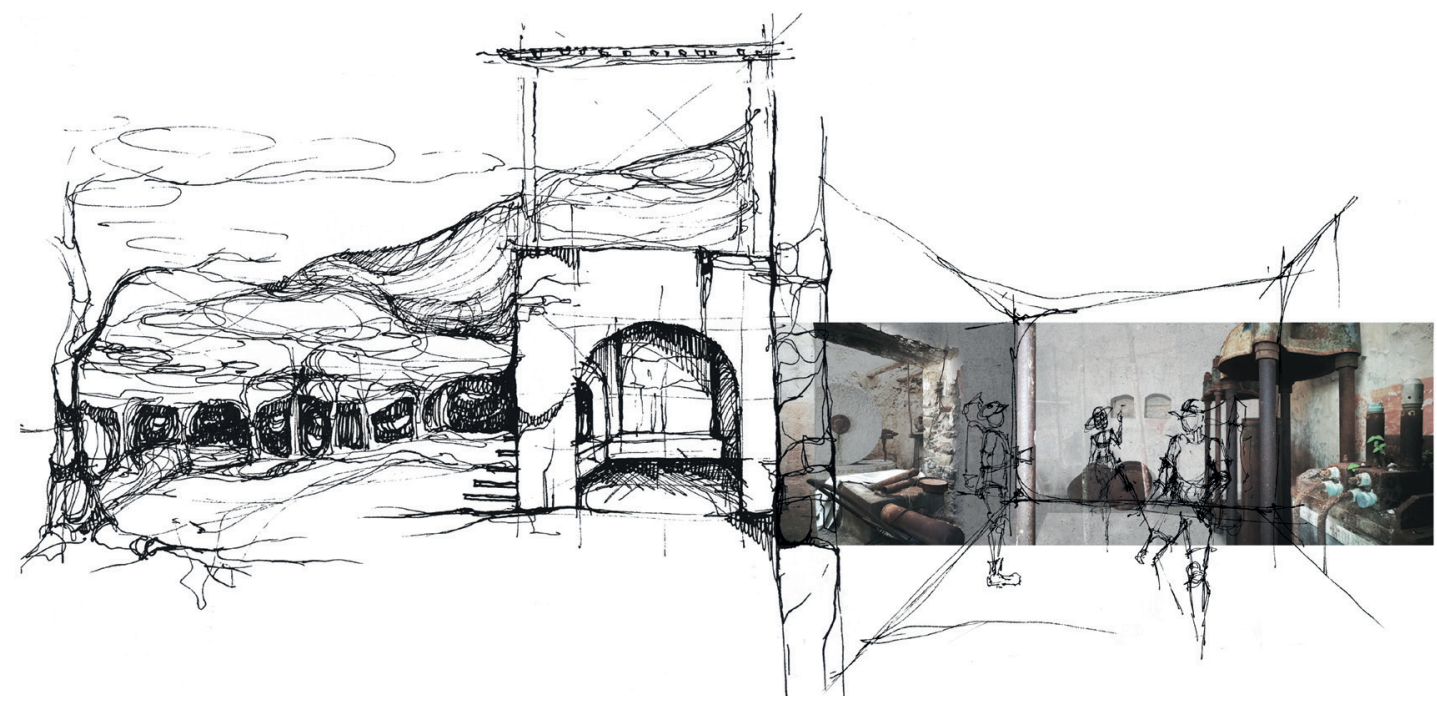



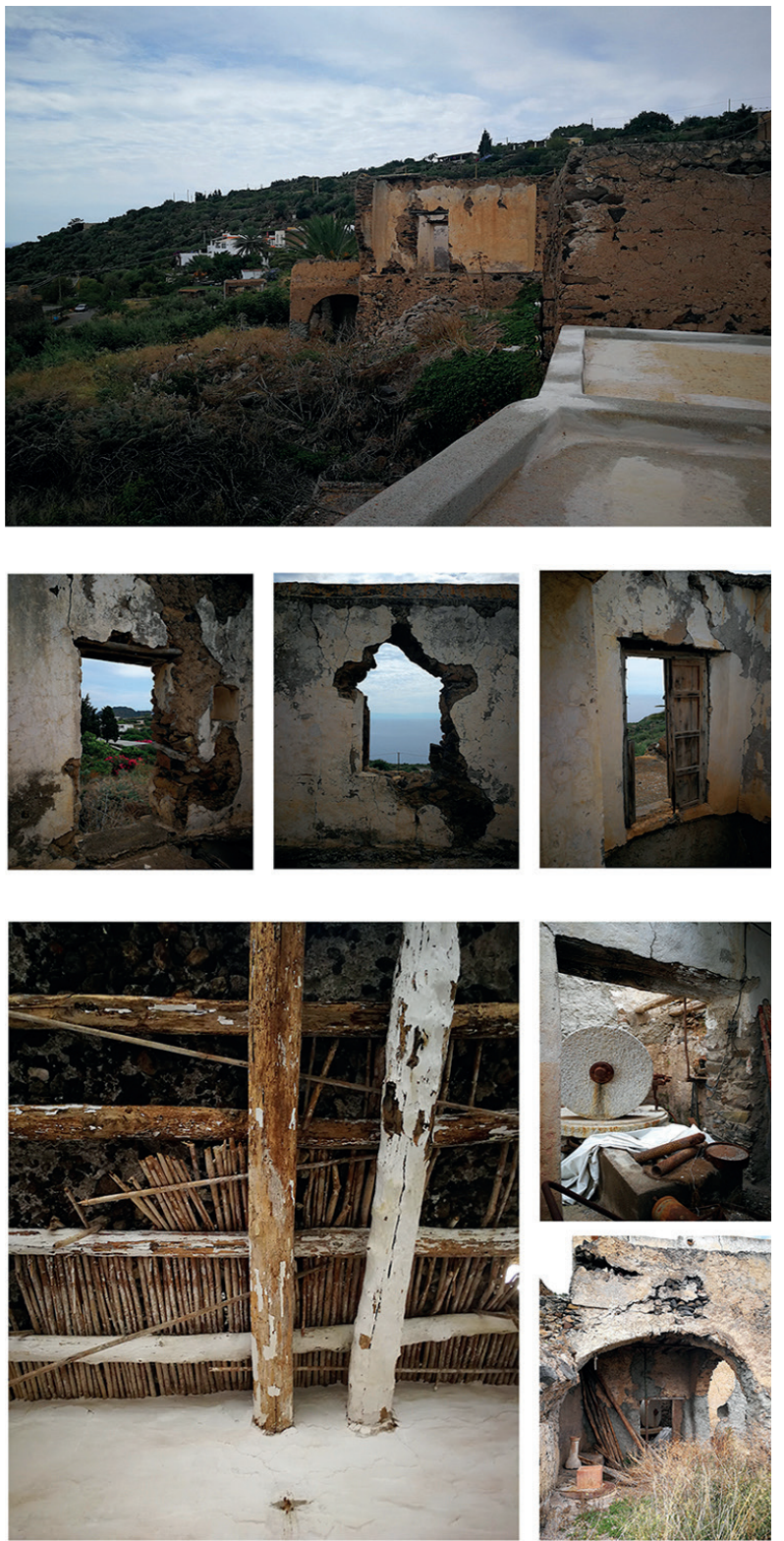

Figure 6. Existing conditions of case study building we decided to make a second part of the info point. In the third building, the municipal office was placed. In the vertical part of the building, a waiting space with a toilet was designed, while office rooms were put in the lower part of the building. A naturally created amphitheater links to the office rooms, which created a possibility of the arrangement of public discussions or meetings near the municipality office in a very authentic way.

It is assumed that in winter, when the amount of tourists is considerably less than in the summer period, only the municipal office building can be used. All of the summer exhibition information can be stored in the only closed room of the oil production building on the ground floor, and the "info point" buildings can be inactive during that period. However, basic functions can be found in the municipal office, which will work all year long. In the summer period, all three buildings will work and will be ready to receive tourists.

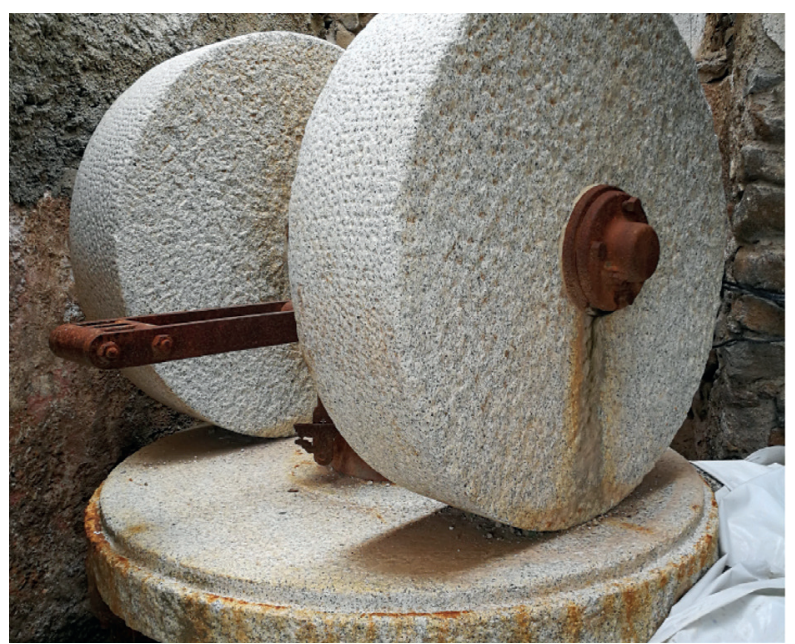

Figure 7. Traditional millstone 

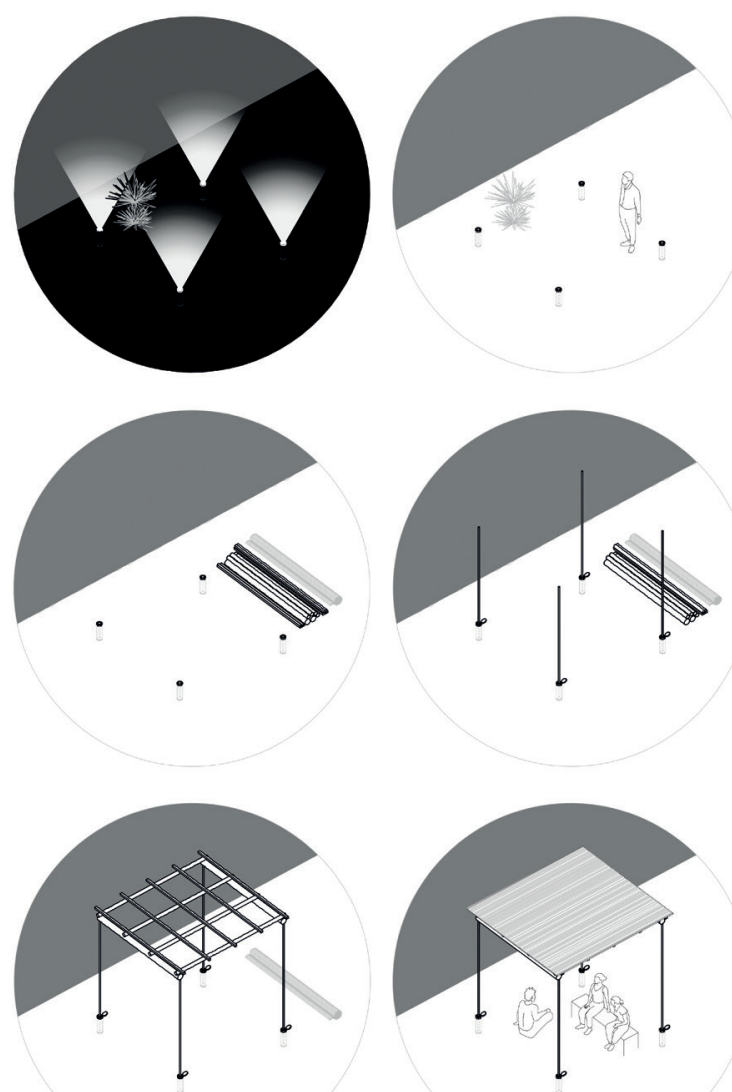

Figure 8. Shading system

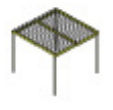

1

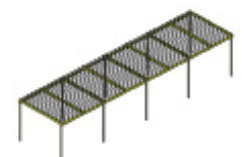

2

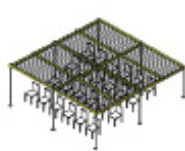

3
Figure 9. Shading combinations

(1 - Meeting point; 2 - Path; 3 - Conference place)

\section{DESIGN PROPOSAL}

The task for the site was to create a touristic info point.

The info point is a building that should have connection with the history of the island, but at the same time, should be well recognizable by the tourists - an object that can be a symbol of the island or of the archipelago area. As a very common element, shading was chosen to be presented as a unique detail of the island architecture. However, to make it different from the rest of the structures on the island, special barring construction was designed. The idea was to put info point shading on very thin metal columns. This solution also helped to achieve an effect of the structure of flying above the ground. Such construction, from one side, can be interpreted as a monument to celebrate vernacular architecture, while from the other side, can serve as a sign for the people. When people will see it, they will recognize the area as the info point. Metal columns could be installed in the system of the ground "sockets". A "socket system" provides modularity and flexibility for the info point area, so the shading can be moved into different positions depending on the circumstances. Those sockets that are not occupied by the columns can be used to light the area in the night, by adding or removing caps on the lamps. The grid light system on the ground gently attracts attention and guides tourists in the night.

The project location can be described as a rather large area that from one side, 
is limited by the road and from the other side, by the pedestrian path. The whole territory is permeated with retaining walls, which prevent landslides. The walls create for natural terraces, on the site. On one of the terraces, a splendid olive garden was found. The other two buildings were closely connected to the pedestrian route and were located on the highest terrace. In the building for oil production, we decided to make a second part of the info point, with further information about the history of the island and a deeper historical overview of the buildings. The combination of the ruins, old machinery, and historical notes with a cafeteria under the shading with a spec-

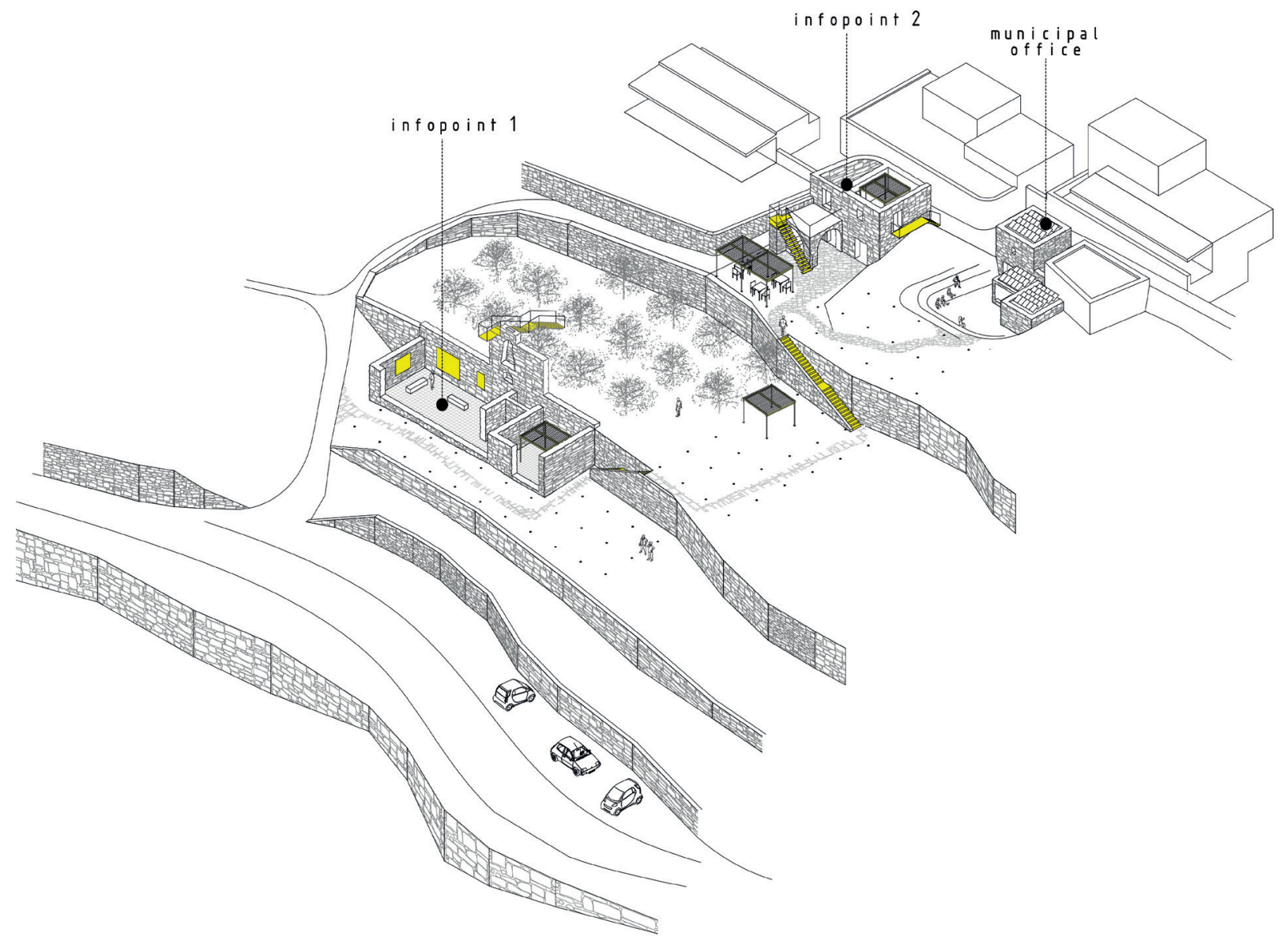

Figure 10. Axonometric view of the site 

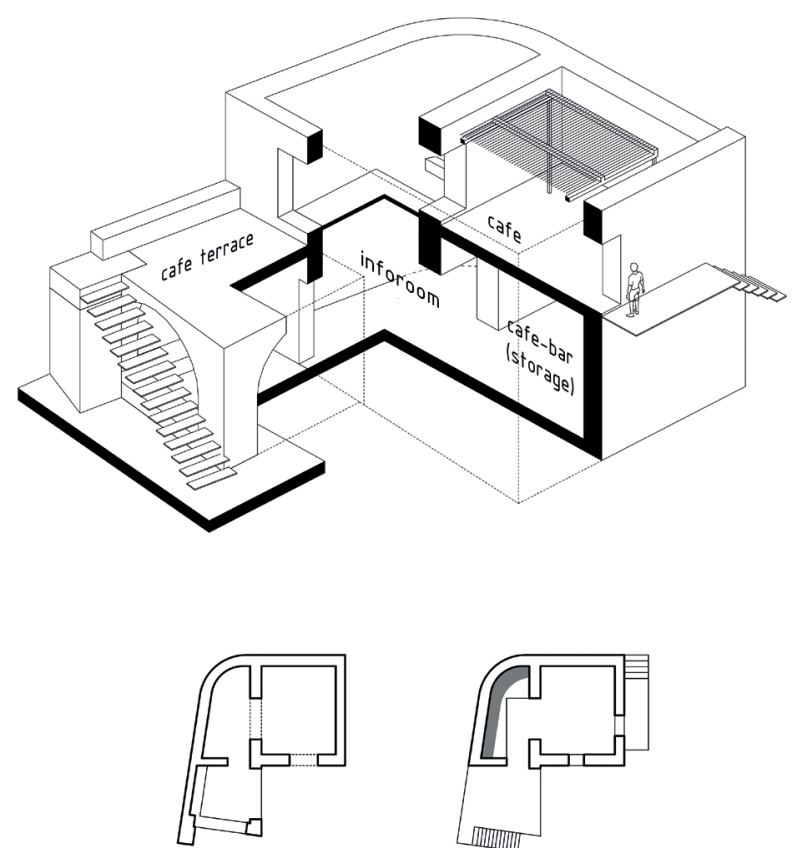

ground floor

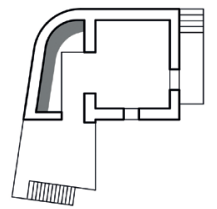

first floor

$\left(\right.$ area $\left.=51 \mathrm{~m}^{2}\right)$

Figure 11. Infopoint 2

tacular view can help the tourist to feel the atmosphere of the place even better. In the third building, the municipal office was placed. In the vertical part of the building, a waiting space with a toilet was designed, while office rooms were put in the lower part of the building. A naturally created amphitheater links to the office rooms, which created a possibility of the arrangement of public discussions or meetings near the municipality office in a very authentic way. It is assumed that in winter, when the amount of tourists is considerably less than

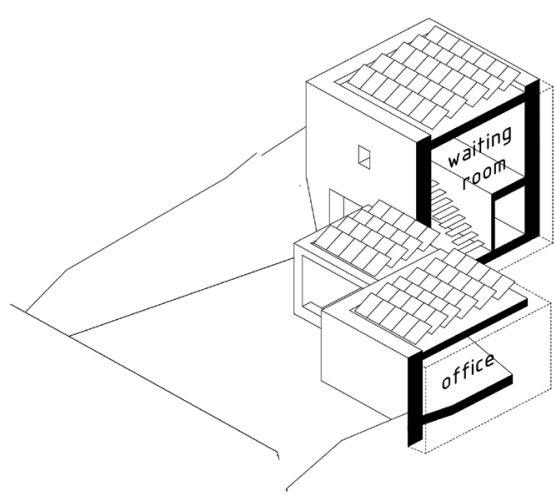

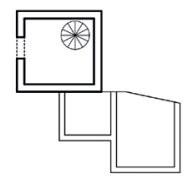

first floor

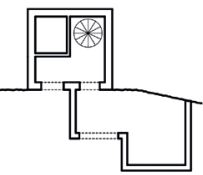

ground floor $(a r e a=44 \mathrm{~m} 2)$

Figure 12. Municipal office

in the summer period, only the municipal office building can be used. All of the summer exhibition information can be stored in the only closed room of the oil production building on the ground floor and the "infopoint" buildings can be inactive during that period. However, basic functions can be found in the municipal office, which will work all year long. In the summer period, all three buildings will work and will be ready to receive tourists. 


\section{DETAIL}

Passing to the interventions, we focused on two aspects: the structure and energy performance. For the first, we decided to reinforce the masonry with a system developed by the Ruredil company, called FRCM (Fabric-Reinforced Cementitious Matrix), which consists of application on the wall of a bidirectional fiber network that creates a reinforced stratus that supports the structure without adding significant weight or modifying the external features. As the last layer, a white plaster is applied, to respect the tradition and harmonize the new intervention with the pre-existence.

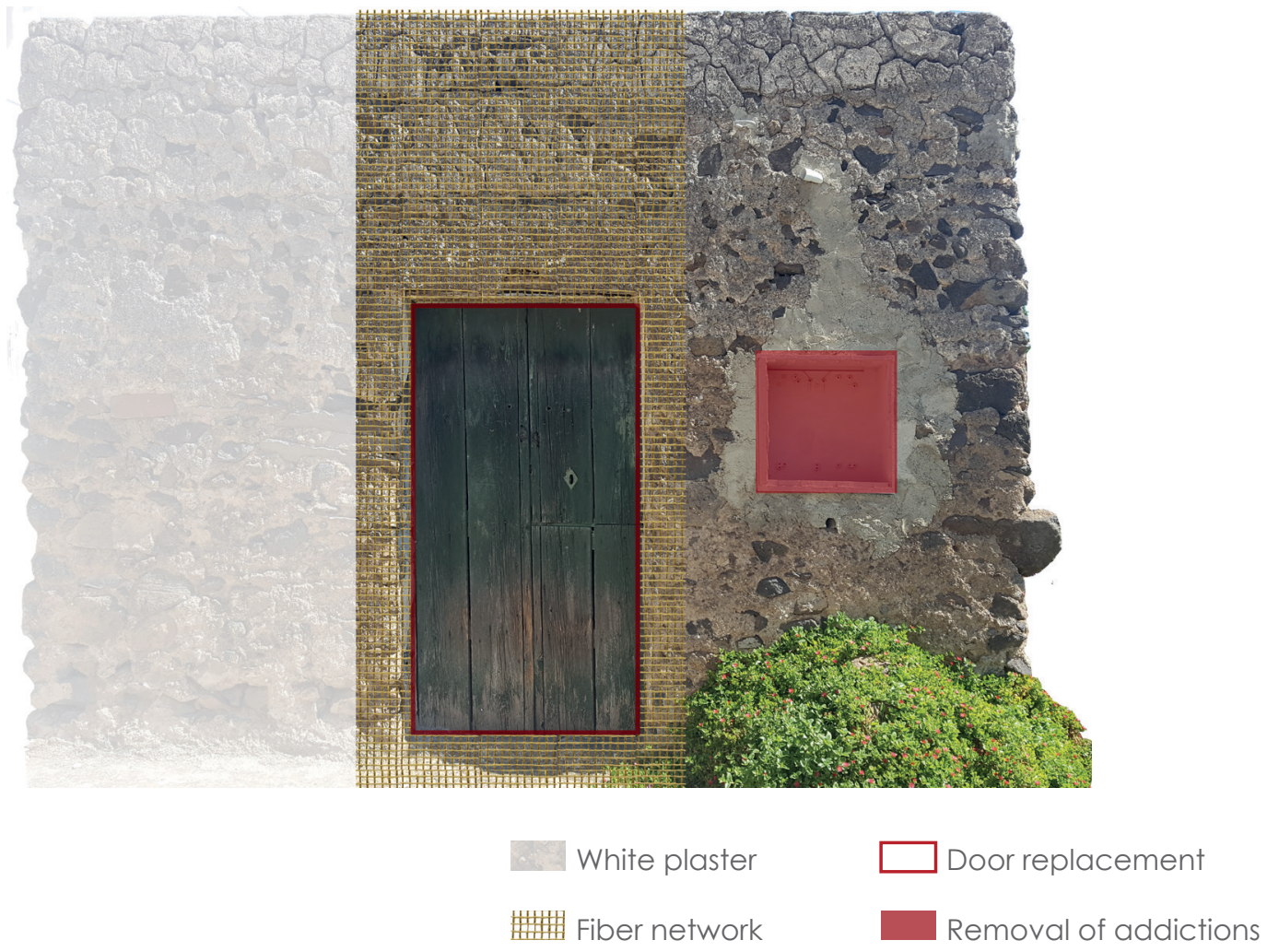

Figure 13. Scheme of interventions 
The intervention on the door instead is very interesting. Our goal is to maintain the building's original appearance, with its traditional elements and, at the same time, improve energy efficiency. Therefore, we decided to remove the door and use it as a shading element for a new door with double glass, hooked to the wall with a metal profile that opens inward. The energy requalification project includes the provision of a photovoltaic system for the production of electricity to be installed on the roof. The aspect of air conditioning has been addressed considering the installation of a heat pump system, while the production of domestic hot water is made with a combined heat pump with storage and solar thermal panels. The frames are equipped with solar shading and double-glazed glass. All these technologies allow the achievement of an energy efficiency class A2.

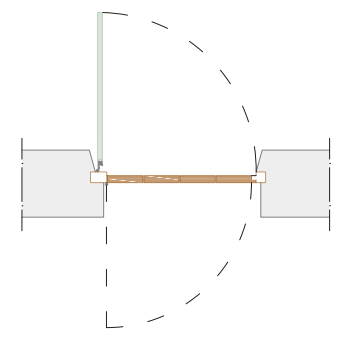

1. Masonry wall

2. Ruregold fiber network

3. Metallic frame

4. Double glazing

5. Original door

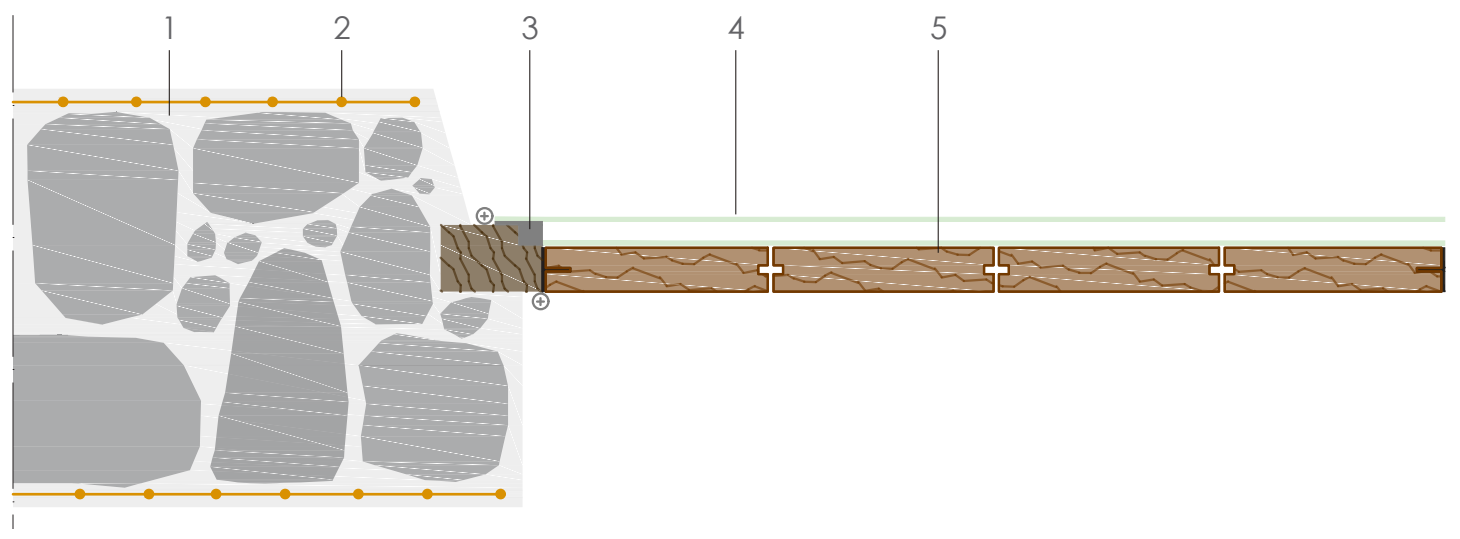

Figure 14. Door detail 

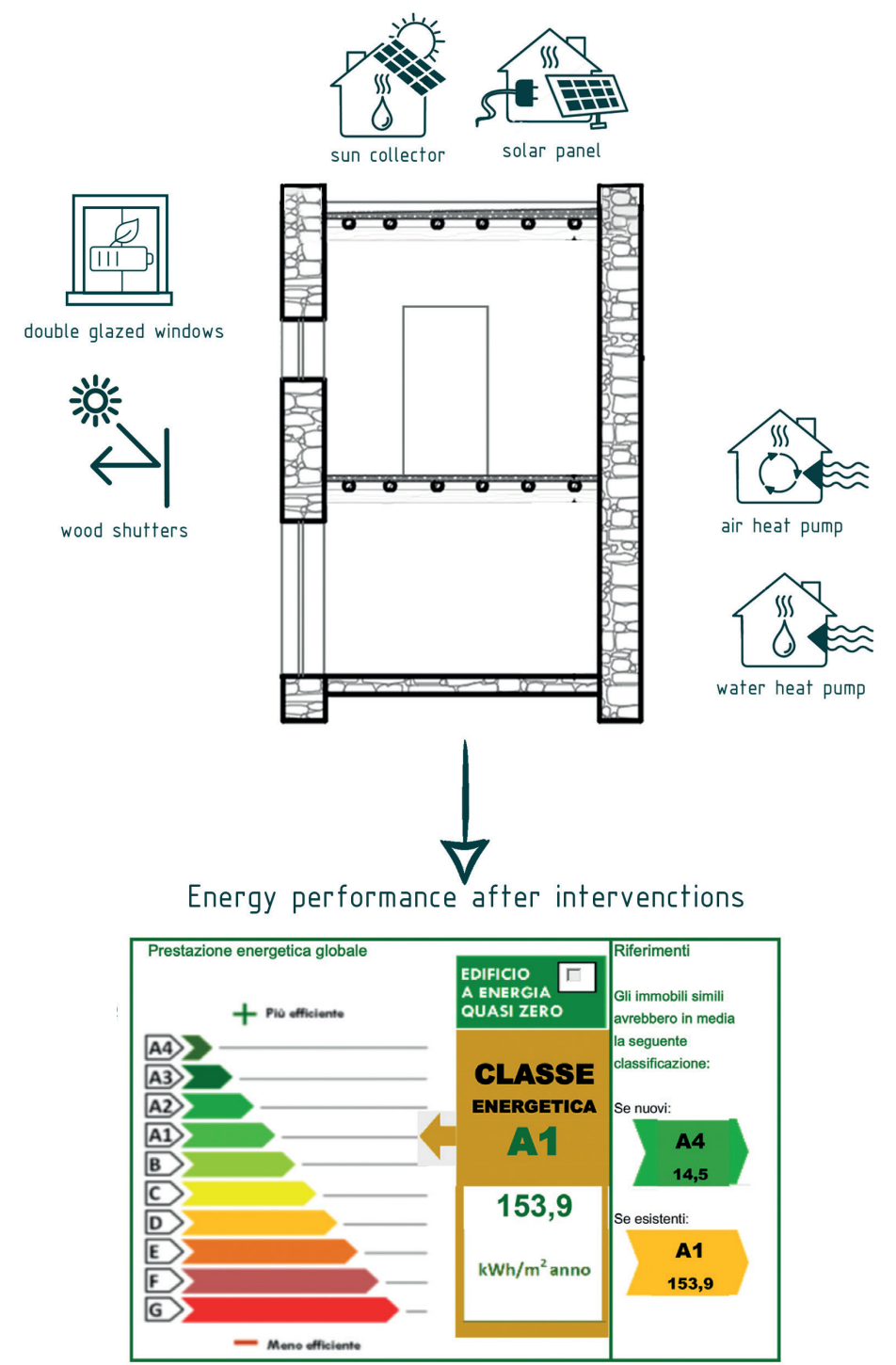

Figure 15. Energetic strategies 


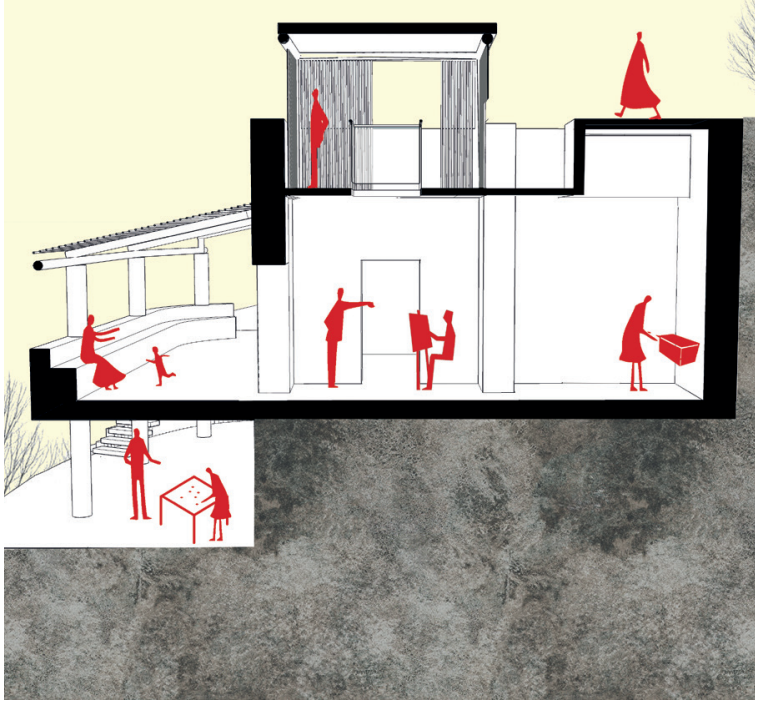




\section{KEEP THE TRADITION}

\section{STUDY CASE}

Portella

DESTINATION OF REFURBISHED BUILDING University center/observation point

\section{ABSTRACT}

In order to revitalize the given site and building and transform it into a real attraction point, the project involved a complete study of the area, the landscape, and the quality of the existing architecture. The interventions aimed to preserve the local character and identity as well as the use of technologies to ensure good energy and mechanical efficiency. From a functional point of view, the destination for the chosen Portella site was a university center and an observation point. The privileged location of the building, the plan, and the used materials made this solution an optimal one. The final result proves both good functionality and energy efficiency, provides a good connection with the surrounding landscape and environment, and offers a unique perspective of Filicudi island.
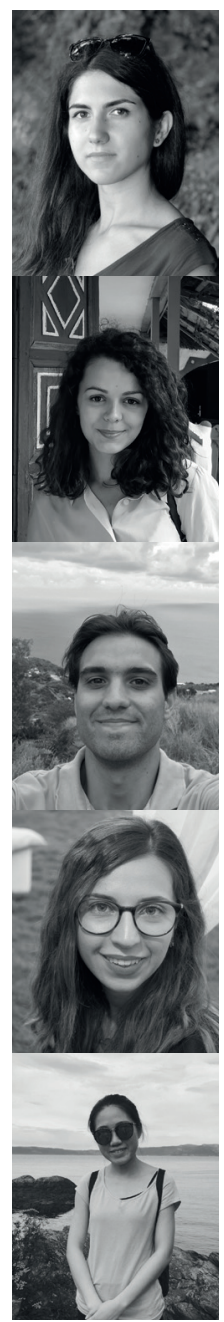

WORK TEAM

NEAGU_Diana_Student at UAUIM

SERBAN_Corina_Student at UAUIM ARTINO_Antonio_Student at UNICT GIBILRAS_Sharon_Student at UNICT ZHOU_Jingjing_Student at NTNU 


\title{
TASK 1 \\ CHECK OF THE AREA
}

\author{
PORTELLA
}

Portella is located in the northwestern side of the inhabited area of Filicudi island, between Stimpagnato and Val di Chiesa. The location offers the advantage of a panoramic view of the island and represents, at the same time, a challenge. The access to the area is made on a path that continves with a series of stone stairs. Being on a rough terrain, the street network is organic and laden with stairs. However, the sinuous route is a very pleasant one, because a lot of landscaped courtyards, houses with special particularities, and spectacular typical vegetation can be observed.

Most of the traditional homes have an eastwest exposure that allows them to enjoy the sun throughout the day. The first visual impact with the houses is given by the bagghiu, the traditional covered terrace, which represents a common feature of the whole area. In terms of colors, the area presents a chromatic balance. The buildings are generally painted in shades of white that emphasize the contrast with the vegetation, pink or light orange.

One of the first houses to welcome visitors is a ruined one that now retains only a few walls and a roof terrace. The components of the traditional local architecture are only partially visible due to its advanced degradation status.
Regarding the vegetation, the area offers a large diversity of plant species, trees, and shrubs. The most common species are citrus, cactus, oleander, and different climbing plants such as Bougainvillea, which often decorate the walls of the houses or even covers the roof of the bagghiu. Generally, the area has medium and low vegetation, the only vertical accent in the studied area being a tall pine, located right in the access area, that can also play the role of a local landmark. It should also be specified that the locals are part of a true community and show an honest hospitality. The stairs and the winding roads sometimes turn into real playgrounds for the children.

Portella has a specific charm and beauty that can be considerably heightened. The traditional Aeolian architecture as well as the topographical configuration of the area and the view upon the island are some of the most valuable characteristics of the area. This proposal aims to emphasize the identity in a modern approach, but without threatening the authenticity of the traditional heritage. 


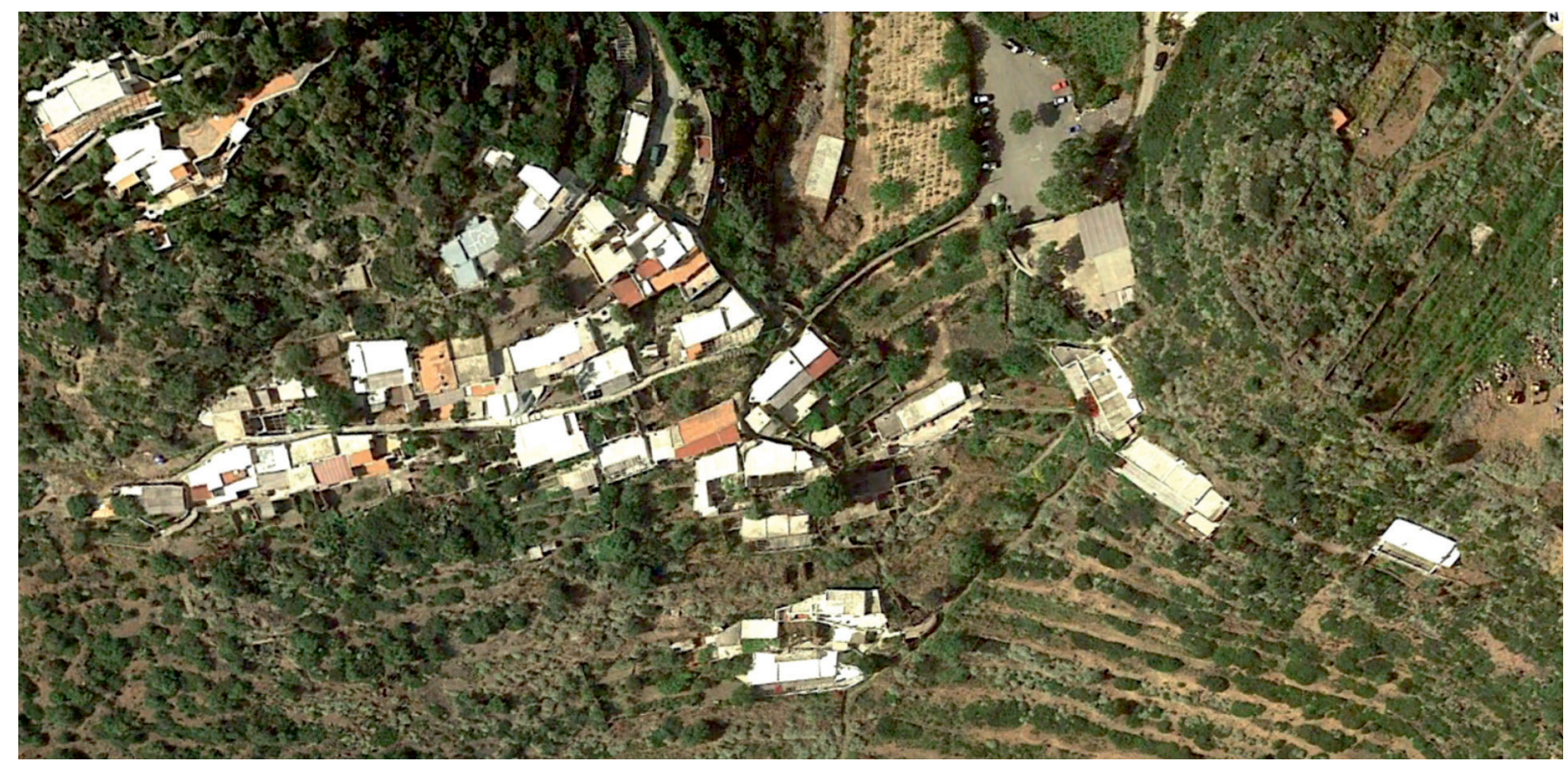

Figure 1. Satellite image of the study area

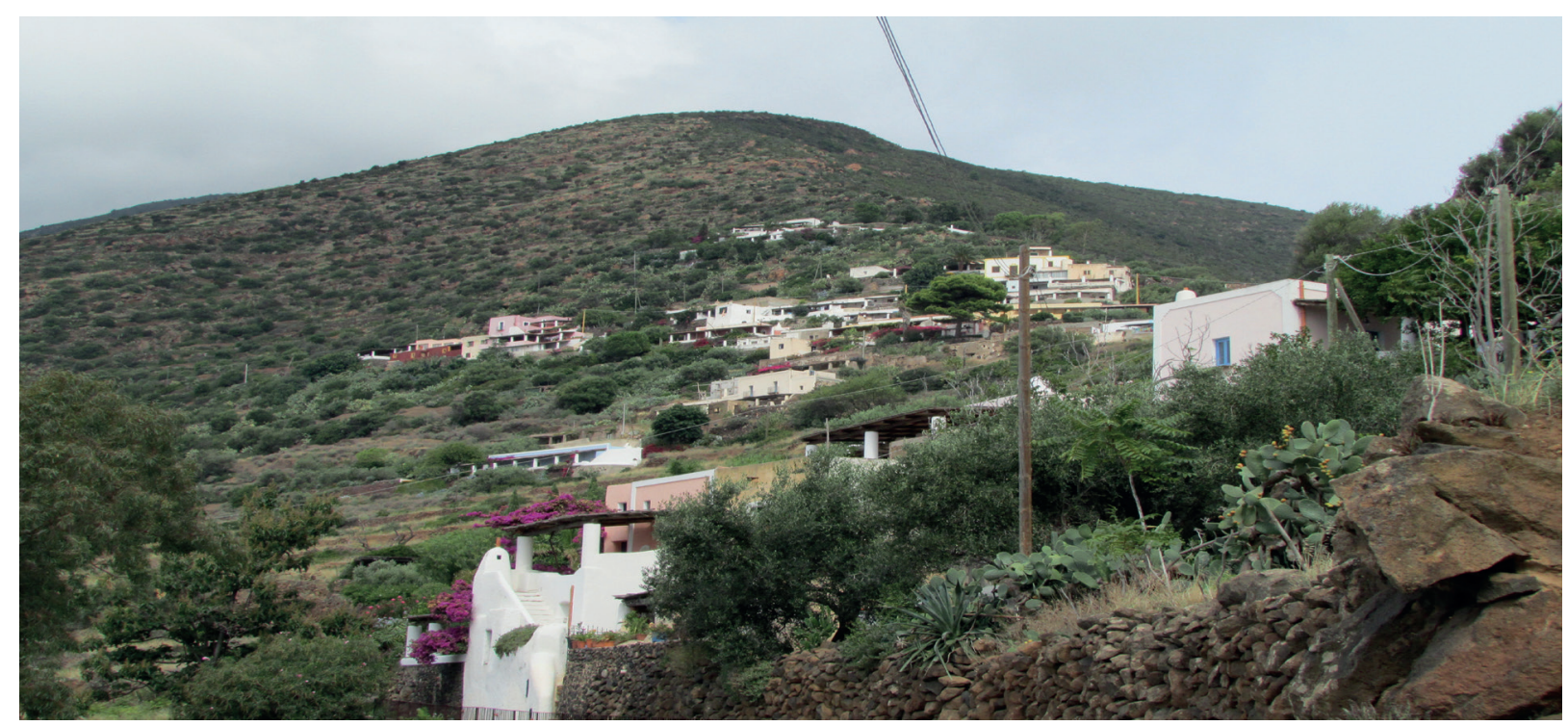

Figure 2. Picture of the study area 


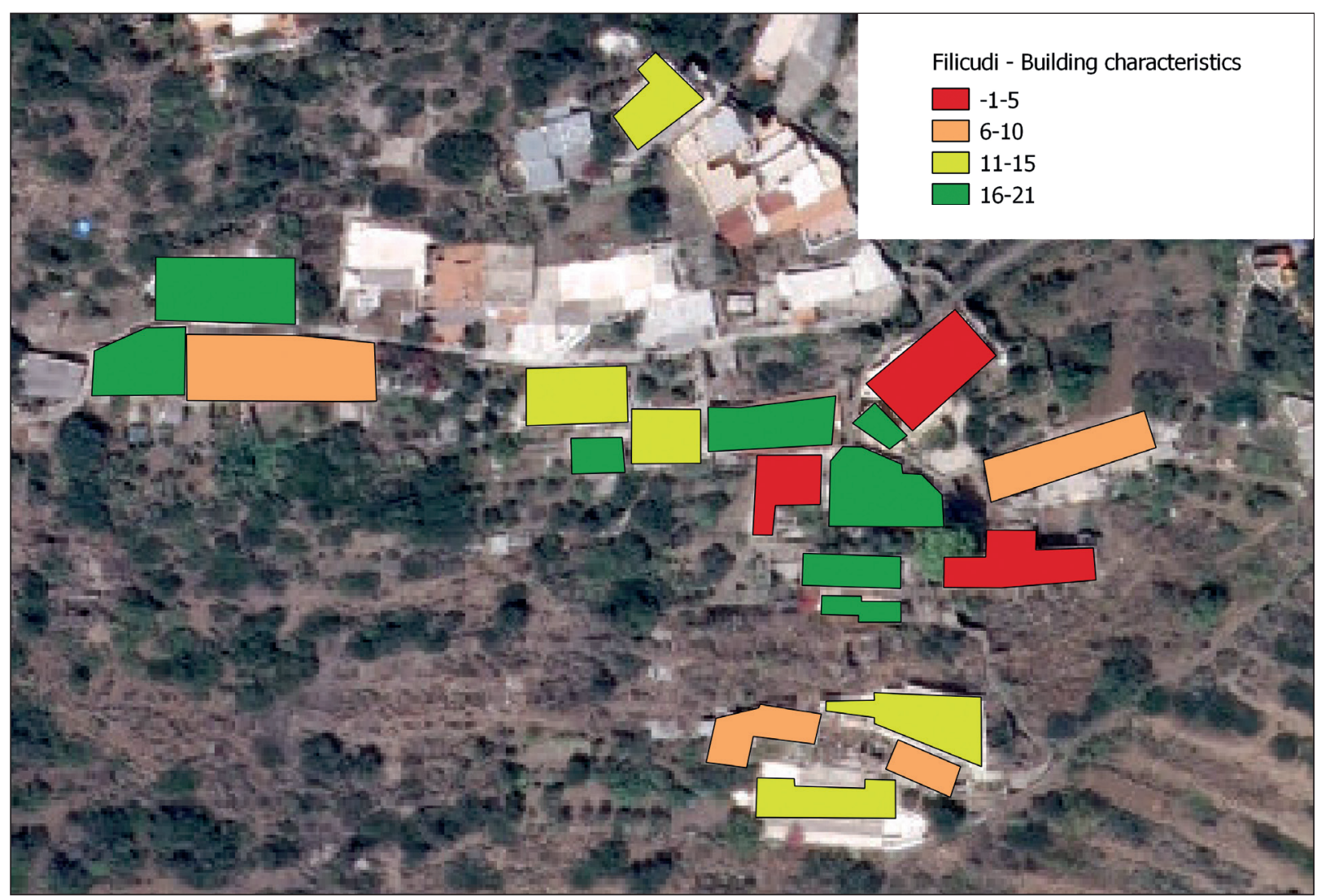

Figure 3. GIS map - Building characteristics

DATA INPUT ON GIS

The buildings of the area under investigation were categorized according to their particular features and to different themes: building, energy, and structural characteristics. For each building and for each theme, they were assigned different scores, according to a predetermined rating scale. As regards the building characteristics, it is noted that both buildings of high and low quality are present with the same rate.
From the energy point of view, most of the studied buildings have a very low score, indicating a poor behavior towards thermal stresses and, above all, low levels of indoor thermo-hygrometric comfort. 


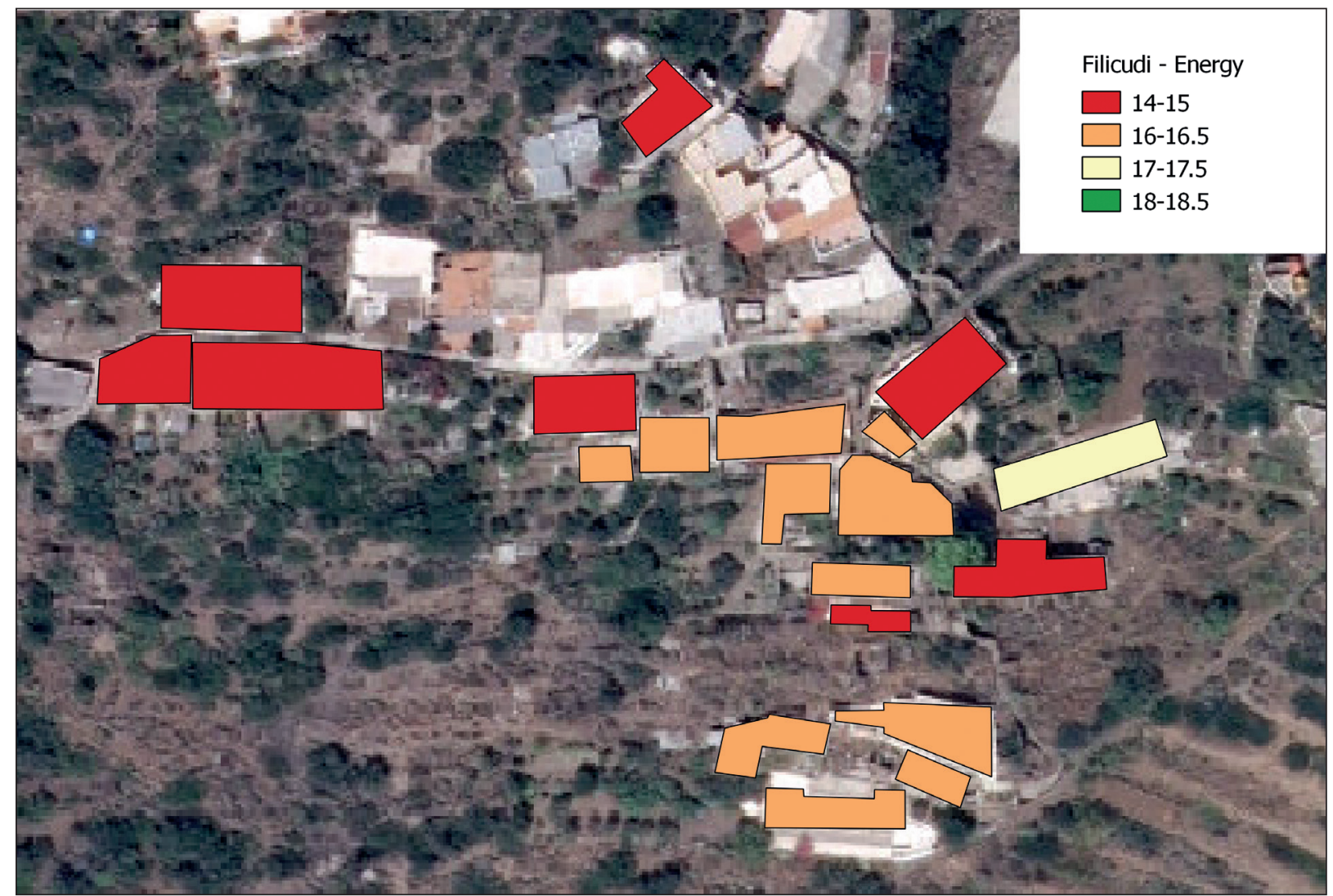

Figure 4. GIS map - Energy features 


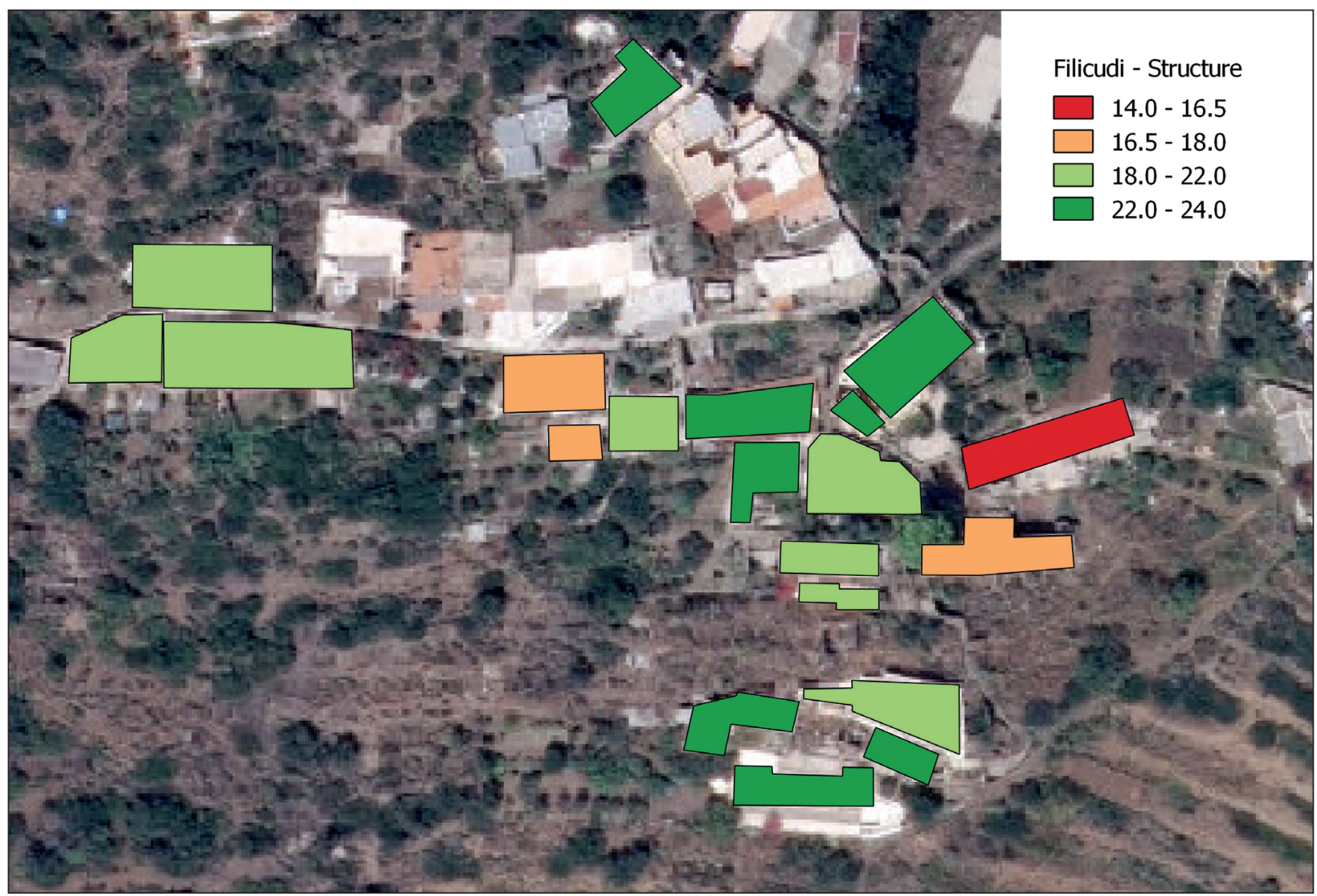

Figure 5. GIS map - Structural characteristics

Regarding the current structural condition of the buildings, it should be noted that, given the particularly high scores, there is good structural safety. This is mainly related to the fact that many buildings have closed structural meshes, also thanks to the more or less effective wall joints, detected during the surveys.

Some buildings in the area, however, are particularly damaged or even in a state of total abandonment or ruins.
Adding the partial scores obtained in the three themes explained above, we obtained a general mapping indicative of the overall quality of the buildings analyzed. From the observation of the relative map (Fig.6), it is clear that around $65 \%$ of the buildings report discrete or good total condition, while about $25 \%$ of the buildings are in bad condition. 


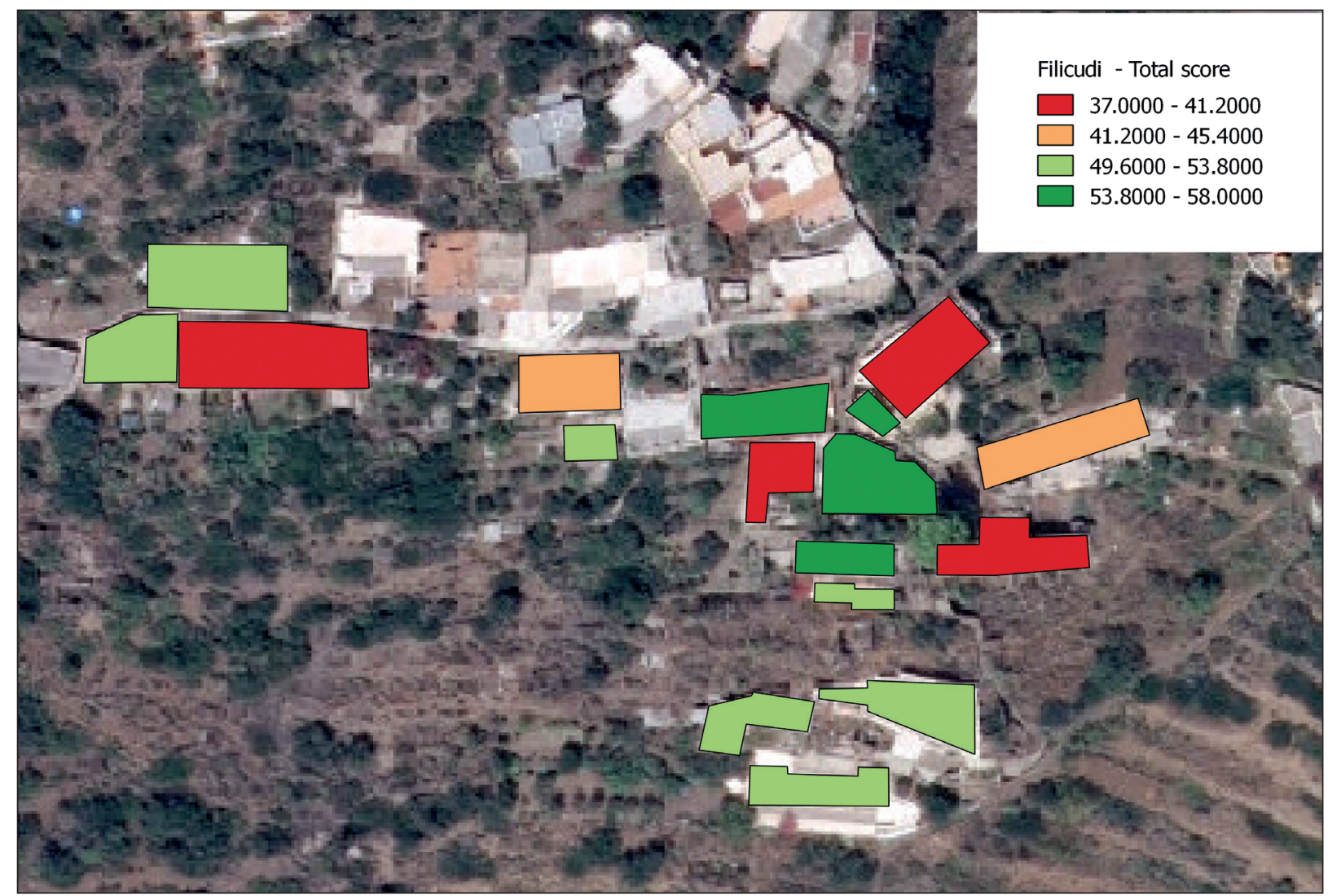

Figure 6. GIS map - Total score 


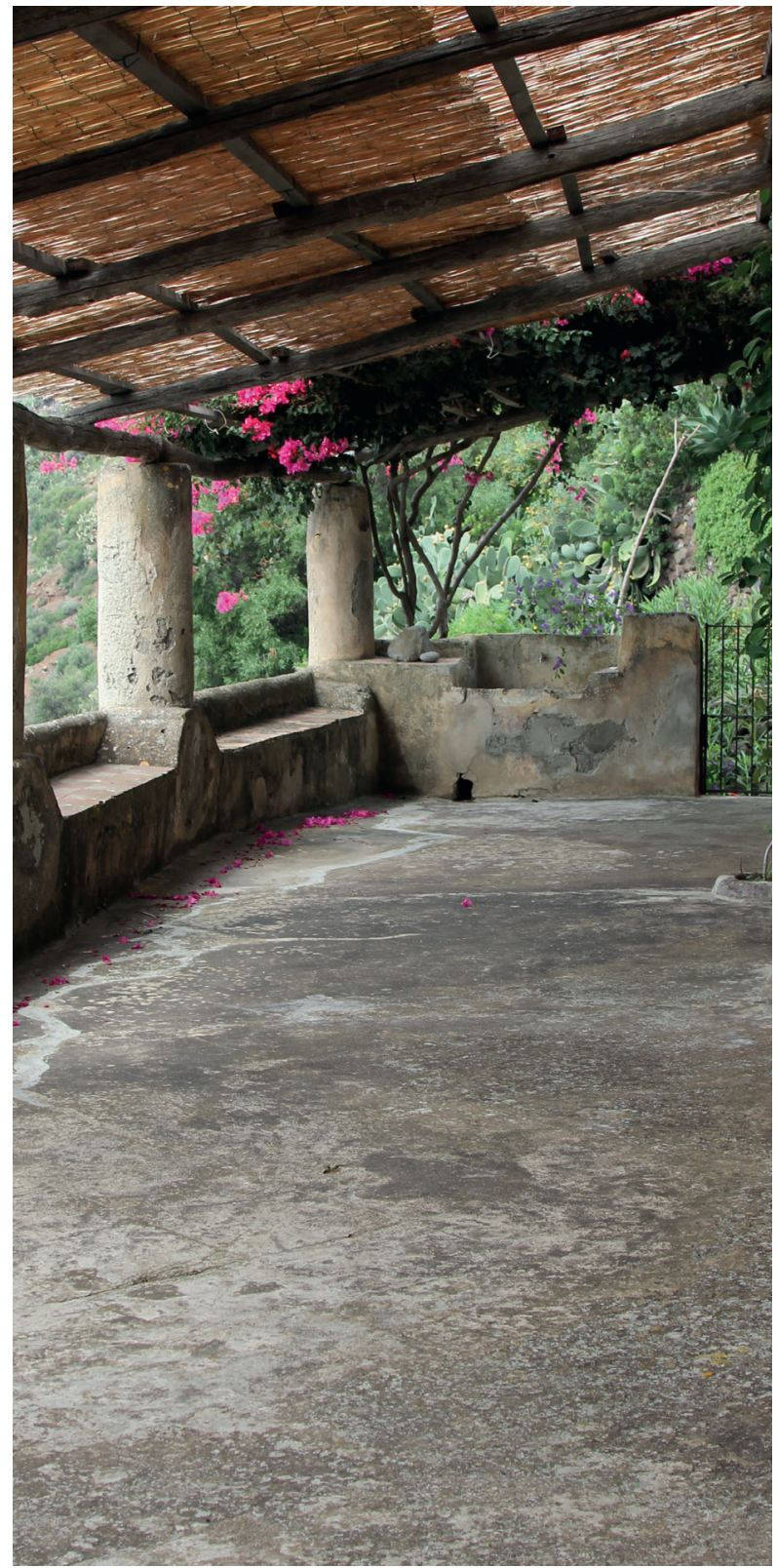

Figure 7. Typical Aeolian house

\section{FEATURES AND QUALITY OF THE LOCAL ARCHITECTURE}

The Filicudian houses are organized on two levels, in general for two independent homes; the staircase is outdoors. A large terrace (called in local dialect "bagghiu") is set up in the front of the house, while at the back, there is a little yard.

The volcanic nature of the Aeolian Islands makes them particularly exposed to earthquakes and strongly influences the masonry type. In response to this circumstance, local builders have set up a really efficient construction system: with vertical elements that are firm and strong and horizontal elements that are light and flexible.

The masonry is composed of rough, basaltic stones. The edges of the building are built with squared stones, bigger and denser. The walls are $60 \mathrm{~cm}$ thick on, the ground floor and $50 \mathrm{~cm}$ thick on the upper one. The roofs are framed with a series of wooden beams that are inserted in the wall for twothirds of its thickness. A cane roofing is set up on the upper side, framed between the wooden beams. The extrados is formed by a casting of lime putty and volcanic pumice. 


\section{TASK 2 \\ DESIGN PROPOSAL}

\section{EXISTING CONDITION}

At first sight, the old house was nothing more than a ruin with no identity, but as we looked closer and after research, we found out much more about the object of our study.

The house was owned by a big family that (similarly to many families on the island) left for a better life. The younger generation left as the old remained unable to tend to the needs of the household. The deserted house deteriorated fast due to the climate and it even suffered a fire.

We found the house with some walls and a part of the roof damaged and a collapsed bagghiu. However, the ruin inspired us because it was situated on high ground and it was perfect for an observatory. Moreover, the fact that it was a big house made it possible for us to find the necessary space for a university center.

The house had three intact rooms, four rooms partially destroyed, and two rooms carved in stone at a lower level that were originally connected with the garden but are now covered in rubble.
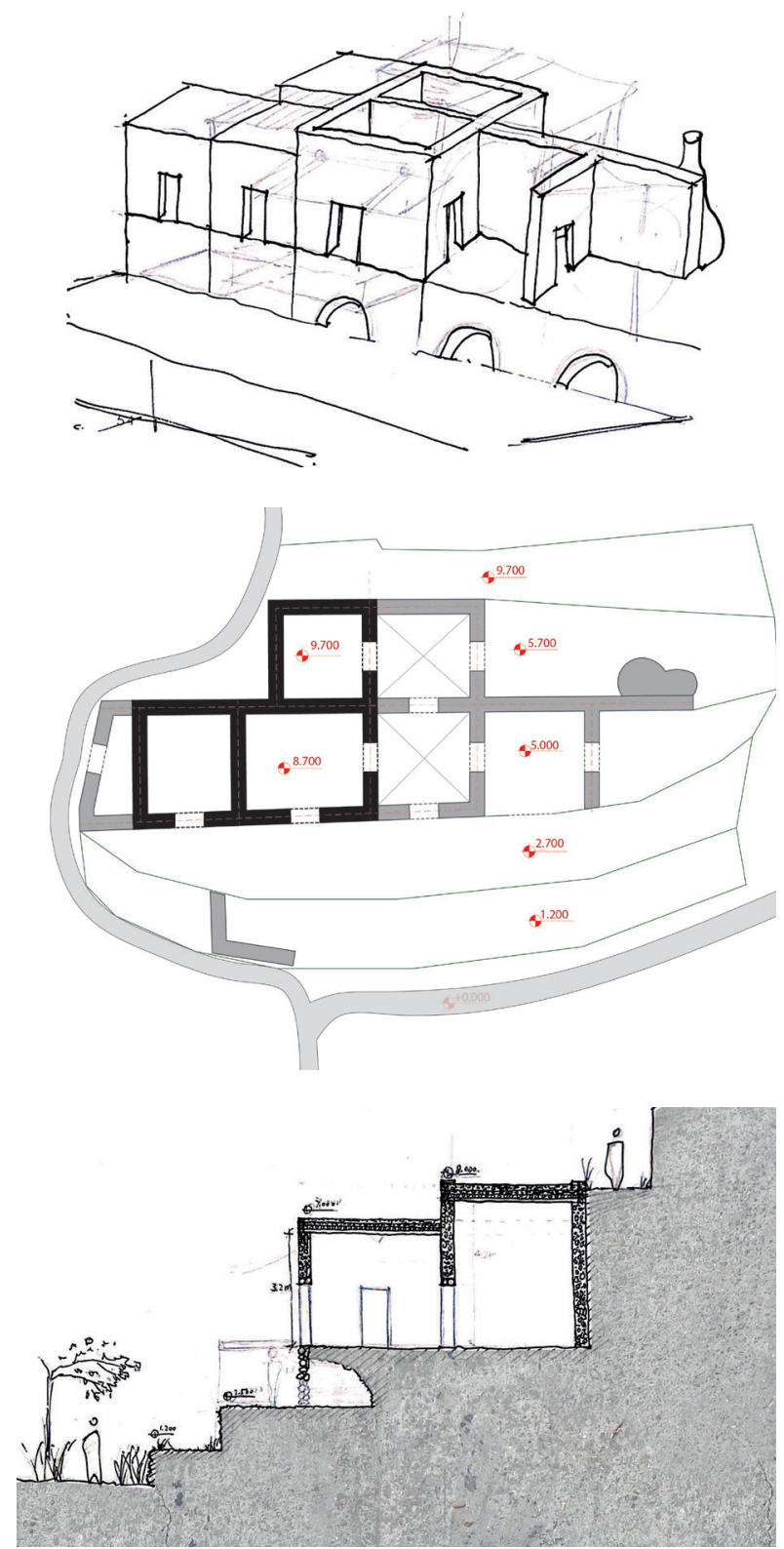

Figure 8. Sketches with the existing condition 

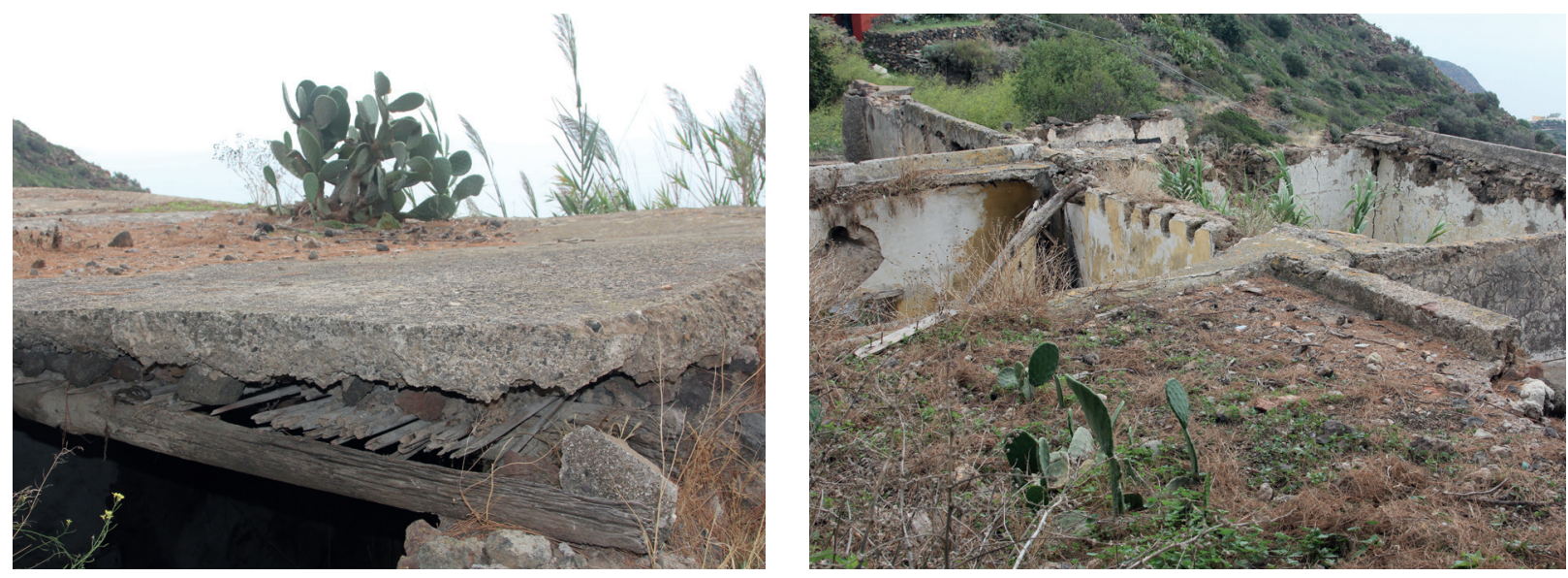

Figure 9. Characteristics of Aeolian house

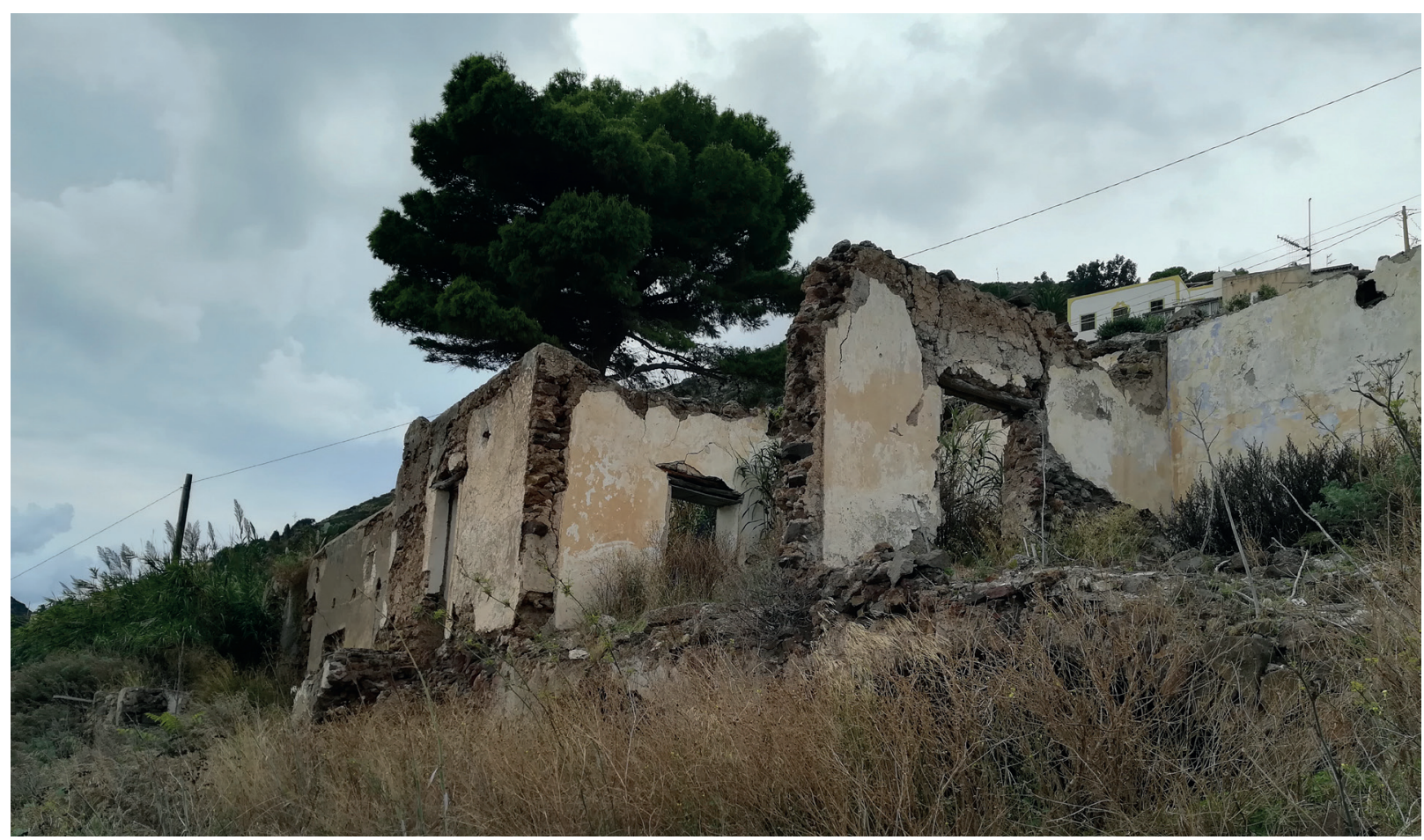

Figure 10. Existing conditions of the case study building 


\section{DESIGN PROPOSAL}

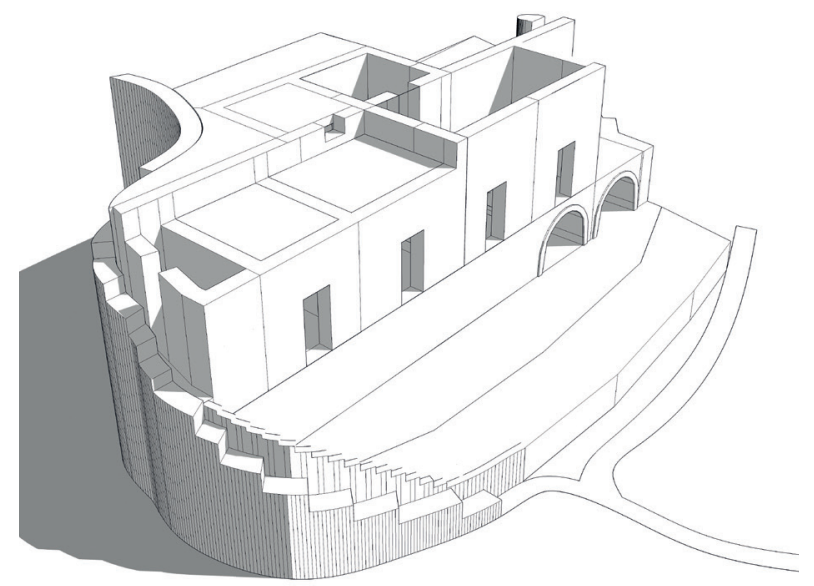

The design proposal is based on strong principles rooted in the specific architectural and social context of the Aeolian Islands.

One of the main targets of our project was to keep the original form of the building. This principle is one of the requirements of UNESCO World Heritage when it comes to building in the Aeolian Islands. This is a way of integration in the context and also a sign of respect for tradition.

Rebuilding the bagghiu was the first and the most important step as it is the iconic element of Aeolian architecture. We also kept its original function, a place of gathering and collective work; it is the focal point of our university center.

The existing structure was reinforced with fiber glass technology and the partitions were kept as they were but with different functions. Therefore, the ground floor went from a utility space to an accommodation space with two bedrooms carved in stone, a storage unit, and open working space below the bagghiu. On the first floor is where the main activity of the university center takes place: offices, a working space, archives, and a small kitchen.

The last floor is the place where we did the observation point. We rebuilt a section of the collapsed roof in a different manner. We raised the slabs to emphasize the idea of a new roof. The addition in height also gives a better view of the landscape around. The structure is lightweight, made of metal wires that resemble the traditional cane sunshades.

Figure 11. Before and after simulations 


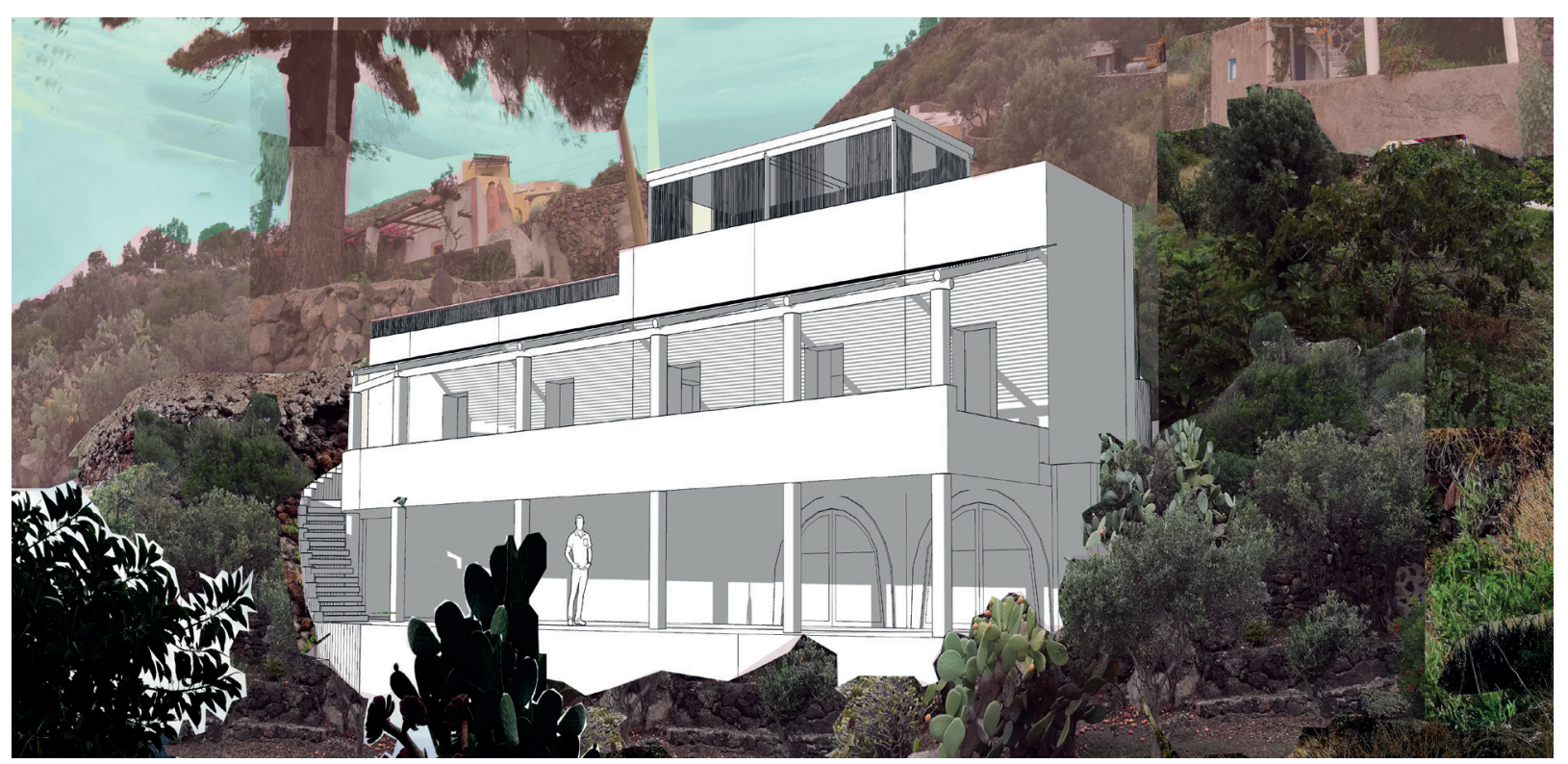

Figure 12. Outside perspective of the new proposal

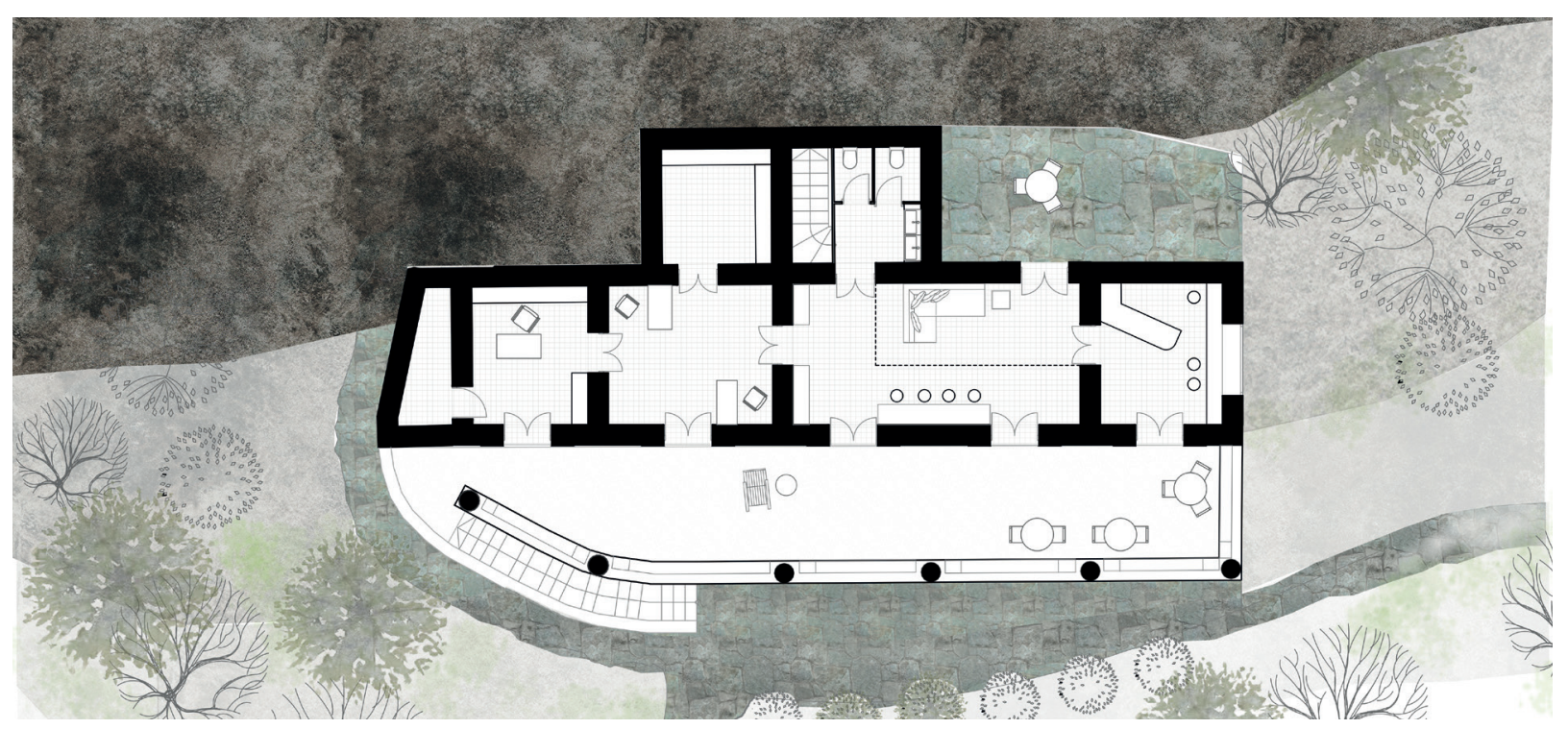

Figure 13. First floor plan of the proposal for case study building 


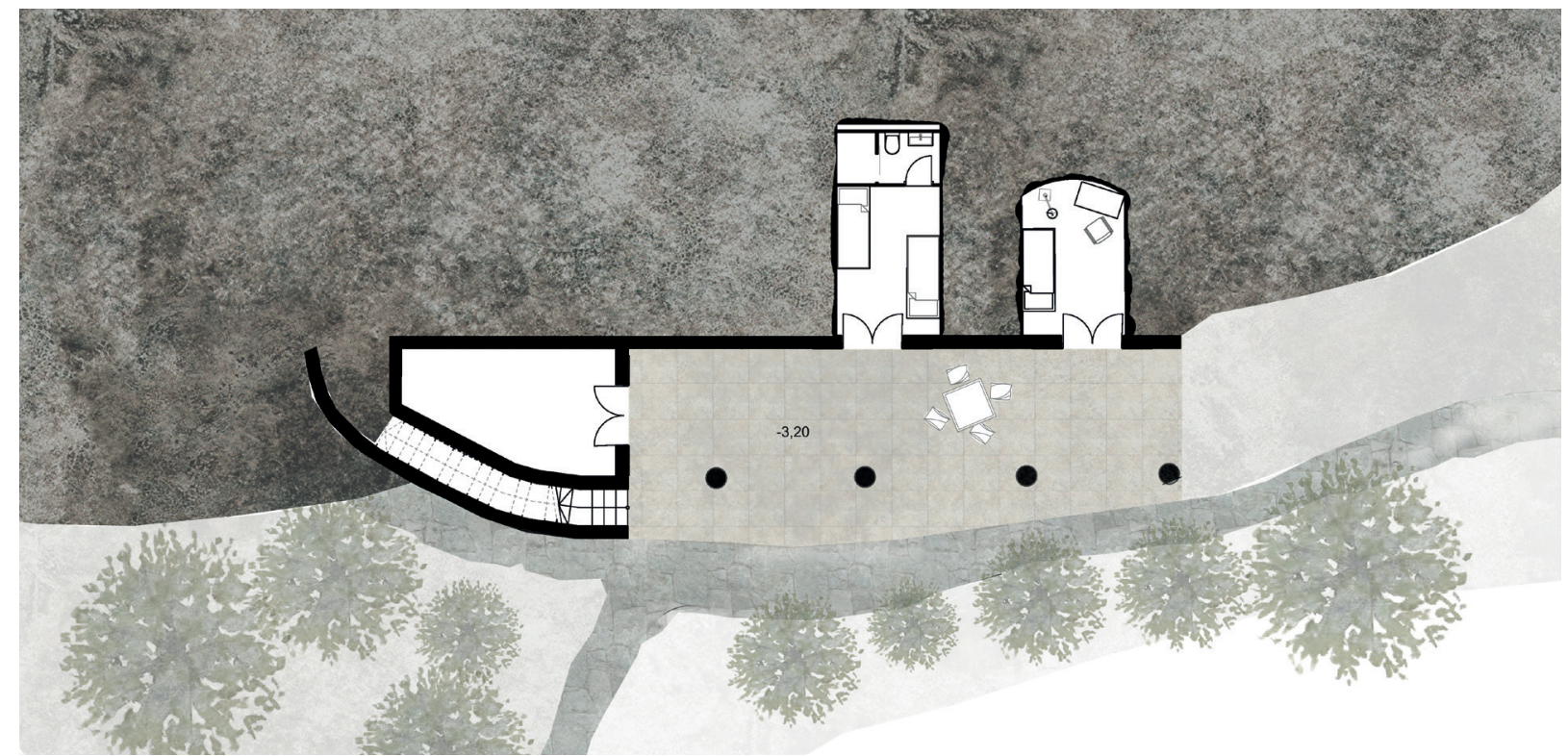

Figure 14. Ground floor plan of the proposal for case study building

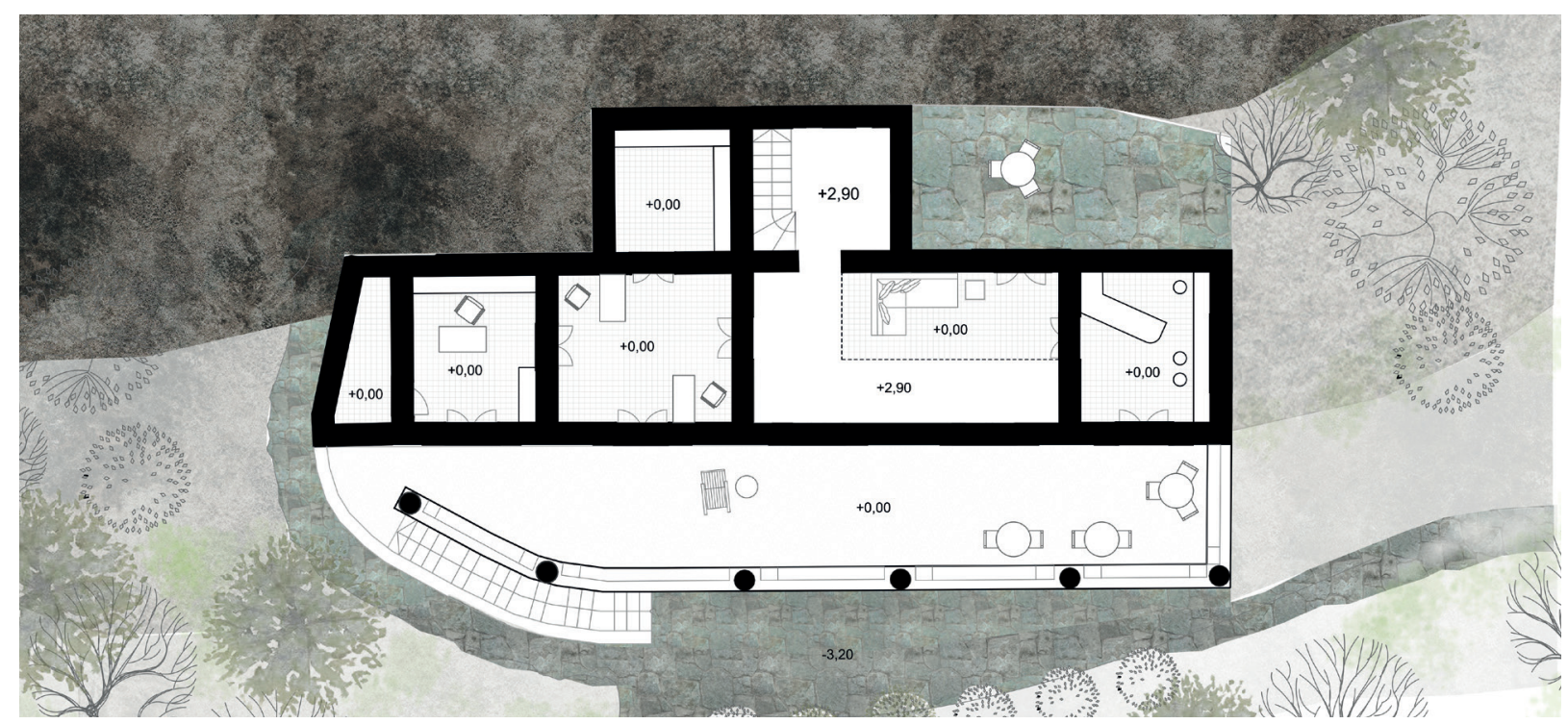

Figure 15. Withdrawn floor above the first floor plan 


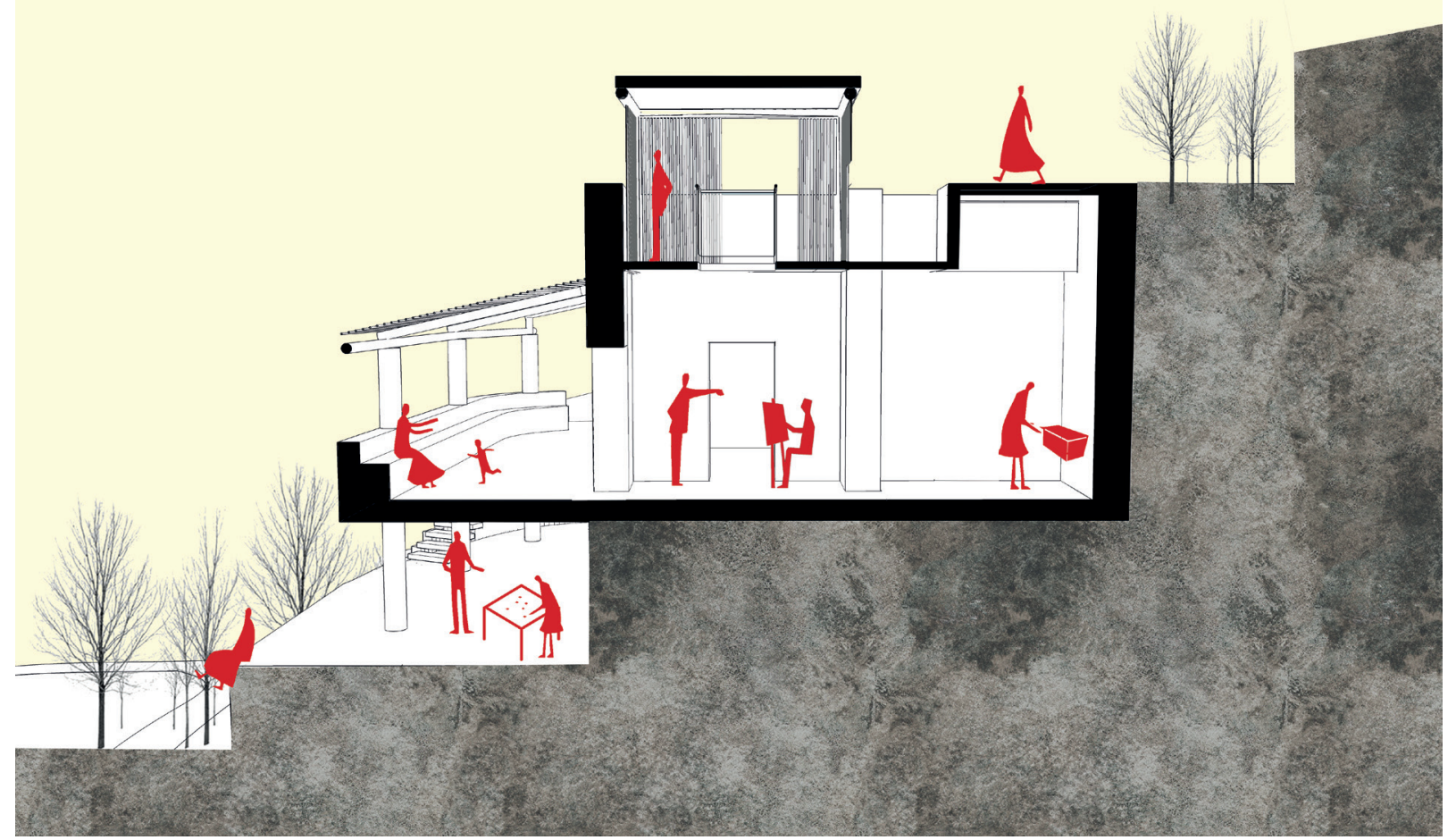

Figure 16. Cross section

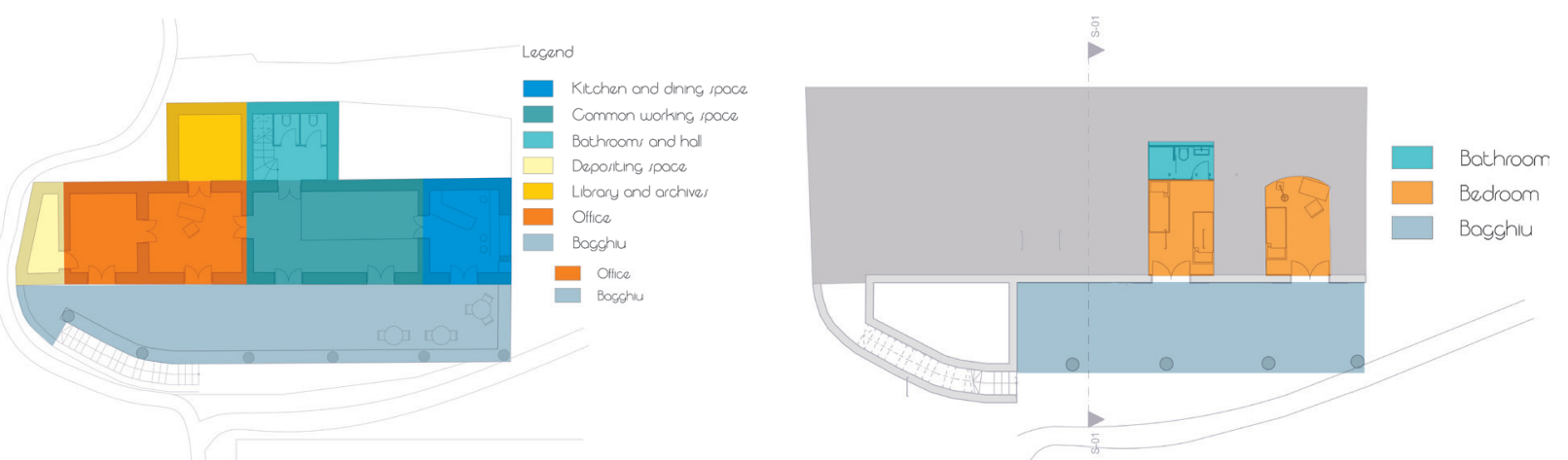

Figure 17. Functional schemes 


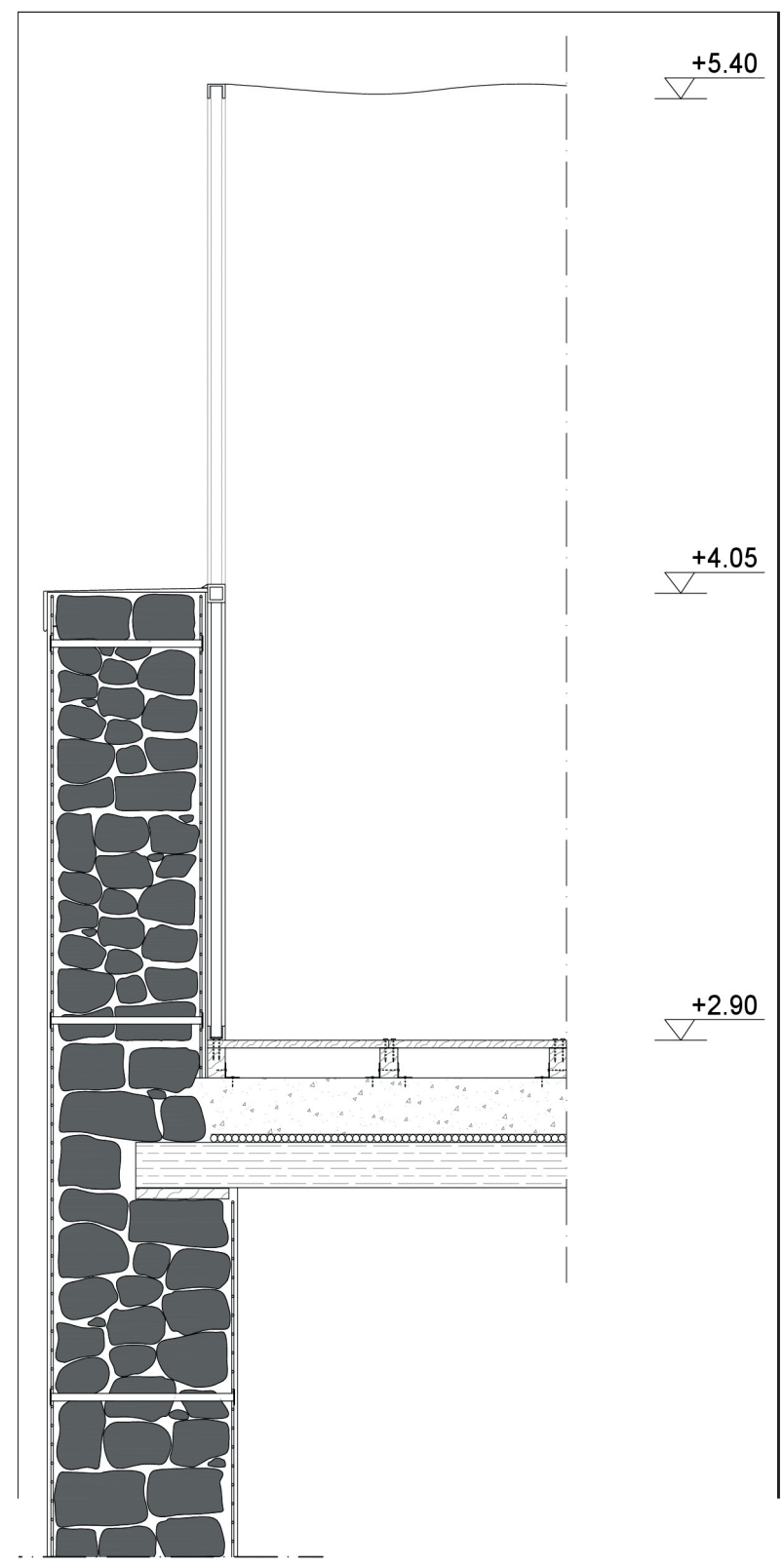

DETAIL

The last floor is the place where we did the observation point. We rebuilt a section of the collapsed roof, maintaining the stratigraphy of the traditional Aeolian roof. Therefore, we have a first layer of $15 \mathrm{~cm}$ wooden beams, a second layer of canes, and an extrados realized by a casting of lime putty and volcanic pumice, $15 \mathrm{~cm}$ thick. On this roof, the new structure was added. We put a first layer of $8 \mathrm{~cm}$ wooden beams, connected to the structure below by means of riveted corner profiles. On these beams, a floor was created with wooden planks.

The new structure has no continuous walls, but canes have been used to recall the traditional architecture and at the same time, create a precise point of view. The canes have been connected to a metal frame so, in this way, the structure is lightweight. Finally, the cover was made with a white cloth that can be opened.

The existing structure was reinforced with fiber glass technology.

Figure 18. Detail section 


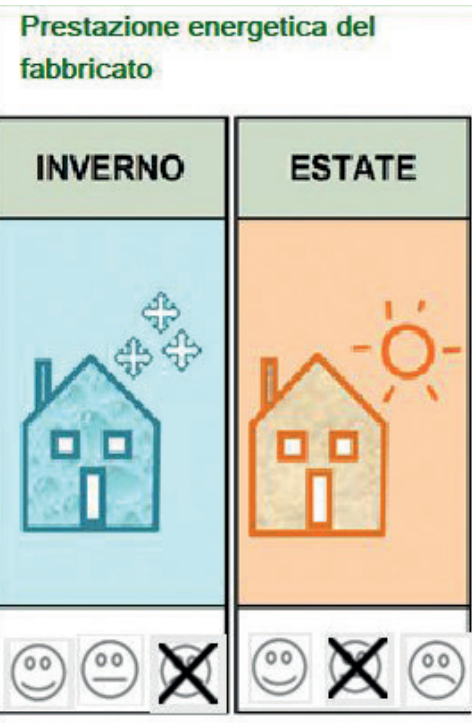

$+\infty$

Prestazione energetica del fabbricato

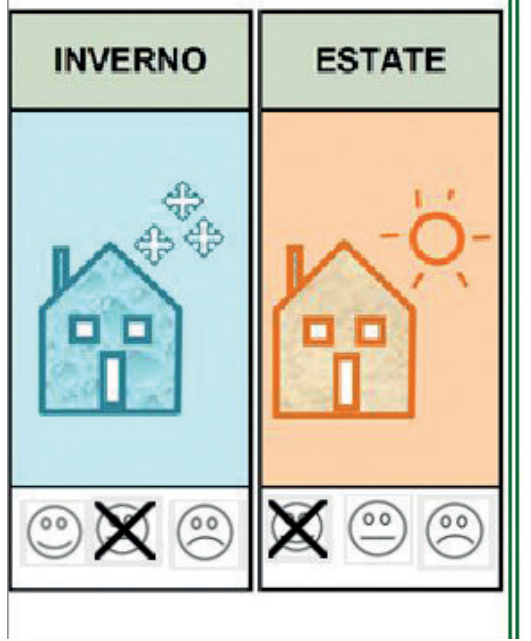

Prestazione energetica globale

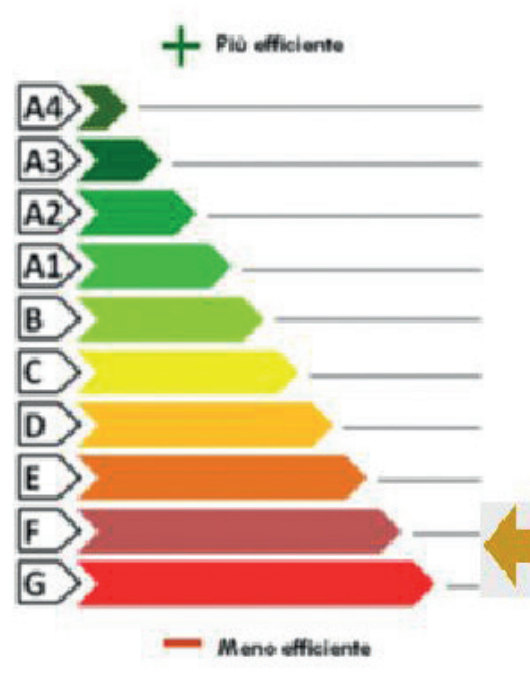

Riferimenti

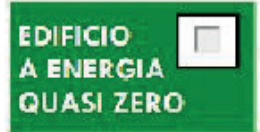

Gli immobili simili avrebbero in media la seguente

CLASSE ENERGETICA

Se nuovi:

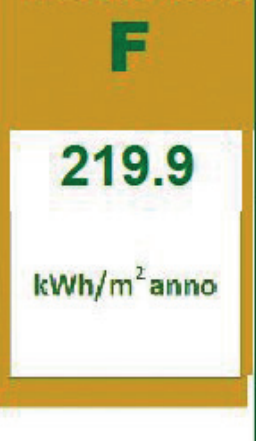

62.6

\section{Se esistenti:}

$\mathbf{F}$

219.9

Figure 19. Energy certification of the existing building

Prestazione energetica globale

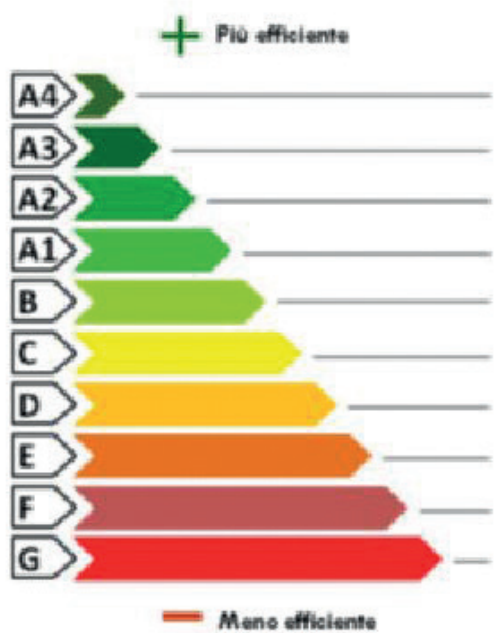

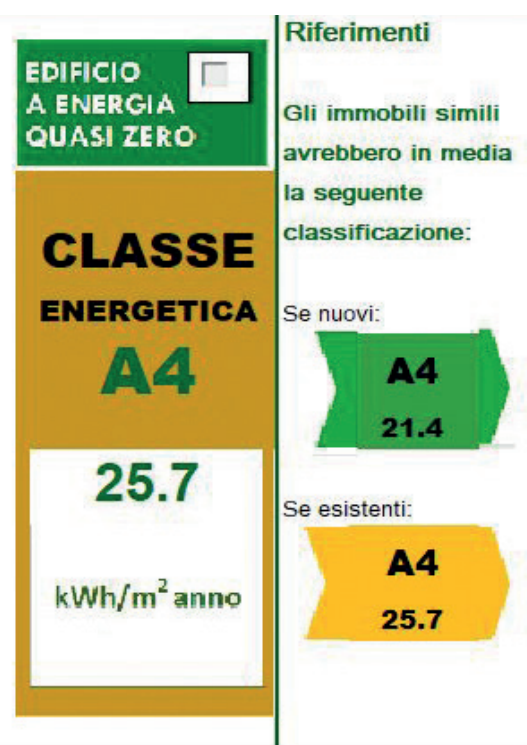

Figure 20. Energy certification of the project 
From the energy analysis of the building, the results of the DOCET program have shown that the worst behavior occurs in the winter months, while in summer, the behavior is better.

Furthermore, by comparing the results obtained for the existing building and those obtained for our proposal, it has emerged that by maintaining the same masonry and inserting only double-glazing, the building's behavior improves. In the same way, the increase in energy class is due to the addition of the heat pumps, used for heating and cooling. 
PART III

AEOLIAN TEACHING MODULE CONTRIBUTIONS

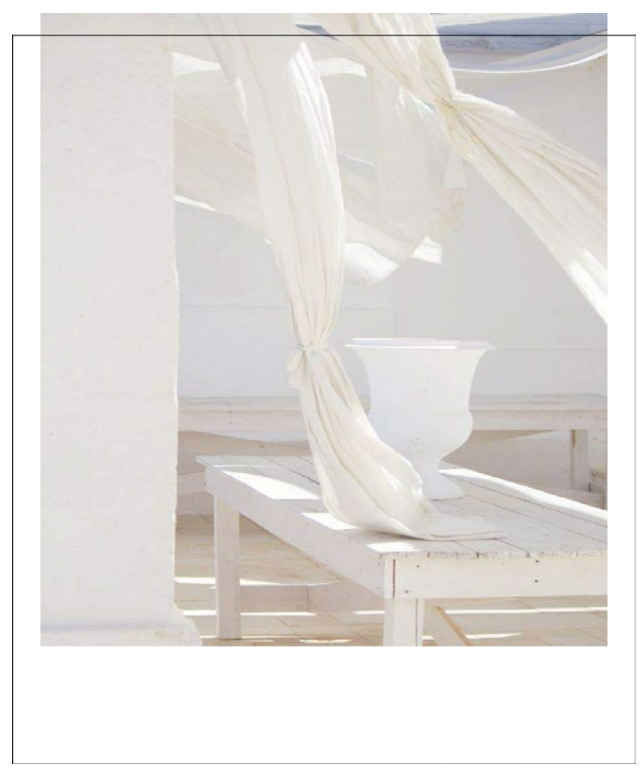




\section{NATURE IN ARCHITECTURE}

\section{STUDY CASE}

Canale Sud

DESTINATION OF REFURBISHED BUILDING

Public library/Community center

\section{ABSTRACT}

"The good building is not one that hurts the landscape, but one which makes the landscape more beautiful that it was before the building was built" Frank Lloyd Wright
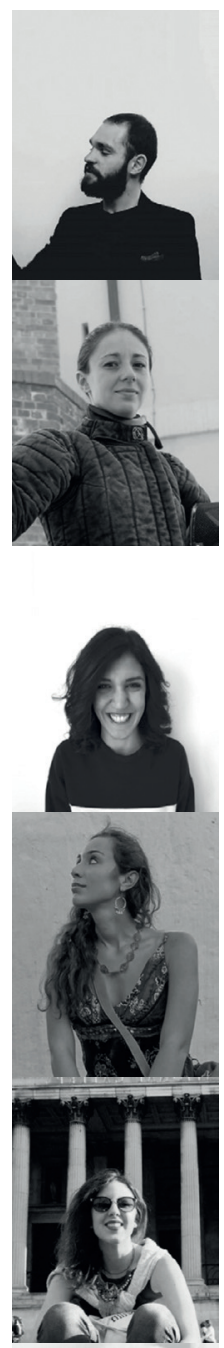

MARGINEAN_Alexandru-Marian_

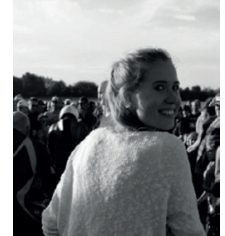




\title{
TASK 1 \\ CHECK OF THE AREA
}

\author{
CANALE SUD
}

Canale sud is located in the south part of the island of Filicudi, in the Aeolian Islands. The site presents a really good orientation; in fact, because of its slope, all buildings receive solar illumination. Buildings are located in a suburban context on a hill, with aligned structure or sometimes, transversal, with respect to the slope. They almost all have south orientation, and therefore, have good solar gains in winter, with protection from the sunshine in summer thanks to some of the architecture's solutions. Buildings are scattered but located mostly all in the central part of the area, around the streets. Canale sud is outlined by a horseshoe bend represented by the main street, a driveway, and some pedestrian paths with stairs too inside the area. Therefore, it is not possible to access every part of the area by car, but just by foot or else by motorcycle. structures are most of all private buildings, but $80 \%$ of people live here just in summer, so in winter, the area is almost abandoned. Maybe because of that, there are not any services for the community.

The relevant characteristics of the traditional architecture from the studied area, extracted from the GIS database, are further presented: more than $80 \%$ of the buildings have bagghiu, most of them having functional pulera and external shadings. Most of the houses have their exterior spaces orga- nized around multiple terraces with external shadings that can vary between 4 and 6 meters wide. The houses without bagghiu and/or pulera are exceptions in this area. It is customary to use wood frames for doors and windows - PVC frames are exceptions in close proximity of our proposed library. Additionally, a common element for the area is the use of white plastered exterior walls. These characteristics are relevant for the implementation of our intervention.

Other traditional characteristics found in the study area are: traditional colors of the facades (white, light blue, terracotta) and window frames (white, cobalt blue), small round windows used for bathrooms, some decorative elements on the facades, and the existence of a water recycling system. The area seems to have a good social capital; the whole housing group forms a maze of social terraces that can serve the community. 


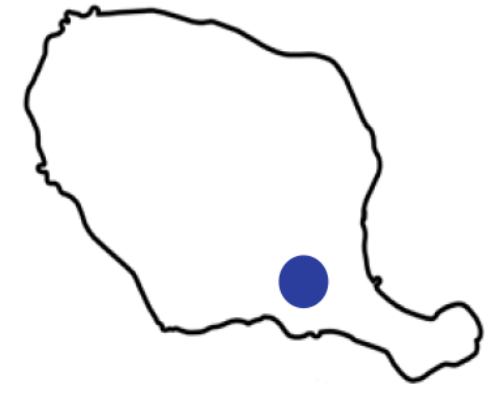

FILICUDI
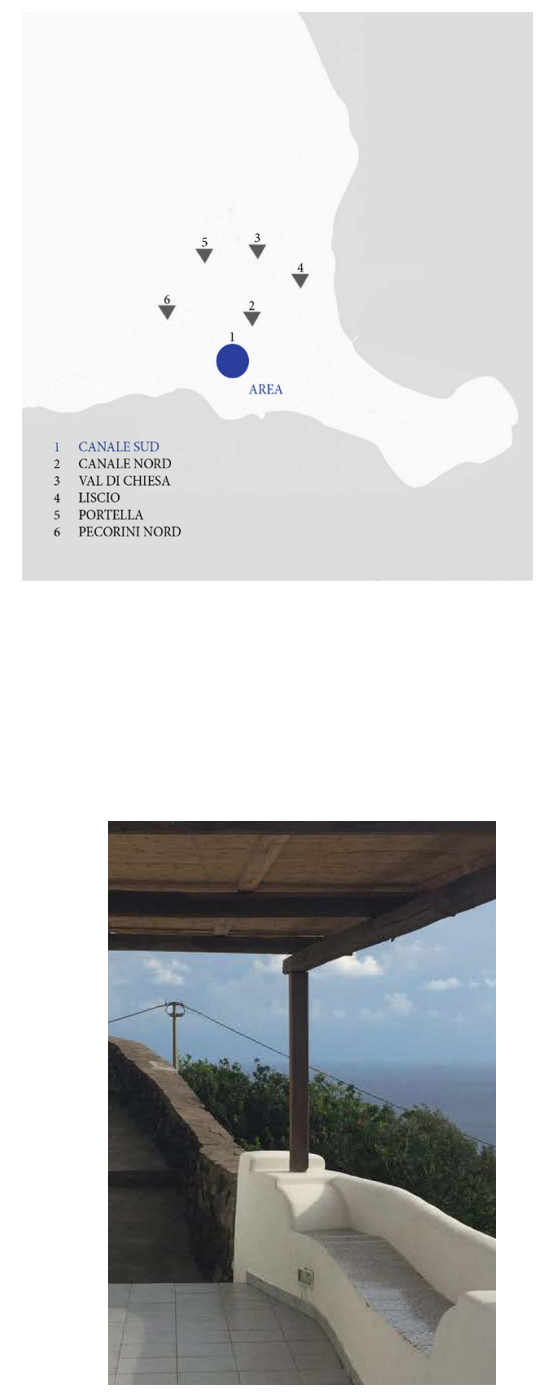
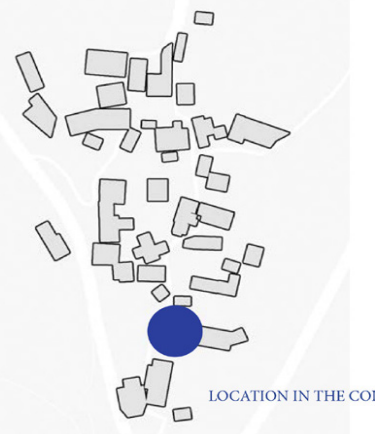

Figure 1. Framework of the study area

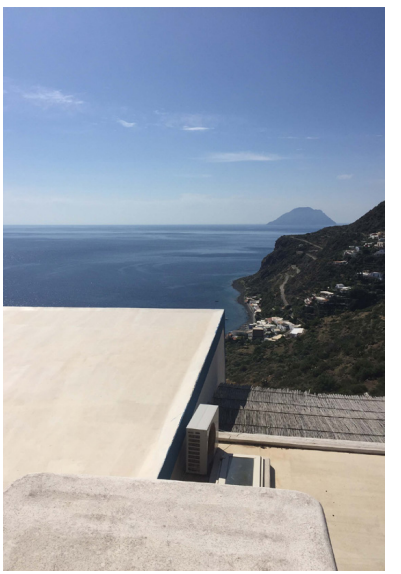

Figure 2. Pictures of the study area 


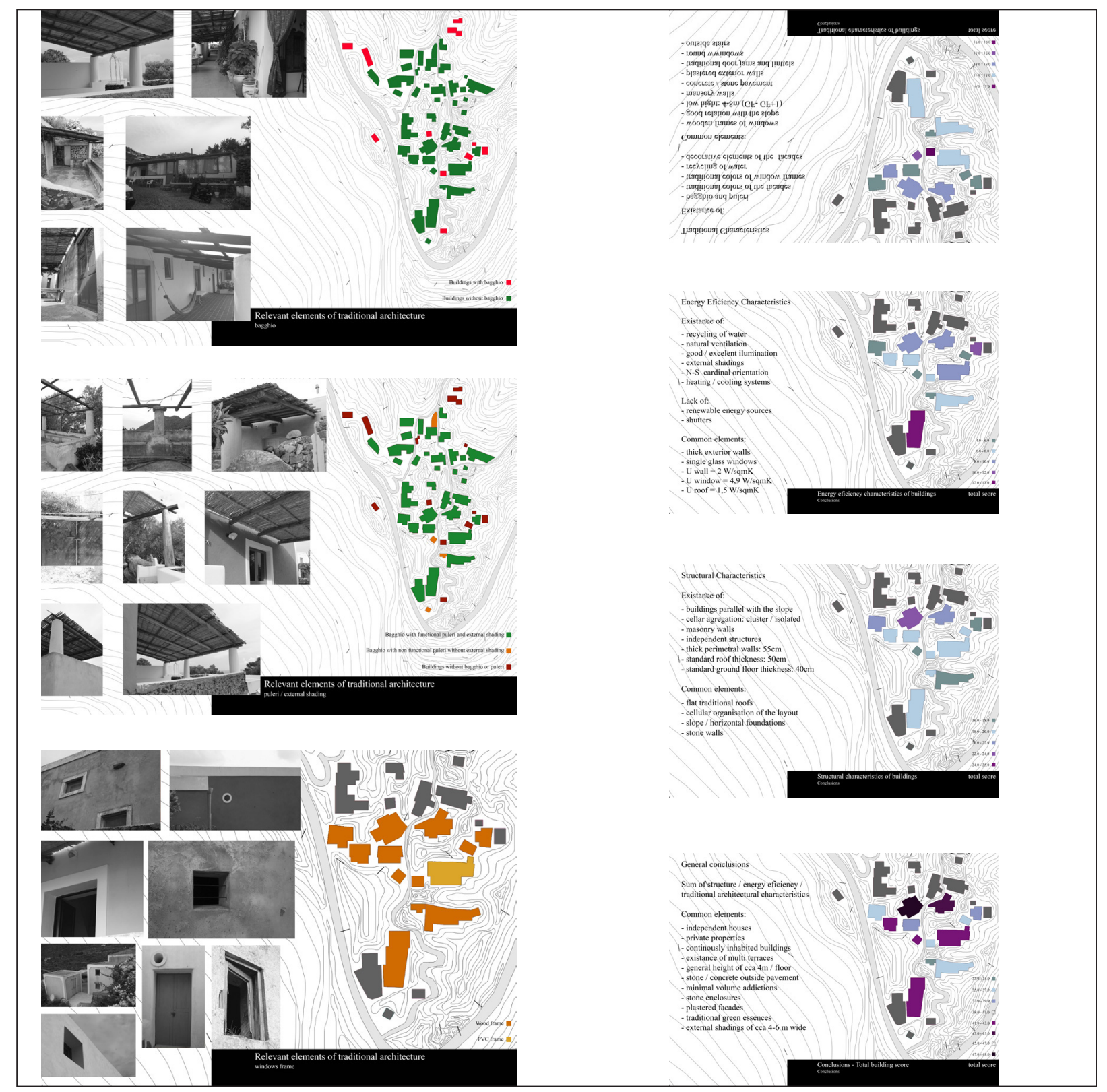

Figure 3. GIS map/masterplan/area pictures 


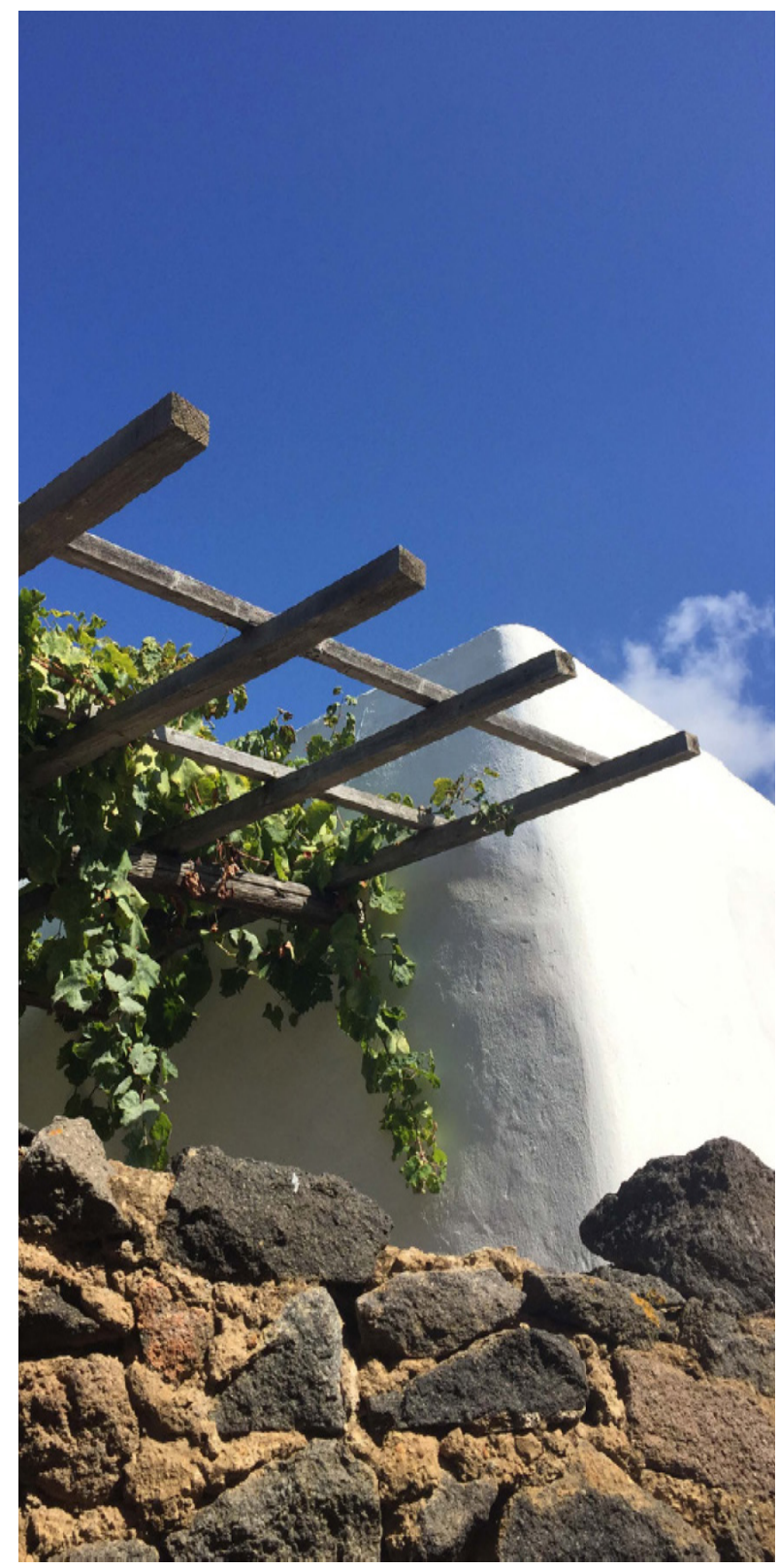

\section{FEATURES AND QUALITY OF THE LOCAL ARCHITECTURE}

In terms of energy efficiency, most of the houses have a series of common elements: thick exterior walls, single glass windows, natural ventilation, good or excellent illumination, external shadings, NS cardinal orientation, and a heating and cooling system. The technical calculations show $U$ wall $=2 \mathrm{~W} / \mathrm{sqmK}, U$ window $=4.9 \mathrm{~W} / \mathrm{sqmK}$, and $U$ roof $=1.5 \mathrm{~W} / \mathrm{sqmK}$. The survey shows that in this area, there is a lack of use of renewable energy sources and shutters for windows and doors.

The analysis of the buildings, in terms structural characteristics, reveals the following main elements found in most of the buildings: flat traditional roofs; cellular organization of the layout, the foundations of the houses are connected, with the orientation of the slope being parallel with the slope and having an independent structure; and the exterior walls are thick and are made of stone or masonry - around $55 \mathrm{~cm}$.

The total GIS database allowed us to create a hierarchy of houses that best meet the criteria for each category - traditional architecture, energy efficiency, and structure - and in the end, to create a hierarchy for the buildings that sum the most characteristics from these three categories. The buildings with the highest scores must be used as models. 


\section{TASK 2 \\ DESIGN PROPOSAL}

\author{
EXISTING CONDITION
}

Our building is located in the south of the area, on a plateau that offers a large panoramic view of the archipelago. We chose this building because of the ratio between the surface of the constructed area and the terrace area, which is a very particular feature. Besides that, the terrace offers huge potential in upgrading the public space of the Canale Sud.

We saw the terraces from the area as a social network intertwined for the inhabitants and our intervention is seen as the center of this whole system - a control center, a place where all the inhabitants could participate in the thinking process of upgrading this area.

The structure of the building was in decent condition, with the steel beams exposed but with only a superficial layer of rust, the walls with sloppy repairs but still the repairs did the job and prevented water infiltration, and the window frames cracked and without glass.

The main feature of the site, the terrace, is in good condition, with only some superficial plants and a little bit of dust accumulation. Sadly, the posts were in bad shape, uneven and cracked, and they have to be rebuilt.
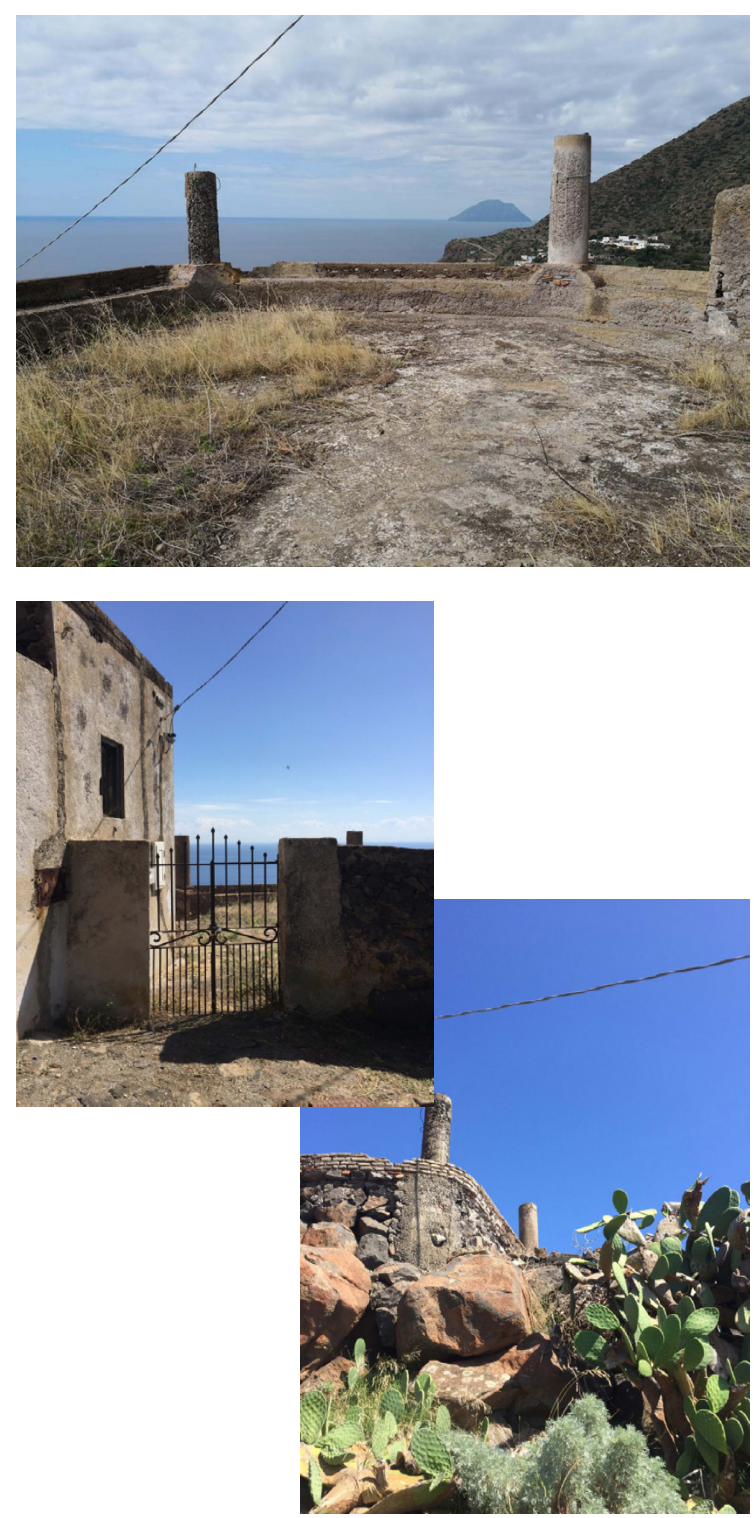

Figure 5. Terrace and current condition 


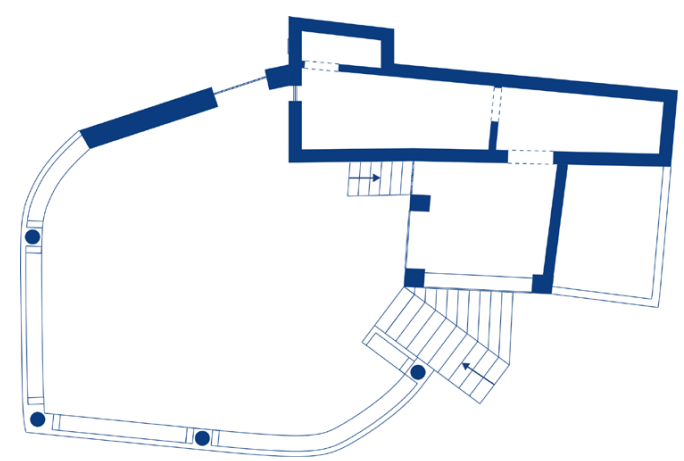

Figure 6. Plan view of the case study building

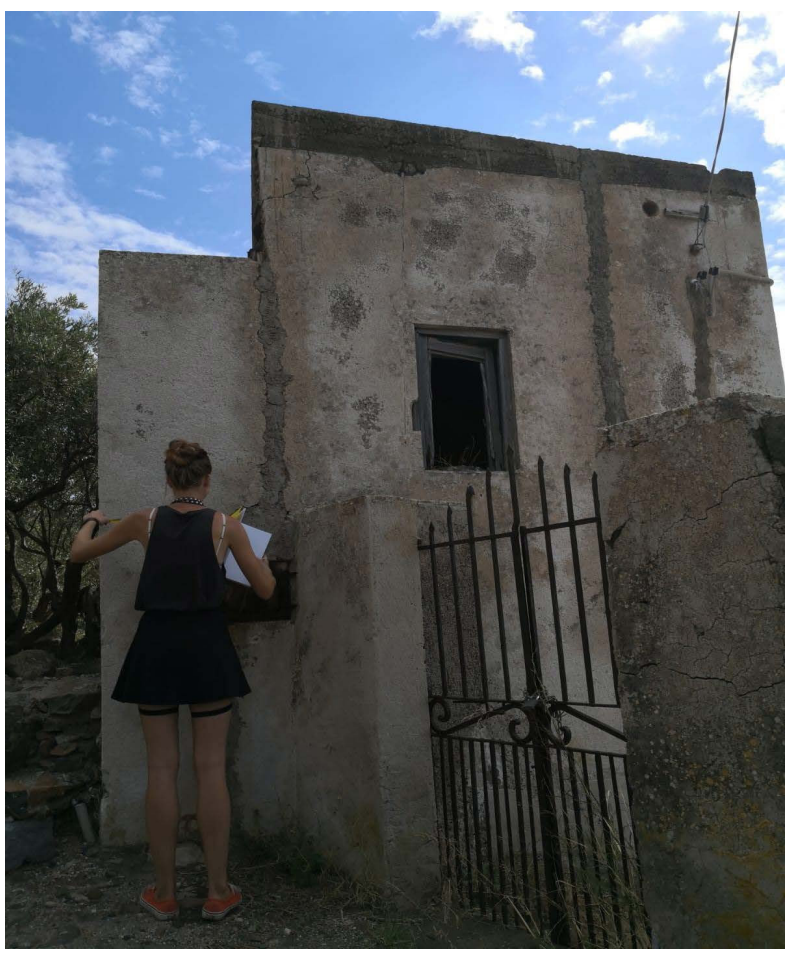

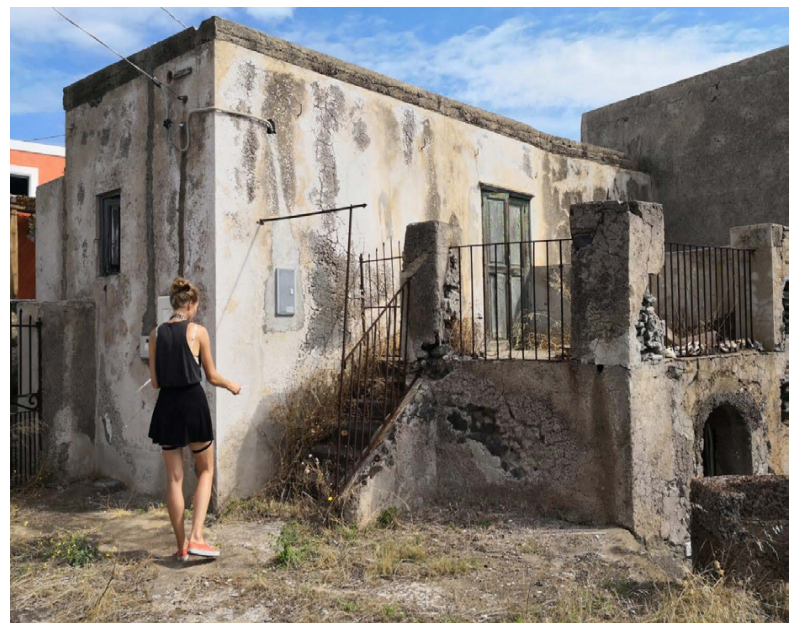

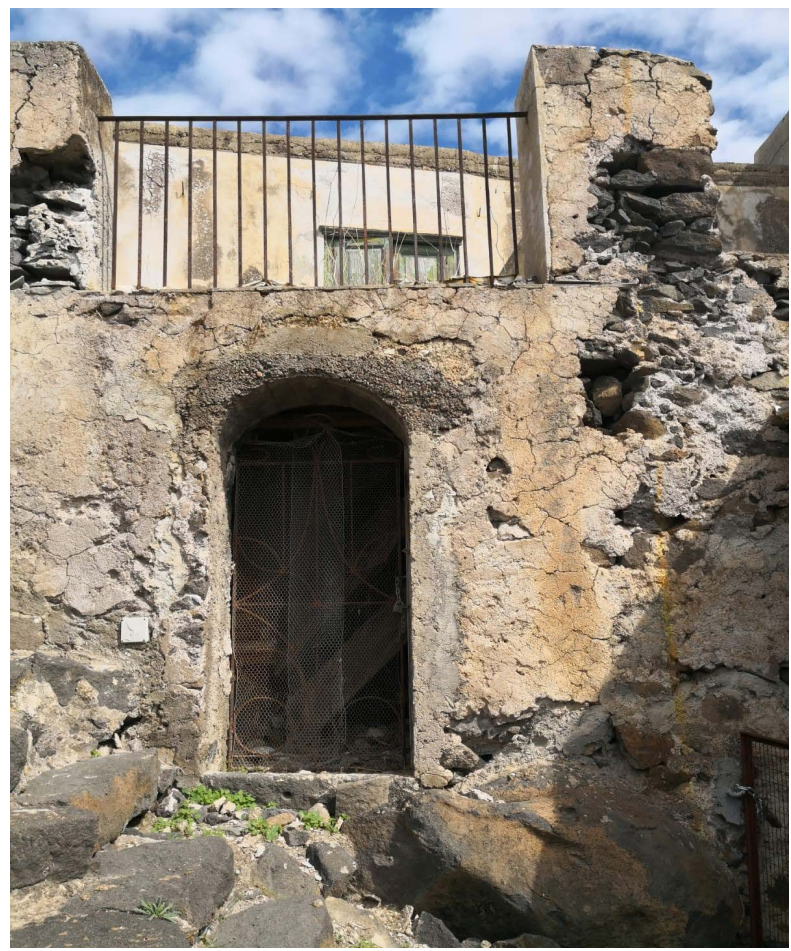

Figure 7. Scale and measurements phase 

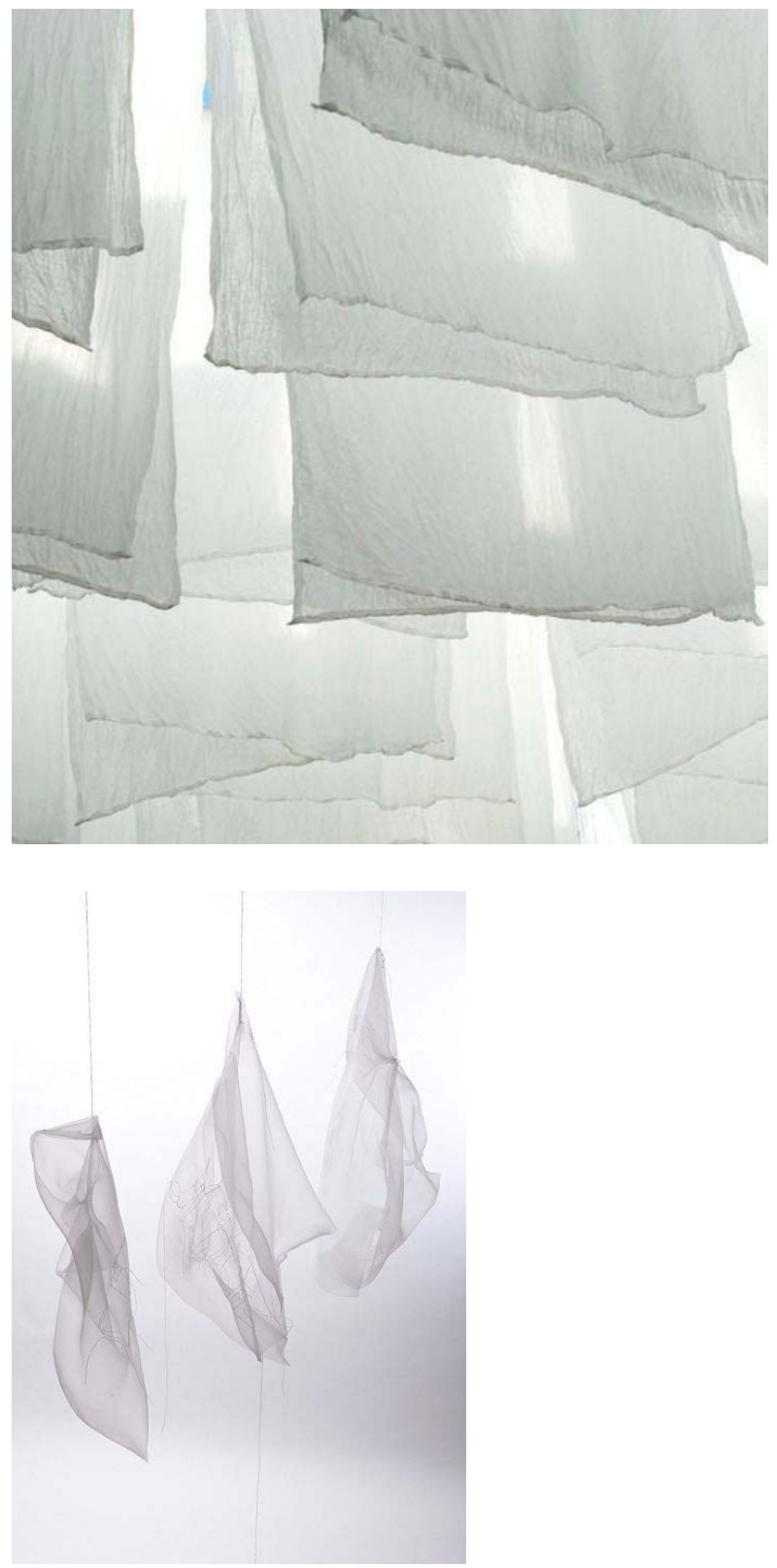

\section{DESIGN PROPOSAL}

The design proposal aims at the social characteristic of the housing typology that Filicudi island has. In our way of seeing the whole area, the terraces are a latent place that can host various activities; by connecting all the terraces in a social system, you can create a new layer of activities for the inhabitants and also for the island's guests. Our project will be the info point that explains all about the archipelago, about the island, and about the life of the inhabitants. The small building will host a public library with an inner sharing system that can function the whole year. By the building, the terrace, which is the control center of the whole social terrace system, hosts a pavilion structure, very light and flexible, that offers the most needed shade in the summer for meeting actions, working events, and cultural events. In addition, the coatings are polyvalent and the user can transform them from a simple shading piece of material to a hammock, video projection, and storage sockets.

For the landscape matter, the light structure creates a very delicate view that is always moving and connecting with the wind, becoming one and the same. 


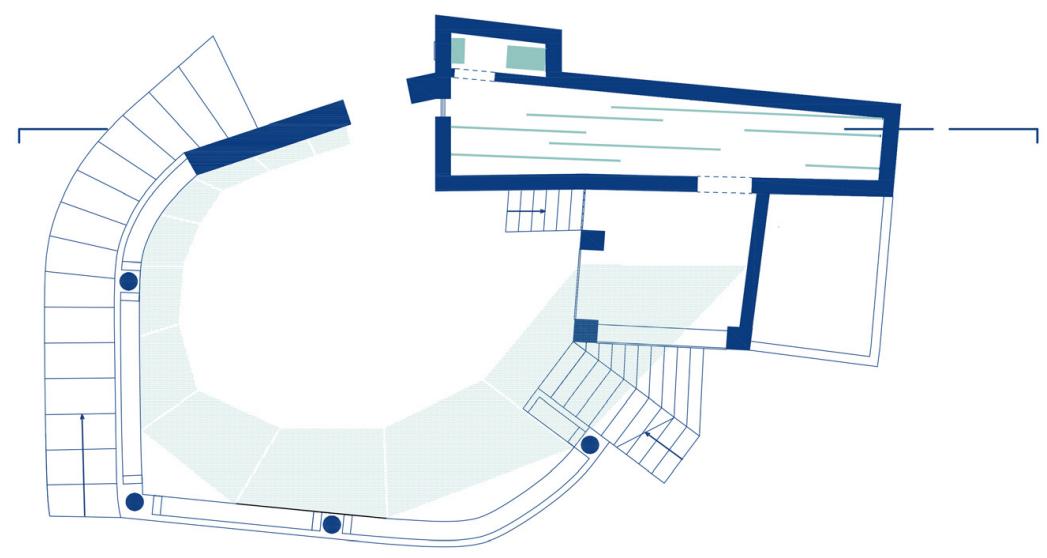

$0_{1,5 m}$

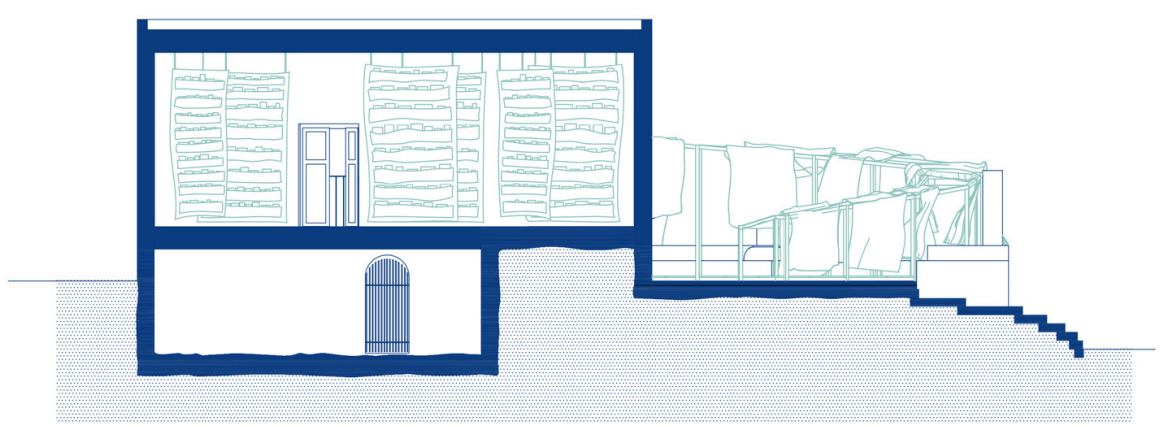

Figure 9. Proposal plan / section 

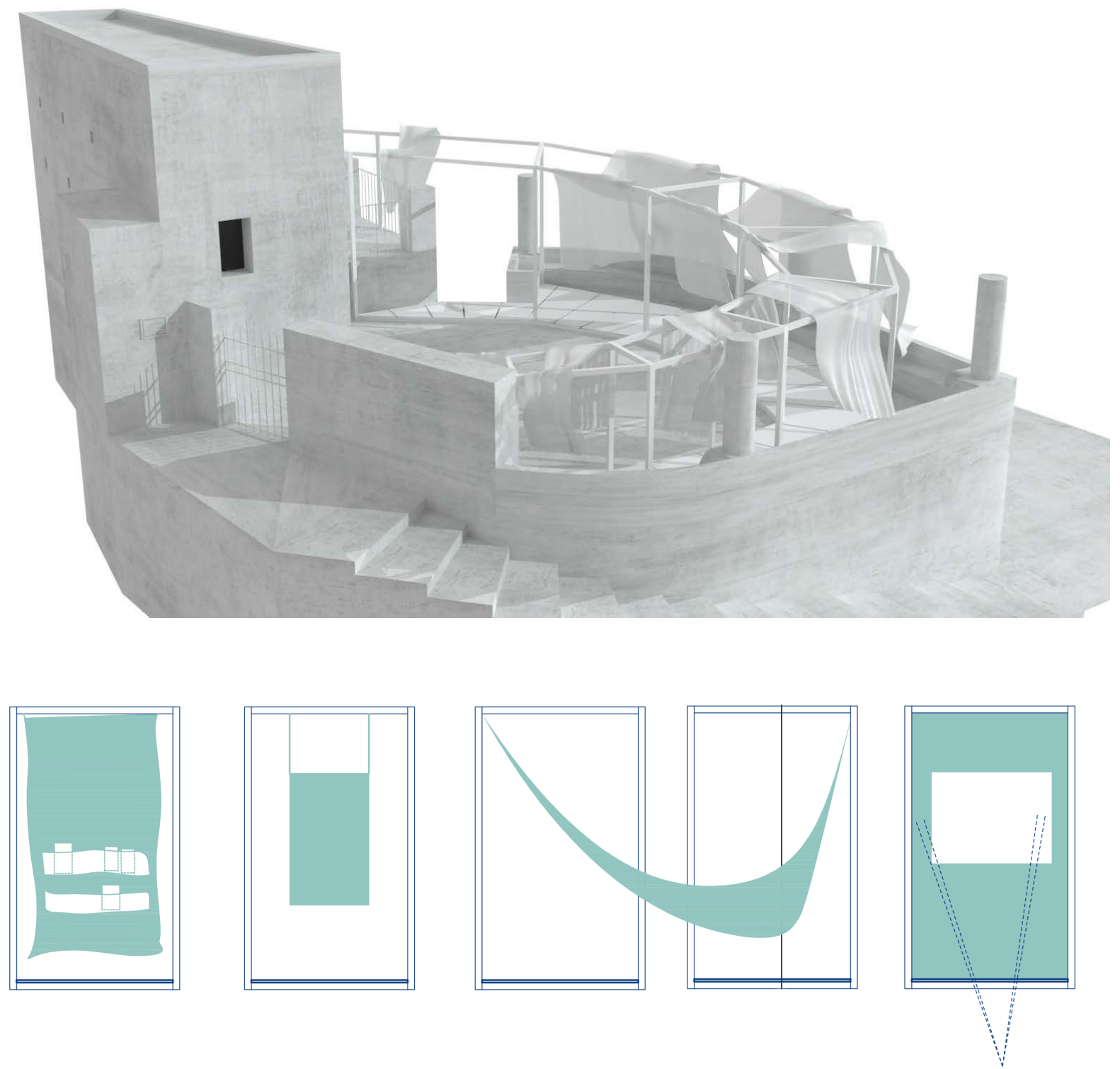

Figure 10. Render images 

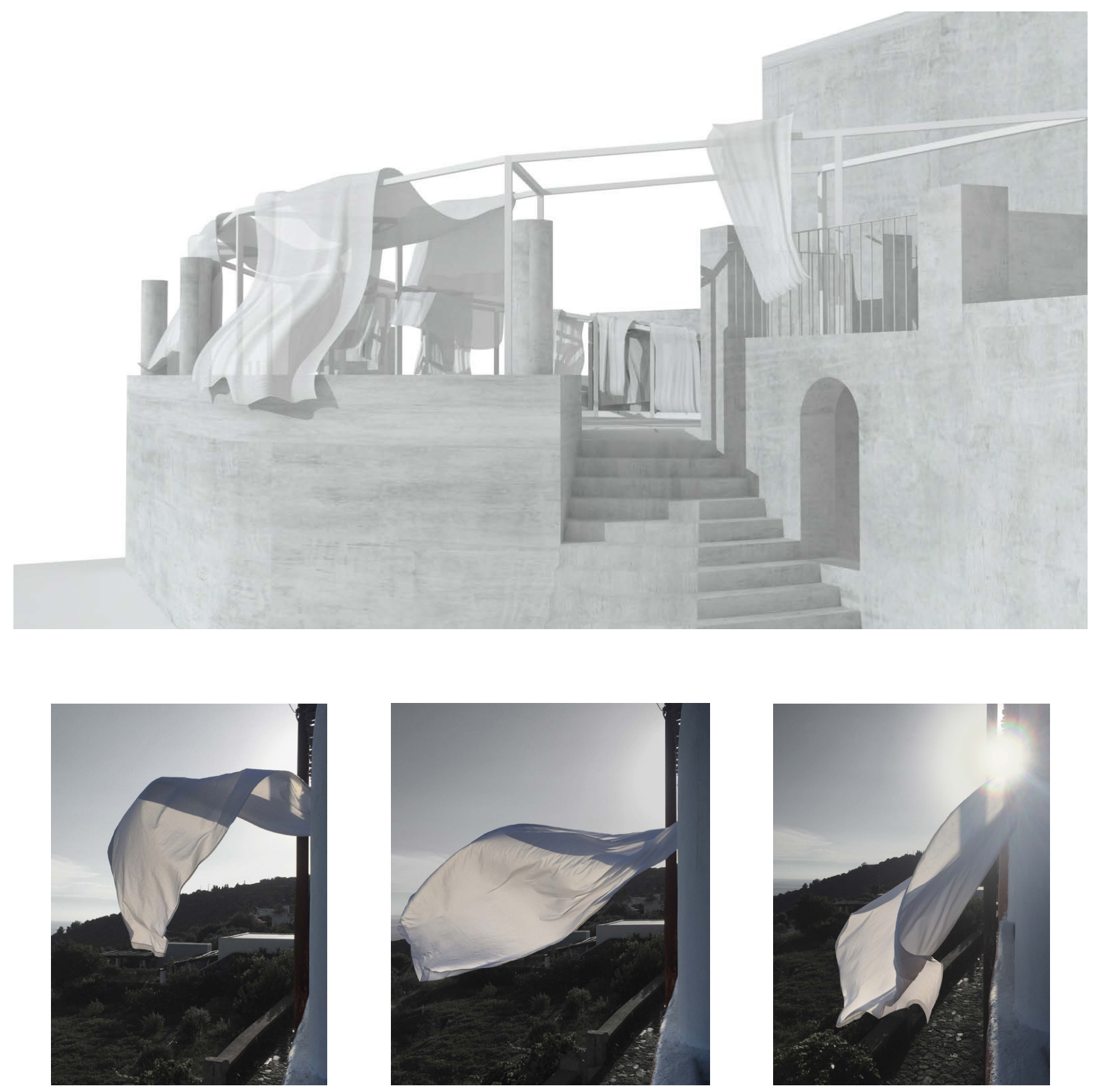

Figure 11. Render images 

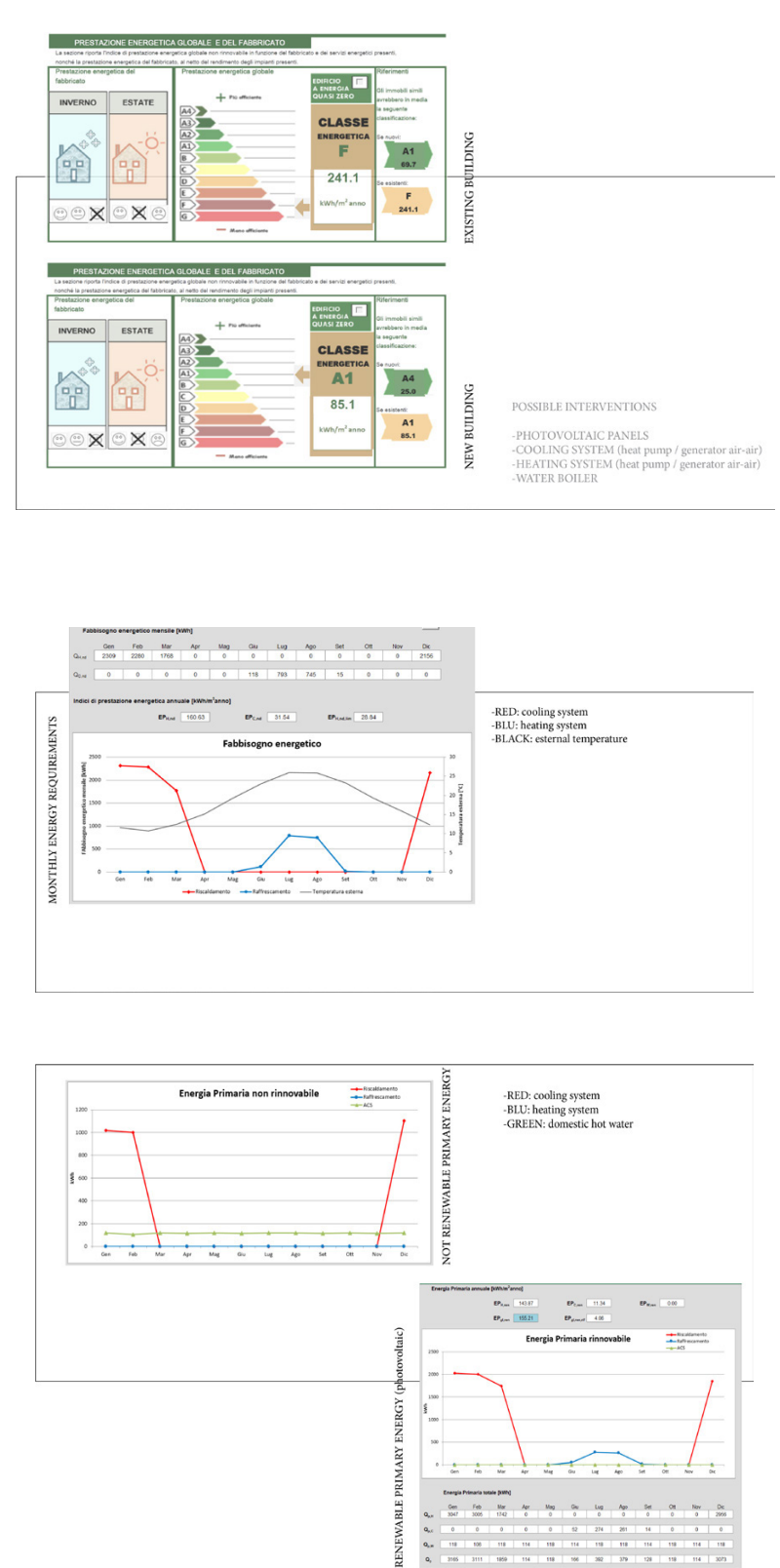

Figure 12. Energy requirements
DETAIL

To improve the structure's performance, it has been decided to modify some aspects. The building needs a structural reinforcement for the containing walls in order to increase resistance and give more stability to the structure. In this way, it is possible to improve the structure's behavior in case of an earthquake. Reinforcement is made of a composite structural reinforcement used for masonry constructions in carbon fibers and without epoxy resins. It is constituted by a grid located between the structure and plaster and is fixed thanks to carbon fiber connectors. The roof is really important because of the comfort indoor.

Therefore, the new stratigraphy includes a primary beam and secondary beam, a layer made up of canes, then a screed, a vapor barrier, and insulation, and finally, a leveling concrete to put over the water proofing. The project includes also the installation of photovoltaics, and so, leveling support with a self-leveling head is provided. 

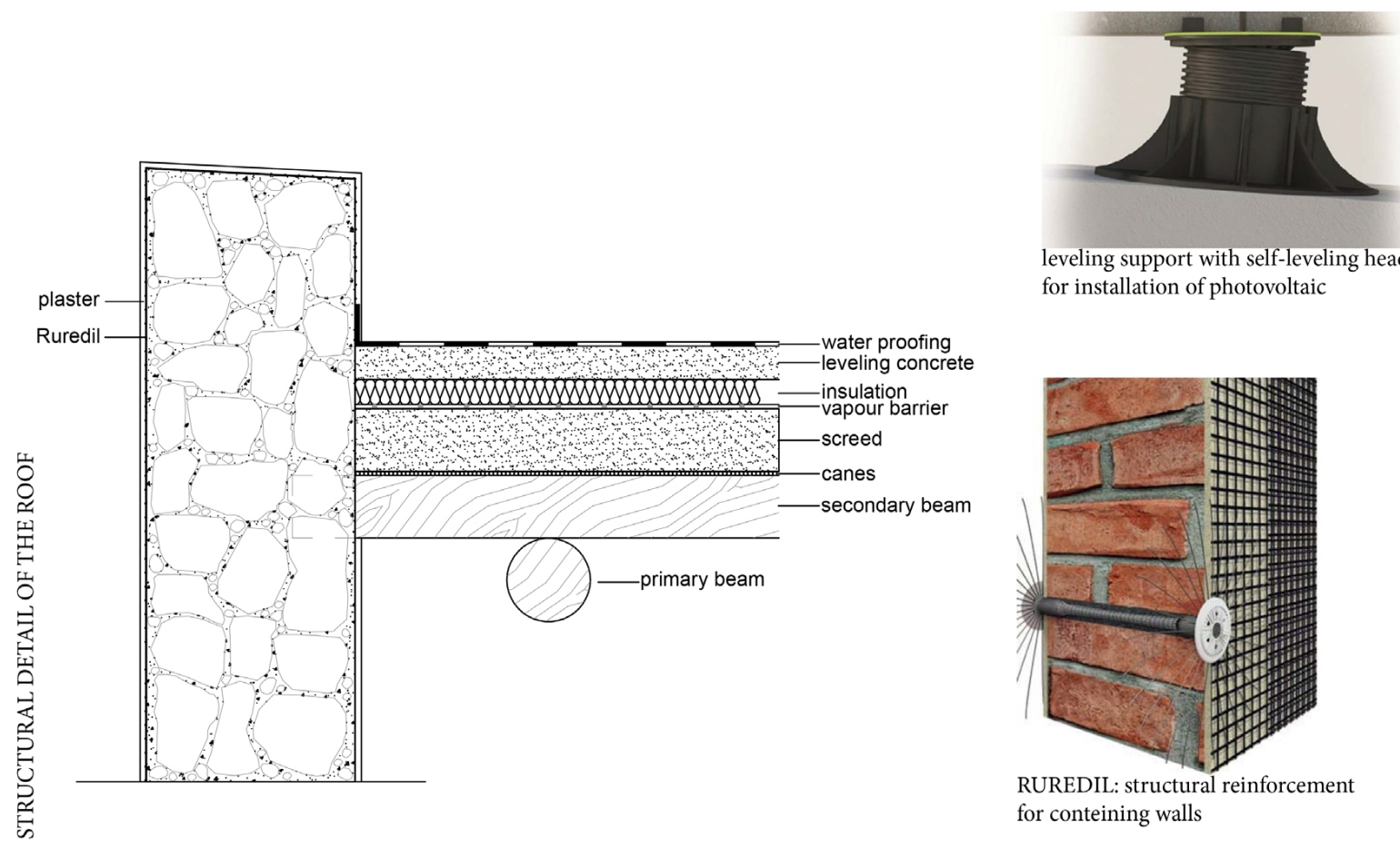

leveling support with self-leveling head for installation of photovoltaic

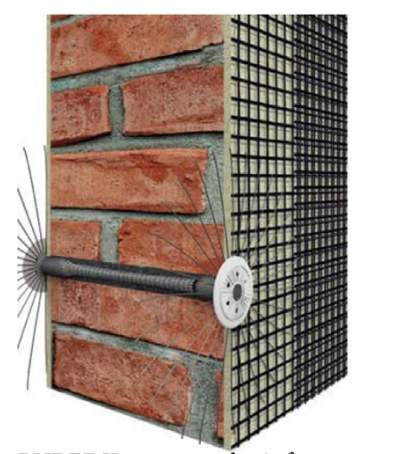

RUREDIL: structural reinforcement for conteining walls

Figure 13. Structural details 


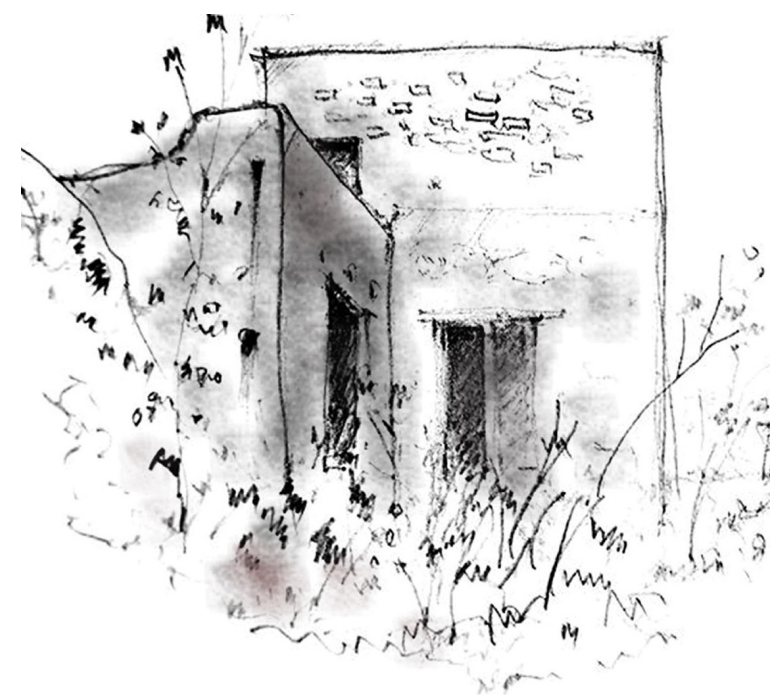




\section{RURAL WELLNESS}

\author{
STUDY CASE
}

Liscio

DESTINATION OF REFURBISHED BUILDING wellness center / medical center

\section{ABSTRACT}

The over goal of the project is to enhance the quality and the relevance of higher education architecture of current approaches of revitalization of rural build heritage environment, rural landscape and traditional construction systems.

Firstly, we had to study the traditional Aeolian architecture, the local materials and the structural systems, so that we could improve the current state of our building by using a sustainable development to vitalize the heritage of our area.

\section{WORK TEAM}

ANGHEL_Oana Maria_Student at UAUIM BRATU_Theodora_Student at UAUIM SERBAN_Nicole Diana_Student at UAUIM TORRE_Claudio_Student at UNICT BETAT_Florian_Student at NTNU

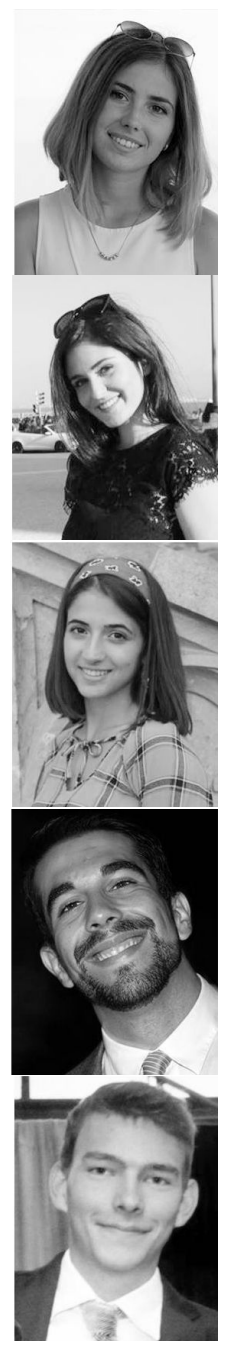




\title{
TASK 1 \\ CHECK OF THE AREA
}

\author{
LISCIO
}

Filicudi is located in the western arm formed by the islands, which is one of the most isolated, with the nearer one, Alicudi. Filicudi boasts the longest history: a prosperous community that traded obsidian, living in the little hill of the Cape of Graziano, from the Neolithic to the Bronze Age. Due to the isolation for which these islands are recognized by UNESCO, Filicudi has preserved its landscape in a more efficient way. During the past centuries, the local people had created a complex terracing system so that they could cultivate their hilly estates.

Although the climatic conditions of the island are similar to the Mediterranean countries, here the climatic changes are extreme. In the summer, the temperature reaches 40 degrees Celsius for several days and the precipitations are limited to $5 \%$ of the total.

In addition, sometimes they face strong westerly winds. Considering the conditions above, the Filicudian builders have created a comfortable, friendly place with minimum energy consumption.

Liscio is situated at the middle height on a level curve, orientated towards a spectacular view of the bay. The houses are located along the slope, very close to each other, almost as if it was one neighborhood. Most of the houses were refurbished but in the traditional way, as there were unusual elements such as cooling systems, the color of the façade and lintels, and modern shutters and pullers made of different materials. In general, the houses were not inhabited, mostly used as a holiday refuge. On the whole, this area had strong potential to revitalize their heritage and to attract tourists. 


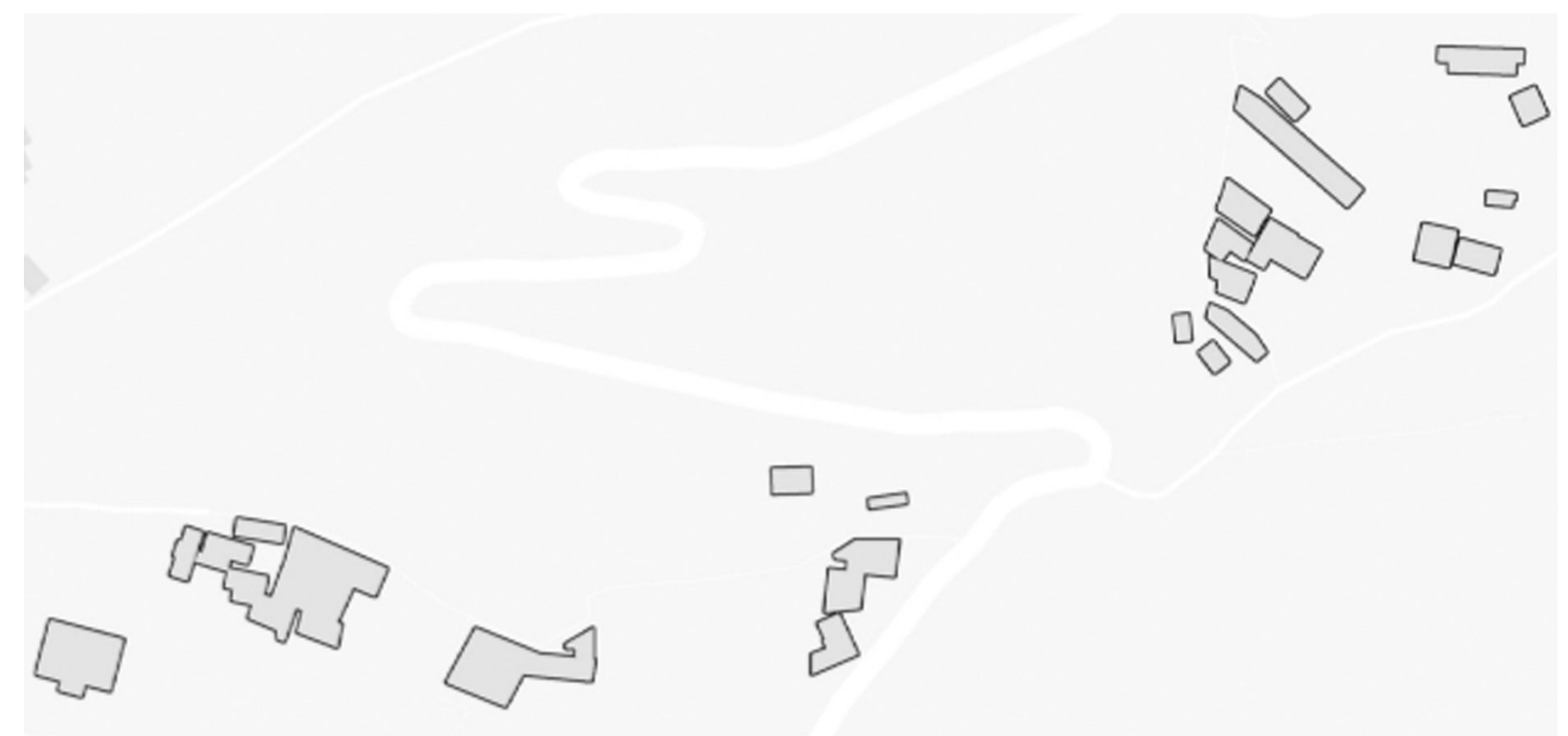

Figure 1. Map of the study area

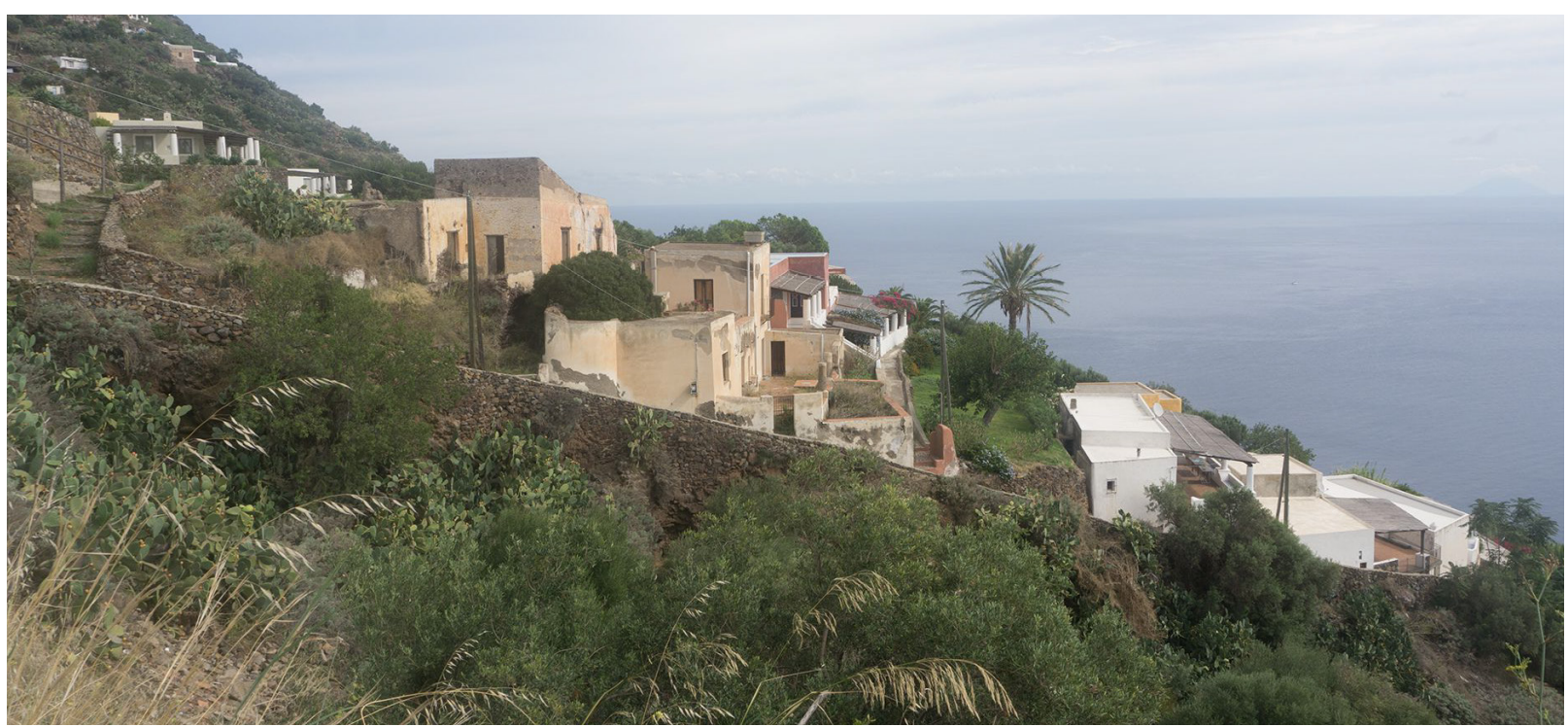

Figure 2. Image of the study area 


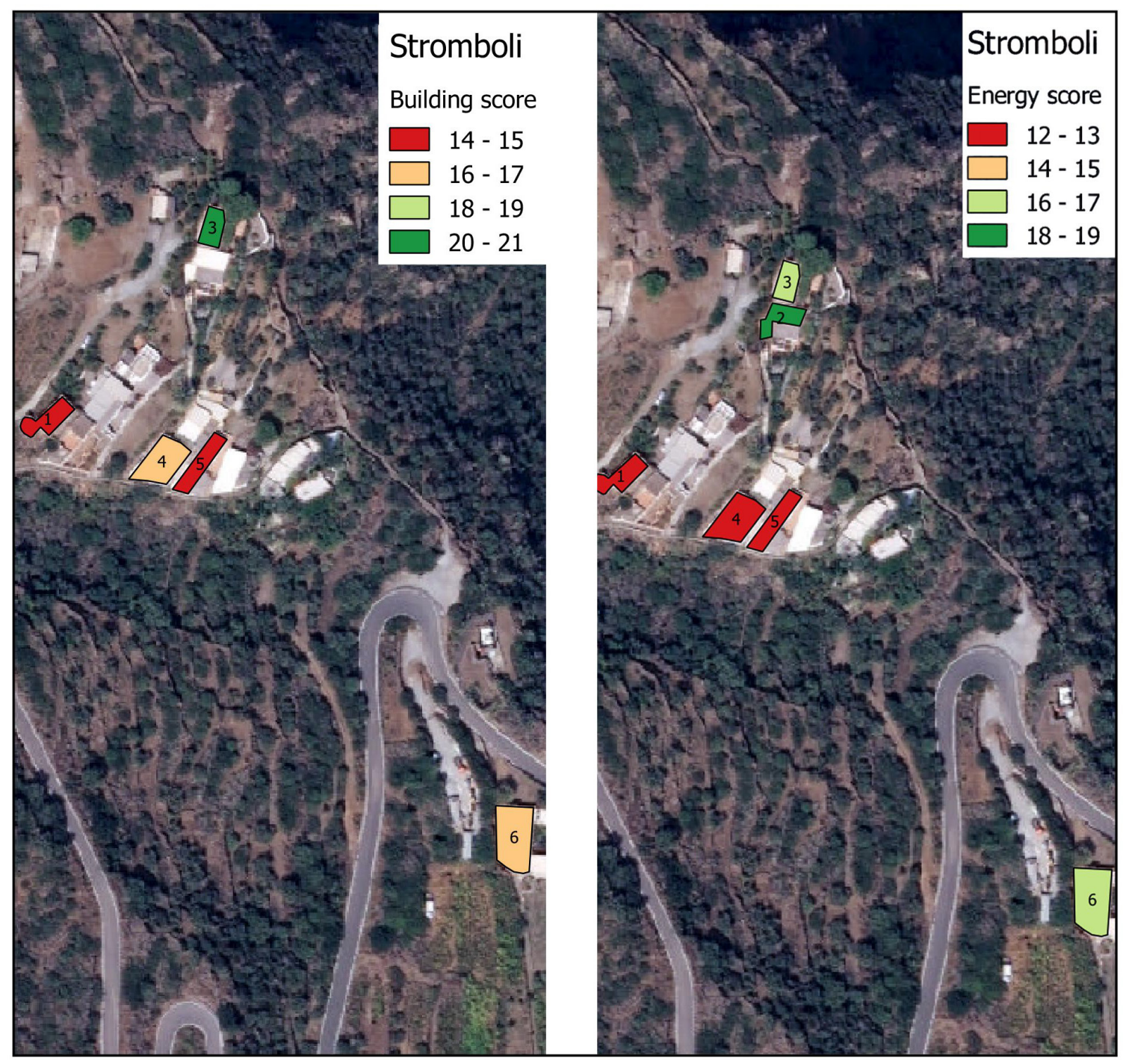

Figure 3. GIS map 


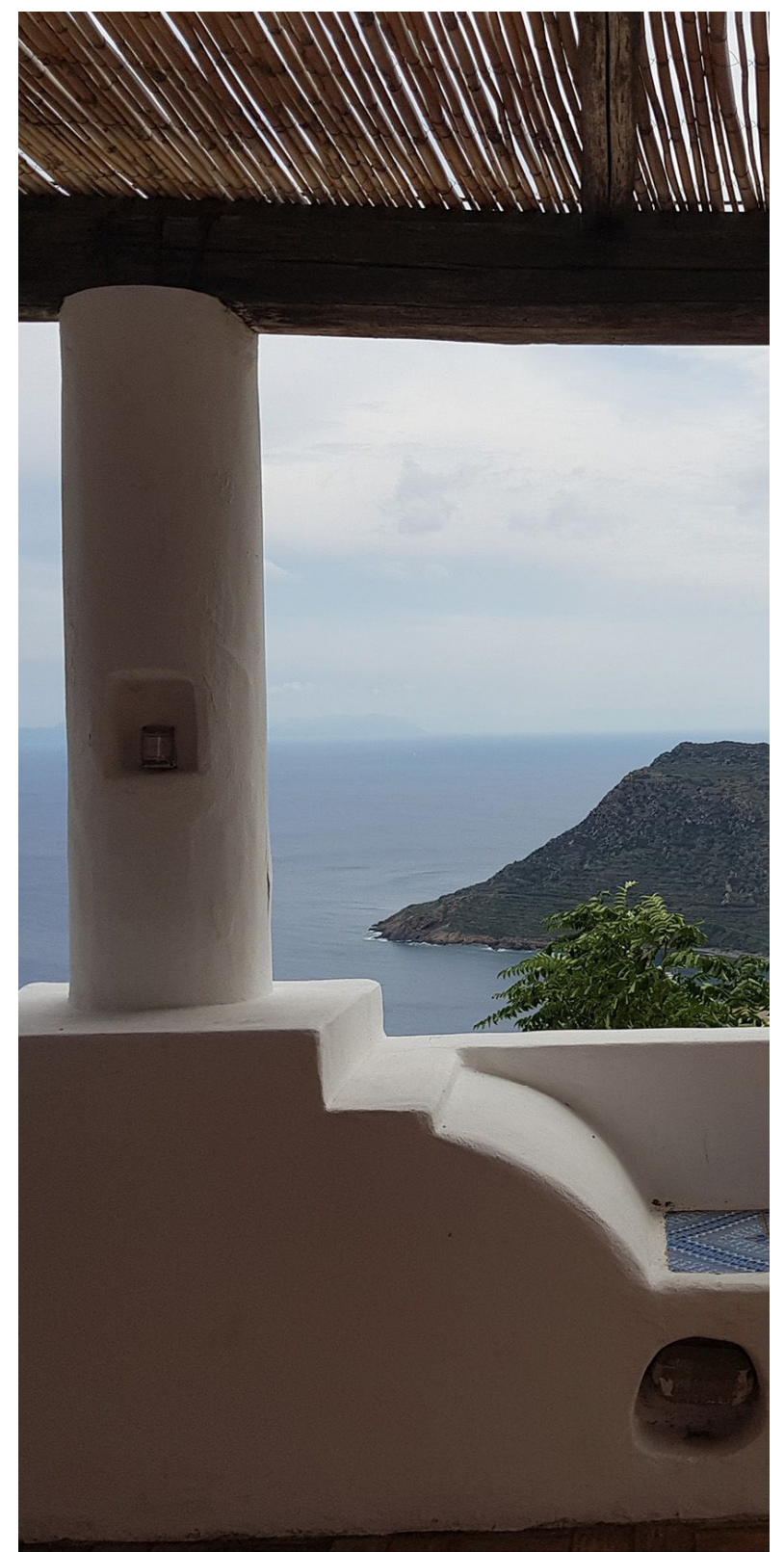

Figure 4. Traditional bagghiu and pulera

\section{FEATURES AND QUALITY OF THE LOCAL ARCHITECTURE}

Analyzing the Aeolian Islands' architecture, we noticed that the Filicudian traditional houses have a distinctive architecture, adapted to the landscape and the climatic conditions. The buildings are organized on two levels, working as two different houses, so that the staircase is outside. The rooms have a generous, squared surface and are directly connected. In general, the building has a regular volume, with two fronts, one to the south, and the other one to the north. In front of the house, there is a large terrace, named in local dialect, bagghiu, while at the back, there is a little yard with local plants. The original purpose of these terraces was to work on the rural products, in the open air, as it was naturally ventilated. The terrace end has a masonry seat, called the bisolu. Most of the time, because of the two level house, the bagghiu is enclosed by a porticos.

Due to the volcanic nature of the Aeolian Islands, the masonry has to be more resistant, with vertical elements that are firm, combined with light and flexible horizontal elements. The composition of the masonry is made of rough basaltic stones, and they used squared stones to reinforce the edges of the building. The thickness of the wall is $60 \mathrm{~cm}$ at the bottom, while the upper one is $50 \mathrm{~cm}$.

The plaster is generally white so that it reflects the sun, which is made of lime and volcanic sand, painted with lime milk. The color of the windows lintel, which is a vivid tone (blue, cyan-sea, red-clay, and green) stands out on the facade. 


\section{TASK 2 DESIGN PROPOSAL}

\author{
EXISTING CONDITION
}

The building we had to refurbish was in a poor condition, but there were still some architectural elements preserved from the old structure. Trying to reach the interior of the house, we entered through a ruined portico, covered by masonry arches and wooden beams used in the structure of the roof. At the ground floor we discovered a cave where they probably sheltered their animals or stored food products, also a space with a water cistern, which collected the pluvial water used for the household. The last room was perhaps a barn, whose roof collapsed and now, it had double the height.

The upper floor, we assumed, was composed of a kitchen, a toilet, and two large rooms, directly connected to the collapsed terrace. The roof was not built in a traditional way, having a slope instead of a terrace. It was also made with a different material, which pointed out to us that it was a later addition. The surrounding yard, which was overgrown, had a big potential for exploitation in our proposal.

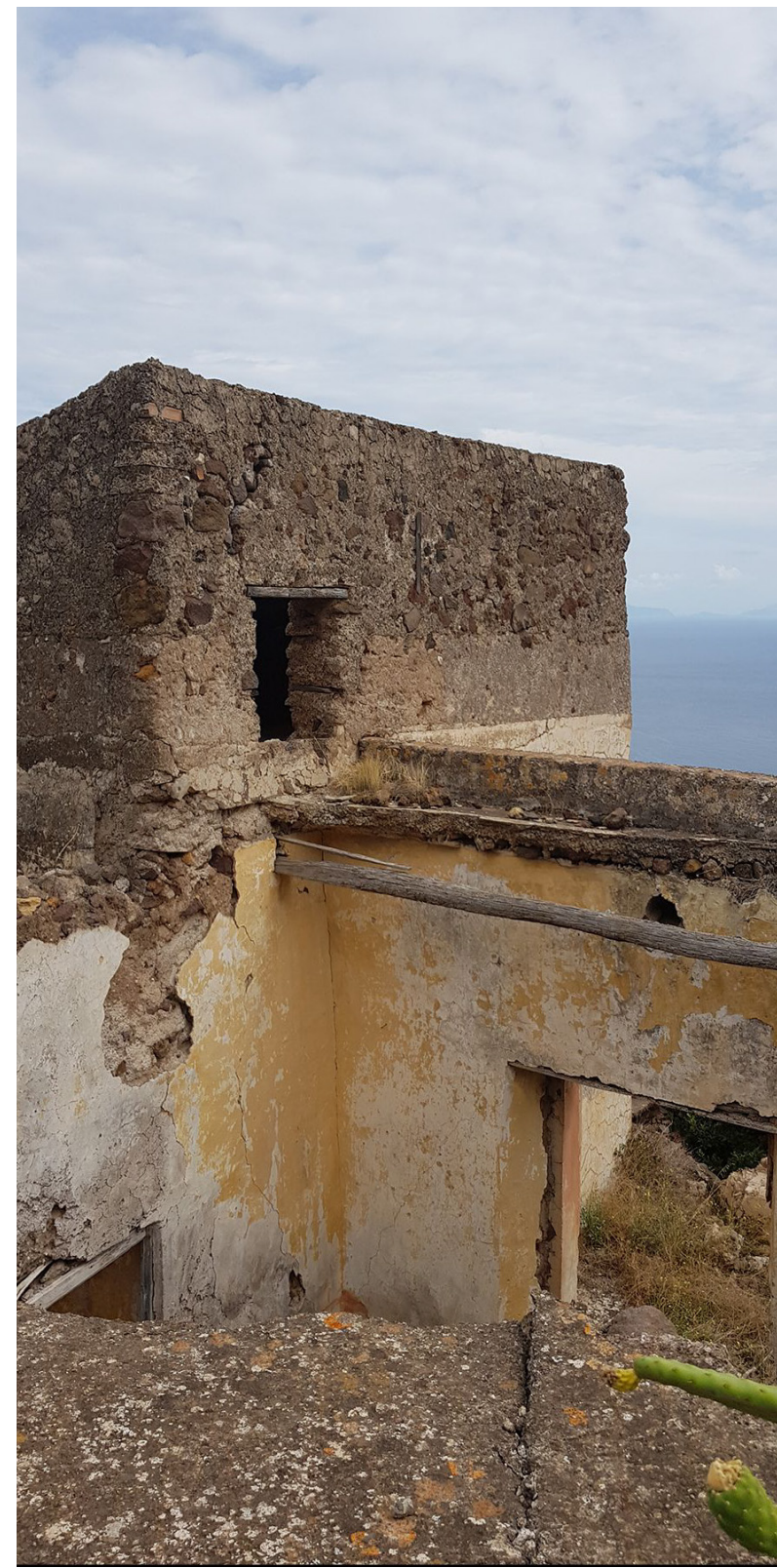

Figure 5. Study case 


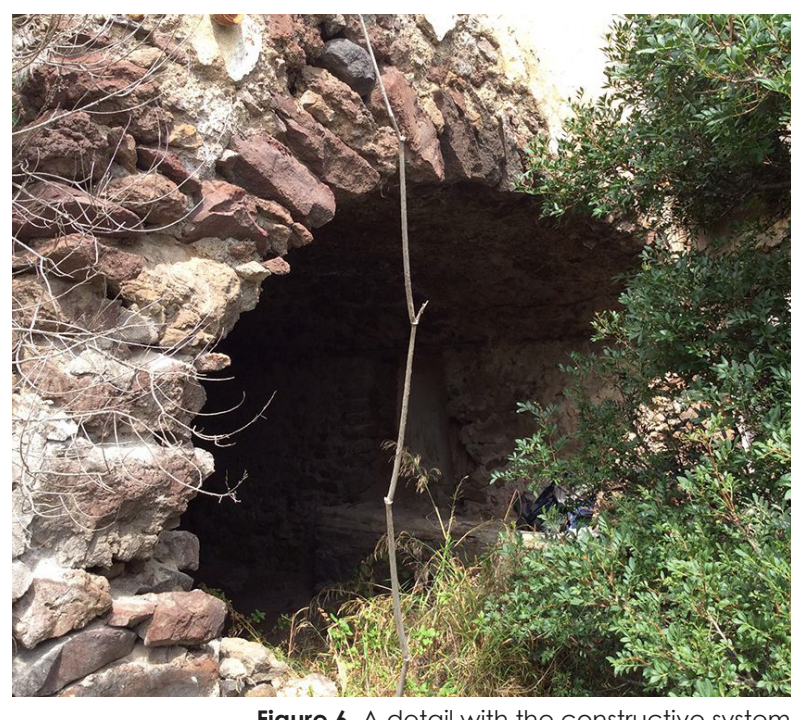

Figure 6. A detail with the constructive system

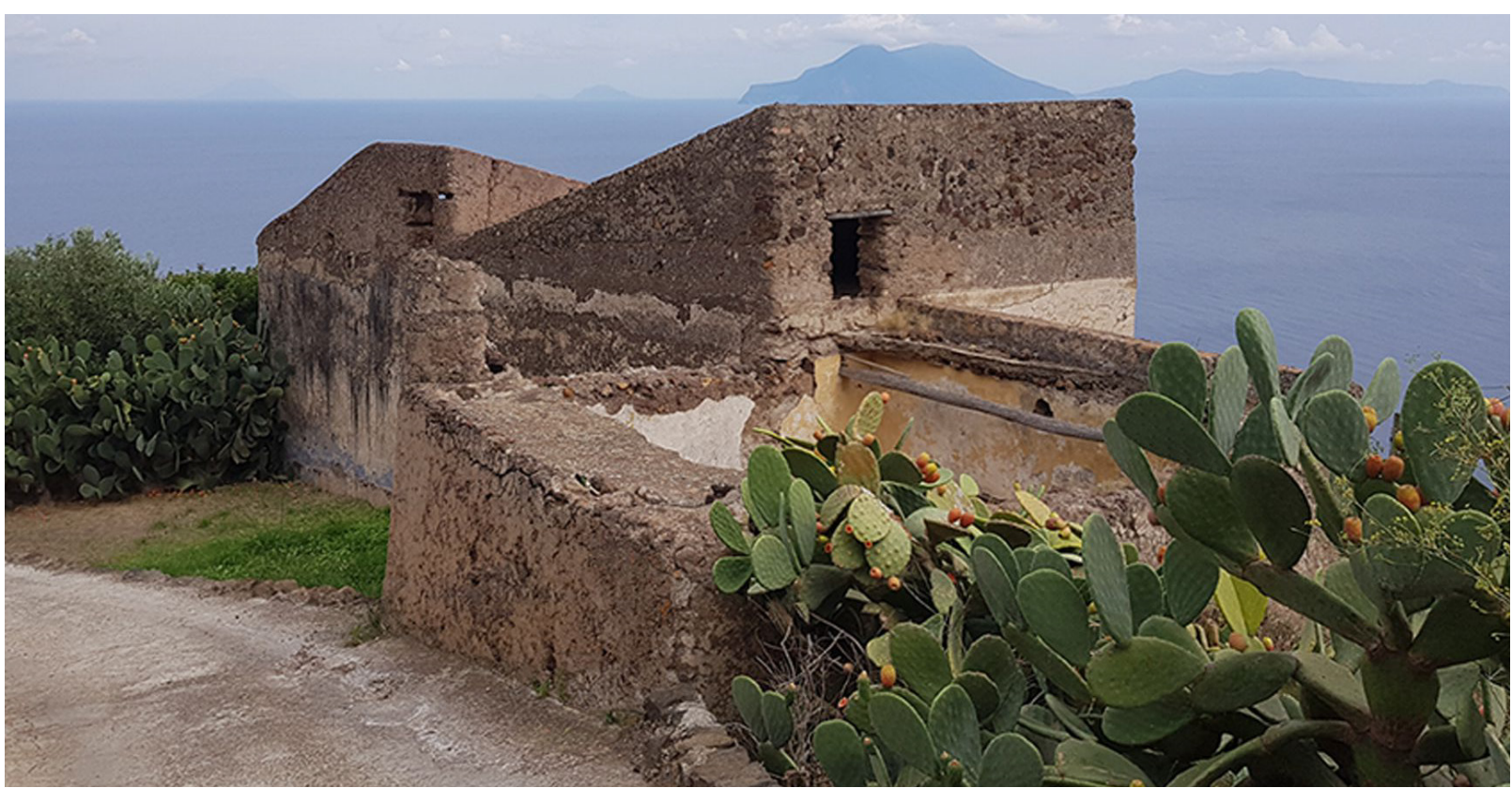

Figure 7. A view of the house 


\section{DESIGN PROPOSAL}
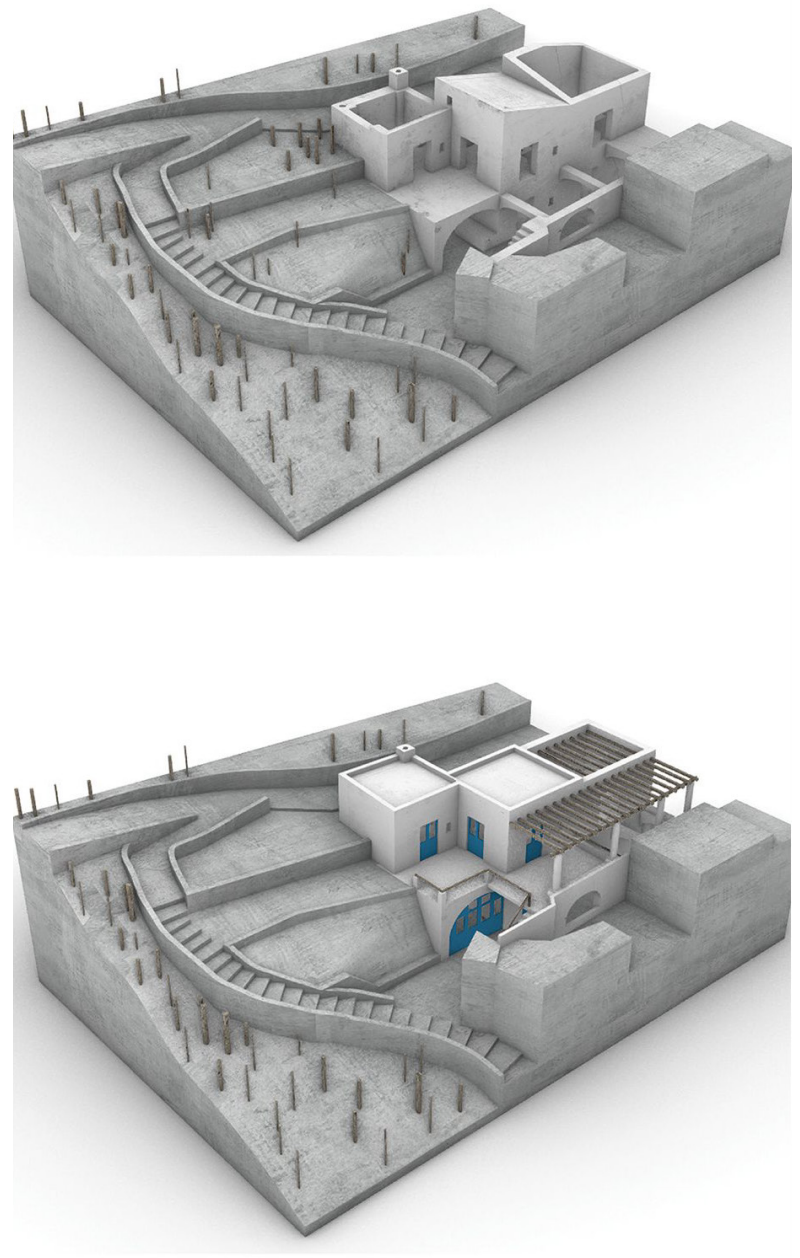

Our function was a medical center in the winter and a wellness center in the summer. In keeping with the traditional idea of two different houses in one building, we separated our functions on each level. Considering the climate characteristics, on the upper floor, we placed the pharmacy and first aid so that they are near the entrance, while the gym is in the double space room, considering it is cooler from the natural ventilation. The cave is used for therapy in the summer but the wellness center is turned into a laboratory in the winter, when there are no visitors and the local people can prepare the medicine since the fruits and the plants are harvested at that time. We recreated the traditional bagghiu with a puller and covered by a special roof made by wooden beams. In addition, to sustain our idea of a wellness center, we chose to cover the arched terrace with local plants with flowers. Moreover, we chose to transform our yard into a large garden which combines medicinal plants with decorative plants, so that it creates a therapeutic circuit. 


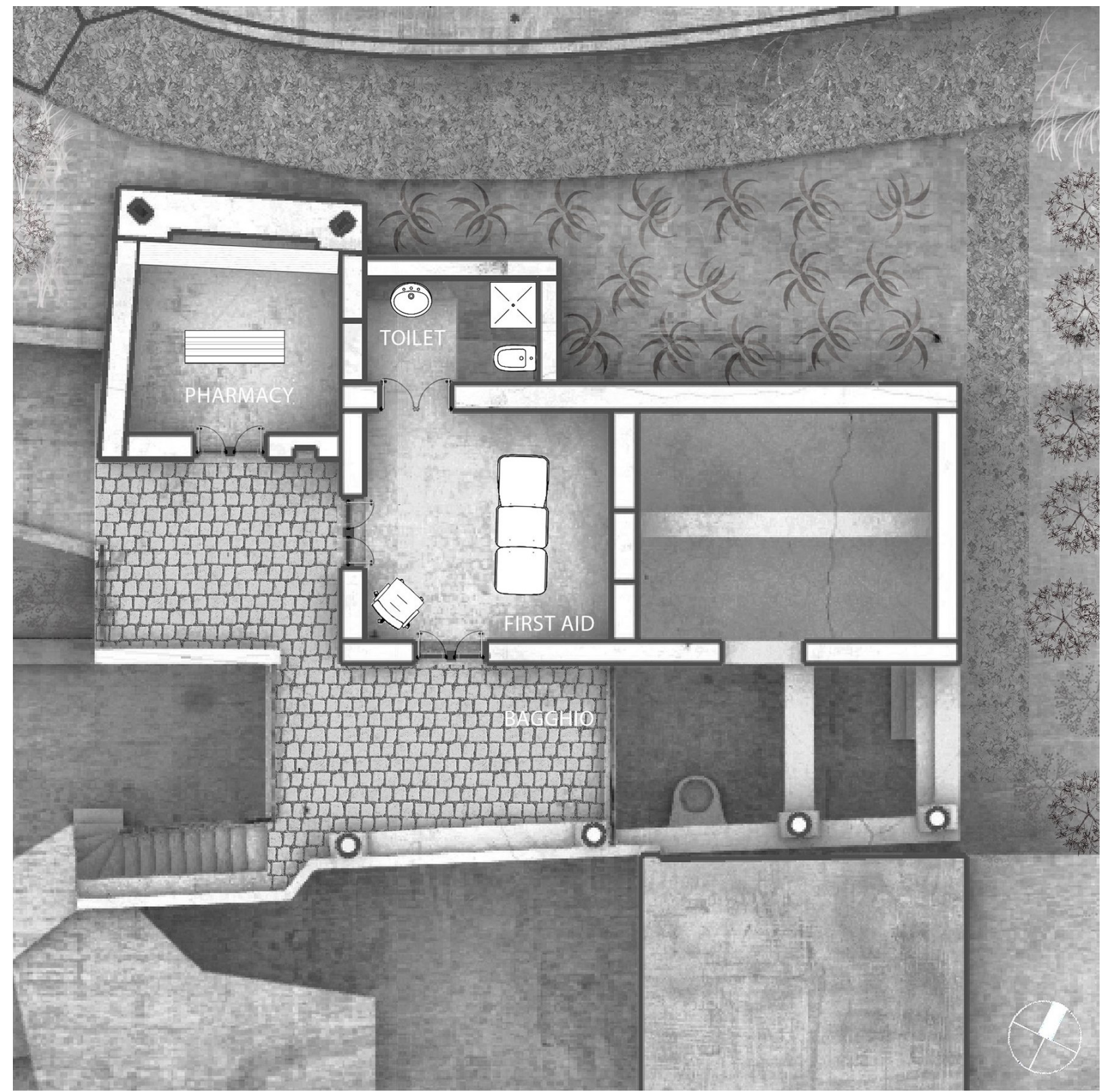

Figure 9. Ground floor of the proposal for case study building 


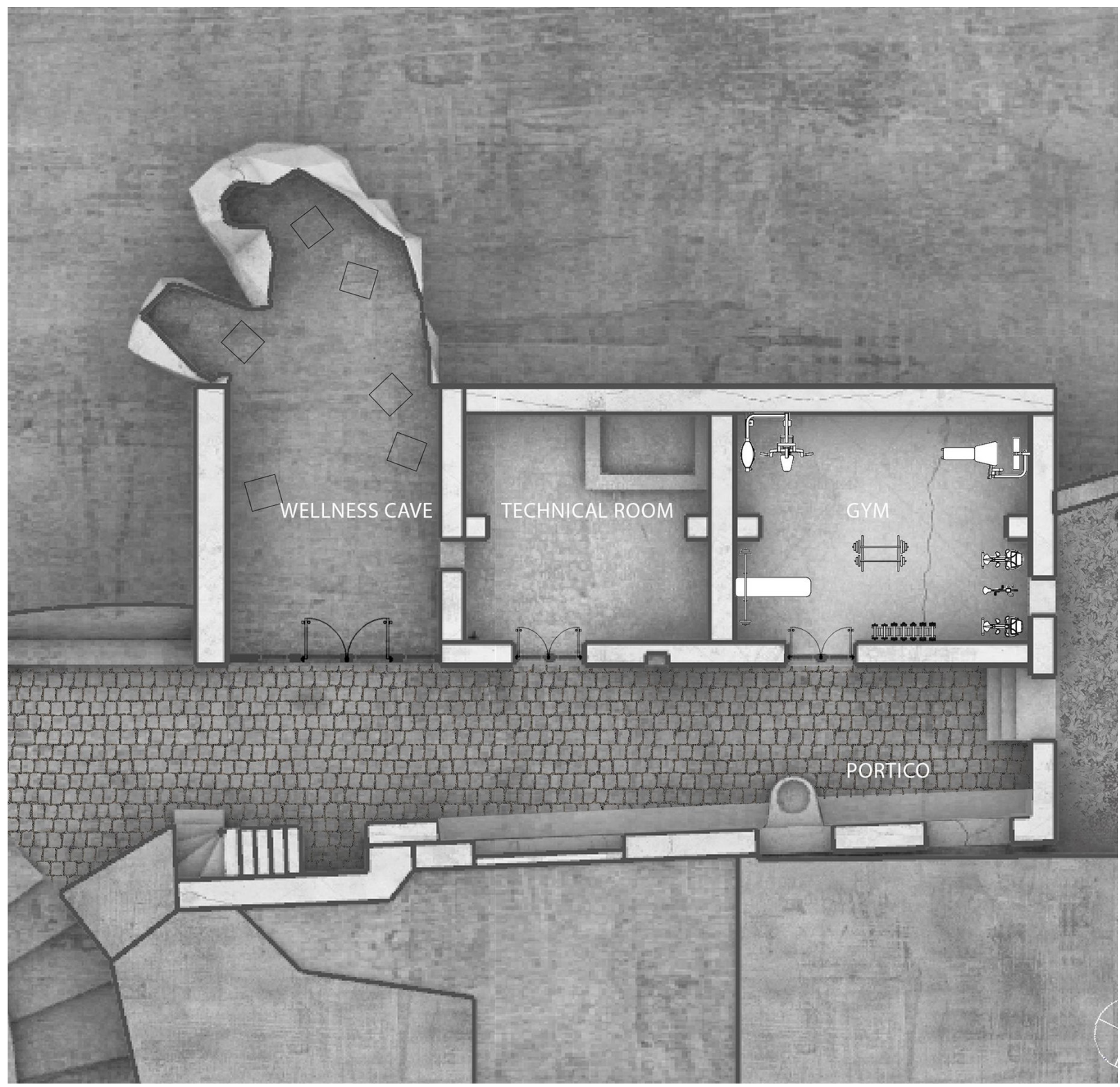

Figure 10. Basement floor of the proposal for case study building 

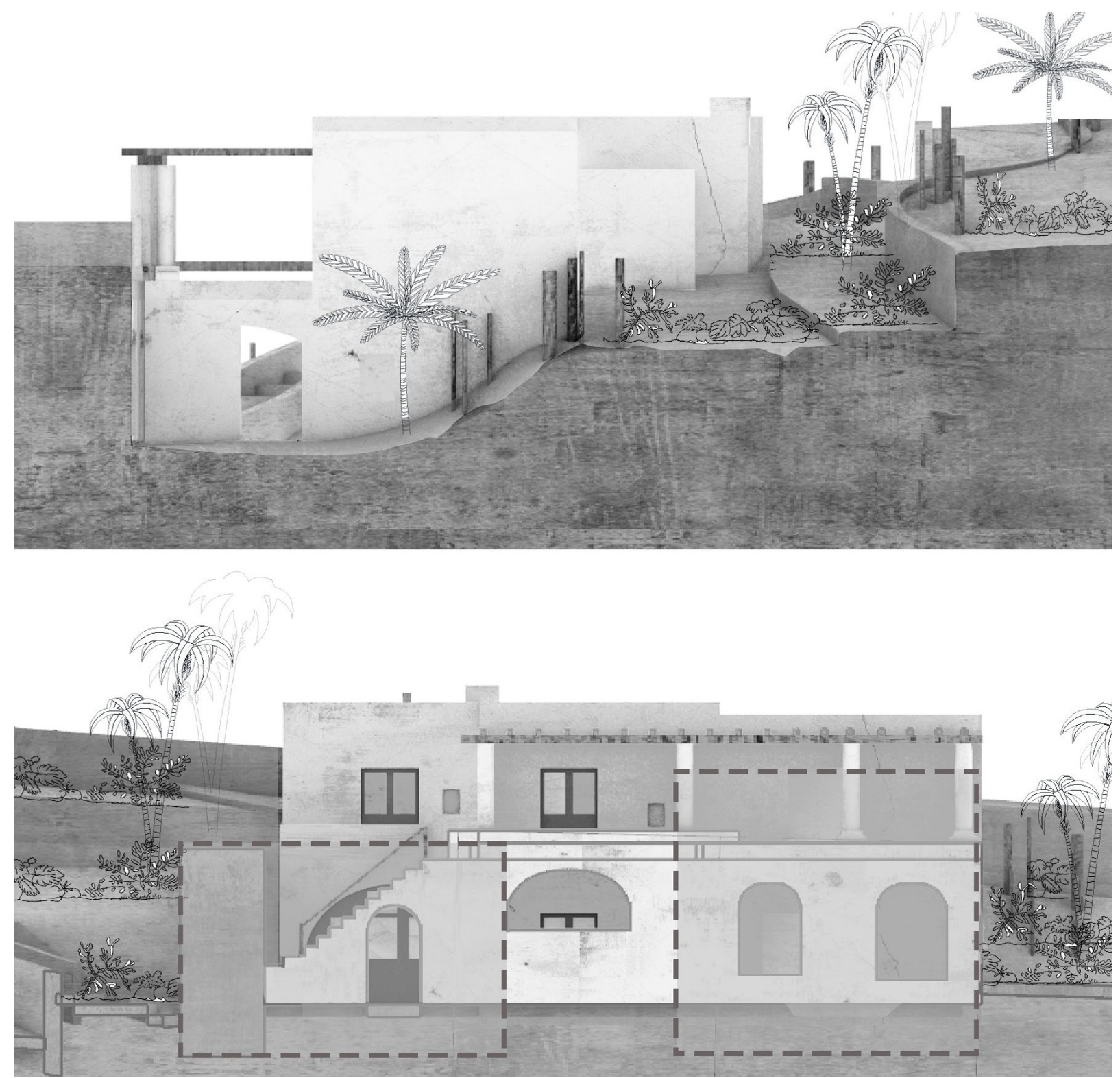

Figure 11. Elevations northwest and southwest 

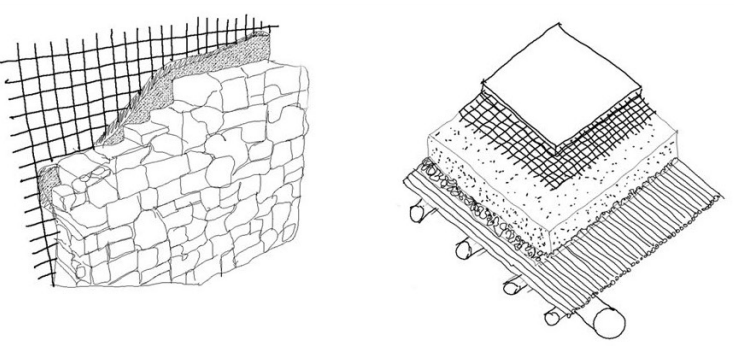

$1^{\text {st }}$ FLOOR REINFORCEMENT ROOF REFURBISHMENT
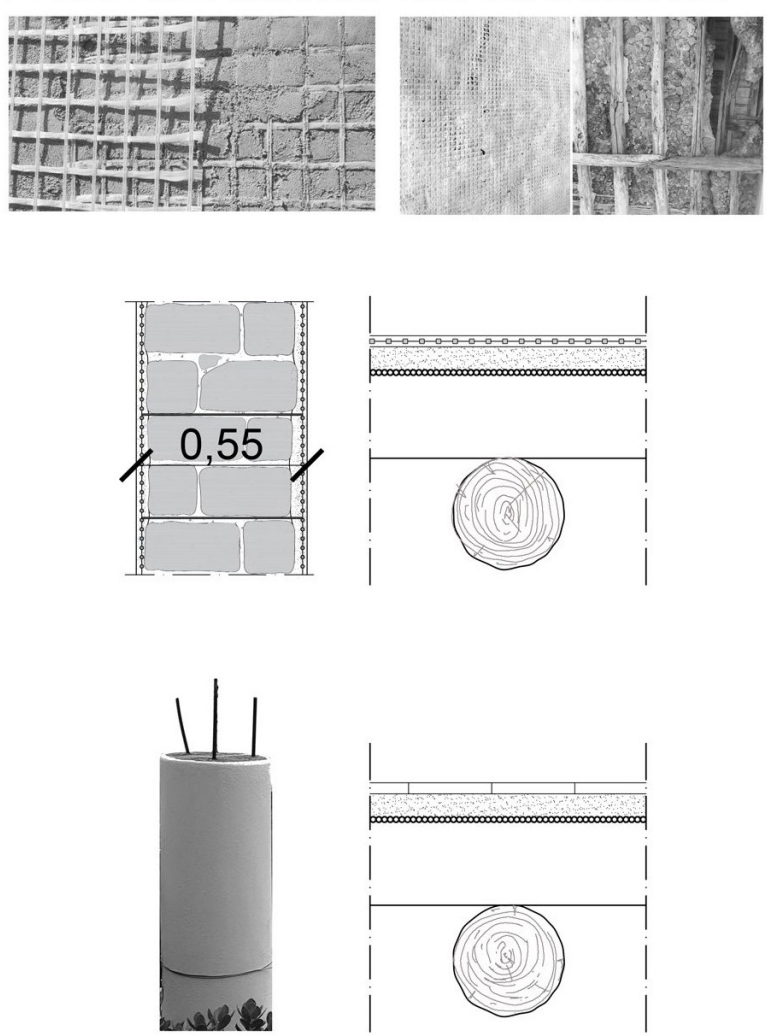

Figure 12. Constructive details

\section{DETAIL}

As regards the energetic and mechanical aspects, we introduce many improvements. The mechanical behavior is improved by the FRCM system on both sides of the walls. In this way, we can guarantee a better compression and flection resistance. The roof is refurbished in a traditional way, but we have used an additional layer as to obtain a waterproof surface, leaving to be breathable.

For the energetic aspect, we have used a ground source heat pump, with another heat exchanger for the thermal water of the wellness cave to improve further the energy efficiency of the building.

In this way, we can obtain the maximum energetic class.

We understood that the traditional way of building turns out to be also the most adequate, and we have just added technology to make it more efficient. 


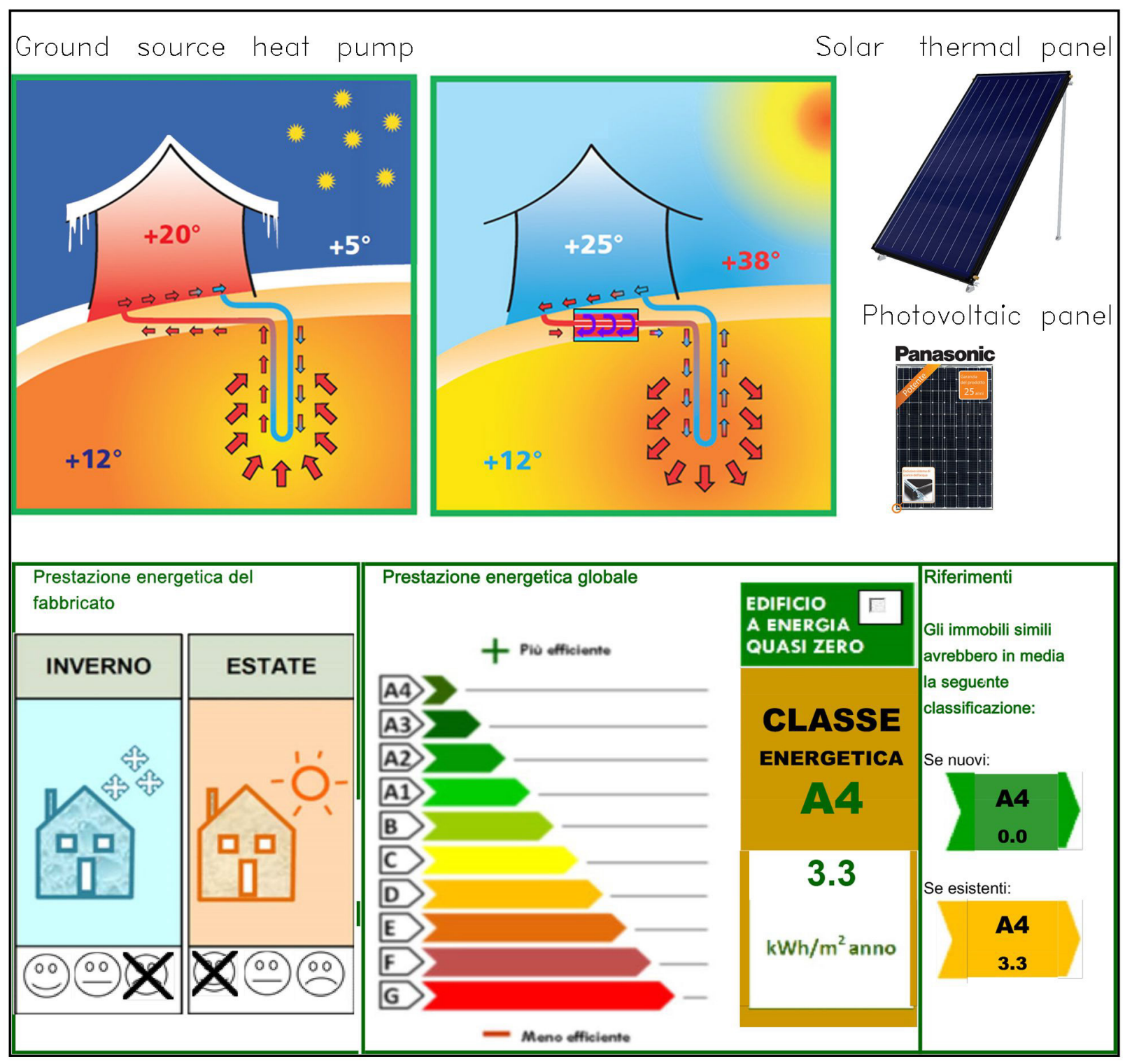

Figure 13. Energy details 


\section{CONCLUSIONS}

ITM is the acronym of Intensive Teaching Modules, which are extra didactic courses organized by the university partners of the Erasmus+ project called VVITA. The University of Catania, which is one of the partners, has curated the teaching design of the ITMS

Each ITM is addressed to the revitalization design of a special place, chosen by the host university. It is mostly developed on the chosen site, which is a big advantage because students can be totally involved in the work and have direct contact with the subject. All this gives them the opportunity of having an experience of learning by doing, with new situations and new relationships. The ITM is effective because it develops learning skills that nowadays are very important, i.e., critical thinking, creative thinking, collaborating and communicating. It is also addressed to develop life skills such as flexibility, social skills, productivity and leadership in working groups.

The ITM is composed of three parts. The main one is the workshop, which is carried out in the chosen location to which the refurbishment and revitalization design is addressed. The workshop is anticipated by introductive lectures, the related practice that makes them concrete. The synergy among the various activities makes the participants able to achieve the designed learning outcomes.

The possibility to take part in more than one ITM gives teachers and students the opportunity to establish a productive relationship among participants, by working in different places with different building traditions.

In Italy, the ITM is called ATM, because it is located in the Aeolian Isles (ATM means Aeolian Teaching Module). The choosing of this place is due to two main reasons: the

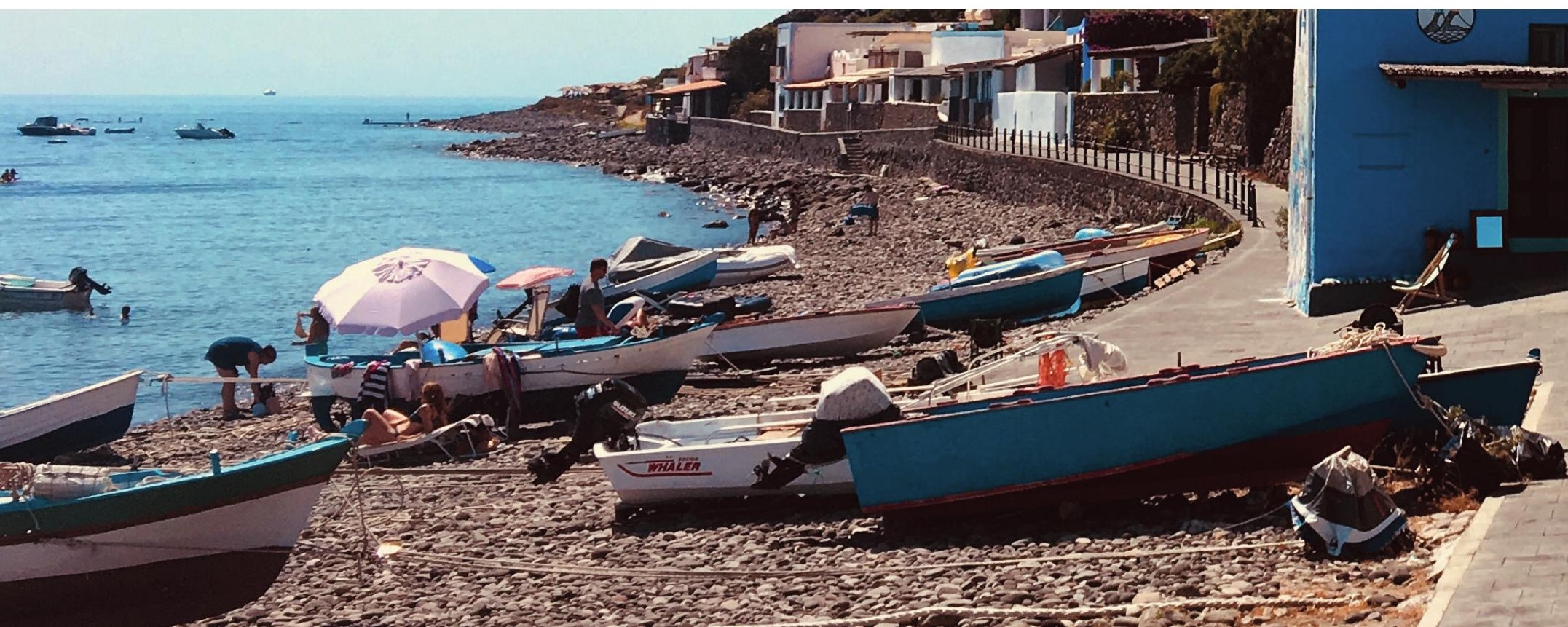


strong interrelation between the features of the landscape; the particularity of the local residential typology, which is called the Aeolian house. The two tasks assigned to the students in the ATM are: a data-entry/editing activity, on Aeolian houses, in the GIS environment; a refurbishment and revitalizing design simulation of local architecture. This double possibility of work, both in the architectonic and in the technological field, increases the knowledge, competence, and skills of the students. This approach has more chance to match their preference, considering that they are coming from different universities and different degree courses with various cultural backgrounds.

The teaching staff is formed by professors of the partner universities. Of course, the ATM is an opportunity of enrichment for them too. The lectures regard the main focus of the ATM: on the particularity of the place, on the evaluation of the local building, on the use of GIS technology, and so on.

The revitalization projects focus on the possibility of introducing flexible functions in the local community, according with the changing number and type of inhabitants of the island among winter and summer. In any case, they based the designs on controlled transformation to achieve contemporary performance standards, while preserving the shape and materials of the existing buildings.

The final works of the student groups achieve a high level of quality. In fact, in a few days, they have been able to understand the main features of the local architecture and also, the relationship with the landscape.

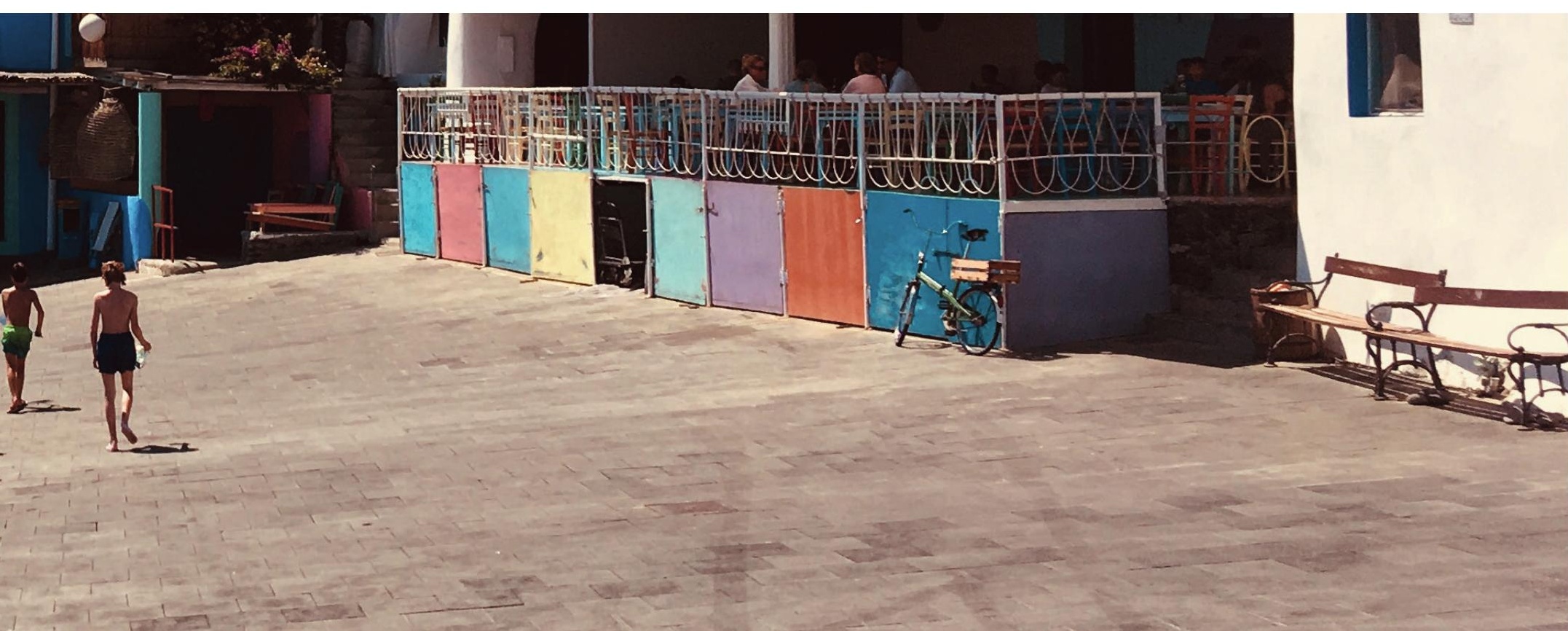




\section{ACRONYMS}

$\begin{array}{ll}\text { ATM } & \text { Aeolian Teaching Module } \\ \text { CAD } & \text { Computer Aided Design } \\ \text { DDS } & \text { Decision Support System } \\ \text { DEM } & \text { Digital Elevation Model } \\ \text { DICAR } & \text { Department Civil Engineering and Architecture } \\ \text { EQF } & \text { European Qualifications Framework } \\ \text { EPI } & \text { Energy Performance Index } \\ \text { FOSS } & \text { Free and Open Source Software } \\ \text { GIS } & \text { Geographic Information System } \\ \text { GPL } & \text { General Public License } \\ \text { GPS } & \text { Global Positioning System } \\ \text { IP } & \text { Intensive Period } \\ \text { ITM } & \text { Innovative Teaching Module } \\ \text { NTNU } & \text { Norwegian University of Science and Technology of Trondheim } \\ \text { QGIS } & \text { Quantum GIS Software } \\ \text { REM } & \text { Rapid Evaluation Method } \\ \text { SWOT ANALYSIS } & \text { Strengthen, Weakness, Opportunity, Treats Analysis } \\ \text { UAUIM } & \text { lon Mincu University of Architecture and Urbanism of Bucharest } \\ \text { UNICT } & \text { University of Catania } \\ \text { VVITA } & \text { Modernizing Learning and Teaching for Architecture through Smart } \\ & \text { and Long-lasting Partnerships leading to sustainable and inclusive } \\ & \text { development strategies to Vitalize heritage Villages through Innova } \\ \text { tive Technologies } & \text { Web Map Service }\end{array}$


267 


\section{BIOGRAPHIES}

\section{VINCENZO SAPIENZA}

Department of Civil Engineering and Architecture, University of Catania, Italy Mail: vincenzo.sapienza@unict.it

Vincenzo Sapienza was born in Catania (Italy, Sicily) fifty years ago. He started working in the University of Catania in 1997, as a researcher of Building Techniques and now, he is an Associate Professor and Vice Head of his department. $\mathrm{He}$ is also Scientific Director of the Enabling Techniques for Architecture Laboratory (ETA Lab). Every year, he has covered a Chair related to his disciplinary competences.

His scientific activity is essentially divided into three thematic areas: innovative building technologies; building sustainability; history of construction.

He has carried out a number of didactic and research periods in foreign universities and in particular, in NTNU of Trondheim University, in Norway (November 2016) and in UAUIM of Bucharest (March, 2017), and UTM of Madrid (February, 2018). $\mathrm{He}$ is on the editorial board of the journal MODULO (by Be-Ma Editor, Milan). He was the curator of a special issue, 38/2016, of ilProgettoSostenibile Magazine. Since 2015, he has been Associated Editor of the journal TeMA - Studies on Architectural Engineering.

\section{MARIUS VOICA}

Department of Architecture, Ion Mincu

University of Architecture and Urbanism, Romania Mail: mvoika@yahoo.com

Marius Voica received his Bachelor degree from "Ion Mincu Institute of Architecture" in Bucharest in 1996 - Faculty of Architecture and Urbanism. He finished his Master's degree in 1999, specializing in "Marketing in Architecture", and graduated from a post-university course in "Project Management".

In 2007, he received his PhD in Architecture with his thesis "Ecological Architecture: Tradition and Contemporary Technology. Sustainable Development and Ecological Management." He has been working in higher education in Architecture since 1998.

He was also manager of the "URBANPROIECT" branch within The National Institute of Research Development in Construction Urbanism, and Sustainable Territorial Development URBAN INCERC.

Currently, he works in architectural and construction management, and coordinates the "E.U. Research Funds Office" and the International Studio in "Architectural Synthesis" Department at the UAUIM.

He has attended scholarships, workshops, and teaching programs at universities in Karlsruhe, Regensburg, Montpellier, Stuttgart, Istanbul, and Vienna.

His activity in architecture, urbanism, and interior design has summed up to over 90 projects. 


\section{LUCA FINOCCHIARO}

Department of Architecture and Technology, Norwegian University of Science and Technology, Norway Mail: Iuca.finocchiaro@ntnu.no

After earning Master's degree in Building Engineering at the University of Catania (Italy), Luca Finocchiaro moved to Scotland where he earned a Master of Architecture at the Glasgow School of Art. He worked in Barcelona twice, first as a visiting researcher at the ETSAB in UPC (developing his $\mathrm{PhD}$ thesis in bioclimatic design of hospitals) and secondly, practicing architecture. Luca is today Associate Professor in "Climate and built forms" and head of the MSc program in Sustainable Architecture at NTNU. His main interest and research focus is the analysis and understanding of climate and its implementation into the architectural design of buildings able to passively address their environmental performance towards comfort. Climate and morphological parametric analyses have been, in different research projects, addressed in design guidelines for both the design of new buildings and the energy retrofitting of existing ones. In 2009 , LUca was initiator of the NTNU proposal for the Solar Decathlon 2012 and later, architect of the LivingLAB and Test Cell projects at the Zero Emission Buildings research center at NTNU.

\section{Alessandra Bonazza}

Institute of Atmospheric Sciences and Climate, National

Research Council, Italy.

Mail: a.bonazza@isac.cnr.it

\section{Simona Calvagna}

Department of Civil Engineering and Architecture, University of Catania, Italy.

Mail: simona.calvagna@unict.it

\section{Rosa Caponetto}

Department of Civil Engineering and Architecture, University of Catania, Italy. Mail: rosa.caponetto@darc.unict.it

\section{Antonio Gagliano}

Department of Electric Electronic and Computer Engineering University of Catania, Italy.

Mail: antonio.gagliano@unict.it

\section{Mihaela Hărmănescu}

Urban Plannig Faculty, Ion Mincu University of Architecture and Urbanism, Romania.

Mail: mihaela.harmanescu@gmail.com

Elena Cristina Mândrescu

Department of Architecture, Ion Mincu University of Architecture and Urbanism, Romania.

Mail: cristinamandrescu@yahoo.com

\section{Michele Mangiameli}

Department of Civil Engineering and Architecture, University of Catania, Italy.

Mail: michele.mangiameli@unict.it

\section{Giuseppe Mussumeci}

Department of Civil Engineering and Architecture, University of Catania, Italy.

Mail: giuseppe.mussumeci@unict.it

\section{Gianluca Rodonò}

Department of Civil Engineering and Architecture, University of Catania, Italy.

Mail: gianluca.rodono@unict.it

\section{Alessandro Sardella}

Institute of Atmospheric Sciences and Climate, National

Research Council, Italy.

Mail: a.sardella@isac.cnr.it

\section{Markus Schwai}

Department of Architecture and Planning, Nonwegian University of Science and Technology, Norway.

Mail: markus.schwai@ntnu.no 


\section{Alv $1 \mathrm{~A}=$}

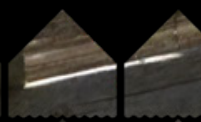

un 1 tete

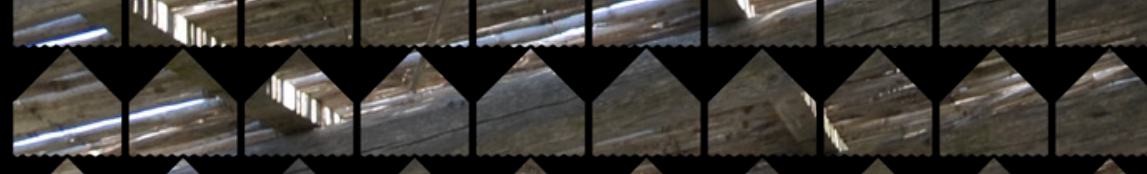

a) if

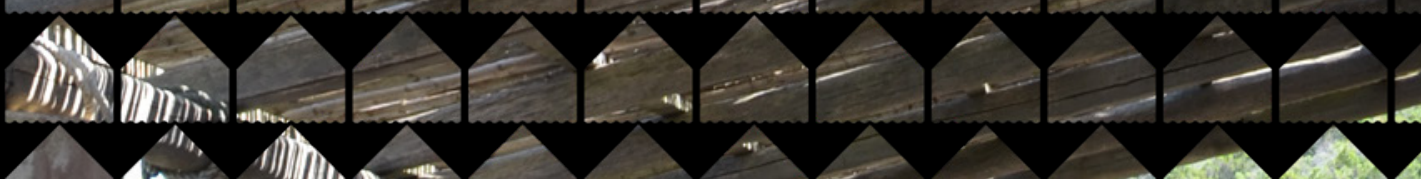

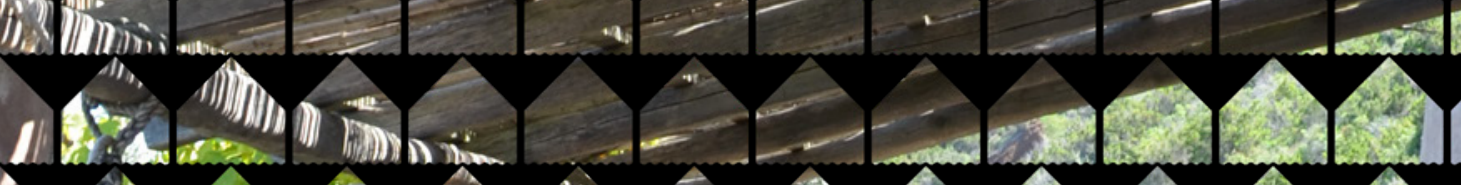
Mn

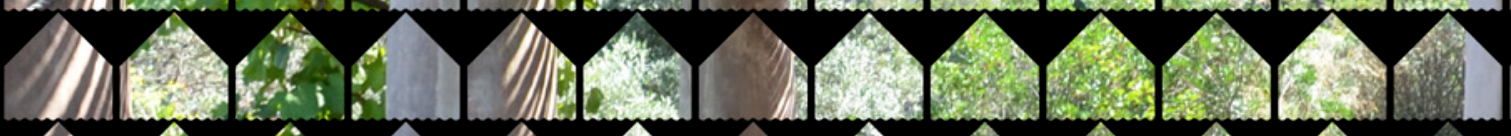

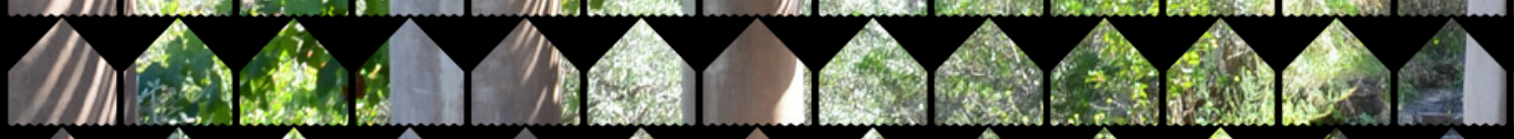

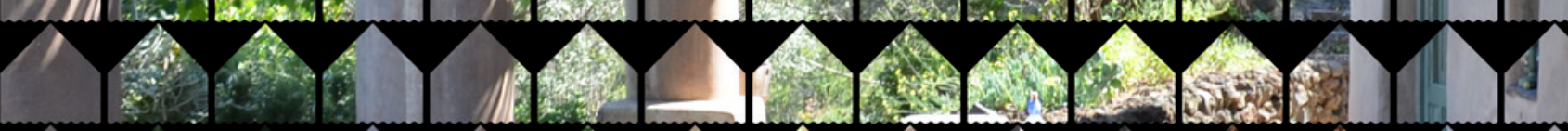
ans
if 10
1
1
10
G 1

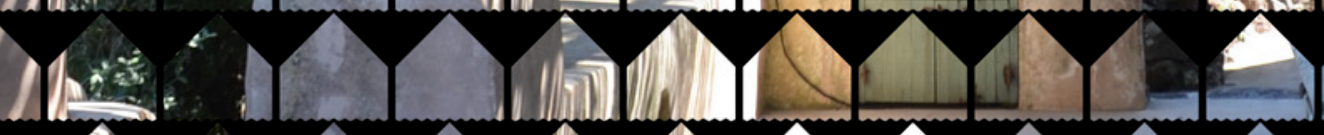

Miney Ime

I milar

AnMinine

978-3-03943-711-5 (PDF)

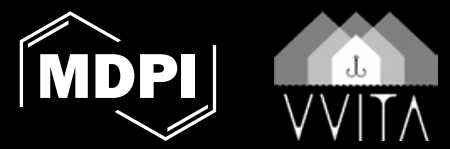

